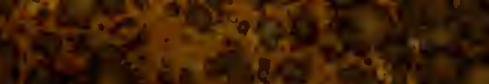

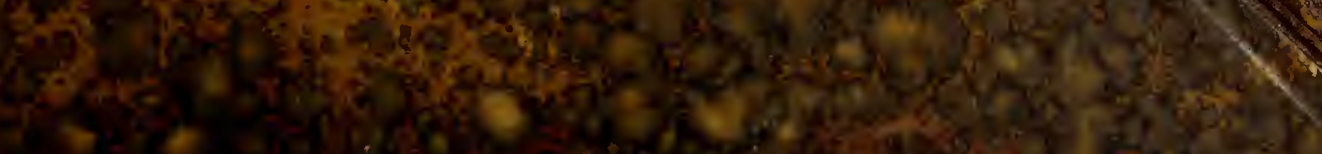

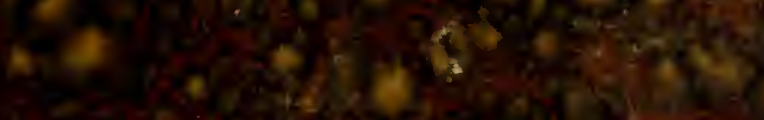

6.

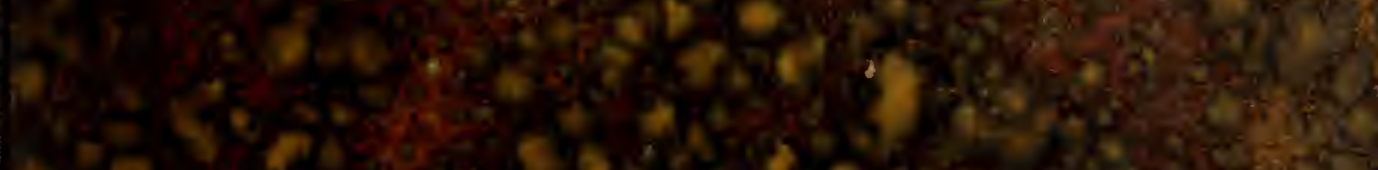

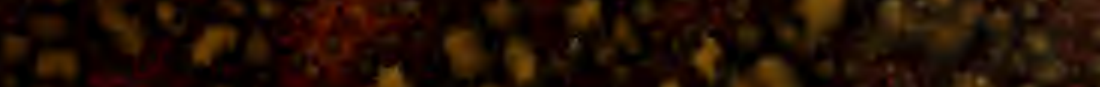

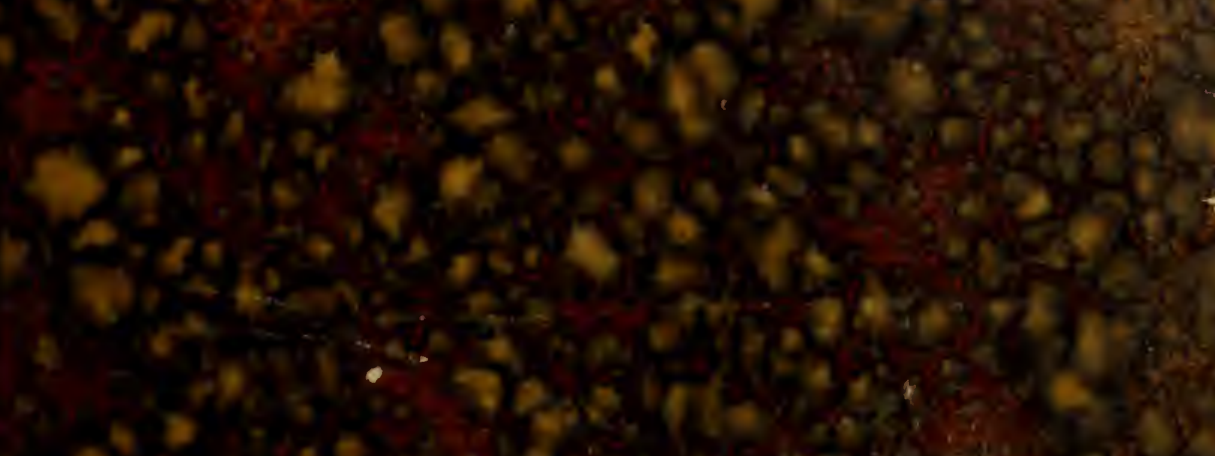

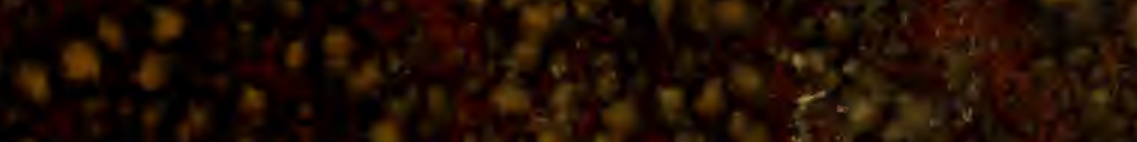

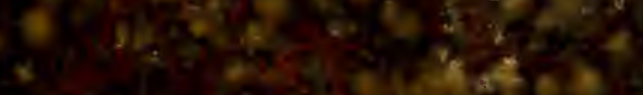

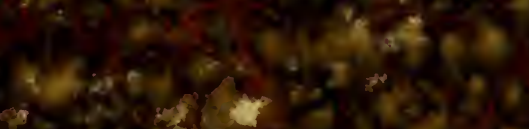

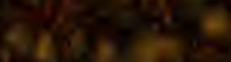

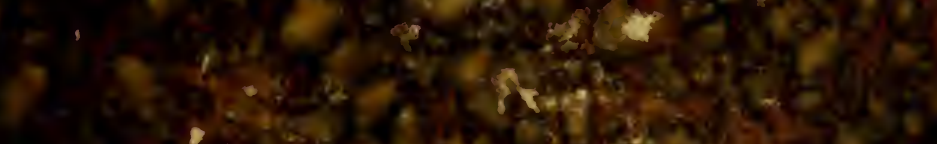

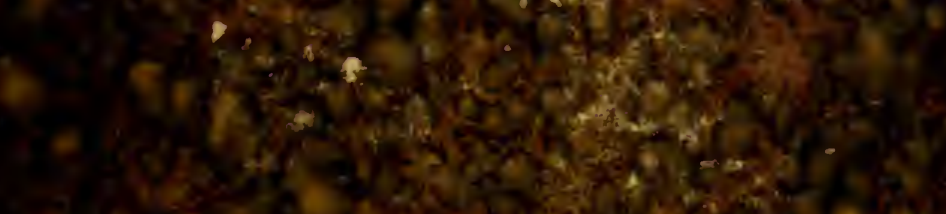

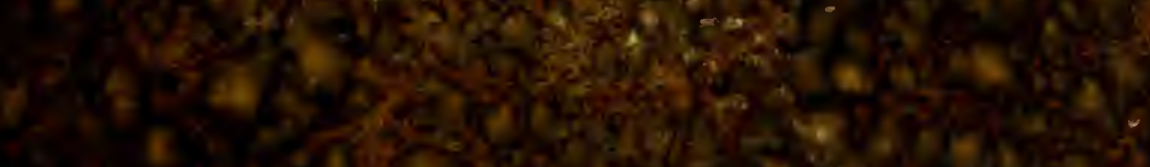
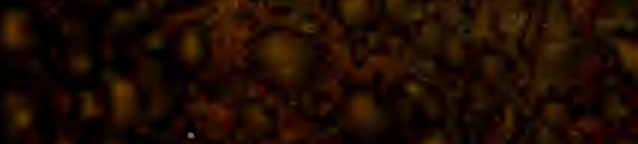
a.

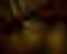

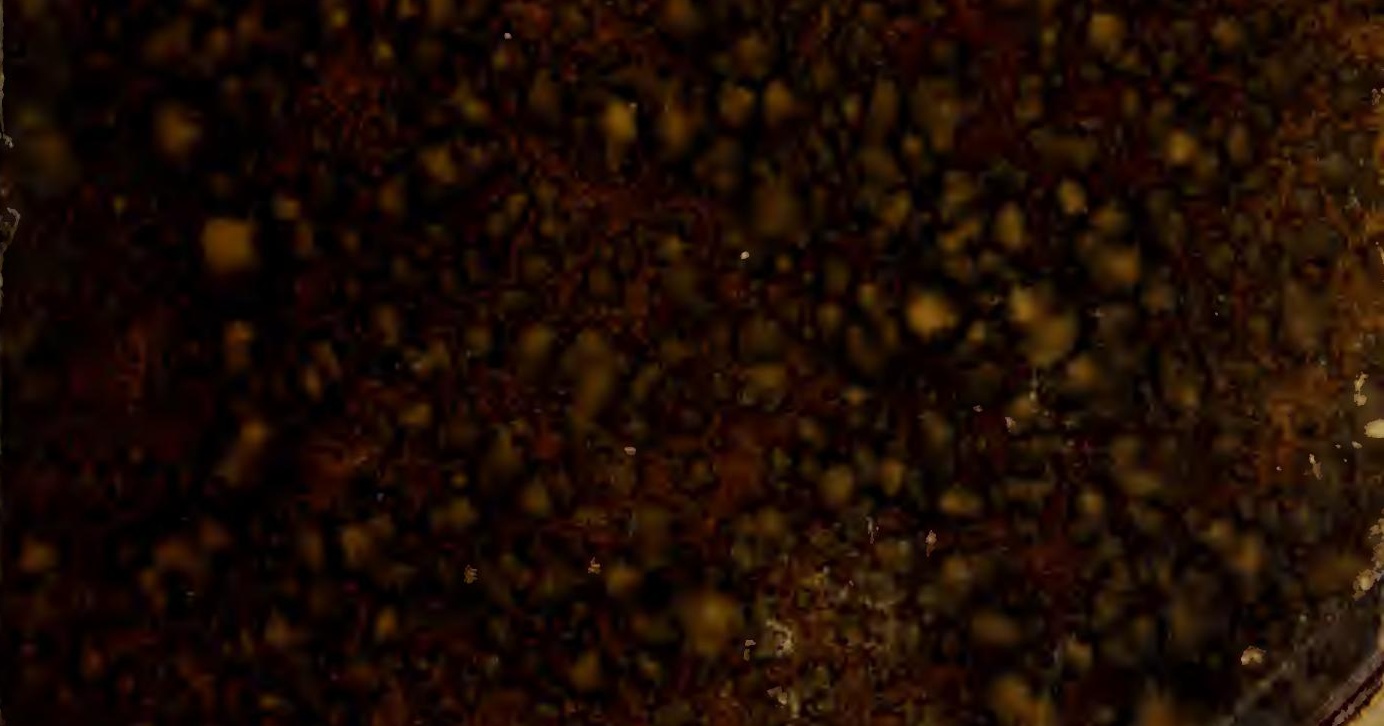
1.5. 
No.

Botany Lib.

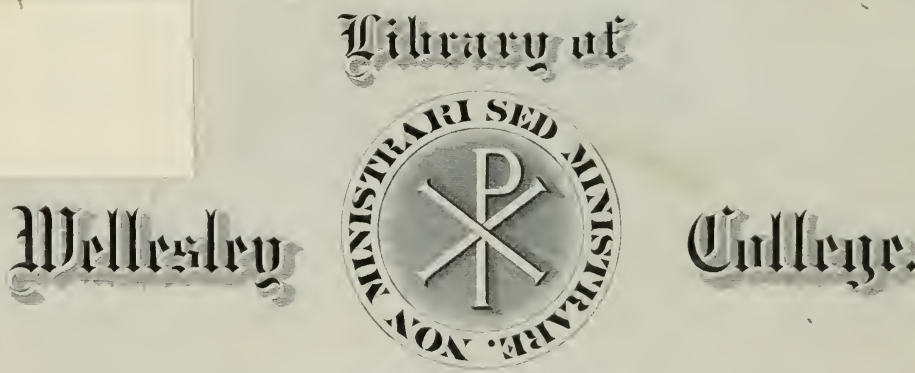

flasutiol liug

No 


$$
\text { , }
$$



Digitized by the Internet Archive in 2016 with funding from

Boston Library Consortium Member Libraries 


\title{
HANDBUCH
}

DER

\section{PHYSIOLOGISCHEN BO'TANIK}

IN VERBINDUNG MIT

A. DE BARY, TH. IRMISCH, N. PRINGSHEIM UND J, SACHS

HERAUSGEGEBEN VON

\section{WILH. HOFMEISTER.}

\author{
ZWEITER BAND.
}

ERSTE ABTHEILUNG.

MORPHOLOGIE UND PHYSIOTOGIE DER PILZE, FLECHTEN UND MYXOMYCETEN.

A. DE BARY.

LEIPZIG

VERLAG VON WILHELM ENGELMANN.

1866. 


\title{
MORPHOLOGIE UND PHYSIOLOGIE
}

DER

\section{PILZE, FLECHTEN UND VIYXOMYCETEN.}

\author{
VON \\ D). A. DE BARY,
}

PROFESSOR AX DFK CNIVISITÄT FRFIBURG 1. 13.

MIT 101 HOIZS('HNITTEN UNI) EINER KUPFERTAFEL.

\section{LEIPZIG}

VERLAG VON WILHELM ENGELMANN.

1866. 


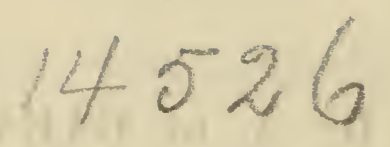

Das Recht einer Uebersetzung in die französische und englische Sprache hat sich der Verleger vorbehalten.

\section{SCIENCE}

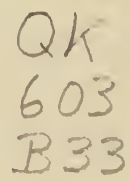

Druck von Breitkopf und Hartel in Leipzig. 


\section{VORWORT.}

Die vorliegende Arbeit hat die Aufgabe eine geordnete Darstellung zu geben von dem gegenwärtigen Stande der Morphologie und Physiologie der Pilze, Myxomyeeten und Flechten. Sie sucht dieselbe zu lösen durch Zusammenstellung der Ergebnisse einer unfangreichen und zersplitterten Litteratur und, soweit möglich, durch eine auf eigene Untersuchungen gegruindete hritische Behandlung und Vervollstindigung dieser Ergebnisse. Die Darstellung der allgemeinen morphologischen Resultate findet, zumal bei einer so formenreichen und ungleichmaissig bearbeiteten Classe wie die Pilze sind, nicht geringe Schwierigkeiten darin, dass sie anf der einen Seite die der Systematih angehörenden Detailbeschreibungen, auf der andern eine allzu sehematische Behandlung vermeiden muss. Wemn dieser Anforderung nicht iiberall genügend entsprochen wurde, so mag dies wenigstens theilweise durch die Beschaffenheit der vorliegenden Untersuchungen erkliirt und entschuldigt werden.

Da der morphologisehe Theil der Arbeit iiberall auf die Systematik Beziehung nehmen muss und die Ansichten über die ststematische lintheilung der Pilze zur Zeit sehr auseinander gehen, so wird es zweckmässig sein die systematischen Anschauungen lier kur\% anzugeben, ron welchen ich in der Arbeit ausgegangen bin.

Pilze nenne ich ausschlieslich diejenigen chlorophỵlffeien und ron organnischen Stoffen lebenden Thallophyten, deren Thallus aus den im 1. Capitel naiher beschriebenen Hỵphen besteht; man kann kurz sagen die chlorophỵllfreien Conferven (Siphoneen) und Lichenen. Ausgeschlossen von den Pilzen 
sind hiernach die Myxomyceten, Chytridieen und Schizomyceten Nägeli's. Was von den beiden letztgenannten Gruppen in vorliegender Arbeit zu erwähnen ist, wurde jedoch in dem von den Pilzen handelnden Theile an geeigneten Orten eingeschaltet.

Die Pilze gliedern sich in folgende Ordnungen I. Phycomycetes. Unter diesem Namen kann man die miteinander nahe verwandten Familien: $a$. Saprolegnicae, b. Peronosporeae, $c$. Mucorini zusammenfassen. II. Iypodermii. Fries S. v. Sc. a. Uredinei Tul. b. Ustilaginei Tul. III. Basidiomycetes. a. Tremillini Tul. b. Hymenomycetes c. Gastromycetes. IV. Ascomycetes. a. Protomycetes (Protomyces macrosporus) $b$. Tuberacei. c. On ygenei. d. Pyrenomycetes $e$. Discomycetes.

Diese Gruppen entsprechen einerseits im Wesentlichen den gleichnamigen der gangbaren Pilzsysteme. Auf der andern Seite fehlen in der obigen $\mathrm{Zu}-$ sammenstellung sowohl die IIaplo- oder Hyphomyceten (mit Ausnahme der Iypodermii), als die Gymnomyceten Fries. Was die ersteren betrifft, so ist es zur Zeit zweifellos, dass sie nicht eine $\Lambda$ btheilung des natürlichen Systems bilden, sondern nur eine Gruppe ron Formen darstellen, welche durch ahnlichen Bau und llabitus der Vegetationsorgane iibereinstimmen, etwa wie die Baimme oder Str:iucher unter den Phanerogamen. Sie gehören theils den Phycomyceten an, theils stellen sie Entwicklungszustinde, Organe, von Pilzen aus den Ordnungen III und IV dar. Letzteres gilt nicht minder für dic Gymmomyceten, für die seitherigen Unterordnungen Sphaeropsideen Lév., Gytisporeen, u. s. f., alle diese sind daher aus dem natürlichen System zu streichen.

Es muss allerdings zugegeben werden, dass es :zur Zeit nicht möglich ist, alle IIyphomyceten, Gymmomyceten u. s. f. an ihre naturgemaisse Stelle im System zu setzen, und die genannten Abtheilungen werden als Nothbehelf da noch beibehalten werden muissen, wo es sich darum handelt eine Anleitung zum Bestimmen der Pilze oder auch nur eine vollständige Liste der beschricbenen Formen zu geben. Für den Zweck der vorliegenden Arbeit war es aber nicht nur möglich, sondern nothwendig, das natüliche System, dessen Grundzïge sicher gestellt sind, an die Stelle des veralteten zu setzen.

Die Saprolegnieen kniipfen die Phycomyceten unmittelbar an die Conferven (Siphoneen) an, sie können nit gleichem Rechte diesen wir den Pilzen zugezihlt werden, Da ihre Entwichelungsgeschichte wie zu erwarten steht 
auch in dem algologischen Theile dieses Ilandbuches Besprechung finden wird, habe ich sie hier verhältnissmässig kur" behandelt.

Ueber die Systematik der Flechten ist hier nur das Eine zu bemerken, dass ich mich in der Nomenclatur vorzugssweise an Körber's Systema Lichenum und Parerga gehalten habe; nicht um für irgend eines unter den Lagern der Lichenographen Partei zu nehmen, sondern weil die genannten Bücher relativ vollstiindig, fertig und allgemein verbreitet sind.

Ich bedauere einige in neuester Zeit erschienene mycologische Arbeiten für die vorliegende Darstellung nicht mehr haben benutzen zu können, es schien mir aber im Interesse der letzteren geboten, nachdem das Manuscript abgeschlossen und der Druck begonnen war, nachtriggliche Einschicbungen zu vermeiden, zumal da solche nirgends erhebliche Neuerungen und Abainderungen der vorgetragenen Ansichten veranlasst haben würden.

Freiburg im December 186 . 



\section{N II A I ‘'I'.}

I.

\section{Pilze.}

\section{Erste Abtheilung. Morphologie des Pilzthallus.}

\section{Cappitel 1. Histiologische Eigenthümlichkeiten.} Hefepilze. Chytridieen. Schizomyceten . . . . . . . . . . . . . 3 Zellnembran . . . . . . . . . . . . . . . . . . . 4 Protoplasma, kern, Zellinhalt . . . . . . . . . . . . . . . . . . . . . 9 Oxalsaurer Kalk . . . . . . . . . . . . . . . . . . . . . 13 Zelltheilung, Verzweigung . . . . . . . . . . . . . . . 14 Verbindung der Hyphen mit einander . . . . . . . . . . . . . . . 15

\section{Capitel 2. Bau des Thallus. Mycelium.}

Unterscheidung von Mycelium und liruchtträger . . . . . . . . . . . . . 17

Myceliun : 1. Fädiges . . . . . . . . . . . . . . . 18

2. Häutiges Mycelium . . . . . . . . . . . . . . . . . . 19

3. Myceliumstränge (Rhizomorphen etc.) . . . . . . . . . 20

4. Sclerotien : Aufzählung . . . . . . . . . . . . . . . . . 29

Baı . . . . . . . . . . . . . . . 30

Entstehung ....................... 34

Austreiben . . . . . . . . . . . . . . . . . 38

5. Dauer der Mycelien . . . . . . . . . . . . . . . . 43

Capitel 3. Der Fruchtriger.

1. Fruchthyphen

II. Fruchtkörper :

1. Gymnocarpe Fruchthörper,

a. Structur . . . . . . . . . . . . . . 49

b. Entwickelung und Wachsthum . . . . . . . . . . . . 59

2. Fruchtkörper der beschleierten IIymenomyceten . . . . . . . . 66

3. Gastromyceten . . . . . . . . . . . . . . . . . 75

4. Elaphomyces. Tuberaceen . . . . . . . . . . . 90

s. Pyrenomyceten . . . . . . . . . . . . . 95 


\section{Zweite Abtheilung. Fortpflanzungsorgane.}

Capitel 4. Geschlechtslose Fortpflanzung.

I. Entwickelung der Sporenmutterzellen und Sporen.

1. Sporenbildung in Ascis . . . . . . . . . . . . . . . . . . 101

2. Sporenabschnürung. Basidien. . . . . . . . . . . . . . . 111

Simultane Abschnürung . . . . . . . . . . . . . . . . . . . 111

Succedane Abschnürung. Köpfchen . . . . . . . . . . 117

Einfache Ketten... . . . . . . . . . . . . 118

Aestige Ketten . . . . . . . . . . . . . . . . 119

3. Sporenbildung durch Theilung,

a. ohne Scheidewandbildung . . . . . . . . . . . . . 121

b. mit Scheidewandbildung (Sporenkörper, septirte Sporen) . . . . 122

II. Bau der Sporen . . . . . . . . . . . . . . . . . . . . . . . . 126

III. Ausstreuung der Sporen und Sporangien . . . . . . . . . . . . . . . . . . 136

IV. Keimung der Sporen.

Keimschläuche . . . . . . . . . . . . . . . . . . 148

Promycelium. Sporidien .................... 150

Hefeartige Sprossung . . . . . . . . . . . . . . . . . . 153

Theilung .. . . . . . . . . . . . . . . . . . . 154

Capitel 5. Geschlechtliche Fortpflanzung und Copulation.

Geschlechtsorgane der Saprolegnieen . . . . . . . . . . . . 155

Geschlechtsorgane der Peronosporeen . . . . . . . . . . . . . . 158

Copulation der Mucorinen . . . . . . . . . . . . . . . . . 160

Zweifelhafte Copulationen : Ustilagineen, Protomyces etc. . . . . . . . . 161

Befruchtung der Erysipheen . . . . . . . . . . . . . . . . . . 162

Muthmassliche und angebliche Geschlechtsorgane der Ascomyceten . . . . . . . 164

Spermogonien. Spermatien . . . . . . . . . . . . 165

Angebliche Geschlechtsorgane der Hymenomyceten.

Cystiden. Pollinarien . . . . . . . . . . . . . . 170

Karsten's und Oersted's Oogonien . . . . . . . . . . . . . 172

\section{Dritte Abtheilung. Entwickelungsgang der Pilze. Pleomorphie, Generationswechsel.}

Capitel 6.

Einleitung . . . . . . . . . . . . . . . . . . 173

1. Saprolegnieen . . . . . . . . . . . . . . . . . 174

2. Peronosporeen . . . . . . . . . . . . . . . . . 1776

3. Mucorinen . . . . . . . . . . . . . . . . 176

Die Hefefrage. . . . . . . . . . . . . . . . . . 181

4. Uredineen . . . . . . . . . . . . . . . . . . 184

๖. Ustilagineen . . . . . . . . . . . . . . . . . . . . . 188

6. Hymenomyceten. Gastromyceten . . . . . . . . . . . . 189

7. Tuberaceen. 8. Protomyces. . . . . . . . . . . . . . . . 193

9. Pyrenomyceten. . . . . . . . . . . . . . . . 193

10. Discomyceten. . . . . . . . . . . . . . . . . 200

Allgemeine Regeln des Entwickelungsganges . . . . . . . . . . . . 202 


\section{Vierte Abtheilung. Physiologische Eigenthümlichkeiten der Pilze.}

\section{Capitel 7.}

I. Entstehung der Pilze ................... . 20 . . .

II. Keimungsbedingungen.

1. Keimfähigkeit . . . . . . . . . . . . 209

2. Aeussere Bedingungen der Keimung ... . . . . . . . 211

III. Ernährung.

1. Nahrungsmittel. Nahrungsaufnahme . . . . . . . . . 212

a. Saprophyten . . . . . . . . . . . . . 213

b. Parasiten. Pflanzenbewohnende. . . . . . . . . 215

Thierbewohnende... . . . . . . . 222

2. Assimilation. Ausscheidung . . . . . . . . . . 227

IV. Wärme- und Lichtentwickelung. . . . . . . . . . . . . . 228

V. Wirkungen der Pilze auf ihr Substrat.

Verwesung und Gährung .............. . . 230

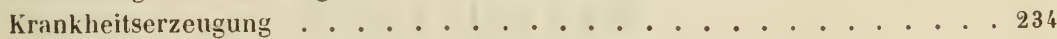

II.

\section{Flech te 1.}

Capitel 8. Der Thallus der Flechten.

I. Geschichteter, heteromerer Thallus.

1. Bau der strauch- und laubartigen Formen . . . . . . . . . . . . . . 242

2. Bau des krustenförmigen, heteromeren Thallus . . . . . . . . . . . 251

3. Stoffliche Beschaffenheit der Mark- und Rindenschicht . . . . . . . . . 254

4. Die Gonidien . . . . . . . . . . . . . . . . . 257

II. Der Thallus der Graphideen . . . . . . . . . . . . . . . . . . . . 260

III. Der Thallus der Gallertflechten.

Allgemeiner Character . . . . . . . . . . . . . . . . 262

Die Gonidien . . . . . . . . . . . . . . . . . . . . 263

Die Hyphen . . . . . . . . . . . . . . . . . . . . . 263

Die Gallerte . . . . . . . . . . . . . . . . . . . 266

Wachsthum der Gallertflechten . . . . . . . . . . . . . . . 267

IV. Inomale Formen.

Myriangium. Lichina . . . . . . . . . . . . . . . . . 267

Ephebe und Verwandte . . . . . . . . . . . . . . . . . . 268

Coenogonium. Cystocoleus . . . . . . . . . . . . . . . . 270

Capitel 9. Fortpflanzungsorgane der Flechten.

I. Soredien. . . . . . . . . . . . . . . . . . . . . . . 271

II. Spermogonien . . . . . . . . . . . . . . . . . . . . . 274

IIl. Pycniden. Stylosporen . . . . . . . . . . . . . . . . . . 276

11. Apothecien. . . . . . . . . . . . . . . . . . . . . . . . . 277

1. Entwickelung und Bau des Apotheciums . . . . . . . . . . . . 277

2. Isci und Sporen. Keimung . . . . . . . . . . . . . . . 282 


\section{Capitel 10. Entwickelungsgang der Flechten.}

Entstehung des Thallus aus der Spore . . . . . . . . . . . . . 287

Bedeutung der beschriebenen Fortpflanzungsorgane für den Entwickelungsgang . . . 288

Genetische Bezielıungen von Palmellaceen, Nostocaceen, Chroolepus zur Entwickelung

der Flechten. . . . . . . . . . . . . . 289

\section{Capilel 11.}

Physiologische Processe

III.

\section{Myxomyceten.}

Capitel 12. Bau und Entwickelung der Myxomyceten.

I. Sporenhehälter und Sporen . . . . . . . . . . . . . . 293

II. Keimung der Sporen und Bildung der Plasmodien . . . . . . . . . . . 302

III. Das Plasmodium . . . . . . . . . . . . . . . . . . . . . . 304

IV. Entwickelung der Sporenbehälter . . . . . . . . . . . . 308

V. Ruhezustände . . . . . . . . . . . . . . . 310

Anhang: Cienkowski's Monaden . . . . . . . . . . . . . . . 313

Erklärung der Tafel . . . . . . . . . . . . . . . . . 315 


\title{
I. \\ P i l z e.
}

\section{Erste Abtheilung.}

\section{Morphologie des Pilzthallus.}

\author{
Capitel 1.
}

\section{Ilistiologische Eigenthiumlichkeiten.}

Der gesammte vegetative Körper Phytom der Pilze, welcher gleich den verwandter Gruppen des Pflanzenreiches als Thallus bezeichnet wird, besteht, mit Ausnahme cinzelner zweifelhafter Falle, aus fadenförmigen, mehr oder minder verzweigten Elementen, Pilzfiden, II! phae oder schlechthin Fäden genannt.

In einer Anzahl von Fillen Saprolegnieen. Peronosporeen, manche Hucorinen ist der Faden eine einzige, lang sehlauchförmige Zelle mit Spitzenwachsthum und, meist reichlicher Asthildung. in Bau und Wachsthum den lang schlauchformigen Zellen anderer Gewichse, zumal der Siphoneen Vaucheria ete., vollkommen ihnlich.

Bei der überwiegenden Mehrzahl der Pilze ist die Hypha dagegen eine Zellreihe Zellenlinie Niggeli!, die gleichfalls durch spitzenwachsthum in die Liinge wiichst und sich dichotom oder durch Seitenzweige von den Gliederzellen aus veristelt. Spitzenwachsthum und Astbildung erfolgen nach den für Zellreihen ibbrhaupt geltenden, im ersten Bande dieses Handbuchs dargestellten Gesetzen. Das Lingenwachsthum des Fadens, soweit es auf Zellenneubildung beruht, erfolgt entweder durch alleinige Theilung der Scheitelzelle: der einfache Faden oder Ast besteht nur aus dieser und aus Gliederzellen ersten Grades (z. B. fruchttragende Aeste von Botrytis cinerea, Acrostalagmus u. s. f.); oder es treten in den Gliederzellen ersten Gades noch regehnissig weitere Quertheilungen auf, wie dies besonders in den zusammengesetzten Körpern grösserer Pilze der Fall ist. Exquisite Beispiele Glaviceps, Rhizomorpha subterranea u. A.). Aus der Keinzelle entwichelt sieh, in später zu beschreibender Weise, zunächst die einzelne Hyphe. Diese bildet bei den einfacheren Formen, welche als Fadenpilze, II yphom g eeten, Haplom yceten bezeichnet werden, für 
sich allein auch den fertig entwickelten Thallus. Nicht minder ist aber auch der Körper der ggösseren, massig entwickelten Pilze, der Schw:imme des gewöhnlichen Sprachgebrauchs, immer aus den soeben characterisirten Pilzficten zusammengesetzt, indem solche nach bestimmten Reg̣eln zur Bildung eines grösseren Ganzen zusammentreten und miteinander heranwachsen. Der Körper der grösseren Schwimme ist daher passend eine Colonie von Pilzfïden oder von Haplomyceten genannt worden; er sei in folgendem mit dem Namen zusammengesetzter Pilzkörper bezeichnet, zur Lnterscheidung ron dem freifadigen Körper der e in fa chen Haplomyceten.

Das Wachsthum des zusammengesetzten Schwammes, soweit es in Neubildung ron Zellen und nicht in Ausdehnung der bereits rorhandenen besteht, kommt lediglich durch das Lingenwathsthum der Hyphen, aus welchen er besteht, und durch die Bildung neuer Zweige an ihnen zu Stande, welch letztere sich theils zwischen die vorhandenen einschieben, theils den oberflichlichen aussen anlegen.

An dem fertig entwickelten Schwamme laisst sich die Zusammensetzung aus IIyphen meist leicht erkennen, mit blossem Aug̣e als feine Faserung, mit dem Vikroskop ist der Verlauf der cinzelnen Fäden und ihrer Zweige oft auf reite Strecken hin zu verfolgyen, sei as dass sie parallel nebeneinander stehen, oder dass sie vielfach durcheinander geschlungen und rerflochten sind. Beispiele dafür werden in den folgenden Capiteln violfach angeführt werden. In den früheren Lehrbuchern ist das Fadengeflecht der Pilze als Filzgewebe tela contextaj bezeichnet worden. S. Schleiden, Grundz. 3. Aufl. I, 269. Unger, Anat. u. Plı̣siol. d. Pfl. p. 149

Bei eincr Anzahl von Schwimmen scheint allerding der ganze Thallus oder einzelne Theile desselben eine andere Zusammensetzung zu haben. Das ausgebildete Gewebe besteht hier aus isodiametrischen, rundlichen oder polyedrischen Zellen, welche, zumal auf diumen Durchschnitien, eine Anordnung in Reihen nicht mehr erkennen lassen. Es ist somit dem Parenchym höherer Gewïhse dem Ansehen nach ihnlich. Beispiele hierfür bieten die Hüte von Russula, Lactarius, die Rinde vieler L reoperdaceen-Peridien, manche Sclerotien, vor Allem der sticl der Phalloideen, und Andere, von denen später die Rede sein wird. Entersucht man solche Gewebe jedoch genauer, und rerfolgt man besonders ihre Entwichehungseschichte, so zeigt sich aufs deutlichste, dass sie aus Pilzfiden entstehen und bestehen und dass sie ihre scheinbar parenchrmatische Structur nur der festen Vereiniğung der Hyphen, der Gestalt, Ausdehnung und Verschiehung ihrer Gliederzellen verdanken. Das Parenchym der Cormophyten, der Fucoideen, Florideen u. s. w. entsteht durch Zelltheilungen, bei denen die successive entstehenden Scheidewinde abwechselnd nach drei oder zwei Raumdimensionen gerichtet sind Zellkörper, Zellflichen Nigeli. Die Pilzfiden sind nach dem Angegebenen durchweg Zelllinien; Theilungen. welche Zellfliachen und Zellkörper produciren, hommen nur bei gewissen Reproductionsorganen, nie im Thallus der Pilze vor. Es ist daher rom anatomischen Gesichtspunkte aus nothwendig, die parenchimaihnlichen Gewebe der Pilze von dem eigentlichen Parenchym wohl zu unterscheiden, und will man für sie einen besonderen Namen hahen, so wird die Bezeichmung als Schein parench y oder Pseudoparench ym passend sein. 
Die in Vorstehendem darg̣estellte Anschauung über die Structur und das Wachsthum des Pilzhallus ist schon in Ehrenbergs Epistola de Mrectogrenesi Nov. Act. Ac. Nat. cur. tom. I bestimmt mgedeutet. Klar ausgesprochen findet sie sich in Villadini's Monoger. Lycoperdineorun (81) in Mém. Acad. Turin. Gor. II, Tom. V, 1. 116. Die Insichten Spaterer Montagne, Esquisse oreranographigue de. sur les champignons, Paris 1841, deutseh Prag 184. Solıleiden, Grunclz. 3. Auil. II. p. 34 deuten ahnliches an. Vollstindiger hegründet und durchgofüht konnte sie erst durch neuere anatomische Entersuchungen worden, zu wolehen Bonorden und sichacht den hauptsichlichsten Instoss und die ersten hedentenderen Materialien galiefert haben. Vgal. Bo-

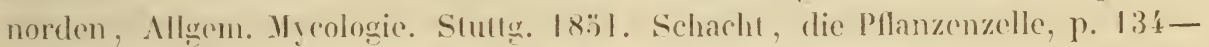
150. de Bary, Cnters. üb. d. Brandpilze. p. 8\%.

Was die vereinzelten oben angedouteden Ausnahmsfalle von Pilzen, welche nicht aus Hypleen des beschriebonen Baues bestehen, anlangat, so gechören zu denselben erstlich die sog̣enamnten II fepilze Hormiscium, Cryptococeus, Torula ex parte auct. , Organismen, welche aus ovalen, rundlichen, liinglichen Zellen bestehęn, die zu verzweig̣ten rosenhranzförmig̣en Reihen locher verbunden sind und sich durch eigenthiumliche. im flen Capitel niher zu beschreibende Sprossung vermehren. Die Art ihree Verumehrung stimmt mit der Bil-

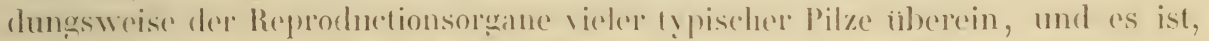

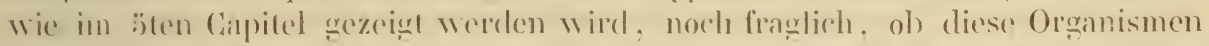
fiir sich eigene liten reprisentiren, oder ob sie nichts weiter als eben Reproductionsoresane ly pischer Pilse sind.

Zweilens sind hier zu nemnen dis von . B. Braun entdeckten Chytridieen, Oreanismen, welehe mit den Pilzen in ihrem physiologrischen Verhalen iibereinstimmen, in morphologisher Bozichung aber als aine besondere, von den lypischen Pitzen versedicelene Ordumg zu betradren sind, wemn sie atuch Anknüpfungspunke an jene darbielen. Sie bestelen aus einer nahezu isodiametrischen, je nach den Arten verselneden gestableten Zelle, woleder, nachdem

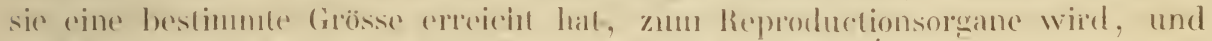

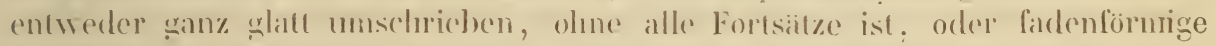
wurzelithnliche Fortsitze aussendel. Letztere sind entweler on soleher Zartheit, dass sie heinerlei struelur erkennen lassen; in anderen Fillen zeigen sie

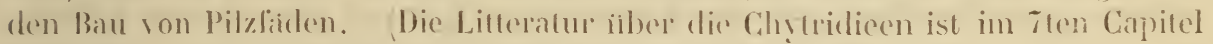

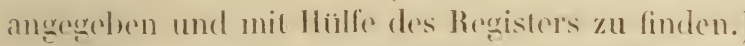

Driltens emdlich ist cine Gruppe von Organismen den Pilzen angereiht und von Nigeli Verhandl. d. Naturforschervers. zu Bomn) als Schizonyceten hezeichned worden, welche, morpholog̣isch hetrachter, von den Pilzen auszuschliessen und den Oscillarieen an die Seite zu stellen sind, wenn auch ihr legelationsproess dem der Pilze gleich ist. Sie bestolen aus Zollen von rundlicher oder hur\% cylindrischer form, die sich durch fortwihrende Zweitheilung vermehren und entweder frei, oder zu Reihen oder hleinen' hörpern vereinigt sinel, die an allen Punkten gleichmissig durch Zelltheilung wachsen. Hierher gehören die in Bezichung auf ihre Organisation noch hijehst ungeniigend bekamnten, meist ibleraus kleinen Formen, wolehe mit den Gattungsnamen Vibrio, Bacterium, Zoogloea Cohn. Yosema Xig. Sarcina u. s. w. bezeichnet, theilweise auch noch dem Thierreiche zugezihlt werden. 
Bei den Iypischen Pilzfiden ist die Gestalt der Zellen sehr mannigfaltig, meistens wohl, und besonders in jugendlichen Zustanden, mehr oder minder lang cylindrisch. Die einzelnen Formen hier aufzuzählen ware zwecklos.

Bau und Wachsthum der Zellen des Pilzthallus stimmen im Allgemeinen mit den fiir die Pflanzenzelle iiberhaupt bekannten iiberein.

Die Zellenmembran bleibt bei denjenigen Pilzen, welche schnell wachsen und im erwachsenen Zustande nur kurze Lebensdauer haben, in der Regel stets zart, structurlos, ohne merkliche secundäre Verdickung. Zahlreiche Fadenpilze und die meisten fleischigen Schwämme liefern hierfür Beispiele. Zufällige Verlangsamung der Grössenzunahme kann aber auch hier eine beträchtliche Membranverdickung zur Folge haben, wie Coemans bei Pilobolus gezeigt hat. Die Zellenwand vieler holziger und lederartiger Schwämme, zumal Gastromyceten und IIymenomyceten (Polyporus, Thelephora u. s. f.) ist oft schon in der Jugend relativ dick, im erwachsenen Zustande nicht selten gewaltig, selbst bis zum Verschwinden des Lumens, verdickt. So haben z. B. die Fäden der Hutsubstanz von Polyporus fomentarius, von Crucibulum vulgare (Sachs, Bot. Ztg. 18:35) und viele andere stellenweise das Ansehen solider Cylinder, wailrend sie an anderen Punkten mit deutlicher Höhlung versehen sind. Die verdickten Zellwinde sind entweder fest, spröde oder biegsam, oder aber gallertartig weich. Bei geringer Verdickung, wie an den Seitenwinden vieler Fadenpilze (Dematieen, Botrytis (inerea, Peronospora) ist die Membran in der Regel homogen, ungeschichtet, selbst die Querwinde sind meistens nicht oder nur schwer in zwei i.amellen trembar. Stark verdickte Zellwinde zeigen dagegen oft sehr deutliche Schichtung, entweder ohne Weiteres oder nach Einwirkung von Reagentien, welche Quellung bewirken, wie Kalilisung, Schulze'sche Mischung, Schwefelsiaure. So besonders die Hyphen und fruchttragenden Zweige von Cystopus, die Zellen dex festen Rindensubstanz von Rhizomorpha subterranea, die zuweilen vorkommenden verdichten Membranen von Pilobolus (Coemans). Die Zellenhäute vieler trockener, dauernder Pilzgewebe (Polyporus zonatus, P. versicolor, Daedalea, Trametes Pini. Lenziles betulina, die derberen Faden von Thelephora hirsula, die Capillitimfaiden von Bovista plumbea, Geaster, Tulostoma und viele andere, lassen oft wenigstens zwei Schichten deutlich unterscheiden, eine iussere, festere, oft lebhafter gefirbte und eine innere weichere, hellere. Auch künstlich, "io durch kochen mit Kali, ist eine weitere Schichtung hier meistens nicht sichtbar zu machen; doch gelingt dies oft bei den Hyphen der älteren Ilutsubstanz von Polyporus officinalis. An dieser sieht man in $W$ asser eine iussere dimne, anscheinend feste und eine innere, sehr dicke, oilenbar weiche Lage. Beim Erwirmen mit Kalilösung wird die aussere Schicht nicht merklich veraindert; die innere quillt stark auf, so dass sie an den Enden von Bruchstiucken oft tropfenartig aus der ausseren hervortritt, und sondert sich dabei of in zahlreiche zarte Schichten.

Sehr schöne Schichtung zeigen besonders viele Pilzzellen mit gallertiger, in Wasser stark quellbarer Membran. Bei Geaster hygrometricus hat sie Tulasne Ann. sc. nat. 2 Sér. XVIII.) schon vor 20 Jahren abgebildet. Die innere Schicht der sternförmig aufreissenden ausseren Peridie dieses Pilzes besteht aus geraden, gleichhohen, dicht aneinandergedraingten Fäden, welche unter einander parallel und auf der iusseren Schichte senkrecht stehen. Sie haben eine 
dicke, im trockenenen Zustande knorpelharte, im Wasser zu zäh-gelatinöser Consistenz aufquellende Membran, welche auf Querschnitten drei bis fünf Schichten von verschiedenem Lichthrechungsvermögen zeigt. Mit den äussersten Schichten stossen die Fiden fest aneinander, ihre Grenzlinien bilden auf dem Querschnitte ein scharf gezeichnetes Netz. An alten Exemplaren ist diese Structur oft verwischt.

Ganz ihnlich der beschriebenen Schichte ron Geaster is das trocken knorpelige, im Wasser gallertig quellende Gewebe anderer Pilze beschaffen. Die Wand der Kammern von Hy̧sterangium clathroides (Tulasne, funģ hỵpog̣.), die innere Substanz vicler Sclerotien, \%. B. der schwarzrindigen Peziza-Sclerotien Scl. compactum, variunı, durum Auct.), des Scl. ('omplanatum und Anderer, erscheint bei der mihioskopischen Lntersuchung auf don ersten Blick aus einem ziemlich lockeren Greflecht diinner Fiden gerbildet, wolche riner homogenen durchsichtigen Gallerte oingebettet sind. Die Firlen schen aus wie enge, in die Gallerte gebohrte Kanile, deren jeder aine diinne glimzende, wenig quellbare Membran besitzt. Dimne Durchschnitte, oder Bohandlung der Praiparate mit Alkohol zeigen, dass die durchsiehtige Gallente heineswegs eine homogene structurlose Masse darstellt. Vichmehr besteht sic aus ebensoviclen durchsichtigen Gallertschoiden, als Fidden vorhanden sind, und diese Scheiden stehen zwar allenthalhen in imnig̣er Beriihrmọ mit cinander. dic Grenzen der einzelnen sind jedoch auf geeigneten Priparaten sehe leutlich als zarto Linien erkennbar. Somit besteht die Wand des einzelnen Fadens aus zwei Lağen, der gelatinösen dorchsiehtig̣en Scheide und der dimmen galinzenden Ilaut, welche das Lumen Immitlelhar umgiht. Beide Theile sind oft durch eine scharfe Linie von einander getrennt, sehr hiuffig aloer auch - und dies beweist, dass sie zusammengchörige Theile cines Ganzen sind - fliessen sioganz allmiblich in cinander über. Bei sel. durum sah ich die innere galinzende Lagge durch Erwarmen in Kalilösung moistens in zwei scharf getremnte sohichten zerfallen.

Der untere Theil Stiel der istigen Körper von Calocera viseosa besteht aus Ifyphen, welche alle der Langsadise des lilz's nahe\%u parallel verlaulen. Dünne Querschnitle durch den Sticl geben daher die hreisfömig̣en oder polygonalen Dnrchschnitte der einzelnon Zellen. Die ausserste der drei concentrischen Gewoheschichten, aus welchen der Stiel besteht, ist im frisehen Znstand von klebriğgallertarliger beschaffenheit, sie wird von dünnen, derhwandiggen Faiden grobildet, welche auf den ersten Blick einer wrichen, homogenen Gallerte eingebellet sind. Macht man aber diimme Querschnitte dorch den eingetrockneten Sticl mol lisst dieselben alsdann langsam in Wasser aufquellen, so erkennt man auch hier, dass die Gallerte aus ehensoviclen gूelatinösen, einander allenthalhen imnigg beribluenden Membranschichten gebildet wird, als Fiden vorhanden sind. Liingere Einwirhung von $\mathbb{W}$ asser lisst die zarten Grenzlinien der Scheiden vollstiindig verschwinden, diese in eine homogene Masse verfliessen.

Dic oben beschriebenen Fille zeigen einerseits das Vorhonmen ron Schichten versehiedener Diehtigheit und Quellbarkeit an rerdickten Zellmembranen, andrerseits folgt aus den mitgetheilten Thatsachen, dass die scheinhar homogene Zwischensubstanz zwischen den Hyphen der bezeichneten Pilze, ogleich der Pseudointercellularsubstanz vicler Fucoideen, Florideen u. s. w., nicht als eine von der Zellmembran differente homogen ausgeschiedene Intercellularsubstanz 
zu betrachten, sondern durch die imnige Berihrung und theilweise Versehmelzung der iusseren gallertigen Verdickungsschichten sämmtlicher Fiden zu Stande gebracht ist.

Sehr vicle Pilzạewebe Melanogaster. Tremella, Exidia, Guepinia, Dacryomyces. Bulgaria, Thelephora mesenterica, Mitremyces, Cyttaria, Panus stypticus, die Peridien der Phalloideen, die jugendlichen Nidularieen. die zerfliesslichen Körper ron Ceratium, die Oberfläche vieler IIymenomyceten, z. B. Agaricus Mycena Sect. glutinipedes Fr., Amanita muscaria, Boletus luteus und viele anderej haben gallertige Beschaffenheit und stimmen, was ihren Bau betrifft, mit den beschriebenen Geweben ron Calocera, Hỵsterangium u. s. w. überein, nur dass die interstitielle Gallerte meist wirklich als eine homogene Masse erscheint und bis jetzt nicht in den einzelnen Faiden angehörige Theile hat zerlegt werden können. Vielleicht gelingt dies noch bei manchen hierhergehörigen Formen. Nach den mitgetheilten Beobachtungen bei Calocera, und bei der nahen Verwandschaft und sonstigen Uebereinstimmung des Baues, welche zwischen Calocera, Guepinia, Tremella, zwischen Ily sterangeium, Phallus u. s. w. vorhanden ist, scheint es aber jedenfalls gerechtfertigt, die homogene Gallerte aller der erwihnten Pilze für nichts anderes als ein Product der Verschmelzung weicher, gallertartiger Verdichungsschichten der Zellmembranen zu halten. Auch H. Iloffmann deutet diese Ansicht an. wem er lcon. analỵt. fung. p. 12, 25) die Gallerte in der Hutoherfliche fleischiger Itymenomyceten als ein Verflüssigumasproduct der Membran bezcichnet. Fiir die simmtlichen oben besprochenen Gewebe werde ich in den spateren 1 bschnitten die Ausdrucke Gallertgewebe oder Gallertlilz colorauchen.

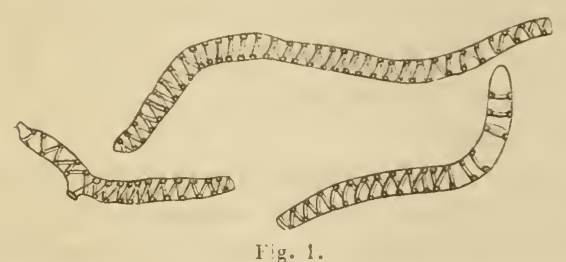

finden sich auch fiur ihr Vorkommen Beispiele.

Die spindelförmigen. zwischen den reifen Sporen von Batarrea zerstreuten Capillitium- Zellen zeigen, wie Berkeley zuerst angab Hookers Journ. Vol. II. I8:3. anch Introd. to crypt. Bot. p. 8, 343 zierliche Spiral- und Ringlasem Fig. 1). Die Wand der Capillitiumröhren von Podaxon carcinomatis L. Berkeley. Hookers Journ. Vol. IV. p. 292 zeigt, vielen Holzzellen ihnlich, eine zarte spiraligye Streifung. und zerreisst leicht in der llichtung der Streifen zu einem spiraligen Bande Fig. 2.

Zarte Tuipfol finden sich an den Capillitiumfasern von wie es scheint allen Lycoperlonarten z. B. L. pusillum, L. Bovista. L. giganteum: sie fehlen dagegen an den gleichnamigen Organen

Fig. 1. Capillitiumzellen von Batarrea Steveni Fr., 390 fach vergr.

Fig. 2. Podaxon carcinomatis L. Stiick einer Capillitiumröhre, $390 \mathrm{mal}$ vergr. Nach Exemplaren aus dem Kunze'schen Herbar in Leipzig.

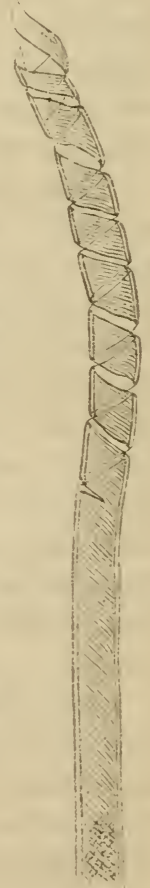

Fig. 2. 
anderer verwandter Genera Tulostoma. Bovista, Geaster etc. . Die dicken, aus zwei halblinsenformigen Lamellen bestehenden Querwinde von Dactỵlium macrosporum Fr. zeig̣en in ihrer Mitte einen grossen Tüpfel, in ganz ähnlicher Weise wie die Querwinde von fadenförmig̣en Florideen, z. B. Callithamnion Fig. 3.

Bei anderen Fadenpilzen fand ich derartige Tüpfel nicht. ihre Querwinde sind meist zart, manchmal, z. B. bei Botrytis cinerea, scheinen diesolben allerdings in der Mitte diinner als am Rande zu sein.

Dis angeführten, zum Theil laingst bekannten Thatsachen zeigen, dass die Zellwand der Pilze keineswegs allgemein so ung̣leich einfacher als z. B. die der Algen gebaut ist, wie man nach ganz neuen Angaben Schacht, L.ehrb. Anat. Phỵsiol. I, 158 glauben sollte. Dass die Struetur der Membran wenig in die Augen fillt. hat seinen Grtind wohl vielfach in der geringen Breite derjenigen Pilzzellen. welche verdickte Winde haben.

Was die stoffliche Zusammensetzung der Zellmembran betriff, so haben die Analysen in einer Reihe von Fillen Polyporus iqniarius, $\Lambda$ garius campestris [Payen]. Polyporus officinalis [Frombere], Polyporus fomentarius, Daedalea quercina Schossherger und Döpping das iibereinstimmende Resultat ergoged)en. dass sic. nach gehöriger Reinigung, die clementare Zusammensetzung der Cellulose zeight. ^. Kaiser hat dies noch neuerdings für Amanita muscaria bestiitiọt. Bracennot's Fung gin ist Cellulose mit fremden Beimengungen. Die characteristischen Reactionen der Codlulose gegen Jod zeigt auch dic nicht gefirbte und nicht verdichte Collulosemembran der meisten Pilze nicht, auch nicht wenn sie mit kali oder der Schulzeschen Mischung behandelt worden ist. Sie wird durch Jod, Chlorzinkjod, Jod

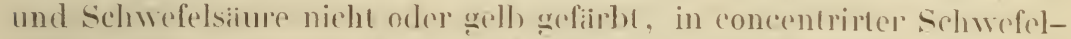
sibure quillt sio weit weniger oft haum merklieh und wired woit schwierig̣er zerstört, als l! pische Collulose. In hupferorydammoniak scheint sie direed nic löslich zu sein. Sie kann füg̣lich als eine beson-

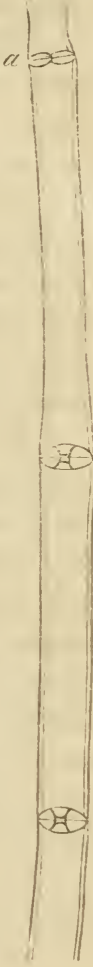

Fig. 3. deie For'm mit der Bezcichnung Pilzoellulose unterschieden werden. (A. Kaiser fand die Cellulose des Strunkes von Amanita muscaria löslich in Salzsidure.

Die gewöhnliche Celluloseform. welche durch Jod und Schwefelsimere und Chlorzinhjod blau oder violett wird. hommt ibrigens einer nicht unbetrachtlichen Zahl von Pilzen zu. So zunichst allen Saprolegnien: simmtlichen Peronospora - und Cystopus-Arten, dem Protonyces macrosporus Lnger. Bei diesen "ird die Jlembran der ganzen Pflanze durch Jod und Schwefelsiure schön und rein blau, nur bei der Peronosp. infestans fand ich öfters keineswegs immer) die blaue Fïrbung auf die fruchtlagenden Iyjhen beschrinkt.

Enter den Mucorinen fand ich die jugendlichen Membranen von Mucor Mncedor und Ilucor fusigger Lk. durch Jod und Schwefelsiure blau werdend,

Fig. 3. Dactylium macrosporum Fr. Zellmembranen eines stückes von cinem fruchttragenden Faden, mit zwei alten, stark verdickten und von einem eentralen Tüpfel durchsetzten, und, bei $a$, einer jüngeren Querwand. Vergr. ungefähr 300.

1) Ich habe diesen Pilz früher (Bot. Ztg̣. 1854, pag. 466) mit Rhizopus nigricans Ehr., der durch Jod und schwefelsäure nicht blau wird, verwechselt. 
aittere Membranen fäben sich, auch nach Maceration in Kali, nicht mehr. M. macrocarpus C. zeigte nie Blaufirbung. Coemans sah die Membran von Pilobolus, Mucor, Hydrophora, Ascophora durch Chlorzinkjod rosenroth gefirbt. Das Gleiche gibt er für Aspergillus und Polyactis an, wo ich es bis jetzt nicht bestiitigen konnte.

Blaue und violette Cellulosefarbung zeigen ferner die Membranen von Anthina pallida, purpurea, flamınea. Bei Clavaria juncea beobachtete ich in einer Anzahl von Fällen intensive Violettairbung, in anderen Fiallen war dieselbe nicht hervorzurufen. Andere Clavarien zeigen nur Pilzcellulose.

Hierher gehören vielleicht auch die Beobachtungen von H. Iloffimann, der bestimmte Stellen des Hutes von Amanita phalloides in Jod und Schwefelsiure blau werden und mehrfach, z. B. bei Agaricus metatus, Pilzzellen nach lingerer Maceration in Wasser blaue oder violette Jodfirbung annehmen sah. Joch ist es nicht ausser Zweifel, ob diese Erscheinungen die Meunbran allein oder den Zellinhalt betreffen.

Eigenthümlich verhält sich die Membran junger Hyphen von Syzygites megalocarpus Ehr. In wässeriger Jodlösung nimmt sie sofort lebhaft violettrothe Farbe an; bei Zusatz diluirter oder concentrirter Schrefelsiure wird sie farblos und quillt auf etwa das Doppelte ihrer urspriinglichen Dicke auf. Chlorzinkjod ruft ahnliche, doch mehr braunviolette Farbung hervor wie Jod. Nle Hyphen zeigen keine Färbung mehr. - Aehnliches beobachtete Schacht an den Hyphen eines unbestimmten Pilzes in faulem Eichenholz. Jodlösung und Chlorzinkjod farbten ihn blau - ob aber die Membran allein, oder den Inhalt ist ungewiss durch Zusatz von Schwefelsaure verschwand die Farbe. Nach Behandlung mit kochender Kalilösung wurde er durch Jod und Schwefelsiure violettroth. Eine Blaufarbung der Membran durch einfache Jodlösung ohne Sehwefelstiure tritt an den Zellen und fadenförmiggen Anhängseln der Fruchtbehialter Perithecien) mehrerer Erysiphe-Arten cin Tulasne, Ann. sc. nat. fe Sèr. Tom. VI, p. 318).

Ferner werden durch Jod rasch dunkelblau gefiirht die Fiden des Thallus von Polystigma rubrum und fulvum, weleher die Blitter von Prunus-Arten bewohnt. Bei völlig ausq̣ebildeten Exemplaren hat es den Ansehein, als seien die Fäden von unregelulissig-stabförmigen, den Zellen derselben fast gleichbreiten Stirkekörnern ausgefiillt; nur schmale nicht blau werdende Querzonen tremnen letztere von einander. Die Entwickelungsgeschichte zeiggt aber, dass die Amylumreaction einer ungeschichteten Verdickungsmasse der Membran angehört, welche, durch die genannten schmalen Querzonen unterbrochen, einer diunnen aiussersten Membranschichte innen angelagert ist, und in den erwachsenen Fiden das ganze Lumen der Zellen ausfiillt.

Hier ist endlich H. r. Mohl's Beobachtung anzuführen, nach welcher bei Septoria Ulmi die gallertartige Masse, die zwischen den papillenförmigen, wahrscheinlich sporenabschnürenden Zellen des Fruchtlagers liegt, durch Jod dunkelblau gefirbbt wird.

Was die gallertigen Membranen betrifft, von denen oben die Rede war, so ist ihre elementare Zusammensetzung noch bei keinem Pilze untersucht worden. Ihr Verhalten gegen Reagentien entspricht im Allgemeinen den für die gleichnamigen Substanzen anderer Pflanzen bekannten. Blaufärbung durch Jod habe ich nirgends gefunden. Ein eigenthuimliches Verhalten fand ich bei der Gallerte 
des schliupferigen Ueberzugs von Agaricus vulgaris. Während sie pin dem Verhalten gegen Wasser und Alkohol mit der von anderen Pilzen übereinstimmt, durch Jod, Salpetersäure, Zucker und Schwefelsäure nicht veräindert wird oder höchstens unter Einwirkung von Schwefelsäure etwas schrumpft, bewirkt Kalilösung in weit höherem Grade als Alkohol augenblickliches Zusammenschnurren; ein grösseres Stiick der Gallertmasse erhäilt durch genanntes Reagens rasch das Ansehen einer gerunzelten Haut.

Die Membran iilterer Zellen ist, besonders bei den Pilzen von lingerer Lebensdater, sehr oft gefïlbt, meistens in verschiedenen Nüancen von Braun, selten anders, z. B. rosenroth bei Dactylium macrosporum, blau bei Peziza cyanoderma m. Die Firbung deutet ohne Zweifel eine Veränderung, eine Verholzung der ursprüglichen Cellulose an. Die so beschaffenen Membranen zeigen meist eine ausserordentliche Resistenz gegen coneentritte Schwefelsiure, sie können in dieser lange Zeit anscheinend ganz unverindert bleiben. Schacht fand, dass das bramngefirbte Gewebe ron Polyporus igniarius durch mehrmaliges Kochen mit Kali entfirbt wirl, und alstann in Schwefelsiure ebenso wie das jugendliche zerfliesst. In der Schulze'schen Mischung löste sich das ganze Gewebe auf; das namliche geschah unit den grefirbten Spitzen der Paraphysen von Helvella escoulenta.

Ausgedelıntere Éntersuchungaen der verholzten Pilzmenthanen fehlen zur Zeit noch.

Ueber die Beschaffenheit der Pilzzellnembluan sind, ausser den oben citirten Schriften, zu vergleichen:

Schacht, die Pflanzenzelle, p. 136 fr. Idem, Lehnbuch d. Inat. d. Pfl.

Coemans, Monographie du genre Piloholus, in Mem. des savants etrang̣. Acad. Brus. Tom. .xx.

Caspary, Monatsber. der Berliner Ieatenite, Mai 18303.

H. Itoffinann, Bot. Zeitg. 1856, p. 1:38.

H. v. Mohl, Bot. Zeitg. 18̈34, p. 771 .

de Bary, Untsrs. über d. Brandpilze. Idem, iiber Inthina, Hedwigia, I, 36). Idem,

Bot. Zto. 1854, P. 466.

Braceonot, Ann. de Chimic XII, 172.

Payen, Mémoire sur le développenent des veggetaux. Mémoires présentés à l'Acad. des sc. de France. Tom. IX 1846$\}$ p. 21.

Mulder, Physiol. Chemie, Brannschw. 1844-51, p. 202, 203. Daselbst die Resultate v. Fromber $\underline{\mathrm{g}}$.

Sehlosiberger, Ueher die Natur der Hefe, Ann. d. Chem. u. Pharm. Band 31, p. 206. Schlosiberger u. Döpping, Beitr. z. Kienntı. d. Sehwämme. Ibid. Band 52, p. $1 / 6$.

A. Kaiser, Chemp. Unters. des Igarieus muscarius L. Inaugural-Diss. Göttingen 1862.

Ueber das Protoplasma der Pilzzelle sind hier heine Besonderheiten zu berichten: Auch die Besonderheit ist zuriickzuweisen, welche Sachs Bot. Ztg. 18:3:) angibt, dass nimlich die spitzen wachsender Hỵphen aus einer Masse bestimden, in welcher Membran und Inhalt noch nicht gesondert wairen. Ich habe in solehen lebhaft waehsenden Spitzen imnter nur, wie bei anderen Pflanzen, rine dichte, von einer zarten Membran ringِsumgebene Protoplasmamasse gefunden. Vacuolenbildung innerhall) des Protoplasmas findet sich in alteren Zellen der Pilze allgemein und wesentlich in derselben Weise wie bei anderen 
Pflanzen. Die Protoplasmastreifen, welche zwischen den Vacuolen liegen, haben bei cylindrischen Pilzzellen oft alie Form quergesteller, dünner Plittehen, sie sind daher früherhin nicht selten mit den der Membran angehörenden Querwänden verwechselt worden, ron denen sie durch Reagentien leicht unterschicden werden können.

Zellkerne sind in den Zellen des Pilzthallus bis jetzt nicht nachgewiesen. Schachts Angaben uber ihr Vorkommen und ihre unendliche Kleinlreit sind nicht zurerlaissig, weil er in anderen Zellen der Pilze die deutlichen Kerne mit anderen Körpern Oeltropfen confundirt. Die Frage nach dem Vorkommen des Zellkerns in dem Pilzthallus ist jedoch um so weniger als abgeschlossen zu betrachten, als er jedenfalls sehr klein muss, und als er neuerdings in den Fortpflanzungszellen der Pilze, wo er lange ibersehen war, immer häufiger gefunden wird.

Wasserige Flissigkeit, Zellsaft sammelt sich mit der Vacuolenbildung innerhalb des Protoplasma an; alte Zellen, zumal fleischiger Pilze, sind ron ihr meist fast vollstindig ausgefüllt, bis auf eine oft ausserst dünne wandstindige Protoplasmaschichte. Dic 86. 90 und selbst 9' Procent Wasser, welche Schlossberger und Döpping in der Substanz fleischiger Hymenomyceten fanden, hommen jedenfalls zum grössten Theil auf Rechnung des wässerigen Zellsafies.

Die Quantiliat der wässerigen Flüssigkeit hann ibrigens, ohne das Leben des Pilzes zu beeintrichtigen, innerhalh weiter Grenzen schwanken. Bei Trockenheit der ungebenden Luft geht eine of grosse Menge derselben verloren: in Zellen mit fester rigider Membran treten Lultblasen an seine Stelle, zarthäutige collabiren. Reichlichere Wasserzufuhr und Beschriinkung der Transpiration stellen die frühere Beschaffenheit und Turgescenz wieder her. Das abwechselnde Turgesciren und Zusammensinken ist besonders bei vielen Hyphomycetenformen Penicillium, Botrytis u. s. w.) auffallend, deren Zellen im völlig feuchten Zustande strafl gespannt und e lindrisch sind. bei spirlicherer Wasserzufuhr aber zu der form platter, meist im ihre Lingsachse gedrehter Bänder collabiren. (Val. z. B. Fresenius, Beilr. z. Mycol. Taf. II.

Von anderen mit dem Mikroshop erkennbaren Inhaltshestandtheilen haben Schlossberger und boppping in dem ausgepressten Safte des Cantharellus cibarius Amylumkörnohen grofunden. Es ist anzunchmen, dass dicse zufällig von aussen in den Saft gehommen 1 aren, denn weder bei diesem noch irgend einem anderen Pilze hat die histiologische Entersuchung bis jeizt Stirkekörner naehweisen können. Von den scheinbaren Amỵlumkörnern bei Polystiğma war oben die Rede.

Fett, fottes Oel fehlt wohl haum einem Pilze. Es findet sich in Form gefirbter oder farbloser runder gylinzender Tropfehen von sehr verschiedener Grösse in dem Protoplasma oder den Zellsafte suspendirt.

Besonders reichlich, die Ilauptmasse des Zellinhalts ausmachend, sind Oeltropfen z. B. in dem Thallus von Sphacria Stigma Ilofhn.; Sph. discreta Schur., Sph. eut!pa Fr., in den Sclerotien ron Vermicularia minor Fr. und Clariceps purpurea (Tulasne. Letztere, das Mutterkorn, enthalten nach Winkler über 32 Procent fettes Oel (Jahm). 1. pract. Pharm. Bd. 26, p. 129). Offenbar ist in diesen Fällen das Fett wie in vielen Fortpflanzungszellen als Reservenahrung aufgespeichert. 
Farbstoffe. Für die Pilze durchweg characteristisch ist der mit ihrem Ernihrungsproeesse im nichsten Zusammenhange stehende Mangel ron Ch lorophill und rerwandten Pig̣menten. Eine grosse Anzahl ron Pilzen ist. zumal in der Jugend, ganz farblos. Viele, vielleicht die meisten Firbungen, welche man bei Pilzen wahrnimmt, sind jedenfalls, wie oben angefuhrt wurde, in der Zellmembran enthalten.

Von den dem Zcllinhalt eigenen Piğmenten sind in erster Linie diejenig̣en zu nennen, welche die orangegaelbe bis ziegelrothe Färbung so vieler Pilze Erelineen, Tremellinen, Thelephora hirsuta, Sphaerobolus, Pilobolus, viele Pezizen, wie P. aurantia, çanoderma und viele Andere - bedingen. Diese Färbungen rühren ron Substanzen her, welche, soweit ich sie priffen homnte, alle nach ihrer Lnö̈slichkeit in Wasser, ihrer Löslichkeit in Nlkohol und Aether, ihrem Lichtbrechung̣svermog̣en, den Felt - oder harzartị̣en körpern zügehören. Sie sind entweder in sche foiner Yertheilung dem Protoplasma allenthalben beigemengt, so dass sie diesem eine gleichförmige Firbung ertheilen Uredineen. pilobolus ete., oder sie bilden görossere runde Tröpfehen und Körnchen. welche

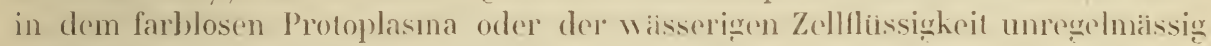
zerstreut sind. Beiderlei Formen der Vertheilung kommen afters bei derselben

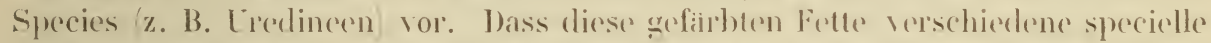
Eigenschaften halben, erelnt theils aus den verschiedenen Vüaneen des Colorits. theils aus dem verschiedenen Verhalten zu einig̣en Reagentien hervor.

Die rollegelbe Substanz der Lredineen nimmt dureh Schwefelsiiure sofort intensiv blane farbe an, welehe bald in selnmutzig̣es firin iiberg̣eht. und dann

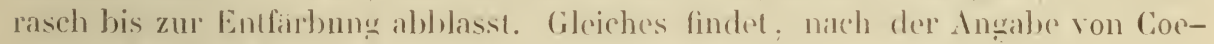
mans, bei Jilolodus stall.

Bei den untersuchten orangạefarlig̣en Pezizen. Trentellinen. Thelephora ete. fand ich diese Reaction nicht, die Farbe wird in Schwefelsime hlasser. Auch

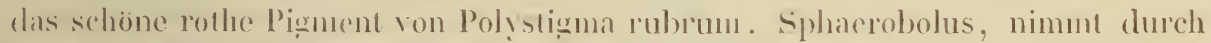
die siture nur cine edwas mehr violettrothe Firbunge an.

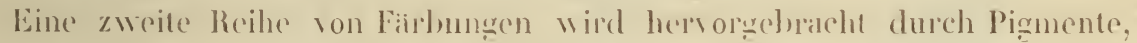
welche den Pilzzellen eigen sind, und, allem Anscheine nach in klarer wisseriger Lisung sowohl Membran als Inhalt der Zellen gleichmissig durchdringen. Dahin getoben verschiedene liabende Stofle, welehe sich an der Oberfliiche fleischiger Schwamme finden, z. B. der scharlachrothe des Fliegenschwammes, der blaugerime des Agaricus acruginosus, der gelbe des Boletus luteus: ferner das gelbe Pigment von-Sclerotium muscorum, der rothe von Cryptococeus gytutinis Fres. Beitr. z. Mryeol. II. p. 80 u. s. w. Auf dümen Turehschnitten erseheinen diese Pigmente so cyleichmissig rertheilt, und oft so blass. dass es mir meist unmioglich war sicher zu entscheiden, ol, sie der Membran, dem einen oder anderen Bestandtheile des Inhalts. oder allen geleichmissig̣ angehören.

1) Gleich dem rothen Sporeninhalt vieler Alqen, wie Vaucheria, Bolbochacte, sphaeroplea, dem Pigment der Bliithen von Gorteria, Calendula, den sogen. Iugenpunkt von Euslena, Rotiferen u. s. w. Siehe Abhandl. 1.-Senckenb. Gesellsch. J, p. 92. Bericht der naturf. Ges. Freibur@, 1sร6, p. 222. - In meinen Lnters. uiber die lirandpilze, p. 26, habe ich die Erscheinung, welche durch $\mathrm{SO}_{3}$ alle in hervorgerufen wird, irrthimlicher Weise der Wirkung von $\mathrm{J}$ und $\mathrm{SO}_{3}$ zugeschrieben. 
Die Diirftigheit dieser Angaben zeignt deutlicher als jede Auseinandersetzung, wie unvollstindig unsere Kenntniss der Pilzfarbstoffe ist und wie selır alle noch genauer untersucht werden missen.

Von den der Pilzzelle eigenen Pigmenten sind diejenigen zu unterscheiden, welche von dem Pilz unverändert aus dem Substrat aufgenommen werden. Man findet nicht selten den Inhalt von lebenden, normaler Weise farblosen Schimmeipilzen gefärbt, wenn sie Körper bewohnen, die einen löslichen Farbstoff enthalten. Fresenius, Beitr. p. 80). Ich fand dies z. B. bei Eurotium, Mucor, Rhizopus. Auch den in der Regel farblosen Zellinhalt von Peronospora infestans Mont. fand ich mehrmais lebhaft violettroth, wenn der Pilz auf rothen und. blauen Kartoffelknollen wuchs.

Ein sehr auffallendes hicrher gehöriges Beispiel stellt die Peziza aeruginosa Fl. dan. dar. Dieser Pilz bewohnt das in Wäldern hảufige gruinfaule Holz und ist gleich diesem oft lebhaft blaug̣iin gefairbt. Es wird bis in die neueste Zeit vielfach angegeben, dass das grünfaule Itolz durch die in ihm wuchernden Fiden des Pilzes seine Farbe erhalte, allein die Sache verhiilt sich gerade umgekehrt. Die Zellwinde des Ilolzes selbst besitzen die grüne Fäbung oft ohne dass auf weite Strecken eine Spur von Pilz zwischen ihnen zu finden wire, wie Güinbel richtig angibt. Man findet das bezeichnete Holz ungleich hiufiger olnne die Peziza, als mit derselben. Der Grund der Fäbung ist also keinesfalls in dem Vorhandensein des Pilzes, sondern vielmehr in dem Holze selbst, wohl wie fiumbel meint in einer besonderen Art der Verwesung desselben zu suchen. Kommt die Peziza auf solehem Holze vor. Was wie gesagt verhiiltnissmissig selten ist, dann nehmen meist alle Theile derselben den grimen Farbstoff auf, oft in so reichlicher Menge, dass sie dunkler gefaibt sind, als das Holz selbst; und zwar durchdringt das Pigment, soweit ich es unterscheiden konnte, gleichförmig alle Theile der Zellen. Manchmal findet man ibrigens einzelne Exemplare von der Peziza in ihrem oberen Theile rein weiss, zwischen anderen, mehr oder minder griin gefirbten. Vyl. Giimbel, Flora 18.58, p. 113. Bley; Archir f. Pharmacie $18: 38$. Vaupuclin, Ann. Mus. hist. nat. Tom. VIII (1806), P. $16 \pi$.

Es mag̣ hier erlaubt sein, einer streng genommen nicht in die Betrachtung der Farbstofle gehörig̣en Erscheinung zu erwähnen. Bekanntlich nimmt das ursprünglich gelle Fleisch einiger Boleti, zumal des B. luridus, eine blaue Farbe an. sohald es mil der Luft in Berührung kommt. Schönbein hat die Erseheinung niblher untersucht und gefunden, dass ein aus dem Pilze durch Alkohol auszichbarer, wahrscheinlich harzartiger Stoff der an der Luft blau werdende ist. Die Blitumng tritt an der alkoholischen Lösung derselben unter den nimlichen Bedingِung̣en ein, wie das Blauwerden einer Lösung ron Guajacharz, und da von letzterem nachgewiesen ist, dass seine Bliuung ihren Grund in ciner Verhindung mit ozonisirtem Sauerstoff hat, schliesst Schönbein auf die gleiche Ursache fïr die Blïunng des Pilzfleisches. Der Alkoholauszuğ des Boletus wird für sich allein an der Luft nicht blan: es muss daher in dem Pilze noch eine andere Substanz enthalten sein, welche den atmosphärischen Sauerstoff ozonisirt und tann mit dem blauwerdenden Harze eine Verbindung eingehen lïsst, ihn an letzteres im Ozonzustande abgibt. Anderweitig nachgewiesene Erscheinungen solcher Art berechtigen zu dieser Vermuthung. In der That wird 
Guajactinctur sowohl wie der Alkoholauszug des Boletus sofort blau, wenn sie auf das frische Fleisch einiger sich selbst nicht blaiuender Agarici, zumal des A. sanguineus, getröpfelt werden. Der ausgepresste filtrirte wässerige Saft des letzteren erzeugt in den beiden genannten Tincturen sofort blaue Farbe. Aus diesen Erscheinungen ist zu schliessen, dass cine Anzahl fleischiger Pilze einen im Wasser löslichen Körper enthalten, der Sauerstoff absorbirt und denselben in ozonisirtem Zustande in andere Körper abgibt. Die sich bliuenden Boleti enthalten jenen Körper neben einem zweiten harzartigen, der gleich dem Guajacharz durch Ozon blau wird.

Vyl. hierüber Schönbein, Verhandl. d. Naturf. Ges. Basel. 3. Heft. 1836. p. 339. Abhandl. d. K. Baier. Akad. Bd. VII. 1853. Auch Bot. Ztg. 1856. p. 819. Ferner: Bulletin de l'Acad. de Belgique. 2e Sér. Vol. VIII, p. 365 u. 372 . - Comptes rendus, 16 Jul. 1860.

Bei der Untersuchung der Pilzgewebe findet man überaus hïufig hrvstalle, wie schon Schinitz (Limnaea XVI, XVII, Sachs (Bot. Ztg. 18.5:), Tulasne (Mém. sur les Trémellinées u. Carpol. I, 11 : $)$, auch Corda (Icon. I, V Doratomyces) fiir einzelne Fälle angeben. Die hirystalle, welche ich chemisch untersuchte iels habe sie in der unten folgenden Aufzahlung mit (*) bezeichnet), sind unlöslich in Essig̣saiure, lösen sich ohne Gasentwickelúng in Salzsiure und Schwefelsiiure, in letzterer unter reichlichem Ansehiessen von Gypsnadeln: sie behalten beim Gliihen ihre Form und lösen sich nach demselben in Essigsiiure wie in Mineralsiuren unter lebhafter Gas- Kohlensiure-) Entwickelung. Sie müssen hiernach aus oxalsauerm Kalk bestchen. Für andere, bis jetzt nicht analysirte Fialle sie sind in der folgenden Jufzihlung olne*; ist die gleiche Zusammensetzung der Kirgstalle nach der Form und dem Vorkommen anzunehmen.

Im Innern von Zellen fand ich die Kirstalle his jetzt nur bei zwei Pilzen. Bei Russula adusta hommen kleine stabfömige krystallehen hie und da in den blasigen Zellen des stieles und Hutes vor. An den schmalen eylindrischen Fälen des Myceliums von Platlus caninus ${ }^{*}$ ) (rgl. meine Beitr. z. Morph. d. Pilze I.) finden sich einzelne zu grossen kugeligen oder flaschenförmigen Blasen erweiterte Zellen, welehe fast ausgefüillt sind ron einer grossen, aus oxalsauerm halh bestehenden glinzenden Kugel, die ein strahlig krystallinisches Gefüge besitzt (Fig. 1).

Meistens findet sich der oxalsaure Kalk

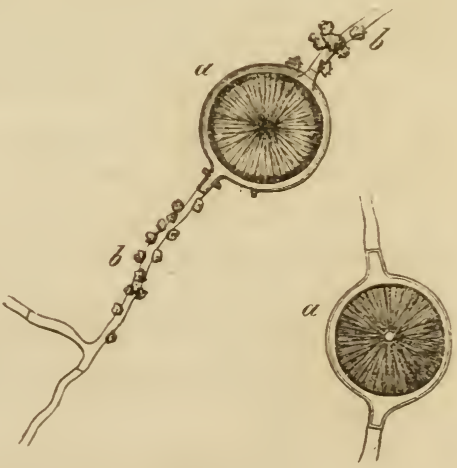

Fig. 4 . auf der Aussenfliche der Pilze oder in den Interstitien ihres Gewebes, und zwar vorzugsweise in jugendlichen Entwickelungsstadien, an alten Exemplaren ist er oft wenigstens schwieriger aufzufinden. Er tritt auf entweder in Form regel-

Fig. 4. II! phen von der Obertläche eines Myceliumstranges des Phallus caninus, $390 \mathrm{fach}$ vergr. a Blasenförmig̣e von einer kr!stallinischen kugel oxalsauern halks serfüllte Zellen. $b$ unlegelmässige kleine Drusen dieses Salzes, der Aussenfläche der Hỵhen aufsitzend. 
maissiger Quadratoctaeder, oder, am hiufigsten, unregelmiissiger Drusen oder Nadeln oder eckiger Körnchen.

Beispiele für sein Vorkommen, sowohl auf der Aussenfliche als in den Interstitien zwischen den H!̣hen, liefern zunichst viele Mycelien, die ihre weisse Farbe zum Theil jedenfalls dem Kalke rerdanken. Nadeln verschiedener Grösse finden sich reichlich auf dem Mycelium ron Agaricus aeruginosus ${ }^{*}$, A. campestris $\left(^{*}\right)$; die freien Hyphen desselben sind von den Krystallen oft wie ron Stacheln oder Härchen bedeckt Fig. :). Lnregelmaissige Drusen, Körnchen, selten Octaeder auf und in den Mycelien ron Hypochnus centrifug̣us Tul. (*), Agaricus nebularis (*), praecox (*), dryophilus *), Phallus caninus (rgle Fig̣. 4), Ph. impudicus, Sphaerobolus stellatus ${ }^{*}$, Clathrus cancellatus :) auch Stiibchen. Auch in den halberwachsenen Trieben ron Rhizomorpha subcortiealis liegen oft zahlreiche interstiticlle Octaeder und Drusen.

Drusen und Octaeder, selten kleine Körnchen kommen häufig in den Fruchttaigern fleischiger und lederartiger Schwimme vor, theils in den Interstitien des Gewehes, theils, bei Hymenomyceten, auf der Hymenialfliche. Zahl, Grösse und Form der Krystalle wechselt nach Arten und Individuen. Beispielsweise seien genannt: Vor allen Tremella $\left(^{*}\right)$, Hydnum gelatinosum **), Exidia auricula, E. glandulosa (*), Guepinia helrelloides ${ }^{*}$ ), Corticium calceum, das sein kreidiges Aussehen dem oxalsauern Kalke verdankt, C. amorplium Fr. $\left.\left.\right|^{*}\right)$, C. come-

Fig. 5 .

dens, Thelephora hirsuta (*), rubiginosa, incarnata; Stiel und Hut ron Agaricus praccox, dryophilus, rulgaris, campestris, Coprinus micaceus; Lenzites; Nyctalis asterophora. Ferner: Innere Peridie von Cyathus und Crucibulun Octacder, nach Schmitz und Sachs, Sticl von Tulostoma mammosum. (*); Geaster mammosus hat zahlreiche Ochaeder und Drusen zwischen den reifen Sporen. Ferner Stiel und Cupula ron Peziza tuberosa (*), Sclerotiorum (*), Fuckeliana; stiel ron Xylaria hulbosa (*), X. Hỵoxylon.

Das Vorkommen des oxalsauern Kalkes dürfte hiernach unter den Pilzen sehr verbreitet sein. Termisst hahe ich denselben bis jetzt bei allen IIyphomycetenformen, Lycoperton- und Bovista-Arten.

Eine ausführliche Zusammenstellung der chemischen Analysen von Pilzen wird der Leser hier nicht suchen. Es ist in dieser Beziehung auf die chemische Litteratur zu rerweisen, zumal auf Rochleder's Phytochemie, die oben citirten Aufsätze Schlosshergers und die Dissertation ron A. Kaiser (siche S. 9). Einzelnes hierher gehörige wird in der dritten Abtheilung dieser Arbeit noch zu erwihnen sein.

Was die Art der Zellentheilung anlangt, so ist hier nur hervorzuheben, dass sic bei den Pilzen in derselben Weise erfolgt, wie bei den übrigen Pflanzen (de Bary, Bot. Zıg. 18.4, 129. Champ. paras. Coemans, Monogr. Piloholus). Es ist diese Bemerkung nicht ïberfliissig gegenüber der irrigen Angabe von Reisseck, nach welcher die zwischen Vacuolen querstehenden Protoplasmaplittchen direct zu Cellulosequerwainden erhärten sollen. Ygl. Bot. Ztg. 18:33,

Fiğ. 3. Hyphenende rom IIycelium des Agaricus campestris, mit kleinen stabförmigen Kirystallen oxalsauern Kalks bedeckt. Verggr. ungefähr 390 . 
337. Eigenthümlich ist die Erscheinung, dass bei dem zirrlichen Botryosporium pulchrum Corda's di Querwinde der gabelig getheilten Ilaujtfïden immer in der Jitte offen bleiben.

Auch in den Ilyphen derjoniggen Pilze, deren Thallus Iypisch einzellig. (l. h. eine schlauchförmig̣e rẻristelte Zelle ist Mucorinen, Saproleğnieen, Peronosporecen beobachtet man nicht selten mehr oder minder zahlieiche, unregelmissig georlnete Querwinde, theils im Alter, theils bei einzelnen zumal ofters Peronosp. infestans bei besonders ippigen Individuen.

Dic Verzweigung der Ifyphen geschielı in selteneren Fillen durch Zweioder Dreigabelung der jugendlichen, wachsenden spitze Botryosporium, Peronosporae Spec. Syzygites; in der Regel durch ichte, untcrhall des Vegatationspunhtes auftretende Astbildung. Von den nach Arten sehr manniggaltigen Formen der Zweige sind hicr die Bildungen zu rwilhnen, welche Hoffmann Schnallenzellen, schnallenförmigge dusstulpungen, genannt hat. Sie finden sich selı hiufig, zumal bei Igaricinen, Typhula, Hypochnus, II!menogaster,

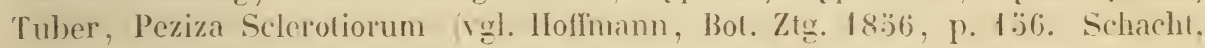
Pflanzenzelle, Taf. VI, 13. Tulasne, Carpol. I, 11:3. Bail, Hedwigeia I, 96, 98.

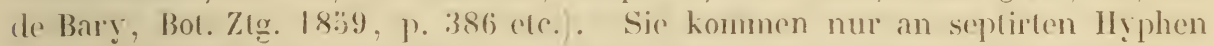
vor und sind kleine, dem Querdurchmesser des Fadens elwa gleiehgrosse Zellen oder Ausstiilpungen, ron meist unregchubissig halbkugghiger Form, welche aussen an den Querwinden dem Faden fest angerdrichi mnd so gestellt sind,

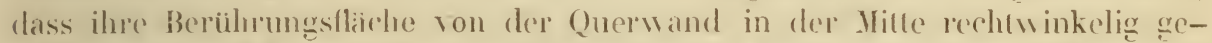
schnitlen wird. Sie entstehen, indem sich eine der in der Querwand zusammenstossonden Zellen dieht nohen dieser wic zur Zwrig̣bildung aussackt: die lussackung drücht sieh mit der einen Seite an den Rand der Querwand und an

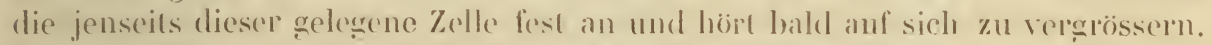
Entweder bleibt es herbei, die Aussachung verbleibt in offener Communication mit der Zelle, aus weleher sie entstanden ist so \%. B. steds bei IIypochnus cenurifugus Tul. ; oder die Aussachung trennt sich von ihrer Jutterzelle dureh rine

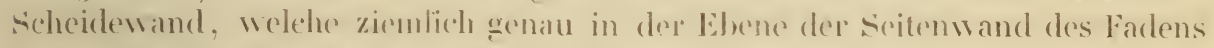
liceret, und sitzt letzlexem damn als besondere hleine Zelle auf, wic eine Schmalle auf eincou Bandl. Loberơinge dieser Schnallenbildumgren in verlingerte abstehende \%woige sind nicht sellen. Iuch homment es ror, dass die Aussachumgen ron ihrel Lrsplungsstelle an erst eine hurze sllecke mach aussen wachsen und damn in einem Bogren nach der jensoits dor Querwand geleg̣enen Zelle

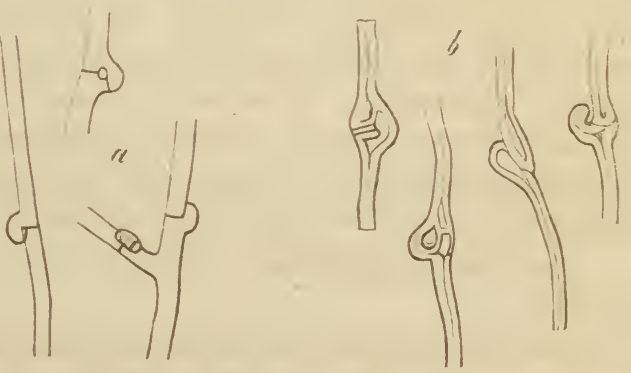

Fig. 6. umbiegen, um mit ihrer spitze der fotzteren fist anzuwachsen. Sie bilden somit an der Aussenflicho des Fadens ein kleines Oehr. Auch die von Tulasne und Sachs erwihnten Anschwellungen an den Ilyphen des Funiculus der Nidu-

Fig. 6. Schnallenförmige Ausstülpungen. a Vom Irycelium des IIypochnus centrifugus Tul., Verur. 390. $b$ lom Funiculus des Cyathus strialus, Vergr. etwa 720. 
larieen sind solche Schnallenbildungen. Ihr eigenthümliches Aussehen hat seinen Grund theils in ihrer betrachtlichen relativen.Dicke, theils darin, dass die Wand der Hyphen grösstentheils bis zum Verschwinden des Lumens verdickt ist, letzteres aber in den erweiterten Zellenden und Schnallenfortsätzen plötzlich sichtbar wird. Vgl. Fig. 6 .

Die Verbindung der Hyphen untereinander zu den zusammengesetzten Pilzkörpern kommt meistens dadurch zu Stande, dass sie miteinander verflochten sind, je nach der einzelnen Species in verschiedener Richtung und mit verschiedener Dichtheit des Geflechtes; locker verflochten, mit weiten meist Iuftührenden Interstitien sind die Hyphen der »flockigen, filzigen « Gewebe (Zunderschwamm, Daedalea, Stiel und Hut der Amaniten etc.), fast bis zum Verschwinden jeglicher Intercellularräume in den festen, oft horn- und holzharten Geweben, wie z. B. der schwarzen Rinde der trockenen Pyrenomyceten, der Tuberaceen, vieler Sclerotien etc. Von der zufalligen lockeren Verllechtung gesellig wachsender Hyphomyceten bis zu der, welche die Ityphen der festen, bestimmt geformten Pilze zeigen, sind alle Zwischenstufen $\mathrm{zu}$ finden; manchmal kommen selbst die verschiedensten Abstufungen bei ein und derselben Species vor, wie besonders bei Penicillium glaucum, welches als ganz einfacher unscheinbarer Hỵhomycet seine vollstindige Entwickelung durchmachen kann, oder, auf der Oberfliche von Flüssigheiten, seine IIyphen zu festen Ilauten verflechten, die sich wie ein Tuch abheben und aufrollen lassen, oder endlich aufrechte, bis zu 2 und 3 Millim. hohe, in ein fruchttragendes Köpfehen endigende Körper bildet, die von Link den besondern Namen Coremium glaucum erhalten haben. (S. Berkeley, Crypt. Bot. 370. Iloffinann, Bot. Ztg. 1860, p. 43. Tulasne, Fung. Carpol. 103, 227;.

Bei parallelem Verlaufe der IIphen, wie z. B. im Stiele von Agarieus Mycena, Coprinus u. s. f. wird die Verbindung durch Verklebung oder Verwachsung der Membranen zu Slande gebracht; und auf dieselbe Weise wird sie in den Geflechten oft bedeutend befestigt. In harten Geweben, $z$. B. der Rindensubstanz vieler nichtlleischiger Pilze, sind die Aussenflaichen der Hyphen oft untrennbar ancinander gewachsen, oder durch einen schmalen Streif homogener fester Substanz rerklebt; in fleischigen Pilzen ist oft eine in Wasser erweichende und eine künstliche Trennung der llỵ)hen ermöglichende Zwischensubstanz vorlanden. In wieweit dieselbe als ein Secret der Hyphen Intercellularsubstanz oder als Theil der Zellmembran selbst zu betrachten sei, lasse ich unentschieden, doch scheint mir kein Grund rorzuliegen sie anders, als die Bindesubstanz der Gewebe höherer Pflanzen zu deuten.

Von den gallertartigen Geweben ist schon oben ausführlich die Rede gewesen.

Auch bei gesellig wachsenden Hyphomyceten ist eine feste Verklebung der Aussenflichen ursprünglich freier Hyphen nicht selten; meistens kommt sie so zu Stande, dass kurze Zweige eines Fadens gegen den anderen wachsen, und ihre Enden diesem fest anlegen und ankleben.

Hier schliesst sich endlich eine Form der Verbindung an, die als Verschmelzung bezeichnet sein möge, da der oft für sie gebrauchte Ausdruck Copulation darum unpassend ist, weil er nur das Verschmelzen zweier Zellen. zum Zwecke bestimmter Fruchtbildungen bedeutet. Der Vorgang besteht darin, 
dass die Seitenwand oder das Ende eines Fadens sich fest an einen anderen anlegt, die Membran beider an der Beruhrungsstelle schwindet, und die Lumina der beiden verbundenen Zellen somit zu einem einzigen vereinigt werden. Diese Verschmelzung kann man häufig zwischen den Fäden gesellig wachsender Ilyphomyceten beobachten, besonders solchen, welche erst frisch aus den Keimen entstanden sind. Oft vereinigen sich viele derselben zu einem einzigen, netzförmigen Faden oder Schlauch. Aeltere, parallel laufende Hyphen treiben oft Zweige senkrecht gegeneinander, und verschmelzen mittelst dieser zu_Hförmigen Figuren. (Vergl. unten Fig. 60).

Es liegt nahe anzunehmen, dass die Hförmigen Verbindungen der Hyphen, welche man im Innern des Gewebes zusammengesetzter, zumal fleischiger Pilze findet, wenigstens oft solche Verschmelzungsproducte sind. Der Verschmelzungen und Ilförmiggen Verbindungen geschieht melıfach Erwihnung von Tulasne, Iloffmann (Icon. anal.) und schon Morren (Bullet. Acad. Brux. VI. [18:39] ]. 39 ).

\section{Capitel 2.}

\section{Bau des 'Thallus. Mycelium.}

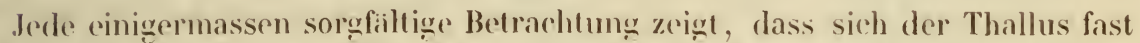
simmtlicher typischer Pilze aus zwei Hauptgliedern zusammensetz. Erstlich einem in oder auf dem Substrate verbreiteten, Nahrung aufuehmenden und aufspeichernden Theile, welcher seit Trattinick Fumg. anstriac. 1805, mit dem Namen I ycelium allgemein bezeichnet wird, von Necher, der sieh wunderbare Vorstellungen ïber seine Entstehung machte, Careithium, von lleyne und Ehrenberg Rhizopodium genannt wurde. Necker, Traite sur la mycetologie, 178.3. Ehrenberg, Epist. de Myeetogenesi. Nov. Act. Acad. L. C. Tom. X, 1821).

Das Myeclimm ist immer der aus den Keimen zuerst entwichelte Theil des Thallus. Von ihm entspringen damn zweitens die Fruchttriger Encarpium Trattinick, Reeeptaculum léveillé, Körper, welche die Fortpflanzungsorgane tragen. Das Myeelium vermag ihrel bei gehöriger Emährung oft einc grosse Zahl zu bilden.

Der Fruchttriger ist in den meisten Fällen der weitaus auffallendste Theil des Thallus; so selır, dass er vielfach für den ganzen Pilz genommen wurde und im gewöhnlichen Leben noch genommen wird, wie \%. B. bei den gestielt schirmförmigen nSchwimmen«. Sein frïherhin oft übersehener Lrsprung aus einem Myeclium ist jedoch gegenwärtig allgemein nachgewiesen; nur die oben als zweifelhaft bezeichneten Hefepilze haben bis jetzt ein Myceliun nicht mit Sicherheit auffinden lassen.

Bei wenigen einfachen Pilzen fehlt die Gliederung in Fruchtträger und Mycelium, die Fortpflanzungsorgane (z. B. die Asci von Protomyces, die Geschlechtsorgane der Peronosporeen) sitzen dem Mycelium unmittelbar an.

Ausser der bezeichneten Verschiedenheit ihrer Function unterscheiden sich Aycelium und Fruchttriger in der Regol durch die Art ihres Wachsthums. Die Mycelien pflegen, hinreichende Ernihrung vorausgesetzt, ein unbegrenztes peri- 
pherisches oder Spitzenwachsthum zu zeigen, die Fruchttriger ein Wachsthum, welches nach Ausbildung einer bestimmten Menge von Fortpflanzungsorganen thatsächlich wenn auch nicht potentiell) begrenzt ist. Beide Theile sind daher vergleichbar einerseits den vegetativen Sprossen, andrerseits den durch Bildung einer Auzahl von Blüthen in ihrem Wachsthum factisch begrenzten Inflorescenzen phanerogamer Pflanzen. Wie bei diesen in der Dornenbildung, den Blüthenständen von Ananassa, Melaleuca, Callistemon u. s. w. typische Ausnalımen von der Regel häufig̀ vorkommen, so finden sich solche Ausnahmen auch beim Pilzthallus in bestimmten, unten näher zu beschreibenden Fällen, wie der Sclerotienbildung, dem Wachsthum der Fruchttriger bei den Polypori placodermei, u. s. f.

\section{Das Mycelium.}

Die Mycelien sind bei ihrer Entstehung stets freie Hyphen. Entweder behalten sie diese Beschaffenheit immer, bei dem weitern Wachsthum verflechten sich die Hyphen höchstens locker, ohne zu bestimmt geformten Körpern zusammenzutreten : einfacli-fädige, flockige Mycelien; oder die Hyphen vereinigen sich zu verlingerten, aistigen $\mathrm{Str}_{\mathrm{r}}$ ïn $\underset{\sim}{\mathrm{y}} \mathrm{e}$ (fibröses, fibrillöses Mycelium), häutigen Ausbreitungen, oder knollenfölmigen, compacten Körpern, Sclerotien.

1. Die e infach-fädig̣e Ṃceliumform ist jedenfalls weitaus die häufigste, für die meisten Pilze ist sie allein bekannt. Ihre Beschaflenheit ist im Wesentlichen durch dasjenige beschrieben, was oben über die Pilzfiiden im Allgemeinen gesagt wurde. Besondere Eigenthümlichkeiten der Hyphen sind so
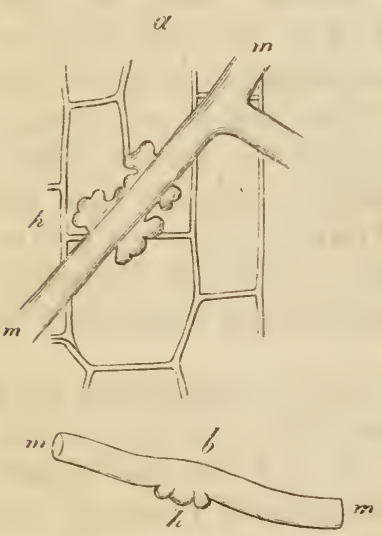

Fig. 7 . wenig vorhanden, dass es in vielen Fïllen schwer ist, ron einem sterilen Mycelium auch nur annähernd zu bestimmen, welcher Pilzspecies es angehört. Die Myceliumfaiden liegen meistens einfach auf oder in dem Substrat, olıne dass besondere Ilaftorgane oder Saugorgane zu bemerken waren. Es gilt dies sowohl für die auf todten Körpern lebenden, als auch für die Mehrzahl der Schmarotzerpilze. wenigstens konnte ich solche Organe bei parasitisehen Ascomyceten, Uredineen u. s. w. bis jetzt nicht finden.

Eine Anzahl parasitischer Pilze macht hiervon eine Ausmahme. Die Myceliumfiden von Er y s ip he, welche auf der Oberfliche lebender Pflanzentheile auswebreitet sind, hahen bei mehreren Species an ilıer unteren, die Epidermis berührenden Seite zahlıciche, unreg̨elmaissig g̣elappte Ausstiilpungen, welche sich den Epidermiszellen fest anlegen und alluählich ein Braumwerden und Absterben derselben verursachen. Zanardini hat diese Oræane bei dem Traubenpilze Erysiphe =

Fig. 7. Erysiphe Oidium) Tuckeri Berk. a Stiick eines Myceliumfadens (m-m) auf der Aussenfläche der Epidermis einer Weinbeere kriechend und mit dem Haustorium $h$ befestigt. Ansicht von aussen. $b$ freipräparirtes Fadenstück von der Seite gesehen. $h$ Haustorium. Vergr. 570. Nach v. Mohl, Bot. Ztg. 1853, Taf. XI. 
Oidium Tuckeri) entdeckt, v. Mohl und Tulasne haben sie genauer beschrieben. Bei E. Castağnei Lév. fand ich die Myceliumfaiden nur mit kleinen kreisförmigen, nicht ausgestiulpten Stellen ihrer Wand der Epidermis angedrückt und aufgewachsen. Ins Innere der Epidermiszellen dringen die Saugorgane Haustorien) von Erısiphe in den bis jetzt untersuchten Fillen nicht ein.

Inter den im Innern lebender Pflanzen regetirenden Parasiten sind die Peronosporeen mit Haustorien versehen. Die dicken Schlaiuche des Myceliums dieser Pilze kriechen zwischen den Zellen der Nihrpflanze, schmiegen sich diesen fest an, und treiben ins Innere derselben verschieden gestaltete Saugorgane, welche die Meunbran der Zellen entweder durchbohren, oder in seltneren Fiallen nur tief einstülpen. Bei Cystopus Fig. $8 A$ sind diese Organe Aussackungen der Seitenwand des Myceliums, wolche die Gestalt gestielter, kuggelig̣er Blischen besitzen, der sehr dünne Stiel durchbohrt die Wand der Nihrzelle, die Blase lieggt innerhalb derselben. Die Lainge der ganzen Organe hommt dem Querdurchmesser der Myceliumschlauche haum gleich. Bei den Peronospora-Arten sind die Haustorien theils den beschriebenen ähnlich, theils hahen sie die Form verzweigter, fadenformiger oder heuliger, ins Innereder Zellen eindringender Aeste (Fig. 8 B) .

2. Zu haiuligen lagern verflechten sich die Mycoliumfaiden nicht selten bei llyphomyreten, besonders dem schon oben erwibuten Penicillium graurum. Hie Iläule bedecken sich hier meistems bald mit Fruchutrigerern, und an diesen ist ilue Herhunft leicht zu erkennen. Steril wurden sie friilserhin oft als besondere Pilzformen hetrachled. und die Gatlung Mycoderma Pers. Mycol. europ. P.96 mag wenigstens zum Theil aus ihnen bestehen.
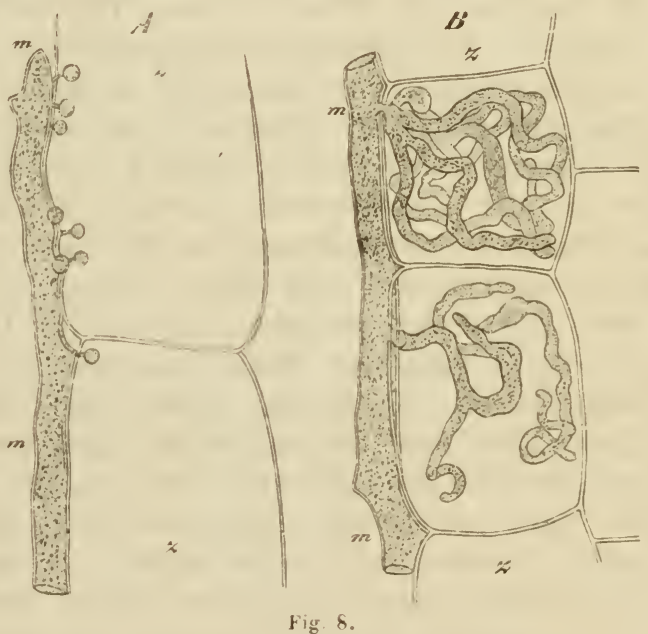

Ein aus focher verfochtenen

Fialen gehildetes hiuliges Mycelium von oft vicle Fuss breiter Ausdehnung, whches wohl anch einem Hyphomyceten angehört, ubrigens in seiner Genese und Weiterentwichelung noch gar nicht genaucr bekannt ist, ist das Racodium eellare Pors. Syn. fung. 701 , das die bekaunten, olivenbraunen Ueberzigge auf alten Weinfisisern in Kellern bildet.

Festere Matute bilden die Mycelien, welche als Athelia Pers. und X!̣lostroma Tod. beschriehen sind. Erstere stellen sterile Zustinde von Thelephora, Ilypochnus dar. IDie Mylostromen sind, wie Fries (Plantae homonemeae p. 21i)

Fig. 8. $m$ Myceliumfäden, kriechend in Intercellularräumen, mit Haustorien, welche die Wand der benachbarten Zellen $(z)$ durchbohren und in diese eingedrungen sind. Vergrösterung 390 .

$A$ von Cystopus candidis, aus dem Marke von Lepidium sativum.

$B$ von Peronospora ealotheca, aus dem Marke von Asperula odorata. 
nachgewiesen und Andere nach ihm bestitigt haben, häutige Mycelien von oft betrichtlicher Ausdehnung und Dicke $\mathbf{X}$. Suber Pers. wird $3-4$ Linien dich, fester, holziger, lederartiger Consistenz, welche in faulem Holze, unter der Rinde cariöser Baumstimme u. s. w. vorkommen und unter günstigen Enstanden die Fruchttriger holziger Hymenomyceten entwickeln: Polyporus abietinus, Thelephora hirsuta, crocea Schrad., suaveolens, setigera Fr., Daedalea quercina und andere Species dieser und verwandter Gattungen. Vgl. Fries, 1. c. Elenchus fungor. 1, 208. Tulasne, Carpolog. p. 99, 129).

Der Bau dieser Xylostromen, von denen in Rabenhorsts Sammlungen (Herb. Mỵcol. Ed. 2. Cent. 1 ï und Fungi Europaei Nr. 100) Exemplare enthalten sind, zeigt nichts Eigenthimbliches; sie bestehen aus dicht und unregelmaissig verflochtenen, festen und biegsamen, dünnen Fiden.

3. Bei vielen Pilzen vereinigen sich die Hyphen des Myceliums zu verschieden dicken, grösstentheils aus parallellaufenden Fiden gebildeten Strängen, welche reich rerzweigt und in ihrem iusseren Ansehen den Wurzelfasern höherer Gewijchse mehr oder minder ihnlich sind. Als Beispiel hierfür nenne ich zunichst die Phalloideen Phallus impudicus, caninus, Clathrus cancellatus. Aus zahlreichen Beschreibungen ist bekannt, dass die Fruchtkörper von Ph. impudicus von einem im Boden kriechenden Mycelium entspringen, dessen Hauptstimme cylindrisch, oft mehrere Fuss lang, bis 2 Mill. dick und in zahlreiche, verschieden starke Zweige getheilt sind. Hiiufig anastomosiren Zweige der verschiedenen Ordnungen miteinander, so dass das Mycelium strechenweise ein grobmaschiges Netz darstellt. Ein Querschnitt durch die stärkeren Stränge lisst eine diume, feste, weisse ajussere Lage oder Rinde und einen von dieser umschlossenen, dicken Crlinder von brïunlicher Farbe und gallertig̣em Aussehen Mark unterscheiden. Die mittlere grössere Partie der Marksubstanz besteht aus einem zihen Gallertfilz, dessen Hyphen longitudinal, leicht geschlingelt verlanden und ron ungleicher Dicke sind. Der iussere Theil der Marksubstanz wirl ausschliesslich von dickeren Fiden gebildet. Jie Rinde besteht aus ciniggen wenig̣en Lagen weiter, dünnwandiger Hyphen, welche in einer sehr engen Spirale fest um den Markerlinder gewickelt sind, wie der Draht einer umsponnenen Saite. Man erkennt leicht, dass diese Fäden von den peripherischen Elementen des Marhes als Zweige entspringen, bogig nach Aussen laufen und dann in das Geflecht der Rinde eintreten. Sie treiben an der Oberfliche kurze abstehende Zweiglein, welche dem Strange ein kurzhaariges Ansehen verleihen. Die ganze Oberfliche des Stranges ist mit oxalsauerm Kalk bedeckt.

Bei Phallus raninus verlaufen alle Hyphen der Strange parallel, die weisse Rinde ist durch lockerere Verflechtung der Hyphen, lufthaltige Interstitien und reichliche Ablagerung von oxalsauerm Kalk auf den Hyphen und in den oben Seite 1:3 beschriebenen blasigen Zellen von der gallertigen, gelblichen, luftreien Marksubstanz ausgezeichnet. Aehnlich verhält sich, soweit ich es untersuchen konnte, Clathrus. In den diunneren Zweigen höherer Ordnungen sind Rinde und Mark oft weniger scharf ron einander gesondert, erstere jedoch immer durch Kalküberzug ausgezeichnet. Die Enden der Stränge lösen sich nicht selten in ein lockeres Fadengeflecht auf oder breiten sich zu dünnen, 
weissen Iiauten aus, entweder einzehn, oder so, dass mehrere zu e inem Geflechte oder einer Haut zusammenfliessen. Holzstüchchen, Wurzeln u. s. W. werden von lelzterer oft vollstiandig umsponnen.

Myceliumstriange von wesentlich der gleichen Form wie die beschriebenen, verschiedener Grösse, Dicke und Farbe kommen zahlreichen zusammengesetzten Pilzen zu. So von Gastromyceten: vielen Lycoperdaceen Lycoperdon, Scleroderına, Geaster), IIymenogastreen, Nidularieen, Sphacrobolus. Von Hymenomyceten vielen $\Lambda$ garicinen, z. B. Igaricus campestris, praecox, dryophilus, aerugrinosus, metalus, androsaceus, Rotula. Yon Ascomyceten: Arten von Elaphoinyces, Genea, Peziza Rapulum Bull., P. cyanoderma m., auch das endophyte Mycelium von Polystigma stellare Lk. ist hierher zu rechnen.

Alle diese Myeclien bestehen ledigglich aus longitudinalen, geraden oder leicht geschlaingelten Iyphen; bei Agar. eampestris, acruginosus, praces, Lycoperdaceen, haben die Sträge das Insehen der düneren Aeste von Phallus caninus und im Wesentlichen den gleichen Bau. Das Vorkommen des hleesauren Kalkes ist nach den einzelnen Arten und Gattungen, wie oben Scite 14) erwihnt wurde, verschieden. In anderen Fiillen sind die Stringe durchaus yleichartig zusammengesetzt aus locker verfilzten Elaphom!ces, Nidularicen, Scleroderma, wohl auch llymenogastreen, oder der Liinge nach fest mit einander verwach-

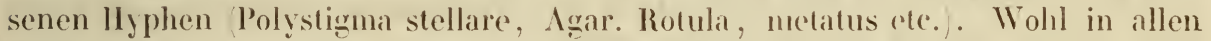
Fälen kommen Anastomosen der Strimge, hiutig̣e oder flochige Endausbreitungen nicht selten vor.

Soln häufig findet man im Freien sterile Mrecliumstrange von der beschriebenen Beschaffenheit, Welche im Waldhoden, an fouchtev, dumpfigen Orten, wie in Kellern, Bergwerhen u. s. f. oft rine grosse Austehmung erlatern, ohne Frucht zu tragen. Bei der gaeringen Jufmerhsimuheil, wolehe man bisher dem Studium der Mycelien zugewendet hat, ist es oft nichıt mọ̈lich zu entscheiden,

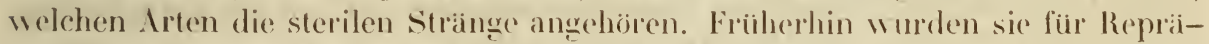
sentanten eigrener species gehalten, und je nach der Gestalt, Verzweigung, Anastomosen, hiutigen Ausbreitungen in besondere Gattumgen verdheilt, wie Ilimantia Pers., Ozonium P., Mỵpha P., Hỵhasma P’. Fibrillaria P., Ceratonema P., Byssus Dill, Dematium Lh. zum Theil, Corallofung̣us Vaill. Schon Palisot de Beaurois, Dutrochet, Turpin, Fries und in neuerer Zeit besonder's Léveillé und Tulasne haben klar erkannt, dass diese Gebilde in der That nur sterile formen von Pilzen sind, welche ilner Fructification nach verschiedenen wohlbegriindelen Gattungen angehören.

Den sterilen Myceliumstringen schliessen sich wohl auch die $A$ nthinen an, welche von Manchen Junghuhn, Limnaca 1830, 388 mit den Ilimantien zusammengestellt, von Fries Pl. homon. 169) als besondere Galtung betrachtet werden. Die Anthinen, von denen ich hier rede, und von welchen iels die $\mathrm{Ab}_{\text {- }}$ theilung Pterula Fr. ausschliesse, weil sie durch fruchttragende Pilzhörper ausgezeichnet zu sein scheint, sind eylindrische oder bandförmige, durchschnittlich zollhohe, bis etwa I Mill. diehe Pilzhörjer, welehe sich senkrecht von einem flockigen (in faulem Holz. Laub u.s. w. wuchernden Mycelium erheben und in ihrem oberen Theile gabelig oder ficherförnig veriisteln. Sie sind lebhaft roth A. flammea, \. purpurea oder blasshraun 1. pallidal gefirbt. Sie bestehen aus einem Strange paralleler, durch eine homogene Zwischensubstanz fest mit 
einander verbundener Hyphen, entstanden aus dem Zusammentreten der in dem Substrat wuchernden. Indem sich das Bündel oben spaltet oder seine Faden strahlig auseinandertreten, entstehen die gegabelten oder ficherförmigen Enden. Oefters findet man Exemplare, deren Spitzen gegen den Boden gebogen und hier in ein flockiges Mycelium aufgelöst sind, oft auch netzförmiğe Anastomosen. Eine Fructification fand ich bei diesen Gebilden nicht, obgleich Fries von A. flammea sagt: affusa aqua secedunt sporidia. Die kleinen, den Fiden seitlich ansitzenden Zellen, welche ich bei A. pallida hie und da gefunden und friiher als Sporen bezeichnet habe, möchte ich jetzt als sehr zweifelhafte Gebilde betrachten.

$\mathrm{Zu}$ welchen Pilzen die Anthinen gehören, ist zweifelhaft.

$\mathrm{Zu}$ den Myceliumstriingen sind auch die Pilzbildungen zu rechnen, welche nach ihrer Aehnlichkeit mit alten Wurzelfasern ron Gefisspflanzen den Namen Rhizomorpha führen. Die borstendicken Fiden mit glatter, glänzender Oberfläche, gebildet aus parallelen, fest verbundenen Hyphen, von denen die peripherischen mit derber, brauner, die inneren mit zarter, farbloser Membran versehen sind, welche Persoon (Syn. fung. 703 Rhizomorpha setiformis Ceratonema hippotrichoides Pers. Mỵc. eur.) genannt hat, sind schon von Fries (S. M. I, 136) als das Mycelium von Agaricus androsaceus und Rotula erkannt worden. Man sieht sie oft in Menge von den Stielen dieser Pilze entspringen und sich zwisehen den Tạnnennadeln und dem faulen Laub des Waldbodens verbreiten, diese mit ihren Aesten und Ausbreitungen umspinnend.

Nach den gegenwairtigen Kenntnissen sind auch die grossen, in faulem, in der Erde liegendem Ilolz, Bergwerken u. s. w. rorkommenden Rhizomorphen hier zu nennen: die $\mathrm{kh}$. fragilis Roth, wurzelikhnliche dicke, reich verzweigte und durch Anastomosen oft netzförmige Sträinge von dunkelbrauner Farbe, deren Jauptstimme entweder cylindriseh und bis uiber 3 Mill. dick R. subterranea P.), oder, wo sie zwischen Holz und Rinde, zwisehen festen Holzlagen oder in sehr engen Gesteinss]alten wachsen, zusammengedrüicht, oft ron der Form breiter, papierdiinner Binder sind (dies Rh. subcorticalis P.j.

Von dem Bau und der Enlwichelung dieser Rhizomorphen hat Sehmitz schon vor 20 Jahren cine vortreffliche, von Neueren zu wenig beriichsichtigte Beschreibung gegeleen, welche ieh in den llauptpunhten bestitigen kann, in mancher Beziehung zu berichligen und zu vervollstiandigen habe.

J) ie erwachsenen Strainge bestehen aus einer schwarzlnammen, papierdicken, spröten, meist glatlen Rinde, welehe ein weissliches, feinfilzigges, zaihes Mark umgibt. Die Rinde wird gebildet von mindestens 12 bis $1: 3$ Lagen von Zellreihen Ilyphenj, welehe der Linge des Stranges nach parallel laufen und mit einander fest und ohne Intereellularrimme verwachsen sind. Die IIyphen der ausseren Lagen sind aus eng̣eren und dickwandigeren Zellen zusammengesetzt, als die inneren, die cinzelnen Zellen 2 - vielmal so lang, als breit, mit derber, brauner, deutlieh geschichteler Membran versehen, im Querschnitt oft polygonal. Die soitliehe Verbindung der Membranen ist oft so fest, dass dieselloen eine homogene Masse z.u bilelen scheinen: anf dünnen Querschnitten, zumal bei Einwirhung von Kalilösung, treten jedoch deutliche Grenzlinien hervor, welche die anscheinend homogene Masse in eine der Zahl der vorhandenen Zellenlumina entsprechende Anzahl von Membranen sondern.

An die Innenseite der Rinde legt sich eine meist diinne, zuweilen jedoch 
die Rinde selbst an Michtigkeit übertreffende Gewebslage an, welche hellbraun, auf dem Querschnitt sehr unregelmässig engmaschig und aus dïnnen, verfilzten Fidden zusammengesetzt ist, die einerseits von den inneren Rindenelementen entspringen, nach der anderen Seite hin allmählich in die farblosen Hyphen des Markes übergehen. Dieses besteht hauptsächlich aus dünnen, etwa 1/560 Mill. starken, der Länge nach verlaufenden und spitzwinkelig verflochtenen Fäden. Die Membran derselben ist ziemlich derb, Querwinde und Zweige finden sich bei erwachsenen Exemplaren nur selten. Zwischen diesen Fiiden zerstreut, aber oft in ziemlich regelınissigen Abständen von einander finden sich dünnwandige, farblose Zellen, von der Gestalt cylindrischer Schlauche, bis zehnmal so dick wie die genannten Fiden. Sie sind bei alten Exemplaren oft schwer aufzufinden. Die Interstitien des Markgeflechtes enthalten Luft.

Alte schr starke Exemplare der cylindrischen Form Rh. subterranea haben oft eine unebene, rmmzelige Rinde, in welcher, wohl durch spiitere Wucherung, die Zahl der Zollensehichten stark vermehrt und ihre Stellung unregehmässig ist. Im Innern soleher Exemplare fand ich ofters, doch nicht immer, eine braune, der Rinde concentrisehe Zone, von dieser durch eine schmale Schicht gewöhnlichen Markgewebes getremnt und ihrerseits einen Strang des letzteren umschliessend. Diese Zone besteht aus Fiden, welche braunhiutig und sehr fest miteinander verflochten, im Lebrịgen den gewöhnlichen Elementen des Markes gleich sind, in letzlere auch continuirlich ubergehen. Eschweilers Darstellung vom Bau der Rhizomorphen ist wohl ohne Zweilel auf die Entersuchung soleher Exemplare gegrinder.

Cultivirt man kriftig̣e Rhizomorphen in einem feuchten kamm, so treiben sie oft sehon nach acht Tagen neue Zweige. Zuerst treten an beliebigen Punkten der Oberfliche kleine (etwa 1/2 - M Millim. grosse; weisse Flocken auf, gew ïhnlich mohrepe zn Gruppen zusammengestellt. Sie bestehen aus verzweigten, geschlingalten, zil einem Büschel vereingten Hỵhen, deren freie Enden farblos und zartwandig, deren Basis dagegen mit derber, brauner Membran versehen ist. Sie entspringen von den immeren Rindenzellen als \%weige, wachsen von hice aus zu cinem rylindrischen Strang vereinig̣t senkrecht nach aussen, durchbrechen die iussersten Rindenlagen und treten dann strahlig̣ auseinander. Dieso Biischelehen sind die Vorliater der Aeste; nit dem Erseheinen dieser repschwinden sie, man finder nur mehr ihre zerfillenden Reste, In denselben Stellen, wo aussen die Büschelehen entstehen, begsinnt gleichzeitig eine Neubildung auf der lnmegfliche der Rinde. Es entsteht hier ein, dichtes parenchymahnliches Gewebe, aus ziemlich weiten, unregelmissig-langlichen, sehr zartwandigen, wasserhellen Zellen bestehend, welche theils ganz ordnungslos, theils in senkrecht zur Oberflache verlaufende Reihen gestellt sind. Soweit ich es bei der grossen Zartheit und festen Verbindung seiner Zellen entscheiden komnte, verdankt dieses Gewebe immer Sprossungen, welehe von den innersten Rindenzellen ausgehen, seinen L'rsprung. Seine Elemente vermehren sich rasch und betrichtlich, sie legen sich fest an und zwischen die peripherischen Markhyphen, dräingen viele derselben oft dergestalt aus ihrer geraden Liingsrichtung heraus, 'dass sie bogig dureh das neugebildete Gewebe verlaufen, und heben die Rinde, mit der sie stets in festester Verbindung stehen, etwas ron dem Marke ab. Unmittelbar unter den Buischelehen ist die Neul,ildung oft besonders 
lebhaft, die Rinde wird hier zuweilen in Form eines von dem farblosen jungen Gewebe ausgefülten Cylinders, der das Büschelchen als kurzer Stiel trägt, nach aussen gehoben.

Von dem neugebildeten Gewebe geht nach wenigen Tagen die Anlage eines oder mehrerer Zweige aus. Eine Portion jenes Gewebes wiichst zu der Form einer conischen, mit der Spitze gegen die alte Rinde gewendeten Warze aus, durchbricht jene und tritt aus dem Riss als ein weisser, kegelförmiger Körper, Zweiganfang, hervor. Die oberflichlichen Zellen an der Basis dieses erhalten sofort braune Membranen; sie stellen eine aus rundlichen oder langlichen Zellen gebildete Rinde mit unebener Oberflache dar, welche mit der Innenrinde des alten Stammes fest verwachsen bleibt. In der Mitte der Zweiganlage strecken sich die Zellen in der Richtung der Längenachse, ihre reihenweise Anordnung tritt mit der Streckung immer deutlicher hervor, sie bleiben farblos und zartwandig, mit dem unregelmässigen Scheinparenchym unter der alten Rinde in festem Zusammenhang. Gegen die Spitze der Zweiganlage convergiren die Zellreihen (Hyphen), welche sie zusammensetzen. Die axilen verlaufen gerade, die peripherischen neigen sich bogig gegen dieselben; so entsteht ein mehr oder minder abgerundetes conisches Ende, welches als der Vegetationspunkt des jungen Zweiges zu bezeichnen ist. Die Dicke der Ilyphen und die Lainge ihrer einzelnen Zellen ninmt gegen den Vegetationspunkt hin stetig ab; erstere betrigt hier etwa $1 / 450 \mathrm{Mm}$. Alle nach dem Vegetationspunkt convergirenden Hyphen sind fest aneinandergelegt, die peripherischen stets ganz lüchenlos, zwischen den axilen sind oft schon sehr friih enge lufthaltige Interstitien vorhanden. Die ganze Aussenfliche der beschriebenen Zweiganlage wird von einem locheren Geflecht verzweigter, meist 1/450 Mm. dicher, hie und da stirherer H!phen überzogen, welehe als Aeste von den oberflichlichen Zellen der Zweiganlage entspringen. Zwischen diesen Fäden liegt eine homogene, farblose, in Wasser stark quellende Gallerte, daher die Oberfliche des Zweiges schluipferig ist. Die Dicke der jungen Zweige betrug in meinen Culturesemplaren durchschnitt!ich 1 Millimeter.

Nach dem Hervortreten aus der alten Rinde wächst der Zweig in die Länge, durch fortdauerndes Spitzenwachsthum aller in dem Vegetationspunht vereinigter Hyphenenden. Dieser behailt fortwaihend seine urspringliche Beschaffenheit bei;

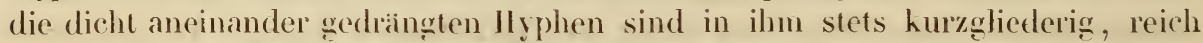
an Proloplasma und, soweit es unterschieden werden hamn, alle einander gleich. Dicht unter dem Vegetationspunkt beginnt die Strechung der Zellen und die Sonderung des Gewebes in eine axile Portion, die ich prim i res If a rk nemnen will, .und eine peripherische, die Rinde. Jenes bildet einen weissen, schmalen Cylinder, aus IIyphen bestehend, deren cylindrische, zartwandige und grösstentheils wasserhelle Fliussigheit enthaltende Zellen schon ziemlich dicht unter dem Vegetationspunkte eine Dicke von $1 / 75-1 / 50 \mathrm{Mm}$, bei $2-8$ mal grösserer Lïnge, erreichen. Zwischen den Hyphen treten luftführende Interstitien auf. Zuweilen sind die Zellen benachbarter Hyphen paarweise in Form eines H verschmolzen. Gegen die Peripherie hin werden die IIyphen des primiren Marks schmiler und gehen allmïhlich in die der Rinde iber. Diese besteht aus engen und fest aneinander gelegten Hyphen, von denen die alleräussersten in der jungen Rinde mit den übrigen in lockerem Zusammenhang, nur durch 
weiche, farblose Gallerte mit ihnen und miteinander in Verbindung gehalten sind. Von ihnen entspringen die Fäden des oben erwähnten losen und von Gallerte umgebenen Geflechtes, welche den jungen Rhizomorphenzweig stets umgeben und welchen von dem Vegetationspunkt aus stets neue hinzugefügt werden. (Vgl. Fig. 9).

Auf eine Streche von wenigstens 23 Millimeter unter dem Vegetationspunkt ist der junge Zweig immer ganz farblos. Weiter nach unten beginnt die Rinde eine immer intensiver werdende schön braune Firbung anzunehmen : zunächst sind es die Membranen von etwa sechs un ter der Oberfliche gelegenen Hyphenlagen, welche sich firben, indem sio sich gleichzeitigr verdichen; eine ausserhalb liegende, etwa gleichstarke Schicht zeigrt die Firbung und Membranverdichung spater und langsamer. Gleichzeitig mit letzlerer nimmt das lockere Fadengeflecht der Oberfliche braune Farbe

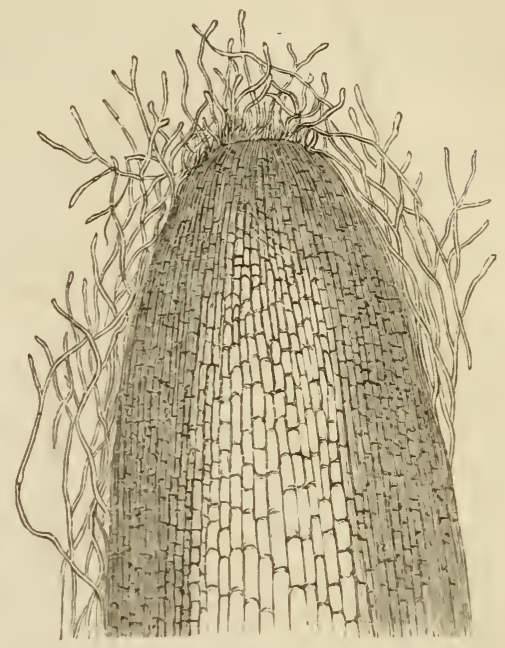

Fig. 9. an, die Gallerte wird fester und wenig̣er quellhar, gyleichfalls braum. Letztere Theile entwickehn sich so zuden ausseren, engzelligen, die zuerst gefoirbten Lag̣en zu dem inneren Rindengewebe. In wenigen Fïllen sah ich auf den Ilỵphen der eleen braunwerdenden Rinde zahlreiche farb!ose Zweige.hervorsprossen, welche zusammen einen dichten Eeberzuy von gleichlohen, rechtwinhelig abstehenden, dureh Gallerte verbundenen Hatren bildeten, der spiter verschwand. Meistens hommen diese Gebilde nicht vor. lig. 10).

bie imnersten braunen Rindenzellen und die ausseren Lagen des primiiren Markes dehnen sich schon ror Begrinn der Braunfirbung betraichtlich in die Jiche und Breite aus; die axilen Roihen des Priniirmarkes zeigen die Ausdehnung nach den bezichneten Richtungen in geringerem

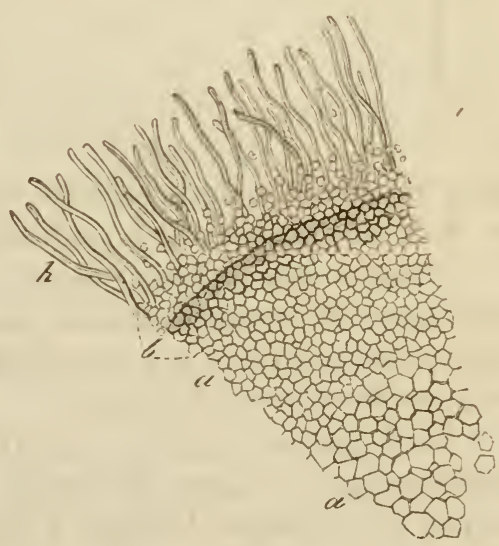

Fig. 10 . Maasse, sie strecken sich nur stark bis zum פofachen des Querdurchmessers in die Linge. Der Zweigy nimmt daher an Lufang zu, die axilen Iyphen werden auseinandergezert, die luftührenden Lüchen zwischen ihnen bedeutend erweitert.

Das primire Mark hat, wie ohne weiteres cinleuchtet, eine von dem Marke

Fig̣. 9. Rhizomorplıa subcorticalis. Längsschnitt durch den Vegetationspunkt eines jungen Triebes, $100 \mathrm{mal}$ verger.

Fig̣. 10. Rhizomorpla subenticalis. Querschnitt durch einen jungen Trieb, 190 fach vergr. a $\iota$ primàres Mark. 6 Rinde. $h$ der oft fehlende Haaruberzug. 
der fertigen Rhizomorphe total verschiedene Struetur. Da wo die Briunung der Rinde anfangt, beginnt nun die Bildung des definitiven Markes. Alle innerhalb

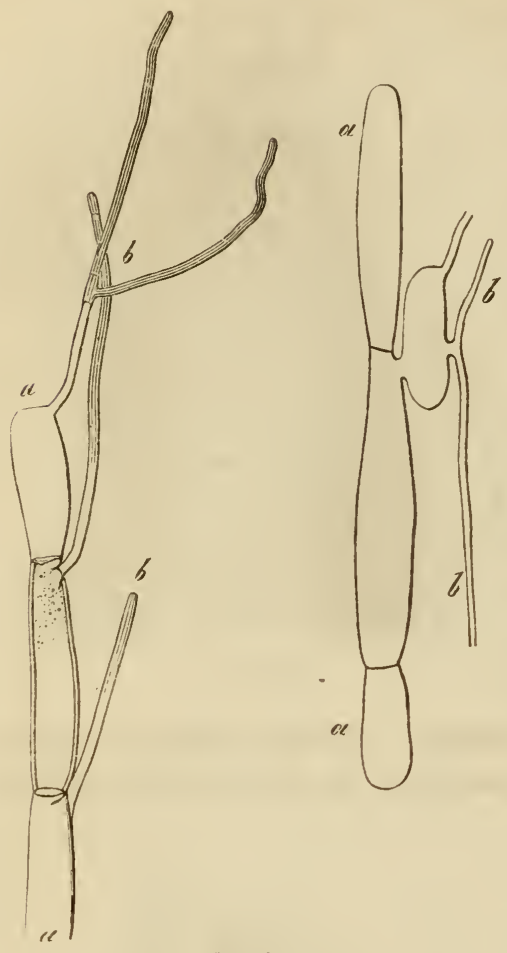

Fig. 11 .

der Rinde gelegenen farblosen Zellen, sowie die innersten Rindenzellen selbst treiben nämlich jetzt, theils aus ihrer Seitenwand, theils besonders aus ihren Enden dünne, verzweigte Hyphen, welche, anfangs zartwandig, mit deutlichen Qucrwänden und trübem Protoplasmainhalt versehen, sich rasch verlängern und die Beschaffenheit der fertigen Markhyphen annehmen. Das Wachsthum dieser Fäden ist der Längsachse des Zweiges parallel, theils nach der Spitze, theils nach der Basis dieses gerichtet Fig. 11); sie schieben sich allenthalben zwischen die Zellen des primären Markes. vermehren und verlangern sich, so dass sie jene bald verdringen und zusammendriicken, und die Hauptmasse des von der Rinde umschlossenen Gewebes bilden: einen dichten, feinfailigen Strang, in welchem die Zellen des primären Gewebes zerstreut liegen, als weite, diinnwandige, manchmal nur mit Mühe aufzufindende Schlizuche. Oft hat das Mark schon 1-2 C.m. unter dem Vegetationspunkte diese Structur. Aus der Basis des jungen Zweiges treten die Markfaiden desselben zwischen die des alten Hauptstammes und verflechten sich mit ihnen, so dass zuletzt das Marh des letzteren sich continuirlich in das des Zweiges fortsetzt.

Welcher oder welchen Species ron Pilzen die Rhizomorpha fragilis angehört, muss nach den Fruetificationsorganen bestimmt werden. welche sich an ihnen entwickeln; nach den gegenwirtigen Beobachtungen ist dieses aber noch keineswegs mit Bestimmtheit möglich.

Nach alteren Angaben von Deeandolle, Eschweiler, Acharius sollen die Rhizomorphen cine ganz cigenartige Pyrenonyedenfrucht tragen, welche Rhizomorpha als besondere Gattung legitimiren soll. Schon Palisot de Beaurois und Ehrenberg fanden aber, dass die körper, welche man zuweilen für Fruchtbehiblter anzusehen versucht ist, nichts weiter als einfache Auswiichse und Zwrigrudimente sind. Aus der Beschreibung welche Eschweiler von den von ihm beobachteten fruchtihnlichen Körpern gibt, ist kein bestimmter $\Lambda$ ufschluss uber die Natur derselben zu erhalten. Deeandolle fand an Rhizomorpha zerstreute oder gehiufte Ansehwellungen von kugeliger Form ohne Oefinung und mit »pulpa atra seminifera» erfüllt. Léveillé hat solche Körper beobachtet,

Fig. 11. Rhizomorpha subcorticalis. Frei gelegte Zellen des primären Markes $(a)$, die dünnen definitiven Markhyphen $(b)$ austreibend. Vergr. 390. 
allein ibber ihre Bedeutung keine Gewissheit erhalten. Nach der neuesten, von Tulasne angestellten Untersuchung sind diese Körper mit kleinen Höckerchen besetzt, deren jedes von einem kleinen Loche durchbohrt wird, und welche Tulasne für alte, durch Insecten verursachte Gallen hält. Die Erzeugung ron Gallen auf Pilzmycelien hat Tulasne an Thelephora lactea und Polyporus radiatus direct beobachtet.

Hiergegen spricht Fries auch noch neuerdings die bestimmte Behauptung aus, dass IIornemann reichliche Exemplare von Rh. fragilis Roth gefunden habe. welche auf ihren Zweigen zahlreiche, einzeln stehende Perithecien trugen. Fries betrachtet daher Rhizomorpha als eine besondere Gattung ron Pyrenomyceten (Summa reget. Scand. p. 382 .

Eine hiervon sehr verschiedene, aber gleichfalls den Rhizomorphen speciell eigene Fruetifieation hat $\mathrm{O}$ th neuerdings beschrieben. Er fand auf Rh. subcorticalis hleine, schwarze, borstendicke und 2-4 Millim. lange Körjer, welche in ziemlich grosser Zahl der Rinde aufsitzen, gleich kleinen, rechtwinkolig abstehenden Zweiglein. Dieselben tragen an ihrer spitze eine der Gatlung Stilbum oder Graphium gleiche Fructification. Oth hiilt diese Körper für Organe der Rhizomorpha, Tulasne und Bail theilen diese Ansicht, wihrend Montagne und Cesati die borstenförmigen Köper für (rin auf der Rhizomorpha schmarotzendes stilbum halten. Ich habe mich, nach Entersuchung originaler und anderer Exemplare nieht davon iiberzeugen homnen, dass die erwihnte Stilbumfructification mit dem (iewehe der Rhizomorpha sellost in einem genetischen Zusammenhange steht, doch wire zu einem ganz sicheren Urtheil hieriiber die Beobachtumg der ersten Entwichehung des Stilloum nothwendig̣, welche bis jetzt noch Niemandem gegeliicht ist. Wie dem aber auch sei. so steht gegenwirtig fest, dass, wie unten angegeben werden wirl, die als stilbum bezeichneten Formen und ihre Verwandten für sich allein heine selbstiandigagen Pilzspecies characterisiren; mit der Anftindung der Oulischen körper, auch wenn sie Organe der Rhizomorpha selloer sein sollten. ist also die Frage nach der Fructification der letzteren heineswegrs abgeschlossen.

Eine Reihe anderer Beobachter ist der Insicht, dass die Rhizomorphen Mycelien sind, welche unter giinstigen Bedingangen die für behannte grösscere Pilzspecies rharacteristischen Fruchttriger erzeugen. Auch hier geben aber versehiedene Beobachter verschiedene fruchthare Pilze als die Entwichehungsproducte ion Rhizomorpha an. Schon Palisot de Beaurois fand rine, der Abbildung nach haum zweifelhafte achte Rhizomorphe, deren \%weigenden sich zu einem unregelmisisigg rerbreiteten X̣̣lostroma vereinig̣en. Der Rand des letzteren entwickelte sich zu einem mzweifelhaften fruchttragenden Polyporus. Caspary sah neuerdinges die Fruchttäger von Trametes Pini aus einem Xilostroma-Myeelium hervorgehen, welches aus einer Vereinigung der Zweige von Rhizomorjula hervorgegangen war. Achnliches glaubt Caspary für Polyporus-Arten und Agaricus ostreatus daeq. gefunden zu haben. Tulasne hat bestitigende Beobachtungen mitgetheilt. Er sih aus Rh. subcorticalis fruchttragende Polyporus cuticularis (Bull) und P. alneus P. sich entwickeln und in anderen Fillen wenigstens die Zweige der Rhizomorphen unter der Rinde und im Holze ron Bämen sich zu Xỵlostromen vereingen. Von denen behannt ist, dass sie Mycelien von Hymenoii! ceeten sind. 
Auf der anderen Seite gibt schon Haller an, dass die fruchttragende Xylaria Hypoxylon zuweilen in eine »Wurzel " auslaufe, welche zwischen Holz und Rinde abgestorbener Bäume ausgebreitet ist, und, der Beschreibung und den citirten Abbildungen nach, der Rh. subcorticalis entspricht. Bail hat in neuester Zeit dasselbe beobachtet, ebenso Lasch. Ich habe, gleich dem letztgenannten Beobachter, ofters Weissbuchenstumpfe mit Rhizomorpha durchwuchert und aussen Xylarien tragend gefunden, bei welchen letztere öfters der Rhizomorpha aufsassen ; doch blich mir der genetische Zusammenhang beider immer zweifelhaft.

Nach diesen Angaben würden die Rhizomorphen Myceliumstränge sehr verschiedener Pilzspecies darstellen. Allein gegen die Anerkennung dieser Folgerung ist zweierlei cinzuwenden. Einmal ist in keinem der mitgetheilten Fälle bestimmt und genau angegeben, ob die jeweiligen Rhizomorphen genau den oben beschriebenen characteristischen Bau der typischen Rh. fragilis, subterranea und subcorticalis hatten. Es ist daher zweifelhaft, ob es sich in allen Fallen um die wirkliche alte Rhizomorpha oder nur um ihr ahnliche Myceliumstringe handelte. Die hurze Angabe Caspary's über die Rhizomorphe der Tranetes Pini macht es sogar ziemlich wahrscheinlich, dass die von ihm beobachteten Strange eine andere als die typische Rhizomorphenstructur gehabt haben. Bail's Angraben iber seine Xylarien tragende Rhizomorphe sind ungeachtet der grossen Ansprüche, mit welchen ihr Verfasser auftritt, sehon darum ungenau, weil er über den genetischen Zusammenhang der Gewebstheile von Xylaria und Rhizomorpha gar nichls sagt',

Diesen Lüchen in den vorhandenen Beschreibungen gegenuiber muss die beschriebene ganz eigrenthimliche Structur und Entwickelung der typischen Rhizomorphen hervorgehoben werden. Es ist in der That wenig wahrscheinlich, dass diese sich inmmer ggleich bleibenden Eigenthümlichkeiten so ganz verschiedenen l'ilzspecies zukommen sollten, weniogstens muss dies bezweifelt werden, bis der genauere Nachweis dafür gaeliefert ist. Dass es rhizomorphen:ihnliche, abex von den typischen Rhizomorphen im Bau entschieden ab-

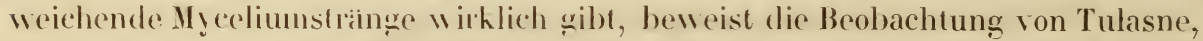
welcher cine Form derselben Iylaria Ilypoxylon, von welcher Bail und Lasch deu Lrsprung aus Rhizomorpha behaupten (die Xyl. Ilyp. var. cupressiformis P.) aus einem langen, schwarzen Rhizomorphastrange entspringend fand. Die weisse Mittelsubstanz des letzteren bestand aus dicken Fasern, deren Membran his zum Versehwinden des Lumens verdicht war; sie w urde ungeben von einer schwarzen Rinde atus rundlich-tafelförmigen oder hugelig-polyedrischen Zellen. Auch die rhizomorphenartigen, bis fusslangen, im Boden verbreiteten Wucherungen von X! laria carpoplıila, welche Lasch beschreibt, zeigten mir, wenigstens an 3-1 Zoll langen Excmplaren dieselbe von den Rhizomorphen verschiedene Structur wie dio fruchttragenden Sticle dieser Species: eine weisse, feste Marksubstanz, aus dicht und spitzwinkelig verflochtenen Hyphen gleichmiissig zusammengesetzt, nach aussen allmählich übergehend in eine fest anliegende, schwar\% Rinde, die aus Hyphen gebildet wird, welche denen des Marks an Dicke gleich hommen und vereinzelte dichere Zweige tragen, die als Haare von der Oberfliche abstehen.

1) Nachträgliche Anmerkung. Bail hat kürzlich /Flora 1864, p. 559 mitgetheilt, dass seine $\mathbf{X}$ !larien nicht aus der Rhizomorpha entspringen, sondern derselben bloss aufsitzen. 
4. Eine besondere Form des Myceliums sind die Sclerotien, knollenförmige Körper, von verschiedener Gestalt und knorpeliger, fleischiger oder korkartiger Consistenz. Seit Tode wurden die Sclerotien lange Zeit als besondere Pilzgattung betrachtet, characterisirt durch die eben angedeuteten, von der Form und Consistenz hergenommenen Merkmale, aber olıne deutliche Fruetification. Fries beschreibt im Syst. mycol. u. Elenchus einige :30 Arten, in spiteren Zeiten wurde die Artenzahl auf 70 bis 80 vermehrt ${ }^{1}$ ). Obgleich man lïngst beobachtet hatte, dass die Fruchttriger verschiedener Pilze, wie Botrytis, Typhula, Agaricus aus Sclerotien hervorwachsen, war es doch erst Léveillé, welcher 1843 nachwies, dass die Sclerotien nichts weniger als Repräsentanten eines selbständigen Genus, sondern vielmehr eine Form des Myceliums sehr verschiedenartiger Pilze sind. Léveillé's Ansicht wurde lange wenigg beachtet. bis in neuester Zeit Tulasne auch hier neue Anregung und Aufkliarung brachte. und dadurch zahlreiche weitere Arbeiten ins Leben rief.

Man kennt jetzt von einer ziemlich grossen Anzahl Sclerotien die Entwickelung, besonders die Fruchttriger, welche aus ihnen hervorgehen. Andere sind noch minder genau bekannt, so dass in der Nomenclatur noch manche mit den alten Selerotium-Artnamen, andere mit den richtiggen Speciesbenennungen zu bezeichnen sind. Die Pilze, won denen man bis jetzt ein Sclerotienmycelium mit Sicherheit kennt, sind aus den verschiedensten Ordnungen und Familien, und es ist nach den vorliegenden Thatsachen mehr als walıscheinlich, dass ihre Zahl durch genauere Intersuchung gewaltig vermehrt werden wird. Es wird zweckmiassig sein, hier zuerst eine Aufzihlung der sicher bestimmten bekannten Pilzspecies, welche Sclerotien bilden, mit Hinzufiigung des alten Artnamens der zugehörigen Sclerotien zu geben.

Bolrytis cinerea P. (Eolyactis selerotiophila Rabh.) aus Scl. durum. - Botr. erythropus Lev. Beicle gehören, wie im 6ten Capitel nachgewiesen werlen wird, in den Formenkreis von Peziza - Arten. - Typhula erythropus aus Sel. erustuliforme Desm. , T. lactea Tul., T. Todei Fr., T. (aespitosa Ces., T. gyrins, T. Euphorbiae Fuchel (aus Scl. Cyparissiae I)C.?), T. varialoilis Riess (aus Sel. Semen T. und Sel. vulgatum Fr.!) - Pistillaria phacorhiza Fr. sclerotioides, Pist. micans (aus Scl. laetum Ehr.), P. hederaecola Ces. - Clavaria ${ }^{2}$ complanata (Scl. complanatum Tod.), Cilar. scutellata, Clav. minor Lév. - $\Lambda$ garicus arvalis ( $\mathrm{Scl}$. vaporarium), $\Lambda \mathrm{g}$. racemosus $\mathrm{P}$. (Scl. lacunosum), Ag. tuberosus Bull (Scl. cornutum), Ag. grossus Lév., Ag. fusipes Bull, Ag. cirrhatus (Scl. truncorum Fr. nach Tulasne). Viel-

1) Einzelne der früher als Sclerotien beschriebenen Körper sind keine Pilze ; so die Wurzelknöllehen von Leguminosen (vgl. Treviranus, Bot. Ztg. 1853, p. 393), wrlehe in den mycologischen Werken lries, Syst. Myc. II, 250) als Scl. rhizogonum P., Scl. Medicaginum, Lotorum Biv. aufgeführt werden. Die Bedeutung der oft faust- und kopfgrossen, unterirdischen. Pilzknollen: Sclerotium stipitatum Berk. aus Malabar, Sclerotium Cocos Schweinitz. (Tukahu der Amerikaner) aus Nordamerika, des Hoelen, Tschuling der Chinesen, auch der neulıolländischen knollenförnnigen Mỵlitta australis Berk. ist noch zweifelhaft. Mỵlitta Pseudacaciae Fr. gehört nach Tulasne zu den Gallen.

2) Clav. complanata nenue ich die aus dem Scl. compl. Tode, Clav. scutellata die aus dem Scl. scutellatum AS. sich entwickelnde Form. Beide würden nach der älteren Alogrenzung der Arten zu Clav. juncea gehören, sind aber durch die Sclerotien selır gut unterschieden. 
leicht, doch sehr zweifelhaft, Ag. volvaceus aus Scl. mycetospora, Nees in Nov. Act. Ac. Nat. Curios. XVI, 1). Agar. Tuber regium Fr. Noch näher zu bestimmende Agarici aus Scl. pubescens P. und Scl. fungorum. Agar. Sclerotii Kühn aus einem auf Rüben wachsenden Sclerotium. - Coprinus stercorarius Fr. (Scl. stercorarium), Copr. spec. (aus »Sel. varium ( Tulasne). - Il y pochnus centrifugus Tul. - Poly porus Tuberaster Jacq. - Tulostoma brumale Fr. (Tulasne). - Peziza Candolleana Lév. (Scl. Pustula DC.), P. Fuckeliana n. sp. ${ }^{1}$ (Scl. echinatum Fuck.), Pez. Sclerotiorum Lib. (Scl. compactum, varium), Pez. Curreyana Berk. (Scl. roseum Kneiff), P. Duriaeana Tul. Scl. sulcatum Desm.), Pez. ciborioides Fr. (Hoffnamn), Pez. tuberosa Bull, Pez. Tuba Batsch (Micheli). - Claviceps purpurea, microcephala, nigricans Tul. Scl. Clavus DC. , Clav. pusilla Ces. - Il pom yces armeniacus Tul. - Vermicularia minor Fr. (Tul.) - X y la ri a bulbosi P. scheint sich hier anzuschliessen.

Zweifelhaft scheint es mir, ob sich die Formen von Mucor, Penicillium, Stachylidium, von welchen solches durch Berkeley, Léveillé, Corda angegeben wird, wirklich a us den Sclerotien entwickeln und nicht bloss a uf denselben angesiedelt waren.

Die Sclerotien finden sich, je nach der Species der sie angehören, auf oder in dem Erdboden, oder lebenden oder abgestorbenen Pflanzentheilen. Form und Grösse sind gleichfalls nach der Species verschicden. Senfkorngrosse Kügelchen stellen z. B. die Sclerotien ron Typhula variabilis meistens dar, unregelmiissig gestaltete, bis zollgrosse Brocken die von Peziza Sclerotiorum, tuberosa U. S. W.

Ueber den Bau dieser Körper sind, mit Ausnahme der trefflichen Arbeit Tulasne's über Claviceps, nur sehr wenig genane Untersuchungen vorhanden. Einzelnes haben Corda, Bail, Cocmans, Hoffmann geliefert. Aus der Untersuchung von etlichen und zwanzig Formen, welche mir zu Gebote standen, ergibt sich, dass die Sclerotien allerdings alle in den gröbsten Verhilınissen des Baues übereinstimmen; alle bestehen aus einem gleichförmigen, compacten Gewebe ich will es Mark nennen), welches on einer Rinde oder Oberhaut besonderer Structur rings umgeben wird. Nur bei einer Form, fehlt die Rinde. Dagegen sind die feineren Structurverhailnisse nach den einzelnen Arten sehr verschieden, oft selbst bei solchen Sclerotien, welche sich iusserlich sehr ïhnlich sehen und friberhin als eine und dieselhe Art betrachtet w orden sind. Es ist gewiss, dass schon die Berüchsichtigung des feineren Baues zur Unterscheidung von zahhreicheren Formen als bisher fühen muss. Die Sclerotien verschiedener Arten einer Gattung sind im Bau einander oft ithnlich, oft sehr von einander verschieden. Ich gebe im Folgcenden eine Tebersicht von den Structureigenthümlichkeiten solcher Sclerotien, welche lange behannt sind und meist lägst behannten Pilzen angehören. Eine Anzahl unbeschriebener Formen, die ich untersucht habe, iibergehe ich.

a. Die Sclerotien von Peziza tuberosa, Sclerotiorum, Candollei, Fucheliana Scl. compactum, varium, bullatum, Pustula, echinatım, durum, denen sich

1) Mit obigem Namen bezeichne ich die anderweitig ausführlich zu beschreibende der P. Candolleana nahe, verwandte Peziza, die auf Rebenblättern kleine, schwarze sclerotien Scl. echinat. F.) bildet. 
das in seiner Weiterentwickelung noch unbekannte Scl. areolatum anschliesst) sind mit einer dïnnen, schwarzen, glatten oder rauhen Rinde und einem im trockenen Zustand weissen oder weisslichen Marke versehen. Letzteres ist ein festes, knorpeliges Gallertgewebe, ohne alle oder mit sehr vereinzelten luftführenden Lücken. Seine Fïden sind cylindriseh, weit, septirt, nach allen Richtungen durcheinandergeflochten; auf diunnen Durchschnitten haben daher ilıre Lumina alle möylichen Formen, je nachdem sie der Schnitt quer oder schr:ïg oder der Länge nach getroffen hat. Fìg. 12).

Der Inhalt der Zellen ist im feuchten Zustande fast nur wiisserige Flüssigkeit, im trochenen Luft.

Gegen die Rinde hin werden die Fäden kur\%-

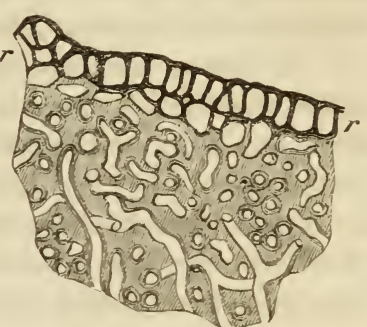

Fig. 12. gliederigg, Durchschnitte zeig̣en daher hier vorherschend rundliche Zellenumrisse.

Die Rinde selbst besteht aus isodiametrischen, rundlich-echiggen Zellen, welche eine derbe, schwarzbrame Hembran haben und fest untereinander verwachsen sind. Bei kleinen Formen Fig. 12, ist sie nur aus einer bis zwei, bei grösseren Pez. luberosa, P. Sclerotiorum, aus drei bis vier und mehr Zellenlagen gebildet. In Jetzleren Falle sind die Zellen meist in mnregelmässigge, radiale, zur Oberfliche senkrechte Reihen georther. Es ist meistens leicht nachweisbar, dass die Elemente der Rinde die oberflichlichsten Glieder der das Mark zusammensetzenden IIyphen sind.

Dir Write der Hyphen ist nach den Arten und theilweise atteh nach den Individuen verschieden, sic scheint im Allgemeinen um so beträichtlicher zu sein, je groisser das sclerotium ist.

Eine Anzahl der hierher gachörigen Formen homml auf der Oberfliche laulender Pflanzentheile oder in Bodern, andere innerhalb faulender Pflanzentheile vor. Jene \%, B. Pez. Iuberosa, himfigy P'. Soleroliormu zeigen den beschriebenen Bau ganz rein. Von den anderen schliessen manche wie manchmal Pe\%. Sclerotiorum, Scl. durmu häufig einzehne abgestorbene Zellen oder grössere Gewelsportionen des Pflanzentheiles, den sie bewolnnen, in ihre Substanz ein, was schon Corda beschreibl. Dic ringeschlossenen fremden Körper sind ganz unregelnäissiy und unbestimeligy in dem Marhe zerstreut, in manchen Faillen von einer Schichte sehwarzhraumer Rindenzellen ungeben.

Die kleineren Sclerotien dieses T!pus dagegen, welche aussihliesslieh auf faulen Bliallern vorkommen seler. areolatum Fr., Peziza Candolleana Lés., P. Fucheliana nehmen an den Punkten, wo sie sich entwicheln, regehniassig ron der Blallsubstanz Besit\%. Sic stellen schw ielenarlige Anschwellungen des Blalles dar, wolche aus den Gewebselementen des Sclerotium bestehen, zwischen denen die abgestorbenen des Blatles mehr oder minder verschoben und auseinandergedraingr eingelagert sind. Dic Art und Weise wie das Sclerotium das Blattzewebe occupirt ist nach Species verschieden. Das Selerotium der P. Fucheliana lewohnt nur das Parenchym und die Oberhaut der Weinrebenblitter, zuweilen

Fig. 12. Stück eines dünnen Querschnittes durch ein Sclerotium von Peziza Fuckeliana, 390 fach verger. $r$ Rinde. 
überw uchert es aber selbst die IIaare, so dass es stachelig erscheint; es kommt häufig längs der Blattrippen vor, aber immer nur ausserhalb der Holzbündel. Das von Peziza Candolleana auf Eichenblattern fand ich ebenfalls nur im Blattparenchym, Scler. areolatum Fr. dagegen dringt sich zwischen alle Formelemente der Prunus - Blattrippen ein.

b. Einen von dem ersten Typus wenig verschiedenen Bau haben die Sclerotien mehrerer Hymenomyceten, nämlich des Agaricus cirrhatus P. (?) und $\Lambda$ gar. tuberosus Bull (Scler. fungorum, pubescens, cornutum und des Ilypochnus centrifugus Tul. Der Hauptunterschied von dem Typus a beruht darin, dass die Wand ihrer Rindenzellen nicht schwarz, sondern gelbbraun gefarbt ist; die Oberfläche ler Rinde ist meistens ziemlich glatt, bei Hypochnus centrifugus uneben oder filzig durch einzelne bleibende Reste der Hyphen, wolche das jugendliche Sclerotium ungeben. Die Fäden des Markgewebes und ihre Membranen haben je nach der Species verschiedene Dicke; sie enthalten meistens wisserige Flüssigkeit resp. Luft, bei Hypochnus centrifugus Oeltropfen. Auch bei denjenigen der genannten Sclerotien, welche sich, wie Scl. fungorum häufig, im Innern faulender Pflanzentheile entwickelt haben, fand ich niemals Gewebselemente der letzteren in dem Marke des Sclerotiums eingeschlossen.

c. Etwas abweichend von dem beschriebenen ist der Bau eines in Rabenhorst's Herb. mycol. Nr. 1791 enthaltenen Sclerotium, dessen Bestimmung als Scl. stercorarium jedenfalls unrichtig, dessen Herkunft zweifelhaft ist. Sein weisses Markgewebe besteht aus cỵlindrischen, diunnwandigen, wisserige Flüssigkeit enthaltenden Hỵphen, meist ziemlich locker verflochten, mit lufthaltigen Interstitien. Gegen die Oberfliiche hin geht das Mark allmählich über in eine vielschichtige IIille von engeren Fïlen, welche vorzugsweise parallel der Peripherie verlanfen und zu einem dichten, völliğ luftereien Gewebe verbunden sind. I ie inneren Lagen dieses Gewobes sind farblos, nach aussen zu werden die Membranen allmahlich gelbbraun, die der aussersten Lagen sind bis zu sehr beträichtlicher Verengerung des Lumens verdickt; das ganze Sclerotium ist somit von ciner festen, mehrschichtigen, mebenen Rinde umgeben.

d. Das leblaft gach gefirbte, jedenfalls auch einem Agaricus angehörende sicl. muscorum besteht aus einem Geflecht weiter, dünnwandig̣er Hỵphen mit engen, lufthaltigen Interstitien. Die Hyphen sind ordnungslos theils aus gestrecktcylindrischen, theils aus kurz - blasigen Zellen zusammengesetzt. Letztere enthalten cine homogene, tribe, gelbliche Protoplasmamasse, oder wiisserige Fluissigheit, in welcher gelbe Oeltröpfehen suspendirt sind. Die Oberfliache des Sclerolium ist für das blosse Auge etwas dunkler gefarbt, als die Mitte, auf Durchschnitten zeiğ aber das Mikroscop überall die gleiche Structur, Mark und Rinde sind nicht deutlich von einander zu unterscheiden. Einzelne Zellen der Oberfliche ragen als cylindrische Papillen nach aussen hervor.

$e$. Das Sclerotium des Coprinus stercorarius Fr. (Scl. stercorarium DC. Fr. "liberum subrotundum nigrum . . . intus albuma) hat in seinem schneeweissen Mark einen ähnlichen Bau, wie Scl. muscorum. Dasselbe stellt ein Pseudoparenchỵm dar, aus weiten, unregelmässig rundlichen oder länglichen, ausgebuchteten Zellen und einzelnen cylindrischen Ilyphen gebildet, alle Zellen sind sehr dünnwandig und von einer farblosen, gleichförmig - feinkörnigen, ziemlich stark lichtbrechenden Substanz (Protoplasma?) gefüllt, welche sich, aus den 
verletzten Zeilen ausgetreten, in Wasser vertheilt und dieses trübt. Diese Zellen bilden ein dichtes, im trockenen Zustande hartes Gewebe, mit zahlreichen, engen, lufthaltigen Lücken. Gegen die Peripherie hin werden die 7cllen des Markes plötzlich kleiner. Dic Oberfliche des Sclerotium wird von einer, dem blossen Auge schwarzen', im trockenen Zustande runzeligen, festen Rinde gebildet. An der Grenze des Markes zeigt diese vier bis fün unregelmässige Lagen kleiner Zellen, von der Gestalt und Grösse der äussersten Zellen des Marhes, aber mit brauner Membran und wie es scheint stets wasserhellem Inhalt. Diese Schicht wird umgeben von der aus drei oder mehr Lagen grosser Zellen bestehenden oberflächlichen Rindenschicht. Die Zellen der letzteren sind meist von unregelmässig rundlicher Gestalt, an Umfang den grössten Markzellen mindestens gleich, sie haben eine dunkle, violettschwarze Membran und enthalten Wasser, resp. Luft. Von denjenigen dieser Zellen, welche die iusserste Oberfliche der Rinde bilden, ragen viele unregelmissig über die anderen nach aussen vor, manche verlängern sich zu kurzen, unregehmässigen Ilaaren oder Papillen, bei anderen ist der nach aussen gewendete Theil der Membran unregelmissig zerrissen - daher die Rauheit der Oberfliche.

f. Die Sclerotien von Clavaria complanata, Cl. scutellata, Typhula Lasehii, Typh. Euphorbiae Fuck. und andere gleichfalls wohl zu Typhulae oder Pistillarien gehörige, wie Scl. fulvum Fr., haben die gallertartig - knorpeligge Marksubstanz des Typus 1 , hinsichtlich der Dicke und Festigkeit der Membranen sind geringe Artversehiedenheiten vorhanden. Der Inhalt der IIyphen besteht aus hlarer oder von spairlichen Körnchen durchsäeter wisserig̣er Fliissigkeit, nur Sel. fulvum zeigrt die Fiden von homog̣en trübem Protoplasma dicht erfültt. Die Rinde dieser Formen ist eine einfache Lage gleichhoher und mit ihren Seitenwinden liickenlos verbundener Zellen, welche deutlich als
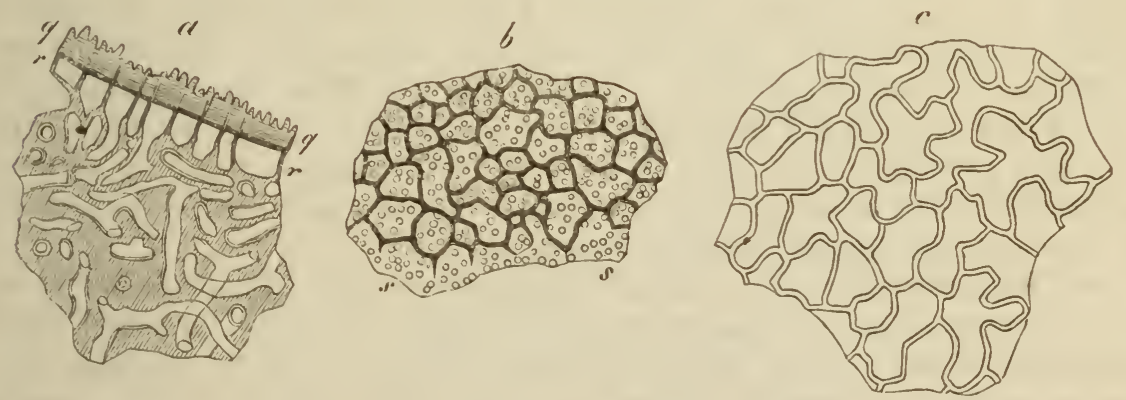

Fig. 13.

peripherische Glieder der Markhyphen zu erkennnen sind, so unähnlich sie diesen auch in der Structur sein mögen. Die Zellen haben tafelförmige oder kurz

Fig. 13. $a$ und $b$. Sclerotium der Clavaria scutellata. a Stück eines dünnen Querschnittes, $r$ Rindenzellen, $q$ Cuticularschichten derselben. $b$ Stück der Rinde, flach ausgel)reitet, von Aussen gesehen, bei $s$, an Rande des Präparats, ist nur die warzige Aussenseite der Cuticularschichten, ohne die Seitenwände der Zellen vorhanden. Verọr. 390. - c. Flach ausgebreitete Rindenschicht des Sclerotium von Clavaria complanata, von aussen gesehen. Vergr. 390. 
prismatische Gestalt, ihre Seitenwände sind hïufig̣ wellenförmig ausgebuchtet, Innen - und Seitenwände wenig, die Aussenwaindle dagegen sehr stark und nach Art der Cuticularschichten von Gefässpflanzen verdickt, mit glatter Fig. 13c) oder warziger (Fig. $13 a, b$ ) Aussenfläche. Die Rinde gleicht somit auffallend der derben, spaltöffnungsfreien Epidermis vieler Gefasspflanzen.

g. Bei den Sclerotien von Typhula variabilis Riess, Peziza Curreyana und nach Bail's Angaben auch von Typhula phacorhiza Fr. hat die Rinde im Wesentlichen den gleichen Bau, wie beim vorigen Typus. Dagegen ist die weisse oder rosenrothe (P. Curreyana) Marksubstanz aus einem mit unzahligen lufthaltigen Lücken versehenen Geflechte cylindrischer Hyphen gebildet. Diese sind bei Typhula zartwandig, mit dicht körnigem Inhalt, bei P. Curreyana mit verdickter, geschichteter Membran versehen. Bei letzterer Art wird das Markgeflecht nach der Oberflache zu dichter, dem des Typus $a$ ähnlicher.

$h$. Die stumpf dreikantigen hornförmigen Körper, welche sich in den Blüthen von Gräsern und Cyperaceen entwickeln, das sogenannte Mutterkorn (Ergo ), sind, wie durch Tulasne's Untersuchungen bewiesen ist, die auf Kosten der Fruchtknoten entwickelten Sclerotien von Claviceps-Arten. Sie bestehen bei der Reife der Hauptmasse nach aus einem schmutzig weissen Gewebe (Mark), welches von einer violetibraunen Rinde umgeben wird. Das Mark hat die Beschaffenheit eines Pseudoparenchyms, von cylindrisch - prismatischen Zellen, die durchschnittlich ein - bis viermal so lang als breit sind, gebildet. Die Zellen sind deutlich in gerarle oder geschlingelte Liingsreihen geordnet, von welchen durch die Entwickelungsgeschichte leicht nachgewiesen werden kann, dass sie die Eigenschaften der Pilzhyphen besitzen. Auch in reifen Sclerotien ist dieses häufig noch deutlich zu erkennen; im Innern derselben befinden sich nämlich nicht selten Risse und Spalten, welche von einem dünnen Filz ausgekleidet oder locker erfüllt werden. Durchschnitte zeigen, dass dieser aus einem Geflecht von Hyphen besteht, welche als Aeste von den Zellreihen des dichten Gewebes ausgehen und, ausser der lockeren Verflechtung, die gleiche Beschaffenheit wie letztere besitzen. - Gegen die Oberfliche des Sclerotium hin ist das Markgewebe in der Regel kurz - und weitzelliger, als in der Mitte. Die Zellen sind allenthalben mit einer ziemlich derben, farblosen Membran versehen und untereinander meistens nach allen Seiten hin fest und lückenlos rerwachsen. Sie enthalten grosse, fàrblose Oeltropfen.

Die Marksubstanz wird zunichst umgehen von einer allenthalben fest mit ihr verwachsenen inneren Rindenschicht: eine bis zwei Lagen von Zellen, deren Inhalt kein Oel zeigt, deren Membranen stark, aussen oft mehr als innen verdickt und dunkel violettbraun gefirbt sind. Um diese innere geht eine äussere Rindenschichte, gebildet aus wenigen oder bis zu zwanzig Lagen longitudinal geordneter oder unregelmässig rerzweigter Zellreihen. Ihre Zellen sind eng und mit blass braunvioletter Membran versehen. Sie bildet den feinen, blassvioletten, oft lingsstreifigen oder unterbrochenen Reif, welcher das frische Mutterkorn aussen bedecht und sich ron der festen Innenrinde leicht abbröckelt oder abreiben lässt.

Was die Entstehung der Sclerotien betrifft, so entwickeln sich alle als secundäre Bildungen auf und aus einem zuerst vorhandenen (primären) fädigen oder flockigen Mycelium. Die Hyphen dieses letzteren zeigen an be- 
stimmten Stellen besonders üppiges Wachsthum, verflechten sich zu einem dichten, anfangs überall gleichartigen Pilzkörper, dieser differenzirt sich zuletzt in Mark und Rindenschicht und grenzt sich durch letztere von dem primiren Myceliun ab. Die speciellen Vorgạinge dieser Entwickelung sind nach den Arten verschieden.

Für die hïufigst vorkommende Entwickelungsweise liefert Peziza Sclerotiorum das beste Beispiel. Auf dem ïber das Substrat rerbreiteten flockigen primiiren Mycelium erheht sich der erste Anfang eines Sclerotium als ein Büischelchen locker verflochtener Fiden. Zweige der primiren, zartwandigen Hyphen, diesen in allen Stücken gloich. Dureh lebhaftes Wachsthum umol Verzweigung seiner Fïden wïchst der Büschel rasch zı einem dichten weissen Ballen von der Grösse des Seterotiums lıeran: bis diese Grösse erreicht isl, bleibt der Bau der

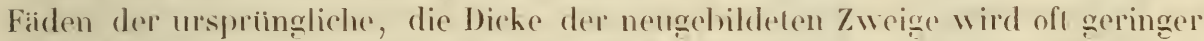
als die der primbiren Hyphen, ihre Beschaffenheit ist in allen Reg̣onen des Ballens die gleiche. Die Lïcken des Geflechts sind lufthaltigr, die Oberfläche durch abstehende Hyphenzweige feinhaarig̣, das Ganze weich, leicht auf ein versohwindend kleines Volmmen zusammenzudrüchen. Durch Neubildung in

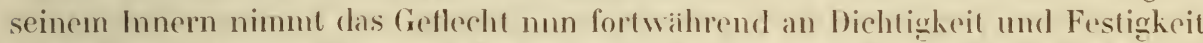
zu. Zuletzl trill die für die Species characteristische Verdickung der Membranen, gleichzeitigg das Verschwinderf der lufthaltig̣en Interstitien und die Diflerenzirmng in Mark - und Rindensehichte ein. Dieser Ausbildungsprocess beginnt im Innern des Geflechtes und schreited rasch gegen die Peripherie hin fort. Die oberflichliche Lage des weissen Ballens nimmt an denselben aber keinen Theil, sie verhleibl rine \%eit lang als weisser Filziiberzug iiber der sich von ihr abgarenzenden Rinde, $11 \mathrm{~m}$ zuletzt zu collabiren und unhenntlich zu werden. Das reife Selerolium löst sich als scharf muschriebener kiorper von seiner filzigen Imgebung al).

Wesentlich die gyleiche Enfwirkelung haben die in der Regerel auf der Oberfliche des Substrats entstehenden Selerotien von Coprinus stereorarius, $\Lambda$ garicis Selerotium fungerum, pubescens rete), I!̣pochnus centrifugus bei welch letzterem ein Theil der Fiden des oberflichlichen Geflechtes derbwandig wird und als persistente llaare anf der fertig̣en Rincle verbleibt, Auch die Entstehung der selepotien von Peziza Fucheliana und Verwandten Scler. durum, erfolegt in wesentlich der gleichen Weise, mit Modificationen, dir sich aus ihrer Bildung im Innern des Substrats ron sellost ergaben.

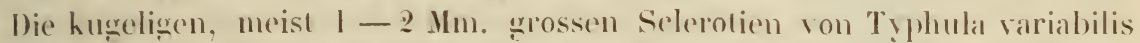
entwicheom sich im Winter und Fruhling auf faulem Laube. Das zarte, firligge Primaimycelium ist in dem Parenchym der faulen Blitter verbreitet; wo ein Selerolinm entsteht, trilt ein Bündel seiner Fiden an die Oberfliche, $1 \mathrm{~m}$ sich hier zu einem galatten, weissen, hugehchen körperehen zu verflechten, welches dem Blatte mittelst eines kurzen, diinnen Slielchens aufsitzt. Die Kuged veregrossert sich rasch durch Bildung newer Zellen und Zwoige in allen ihren Theilen. Sie ist zuncichst aus lauter gleichattgen, protoplasmareichene zartwandig̣en, stark ver:istolten IIyphen gebildet, diese dicht, doch mit lufthaltig̣en Interstitien verflochten. Nu diejenigen Theile der Iyphen, wolche die iusserste Oberfliirhe der Kugel bilden, sind von Anfang an dicht und lückenlos ancinandergedraingl: bei Untersuchung sehr junger Entwichelungszuslande erkennt 
man, dass die Oberfliche aus einer Schicht kurzer, gleichhoher Zellen gebildet wird, den Endzellen zahlreicher nach der Peripherie hin laufender Hyphenzweige. Anfangs sind diese Zellen zartwandig, gleich den übrigen Theilen der Fäilen, ihre Membran farblos, ihr Inlaalt Protoplasma. In der Mitte der Kugel dauert das Wachsthum durch Neubildung von Hyphenzweigen noch langere Zeit fort; das Mark nimmt hierdurch bedeutend an I'mfang zu, die Dicke seiner Hyphen wäichst höchstens auf das Doppelte der ursprünglichen, ihre Verflechtung bleibt die gleiche wie Anfangs. Zwischen die Zellen der oberflichlichen Schicht werden schon in sehr frühem Entwickelungsstadium keine neuen eingeschoben, dagegen dehnen sich die vorhandenen nach allen Seiten aus, und in der Richtung der Kugeloberfliche stark genug, um stets eine ununterbrochene Schicht zu bilden. Ihre Seitenwände erhalten dabei die oben erwähnten unregelmässig̣ welligen Ausbuchtungen, ihr Protoplasmainhalt verschwindet, die Membranen rerdicken sich um den oben beschriebenen Cuticularüberzug zu bilden und farben sich dabei gelb Sel. vulgatum Fr.) oder zuerst gelb, dann blass - und endlich dunkel schwarzbraun Scl. Semen;. Sobald die Ausbildung und Färbung der Rindenschicht beginnt, erkennt man, dass sie sich auch an der Insertion des Stieles iiber eine in der Richtung der Kugeloberfläche verlaufende Zellschicht fortsetzt. Die Kugel wird somit von ihrem Sticlchen scharf abgegrenzt, dieses schrumpft und rertiocknet, das Sclerotium löst sich von seiner Ursprungsstelle leicht ab.

Ganz ahnlich erfolgt die Entwickelung des Sclerotium von Clavaria complanata und ohne Zweifel aller, die dem oben mit $f$ bezeichneten Structurtypus angelıören.

Mehrfache, durch den Parasitismus des primären Myceliums und die Bildung der sogenannten Sphacelia bedingte Eigenthümlichkeiten zeigt die Entstrhung des Sclerotiums ron Claviceps, des Mutterkorns. Tulasne hat dieselbe zuerst genau dargestellt und hierdurch die alte Ansicht Decandolle's, dass das Mutterkorn ein Pilz sei, sichor begründet, dic entgegengesetzten Meinungen, nach welchen es ein degencrirtes Ovarium sein soll, beseitigt. Der Pilz beginnt seine Entwicholung in der ganz jugendlichen, von den Spelzen umschlossenen Grasbliithe. Zunächst erscheint an der Basis des jungen Fruchtknotens auf der Oberfliche eine aus zarten H! phen gebildete, farblose Pilzmasse, welche selten auf diesen Ort beschränkt bleibt, sondern sich vielmehr meist über den ganzen Fruchthnoten, mit Ausnahme seines Scheitels, ausbreitet, sowohl die Oberfliche überziehend, als auch die Zellen der Fruchtknotenwand, wenigstens die ausseren Lagen, durchwuchernd und völlig occupirend. Die innere Fruchtknotenwand und das Ei bleiben hiufig von dem Pilze verschont und in ihrer normalen Beselaffenheit eine Zeit lang erhalten, um jedoch bald zu schrumpfen. An die stelle des Fruchtknotens tritt auf diese Weise ein weicher, weisser Pilzkörper von der ungefähren Gestalt jenes, die beiden Griffel oft auf dem Scheitel tragend. Die Oberfliche der Pilzmasse zeigt viele unregelmässig gewundene, tiefe Einsenkungen und Furchen; sie ist allenthalben bedeckt ron einer im 6ten Capitel zu beschreibenden conidientragenden Schichte. Léveillé hat diese Körper früher nit dem Gattungsnamen Sphacelia benannt, welcher jetzt zur Bezeichnung des beschriebenen Entwickelungszustandes des Pilzes angewendet werden kann. Hat die Sphacelia ibre volle Entwickelung 
erreicht, so erscheint in ihrem Grunde, dem Blüthenboden aufsitzend, der Anfang des Sclerotium, als ein kleiner, länglicher, von dem weissen Gewebe der Sphacelia umgebener Körper, vor letzterer durch grössere Dichtigkeit ausgezeichnet (Fig. 14;. Er besteht zunächst aus dünnen, zarten, von einander trennbaren Pilzfiden, welche in die der Sphacelia continuirlich übergehen, nur etwas derber als letztere, und fester ancinandergedriangt sind.

Schon sehr frühe erhält die Oberfliche des Körper's violette Farbung, indem hier die Zellen die Besellaffenheit der späteren Rinde anzunchmen begrinnen. Das Selerotium ninmmt num an Dicke zu und verlängert sich zu dem bekamnten hornformigen, manclumal über zollangen hörper, der, mit der Basis auf dem Blithenboden befestigrt, zwischen den Spelzen hervoltritt. Sein Wachsthum seheint anfangs

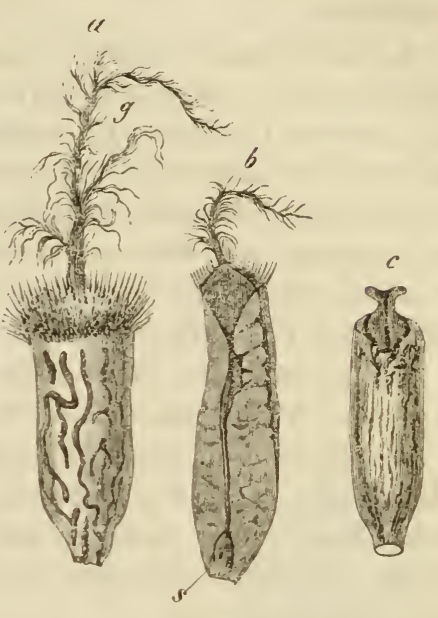

Fig. 14. allenthalben gleichmaissig statlzufinden, an der Basis und in der Vittellinie aber an lingsten anzudauern. Dasselbe homml jedenfalls zu ('inem gouten Theil durch Ausdehnung der anfinglich vorhandenen Elemente zu Stande; wenigstens gilt dies für dis Dickewachsthum, da die Zelleeihen des erwachsenen Selorotium mehr als viermal dicker sind, als in deur jung angelegren. Die Anordnung der Zellreilien ist tibrigens von Anlang an die gleiche wie bei der Reife, seln friih beginnt in ihnen die Ansammlung von Oeltropfen.

Die Splıacelia hört zu wachsen auf, sobald das Sclerotium sich zu entwicheln beginnt. Dieșes sprengt den untern Theil der Sphacelia, von welchem es zuerst eingeschlossen ist, ron dem Bliithenboden los und schiebt dieselbe, indem es sich streckt, zwischen den Spelzen hervor, als eine Kilppe welche dem Scheitel des Selerotium aufgersetzl ist, um bald zusammenzuschrumpfen und fruiher oder spiter abzufallen. Fig. 13.)

Fig. 14. Claviceps purpurea Tul. a junger Fruchthnoten des Rogrgens vou der sphacelia bedeckt, von aussen gesehen. Am scheitel ragen die Haare des Fruchtknotens und Griflelreste $(g)$ aus dem Pilzüberzugr hervor. b Längsschnitt durch

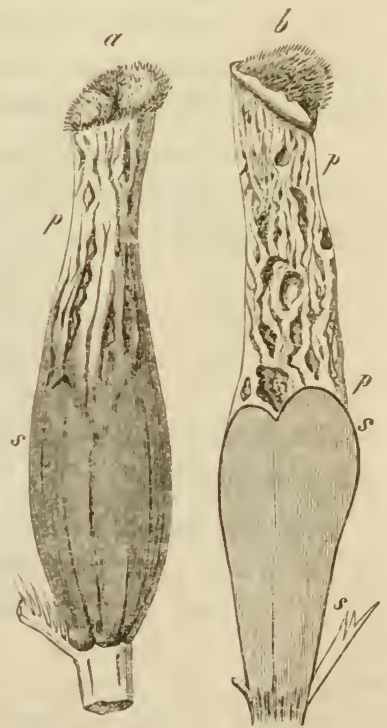

Fig. 15. einen ähnlichen Entwichelungszustand vom Roggen. $s$ Infang des Sclerotium. c Aehulicher Juggendzustand des Pilzes auf dem Pistill von Glyceria fluitans, der Scheitel des Pistills ragt üher die sphacelia hinaus. Schwach vergr., nach Tulasne copirt.

rig. 13. Reiferes Sclerotium von Claviceps (vom Roggen) auf den Blithenboden sitzend. $a$ von aussen geschen, $b$ Längsichnilt. $s$ sclerotium, $\mu$ sphacelie. Schwach verg̣r., nach Tulasne copirt. 
Die ganze Entwickelung dieser Sclerotien geschieht zienlich langsam. In den Blüthen von Brachypodium sylvaticum bedurften sie z. B., nach Tulasne's Beobachtungen, in den Monaten Juli und August etwa vier Wochen zu ihrer Ausbildung.

Selten kommt es vor, dass der Pilz den Fruchtknoten nur zu kleinem Theile zerstört, oder sich unter dem Fruchtknoten entwickelt, so dass dieser seine normale Form und Entwickelung behält und, dem Scheitel des Sclerotiums aufsitzend, zwischen den Spelzen hervorgehoben wird. Tulasne und Kühn bilden Fälle ab, wo normale Früchte des Roggens auf dem Scheitel reifer Sclerotien aufsitzen, ich habe solche Exemplare einige Male, wenn auch sehr selten, gefunden. Sie zeigen auch ohne genaue Untersuchung, dass das Sclerotium kein degenerirter Fruchthnoten ist.

Schliesslich ist zu erwihnen, dass wie es scheint bei allen Sclerotien zur Zeit wo die Differenzirung und definitive Ausbildung ihres Gewebes erfolgt, auf der Oberflache eine grosse Menge von Flüssigkeit ausgeschicden wird; sie bedecken sich mit grossen farblosen oder gell)lichen Wassertropfen (Peziza Sclerotiorum, Fuckeliana, Agaricus cirrhatus, Hypochnus centrifugus, Coprinus stercorarius, Typhula, Clavaria, oder (Claviceps) schwitzen eine klebrige zuckerhaltige Flüssiggkeit aus.

Einen der Sphacelia von Claviceps entsprechenden besonderen Fruchttriger sah ich bei heinem anderen Sclerotium dem Auftreten des Sclerotium sellost vorhergehen. Besonders hebe ich dieses herror in Bezug auf Peziza Sclerotiorum Scler. varium, bei welcher Coemans Körper fand, welche er der Sphacelia von Claviceps rerogleicht. Schon Tulasne Fung. Carp. p. 1030 hat die Vermuthung ausgesprochen, dass Coenans durch Schimmelbildungen getiuscht worden sein duirfte, welche der Entwichelung des Sclerotium fremd sind.

Alle Sclerotien gehen nach ihres Ausbildung in einen Ruhezustand iber, in welchem sie versehieden lange Zeit verharren können oder miissen. Zuletzt tritl ein Wiedererwachen ihrer Vegetation, ein Hervorsprossen von Neubildungen an ihnen ein. Sie sind daher passend als Da uerm ycelien bezeichnet und den Knollen phancrogamer Pllanzen veregchichen worden.

Der Ruhezustand dauert verschieden lange; bei sScl. duruma oft nur einige Wochen. Bei Peziza sclerotiorum wihrte er in den Versuchen von Coemans 2-3 Monate, Wihrend Tulasne 16, Münter 18 Monate auf das Wiedererwachen warten mussten.

In der freien Natur entstehen die Sclerotien meist in Frühling, in warmer Winterszoit und im IJerbst; das Austreiben erfolgt in dem darauf folgenden Frïhling oder Herbst, also je nach dem einzelnen Fall nach einer Ruhe von ? bis :3, 6, 9 Monaten. Die Sclerotien ron Claviceps entstehen während des Sommers und treiben, nach Tulasne zuweilen im Spätherbst, in der Regel jedenfalls im folgẹenden Fruilijahre aus, ebenso Peziza Curreyana und Duriaei. Bringt man die sclerotien lang̣e vor der gewohnlichen Zeit ihres Austreibens in die hicrzu giinstigen Bedingungen, so kann dadurch, soweit die vorliegenden Beobachtungen reichen, ihre Ruhezeit nicht oder nur wenig abgekürzt werden.

Durieu's und Tulasne's Erfahrungen zeigen ferner, dass wenig̣stens einigge Sclerotien (Claviceps, Peziza Duriaei) ubber ein Jahr trocken aufbewaht werden 
können, ohne ihre Entwickelungsfïhigkeit einzubüssen. Peziza Sclerotiorum verhiilt sich ebenso.

Die Hauptbedingung für die Weiterentwickelung aller Sclerotien besteht darin, dass sie in eine constant feuchte Umgebung kommen, also in der freien Nitur, und auch in Culturversuchen am besten, in oder auf feuchten Boden.

In fast allen bekannten Fillen treten aus dem austreibenden Sclerotium direct die Fruchttriger der Species hervor. Ihre Entwickelung findet in der Regel folgendermassen statt. An irgend einer Stelle des Sclerotium bilden sich an den dicht unter der Rinde gelegenen Markhyphen zahlreiche neue Zweige, zu rinem Bündel dicht zusammengedrängt, welches senkrecht gegen die Rinde wichst. Diese wird nach aussen vorgetrieben und bald durchbrochen. Aus dem Riss ins Freie getreten, sondern sich die Hyphen des Bündels bei der conidienbildenden Peziza Fuckeliana und Verwandten (Botrytis cinerea) von einander, jede wird zu einem

freien fruchttagenden Faden.

Bei den meisten anderen Sclerotien bildenden Pilzen bleiben die IIyphen zu dem Biindel vereinigyt, dieses wiichst zu dom für die jeweilige Species characteristischen zusammengesetzten Fruchttriger heran. Auf diese Weise treten aus dem Sclerotium hervor die fruchttriger von Claviecps, von
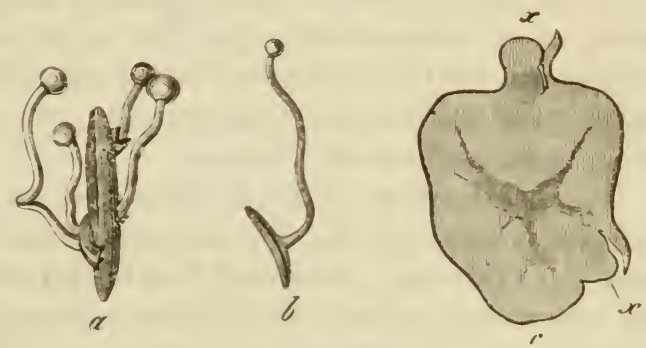

Fig. 16. simmtlichen oben erwibnten Typhulae, Clavaria complanata, scutellata, Agaricus tuberosus, Peziza tuberosa, P. Fuckeliana, P. Sclerotiorum von wolch letzlerer Coemans unrichtig angibt, dass die Rinde selbst zu dem Fruchttriger auswachse). Gute Priiparate zeigen in den gemannten Fillen immer die Hyphen des Markes mit denen der Fruchttriger in unmittelbarem Zusammenhangeg die Basis der letzteren wird ron den Lappen der gesprengten Rinde wie von einer kurzen, unregelnaissigen Seheide umgeben. Vergl. Figgg. 16, 17.) Mit dem llerrorsprossen der Fruchttriger beginnt das Markgewebe im Intheis ihrer Lisprungsstelle weich und locker zu werden. Bei Clavieeps verschwindet, nach Tulasne, das Oel, und wird dureh wisserige Fluissigkeit ersetzt, die Zellmembranen werelen dimner, zuletzt sehr zart, die ein-

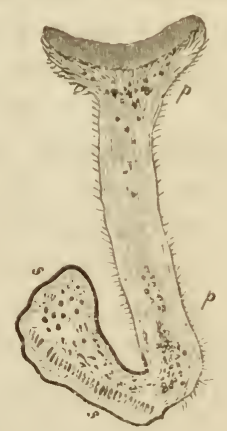

Fig. 17.

Fig. 16. $a$ Claviceps purpurea, $b$ Clar. microcephala T. Sclerotien mit entwickelten Fruchtträgern. Natiirl. (irosse. $c$ Clav. purpurea, Querschnitt durch ein Sclerotium mit zwei jungen, aus dem Innern hervorbrechenden Fruchtträgerı $x_{;}$; schwach vergr. Cop. nach Tulasire.

Fig. 17. Peziza Fuckeliana, sehr kleines Exemplar. $s$ Querschnitt durch ein Sclerotium, aus dem ein längsdurchschnittener Fruchtträger hervorgewachsen ist. Die dunkeln Flecke in dem sclerotium sind die todten Zellen des von ihm occupirten Blattes; die Flecke und Punkte bei $p$ oxals. kalk in Drusen. Vergr. 20. 
zelnen Zellen trennen sich leicht von einander. Bei den knorpelig - gallertartigen Sclerotien von Peziza Fuckeliana, Sclerotiorum, Iuberosa, Clavaria complanata etc. werden die gallertartigen Verdickungsschichten der Hyphen weicher, blass, allmählich ganz unkenntlich, so dass nur die innerste Lage der Membran als eine zarte Haut deutlich erkennbar bleibt. Die frühere feste Verbindung der Fäden hört damit natürlich auf. In dem Lumen der Zellen sammelt sich gleichzeitig reichlicher körniger, durch Jod gelb werdender Inhalt, der zuletzt wieder in dem Maasse abnimmt, als die Fruchtträiger grösser werden. Aus den vorhandenen Beschreibungen geht hervor, dass in allen Fällen ein ihnlicher Auflösungsprocess des Markes wahrend der Entwickelung der Fruchttriger stattfindet. Derselbe setzt sich oft allmählich ïber das ganze Mark fort, die Rinde nimmt keinen Theil daran. Mit der Erzeugung eines oder mehrerer Fruchttriger werden daher viele Sclerotien weich, wasserreich, beim Eintrocknen schrumpfen sie zu einem dünnen, unscheinharen Körper zusammen. Nach dem Mitgetheilten ist es einleuchtend, dass die in den Sclerotien abgelagerten assimilirten Substanzen, wie Oel, gallertige Verdickungsschichten u. s.w. als Reservenahrung dienen. Die chemischen Umsetzungen, welche bei ihrem Verbrauch vor sich gehen, sind noch zu untersuchen.

Das Hervorsprossen der Fruchttriger ist in den bekannten Fällen nicht an einen bestimmten Ort der Sclerotien gebunden. Von grösseren Sclerotien, wie denen von Claviceps, sind auch Bruchstücke fortbildungsfihig. Ein Sclerotium kann einen oder mehrere Fruchtrijger er'teugen, und zwar steht die Zahl und Kraftigkeit der letzteren zu der Grösse der Sclerotien im Verhiiltniss. Aus den grossen Sclerotien von Claviceps purpurea, wie sie in den Aehren von Secale, Triticum vulgare entstehen, wachsen of 20 bis 30 starke Fruchttriger hervor, aus den kleineren, in den Blüthen von Bromus, Lolium, Anthoxanthum entstandenen Exemplaren nur wenige, schmichtig̣e.

Bei cinigen Sclerotien scheint das Austreiben der Fruchttriger in einer von der beschrichenen Regel abweichenden Weise stattzufinden. Auf dem Sclerotium, welches den alten Namen Scl. fungorum fiuhrt, erscheint bei Cultur auf feuchtem Boden in IIerbste constant ein kleiner, weisser, dem A. cirrhatus jedenfalls sehr ahnlicher Agaricus. Auf dem Scl. stercorarium, das sich aus dem Mycelium von Coprinus stercorarius entwichelt, tritt in der Cultur wiederum der Fruchthriger hesagten Coprinus' auf. Die ersten Anlagen sowohl wie die fertigen Stiele der Fruchttriger aber sitzen bei beiden Mrten aussen auf der undurchbrochenen Rinde. Die zarten Hỵhen aus welchen ihre Basis besteht, sind der letzteren einfach aussen angelegi. Dabei behailt das Scl. fungorum bis zur Reife des Agaricus meist seine ursprüngliche Structur und Consistenz. Die genannten Fruchttrigererscheinen auf den betreffenden Sclerotien so constant, dass es wenig wahıscheinlich ist, dass sie nicht a us dem Sclerotium entstehen. Wie dieses aber geschieht, ob viclleicht die Elemente des Markes einzelne feine Zweige treiben, welche die Rinde durchbohren und dann zu dem Anfange des Fruchttrigers heramwachsen, oder ob die Hyphen des letzleren vielleicht als Zweige einzclner Rindenzellen entstehen, konnte ich bis jetzt nicht ermitteln. Das Letztere ist darum nicht ganz unwahrscheinlich, weil die conidientragenden Fiden von Peziza Fuckeliana und Verwandten Botrytis cinerea P.) zuweilen deutlich durch einfaches Auswachsen einzeiner Rindenzellen entstehen. 
Die Sclerotien von Hypochnus centrifugus sah Tulasne, nachdem sie Ende April in feuchten Sand gebracht worden waren, in August und September ein fädiges, spinnwebeartiges Mı̣celium austreiben, welches später die gewöhnlichen Fruchtträger des Hypochnus entwickelte. Von dem Zusammenhang der Myceliumfäden mit dem Sclerotium wird nur angegeben, dass jene von der Oberfliche des letzteren ausstrahlten. Consistenz und Structur der Sclerotien blieben nach dem Austreiben unverindert; Tulasne betrachtet daher die Kenntniss dieser Sclerotien mit Recht als nicht abgeschlossen.

Wie es sich mit anderen Fällen, in denen angegeben wird, dass faidige oder strangförmige Mrcelien aus den Sclerotien entspringen, verhält, ist vorlaufig zweifelhaft. Die Angaben Léveillès, nach welchen aus den Sclerotien von Agaricus grossus, stercorarius, racemosus, tuberosus zuerst ein flockiges Mycelium entstehen soll und auf diesem später die Fruchttriger, diurfen auf Tïuschung beruhen, zumal da bei den zwei letztgenannten Irten das directe Hervorwachsen der Trigger aus den Selerotien unzweifelhaft Regel ist. Zu der Täuschung diirfte zunichst ein Unstand Anlass gegehen haben, auf welehen schon Tulasne aufmerksan gemacht hat; dass nämlich, wenn die Sclerotien tief inı Boden liegen, die Fruchttrigger selbst in Form dünner IIyphensträng̣e aus ihnen hervortreten und erst wenn sie über die Bodenobrefliche gelangt sind, ihre normale Besehaffenheit annehmen. Ferner erscheinen meist an der Basis der aus dem Selerotium hervorgetretenen Fruchthörper flochige Fadenwucherungen oder kurze ingeeliumartige Stränge, unzweifelhaft secundiare Producte des Fruchttrigers solbst, aber mit einem ilm erzeugenden Mycelium leicht zu verwechseln.

Dass die sterilen, Anthina-ihhlichen Körper, welehe bei Culturen nicht selten aus Typhula - und Clavaria-solerolien hervorsprossen, nichts weiter als monströse Fruchltriger sind, ist wohl nicht zweifelhaft.

8. In die Betrachtung der Scherotien knüpft sich nothwendig die, wenn auch nicht rein morphologrische Frage nach der Da uer der II teclien überhaupt an. Sic ist kurz dahin zu beantworten, dass die Mveedien der Pilze je nach den Arten in Beziehung auf ihre Dauer dieselhen Verschiedenheiten und dieselbe Mamnigalligheit zeigen, wie der vegetative Kiorper anderer Pflanzen. Belege hierfuir sind zalılreich vorhanden, obyleich dic Pilzm! celien bis jetzt verhiiltnissmiissig wenig beachtet wurden.

Eine Anzahl Mycelien ist typisch monocarpisch, d. h. sie erzeugen inmer nur wahrend einer Vegetationsperiode Fruchterager diese allerding mes me in Mehrzahl. Einjahriga, innerhalh einer Vegetationsperiode, und oft in sehr kurzer Zeit ihre ganze Entwickelung vollendend, sind die einfach fiidigen Ireclien einer Anzahl ion endophyten Schmarotzerpilzen, z. B. Protomyces macrosporus, Puccinia Violarum, Lromyces Phaseolorum, appendiculatus, Puccinia graninis und andere, mögen dieselhen ein-oder mehrjihrige l'flanzen bewohnen: den meisten specifischen Parasiten einjahriger Phanerogamen kommt wohl jedenfalls eine Ịpisch einjihrige Entwickelung zu. Typisch monocarpisch und einjahrig, wenn man ron den priniiren Mycelium absieht, sind die meisten Sclerotien, z. B. von den meisten oben genannten Pezizen, T!phula variabilis, Claviceps. Sie sind nach Entwichelung eines oder mehrerer nahezu gleichzeitig auftretender Fruchllriger erschöpft. Das ganze M!̣celium ron Claviceps ist dagegen 
typisch zweijährig, indem es, wie oben angegeben wurde, in einer Vegetationsperiode die Sphacelie und das Sclerotium, in der folgenden aus letzterem die Fruchttrigger entwickelt. Typisch mehrjährige monocarpe Pilze sind meines Wissens nicht bekannt.

Um so zahhreicher sind dagegen die typisch pleocarpen Mycelien, d. h. diejenigen, welche perenniren und alljihrlich zu bestimmter Zeit neue Fruchtträger entwickeln. Für grössere, zumal nichtfleischige Schwämme ist dies längst bekannt, Fries (Linnaea V, p. 501), Tulasne (Carpol. I, 136), Berkeley (Outlines p. 43) führen eine Menge Beispiele hierfür auf, wie Agaricus platyphyllus Fr., Hydnum coralloides Scop., H. erinaceus Bull, Polyporus fomentarius u. s. f. Die Pietra fungaja in Unteritalien, aus welcher, wenn sie im Keller cultivirt wird, jahrelang die essbaren lläte des Polyporus tuberaster Jacq. erzogen werden können, besteht wesentlich aus dem Mycelium dieses Schwammes, welches Erdschollen, Steine u. dergl. umwachsen und zu einer festen Masse zusammengeballt hat. Vielleicht mit Ausnahme des letzterwihnten sind die angeführten Beispiele solche, bei denen das Mycelium faidige oder flockige Beschaffenheit hat. Auch das faidige, oft sehr zarte Mycelium vieler pflanzenbewohnender Schmarotzerpilze perennirt, wie Tulasne und ich gezeiğt haben, in den ausdauernden Theilen der Nihrpflanzen, um alljährlich Zweige in die grünen einjährigen Theile zu senden und hier die Fruchtträger zu entwickeln oder auch in einzelnen Jahren die Fructification auszusetzen und später wieder aufzunchmen. So z. B. Endophșllum Euphorbiae, Sempervivi, Uromyces scutellatus, Puccinia Anemones, Sorisporium Saponariae, Podisoma Juniperi, Peronospora infestans, P. Rumicis und viele andere. Das Perenniren des Myceliums erklint, warum diese Pilze auf denselben Pflanzenstöcken immer wieder erscheinen, warum sie auf Pfropfreisern, Stecklingen u. s. w., welche von diesen entnommen sind, wieder auftreten; seine Beachtung ist für das Verstindniss der Parasilenentwickelung und ihrer Folgen von erster Wichtigheit. Von peremnirenden, alljahrlich Fruchltager treibenden Myceliumstrangen sind die der Phalloideen, wenigstens der einheimischen, zu nennen; auch die Rhizomorphen, deren Fruchttäger freilich noch unbekannt sind, schliessen sich hier an.

Pleocarpe, wenigstens zwei Jahre in bestimmter Jahreszeit Fruchttriger bildende Sclerotien sind die von Clavaria complanata, T!phulae spec., Agaricus racemosus P., nach Tulasne. Nach der Angabe Léveillés und Hoffimann's (I'on. anal.) scheint sich $\Lambda$ gar. fusipes hier anzuschliessen, doch ist die Art wie el peremnirt noeh genauer zu untersuchen. Auch die l'ietra fungaja gehört vielleicht hierher. Ëine eigenthünliche Erscheinung berichtet Vicheli (N. plant. genera p. 203̈) von seinem Fungoides Nr. 5, der Peziza Tuba Batsch. Ihr im Boden liegendes Selerotium treibt im Frühling eine Anzahl von Fruchttrigern und ein neues Sclerotium (dessen Entwickelung verfolgt werden müsste), welches zur Fruchtbildung im nächsten Jahre bestimmt ist. Das erschöplte vorjaihrige ist, wemn das neue entsteht, meist noch vorhanden, der unterirdische Theil des Pilzes besteht daher im Frihling aus drei ungleichen Tuberculis.

In dem Perenniren flockiger oder faseriger Mycelien findet wohl die Erscheinung der sogenannten Hexenringe, soweit sie hierher gehört, ihre Erklarung, d. h. die auf Waldboden und Rasen of vorkommende Anordnung zahlreicher gleich- 
artiger Fruchtträger von Agaricis zu grossen Ringen oder Halbringen. Eigentliche Untersuchungen über die Ursache dieser Erscheinung liegen zwar nicht vor. Bei der Cultur von rasch wachsenden Schimmel- und Schmarotzerpilzen sieht man aber hiufig die Bildung der Hexenringe im kleinen Massstabe. Das Mycelium verbreitet sich von dem Punkte seiner ersten Entwickelung aus in centrifugaler Richtung und bildet in derselben Folge immer neue Fruchtträger; diese ordnen sich sehr oft (z. B. Oidium fructigenum, viele Puccinien, Uromycesarten) in concentrische Ringe. Sterben die Fruchttriger sehr schnell ab, wie z. B. bei Peronospora infestans auf Kartoffelblaittern, so ist immer nur ein Ring frischer Fruchtträger vorhanden.

Es ist leicht aus diesen Erscheinungen die Bildung der Hexenringe zu erklären, wenn man im Auge behäl, dass die in Frage kommenden Pilze häufig nur einmal im Jahre zu bestimmter Zeit ihre rasch vergainglichen Fruchttriger bilden, und wenn man annimmt, dass ihr Mỵcelium perennirt, in centrifugaler Richtung alljihrlich sich ausbreitet und in der Niblhe seines Verbreitungscentrums entweder abstirht, oder keine Frucht nehr bildet weil der Boden' für den Pilz erschöpft ist. Jedenfalls wird genauere Berüksichtig̨ung des Myceliums auch hier nothwendig sein, un eine sichere Erkliarung zu finden.

Wie alt ein perennirendes pleocarjes Mycelimm werden kann, ist nicht genau anzugeben. Fries beobachtete das von $\mathrm{Ag}$. platyphỵllus sieben Jahre lang; ich fand das von Phallus caninus fünf Jahre, Puceinia Inemones vier Jahre, Aecidium elatinum bis zu sechzehn Jahren perennirend. I)a die meisten Myeelien ihr Substrat rasch zerstören und den für sie vorhandenen Vahrungsvorrath erschöpfen, so dürften sie selten ein sehr hohes, Alter erreichen.

Die oft rasche Eischöpfung des im Substrat enthaltenen Nahrungsvorrathes ist jedenfalls sehr $z u$ berücksichtigen, wenn es sich um die Bestimmung der typischen Dauer eines Mẹceliums handelt. Sie ist jedenfalls hiufig die Ursache, warum die Vegetation von Pilzen, welche bei genügender Ernäiluung lange ausdauern kömnen, factisch sehr rasch zu Ende geht. Das primaire Mycelium von Peziza Sclerotiorum liört z. B. nach wenigen Wochen zu wachsen auf, wenn es auf einer Frucht, oder Rübe u. s. f. cultivirt wird, aber nur weil es in dem zersetzten Substrat die geejọnete Nahrung nicht mehr findet. Jurch Zuführung immer frischen Nahrungsmaterials habe ich es über ein Jahr lang in üppiger Vegetation erhalten und diese hörte erst auf, als die Cultur absichtlich geendet wurde.

Nach den gegebenen Darstellungen brauche ich hier wohl nicht auf die antiquirte Streitfage einzugehen, ob das Mycelium der Pilze für cine Wurzel oder ein Rhizom oder einen Stengel zu halten sei. End auch die I'nterscheidung verschiedener Myceliumformen mit den Namen Radix, Iyphasma, IIyphostroma, Macula, Circumseriptio, wie sie sich in Corda's Anleitung und bei Krombholz Essbare Sehw:imme p. "33) findet, kann hier nach kurzer Erwihnung übergangangen werden, da sie sich nur auf Verschiedenheiten im iusserlichen Ansehen gründet und als überfluissig lingst verlassen ist. 


\section{Litteratur.}

Mycelien im Allgemeinen:

Ehrenberg, de Mycetogenesi, l. c.

Tulasne, Fungorum carpol. I, Caput VIII.

Die allgemeinen mycologischen Werke behandeln dieses Capitel meist sehr dürftig.

Haustorien des fadenformigen Myceliums:

H. v. Mohl, Bot. Zeitung 1853, p. 593 .

Tulasne, Fung. Carpol. I. Ann. sc. natur. 4e Série, tom. VI, 299.

de Bary, Champignons parasites. Ann. sc. nat. 4e Série, tom. XX.

I yceliumstränge, Xylostroma etc. :

Rossmann, Beitr. z. Kenntn. d. Plıallus impudicus. Bot. Ztg. 1853, Nr. 11.

Tulasne, Fungi hypogaei, p. 2. Fungor. Carpolog. 1. c.

H. H of fma n II, Bot. Ztg. 1836 , p. 155 .

Palisot de Beaurois, Annales du IIuséum d'hist. natur. Tom. VIII. (1806.) 334.

Dutrochet, Nour. Inn. Mus. d'hist. nat. III. (1834.) p. 39.

Turpin, Mémoires de l'Acad. des sciences. Tom. MIV. 1838.)

(Turpin u. Dutrochet beschreiben einen und denselben Gegenstand, die Entwickelung des Cantharellus Crucibulum Fr. aus netzförmig verzweigtem Mycelium.)

Fries, Plantae homonemeae, p. 213-17.

Léveillé, Ann. sc. nat. 2. Sér., tom. XX, p. 247.

de Bary, Ueber Anthina. Hedwigia I, p. 3ə̆. Beitr. zur Morphol. u. Physiol. d. Pilze I, 1864 .

Rhizomorphen speciell.

Aeltere Litteratur s. Streinz, Nomenclator. Bail, Tulasne, ll. cc. Palisot de Beaurois l. c.

Ehrenberg, De Mycetogenesi, l. c. p. 169.

Eschweiler, Commentatio de generis Rhizomorphae fructificatione. Elberfeld 1822.

Nees r. Esenbeck, Nor. Act. Ac. Natur. Curios. XI, 634 ; XII, 875.

Schmitz, Leher den Bau etc. der Rhizomorpha fragilis Roth. Liınaea 1843 , p. 478.

Taf. $16,17$.

Tulasne, fungi hỵpogaei p. 187. Fung. Carpol. l. c.

Ba 1 in lledwigia I, p. 111. Mhandl. iilser Rhizomorpha und Hypoxylon, N. Act. Ac.

Nat. Curios. Band 28. (1861.)

L. asch, Bemerkğn. über Rhizomorpha. Hedwigia I, 113.

$0 \mathrm{th}$, Ueber die Fructification der Rhizomorpha. Mittheilungen der Naturf. Ges.

Bern 4556.

v. Cesati, Rahenh. Herl. Mreol. Nr. 1931.

Caspar!, Bemerkg. über Rhizomorphen. Bot. Ztg. 1856, p. 897 .

Sclerotien und verwande formen :

II icheli, Nova plantarum genera. Flor. 1729.

Tode, Fungi Ilecklenburg. p. 2.

Fries, syst. Mycol. II.

Decandolle, Mem. Mus. dhist. natur. Tom. II, 420.

Léveillé, Mémoire sur le senre Sclerotium. Ann. sc. nat. 2e Série, tom. Xx.

Corda, Icon. fung. Tom. III.

Tulasne, Mémoire sur l'Ergogot des glumacées. Annales sc. nat. 3e Série, tom. XX. 1833.

k ühn, Krankh. d. Culturgewächse p. 113, Taf. Y.

Die nngemein umfangreiche Litteratur über das Sclerotium von Claviceps = Secale cornutum, Mutterkorn, siehe bei Tulasne 1. c. und in den pharmacognostischen Handbuicher, die ältere bei Wiggers, Dissert. in Secale cornutum. Götting. 1831.) 
Tulasne, Ann. sc. nat. 4 e Série, tom. XIII. (1860) p. 12. Select. Fungor. Carpolog. Caput VIII.

Berkeley, Crypt. Bot. p. 2 ว 6.

Bail, Sclerotium und Typhula. Hedwigia I, 93.

v. Cesati, Note sur la véritable nature des Sclerotium. Bot. Ztg. 18ว3, p. 73 .

Coemans, Rech. sur la genèse et les métamorphoses de la Peziza Sclerotiorum Lib.

Bullet. Acad. Belğ. 2e Sér. T. IX, Nr. 1.

Wertendorp, Ibid. Tom. VII, p. 80 .

M ü nter, Ibid. Tom. XI, Nr. 2.

Fuckel, Bot. Ztg. 1861. - Enumeratio Fungor. Jassoviae I. (1861) p. 100. Tỵphula, lapsu calami Claviceps Euphorbiae.)

Kühn, Mittheil. d. Landw. Instituts Halle I. 1863.

Hoffmann, Icon. anal. Fung. Heft 3 .

Gasparrini, Ricerche sulla natura della pietra fungaja e sul fungo vi soprannasce. Napoli 1841.

Leber denselben Gegenstand: Treviranus, Vers. d. Naturforsch. in Bremen. S. Flora 1843, 17. Berkeley, crypt. bot. 2ss. Tulasnel. c.

M ylitta und verwandte Formen:

Oken, Isis, 1825 .

Léveillé, 1. c. Tulas ne Fungi hypogaei, 197. Sel. Fung. Carpol. 1. c.

Corda, Icon. fung. VI, tab. IX, 93.

Berkeley, Crypt. Bot. 254, 258. Gardener's chronicle 1848, p. 829.

Berkeley, Currey, Hanbury. Procelings Linn. Soc. London. III. 18js, 102.

Transact. Linn. Soc. London. XXIII, 91, Tab. IX, X.

\section{('apitel 3.}

\section{Der rruchteriger.}

Als Fruchtträger sollen die von lem Mrcelium entspringenden, die Fortpflanzungsorgane erzeugenden und tragenden Körper bezeichnet werden. Fortpflanzungsorạane nemne ich hierhei die in dem niichsten Abschnitte zu beschreibenden Zellen, welche die Keime neuer Individuen sind Sporen, Conidien u. S. w.. ich will sie hier schlechthin Sporen nennen), sowie die Jutterzellen, von welchen sie unmittelbar erzeuğt werden Sporenmutterzellen, Basidien, Asci u. s. w. . .

Es mag hier wiederholt werden, dass die Fruchtträger von den Mycelien der Regel nach durch ihr factisch mit der Sporenbildung begrenztes Wachsthum unterschieden sind, wie die Inflorescenzen der Phanerogamen von den unbegrenzt wachsenden Laubtrieben. In den weitaus zahlreichsten Fälen ist ihre Entwichelung mit einmaliger Fructification und meist binnen sehr kurzer Zeit abgeschlossen, wie schon das allbekannte Beispiel der fleischigen Hutschwämme lehrt. Nicht selten steht aber das Wachsthum zwar mit der ersten Fruchtbildung still, um jedoch später von neuem anzuheben und wiederholte Fruchtbildung eintreten zu lassen. Es ist ferner hier einstweilen kurz anzugeben, dass eine und dieselbe Pilzspecies oft mehrerlei in Form und Bau ron einander verschieschiedene Fruchttriger bilden kann, sei es dass dieselben einander in einem 
Generationswechsel folgen, sei es dass sie in bestimmter Succession oder anscheinend regelloser Folge von ein und demselben Mycelium erzeugt werden.

Nach ihrem Bau sondern sich die Fruchtträger zun:̈chst in zwei Gruppen, solche die aus einem einzelnen Pilzfaden bestehen: Fruch th y phen, Fruch tfäden, und solche, die einen zusammengesetzten Pilzkörper darstellen: Fruchtkörper.

\section{Fruchth y phe n.}

Die Fruchthyphen sind Zweige der Myceliumfiden, meist vertical von diesen sich erhebend, ihrerseits oft mannigfaltig und meist sehr characteristisch verzweigt, im Uebrigen nur Gattungs - und Artunterschiede darbietend, deren Besprechung nicht hierher gehört. Nach einem für jede Species bestimmten, einige Millimeter nur selten (z. B. bei Jucorinen) überschreitenden Längenwachsthum, bildet sich die Endzelle des Fruchtfadens und seiner Zweige zur Sporenmutterzelle aus, oder, bei einzelligen schlauchförmigen Hyphen, erzeugt jedes Ende eine bis viele Sporen auf die in den folgenden Capiteln zu beschreibende Weise. Das Spitzenwachsthum des Fruchtfadens steht hiermit still und zwar in den meisten Fällen für immer, nach Ausbildung der Sporen geht der sie tragende Faden schneller oder langsamer zu Grunde (Penicillium, Eurotium, Mueorinen, die meisten Peronosporae etc.). Gerade die fadenförmigen Fruchtträger bieten aber auffallende Beispiele für den Fall dar, dass nach dem Reifen der ersten Sporen ein neues Wachsthum des Trägers anhebt, welches bald durch eine neue Fruchtbildung begrenzt wird, und dass derselbe Process sich an einem Faden oder Zweige oft mehrmals hintereinander wiederholen hann. Einen solchen Fall
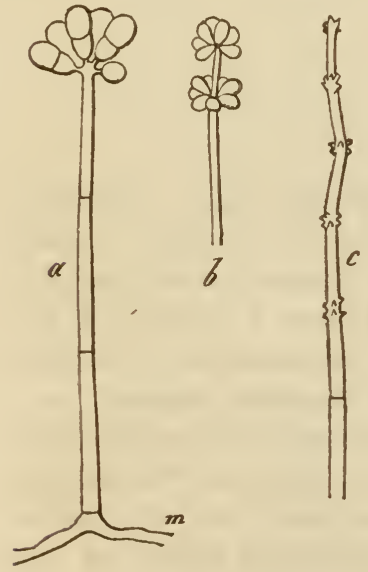

Fig. 18. stellt schon das oft beschriebene Durchwachsenwerden der entleerten Sporangien ron Saprolegnia, das Hervorsprossen neuer fruchtbildender Zweige unter denen von Achlya prolifera dar, und die ahnlichen bei anderen Saprolegnieen beobachteten Erscheinungen. (Vergl. die im ften und Sten Capitel zu citirenden Beschreibungen.) Ein Paar andere Beispiele mögen hier noch beschrieben werden.

Die Fruchthyphen ron Gonatobotrys und Arthrobotrys sind kurze, aufrechte, der Regel nach einfache oder mit einzelnen Zweigen versehene Reihen cylindrischer Zellen. Die Spitze der obersten Zelle schwilt leicht an und treibt zahlreiche, dicht gedringte Ausstuilpungen, welche miteinander ein kugeliges Köpfchen darstellen und zu Sporen heranwachsen. Nach ihrer Reife beginnt die Spitze des Fruchttragers von neuem sich zu verlängern und wïchst durch das Köpfehen durch, dieses wird hierdurch zu einem die Seitenfliche des Fruchttrigers umgebenden Quirl; das durchgewachsene Ende des

Fig. 18. Arthrobotrys oligospora Fres. a Fruchtträger mit dem ersten Sporenköpfchen. $m$ Mycelium. $b$ Zweites Köpfchen über dem ersten. $c$ Ende eines Fruchtfadens mit den Spuren von 5 Köpfchen. Nach Fresenius copirt. 
Fruchttrïigers erreicht etwa die Länge einer der Gliederzellen des letzteren, grenzt sich über dem ersten Sporenköpfchen durch eine Querwand ab und bildet dann auf seinem Scheitel ein neues, dem ersten gleiches. Derselbe Vorgang kann sich sechsmal und noch öfter wiederholen, so dass der Fruchtträger zuletzt mit zahlreichen, um eine Zcllenlänge von einander entfernten Sporenquirlen besetzt ist, oder, nach dem Abfallen der Sporen, ihre früheren Ansatzstellen erkennen lïsst. S. Fresenius, Beitr. Taf. III, V. Corda, Prachtflora. Coemans, Spicilège, Nr. 8.) (Fig. 18.)

Die Fruchtträger von Peronospora infestans sind gerade, aufrechte, querwandlose Iyphen, welche unter ihrer Spitze zwei his mehrere wechselstiindige, kurze Zweige treiben. Diese sind sammt dem Ende des Stammfadens zuerst fein zugespitzt, sie verhalten sich dem letzteren bei allen ferneren Verïnderungen gleich und diese erfolgen in ganz normalen Fiillen gleichzeitig in den Stanmwie in den Zweigspitzen, beide können daher miteinander kurzweg die Spilzen heissen. Jede Spitze bildet nun eine endstindigge Fortpflanzunğszelle Conidie), welche die Form einer Citrone hat und deren Lïngsachse genau in der Verlängerung ihres Trüigers liegt. Die Basis jeder Conidie verschmälert sich plötzlich in ein kurzes, von dem Trigger durch eine Querwand abgegliedertes stielchen. Sobald mit der Entstehung letztgenannter Querwand die Reife der Conidien erfolgt ist, schwillt die Spitze unterhalb des Stielchens leicht an, beginnt sich vorzuschieben und dräng hierdurch die Conidie derart zur Seite, dass diese alsbald mit ihrem Triguer einen rechten Winkel hildet. Xun schwillt der Trigiger an der Ansatzstelle der Coniclie zu einer kleinen, schmal flaschenförmigen Blase an und sein oberes Ende strecht sich gleichzeitig in die Linge, um wiederum die Beschaffenheit einer preiemenförmigen, conidienbildenden spitze anzunchmen. An dieser findet nach einiger Zeit der soehen beschriebene Vorgang von neuem statt. Derselbe wiederholt sich an cinem Triger in der Regel drei-bis vier-

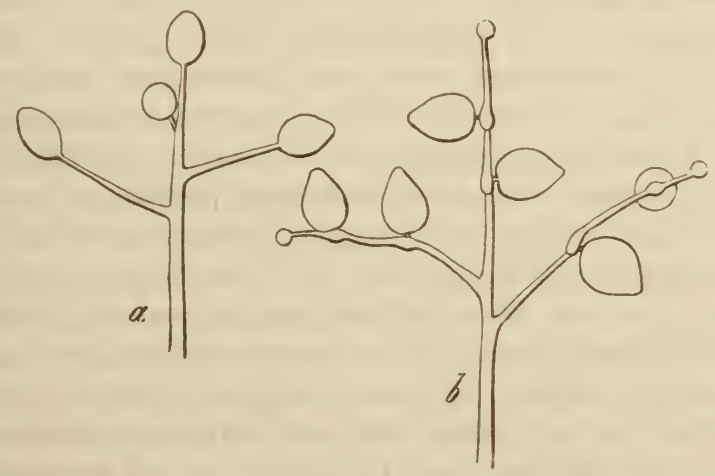

Fig. 19.

mal, an schr üppigen Exemplaren aber bis zu zwölf - und vierzehnmal. Aeltere Fruchthyphen tragen daher, wenn man sie trocken betrachtet, eine Anzahl seit-

Fig. 19. Peronospora infestans. Ende der Fruchthyphen. a Bildung der ersten Conidie auf den spitzen. $b$ je zwei Conidien reif, die Bildung der dritten beginnend. Vergr. elwa 200. 
licher, ziemlich gleichmïssig von einander entfernter, rechtwinkelig abstehender Conidien, von denen jede einer flaschenförmigen Anschwellung ansitzt (Fig. 19). Da die reifen Conidien im Wasser augenblicklich abfallen, so findet man an mit Wasser behandelten Präparaten die älteren fruchttragenden Zweige von Strecke zu Strecke flaschenförmig angeschwollen und höchstens auf der Spitze eine noch nicht völlig reife Conidie.

Die unter dem Namen Botrytis cinerea bekannten Fruchthyphen gewisser Pezizen tragen unter ihrer Spitze mehrere rispenartig zusammengestellte Seitenzweige, von denen die unteren wiederum verïstelt sind. Die etwas angeschwollenen, abgerundeten Enden des Hauptfadens sowohl als der Zweige schnüren auf ihrer Oberfläche gleichzeitig viele Sporen ab. Mit der Reife letzterer stirbt sowohl die sporentragende Endzelle des Fadens als auch die ganzen Seitenzweige ab, sie vertrockenen und sind zuletzt kaum mehr kenntlich, die Sporen selbst werden regellos zusammengeballt. Dagegen beginnt in der unter dem vertrockneten fruchttragenden Ende gelegenen Zelle ein neues Wachsthum; sie streckt sich entweder einfach in die Länge, um alsbald einen neuen Fruchtstand zu bilden, oder sie treibt gleichzeitig einen bis mehrere starke Seitenäste, welche sich dem Hauptfaden gleich verhalten. Bildung und Durchwachsung der Fruchtstände kann sich auch hier an einem Faden mehrmals wiederholen; an alten Exemplaren sicht man die Spuren der abgeworfenen sporenbildenden Zweige in Form kreisrunder, etwas nach aussen vorspringender Narben ( $\mathrm{vgl}$. Fresenius, Beitr. Taf. II.).

Diesen Beispielen schliessen sich streng genommen viele Fälle der im ften Capitel zu beschreibenden succedanen Sporenabsehnürung an.

\section{F r u c h $\mathrm{t}$ ö r per.}

Die aus vielen Ilyphen zusammengesetzten Fruchtkörper sind den Formen nach sehr mannigaltigr. Die bemerhenswerthesten, wie die gestielten oder stiellosen, schirm- oder fächerförmigen Hüte (pilei) der Hỳmenomyecten, die Peridien der Gastromyceten und Tuberaceen, und von den übrigen, welche unter den Namen Stromata, Receptacula zusammengefasst werden, die ver'zweigten, strauchartigen Körper der Clavarien, die Becher der Pezizen, u. s. f. - alle diese dürfen hier wohl als behannt betrachtet werden.

Die specielle Besehreibung der einzelnen Formen ist Sache der Systematik.

Bei der Darstellung des Baues und der Entwickelungsgeschichte, um die es sich hier handelt, ist vor allem die fast ganz allgemeine Erscheinung hervorzuheben, dass die Fortpllanzungsorgane Sporenmutterzellen) an dem Fruchthörper nicht vereinzelt, sondern in grosser Zahl bei einander gebildet zu werden pflegen. Sie stellen für sich aỉlein oder mit zwischengestellten haarähnlichen Organen geschlossene Schichten oder Complexe von oft beträchtlicher Ausdehnung dar. Man bezeichnet diese zweckmissiger Weise mit dem gemeinsamen Namen H !menium, Fruchtschicht, Fruchthaut, Sporenlager, wenn auch die beschreibende Mỵcologie für die Hymenien einzelner Ordnungen passend hesondere Wörter gebraucht und den Ausdruck Hỵmenium speciell für die $\mathrm{Hy-}$ menomỵceten reservirt. Nur bei wenigen Fruchthörpern, nämlich den unter den Namen Isaria, Ceratium bekannten Formen (Corda, Icon. IV, Taf. X), kann 
von einem Hymenium im Grunde nicht geredet werden; die Reproductionszellen sind hier vereinzelt über die Oberfläche des Trägers zerstreut.

Ihrem Bau und besonders ihrer Entwickelungs- und Wachsthumsweise nach sondern sich die Fruchtkörper zur Zeit in vier, den Abtheilungen des Systems nicht überall entsprechende Gruppen, nämlich:

1) Gymnocarpe Fruchtkörper:

2) Fruchtträger der mit Schleier versehenen Agaricinen und Boleten:

3) Fruchtkörper der Gastromyceten und Tuberaceen: und

4) die der Pyrenomyceten.

\section{Gymnocarpe Fruchthöper.}

Unter diesem Namen fasse ich alle diejeniggen Fruchtkörper zusammen, bei denen sich das Hymenium auf der freien Oberfliche des Trigers entwickelt und zu keiner Zeit von einer besonderen, dem Pilze selbst angehörenden Hülle oder Decke eingeschlossen ist. Es gehören dahin weitaus die meisten Fruchtträger; welche ausgeschlossen sind, wird durch die Benennung der drei anderen Gruppen angezeigt, und es ist hier nur das Eine noch zu bemerken, dass auch ron den $A$ garicinen und Boleten nur verhiiltnissmissig wenige, unten specieller zu bezeichnende der zweiten Gruppe angehören: viele derselben, sowie alle übrigen Hymenomyeeten gachören zu der ersten.

Von der iusseren Gestalt der gy mmocarpen Fruchthörper ist hervorzuheben, dass sie entweder in Form flacher, mehr oder minder hautartiger Ausbreitungen dem Substrate aufliegen (z. B. Credineen, die sogenannten ungewendeten resupinati] Hymenomyceten), oder sich mehr oder mincler von dem Substrat erheben. In dem ersten Falle pflegt die ganze freie Oberfliche des Körpers ron dem Ilymenium bedeckt zu sein, in den anderen nimmt letzteres nur einen bestimnten Theil ein; bei den stiel- und strauchartigen Formen Clavaria, Typhula, Calocera) die obere Region, bei den becherfömigen Guepinia. Peziza) die Innenfliche des Becher's, bei den schirm - und fächerförmigen Hüten der Hymenomyecten die mutere Seite des Hutes. Lis ist daher in den letztgenannten Fillen zwischen der sterilen und hymeniumtragenden Region oder Hyme$\mathrm{n}$ ia lf la che des Fruchthörpers zu unterscheiden.

Jie IIymenialflaiche selbst ist, unabhägrg ron den soeben bezeichneten Verschiedenheiten, entweder glatt, höchstens mit unbedeutenden, so zu sagen zufïlligen Prominenzen versehen und von der sterilen Oberfliche nur durch den anatomischen Bau und durch Farbe, Glanz, Beharung unterschieden z. B. Clavaria, viele Thelephoren. Guepinia, Peziza u. s. f.!, oder sie ist ausgezeichnet und oft ausserordentlich vergrössert durch bestimmt gestaltete Falten und Vorsprünge: z. B. unregelmässige, durch tiefe, enge Furchen getrennte Runzeln (Tremella, Ilelvella); Platten oder Lamellen, welche strahlig gegen den Rand des schirm oder ficherförmigen Hutes divergiren (Agaricini) oder mit dem Ilutrande concentrisch verlaufen Cyclomyces); stachel-oder zahnartige Vorsprünge (Ilydnum, Radulum, Irpex); netzförmig anastomosirende Platten oder Falten, welche im Vergleich zu der Weite der Maschenraume zwischen ihnen entweder niedrig, flach (Merulius, Favolus, Morchella) oder von so bedeutender Uöhe sind, dass die Maschen als lange, enge, seitlich mit einander verwachsene Röhren (Tubuli, Pori) erscheinen (Polyporus, Boletus). Bei Fistulina ist 
die Hymenialfläche dicht besetzt mit engen, untereinander freien Röhrchen, welche innen vom Hymenium ausgekleidet werden.

Der innere Bau des Fruchtkörpers muss, nach dem was wir für die Structur der Pilze überhaupt kennen, abhängen von der Anordnung der ihn zusammensetzenden Hyphen und von der Form, Verbindung und speciellen Structur ihrer einzelnen Glieder. Den einfachsten Bau dürfte er bei der Discomycetengattung Exoascus besitzen, wo er eine einfache Lage von Zellen darstellt, wie unten näher beschrieben werden wird.

Bei den massiger entwickelten Körpern lassen sich im erwachsenen Zustande die einzelnen Hyphen entweder deutlich von einander unterscheiden und trennen, der ganze Körper erscheint daher aus Fäden zusammengefügt, von f a d i g e r oder fa s e r i g e r Structur; oder die Hyphen sind derart zwischen einandergeschoben, verflochten und gleichzeitig kurzzellig, dass sie das im 1 ten Capitel als Pseudoparenchy m bezeichnete Gewebe bilden. Auch an intermediiiren Bildungen und Combinationen zwischen den beiden Structurformen fehlt es nicht.

Bei fiidiger Structur ist die Anordnung und der Verlauf der Hyphen oft schon mit blossem Auge auf der Durchschnitts - oder Bruchflache als FaseI. ung zu erkennen, und steht in den meisten, wo nicht in allen Fällen zu der Gesammtform des Fruchtträgers in bestimmter und sehr einfacher Beziehung. Die Hauptmasse der Hyphen verläuft nämlich von der Anheftungsstelle (Basis) des Körpers gegen seine freien Enden oder Ränder : ein parallel-faseriges Bündel bildend bei den stiel - und strauchartigen Formen, ficherartig ausstrahlend bei den schirnı-, fächer - und becherförmigen, nach Art von Kugelradieñ divergirend wenn der Fruchttriger die Gestalt einer Kugel oder eines Kugelabschnittes hat. Sind die Becher, Hüte u. s. w. gestielt, dann steigen die Hyphen im Stiele parallel aufwärts, un von seinem oberen Ende aus der Gestalt des Körpers entsprechend zu divergiren. (Vgl. z. B. Fig. 17 Seite 39 und die in diesem Kapitel folgenden Figuren). Häufig, wie in den Stielen vieler $A$ garicinen, den Iliuten von Thelephora hirsuta u. a. ist der bezeichnete Verlauf höchst regelmässiğ, dic IỊphen laufen schnurgerade oder in ganz glatten Bogenlinien. Senkrecht zur Faserung geführte Durchschnilte zeigen dann, zumal bei fester Verbindung der Ilyphen, nur ihre Querschnitte und haben daher auch hier und da zu unrichtiger Auffassung der Structur verleitet. S. z. B. Corda, Ic. III, fig. 134, Thelepliora hirsuta. Meistens sind die Fäden dagegen vielfach wellenförnig gebogen und dabei durcheinander geschlungen; mehr oder minder zahlreiche Zweige oft nach den verschiedensten Richtungen zwischen die anderen geschoben z. B. Hutfleisch vieler Agarici). Richtig geführte Durchschnitte lassen jedoch in den meisten Fillen auch aus dem anscheinend ordnungslosen Gewirr einen Hauptfaserverlauf herausfinden, welcher der angegebenen Regel ('ntspricht.

Bei den von der Basis nach der Peripherie breiter werdenden und aus divergirenden Fasern bestehenden Körpern sind die Fäden entweder überall durchschnittlich gleich stark und gleich dicht gestellt, oder ihre Stärke sowohl wie die Breite der $\mathrm{Z}$ wischenräume $\mathrm{z}$ wischen ihnen nehmen mit der Entfernung von der Basis ab. Hieraus folgt nach dem was über das Wachsthum der Hyphen im 
Allgemeinen bekannt ist, dass die Zahl ihrer Verzweigungen init der Entfernung von der Basis zunimmt.

Die Zahl derjenigen Fruchtkörper von fädigem Bau, bei denen keine bestimmte Richtung der Faserung wahrnehmbar ist, die Fïden vielmehr regellos nach allen Seiten ausgezweigt und durcheinandergeschlungen sind, llürfte sich bei genauerer Untersuchung als eine relativ kleine ergeben. Vorliufig sind allerdings noch ziemlich viele Gruppen und Genera (Tremella, Uredineen, die parasitischen Discomyceten wie Rhytisma, der Hut ron Morchella, Helvella, Hypochnus u. s. w.) hier zu nennen.

Jie gyunocarpen Fruchtträger mit pseudoparenchymatischer Structur sind in Speciellen höchst mannigfaltig gebaut, ihre Zellen meist anscheinend ganz regellos gestellt z. B. Peziza hemisphaerica, vesiculosa, confluens, Ascobolus furfuraceus). Der Ursprung des Pseudoparenchyms wird meistens verrathen durch mehr oder minder zahlreiche typische Hyphen, welche zwischen seine Zellen eingeflochten sind und mit diesen öfters in refhenweisem Zusanmenhange stehen. Eine Aufzihlung aller bis jetzt behannten - noch sehr zerstreuten Einzelheiten liegt ausserhalb des Zweckes dieser Arbeit. Als Beispiel fiur pseudoparenchymatisches, mit typischen Iyphen constant combinites Gewebe möge hier der Bau der Fruchttrigger bei den Agaricinen - Gruppen Russula Fr. und Lactarius Fr. beschricben werden (vgl. Fig. 20). Corda, Bonorden und Iloffmann haben auf seine Eigenthümlichkeiten aufmerhsam gemacht. Die Fruchutrigger dieser Pilze sind bekanntlich runde, schirmförmige lläte mit centralem, dickem Stiel und von fest fleischiger Consistenz.

Durehschnitte nach versehiedenen Richtung̣en dureh Hut und Stiel der Russulae gefuihrt bei R, integra und R. olivacea von Bonorden, bei R. integra Fr. pileo rubre und R. adusta P. von mir untersucht zeigen, mit Ausnahme der äussersten, hier zunaichst nicht zu betrachtenden Oberfliche, iberall zweierlei Gewebe; nämlich grosse Gruppen von weiten, wasserhellen, rundlichen Zellen und bandartige Stränge, welche von dïnnen, protoplasnareichen, istig̣en Ilyphen gebildet werden. Die wasserhellen, rundzelligen Gruppen haben im Stiele unregehmaissig lingliche Gestalt, abgerundete oder zugeschiirfte Enden, ihr Lingsilurehmesser liuft dem des stieles parallel. In dem Ilutfleisch sind sie rundlich und ganz regellos geordnet. Sie sind allenthalben von den diinnfiadigen Platten und Straingen derart unsponnen, dass letztere auf Durchschnitten ein unregelmaissiges Netzweth darstellen, dessen weite Maschen von dem rundzelligen Gewebe ausgefiillt werden. Die Anordnung der Zellen des letzteren ist in der Mitte des Stieles und im Ilut eine anscheinend ordnungslose: gegen die Oberfliche des Stieles hin stehen sie in unregelmiissig horizontalen Reihen, resp. Lagen. Die Grösse der ganzen Gruppen sowohl wie ihrer einzelnen Zetlen nimmt von der Nitte gegen die Oberflache des Fruchttriggers hin allmahlich ab, die Miichtighkeit der feinfidig̣en Streifen zu. Die Faserung der letzteren ist in Stiele vorwiegend longitudinal, im Ilute ganz ordnungslos. Allenthalben sieht man von ihren Ilyphen vereinzelte Aeste in das rundzellige Gewebe eintreten, in diesem sich, unregelmässiv rerastelt, verbreiten. Genauere Untersuchung zerfaserter Schnitte liisst leicht erkennen, dass die runden Zellen mit den sie umspinnenden und zwischen ihnen verbreiteten Hyphen derart im Zusammenhange stehen, dass sie Glieder bedeutend erweiterter, rosenkranzförmiger Zweige der- 
selben darstellen. Auch fehlt es nicht an Uebergangsformen zwischen den genau rupden Zellen und den schmalen cylindrischen Gliedern der eingeflochtenen und umspinnenden Hyphen. Auf letzteren Punkt hat Bonorden zuerst aufmerksam gemacht. Der Zusammenhang und die Entwickelung der beiderlei Gewebe bleiben ubrigens noch genauer zu untersuchen.

Der Bau der Milchblitterschwämme ist von Bonorden vorzugsweise bei Lactarius pallidus, von Hoffinann bei L. mitissimus, von mir bei L. subdulcis, chrysorrhoeus und deliciosus untersucht worden. Er ist dem der Russulae insoferne gleich, als auch hier Gruppen weiter rundlicher Zellen gleichsam eingesetzt sind in ein Geflecht feiner, cylindrischer Hyphen (Fig. 20). Die Gestalt der grosszelligen Gewebegruppen ist eine :ihnliche wie bei Russula, nur sind sie in der Regel im Vergleich mit den dünnfädigen Streifen schmäler und schärfer umgrenzt wie bei der genannten Gattung. Im Stiele sind sie oft sehr in die Länge gestreckt und nicht selten in longitudinaler Richtung verzweigt oder mit anderen anastomosirend. Auf Querschnitten, zumal im Stiele, zeigen die Zellen von vielen der grosszelligen Portionen eine ei-oder keilförmige Gestalt und sind, in

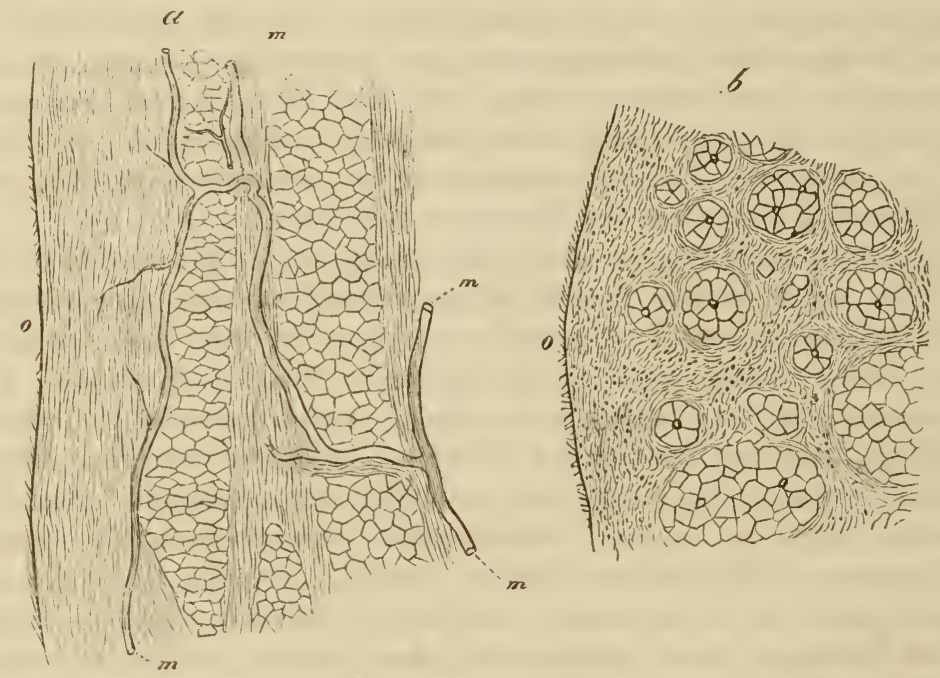

Fig. 20 .

der Regel zu fünf his sechs, um ein kleines Mittelfeld so geordnet, dass ihre schmalen Enden gegen letzteres hin convergiren. Sie bilden somit auf dem Querschnitte eine Rosette. Die so geordneten Zellen setzen entweder allein die grosszellige Gruppe zusammen, oder sind von einer bis mehreren unregelmässig concentrischen. Schichten rundlicher Zellen umgeben; andere Gruppen zeigen im Querschnitte zwei Rosetten, noch andere endlich von der Rosettenanordnung keine Spur. Das kleine kreisförmige Mittelfeld der Rosetten wird gebildet durch den Querschnitt einer engen, cylindrischen, zartwandigen, wasserhellen Inhalt

Fig. 20. Lactarius subdulcis Fr. Aeussere Region des Stiels. a Längsschnitt, $b$ Querchnitt. o Oberfläche. $m$ Milchsaftröhre. Vergr. 90 fach. 
führenden Hyphe, welche, wie Längssschnitte zeigen, in meist stark geschlängeltem Verlaufe die grosszellige Gewebegruppe der Länge nach durchzieht. In den feinfidigen Gewcbestreifen, sowohl dicht noben den grosszelligen Gruppen als von diesen getrennt und niemals in diesclben eintretend verlaufen die für Lactarius characteristischen "Milchsaftgefäse. Dieselben stellen Röhren dar, welche einen im Vergleich mit den ungebenden Hyphen grossen Durchmesser, eine schr weiche dehnbare Mebran besitzen und mit feinkörnigem, trübem, je nach der Species verschieden gefirbtem, aus dem verletzten Pilze in dicken Tropfen hervorquellendem Milchsafte strotzend angefuillt sind. Der Milchsaft gerinnt durch die Siedhitze und durch Einwirkung von Alkohol. Um den Verlauf seiner Behïlter auf Durchschnitten zu untersuchen ist es daher zweckmissig, die Pilze kurze Zeit in Alkohol zu legen: um die Gefisse freizupripariren, werden dic Theile des Pilzes vorher am besten kurze Zeit mit Wasser gehocht. Nach solcher Prïiparation erkennt man, dass besag̣te Röhren nach allen Seiten hin zahlreiche starke Aeste absenden, die häufig̣ IIförmig̨e Verbindungen zwischen zwei Hauptstimmen, niemals jedoch, soweit meine Beob-

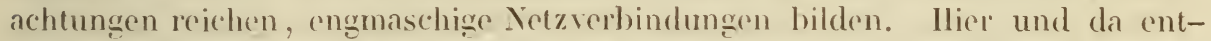
senden die stirkeren Ieste feine, ku1\%, in sehr dünne, gesehlossene. blinde Enden auslaufende Zweig̣e. Zumal in ailteren Exemplaren findet man nicht selten die Milchsaftröhren durch einzelne, weit von cinander entfernte Querwinde getheilt. Besagle Organe durchziehen das IIyphengeflecht des ganzen Fruchthöpers, ihre feinen Verzweigungen dringen bis dicht unter die Oberfliche des letzleren.

Vorstehende Datrstellung stimmt mit IIoffmann's Ang̣aben in der Hauptsache iiberein, nur dass Iloflinann statt der geseshliingelten Ilyphe einen dieser gleichgestalteten Intercellulargang in der Mitte der Roselten beschreibt. Bei den Arten, welche ich untersucht habe, besonders deutlich bei I. subdulcis und deliciosus, hat besig̣ter Gang unzweifelhaft eig̣ene II:inde, welehe sogar hier und da von denen der ang̣renzenden Zellen dureh deulliche Intereellulatraiume getrennt sind. Möglich jedoch, dass hei verschiedenen Irten in dieser Beziehung Lnterschiede vorhanden sind. Russula foetens var. lactiflua Corda Icon. IV. Tab. X hat jedenfalls einen dem beschrichenen selor ihnlichen Bau. Worin die Differenzen zwischen Corda's und der obigen Darstellung ihren Grund haben, lasse ich dahin gestellt. Schleiden's Ang̣abe. derzufolg̣e der Milchsaft ron $\Lambda \underline{a} a-$ ricus deliciosus „) bestimmt in kleinen (iruppen parenchymatischer Zellen "enthalten ist, entbehrt aller Begrindung. Descyleichen die unklare Darstellung bei Külzing Phil. Bot. I. p. $24 i$.

Es mag hier der Ort sein anzufïhren, dass Milehsaft führende Röhren oder langrgliedlerige IỊphen ron de Seynes auch in dem sonst gleichförmig̣ faserigen Gewebe des Fruchttrigers von Fistulina hepatica aufgefunden worden sind. Achnliche Organe, d. h. lange, mit einem dichten, oft glimzenden Inhalt erfiillte Rohren hommen noch manchen anderen fleischig̣en sichwimmen, zumal Agari(cinen, zu z. B. Ag̣ar. praecox. Ig̣ar. olearins nach Tulasne). Sie sind noch genauce zu untersuchen.

Veben der bisher betrachteten allgemeinen Anordnung undGestaltung derFormdemente lassen sich in dem Gewebe der meisten Fruchtkörper verschic dene Schichten unterscheiden. Die nicht fruchttragende Oberfliche wird nämlich in 
den meisten Fällen von einer besonderen peripherischen $\mathrm{Rinde} n=\mathrm{Cortic}$ alschichte (in besonderen Fïllen Pellicula, Cutis u. s. w. genannt) gebildet, auf der fruchttragenden Fläche ist die II ymenialschichte zu unterscheiden, die iibrige meist grösste Masse des Körpers mag als Mark-oder Medullarschichte bezeichnet werden. Je nach dem einzelnen Falle findet zwischen den bezeichneten Hauptlagen eine scharfe Abgrenzung oder ein allmählicher Leberọang statt, und jede derselben kann sich wiederum in untergeordnete Lagen sondern.

Die R inde ist ron der Medullarschichte entweder nur durch Bau, Grösse, Festigkeit der Verbindung ihrer Elemente, bei gleicher Anordnung (Faserung) derselben, oder auch in letzerer Beziehung_verschieden.

In dem ersteren Falle ist es Regel, dass die Rindenelemente enger, dichter miteinander verbunden, die ganze Schicht somit von festerem Gefuige ist, als die Medullarsubstanz. So bei sehr vielen fleischigen oder knorpeligen Schwämmen $\quad$. B. den grösseren Clavarien, Calocera, vielen Agaricinen, Pezizen, dem Stroma parasitischer Discomyceten, wie Rhytisma, u. s. w. . Unter die hierhergehörenden Einzelfïlle sind auch die oben beschriebenen Lactarii zu rechnen (vgl. Fig. 20). Ihre sterile Oberfläche wird, zumal am Stiele, von einer mächtig̣en Lage dichten, feinfiadigen Gewebes ausschliesslich gebildet. Gegen diese Corticallage hin werden die parenchymihnnlichen, grosszelligen Gewebegruppen allmählich hleiner und kleinzelliger. Bei vielen Pilzen von derber, leder - bis holzartiger Consistenz sind dabei die Zellen der Corticalschicht mit gefärbten, verholzten Membranen versehen, die Medullarelemente nicht z. B. Rhytisma, Peziza hemisphaerica u. a., Thelephora hirsuta u. s. f. . Auch der umgekehrte Fall, wrössere Weichheit der Rinden -, festere Consistenz der Medullarsubstanz hommt nicht selten vor. So ist die Oberfliche vieler fest-fleischiger Agaricinen überall Agar. Mycena vulgaris oder theilweise (z. B. Ilut von Russula integra) von einem weichen, in Wasser bis zum Zerfliessen quellenden Gallertfilz überzogen. Bei Agarieus stypticus besteht die Rindenschicht grösstentheils aus einem ziihen, hyalinen Gallertfilz, das Medullargewebe aus einem Geflechte cylindriseher, derbwandiger IIı phen, mit lufterfüllten Lücken. Eine detaillirte Beschreibung aller einzelnen bekannten Fälle würde hier nicht am Platze sein.

Der zweite Fall, dass die Elemente der Rinde eine von denen der Markschicht verschiedene Anordnung zeigen, kommt bei Fruchtträgern mit faseriger Structur hizufig, und zwar in folgender Form vor. Im Umfange des der Gestalt des Körper's entsprechend gefaserten Markes gehen von den Ilyphen desselben ziahlreiche Zweige ab. Welche sich plötzlich oder in einem stets nach dem freien Rande oder der spitze des Fruchttrigger's convexen Bog̣en gegen die Oberfliache wenden, um in dieser nach mehr oder minder reicher Verästelung zu endigen. Die Enden bilden dabei entweder ein ordnungsloses, faidiges oder pseudoparenchymatisches Geflecht \%. B. Auricularia mesenterica, holzige Polypori, oder sie verlaufen untereinander parallel und dicht gedrängt sehrigg oder senkrecht zur Oberflithe, die Rinde besteht somit aus pallisadenartig geordneten Hyphenzweigen. So z. B. Peziza Sclerotiorum: die Stiele von Helvella crispa, elastica besitzen eine aus senkrecht geggen die Oberfliche laufenden, gross- und kurzzelligen IIyhen gebildete, daher einigermassen parenchymähnliche Corticalschichte auf ihrer Aussenfliche, der hohle Stiel von Morchella esculenta auf der 
Aussen - und Innenfliche. Besonders exquisit findet sich die pallisadenartige Structur der Rinde auf der ganzen sterilen Oberflaiche ron Guepinia contorta " und Polyporus lucidus (Fig. 21). Die Marksubstanz des letzteren besteht im Stiele aus dicht und ordnungslos verfilzten Hyphen, im Hute ist sie der ficherförmigen Gestalt desselben entsprechend gefasert. In ihrem Linfange biegen zahlreiche Hyphen nach aussen, ihre Endiaste genau senkrecht zur Oberfliche richtend und genau in gleicher Höhe endigend. Die Endiste sind stumpf-cylindrischkeulenförmig, mit stark verdickten, geschichtetew (in Kali bis zum Zerfliessen quellenden, Membranen versehen, und dicht und lückenlos nebeneinandergestellt. Sie bestehen jedenfalls in der lieg̣ed ob immer lasse ich dahingestellt - aus einer ein-

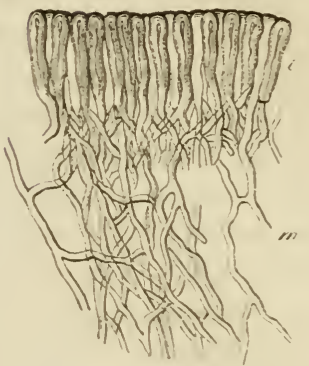

Fig. 21 . zigen Zelle. Der beschriebenen Structur sowie einer dicken. anscheinend homogaenen Cuticula, welche uber die stumpfen Enden der Corticalelemente hinliuft, verdanht der Pilz seine bekannte, für das blosse Auge purpurfarbigge, spiegelglatte Rinde. Enter der beschriebenen Pallisadenschichte bilden die Hyphen ein wirres, die senkrechten Zwoige entsondendes Geflecht, welches im Hute unbedeutend ist. wilnend seine Elemente im Stiel lückenlos verbunden und gleichfalls mit stark rerdickten, braunrothen Membranen versehen sind. Polyporus fomentarius besitzt eine ihnlich gelnaute Corticalschichte; die senkrechten in der Oberfliche endenden II!plenzweige derselben sind jedoch so dickhiutig und spröde, dass ich an meinem Material ihre Gestalt und Structur nicht genau ermitteln konnte.

Schon die angeführten Beispicle zeigen, dass auch in dieser zweiten Reihes von Fiallen die Rindenschichte vielfach dureh grössere Derbheit, Verholzung ihrer Elemente von der Markschichte unterschieden ist, und dass andererseits auch hier Helvella, Morehella das Lmegehehrte vorkommt.

Kleine, einfache Fruchttriger lassen hiufigr keine Differenz von Corticalund Medullargewebe erkennen z. B. Clavaria complanata, Uredineen, Isasia u. s. f. .

Wohl bei der überwiegenden Mehrzahl der Fruchttriger ist die nicht hỵmeniumtrag̣ende Oberfliche mehr oder minder reichlich mit Ha aren. Borsten oder Schuppen bedeckl, Anhïngseln, welche den gleichnamigen Organen höherer Gewichse an Mannigfaltigkeit der Form und Structur kaum nachstehen diurften.

Die Haare sind bei den Pilzen mit deutlich faseriger Structur Hyphenzweige, welche aus dem dicht rerflochtenen peripherischen Gewebe an die Oberfliche treten. Bei den pseudoparenchymatischen Formen entspringen sie. den Haaren

Fig̣. 21. Polyporus lucidus. Dünner Längsschnitt durch die Oberfläche des Hutes, 190 fach rergr. $m$ gegen die Oberfläche laufende Iarkhỵphen. $c$ Rindenschicht.

1) Dacryomyces contortus Rabenh. Herb. Myc. Nr. 19S4. Dieser Pilz ist eine durchaus typische, gestielt-becherförmige Guepinia. Er findet sich in hiesiger Gegend nicht selten im spätherbst und Winter an faulem Roth- und Weissbuchenholze in Wäldern. 
höherer Gewächse ähnlich, von der Aussenseite der oberflächlichsten Rindenzellen, bei Peziza scutellata reicht die oft in mehrere Schenkel gespaltene Basis der derben braunen Haare vielfach in das Medullargewebe, das Haar tritt von da, die Rinde durchbohrend, nach aussen. Was ihren Bau betrifft, so sind die Haare entweder einzellig oder mehrzellig, manchmal verzweigt, ihre Membranen zart oder mehr oder minder verdickt, oft (z. B. Hirneola Auricula Judae Berk.) bis fast zum Verschwinden des Lumens. Grösse, Färbung, Richtung, Besonderung oder Verfilzung wechseln je nach den Arten aufs Mannigfaltigste, der ganze Haariberzug erscheint daher auch unter den verschiedenartigsten Gestalten und Abstufungen, von dem zartesten Reife oder Flaum an bis zur dichten Borstenoder Filzbedeckung. Einzelne Beispiele anzuführen wire überflüssig; die mannigfaltigste Formenreihe der Behaarung dürfte bei den Pezizen zu finden sein.

Bei vielen Pilzen sind die Haare in grösserer oder geringerer Zahl zu Büscheln fest vereinigt, welche, je nach ihrer Länge, Dicke und Zuspitzung dem unbebewaffneten Augge als Borsten oder Schuppen z. B. Polyporus hirsutus, hispidus, Ilydnum auriscalpium oder Warzen Ilydnum gelatinosum erscheinen. Einer besonderen Erwahnung nicht unwerth sind die Warzen auf der Hutoberfläche von Fistulina lıepatica. Dieselben stellen cylindrische Büschel fadenförniger Haare dar, deren etwas erweiterte Enden trichterartig auscinandertreten. Sie sind den Jugendzuständen der fruchttragenden, die Unterseite des Hutes bedeckenden Röhrchen zum Verwechseln ähnlich, und daher schon seit lange (vgl. Fries, S. M. I, 396) als Rudimente der Tubuli bezeichnet worden.

Es liegt in der Natur des Gegenstandes, dass da, wo ein dichter Haarfilz die Oberflache des Fruchtträgers bekleidet, wie z. B. bei Polyporus hirsutus, Thelephora purpurea, Panus stypticus, Zweifel und Meinungsverschiedenheiten darüber bestehen können, ob solcher Filz als Rindenschichte oder als blosser Appendix einer solchen zu betrachten sei. Die Vergleichung verwandter Arten (Polyporus zonatus, versicolor, Thelephora hirsuta u. s. w.) wird hier jedoch meistens eine Entscheidung ermöglichen.

Derjenige Theil des Fruchtkörpers, welcher sich in oder unmittelbar auf dem Substrat befindet, bildet an seiner Oberfliache Haare oder Haarbüschel von besonderer Art, und selbst lange, verzweigte, wurzelartige, aus vielen biindelweise vereinigten IIyphen bestehende Stringe aus, welche man als Wurzelha are, IV urzelfilz, Il a f torgane, oder, in soferne sie leicht und häufig mit dem Mycelium, aus dem der Fruchtträger seinen Lrsprung nimmt, verwechselt werden, als secundiares Mycelium bezeichnen hann. Ton solchen Organen finden sich schon bei manchen einfach-fadenförmigen Fruchttrigern, z. B. Rhizopus nig̣ricans, Andeutungen; auch die myceliumähnlichen Appendices mancher Erysiphen, z. B. Sphacrotheca Lev., dürten hier anzuführen sein. Bei den zusammengesetzten Fruchtkörpern, sowohl den g grmnocarpen als auch den unten zu besprechenden, sind Wurzelhaare allgemein verbreitet, Beispiele für ihr massenhaftes Auftreten liefert die Basis des Fruchttrigers fast aller Hymenomyceten. Nur bei wenigen Pilzen kommen sie an den bis jetzt bekannten Entwickelungszustinden gar nicht vor; so bei Tuber. Die in Rede stehenden Organe zeichnen sich von den Haaren und Haarbüscheln der freien Oberfläche dadurch aus, dass sie sich dem Substrat fest anschmiegen oder in dasselbe ein- 
dringen, und sich daselbst ausbreiten und verästeln wie Myceliumfäden. Sie befestigen daher den Fruchttriger auf seiner Unterlage und führen ihm ohne Zweifel erhebliche Mengen flüssiger Nahrung zu. Sic gleichen in den meisten Bezichungen dem Mycelium, aus welchem die Fruchttrïger entstehen, und die Fadenmassen und Stringe an der Basis der letzteren, wolche gewöhnlich mit dem Namen Mycelium bezeichnet werden, bestehen jedenfalls oft zum grössten Theile aus Wurzelhaaren oder Büscheln derselben. Der einzige durchgreifende Unterschied zwischen diesen Organen und dem ursprünglichen Mycelium, welcher zur Zeit angegeben werden kann, beruht in der Entstehung beider: letzteres entwickelt sich direct aus den Sporen, jene sprossen erst aus der Oberfliche des Fruchttrigers hervor, allerdings oft schon in cinem sehr frühen Entwickelungsstadium desselben. Am deutlichsten tritt dieser Unterschied da hervor, wo das primäre Mycelium zuerst Sclerotien entwickelt, und die Fruchtträger später von diesen erzeugt werden, wie bei Claviceps, Peziza Sclerotiorum, Clavaria complanata u. a. Auch bei nicht sclerotienbildenden Pilzen, z. B. Peziza confluens, den Agaricinen, ist derselbe leicht wahrzunehmen. Die jüngsten Entwickelungsstadien der Fruchttriger sind jedoch noch für zu wenige Fille bekannt, um eine allgemein gültige Entscheidung darüber zu gestatten, was von dem gewöhnlich sogenannten Mỵcelium an der Basis der Fruchtkörper ursprüugliches, was secundires Mycelium sci, und ob die Elemente beider imincr in Form und Structur von cinander verschieden sind. Bei den genannten sclerotiumbildenden Pilzen, welehe his jetzt allein ein sicheres Urtheil gestatten, ist das letztere allerdings immer der Fall. Aus den nimlichen Grüden muss es zur Zeit unentschieden hleiben, ob das secundiire Mycelium gleichsam stolonenartig neue Fruchtrigger zu erzeugen vermag. Bei den sclerotiumbildenden Arten, selbst solchen, die wie Peziza Sclerotiorum in keinem Lebensstadium eizentliche Schmarotzer sind, ist dieses entschieden nicht der Fall. Bei den anderen mag es sich anders verhalten, entscheidende Thatsachen liegen aber zur Zeit nicht vor.

Was die Struetur des hymeniumtragenden Theiles der Fruchtkörper betriflt, für welchen in manchen Fillen der besondere Nanı Il ỹ m e n op h o r u m gebraucht wird, so besteht das Il!menium selbst, wie im flen Capitel beschrieben wird, aus Zellen, welche auf der Hymenialfliiche senkrecht stehen und die Endgglieder reich verastelter Hyphen sind. Letzlere zweigen sich ron denen des Markes ab und wenden sieh, denen der Corticalschichte ähnlich, entweder plötzlieh oder in einem gegen den freien Rand des Fruchtkörpers convexen Bogen zur Oberfliche. In Bezichung auf ihre Structur, Verflechtung und Richtung gilt für den Anfang ihres Weges das oben äber den Bau der Fruchtkörper überhaupt Gesagte. Je näher dem Hymenium, um so zahlreicher, zarter und dichter werden ihre Terzweigungen. Diese sind unmiltelbar unter jenem iberaus reich verzweigt, protoplasmareicher als das übrige Gewehe des Fruchttrigers und eng miteinander rerflochten und rephunden. Bei einfacheren Gattungen, z. B. Hypochnus, lassen sie sich noch auf g̣ıössere Strecken von einander sondern; meistens bilden sie aber ein sehr schwer zu entwirrendes zartzelliges Goflecht: die im ten Capitel nochmals zu erwihnende subhy meniale Schichte oder das subli ymeniale Gewele.

Wo die IIymenialfliche mit bestimmt geformten Vorsprüngen versehen ist, 
wie bei den meisten allbekannten IIymenomycetengenera, da werden die Vorsprünge sowohl wie die $Z$ wischenraume zwischen ihnen von dem Hymenium und subhymenialen Gewebe gleichförmig überzogen. Nur der iusserste freie Rand der Vorsprünge, also die Schneide der Lamellen, die Ylündung der Pori, die Spitze der Stacheln, ist häufig ohne Hymeniumüberzug. Der innere Theil der Vorsprünge, welcher die subhymeniale Schichte trägl, wird der Einschlag, Trama genannt (auch Dissepiment, intralamelläres Gewebe). Die Trama hat in der weitaus grössten Mehrzahl dor Fälle cine deutlich fädig̣e Structur. Sie besteht aus einer Hyphenmasse

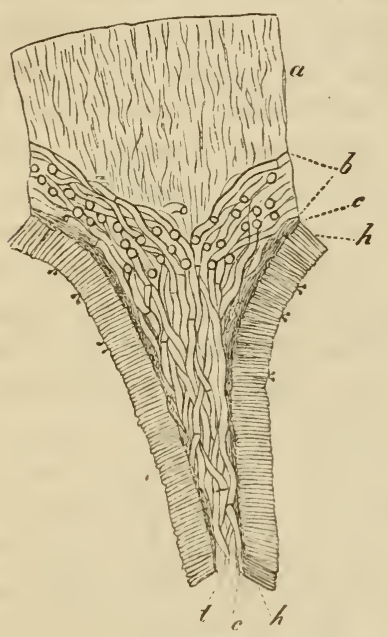

Fig. 2?. von der Form des Vorsprungs, deren Füiden längs der ganzen Insertionslinie des Vorsprungs als Zweige ron denen der Marksubstanz entspringen, bogig oder gerade in die Basis des Yorsprungs eintreten und von da der Oberflache des letzteren parallel gegen den freien Rand zu verlaufen. Die Trama zeigt daher meistens eine deutliche, von der Insertionslinie nach dem freien Rande laufende Faserung $\quad$ z. B. viele Agarici, vgl. Fig. 2.2, Lenzites, Polypori plur. spec., Trametes Pini, Hỵdnum zonatụm, cirrhatum, gelatinosum, Boletus edulis'. Je nach der Species nehmen die einzelnen IIyphen der Trama cinen mehr geraden oder wellenförmigen und verschlungenen Verlauf. Seltener besteht die Trama aus einem ganz wirren Hyphengeflechte ohne bestimmt gerichtete Faserung z. B. Morchella, Polyporus hirsutus. Die Structur, Consistenz, Farbe u. s. w.

der Tramaelemente ist denen des übrigen Fruchtträgers entweder gleich oder davon verschieden, wie ein Blick auf die Gattungscharactere der Hymenomyceten zur Genige zoigt. Subhymeniales Gowebe und IIvmenium entspringen von der Trama in der oben angegebenen Wrise; die Elemente des Hymenium sind zu ihrer Oberfliche iiberall senkrecht gestellt.

Von der oben besonders besprochenen Gruppe oder Gattung Lactarius zeigt, wenigstens bei $\mathrm{L}_{\text {. }}$ subduleis und chrỵsorrhoeus, die ich untersucht habe, die Trama der Lamellen gleichifalls den soeben beschriebenen Bau. Gegen die Ilutunterfliiche hin werden die grosszelligen Gewebegruppen plötzlich seltener und kleiner, die Unterfliche selbst Hymenophorum besteht aus zahlreichen Lagen von Hyphen, welche weilenförmig von der Mitte des llutes gegen scinen Rand rerlaufen, und ron denen sich die Hyphen der Trama abzweigen. Das suhhymeniale Gewebe setzt sich aus kleinen, isodiametrischen Zellen zusammen, deren Anordnung jedoch deutlich erkennen liisst, dass sie zarten, verflochtenen, kurzzelligen Hỵhen als Glieder angehören. Die Milchsaftröhren treten sowoh! in das II!menophor'um als in die Trama ein, in jenem verlaufen sie meistens dem

Fig. 22. Igaricus vulgaris. Tangentialer Durchschnitt durch einen eben erwachsenen Hut, 70 fach vergr., halbschematisch. $a$ obere Hutsubstanz, aus weichem Gallertgewebe bestehend. $b$ untere derbfädige Hutsubstanz. $c$ subhymeniale Schicht. $h$ Hymenium. $t$ Trama der Lamelle. 
Hauptfaserzuge parallel, in der Trama sind sie nach allen Seiten hin reichlich verbreitet und ausgezweigt. Die grösstentheils parenchymatische Structur der Trama, welche Hoffmann für L. mitissimus beschreibt, konnte ich bei obigen Arten nicht finden.

Russula hat eine aus rundzelligem, allenthalben von vereinzelten, ästigen, dünnen Hyphen durchflochtenem Pseudoparenchym bestehende Trama, welche in das gleichnamig̣e Gewebe der Hutsubstanz ganz allmählich übergeht und deren Entwickelung noch zu untersuchen ist.

Die Entwickelungs- und Wachsthumsgeschichte der gymnoearpen Fruchtkörper ist, zumal was ihre ersten Stadien betrifft, bis jetzt nur für wenige Fälle genau bekannt, weil die ersten Anfange der Fruchttriger durch ihre Kleinheit und die Zartheit ihrer Formelemente für die Beobachtung schwer zuginglich sind, und die Aufmerksamkeit der Mycetologen bisher anderen Fragen vorzugsweise zugewendet war.

Besonders einfach und eigenthümlich ist wie der Bau so auch die Entwickelung des Fruchtkörpers von Ex oas eus Pruni, einem auf grünen, lebenden Theilen der Prunusarten, zumal ihren taschenartig ('ntarteten Fruchtknoten schmarotzenden Discomyceten. Das aus schmal evlindrischen Hyphen bestehende Mreelium dieses Pilzes steigh in dem Weichbaste des Gefisshuindel seines Wirthes empor, tritt von da aus in die Intercellularriume des Parenchyms und entsendet zuletzt allenthalben zahlreiche Zweige, welehe sich zwischen den Seitenwinden der Epidermiszellen hindurchdringen, um sieh. an die Aussenwinde letzterer gelangt, zwischen diesen und dep Cuticula in einer Fläche auszubreiten und zu veristeln. Die Zweige benachbarter Hyphen schieben sich zwischen und gegen einander, so dass die Oberfliche der Epidermis von einem immer reich - und engmaschiger werdenden, einschichtigen Hyphennetze äbersponnen wird. In den anfangs langer lindrischen Zellen des letzteren finden nun Quertheilungen statt, bis alle Zellen ungefahr so lang als breit sind, zuletzt dehnen sich alle Zellen his zur innigyen Berihlurung mit ihren Nachbarinnen aus und nehmen dabei rundliche. durch gegenseiligen Druek abgeplat-

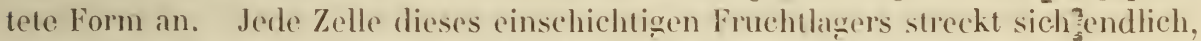
die Cuticula durchbrechend, senkreeht zur Oberfliche des befallenen Pflanzentheils und erhailt damit die Gestalt eines aus eylindrischer Basis keulenförmigen Schlauches, der sich bald dureh eine Querwand theilt in eine grosse, obere, keulenförmig̣e Sporenmutterzelle Aseus, und eine kleine, untere, kurzeylindrische Zelle, welehe jene als Stielzelle trigt. Der Fruchttriger besteht daher aus einer einfachen Schicht eylindrischer Zellen. auf deren jeder eine Fortpflanzungszelle aufsitzt.

Die unscheinbaren Fruchtlager der Urodineen und wahrscheinlich vieler anderer endophytischer Parasiten kommen, soweit bisher ermittelt werden konnte, gleichfalls dadurch zu Stande, dass zahlreiche Iyceliumfiiden von verschiedenen Seiten her zusammentreten und sich zu einem vielschichtigen Lager unordentlich verflechten.

Die sticlförmigen Fruchtkörper der sclerotienbildenden Clavarien und Typhulae, speciell z. B. von Ty ph. variabilis Riess, treten aus dem Sclerotium hervor in Form eines Bündels fest vereinigter, paralleler. mit den Enden kuppelförmig zusammenneigender Hyphen. Der Körper wichst nun in die Länge. 
Die in der kuppelförmigen Spitze vereinigten Hyphenenden bleiben hierbei fortwährend sehr zart, protoplasmareich, verhältnissmaissig kurzzellig. Mit der Entfernung von der Spitze des wachsenden Fruchttrigers nehmen die Glieder der Hyphen eine Strecke weit stetig an Länge, Weite -und Derbheit, der ganze Körper an Dicke und Festigkeit zu; an seinem Grunde findet keine $\mathrm{Zu}-$ nahme mehr statt. Aus diesen Daten geht hervor, dass das Längenwachsthum des Fruchttriggers, soweit es auf Neubildung von Zellen beruht, in und dicht unter der Spitze eingeleitet wird durch das Spitzenwachsthum der zum Fruchtkörper vereinigten Hyphen. Jene ist daher als Vegetationspunkt zu bezeichnen. Die im Vegetationspunkt erzeugten Zellen strecken sich dann, in der Reihenfolge wie sie entstanden sind, rasch in die Länge und nehinen ihre definitive Structur an. Mit dem Beginn der Streckung treten an den oberflächlichen Hyphen des unteren sterilen Theiles die Anlagen zerstreuter einzelliger Haare als Zweige hervor, an dem oberen Theile das dichte Geflecht der IIymenialschichte. Zuletzt steht die Thätigkeit des Vegetationspunktes und das Wachsthum des ganzen Körpers stille. Im Innern der vom Vegetationspunkt entfernteren Theile findet wie es scheint keine, jedenfalls keine betrichtliche Neubildung von Zellen mehr statt, weder durch Theilung der vorhandenen Gliederzellen, noch durch Bildung neuer, zwischen die erst vorhandenen sich einschiebender Hyphenzweige.

Die Fruchttrager von Peziza Sclerotiorum haben in ihrer ersten Jugend schmal cylindrische, zugespitzte For'm und endigen gleichfalls in einen Vegetationspunkt. Dieser ist kegelförmig und besteht aus sehr dünnen, zartwandigen, dicht gedrangten, protoplasmareichen Hyphenenden, welche sich nach abwärts in die Fiden der Marksubstanz unnittelbar fortsetzen. Schon dicht unter der ¿iussersten Spitze gehen von diesen IIyphen zahlreiche kurze Zweige in einem Bogen schräig nach oben und aussen. Sie endigen alle in einer Ebene auf der Oberfliche des Körper's und sind die Anlagen der Corticalsehichte. Nlle Zellen nehmen mit der Entfernung rom Vegetationspunhte eine Strecke weit stetig an Länge und Diche zu, von einem bestimmten Punkte an nicht mehr; das Wachsthum des Fruchthörpers geschicht auch hier ausschliesslich oder ganz vorzugsweise durch Anleg̣ung neuer Elemente im Vegetationspunkt und nachherige, von unten nach oben fortschreitende Vergrösserung und Ausbildung derselben.

In einem etwas spateren Entwickelungsstadium findet man auf Liingsschnitten durch die spitze des Fruchttrigers einen kurzen und engen, oben offenen Lïngseanal mitten in dem Fadenbündel, welches den urprünglichen Vegetationspunkt gehildet hatte. Es sieht aus als seien die Elemente des letzteren an bezeichneter Stelle auseinander gewichen, doch bleibt es zweifelhaft, ob der Canal wirklieh auf diese Art entsteht. oder dadurch, dass die Verlingerunğ der IJyphen in der Mitte des Vegetationspunktes aufhört, in dem Umfange desselben aber fortdauert. Wie dem auch sei, das Spitzenwachsthum dauert jetzt allein in denjenigen Fadenenden fort, welche, etwas nach innen gekrüimnt, rings um den Kand der engen Canalmündung liegen, der Körper vergrössert sich in Folge der Zellbildung in diesem Vegetations rande. Dicht unter dem letzteren entstehen auf der Aussenseite des Körpers die Anfiinge der Corticalschichte in der oben beschriebenen Weise; auf der Wand des Längscanals treten, in centrifugaler Folge, die Anlagen des Iymeniums auf. 
Die Entstehung des Canals beginnt schon in solchen Fruchtträgern, deren Ende von aussen noch dieselbe feine Zuspitzung zeigt, wie in dem ersten Entwickelungsstadium. Ihr Anfang ist nur mit dem Mikroskop sichtbar. Durch die Entwickelung der IIymeniumbestandtheile und die Ausdehnung des Gewebes, welches seine Wand bildet, wird der Canal allmählich erweitert, die Hyphenenden, welche den Rand seiner Mündung bilden, bleiben jedoch nach innen gekrümmt, die Mündung selbst daher sehr eng, das obere Ende des Fruchtträgers schwillt somit zu stumpf-keulenförmiger Gestalt an. Indem nun das Spitzenwachsthum der Hyphen rings um den Rand und die ihm auf dem Fusse folgende Anlegung von Corticalelementen einerseits, von Hymeniumbestandtheilen andererseits eine Zeit lang fortdauert, und in gleicher Folge eine Dehnung der Zellen und besonders eine starke Flächenvergrösserung der Hymenialschichte eintritt, erhält das obere Ende des Fruchtkörpers schliesslich die Gestalt des für die Species characteristischen, trichterförmigen, zuletzt oft seine Riander nach aussen umkrämpenden Bechers.

Bei anderen gestielten Peziza-Arten, z. B. P. nivea, habe ich die erste Anlegung des Bechers nicht beobachtet, dagegen ist es leicht zu bemerken und auch mehrfach schon dargestellt worden, wie sie durch Neubildung in ihrem Anfangs eingerollten Rande eine Zeit lang wachsen und zuletzt durch eine in centrifugaler Richtung fortschreitende Dehnung ihrer Gewebelemente ihre definitive Form annehmen.

Ein sehr geeignetes und fermeren Beobachtern zu empfehlendes Object, um Entwickelung und Wachsthum zu beobachten, sind die Fruchttriger von Thelephora hirsuta (Fi⿳. 23) und vielen anderen ihnlich gestalteten Hymenomyceten. Die lederartigen Fruchtkörper genannter species, welche als halbirte, stiellose, seitlich angewachsene Ilüte bezeichnet werden, stellen bekanntlich in der Regel unregehmässig rundliche, flache Scheiben dar, deren grösserer Theil von dem Substrate rechtwinkelig absteht, wihrend der andere, oft schr kleine Theil letzterem fest angewachsen ist: und zwar hat der abstehende Theil gewöhnlich horizontale Richtung, seine obere Fliche ist mit einem dichten Haarüberzug, seine untere mit dem IIymenium bedeckt. Von anderen, öfters vorkommenden unregelmassigeren Formen kamn hier füglich abgesehen werden.

Die Fruchttriger treten zuerst auf in Form habkugeliger, 1 - 2 Millim. grosser, graw weisser Fadenbüschel. Sie entspringen von derben Myceliumfäden, welche in Masse das todte Holz durchsetzen, das von dem Pilze bewohnt wird. Die Buischel werden von zahllosen Hyphen gebildet, welche ziemlich regelmässig wie Kugelradien von einem Centrum ausstrahlen. In letzteren sind sie dicht mit einander verflochten, gegen die Oberflache hin durch immer weiter wordende Zwischenraume getrennt, die Oberfläche selbst daher mit abstehenden Ilaaren bedeckt. Letztere erscheinen unter dem Mikroskop farblos oder gleichförmig briunlich, die Hyphen des centralen Geflechtes durch Körnchen rothgelbem Pigments gefirbt. Mit der weiteren Entwickelung nimmt die (in Beziehung auf das vertical gedachte Substrat) untere Hailfte des halbkugeligen Körpers rothgelbe Farbe und eine glattere, sammetartig aussehende Oberfliche an. Düne, der Faserung folgende Radialschnitte zeigen, dass, soweit die letzterwihnte Beschaffenheit reicht, zahlreiche, meist rothgelbe Pigmentkörnchen enthaltende Hyphen von dem centralen Geflechte strahlig gegen die Ober- 
fläche gewachsen sind, sich in grosser Menge allenthalben zwischen die ursprünglich vorhandenen Haare eingeschoben und diese zwischen sich eingeschlossen haben. Die obere Hälfte des halbkugeligen Körpers behält ihre ursprïngliche Beschaffenheit bei. Nun beginnt ein lebhaftes Längen- und Spitzenwachsthum derjenigen Hyphen, welche in den Rand der rothgelben unteren Fläche der Hutanlage verlaufen, während die in der Mitte letzterer endigenden sich nicht oder nur wenig verlingern. Die Unterfliche wird daher concav und der horizontale Theil des Hutes hebt sich von dem Substrat ab. An

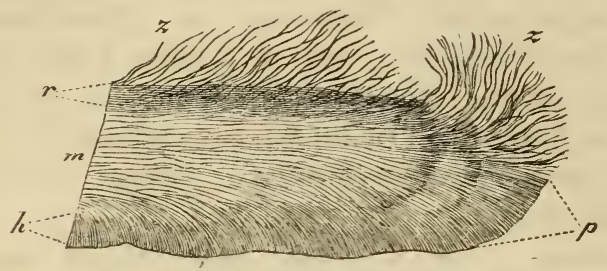

Fig. 23 . dem Rande dieses Theiles schreitet nun das Spitzenwachsthum der Fäden weiter fort. Durchschnitte zeigen, dass derselbe aus einer mächtigen und dichten Lage leicht. gegen die Unterfläche geneigter, stumpfer, ziemlich dicker, meist rothgelbe Pigmentkörner enthaltender Fadenenden besteht. Gegen die Ursprungsstelle des Hutes hin setzen sich diese continuirlich in die fertigen Hyphen der Hutsubstanz fort, welche von ihnen durch vollkommen wasserhellen Inhalt, nicht durch grössere Dicke verschieden sind, und der Hutoberflache parallel strahlig verlaufen. Dicht hinter dem fortwachsenden Rande beginnt die Differenzirung der Hutsubstanz in eine untere, farblose Markschicht und eine obere, dünne, durch hellbraun gefarbte Zellmembranen ausgezeichnete Rindenschicht. Und dem Rande noch niher fängt auf der oberen Fläche die Entwichelung zahlreicher Haare, auf der unteren die des Hymeniums an. Erstere sind abstehende oder zurückgekrimmte, einfache und derbe Hyphenzweige. Die aussersten derselben überragen und bedecken meistens den wachsenden Rand. Gegen die Hymenialfliche hin wenden sich dicht hinter dem Rande zahlreiche Zweige in schräigem, leicht bogigem Verlauf. Je weiter nach der Basis des Hutes hin, desto zahlreichere Hỵmenialelemente schieben sich zwischen die erstvorhandenen ein und desto mehr nehmen alle die zur Oberflache senkrechte Stellung der ausgebildeten Iymeniumbestandtheile an. Der dem Substrat anliegende Theil des Hutes zeigt wesentlich die gleichen Wachsthumserscheinungen, wie der abstehende; nur dringen die Haare seiner Aussenfläche als W u rzelha a re in das Substrat ein. Wie die von Schmitz ausgeführten Messungen und die mikroskopische Intersuchung zeigen, findet die Vergrösserung des Hutes nur zunächst dem Rande statt.

Die central-gestielten, schirmförmigen Hüte der gymnocarpen $\Lambda$ garici (vgl. Fig. 24) stellen in der frühesten Jugend dem Mycelium aufsitzende cylindrische, ovale, selbst kugelige Körperchen dar, deren oberes Ende etwas zugespitzt ist und welche durchweg aus ungemein zarten, festverbundenen, longitudinal verlaufenden Hỵphen bestehen. Schon sehr früh - bei den von mir unter-

Fig. 23. Thelephora hirsuta. Senkrechter, radialer Durchschnitt durch den Rand eines frischen Hutes, schwach vergr., halb schematisch den Hyphenverlauf zeigend. $p$ fortwachsender Rand, hinter demselben 2 Zonen. $h$ Hymenialschicht, $m$ Medullar - , $r$ Rindenschicht, $\approx$ Haarüberzug. 
suchten Formen zur Zeit wo der ganze Körper erst 1/2 - 2 Millim. lang ist wachsen die das obere Ende bildenden Spitzen der Hyphen strahlig divergirend und gleichzeitig sich reich verzweigend auseinander. Es entsteht hierdurch ein halbkugeliges, von dem unteren Theile durch eine flache Ringfurche abgesetztes Köpfchen, dic Anlage des Hutes Fig. 24, a). In den Hyphenenden, welche den Rand derselben bilden, beginnt nun ein lebhaftes Spitzenwachsthum: sie

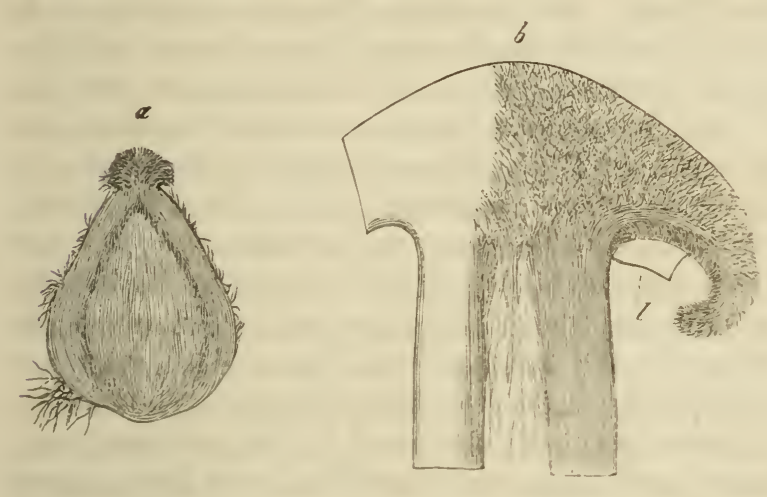

Fig. 24. verliingern sich fort und fort, wobei sich, in allen mir bekannten Fällen, der Hutrand mehr oder minder nach innen rollt. Die Enden behalten dabei die urspriingliche Dicke und bleiben so dicht verflochten wie zu Anfang, sie muissen daher in der Richtumg der Ilutoberflache fortwihrend neue Verzweigungen zwischen die crstrorhandenen einschieben. Ioie gegen den Scheitel des IIutes verlaufenden Fïden hören frülı auf sich zu verlingern. Sie wachsen zu dem Gewebe der Ilutmitte heran, wahrend ron den in den Rand verlaufenden, in dem Maasse als letzterer sich vorschiebt, zahlreiche Zweige gerade oder bogig nach oben und aussen entsendet werden, die gleichfalls bald aufhören sich zu verliingern und sich zu dem Gewobe der Hutsubstanz ausbilden Fiğ. 24, b). Gleichzeitig nit diesen, und gleichfalls in centrifugaler Folg̣e, wachsen von der unteren Fliche der in den Rand verlaufenden Schichte dicht gedraingte Zweige aus bogiger Basis senkrecht gegen die IIutunterfliche: die Anfiinge des lıymeniumtragenden Gewebes und des IỊmeniums selbst. Sie sind zuerst gleichlang, die Iymeniallliche ist, wie Hoflumann richtig gegen eine frubere irrige Angabe von mir lervorlebt, zuerst, wenn auch nur hurze Zeit, glalt. In mit einander abwechselnden radialen streifen tindet die Verliangererung der senkrecht nach unten wachsenden Il!menialhyphen in versehiedenem Grade statt. In den einen danert sie linger an, sie treten über die glatte Fliche hervor, als Lamellentrama, auf welcher sich die Ilymeniumelemente von der Basis gegen den freien Rand Schneide fortschreitend. in der oben bezeichneten Stellung erheben. In den Interstitien zwischen den Lamellen hören die Hyphenenden früher auf sich zu verlaingern und werden direct zu den Elementen des Hỵmeniums.

Wïhrend dieses Wachsthums durch terminale und marginale Yeubildung vergerössern sich die von dem Vegetationspunkte oder Vegetationsrande entfernten

Fig. 24. Igaricus (Collybia) drỵophilus Bull. Radiale Längsschn., schwach vergr., der Fadenverlauf angedeutet.

“ Ganz junges, 1 $1 / 3$ Mm. hohes Exemplar, vollständig. Erster Anfang der Hutanlagge.

b Aelteres Exemplar, Hut 2, $5.3 \mathrm{~m}$. breit. $l$ stück einer Lamelle. 
Theile durch Ausdehnung ihrer Zellen, und zugleich differenzirt sich ihr anfangs überall gleichartiges Gewebe in die verschiedenen beim reifen Fruchtträger vorhandenen Schichten. Auch dieser Process schreitet, wie leicht zu beobachten ist, im Stiele von unten nach oben, im Hute von der Mitte zum Rande fort. Auf der Ausdehnung der stets sehr kleinen ursprünglichen Elemente zu einem Vielfachen ihrer primären Grösse beruht, zumal bei den rasch wachsenden fleischigen Fruchtträgern, die dem blossen Auge wahrehmbare Vergrösserung jedenfalls zum grössten Theile. Bei Agaricus (Mycena) vulgaris z. B. konnte ich durch Messung der Zellen und Bestimmung ihrer Anzahl auf dem Querschnitt feststellen, dass das ganze Längen - und Dickenwachsthum des durchschnittlich 50-60 Mm. lang werdenden Stieles von dem Zeitpunkte an, wo seine Länge $3 \mathrm{Mm}$. beträgt und seine Zellen genau messbar sind, so gut wie ausschliesslich durch Dehnung der letzteren geschehen muss. Dasselbe Resultat erhielt ich für Nyctalis parasitica; ein ähnliches, wenngleich wegen der sehr ungleichen Länge der auf gleicher Höhe stehenden Zellen minder bestimmtes bei Agaricus (Collybia) dryophilus Bull. Im Hute sind genaue Messungen wegen der Krümmungen und Ungleichheiten der Zellen kaum ausführbar, doch zeigt hier der Augenschein gleichfalls eine in centrifugaler Richtung fortschreitende oft gewaltige Ausdehnung der Gewebelemente. Ob überhaupt in den von den Vegetationsrande entfernteren Theilen auch r och eine Neubildung von Zellen durch Quertheilung der vorhandenen primären Hyphenglieder und durch Bildung neuer Zweige stattfindet, scheint mir zweifelhaft. In den soeben erwähnten beiden Fällen findet es nicht statt, diese sind jedoch zu vereinzelt, um eine allgemein gültige Behauptung zu erlauben. Es kommen häufig an den bedeutend ausgedehnten oder in Ausdehnung begriffenen Hyphen Zweige vor, welche die Dicke der primären nicht oder wenig übertreffen, reich an Protoplasma sind und hierdurch wie jung entstandene aussehen. Ob sie dies aber wirklich sind, und nicht vielmehr von Anfang an vorhanden, ohne an der späteren Ausdehnung Theil zu nehmen, muss erst durch fernere Untersuchungen fesigestellt werden.

Unzweifelhaft findet in dem Hymenium noch lange Zeit nach der ersten Anlegung eine Einschiebung zahlreicher neuer Elemente zwischen die erstrorhandenen statt. Die hierdurch und vermittelst gleichzeitiger Dehnung der benachbarten Gewebeportionen stattfindende Vergrösserung der untereń oder hymenialen Seite bewirkt, dass die Theile des Hutes mit ihrer Entfernung vom Rande früher oder spitter aus der zuerst eingerollten Form gerade gestreckt werden. Zuletzt steht das marginale Wachsthum und die ihm folgende Dehnung in Stiele und der oberen Seite des Hutes still. An der Hymenialfläche dauert das Wachsthum durch Einschiebung und Dehnung dagegen häufig fort, und hierdurch wird der Hut zuletzt aus seiner anfangs meist glockigen oder kegelförmigen Gestalt, wie ein Regenschirm aufgespannt, oder sein Rand selbst in die Höhe gerichtet oder nach oben umgebogen.

Auf die Verschiedenheiten, welche in der Entwickelung und Gestaltung des Ifutes einzelner Gruppen und Arten stattfinden, kann hier um so weniger eingegangen werden, als wir erst eine sehr beschränkte Zahl genauer Beobachtungen über solche besitzen. Vorstehende Darstellung gründet sich auf eigene Untersuchungen an Ag. (Ifycena) vulgaris Pers., Ag. (Collybia) dryophilus 
Bull., Nyctalis parasitica Fr.; auf die mit Herrn Woronin gemeinschaftlich verfolgte Entwickelungsgeschichte von Agaricus Clitocybe) cyathiformis, Cantharellus infundibuliformis und auf die Arbeiten H. Hoffmanns. Sie stimmt mit den letzteren überein, bis auf die geringe Differenz, dass nach Hoffmann die Hyphen der Hutmitte bei der Section Mycena nicht radial gegen die Oberfläche verlaufen und in dieser endigen, sondern der Hutoberfläche parallel (so verstehe ich den Ausdruck horizontal laufen sollen. Es mögen in dieser Beziehung vielleicht Artunterschiede vorhanden sein. Bei $\Lambda \mathrm{g}$. (Mycena) vulgaris ist der Verlauf der von mir angegebene und in dem jugendlichen Hute deutlich zu erkennen. Später ist dies allerdings nicht mehr der Fall, indem das ganze oberflichliche Gewebe des Hutes die Beschaffenheit eines ziihen Gallertfilzes annimmt, dessen IIyphen ordnungslos durcheinander gerichtet sind, und die sich als eine zusammenhängende Haut von dem Hute abzichen lässt.

Das an den obigen Beispielen beschricbene Spitzen- oder centrifugale Wachsthum kommt, soweit die vorhandenen Beobachtungen reichen, allen oder doch jedenfalls der überwiegenden Mehrzahl der grösseren gymnocarpen Fruchtkörper zu. Die speciellen Modificationen, welche es nach den einzelnen Formen erleidet, bediurfen hier keiner ausführlichen Erwihnung. Nur das Eine? sei noch besonders bemerkt, dass die verschiedenartigen Vorsprünge auf der Hymenialfliche der IIymenomyeeten eine durchaus ahnliche Entwickelung haben, wie die Lamellen der Agaricinen. In der Jugend und nichst dem sich vorschiebenden Rande ist die llymenialfliche, wenn auch nur eine hurze Strecke weit, glatt, sie wird gebildet von Hyphenenden, wolehe aus bogiger Basis senkrecht gegen sie rerlaufen. Gruppen dieser IIyphen, je nach der Species und Gattung von verschiedener Gestalt, treten allubihlich uber die gylatte Fliche hervor, als die Trama der Vorsprüunge. Auf der Trama entwickeln sich. von ihrer Basis gegen den freien Rand hin fortschreitend, die Elemente des Ilymeniums; die in den Interstilien zwischen den Vorsprüugen liegenden Hyphenenden werden direct zu Ilymeniumbestandhoilen. Die Ausbildung des ganzen Ilymeniums beginnt in den Interstitien und schreitet von hier aus gegen dis freien Ränder der Vorsprünge fort. Die sucessive Entwickelung der ganzen II!̣menialfliiche lïsst sich besonders schön bei langsam wachsenden, lederartigen Formen, z. B. Polyporus adustus, verfolgen.

Bei den meisten hierher gehörenden Fruchträgern, zumal den fleischig̣en. greht das Wachsthum continuirlich vor sich und erreicht bald sein Encle. Es kamn durch ungüinstige Bedingungen kurze Zeit verlangsamt oder zum Stehen gethacht werden, wn später weiterzugehen: starker einwirkende Schaillichkeiten, zumal andauernde Trockenheit und Kiilte, setzen ihm ein für allemal ein Ziel. Die Toleranz gegen die genannten ungüunstigen Einflüsse ist übrigens je nach den einzelnen Arten sehr verschieden. Auf der anderen Seite besitzen die Hüte zahlreicher lederartiger und holziger Hỵmenomyceten die Fähigkeit, das sistirte Wachsthum von neuem zu begeinnen, sobald die hierfür güunstigen Bedingungen (Feuchtigheit, Wirme) wieder eintreten. Es sind daher bei solchen Pilzen abwechselnde Perioden des Stillstandes und des Wachsthums zu unterscheiden. Während jeder Stillstandsperiode nehmen die in dem Rande und der Oberfläche des Fruchtkörpers liegenden Hỵhenenden in vielen Fällen eine andere, meist dunklere Farbe an, wie das übrige Gewebe. Man findet 
dieses daher auf Durchschnitten von dunklen Linien in ebensoviele Zonen abgetheilt, als der Pilz Stillstands- und Wachsthumsperioden durchgemacht hat (s. z. B. Fig. 23). Ferner nimmt das Gewebe der unfruchtbaren Oberfläche am Anfang einer jeden Wachsthumsperiode hïufig eine andere Farbe an, als am Ende, und erhebt sich zugleich oft zu Anfang der Wachsthumsperiode plötzlich in Form eines um den ganzen Hutrand gehenden Wulstes, der sich mit dem fortschreitenden Wachsthum wiederum gegen den Rand hin abflacht. Die Perioden des Stillstandes und Wachsens sind daher auch auf der sterilen Oberflaiche des Pilzes durch concentrische, dem Hutrande gleichlaufende Zonen bezeichnet, welche den inneren meist genau entsprechen, in anderen Fällen jedoch minder deutlich als diese hervortreten. Es ist kaum nöthig, für solche Pilei zonati Beispiele anzuführen, da sie vielen der gemeinsten und bekanntesten Pilze, wie Thelephora hirsuta, Polyporus zonatus, igniarius, fomentarius, Lenzites und ihren Verwandten eigen sind. Die Hymenialseite der meisten dieser Pilze nimmt nur mit der Vorschiebung des Randes fort und fort an Umfang zu, ohne dass damit ein Dickewachsthum nach der Seite des Hymeniums hin verbunden wäre.

Bei einer Anzahl Polyporus-Arten, besonders den Fomentariis Fries (z. B. P. fomentarius, igniarius, Ribis), findet dagegen in jeder Wachsthumsperiode auch eine Verlängerung, der röhrenförmigen Hymenialvorsprüunge gegen die freie Hymeniumoberfliche hin statt. Durchschnitte durch altere Exemplare zeigen die Substanz der Röhrchen daher auf ihnliche Art, wie das innere Hutgewebe in Zonen oder Schichten getheilt, jede dieser entspricht einer Zone der Hutsubstanz und bildet die Fortsetzung derselhen, in die ausserste Randzone des Hutes setzt sich die jüngste Ilymenialschicht fort, und so weiter. Bei Corticium quercinum Fr. wichst die glatte Ilymenialseite (auf noch nicht genau ermittelte Art) schichtenweise in die Dicke, üher dem ersten fruchtbaren Ilymenium bildet sich ein neues und so mehrmals hintereinander. Ob auch bei anderen Gattungen ahnliche Erscheinungen rorkommen, ist noch genauer zu untersuchen.

Persoon (Essb. Schwimme p. 17) und Fries (Epicris. p. 463) halten die. Schichten der erwihnten Polypori für Jahresschichten. So sehr auch die Vergleichung derselben mit den Jahresringen der Dicotyledonen in gewisser Beziehung zutrifft, so ist doch noch nicht bestimmt nachgewiesen, dass bei genannten Pilzen alljihrlich nur eine neue Schicht gebildet wird. Bei den meisten anderen bezonten Schwimmen können dagegen im Laufe eines Jahres unzweifelhaft viele Zonen gebildet werden. Schmitz hat dies für Thelephora hirsuta ausführlich nachgewiesen und eine Menge vielzoniger Hymenomycetenhüte hat nur einjihrige Dauer.

2. Fruchtträger der beschleierten Hymenomyceten.

Von der Gruppe der Agaricinen besitzt jedenfalls eine grosse Anzahl gymnocarpe Fruchttriger. Allerdings kennt man erst von zu wenigen die Entwickelungsgeschichte genau genug, um bestimmt sagen zu können, welches die Gesammtheit der gymnocarpen und welches die auderen seien. Doch kann einstweilen wohl mit Bestimmtheit angegeben werden, dass zu jenen z. B. die Abtheilungen gehören, welche Fries unterscheidet mit den Namen Clitocybe, Mycena, Omphalia, Pleurotus, Paxillus, Gomphidius, Lactarius, Russula, Can- 
tharellus, Nyctalis, Marasmius, Lentinus, Panus, Schizophỵllum, Lenzites. Von der Section Collybia gehört ein Theil, wie A. dryophilus, luberosus, cirrhatus ebenfalls hierher, während nach Hoffmann's Angabe, die ich in Ermangelung genauer eigener Untersuchungen nicht anzweifeln will, andere, wie velutipes und fusipes, nicht rein gymnocarp sind.

Eine andere, gleichfalls betrichtliche Anzahl Agaricinen wird als Agarici velati, Beschleierte, von den gymnocarpen unterschieden. Die Gruppen Amanita, Lepiota, Armillaria, Volvaria, Pholiota, Hỵpholoma, Psalliota, denen sich bestimmt Coprinus anschliesst, gehören sicher hierher. Für die übrigen, bisher nicht genamnten Abtheilungen z. B. Tricholoma, Cortinarius, Hỵgrophorus, Bolbitius u. a. m.) inüssen fernere entwickelungsgeschichtliche Untersuchungen erst zeigen, in wie weit sie den beschleierten oder den gymnocarpen zuzurechnen sind.

Der Fruchurüger der Agarici velati hat zur Zeit seiner Reife in Wesentlichen die gleiche Gestalt und Gliederung, wie bei den $\underset{g}{g} \underline{m}$, wnocarpen. In der Jugend aber ist entweder der ganze Körper oder die II!menialfliche allein von einer geschlossenen Hiille umgeben, welche erst gegen die Reifezeit hin durchbrochen wird und auch an dem völligg entfalteten Fruchttriger bestimmte spuren hinterlisst. Eine solche Hiille, die man nach Persoon Involucrum, narch Fries allgemein Velum, schleier nennt, hommt in zweierlei Formen vor. Erstlich als ein den ganzen Triger, inshesondere auch den Scheitel des IIutes umziehender Sach, welcher anfanğ geschlossen ist. bei der Entlaltung des Hutes aber durchrissen wird, wie z. B. beim Fliegrenschwamme: dies die Volva, oder das Velum universale nach fries. Zweitens in Form eines meist hiutigen Leberzuges, welcher einerseits in den Ilutrand, andererseits in die Oberfliche des Sticles übergeht, also nur die Ilymeniallliche einschliesst, den Scheitel des flutes aher frei läst: Velum partiale Fr. Mit der Entfaltung des Ilutes wird dieses Velum partiale gleichfalls zerrissen, entweder in unregehnassig̣e und oft sehr vergingliche Fetzen, die dem Hutrande anhisingen und damn Schleier, velum im engern Simne Persoon, oder Cortina, Vorlı ang heissen; oder es löst sich liingrs des Hutrandes los und bleibl deen Stiele in Form eines hiutigen Ringes, an nulus, aufsitzen. Je nachelem das Velum partiale in der Jugend von der Insertionsstelle des Ifutes ïber die Itrmenialfliiche, oder von dem Ilutrande abwarts zum Sticle verlief. lat der Ring entweder die form eines nach unten verbreiterten, an Stiele herabhingenten Trichters: annulus superus, armillla, Il anchelte Merar. muscarius, oder eines nach unten dem stiel anliegenden und nach oben erweiterten: annulus inferus Agar. Lepiota granulosus u. s. w. . Die Volva und das Velum partiale hönnen entweder an demselben Hute zusammen vorhanden sein Amanita muscaria); oder die eine Amanita raginata) oder die andere Agaricus campestris für sich allein.

Was das Velum eigentlich ist, in welcher Weise es und die ibrigen Theile in ilm entstehen, dariber sagen die iilteren Autoren nicht viel mohr, als die soeben gegebene hurze Shizze. Nach Fr. Nees ron Esenbeck ist die Volva ron Măaricus volvaceus zuerst ein leeres, geschlossenes Sichchen, in welches Stiel und Ilut vom Grunde aus hineinwachsen. Bonorden definirt das Velum universale als das zu einer besonderen IIulle verwebte Mycelium, das partielle als 
eine in den Hutrand übergehende Fortsetzung der äussersten Zellreihen des Stieles.

Soweit ich mir nach eigenen Untersuchungen ein Urtheil erlauben kann, verhält es sich zunächst mit dem Velum partiale folgendermassen (Fig. 20, 26).
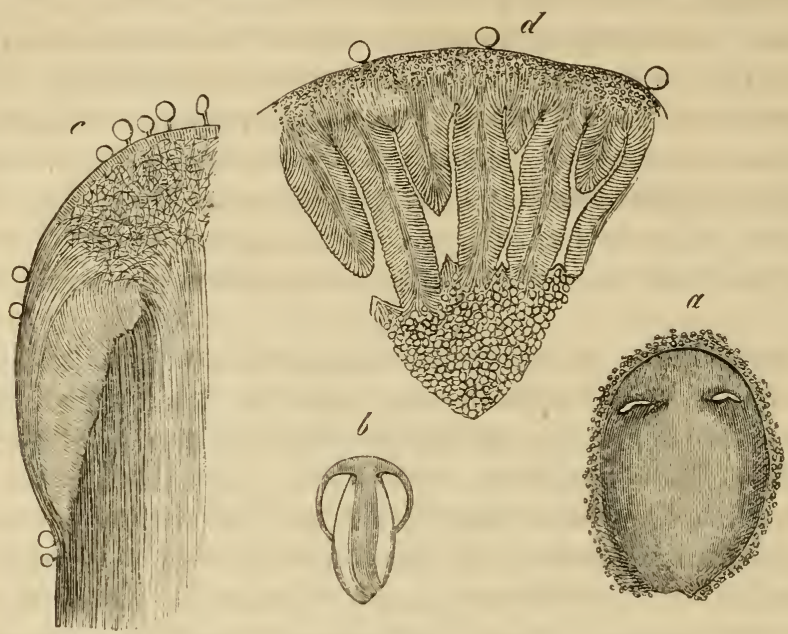

Fig. 25.

Der Fruchtträger mancher Agaricinen (Agaricus campestris, praecox P., Coprinus micaceus und Verwandte ist in der ersten Jugend ein aus zarten Hyphen dicht und gleichförmig zusammengeflochtener Körper. Schon sehr früh werden durch Differenzirung des ursprünglich gleichartigen Geflechtes die Haupttheile des Fruchttriigers abgegrenzt und angelegt. Im Innern des oberen Theiles des Körpers entsteht durch Auseinanderweichen der Gewebselemente eine schmale und enge luftführende Lücke von der Gestalt eines horizontalen Ringes $(2: 3,26, a)$. Was uiber dieser liegt wird zu dem Hute, das von ihr umringte und unter ihr befindliche Gewebe zum Stiele. Das Gewebe an ihrer Aussenseite entspricht dem Ilutrande, seine Ilyphen setzen sich aber ohne Unterbrechung oder Veranderung in die der sticloberfliche fort.

Auf der Ilutunterfliiche, also der oberen Wand der Lücke, treten gleichzeitig mit der Entstehung letzterer, viclleicht selbst schon vorher, die Anfänge des Ilymeniums hervor, in Form dicht gedringter, senkrecht gegen die genannte Flaiche verlaufender, zarter und protoplasmareicher IIyphenäste. Die Anlegung aller dieser Theile geschieht bei Agar. praecox u. campestris in den 1-2, $3 \mathrm{Mn}$. wrossen, bei Copr. micaceus in kaum 1/2 Mm. grossen Körpern. An dem nun folgenden Wachsthum des Körper's nehmen zuniichst alle seine Glieder Antheil. Eine in centrifugaler oder basifugaler Richtung fortschrcitende Anlagerung neuer Gewebselemente an dic vorhandenen, wie sie für die g!mnocarpen Fruchtträger

Fig. 23. Coprinus micaceus Fr. a $2 \mathrm{Mm}$. langes, junges Exemplar. Radialer Längsschn. Ringförmig̣e Luftliicke unter der künftigen Hymenialfläche. (Schwach verğr.) $b \quad 3,5 \mathrm{Mm}$. langes Excmplar, radialer Längsschnitt, schwach vergr. c Dünner radialer Längsschnitt durch ein noch etwas jüngeres Exemplar als $b ; d$ Querschnitt durch die Mitte des Hutes desselben. $d 90 \mathrm{mal}, c$ etwas weniger vergr. 
beschrieben wurde, findet bei den hier in Rede stehenden nicht statt. Auf der Hymenialfläche werden allenthalben neue Hyphen zwischen dic erstvorhandenen eingeschoben und die Lamellen gebildet auf wesentlich die gleiche Weise, wie bei den gymnocarpen Agaricis. In allen übrigen Organen beruht das Wachsthum von einem sehr frühen Stadium an jedenfalls zum grössten Theile auf Ausdchnung vorhandener Zellen; diese geschicht in allen Theilen gleichzeitig, im Stiele allerdings am Grunde beginnend und nach oben fortschreitend. Auch die dem Hutrande und Stiele gemeinsamen IIyphen nehmen an dem allgremeinen Wachsthum Theil, jener bleibt in seiner urspriinglichen Verbindung mit der Oberfliche des letzteren. Die über dem angewachsenen Ilutrande liegenden Portionen von Stiel und Hut vergrössern sich, gleichen Schritt haltend, derart, dass die Hyme-. nialfliche aus der ursprünglich horizontalen Stellung in eine nach aussen und unten geneigte, oder, bei Coprinus, selbst senkrechte, der crlindrischen Stieloberfliche parallele iibergeht. Der Raum zwischen Stiel und Ilutsulsstanz wird meist fast vollstiindig von den Lamellen ausgefuillt, bei Coprinus micaceus und fimetarius wachsen diese sogar mit ihren Schneiden dem Stiele fest an. Fig. $25,26, b, c, d)$.

Früher oder später breitet sich nun der Hut, unter fortdauernder Dehnung seiner Zellen, zu der bekannten Schirmform aus. Bei Coprinus micaceus und Verwandten trennt sich dabei sein Rand glatt von der evlindrischen Stielober-
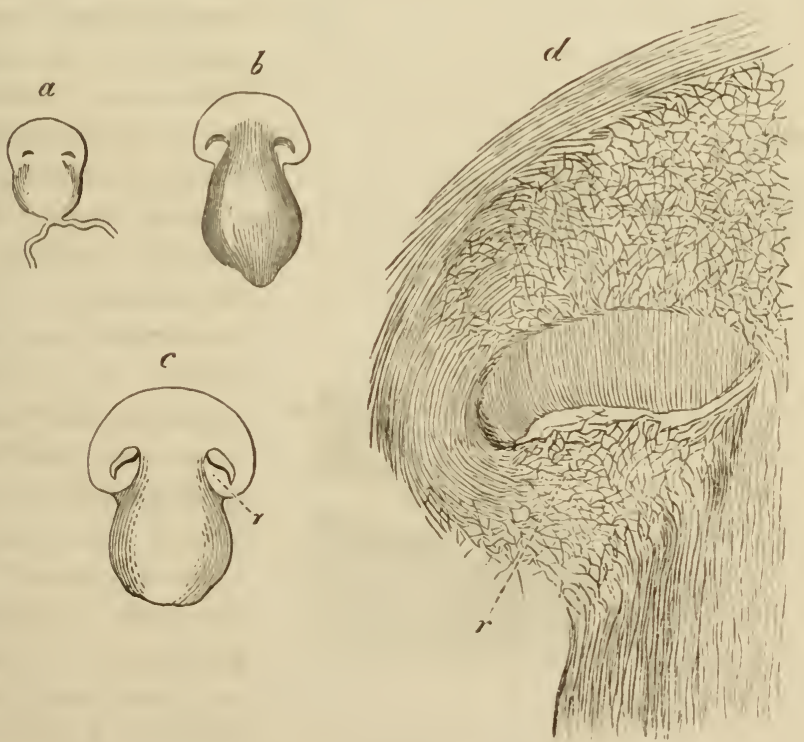

Fig. 26.

fliche $a b$, ohne Ring oder Vorhang zu bilden. In anderen Fiallen (Agaricus campestris, praecox) beginnt der Itutrand schr frühe sich rom Stiele nach aus-

Fig. 26. Agaricus campestris L. $a-c$ Drei Entwichelungsstadien des Hutes, radialer, senkrechter Längsschnitt, wenig uiber natürl. Grösse $(a 6 \mathrm{Mm} ., b 16 \mathrm{Mm}$. lang $)$. Entwickelungsfolge nach den Buchstaben. $d$ Dünner Schnitt von $b$, vergrössert, den Verlauf der Ilyphen anzeigend (nach stärkerer Vergr. halbschematisch). $r$ Ring. 
sen zu richten, löst sich aber von letzterem nicht los, sondern hebt die in ihn iiberlaufende oberflächliche Gewebeschicht ab und zieht sie mit sich; und zwar betrifft dieses nicht nur die unmittelbar an den Hutrand grenzende Zone letzierer, sondern auch ein ziemlich grosses uiber dem Hutrande, an den Lamellenschneiden liegendes Stück derselben. Die durch den Hutrand abgehobene schichte wird allerdings theilweise vom Stiele losgezerrt und gelockert, keinesweggs jedoch nur mechanisch gedehnt und gelöst; das Gewebe, aus welchem sie besteht, zeigt vielmehr eine Zeit lang lebhaftes, je nach den Species verschiedenes Wachsthum, und hialt gleichen Schritt mit der Ausdehnung der übrigen Theile. Diese abgehobene Schichte ist das vom Hutrande zum Stiele ausgespannte Velum partiale, welches zuletzt zerreisst um seine Reste als Ring und Vorhang zurückzulassen. (Fig. 26.)

Ueber die Nalur des Velum universale muss die Untersuchung von Amanita den besten Aufschluss geben, da das genannte Organ bei dieser Gattung am

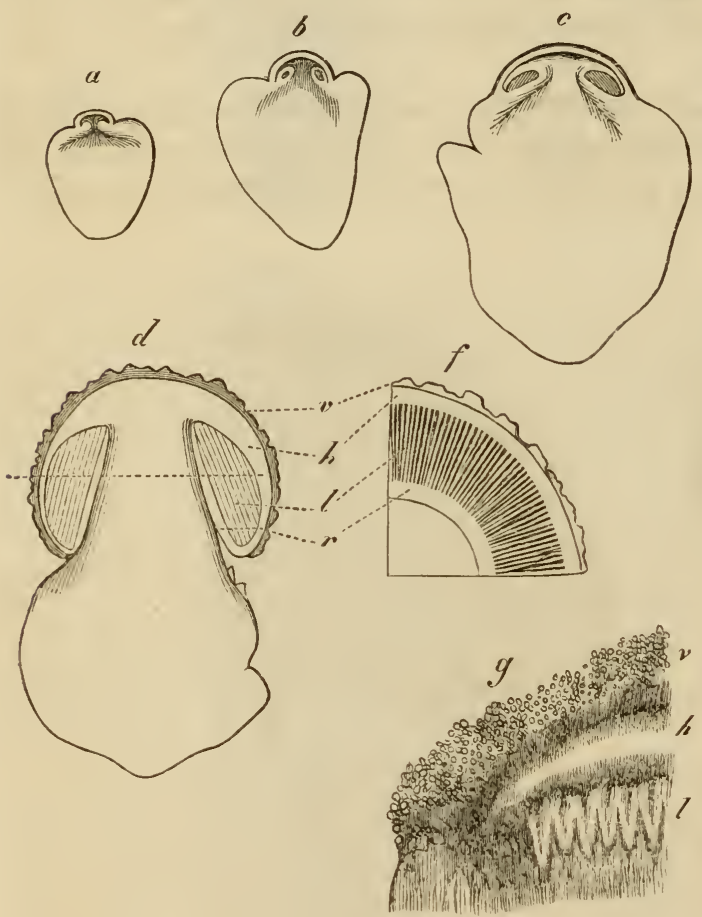

Fig. 27. ausgebildetsten ist. Die Entwickelungsreihe, welche Woronin und ich von A. muscaria und A. rubescens (Fig. 27) erhalten konnten, beginnt mit einem Stadium, wo der Pilz einen etwa $10 \mathrm{Mm}$. langen, unregelmässig ovalen Körper darstellt, auf dessen oberem Ende oder Scheitel ?eine abgeflacht - halbkugelige, von einer seichten Furche umgebene Prominenz hervortritt. Auf dem frischen, radialen, senkrechten Längsschnitte erscheint die Hauptmasse des Körpers weiss gefärbt $(27 a)$. In der halbkugeligen Hervorragung liegt, unter einer gleichfalls weissen oberflichlichen Schichte ein diunner, in reflectirtem Lichte wässeriggrauer, an dünnen Schnitten durchscheinender Meniscus. Yon der Mitte dieses geht ein kurzer Streifen gleichen Ansehens senkrecht nach unten, sich allmihlich verbreiternd und in das weisse Gewebe verlierend.

Fig. 27. Amanita rubescens Fr. $a-d$ radiale Längsschnitte durch Fruchtträger verschiedenen Alters, kaum vergr. ( $a 9 \mathrm{Mm}$. lang u. s. f.) Entwickelungsfolge nach den Buchstaben. $d$ kleines, fast fertiges Exemplar. $f$ Querschnitt durch $d$, in der Richtung der punctirten Linie. $g$ dünner tangentialer Längsschnitt durch die Hut- und Lamellenanlage von $b$, schwach vergr. Von der Volva ist nur die innere Portion erhalten. In allen Figuren bedeutet $v$ Volva, $r$ Ring, $h$ Hutsubstanz, $l$ Lamellen. 
Der Meniskus ist die spätere Hutoberfläche, die weisse Schicht über ihm das Velum universale oder die Volva, der senkrechte axile Streif die Mitte des Stiels, die weisse Hauptmasse des Körpers die knollige Stielbasis (Bulbus). Das Gewebe des grösseren, peripherischen Theiles des Bulbus und das der Volva besteht aus einem wirren Geflechte feiner Hyphen, welchem allenthalben zahlreiche grosse, blasige Zellen eingelagert sind; letztere sind leicht als einzelne oder gereihte Glieder- und Astzellen der dünnen Hyphen zu erkennen. In der Hutanlage und der ganzen an sie grenzenden Mitte des Bulbus fehlen die grossen Zellen, die genannten Theile bestehen lediglich aus einem dichten Geflechte sehr zarter, protoplasmareicher Hyphen, dessen Interstitien, soweit die weisse Färbung reicht, lufthaltig, in den grauen, resp. durchscheinenden Partieen luftrei oder luftarm sind. Beide Gewebeformen gehen allenthalben ganz allmählich in einander über; auch zwischen der Volva und der Hutoberfläche verschwindet die scharfe Grenze mit Austreibung der Luft.

In etwas grösseren Körpern (2\%, b) erscheint die Anlage der Hymenialschichte oder der Lamellen in Form eines schmalen und niedrigen, blassgrauen Ringes, welcher horizontal unter der Hutoberfläche steht und von dieser durch eine Schichte weissen Gewebes (die Hutsubstanz) getrennt ist. Im den Rand der Ilutanlage gehen die weissen Gewebeportionen, Volva, Stiel, Hutsubstanz continuirlich in einander über. Senkrechte, zun IJutrande tangentiale liangsschnitte $27, g$ zeig̣en, dass in der Hymenialzone die Lamellen vollstiindig angelegt sind, in Form messerförmiger, mit der Schneide nach unten sehender Gewebeplatten, aus welchen, mit Ausnahme eines schmalen, der Mitte der spiiteren Trama entsprechenden Streifens, die Luft verschwunden ist. Die Zwischenraume zwischen den Iamellen werden durch Gewebeplatten ausgefült, welche gleichfalls messerförmign, mit der Schneide nach oben gekehrt und etwas schmiiler sind, als die Lamellen. Die Grenze zwischen letzteren und den interstitiellen Platten wird durch eine sehr diunne, lufthaltige Schichte bezeichnet. Die Schneide der Lamellen ist nicht alogegrenzt. Das Gewebe der ganzen Hymenialzone ist ein wirres Geflecht der erwihnten zarten, protoplasmareichen Iyphen: höchstens in der Regrion, welche der spiteren Trana entspricht, kann man eine Andeutung eines senkrecht gegen die Schneide gehenden Verlaufes erkennen. Treibt man die Luft aus, so schwindet jede Grenze zwischen den Lamellen und ihrer Umgebung.

In noch späteren Stadien sind die Lamellen gleich allen ubrigen Theilen grösser, leicht von einander trennbar, die Trama und die auf ihr senkrecht stehenden Hymeniumelemente deutlich und von einer im Wesentlichen gleichen Beschaffenheit, wic bei den gymnocarpen Agaricis. Die Schneide der Lamellen geht aber auch jetzt noch continuirlich in das an sie grenzende Stielgewebe iber. Die interstitiellen Platten sind nicht mitgewachsen; an ihrer Stelle liegt zwischen den Lamellen theils ein vielfach durchbrochener, lockerer, feinfädiger Filz, der bald völlig verschwindet, theils dürften ihre Reste in den feinen leistenförmigen IIervorragungen zu suchen sein, welche sich von der Stieloberflische aus zwischen die Lamellenschneiden einschieben und späterhin auf jener wie feine Fibltelungen erscheinen. Ob zwischen den dem Stiele angewachsenen Lamellen in diesem Entwickelungsstadium noch neue, kleinere und den Stiel nicht erreichende entstehen, ist noch zu untersuchen. 
Nach der beschriebenen Abgrenzung beginnt nun eine gewaltige Vergrösserung aller Theile $(\mathbf{2} \tau, c, d, f)$; in der Hymenialfiache unter andauernder Neubildung von Formelementen wie bei den oben beschriebenen Agaricis, in allen übrigen Regionen jedenfalls unter beträchtlicher Ausdehnung der vorhandenen Zellen; in wieweit auch hier Neubildung stattfindet ist noch zu untersuchen. Indem der Stiel sich oberhalb des Hutrandes stark in die Länge streckt, und der Hut sich, hiermit Schritt haltend, in der Richtung seiner Oberfläche vergrössert, sein Rand aber dem Stiele angewachsen bleibt, werden die Lamellen aus ihrer anfangs horizontalen in eine fast senkrechte, der Oberfläche des conisch-cylindrischen Stiels parallele Stellung übergefülırt; ihre Schneiden bleiben mit dem Stiele verwachsen. Während der Vergrösserung grenzt sich die oberflichliche, den Lamellen angewachsene Gewebeschicht des Sticles allmählich von dem übrigen ab, zu einer besonderen, ziemlich mächtigen Haut velum partiale - , wclche die Lamellenschneiden von der Insertionsstelle bis zum Rande des Hutes überzicht und in letzteren übergeht. Schliesslich steht zuerst das Wachsthum der Volva still, wahrend Stiel und Hut sich zu vergrössern fortfahren und letzterer sich zu der behannten Schirmform ausbreitet. Die Volva wird daher durchrissen, lïngs des Hutrandes ringsum, auf der Ilutoberfläche zu den bekannten Stückchen zerklüftet, welche dem reifen Hute als Warzen aufsitzen. Mit der Aufspannung des Hutes wird das velum partiale zuerst vom Stiele abgehoben, bald lösen sich Lamellen und IIutrand von ihm los und lassen es als Annulus superus oder Armilla am Stiele hängen. Amanita vaginata verhält sich, wenigstens in den auf die Anlegung der Lamellen folgenden Stadien, den beiden besprochenen Arten gleich, mit dem Unterschiede, dass die Abtrennung einer Armilla vom Stiele unterbleibt, Lamellen und Hutrand sich ähnlich wie bei Coprinus loslösen, und dass die Volva am Scheitel aufreisst und als zusammenhängende Haut um die Stielbasis stehen bleibt.

Das Mitgetheilte zeigt, dass die beschriebenen, mit Schleier versehenen Agarici von den gymnocarpen dadurch unterschieden sind, dass sich ihr Fruchttrïger nicht durch einfach centrifugales Wachsthum eines Hyphenbündels aufbaut, sondern zuerst einen aus gleichförmigem Bildungsgewebe bestehenden Körper darstellt, in dessen Innerem die einzelnen Theile durch Differenzirung angelegt, gleichsam aus der homogenen Grundmasse herausmodellirt werden. Bestimmte peripherische Gewebsportionen werden hierbei als Hüllen von Stiel und Ilut abgesondert und zuletzt durchrissen. Die Natur des Velum partiale wird durch Bonordens Definition vollkommen passend bezeichnet. Das Velum universale von Amanita ein Ifycelium oder einen Theil eines solchen zu nennen, ist nicht begründet; es ist einfach die peripherische Schichte des Körpers, welche gleich den übrigen Theilen aus dem noch aufzusuchenden Mycelium entstanden sein muss. Man findet nicht selten junge Amaniten neben den entwickelteren, an welchen von der Differenzirung in Hutoberflaiche und Volva keine Spur vorhanden ist. Sie stellen Knöllchen dar, von denen die einen durchaus aus einem Gewirr feiner Hyphen mit eingelagerten, zahlreichen, blasigen Zellen bestehen, andere in der Region, wo Hut und Stiel spaiter auftreten, nur zart - und dünnfädiges Gewebe zeigen. In wieweit diese Knöllchen normale Entwickelungszustïnde darstellen, müssen vollstaindigere Beobachtungen 
erst zeigen, ich habe sie daher in die obige Entwickelungsreihe nicht aufgenommen.

Die Ausbildung und Entfaltung der angelegten Organe geschicht nicht in centrifugaler Folge. Nur beim Stiele beginnt die Streckung am Grunde, um nach oben fortzuschreiten und, wie die Messungen von Schmitz (Linnaea XVI) zeigen, gegen die Spitze hin an Intensitit stetig zuzunehmen. In dem Hute scheint die Ausbildung sogar in gewissen Fillen centripetal, rom Rande nach der Insertionsstelle fortzuschreiten. Wenigstens beginnt bei Coprinus micaceus und comatus die durch das Schwarzwerden angezeigte Reife der (Sporen auf den) Lamellen am Hutrande und der Schneide und schreitet von da allmählich nach der Iutmitte und der Lamellenbasis fort. Bei C. fimetarius findet die Reifung auf allen Punkten der Hymenialfliche gleichzeitig statt und dasselbe scheint bei Agaricus campestris, praecox und Amanita der Fall zu sein.

Vereinzelte Beobachtungen und die Darstellungen in Hoffmann's Icones analyticae machen es sehr wahrscheinlich, dass bei allen $\Lambda$ garicini velati und auch bei Boletus luteus und Verwandten die Entwickelung und die Natur der Vela die gleichen sind, wie in den beschriebenen Fälen. Ein Velum unirersale scheint mir nur bei verhialtnissmässig wenigen Formen (Amanita und Volvaria Fries) vorzukounmen, alle übrigen Schleierbildungen dagegen nach Art des V. partiale von $\Lambda \mathrm{g}$. campestris, praecox, Coprinus gebildet zu werclen. In wieweit diese Vermuthung richtig ist, muss durch fernere Beobachtung der bisher zu sehr vernachliissigten ersten Jugendzustiande ermiltelt werden. Die Vermuthung steht mit den bestchenden Ansichten und Beschreibungen allerdings in Widerspruch, denn diese reden vom Velum universale auch bei anderen Gruppen, als $\Lambda$ manita und Volvaria. In den Beschreibungen, auch in Hoffinamn's Icones analyticae, ist aber nie klar unterschieden zwischen dem Velum, dessen Entwickelung oben bezeichnet w urde, und beliebigen oberflichlichen Gewebeschichten, Haarüberzug und dergleichen; und es bedarf einer griindlichen, vielleicht auch für die Systematik erspriesslichen Durcharbeitung der Igaricinen, um über die Natur aller als Schleier beschriebenen Ueberziige cine klare Lebersicht zul erhalten.

Der Bau der reifen beschleierten Agaricinen zeigrt im Verowleich mit den gymnocarpen wenig durchgreifende Versehiedenheiten; einzelne Gruppen oder Arten haben natiurlich auch hier ihre besonderen Eigenthümlichkeiten. Unter den letzteren ist der Ueberzug von dicken, borstenartigen oder rosenkranzförmigen Haaren erwihnenswerth, weleber die meisten Coprini in der Jugend bedeckt und oft Velum genannt wird. Bei der Reife des Itutes zerfallen zumal die rosenkranzförmngen in ihre kugeligen Glieder und diese sind dem Fruchttrigger als gliinzendes Pulver aufgestreut C. mieaceus, stercorarius, rgal. Fig. 2j). Vollkommene Uebereinstimmung mit den g!mnocarpen herrscht in dem Bau der Hymenialliache; auch Coprinus ist hiervon, wie Hoflmann urgirt, Corda Icon. I, tab. VII übrigens schon abgebildet hat, nicht ausgenommen, denn die Lamellen zeigen hier die Trama, welche Fries ihnen absprricht, in Form eines schön ausgebildeten Pseudoparenchy̆ms, und es ist wohl nirgends leichter und schöner zu beobachten als hier, wie dieses rundzellige Gewebe sich durch Dehnung der Gliederzellen feiner, fadenförmiger Ilyphen entwickelt, welche denselben Verlauf wie die in den Lamellen ggmnocarper Formen haben. Hut, Stiel, Velum 
zeigen je nach Gruppe und Species faserige oder pseudoparenchymatische Structur. Die Zusammensetzung fast aller ausgebildeten Organe von Amanita aus blasigen Zellen und regellos verworrenen, feinen Hyphen ist vielfach beschrieben worden, am ausführlichsten von Hoffmann (Icon. analyt. Heft l). Was den Verlauf der Hyphen betrifft, so findet man auch bei den beschleierten Hymenomyceten in den meisten Theilen eine der Form entsprechende mehr oder minder deutliche Faserung. Bildungen eigenthümlicher Art sind von Hoffmann auf der Armilla des Fliegenschwammes gefunden, bei verwandten Arten bis jetzt vergebens gesucht worden. Die Aussenflache dieses Organs ist von einer dünnen Schichte einer gelblichen, schmierigen, structurlosen Substanz überzogen. Bringt man letztere in Wasser, so erheben sich rasch aus ihr zahlreiche (mikroskopisch kleine) Körperchen von fettglänzendem Ansehen und der Form cylindrischer, meist in einen Knopf endender Stabchen. Sie zeigen eine lebhafte undulirende und zitternde Beweğung, Gestaltveräinderungen, wie Streckung und Verkürzung, Schlingenbildungen, u. s. f. Der Einwirkung des Wassers überlassen werden die Körperchen nach 2 \& Stunden oder längerer Zeit bewegungslos und nehmen meistens, doch nicht immer, die Gestalt hohler Kugeln mit fettglianzender Wand und wässerigem Inhalt an. Stofflich bestehen die Körper aus fett - oder harzartiger, in Alkohol und Aether löslicher Substanz, welche init einer geringen Menge eines in genannten Flüssigkeiten unlöslichen, durch Jod gelb werdenden Stoffes gemengt ist. Sie gleichen in ihrer Erscheinung den beweglichen Bildungen. welche man an dem sogenannten Myelin ${ }^{1}$ ) unter Einwirkung von Wasser beobachtet, und dürften bei genauerer chemischer Untersuchung wohl gleiche oder :ihnliche Zusammensetzung wie jenes zeigen.

Die Stäbchen für besondere Orga ne des Fliegenschwammes zu halten lieğt kein Grund vor. Die Substanz, aus welcher sie sich entwickeln, mag vielleicht ein Zersetzungsprodukt der in der Jugend vorhandenen interlamellären Gewebeplatten sein.

Montagnites, eine wie es scheint zu den beschleierten $A$ garicinen gehörende Gattung, ist von den übrigen durch den Hangel des Hutes unterschieden. Die Lamellen entspringen strahlig rings um das obere, etwas verbreiterte Ende eines aus einer Volva hervortretenden cylindrischen Stiels (s. Corda, Icon. VI, Tab. XX; Explor. sc. d'Alger. 1. 21). Die Entwickelung dieser sonderbaren Form ist noch zu untersuchen.

\section{Litteratur}

über Bau und Entwickelung der Hymenomyceten - und gymnocarpen Fruchthörper.

schmitz, Leber die Bildung neuer Theile bei den Hymenomyceten.

— Ueber die Längen-Ausdehnung bei den Pileaten. Linnaea Bd. XVI (1842).

- Ueber Entwickelung, Bau und Wachsthum von Thelephora sericea und hirsuta. Linnaea XVII (1843) p. 417.

Bonorden, Allgem. Mỵkologie, p. 156-196 et passim.

—_ Beobachtungen üb. den Bau d. Agaricinen. Bot. Ztg. 1858, p. $201 \mathrm{ff}$.

H. It of $\mathrm{mann}$, Pollinarien und Spermatien von Agaricus. Bot. Ztg. 1856, p. $137 \mathrm{ff}$. (Speciell hierher Gehöriges p. 144. .

- Beiträge zur Entwickelungsgesch. und Anatomie der Agaricinen. Bot. Ztg. 1860, p. $389 \mathrm{ff}$.

1) Vgl. Beneke, Studien über Gallenbestandtheile etc. Giessen 1862. 
H. Hoffmann, Ueber contractile Gebilde beï Blätterschwämmen (die beweglichen Stäbchen an Amanita muscaria). Bot. Ztg. 1853, p. 857.

- Icones analyticae fungorum, Liefg. I-III.

de Bary, Zur Kenntniss einiger Agaricinen. Bot. Ztg. 1859, p. 385 .

J. de Seynes, Organisation des champignons supérieurs. Ann. sc. nat. כe Sér. T. I.

(Bringt fast nichts Neues und das Alte meistens viel unvollkommener, als seine

ihm allerdings oft unbekannten Vorgänger.)

Die citirten Schriften haben hierher gehörende Fragen zu ihrem Hauptgegenstande. Für Einzelheiten sind noch anzuführen :

Fr. Nees ab Esenbeck, Plantarum mycetoidearum in hort. bonn. obs. evolutio.

Nov. Act. Natur. Curios. Tom. XVI, pars I (1832). (Entwickelung des Agaricus

[Volvaria] volvaceus).

Tulasne, Organisation des Tremellines. Ann. Sc. Nat. 3e Sér. Tom. XIX.

de Bary, Beitr. z. Morphol. d. Pilze I. (Exoascus).

- Ueber d. Ascomyceten. (Peziza confluens).

Ferner sind zu vergleichen Corda's oben zum Theil citirte Icones und die descriptiven Werke, besonder's Persoons Synopsis, Fries, Bulliard, hrombholz; auch die in den folgenden Capiteln zu citirenden Monographien.

Aus diesen Quellen und eigenen Beobachtungen ist der vorstehende $A b$ schnitt zusammengetragen. Ihre geringe Zahl möge sẹne Lückenhaftigkeit und die vielleicht allzu schematische Fassung theilweise entschuldigen.

\section{Fruchträger der Gastromyceten.}

Die reifenden Fruchtkörper der t!pischen Gastromyecten, welche Fries in die Gruppen Hymenogastrei, Lycoperdinei, Sclerodermei und theilweise auch Diplodermei Geaster, wohl auch Diploderma, Sclerangium Lér., Mitremyees etc.) vertheilt hat, sind Behälter oder Säcke, ringsumgeben von einer geschlossenen Wand, dem Peridium (auch Cterus genannt, und im Inneren durch meist diumne, gebogene und nach allen Seiten miteinander anastomosirende Gewebeplatten in unzihlige, meist mit blossem Auge eben noch deutlich erkennbare, manchmal jedoch auch grössere bei Polỵsaceum erbsengrosse) Kammern getheilt, von denen die peripherischen unmittelbar an die Peridie angrenzen. Die gekammerte Gewebemasse ist der fruchtbildende Theil des Pilzes, Gleba genannt. Bei vielen Arten (Fig. 28) ist an der Basis eine mehr oder minder stark entwickelte, sterile, die Gleba gleichsam tragende Gewebeportion vorhanden, die polsterartig (z. B. Hy-

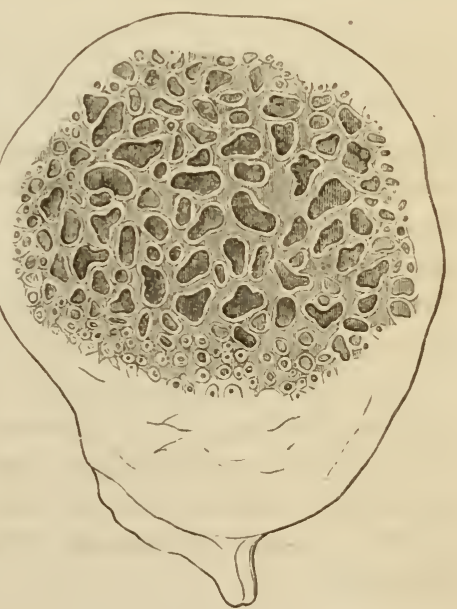

Fig. 29. menogaster) oder in Form einer verlängerten verticalen Mittelsiule Geaster, mit Ausnahme von G. hygrometricus, nach Vittadini) in die Gleba einspringt, oder, wie bei vielen Lycoperdonarten, zu einem dicken Stiele entwickelt ist. Die

Fig. 28. Octaviania asterosperma Vitt., halbirt, smal vergr. Nach Tulasne copirt. 
Basalportion sitzt bei den über dem Boden reifenden und bei manchen unterirdischen allein dem Mycelium unmittelbar auf. Bei einer Anzahl der letzteren (Rhizopogon, Geaster) laufen dagegen Myceliumstränge in jede beliebige und oft in sehr zahlreiche Stellen der Peridienoberfläche ein. Einzelne Arten (z. B. der Gattung Hysterangium) lassen eine Basalportion nicht unterscheiden. Die Hymenogastreengattung Gautieria verhält sich in sofern exceptionell, als ihr die Peridie fehlt, die peripherischen Kammern der Gleba daher nach aussen offen sind.

Was den feineren Ba betrifft, so unterscheidet man in den Kammerwänden der Gleba eine Mittelschichte oder Trama, und auf beiden Oberflächen dieser eine Hymenialschichte. Beiderlei Theile (Fig. 29) gleichen in allem Wesentlichen den gleichnamigen

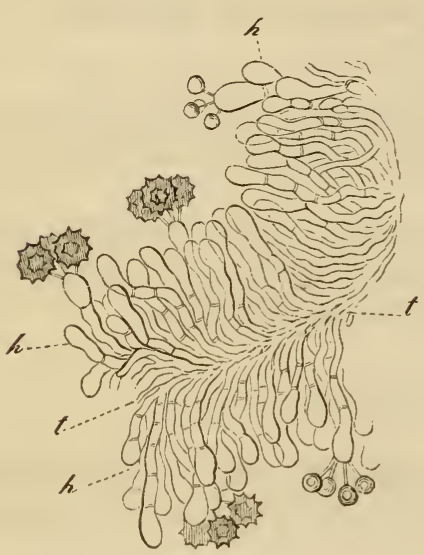

Fig. 29. im Fruchtlager der Hymenomyceten. Die Trama besteht in den genauer untersuchten Fällen Hymenogastrei, Lycoperdon, Bovista, Scleroderma, Geaster) aus einem Geflechte von reich verzweigten Hyphen, welche vorzugsweise der Oberfläche der Wände parallel verlaufen und sowohl von einer Kammerwand in die benachbarten, als auch in das Gewebe der Peridie continuirlich übergehen. Zahlreiche dicht gedrängte Zweige der Tramafäden gehen gegen den Innenraum der Kammern, um hier das Hymenialgewebe $\mathrm{zu}$ bilden. In einer Reihe von Fällen sind sie verhältnissmässig kurz, gleichhoch, pallisadenartig nebeneinander und senkrecht auf die Tramafliche gestellt, sie bilden eine scharf

abgegrenzte, den leeren Innenraum der Kammern austapezirende Iymenialschichte, welche der der IIymenomyceten ganz ihnlich ist IIymenogastrei plurimi [Fig. 29], Geaster spec., Lycoperdon). In einer anderen Reihe von Fällen (Melanogaster, Scleroderma, Polysaccum, Geaster hygrometricus) sind die Hymeniallıphen verlaingert, reich veristelt und alle in eine Kammer eintretenden zu einem diese ausfiillenden Geflechte verschlungen.

Bei den Hymenogastreen behält die Gleba die beschriebene Structur von ihrer ersten Anlage an bis zur völligen Reife. Ihr Gewebe ist dabei entweder fleischig, aus zartwandigen, saftreichen Zellen gebildet, seine Lücken Luft oder Flüssigkeit führend [z. B. Hỵmenogaster Klotzschii Tul., Octaviania carnea Corda ${ }^{1}$ )]; oder es besteht (Hysterangium, Melanogaster) aus zäh-gelatinösem Gallertfilz.

Fig. 29. Octaviania asterosperma Vitt. Dünner Schnitt einer Kammerwand. $t$ Tramá. $h$ Hymenium, mit 5 sporenbildenden Basidien. Vergr. 180. Nach Tulasne copirt.

1) Die beiden genannten Species führe ich deswegen vorzugsweise als Beispiele an, weil sie Vielen leichter zugänglich sein werden, als andere Hymenogastreen. Beide kommen nämlich, wie es scheint häufig, auf Haideerde in den Blumentöpfen der Gewächshäuser vor. Ich fand beide rom Januar bis März, und zwar als oberirdische Piize vegetirend, nur die ersten Jugendstadien unter der Bodenoberfläche zubringend. 
Dic Gleba von Scleroderma hat, nach Tulasne, vor der Sporenbildung gleichfalls die beschriebene Structur. Mit dem Beginn der Sporenreife wird das ganze die Kammern erfüllende Hymenialgewebe aufgelöst, der Pilz trocknet aus, die Trama bleibt als ein vertrocknetes, brüchiges Netzwerk stehen, dessen Maschen ron der staubigen Sporenmasse ausgefüllt werden. Aehnlich verhält sich Polysaccum; nur lässt sich vor dem Austrocknen die ganze hymeniale Gewebemasse aus jeder Kammer herausnehmen als ein glatt umschriebener Körper, der von ciner zarten, besonderen Wand (peridiolum), wohl einer abtrennbaren Schicht der Trama, umschlossen wird.

Auch bei Lycoperdon, Bovista, Geaster und Verwandten ist der junge Fruchtkörper saftig, der reife ausgetrocknet. Wihrend der Jugend unterscheidet man in der Trama zweierlei Hyphen: dünne, zartwandige und protoplasmareiche, septirte, von denen die Hymenialbestandtheile als Zweige entspringen; und dickere, schon in der Jugend derbwandigere (meist querwandlose) Röhren. Letztere sind Glieder oder Aeste der nimlichen Hyphen wie die zarten Elemente. Sie laufen grösstentheils in der Flache der Trama, senden jedoch auch, bei Bovista, Lycoperdon, oft Zweige quer durch die Kammern, ron einer Wand in die gegenuberstehende. Mit Begimn der Sporenreife zerfallen die Hymeniumelemente und die zarten Hyphen, sie lösen sich auf und lassen nur unscheinbare, vertrocknende Ueberbleibsel zurick. IDic dicken Röhren bleiben dagegen, sie werden grösser, ihre Wande stark verdickt mol meist lelıhaft (gelb) bis braun) gefarbt. Sie bilden mit einander eine wollige, das sporenpulver allenthalben durchsetzende Masse, II a a geflecht, Capillitiun genannt. Eine genauere histiologische Bearbeitung der Entwickelung des Capillitiums wäre sehr wünschenswerth.

Das fertige Capillitim besteht in der überwiegenden Mehrzahl der Fïlle aus einer Unzahl cinzelner Röhren oder II! jhenstücke, welche nur locker mit einander verflochten, nicht aber verwachsen, und daher leicht und ohne Zereissung isolirbar sind. Gestalt, Grosse, Structur dieser Capillitiumfasern sind nach Gattungen und Arten verschieden, sie können zur Unterscheidung letzterer vortrefflich benutzt werden, und es ist schwer zu begreifen, wie ein Mann, der sehr vicle Pilze untersucht hat, das Gegentheil hiervon behaupten mag. Neistens sind die fasern unseptirt, einzellig: Einfache, oder nur ausnahmsweise verzweigte, kurz spindelförmige Röhren bei Geaster coliformis Fig. $30, a)$; langgestreckt spindelförmig, meist unverzweigt, mit uberaus fein ausgezogenen Enden und bis zum Schwinden des Lumens verdickter Membran bei G. fornicatus, fimbriatus, mammosus u. a. Bei den meisten Lycoperdonarten sind die gleiehfalls unseptirten Fasorn lanğgestreckt, gekrümmt, manchmal torulös, einfach oder in einzelne, sehr lange Aeste getheilt; die Enden theils fein ausgezogen, theils durch eine breite Querwand geschlossen, weleh letztere die Ansatzstelle der Faser an den früher vorhandenen zarten Tramafaden bezeichnet. Die gleichfalls einzelligen Fasern von Bovista (Fig. 30, b) hahen das Ansehen eines vielstrahligen Sternes. Sie zeigen einen kurzen, dicken Hauptstamm, welcher oft deutlich dic frühere Ansatzstelle erkennen lisst und nach mehreren Seiten kurze Aeste aussendet. Letztere sind durchschnittlich viermal dichotom getheilt, die Lainge der Dichotomien nimmt mit ihrem Grade zu, die Dicke ab, die des letzten Grades sind haarförmig ves.längert und 
fein ausgezogen. Mycenastrum (Fig. 30,c) hat kurze, dicke, einzellige Fasern mit einfach spindelförmigem oder in einige Zweige getheiltem Haupstamme,

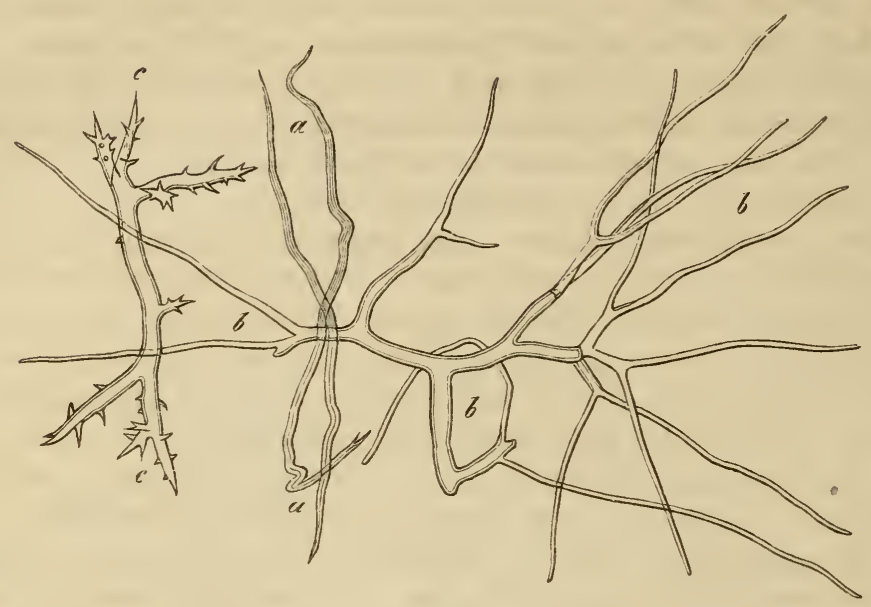

Fig. 30 .

welcher, zumal an den Enden, mit kurzen, spitzen Aestchen wie mit Stacheln besetzt ist. Die Capillitiumfasern von L ycoperdon Bovista, gigan te um sind meist mit Querwïnden versehen, also mehrzellig, im übrigen gleichen sie denen der anderen, oben erwaihnten Arten der Gattung.

Geaster hy grometricus ist unter den hier in Rede stehenden, mir bekannten Formen die einzige, deren reifes Capillitium ein zusammenhängendes Netz bildet. Die reich verzweigten, oft torulösen, ungemein dickwandigen Fasern sind wirr durcheinander gekrünmt und mit ihren oft kopfig angeschwollenen Enden fest aneinander gewachsen.

Die sterile Basalportion des Fruchthörpers ist ein dichtes Geflecht von IIshen, welche denen der Trama ähnlich sind, und ron welchem die Platten der letzteren ausstrahlen IIymenogastrei); oder sie ist in derselhen Weise wie die Gleba gekanmert, die Kammern jedoch steril oder nur mit unbedeutenden Spuren von Fructificationsorganen (z. B. Lycoperdon). Auch in letzterem Falle verschwindet sie mit der Reife des Pilzes nicht. Der Bau der Mittelsäule von Geaster ist noch genauer zu untersuchen.

Die Peridie ist in den einfachsten Fällen (Hymenogastreen) eine gleichförmige Gewebeschicht von verschiedener Mächtigkeit, aus fest verflochtenen, vorzugsweise in der Richtung der Oberflache verlaufenden Iyphen gebildet. Ihre Structur ist bei Octariania carnea ganz gleich der der Trama und sie ist auf ihrer Innenfläche wie letztere vom Hymenium überzogen. Bei Hymenogaster Klotzschii ist sie ebenso beschaffen, aussen jedoch noch von einem dichten und dicken Filz abstehender, gekrümmter Ilaare bedecht. Ganz ähnliche Verhält-

Fig. 30. Capillitiumfasern, $a$ von Geaster coliformis P. 190 fach vergr.

$b$ von Bovista plumbea $P$. 90 fach vergr.

$c$ von Mycenastrum Corium Desv. 90 fach vergr. 
nisse wiederholen sich wohl bei allen Hymenogastreen; die Verschiedenheiten beruhen theils in der Dicke der Peridie, theils darin, ob sie die gleiche oder verschiedene Consistenz und Siructur hat wie die Trama; in letzterem Falle ist sie von der Gleba ablösbar. Die derb lederartigen Peridien von Scleroderma schliessen sich genau an dic der Hymenogastreen an, und im Grunde auch die von Polysaccum. Bei letzterer Gattung sind die inneren Kammern der Gleba fruchtbar, einige concentrische Lagen peripherischer, kleinerer entbehren des IIymeniums und stellen mit cinander die Peridie dar.

Bei den Lycoperdincen, bei Mycenastrum, Geaster, Sclerangium u. s. f. ist die Peridie in zwei concentrische, von einander trennbare Lagen gegliedert - Peridium interius und exterius. Dic innere ist eine meist dünne Haut, spinnwebeartig zart bei Mitremyees, meist von papierartiger Consistenz, bei Mycenastrum aber über 2 Millim. dick, korkartigg. Bei Bovista, Geaster, Lıcoperdon $^{\mathbf{1}}$ ) ist sie eine papierartige IIaut, bestehend aus mehreren Lagen derber, in der Richtung der Oberfliche verlaufender Fïden, welche fest miteinander verflochten sind und im Algemeinen Struetur und Ansehen von Capillitiumfasern haben. Bei Geaster hỵgrometricus sind jene den letzteren völligg gleich und setzen sich continuirlich in sie fort, das Capillitiumnet\% ist also der Poridie allenthalhen angewachsen. Bei den untersuchten Lycoperden, Geaster fimbriatus, fornicatus sind jene Fïden von den Capillitiunfasern durch geringere Dicke und hellere Farbe verschieden, senden aber ins Innere der Peridie unzihlige Zweige, welche, sowcit sie frei sind, alle Eigenschaften der Capillitiumfasern haben. Die innere Peridie von Bovista plumbea hat einen ihnlichen Bau und auf ihrer Innenfliche gleichfalls einen dichten wolliggen Ueberzugg, welcher aus Fasern besteht, die von denen des Peridiengeflechtes entspringِen. Dieselben haben aber mit den Capillitiumfasern weder Achnlichkeit noch Zusammenhang: sie sind lang ausgezogene, feine, unverzweighte Fiden.

Die innere Peridie von Mycenastrum Corium ist ein dichtes, wirres, lufthaltiges Geflecht braunhaiutiger Fiden, in der iusseren Region feinfaseriger und dichter als in der imneren. Auf der Innenfliche endigaen die Fiden mit spitzen, den Capillitiunfasern ïhnlichen, doch stets diinneren Xesten.

Die innere Periclie von Mycenastrum ist von einer weisslichen, weichen, dünnen llaut, der ia usseren Peridic, überzogen, welche aus einem lockeren Geflecht farbloser, diunnwandigger, e lindrischer II! phen besteht, und sich nach der lieife in Lappen abblittert, Imı schliesslich die innere rein zuriickzulassen.

Entwichelter ist das Peridium externum bei Lycoperdon L. Bovista und giganteum lasse ich auch hier bei seite) und Bovista. Es besteht hier aus grosszelligem, meist pseudoparenchymatischem Gewebe, welches in manehen Fillen Bovista plumbea) mehrere Lagen muterscheiden lisst und nach Aussen in Form von Warzen, Stacheln u. s. w. vorspringt. In der Jugend liegt es der inneren Peridie fest an, die Elemente beider gehen in einander über. Mit der

1. L. pyriforme, pusillum, constellatum und Verwandte; ich nenne keine Species, weil mir eine sichere Bestimmung derselhen nicht möglich ist. Lye. Bovista Fr. und giganteum haben einen anderen Bau als die Arten, von denen oben die Rede ist; ich finde denselben nirgends genau beschrieben, und da mir an alten, reifen Exemplaren, welche ich allein untersuchen kounte, manches zweifelhaft bleibt, begnüge ich mich hier damit, den Gegenstand fernerer Beobachtung zu empfehlen. 
Reife erleidet die innere Lage der ausseren Peridie eine Desorganisation, sie verwandelt sich in eine schmierige oder flüssige Masse, die bald vertrocknet oder resorbirt wird; daher schält sich die aussere Peridie häufig von der inneren ganz los und zerfällt (Vittadini). Bei manchen, vielleicht den meisten Arten (z. B. Bovista plumbea, Lycoperdon perlatum nach Tulasne und Vittadini) betrifft die Desorganisation das ganze aussere Peridium, es verwandelt sich in eine schmierige Masse, welche beim Austrocknen zu einer spröden, fast structurlosen Haut wird.

Complicirter ist der Bau der Peridien von Geaster. G. hygrometricus (Fig. 31) stellt bekanntlich bis zur völligen Reife einen unter der Bodenoberfläche sitzenden, rundlichen, bis nussgrossen Körper dar. Kurz vor der Reife unterscheidet man auf dem senkrechten Längsschnitte an der Peridie sechs Schichten. Zu ausserst einen flockig-faserigen, bräunlichen Ueberzug, der sich einerseits in die den Boden durchwuchernden Myceliumstränge fortsetzt, andrerseits in die zweite Schicht übergcht: eine dicke, derbe, den ganzen Körper umziebende, braune Haut. Auf diese folgt nach innen eine weisse Schichte, welche

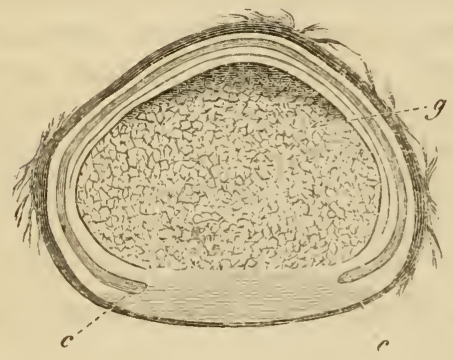

Fig. 31 . an der Basis des Körpers besonders mächtig entwickelt ist und sich hier in die innere Peridie und Gleba unmittelbar fortsetzt. Die beiden letzigenannten Schichten bestehen aus fest verflochtenen, derben, zumeist in der Richtung der Oberfliche verlaufenden Hyphen; sie mögen unter dem Namen Faserschichte zusammengefasst werden. Die weisse Lage derselben ist, mit Ausnahme ihrer in die Gleba übergehenden Basalportion, innen bedeckt ron der Collenehymschicht, einer knorpelig-gallertartigen Schichte, bestehend aus gleichhohen, lïckenlos miteinander rerbundenen Hyphen, welche pallisadenartig senkrecht zur Oberfliche stehen und bogig von den Fäden der Faserschicht entspringen. Die stark rerdickten, geschichteten Zellwiinde der Collenchymschicht sind in hohem Grade quellbar. Innen von den Collenchym folght eine weisse Schichte, deren innerste kegion die innere Peridie darstellt, wihrend dic iussere, die man Spaltschichte nennen kann, aus weichen, locker verwebten, in die innere Peridie vielfach übergehenden Hyphen besteht. Ist der Pilz ganz reif, so reisst, bei Einwirkung ron Feuchtig̣heit, in Folg̣e der Quellung des Collenchymschichte, die äussere Peridie rom Scheitel aus sternförmig in mehrere Lappen auf. welche sich zurückschlagen, so dass ihre obere Fliche convex wird. Die Spaltschichte wird hierbei derart zerrissen, dass ihre Elemente als vergingliche Flocken theils an dem Collenchym, theils an der inneren Peridie hägen bleiben. Es ist bekannt, dass die Collenchỵschicht ibre Iygroscopicitat lange behält und die äussere Peridie lange auf dem

Fig. 31. Geaster hygrometricus, erwachsenes, fast reifes Exemplar, senkrechter, axiler Längsschnitt, kaum vergrössert. c Collenchymschicht, $g$ Gleba, deren Scheitel von reifenden Sporen dunkle Farbe anzunehmen beginnt. 
Boden liegen bleibt, als ein Stern, der seine Strahlen bei feuchtem Wotter ausbreitet, bei trockenem einwiats krummt. Bei G. fimbriatus, fornicatus ist die flockig̣e Umhüllung der ausseren Peridie oft stärker entwickelt, als bei G. hygronotricus, bei G. fornicatus aus höchst feinen Fiden zusammengewebt, und beim Aufreissen der Peridie löst sie sich von der Faserschicht los, einen offenen leeren sack unter jener darstellend. Jie Faserschicht ist bei genannten und anderen Arten relativ diunner, als bei G. hygrometricus und nicht in zwei Lagen gesondert. Die Collenchymschicht besteht aus grosszelligem, durchsichtigem Pseudoparench!m, das gleichfalls in Wasser stark aufquillt und durch seine Ausdehnung jedenfalls das Oeffnen der Peridie verursacht. Bei G. fornicatus, fimbriatus, coliformis $u$. a. isl es zartzellig und wird bald nach dem Aufspringen rissig und zur Krüumnung̣ der Peridienstrahlen untaug̣lich. Bei G. mammosus und, nach Tulasne, rufeseens besitzt es dagegen die gleichen dauernden hygroskopischen Eigensehaften $w$ ic bei (i. hygrometricus.

Von der jusseren Peridie ron Il ilremyer ist bemerkenswerth. dass sie, samment den worzeliihnlichen suringen, welchen sie aufsitz, durehweg aus einem Hemellaartig̣en, zihlen Gallertgewole besteht. -

Ans den Beschreibmngen ist behannt, dass die inneren Peridien der mei-

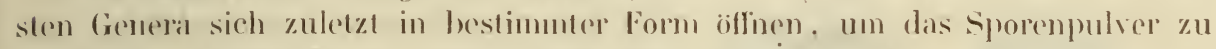
entlassen. Iober die anatomischen Verhailenisse, welehe diesem Vorogang zu Gamde liegen, ist nichts behannt.

Dic ersten Entwichelungwasustande der besprochenen Gastromparen sind bis jetzt kanm untersucht. II!menogaster klotzschii ist in den juingsiten von

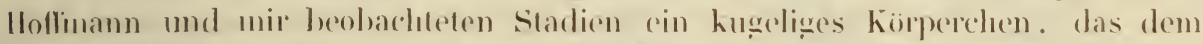

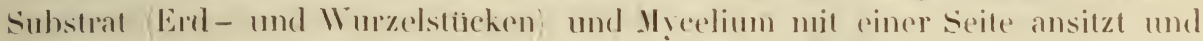
atus fest verflochtenen Ilỵphen mit engen. zum Theil Luft führenden Interstitien bestehl. Bei ganz kleinen, I Mur. messenden Evemplaren ist auf dem

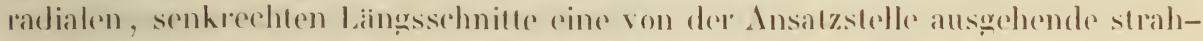
ligne Fasermong

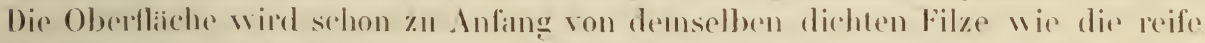

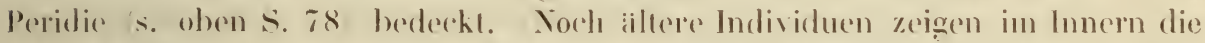

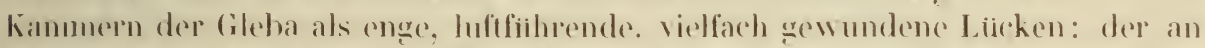

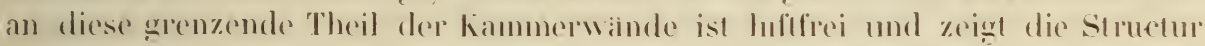

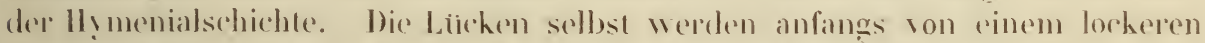

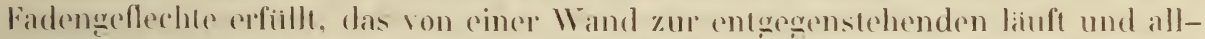
mithlich verselowindet.

Nach diesen Doten ist das line wenig̣stens unzweifelhaft, dass die Anle-

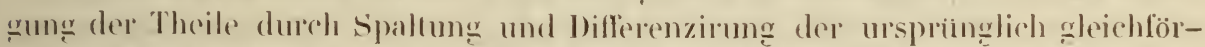
migen Gewehemasse geschieht. Soweit ich unterseheiden konnte, beginnt sie in der Peripherie und schreited nach der Basis fort: an letzterer bleiht ein Stück des urspriinglichen Gewebes Basalportion mzerklibtet. Mit der Weiterentwichelung grlitten sich die Falten der Kanmerw inde mehr und mehr aus, die Kammern werden erweitert. Ausdehnung der Tramazellen hat hieran jodenfalls bedeutenden Antheil.

Erhsengrosse Exmplare von Geaster hygrometrieus bestehen aus einem yleichförmigen, weichen, lufthaltigen Geflechte zarter septirter IIyhen, das im Innern weisslich, im Umfang braun ist, und mitten in einem, den Boden oft auf 
I Zoll im Umkreis durchsetzenden Mrceliumfilze sitzt. Aeltere, bei kriftiger Entwickelung des Pilzes etwa hasehussgrosse Exemplàre lassen in ihrem Umfange die Faserschichte der Peridie unterscheiden, im Innern weichen die Iyphen zur Bildung der Glebakammern auseinander, in welche die Hymenialfiden hineinsprossen; die Collenchymschicht ist noch nicht vorhanden, ihre Entstehung habe ich nicht beobachtet. Auch diese Thatsachen zeigen eine Spaltung und Differenzirung eines ursprünglich gleichförmigen Hỵphengeflechtes an. Für die übrigen Genera darf wohl das Nämliche angenommen werden.

Die Reife der Gleba beginnt bei Geaster hygrometricus Fig. 31) in Scheitel und schreitet ron da nach der Basis fort; nach Vittadini verhält sicle Polysaccum ebenso. Nach Bonorden und Tulasne's Andeutungen beginnt sie bei Lycoperdon, Scleroderma, Polysaccum in der Mittellinie und schreitet centrifugal weiter. Eine genaue Verfolgung der angedeuteten Verhältnisse diurfte keine undankbare Aufgabe sein.

Eine ron den bisher besprochenen typischen Gastromyceten rerschiedene, complicirtere Bildung und Entwickelung zeigt zunichst die Gattung Batarrea Fig. 32). Ihre Jugendzustainde sind un-

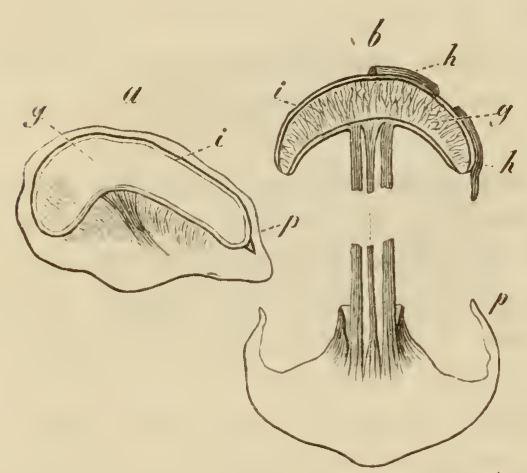

Fig. 32 . bekannt. Ein halbreifes Exemplar von B. Steveni, welches ich untersuchte ${ }^{1}$ ), hat die Gestalt eines polsterförmigen Körpers a mit regelmaissig convexer oberer Fliche und einen Durchmesser von gegen $7 \mathrm{Cm}$. Der senkrechte Durchschnitt zeigt einen Bau, der sich im Groben dem eines fast reifen Geaster vergleichen lässt. Eine innere Peridie ron der Form eines planconvexen, durchschnittlieh $1 \mathrm{Cm}$. dicken, stumpfrandigen Agaricushutes umschliesst die fast reife Gleba; diese zeigt einen sclerodermaihnlichen Bau, nur dass die stärkeren Kammerwande vielfach senkrecht von der oberen zur unteren Fliiche verlaufen: zwischen dem Sporenpulver befinden sich vereinzelte, oben Seite 6 ) beschriebene Capillitiumfasern von unbekannter Entstehung. IDie iussere, der inneren iiberall eng anliegende Peridie stellt über der Oberseite letzterer eine derbe, etwa I $\mathbf{M m}$. dicke Haut dar, ihre untere Portion ist ein massiger, mitten über 2 Cm. dicker, polsterförniger Körper. Spitere Entwickelungszustimle zeigen, dass sich zuletzt ein axiles, unter dem Centrum der inneren Peridie liegendes Stück des basalen Polsters zu einem bis fusslangen und $1-1 \frac{1}{2}$ Cm. dicken, aufrechten Stiele mit rissig-grobschuppiger Oberfliche entwickelt, welcher die innere Peridie emporhebt. Die Scheitel-

Fig. 32. Batarrea Steveni Fr. Senkrechte, axile Längsschnitte, $1 / 3$ natürliche Grösse, halbschematisch. $a$ jüngeres, doch schon grösstentheils reife Sporen führendes, $b$ reifes Exemplar im letzteren vom stiel nur scheitel und Basis gezeichnet). $p$ und $h$ äussere, $i$ innere Peridie, $g$ Gleba; die Strichelung in dieser bezeichnet die Stellung der stärkeren Tramareste.

1) Ich verdanke dasselbe der freundlichen Mittheilung der Herren Walz und Prof. Rogowitsch in Kiew. 
region der äusseren wird hierbei von der Basis abgerissen, sie bleibt in Fetzen auf der Oberseite und am Rande der inneren hängen, die Basalportion umgibt das untere Stielende, der Volva von Amanita ihnlich. Schliesslich trennt sich die Wand der inneren Peridie ringförmig unterhalb des Randes, das obere Stiick fiillt von dem mit dem Stiele verbunden bleibenden unteren und der Gleba ab, die Sporen verstiuben. Das Gewebe ron Bat. Steveni besteht durchweg aus derben Hyphen mit meist luftührenden Interstitien: in der Wand des hohlen Stiels verlaufen die Fiden senkrecht und parallel untereinander, wie es bei den meisten Ilymenomyceten Regel ist. Gallertfilz ist bei der in Rede stehenden Art nirgends vorhanden. Von dem Sticle ist an dem noch mit geschlossener iusserer Peridie versehenen Exemplare nur in sofern eine Andeutung vorhanden, als das Gewebe der Basalportion an der späteren Lisplungsstelle des Stiels etwas dichter und dunkler gefaibht ist, als in Uebrigyen.

Nach Vittadini gleicht die Entwickelung von Tulostoma Fig. 33 der von Batarrea in sofern, als die innere Peridie anfangs von einer iusseren umschlossen, zuletzt durch die Streckung eines an ihrem Grunde sich entwickelnden stiels aus letzterer und über den Boden, in welchem der ganze Pilz sich ausbildet, empor:yehoben wird. Die aussere Peridie zerfiillt alsdann sehr bald, man findet meistens nur dic gestielte innere nit unscheinbaren Resten von jener: ich habe immer nur diesen letzteren Zustand gesehen. Tulostoma gleicht in demselluen ciner gesticlten Bovista; der Sticl besteht aus cyeraden, parallel untereinameler und senhrecht gestellten,
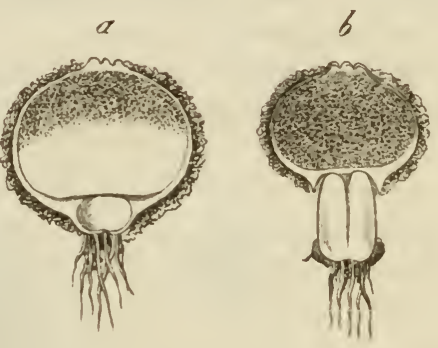

Fig. 3:3. fest vereinigten Ilyphen; von der structur der übrigen Theile sei hier nur erwithnt, dass die Peridie ein wiederum sehr characteristisch gebautes, dem von Geaster hỵrometricus an meisten gleichendes Capillitimnetz umschliesst. Die Ausbildung der Gleba schreitet von dem Scheitel zur Basis der Peridie fort und ist ror der slreckung des Stieles vollcondet.

Die Gruppe der Poda incen ist von den bisher beschriebenen Pilzen dadurch ausgezeichnet, dass ihre Peridien gestielt sind und das Ende des Stiels sich ins Innere der Peridie, meist bis zu ihrem Scheitel fortsetzt, als Mittelsiule, Columella. Von dieser strahlen die Kammerwande der Gleba aus. Ueber die Entwickelumg dieser Pilze kennen wir nur einige auf Secotium bezigghliche Daten dureh Tulasne, nach denen besagte Gattung als eine gestielte und mit Mittelsäule versehene Hymenogastree kurz bezeichnet werden kann. Die übriggen Gattungen schliessen sich, den vorhandenen Beschreihungen nach, theils an die mit Capillitium und rergainglicher Trama versehenen, theils an diejeniggen der oben beschriebenen Gastromyceten an, bei denen die Tramawände vertrocknend persistiren und das Capillitim fehlt. Die meist höehst eigenthümliche gröbere

Fig. 33. Tulostoma mammosun Fr. Natürl. Grösse, axiler Längsschnitt, nach Vittadini copirt. a vor streckung der Stielanlage, Gleba im Scheitel die dunklere Färbung der Reife annehmend. $\delta$ nach Beginn der Stielstreckung. 
Organisalion der hierher gehörenden Formen ist aus den unten zu citirenden Beschreibungen und Abbildungen, auch aus den schönen Copien letzterer in P'ayer's Bolanique cryptoganique zu ersehen. Die feinere Structur zeigt bei den mir bekannten wenig Bemerkenswerthes. Nur das Capillitium scheint auch hier wiederum bei manchen (iallungen ganz besondere Eigenthümlichkeiten zu besitzen. Bei Podaxon spec. ${ }^{1}$ fand ich dasselbe aus sehr derben, braunhaiutigen Röhren zusammengeseizt, welche gewunden, reich rerzweigt sind und einerseits von den IIyphen der Columella entspringen. in Lebrigen aber zu einer ununterbrochenen, netzförmigen Röhre verschmolzen sind. Nirgends fand ich eine Querwand und nirgends ein freies, blindes Astende.

Besser als über die Podaxineen sind wir über Structur und Entwickelung der Phalloideengruppe orientirt. Ohne hier auf alle einzelnen Genera eingehen zu hönnen, will ich die beiden Extreme der reichen und wunderbaren Formenreihe, Phallus (impudicus und caninus und Clathrus kurz besprechen. Aus den vorhandenen Beschreibungen und Abbildungen (zumal Corda, Icon. V, VI lisst sich mit sicherheit entnehmen, dass die iibrig̣en Genera, bei aller Mannigfaltigheit ihrer (iestaltung: im Wesentlichen iilsereinstimmenden Entwickelungrsgang und Organisation zeig̣en.

Jir Fruchltriger von Phallus Fig. 34 entstehen als ovale, etwa $1 \mathrm{Mm}$. grosse Anschwellungen an den Myceiumsträgen und bestehen zuerst aus einem

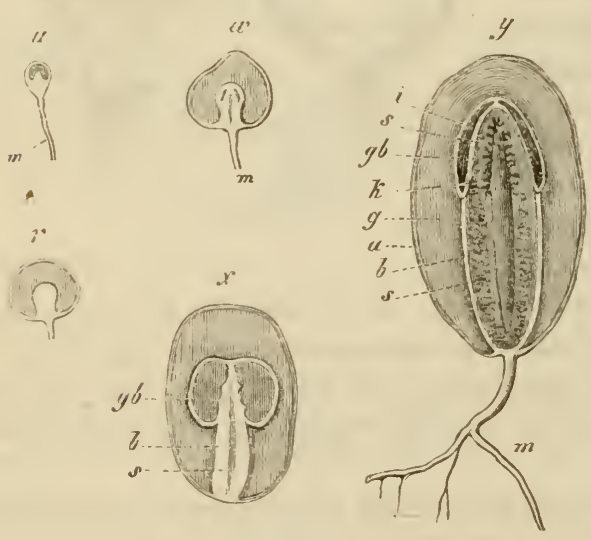

Fig. 34 yleichförmigen, diehten, lufthaltigen Geflecht sohr zarter primiliver Ilythen. In grösser ge"ordenen Exemplaren diflerenzirt sich dieses zunachst in eine kuppelformige, vom Insertionspunkte aus sich senkrecht chebende Millelsiule, eine die letztere umhüllende, glochenförmige Schichte ron Gallertfilz - Gallertschichte - und eine die letzlgenannte umgebende, an der Insertionsstolle in die Mittelsiule uberyedrende weisse Haut, die aussere Peridienwand. Die beiden letztgermannten Theile bestehen aus dem primitiven Gewebe, Mit der weileren Vergrösserunğ, bei welcher der ganze Körper schmalere Eiform erhält und dussenwand sowohl wie Gallertschicht unter gleichbleibender Struclur an

Fig. 34. Phallus caninus, junge fruchtträger zum Theil dem Mycelium (m) aufsitzend, avile, senkrechte Längsschnitte, naturl. (ir. Entwickelungsfolge nach den Buchstaben $u-y$; y nor n nicht vollig erwachsenes, doch sporenreifes Exemplar. a Aussenwand, $i$ Innenwand, $y$ Ciallertschicht der Peridie. $b$ Basalstuck, $k$ hegel, $s$ Stiel, gb Gleba.

1) Ms Podaxon carćinomatis bezeichnet, am Cap von Drège gesammelt, im Kunze'schen Herbar. Die Bestimmung ist mir zweifelhaft, weil sich zwei sehr verschiedene Formon mit derselben Bezeichnung in genannter Sammlung befinden. 
Umfang und Diche zunchmen, nimmt die Mittelsiule die Gestalt eines runden, von cylindrischem Sticl getragenen kopfes an. Hhr zunichst gleichförmiges primitives Gewebe differenzirt sich dabei in die Gleba, das den Phalloideen eigenthïmliche, im vorliegenden Falle einen einfachen spindelförmigen Stiel darstellende Receptaculum dieser, und eine die genannten Theile umziehonde weisse Haut. Diese bildet die innerste Schichte der Peridie, welche letztere somit aus drei concentrischen Lagen besteht: der weissen Aussen - und Innenhaut, welehe an Grunde ineinander ïbergehen, und der zwischen beiden liegenden, weit mächtigeren Gallertschicht. Die Gleha liegt in dem hoplförmigen oberen Theile der Miltelsiiule, in Form eines dichen, auf dem senkrechten Durchschnitt halbhreisfömnigen, horizontal stehenden Ringes, welcher aussen von der inneren Perielienlatut umzogen wird und mit seiner, Innenfliache rinem kegelförmigen, avilen Stiiche der Millelsiule anliegrt. Dieses Stück, welches hurz als Kegel hezeichnet sein hag, geht dureh die ganze Gleba hindurch bis zum Scheitel der Mittelsiule. Die Structur der Gleba grleicht der der anderen Gastromyceten. Thre Kammern sind sehr zahılıeich und eng, die Trama

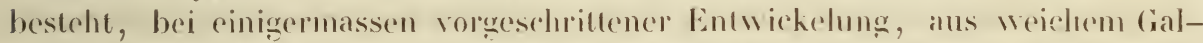
lertgewele, ihre Platten entspringen einerseits von der inneren Peridienwand,

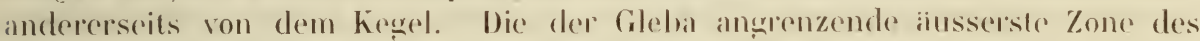
letzteren spalted sich bei Plo. impudicus frible als besondere schichte von dem

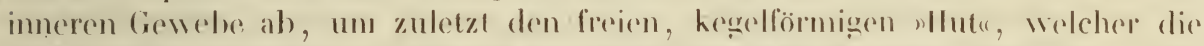

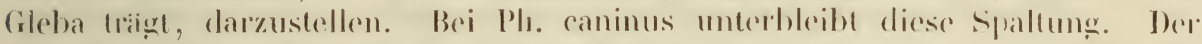

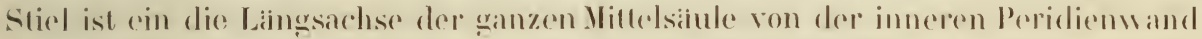
his gegen die Basis hin durehzielunder, erst sehe schmal, spizter breiter spindelförmiger körper. Scine erste Anlagere erseheint als ein durehscherinender

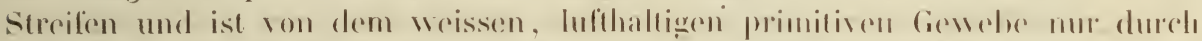

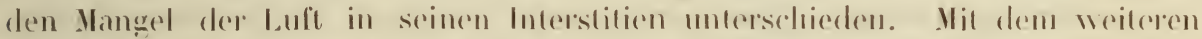

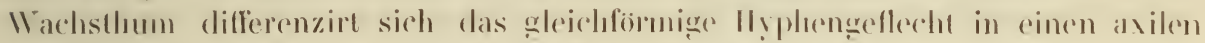

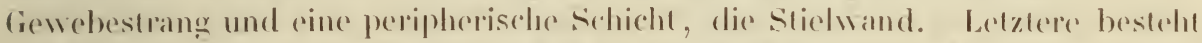

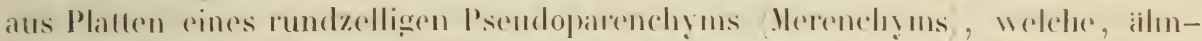

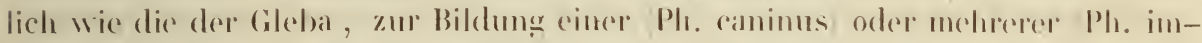
pudicus Schichten ringsum geseshlossener Kanmmern mil einander verbunden

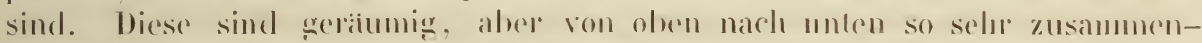

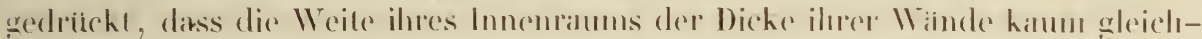

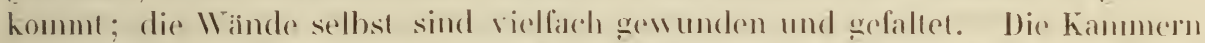

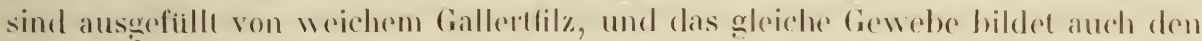
avilen Strang des stieles. In dem obersten Ende ist die sticluand nur mil

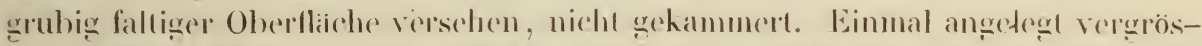
sert sich der Stiel ggewaltig̣, das Jlerenchỵm seiner Wand von dem Zeitpunhte an, 1 o es deutlich unterschieden wird, nur durch Ausdehnung seiner Zellen, die übrigen Theile wohl anch durelı Bildung nener Formelemente. Yit der gewaltigen Vergoosserung des Stiels hialt das Wachsthum der beiden iussoren Schichten und der Innemwand der Peridie, soweit sie die Gleba umgibt, gleichen Sehritt. Das Gewebe des Kogacels und des unterhalb der Gleba befindliehen Theiles der Mittelsäiule nimmt dag̣egen in dem Maasse an Maichtigheit ab, als der stiel sich ausdehnt. Bei Pli. caninus stellt es zuietzt nur noch eine dünne, weisse Ilaut dar; hei Ph. impudicus bleibt es unterhalb der Gleba michtig̣er, 
ein napfförmiges, das untere Stielende stützendes Basalstück darstellend, in dem Kegel wird es gleichfalls zu einer diunnen, weissen Haut ausgedehnt. Die Gleba, in welcher mit der Dehnung des Stiels die Sporenbildung ihr Ende erreicht hat oder demselben nahe ist, wird bei Ph. caninus zu einer dünnen, den oberen Theil des Stiels dicht unter der aussersten Spitze überziehenden, kegelförmigen Schichte ausgedehnt; bei Ph. impudicus vermindert sich ihre Dicke im Verhältniss zu der Ausdehnung ihrer Oberflaiche weniger, die Fïden der Trama zeigen selbst ein actives Wachsthum durch Ausdehnung ihrer Zellen. In der Structur der den Stiel umgebenden Theile tritt während dieser Vergrösserung ausser einer deutlichen Grössezunahme der Hyphen keine hier erwihnenswerthe Veränderung ein. Die Merenchymzellen des Stiels bleiben stets zartwandig und von wisseriger Flüssigkeit erfüllt. Zuletzt steht alles Wachsthum durch Ausdehnung vorhandener oder Bildung neuer Zellen in allen Theilen still. und nun erfolgt eine plötzliche Liingenstreckung des Stiels : dieser drängt die auf seiner Spitze befestignte Gleba gegen den Scheitel der Peridie, durchbricht diesen und hebt die Gleba weit über denselben empor. Die Langenstreckung erfolgy lediglich dadurch, dass die gefalteten Merenchymplatten seiner Wand aufgerichtet und geglättet werden, bis die IIöhe der Kammern ihrer Breite wenigstens gleich ist. Und zwar geschieht die Aufrichtung der Kammern indem sie durch Ausscheidung von Luft in ilırem Innern gleichsam aufgeblasen werden. Der Gallertfilz, welcher sie anfangs erfüllt, zerreisst und verschwindet, und auch der axile Gallertstrang wird zerrissen und durch Luft ersetzt. Bei Ph. impudicus findet dieser Process an allen Punkten gleichzeitig statt, bei Ph. caninus beginnt er oben und schreitet langsam gegen das untere Ende fort. Mit der Streckung des Stiels reisst die innere Peridie von Ph. caninus unter der Gleha ringförmig durch, ilı oberes Stück sammt dem Reste des Kegels wird mit dieser emporgehoben, das untere bleibt rings um die Stielbasis stehen. Bei Ph. impudicus reisst auch die innere Peridienwand an ihrem Scheitel, die Gleba spaltet sich von ihr al, und tritt aus ihr hervor. Ein ringförmiger Querriss im unteren Theile des Kegels trennt das um die Stielbasis stehen bleibende, napfförmịge Basalstuck von der oberen Portion; diese wird in Fetzen zerrissen, der Hut. weleher die Gleba triggt, hieldurch von dem Stiele getrennt, mit Ausnahme seines oberen, der Stielspitze fest angewachsenen Randes.

Es ist aus den Beschreibungen genugsam bekannt, dass die ins Freie getretene Gleba in Folg̣e eines Zerfliessens ilnes Gallertgewebes als eine die Sporen enthaltende sehmierige Masse ron ihrem Triger abtropft. BeiłPh. caninus nehmen der kegel und der die Gleba überziehende Theil der inneren Peridienwand an diesem Desorganisationsprocess Theil, sie werden schon ror dem Zerfliessen jener unkenntlich. In Betreff weiterer Einzelheiten und Artunterschiede rerweise ich auf die unten anzuführenden ausführlicheren Arbeiten und die Beschreibungen in den systematischen Werken.

Clathrus stimmt, wie seit Micheli bekannt ist, mit Phallus überein in Beziehung auf die Beschaffenheit der Gleba und der Peridie. Das Receptaculum aber, welches jene aus letzterer hervorhebt, hat die Form eines grobmaschigen, je nach den einzelnen Arten verschieden gestalteten, die Aussenfliche der Gleba umgebenden Netzes oder Gitters. Wie wir besonders durch Tulasne-Expl. sc. d'Algérie wissen. beginnt die Entwickelung dieser Theile auch hier mit einer 
Sondlerung des gleichförmigen Gewebes des jungen Fruchtkörpers in Mittelsäule. Gallertschicht und äussere Peridienwand. Ton letzterer gehen netzörmig anastomosirende, plattenförmige Fortsätze zur Oberfläche der Mittelsäule, die Gallertschichte wie Septa durchsetzend. Die Mittelsiule differenzirt sich zunächst weiter in die innere Peridienwand, die Gleba und einen rundlichen, knorpeligg geclatinösen, axilen Gallerthörper. Letzterer nimmt den unteren, centralen Theil der Mittelsäule ein, seiner Stellung nach entspricht er dem Kegel ron Phallus; an seinem Grunde sitzt er der Peridie auf und goht in diese ïber. Seine ganze Oberfläche mit Ausnahme der Insertionsstelle wird ron der dicken Gleba überzogen: die Tramaplatten dieser entspringen allenthalben ron dem Gallertkörper, der Limfang desselben erscheint daher auf dem Durchschnitte mit zahlreichen, in die Gleba strahlig einspringenden, ungleichen Fortsätzen und Zacken versehen. Wo die ron der Aussenwand der Peridie ausgoghenden Septa auf die Innenwand treffen, ist das weisse primitive? Gewebe dieser in bestimmten, netzörmig anastomosirenden Streifon machtiger als in den Zwischenriumen zwischen letzleren. In diesen Streifen entstehen nach Anleg̣ung der Gleba die Theile des gitterfömigen Receptaculums. Mit der Reife dehnt sich dies gewaltig und tritt aus der aufreissenden Peridie weil hervor. Die Gleba sitzt dabei dem obersten Theile seiner Innenfliche an; wie bei Phallus zerfliesst ihr gallerliges Gewebe bald zu einer mit den Sporen abtropfenden Schmiere. Der Bau des fortigen Receptaculums gleicht, wie besonders Cordas I)arstellungen zeig̣en, dem ron Phallus so sehr, dass eine Uebereinstimmung der Entwichelung seiner Gewehetheile und seines Austehmungsmechanismus mit den fiir letzlgenannte Gattung beschriebenen haum zweifelhaft ist, obghleich directe Beobachtungen hierüber fehlen.

Noch mehr als die Phalloideen entfernt sich die Gruppe der Tidularieen

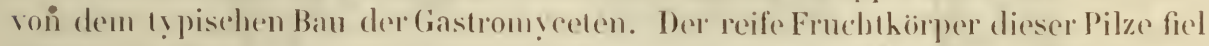
schon den Vitcron der heutigen Botanih auf. da er einen mit wenigen Ausnah.men offenen Becher darstelle, in welehem meist 10-20 linsenförmigye. samen-

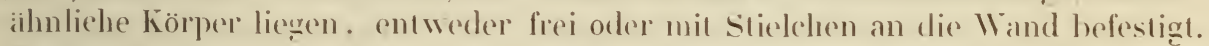
Den Becher bezeichnet man jetzl als Peridium. die samenihnlichen Körper als Peridiolen oder sporangen, ihr Slielehen als Funieulus. Teher die Entwichelung der Nidularieen haben wir durch schnitz. Tulasne und Sachs Aufschluss erhalten. Von der Arbeit des Letzleren sollen die Resultate hier hurz mitgetheilt werelen, theils weil sie die neneste und vollskindigste ist, heils weil Crueibul um vulgare Tul. , mil dem sie sich beschififiğgl, zwischen den ülorig̣en Nidularieenformen in der Mitte steht und daher ein besonders geergunetes Beispiel fiur

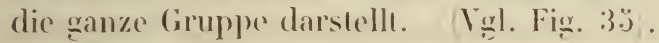

Die Fruchtkörper der qenannten . Irt entstehen als kuggelformige Körperchen dureh reichliche Wucherung und Verflechtung der Fialen des flockiggen, bald schwindenden Myeeliums. Sie bestehen der Hauptmasse nach aus einem dichten, lufthaltigen und daher weissen Geflecht istiger prinitiver Ilỵphen, deren peripherische Zweige sich in Form arabeshenartig veräistelter, braunhäutiger Haare ïber die Oberfliche erheben. Durch andauernde Veubildung in ihrem primitiven Gewelbe wächst die Kugel und nimmt allmählich die Form eines etwa 6 Mn. hoch werdenden, hurzen Cy linders an. Der breite Scheitel dieses bleibt hierbei von den verzweighten Haaren bedeckl, es werelen von letzteren wenig 
oder keine neue gebildet, die erstvorhandenen rücken daher immer mehr und schliesslich so weit auseinander, dass das tiefer liegende weisse Gewebe zu Tage tritt. Unterhalb des Scheitels entsprossen der sich verọrössernden Peripherie radial abstehende braune Fäden, welche miteinander die iusseren Schichten der Peridie bilden, nimlich einen dichten, die Oberfliche iiberziehenden Haarfilz und eine innerhalb dieses liegende, dichter verflochtene Schicht, die Aussenschicht der Peridie. Während dieser Veränderungen tritt im Innern des Körpers eine theilweise Umwandlung des weissen Primitivgewebes in luftfreien Gallertfilz ein. Ausgenommen von dieser bleibt erstlich eine den ganzen Körper umziehende, der iusseren Peridienschicht anliegende, vorzugsweise parallel der Oberflache gefaserte dünne Lage; sie stellt die Innenschicht der Peridie, und aul dem Scheitel des Körpers die von dem rerschwindenden Haariiberzug bekleidete, später selbst rerschwindende Deckelhaut Epiphrag̣ma dar. Ferner bleiben von der besag̣ten Emwandlung ausgenommen eine Anzahl runder, im Innern gelegener Portionen, die Anlagen der Sporangien, und ein ron jeder dieser letzteren zur Peridie verlaufender II! phenstranğ,
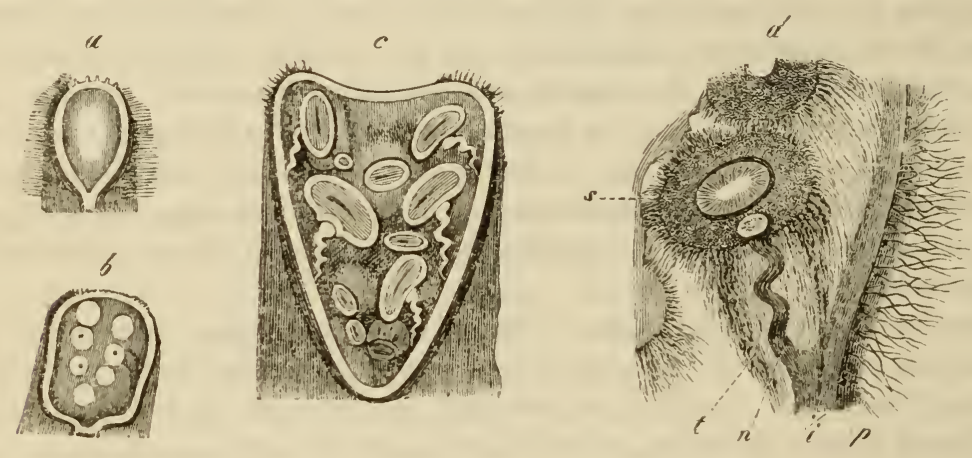

Fig. 35 .

die Anlage des Funiculus. Letzterer verliuft Anfangs in der Vittellinie einer

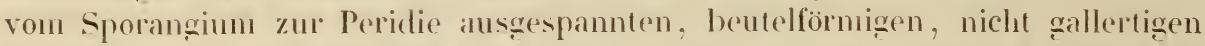
Schichte, welche jedoch spaiter gyleichfalls in Gallertgewebe umgewandelt wird. In der Mitte der Sporangِumanlag̣en bezeichnet ron Infang des Lmwandlumg̣sprocesses an eine runde Gallertmasse die Stelle der künftigen Höhlung des Sporangiums; und eine ebensolche, heine Masse liegt an der Insertion des Funiculus in letzteres; sie ist die Anlage des spiteren "Nabelbuischelsis, der einzigen bis nach der völligen Reife dauernden Gallertfilzportion. Der ganze Process, durch welchen sich die Theile aus dem primordialen Gewebe gleichsam herausmodelliren, begiint im Grunde der Peridie und schreitet langasam gegen

- Fig. 33. Crucibulum vulgare Tul. $a-c$ radiale Längsschnitte, schwach verğ. in reflect. Licht, $a, b$, junge Fruchthorper, in $b$ erste Anlage der Sporangien. $c$ älterer Fruchtkörper, fünf sporangien ungefahr in der Mitte durchschnitten. $d$ dünner Längsschnitt durch ein Stuck eines etwas junğeren körpers als $c$, stärker vergr., in durchfallendem Lichte. $p$ äussere, $i$ imnere Schicht der Peridie, $n$ Funiculus, $t$ der ihn ungebende transitorische Beutel. s Sporan⿳亠丷ium, das durchscheinende Gewebe ist Gallertfilz. - Nach Sachs copirt. 
den Scheitel hin fort. Einmal angelegt wachsen alle Theile in ihrer besonderen Weise. Die Sporangien nehmen linsenförmigre, an der Insertionsstelle des Funiculus genabelte Gestalt an, ihr Anfangs gleichförmiges Gewebe differenzirt sich in drei concentrische Schichten, und ron der innersten dieser sprossen die Elemente des Iymeniums, wie bei anderen Gastromỵceten, in den durch Verschwinden des Gallertfilzes leer gewordenen Innentaum. Der Funiculus nimmt, wohl durch Einschiebung neuer Hyphenzweige, grössere Dichtigheit an; er strecht sich zugleich in die Länge und erhialt korkzieherartige Krimmungen. Die Peridie nimmt an Lmfang zu; das ihren Scheitel bedeckende Epiphragua hört zuletzt auf, ihrer Ausdehnung zu folgen, zerreisst und rerschwindet. (Bleichzeitig wird der ini Innorn befindliche Gallertfilz zerrissen und durch Vertrochnen unkenntlich, die bekannte Form und Structur des reifen Pilzes ist somit hererestellt. Aus Tulasne's Mitheilungen geht hervor, dass die Entwichelung von Cyathus mit Crucibulum im Wesentlichen durchaus übereinstimmt und das Gleiche darf für Nidularia angenommen werden. nur dass hier der Funiculus, wenịstens bei der Reife, ganz fehlt. Von den fertig̣en Theilen des Fruchttriggers zeig̣t der Funiculus einig̣e besonders erwähnenswerthe Structureig̣enthümlichkeiten. Bei Crucibulum besteht derselbe aus einem Strange paralleler, derbwandiger Ilyphen, welche beim Befeuchten weich und in geringem Giade dehubar werden. Einerseits inseriet er sich der Peridie, andererseits der nabelfiormigen Verticfung an der Oberflache des Sporangims. An der letzteren

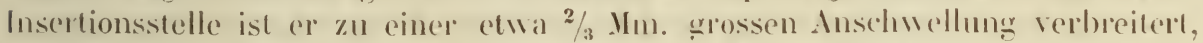
wolche oben Nabelbibchel genannt worden ist. Dieses besteht aus ciner beutelförmigen äusseren Lage, welehe von festen, strafl vom Funiculus zur sporan-

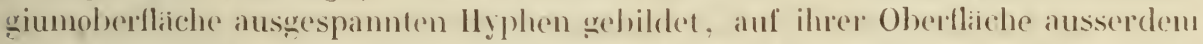

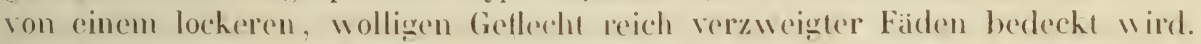
Der Beutel unsehliesst einen Strang langer, dimner, rew\%eigter Fäden, die einerseits dem Sporangium, andererseits dem firmude des Beutels angewachsen und, vielfach hin- und hergebogen, zu einem in Gallerte ringebelleten, dichten

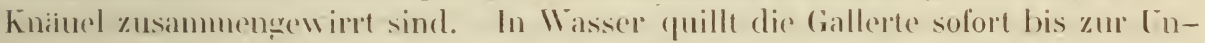
kemullicheit auf. Wird der befenchtete Bentel verlet\%t, so quillt das hinäuel

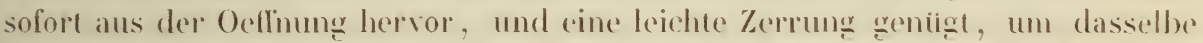
zu einem 3-i. Cim. langen, feinen, fadenförmiggen strange auszustrechen. Etwas complicirter noch und, wie Tulasne gezegot hat, nach den Arten rersehieden, ist der Funiculus bei Cyathus geboutut. Beri C. striatus \%. B3. hat er eine

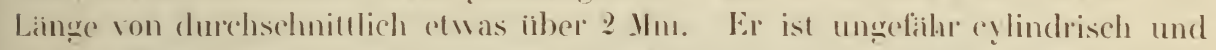

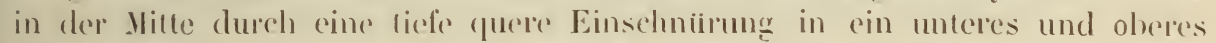
stiich getheilt. Jenes und das diinne Mittelstich besteht aus einem feflechte reich veristelter, dichwandiger aher foiner Ilyphen, welehes trochen sprörle. befenchtet zishe und his auf etwa die doppelte Liinge ausdehnhar ist. Das obere Stuich stellt cinen $10 m$ unteren zur Sporangiumwand ausgespannten. in diese iibergehenden Beutel dar: in diesem liegt ein aus feinen parallelen H! phen bestehender

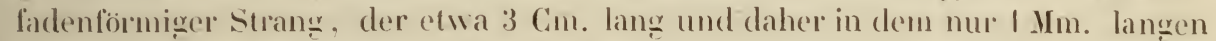
Raume des Beutels in zahlreiche Windungen gelegt ist. Was obere Ende des Stranges ist dem Sporang̣ium inserirt, das untere geht in cin Knauel ubber, welches dem im Vabelhuischel von Crucibulum befindlichen gleich, von Gallerte umhiullt und in das etwas angeschwollene untere Ende des Beutels einge- 
schlossen ist. Die Wand des Beutels ist dem unteren Stiucke des Funiculus im Wesentlichen gleich gebaut. Der ganze Körper ist im trockenen Zustande ziemlich spröde. Durch begierige Aufsaugung von Wasser schwillt er an, wird weich und biegsam; der gewundene Strang lässt sich nach Zerreissung des Beutels zu seiner oben bezeichneten Linge ausstrecken, ohne erheblich über diese hinaus gedehnt werden zu können; das Knäuel am Grunde verhält sich dem von Crucibulum ganz gleich, durch leichte Zerrung werden seine Hyphen in dem Maasse gestreckt, dass der ganze Strang auf eine Länge ron $8 \mathrm{Cm}$. ausgezogen werden kann. Die Hyphen des streckbaren Gewebes der Funiculi sind dünn und mit meist bis zum Yerschwinden des Lumens verdickten Wänden versehen. Sie bestehen aus langen Gliederzellen, die mit angeschwollenen Enden aufeinanderstehen und an diesen die in Iten Capitel Seite 1:5) erwähnten eigenthümlichen Schnallenbildungen zeigen. -

Vergleicht man die Nidularieen mit den typischen stiellosen Gastromyceten, so ist eine Uebereinstimmung in dem Entwickelungsplane unverkennbar, die Nidularieen im Grunde nur durch die geringe Zahl und Weite ihrer durch relativ sehr dicke Wande ron einander getrennten Kammern ausgezeichnet, und dadurch, dass mit der Reife der in Gallertfilz ungewandelte Theil der Gleba rerschwindet, die Kammern der Gleba hierdurch zu den getrennten Sporangien werden.

Bei den Nidularieen sowohl wie den Phalloideen tritt besonders deutlich hervor, wie die verschiedenen Theile des reich gegliederten Fruchtkörpers dadurch entstehen, dass verschiedene Regionen eines ursprünglich gleichförmigen, primitiven Hyphengeflechtes verschiedene Structur annehmen und dann, jede in ihrer besonderen Weise, zu den dauernden oder transitorischen Organen des Pilzes heranwachsen. Es mag hier nochmals daran erinnert werden, dass der gleiche Vorgang bei der Anlegung des Fruchtkörpers sainmtlicher Gastrom yceten und der beschleierten Hymenomyceten stattfindet.

Leber Sphaerobolus kennt man zur Zeit, ausser einigen guten anatomischen Details, welche Corda Ic. V, p. 66 gegeben hat, und der von Tulasne und Bonorden gleichzeitiq gefundenen Thatsache, dass seine Fructification mit der der Gastromyceten übereinstimmt, nicht viel mehr, als die ersten Beschreibungen besağen. Auf diese möge daher verwiesen werden, bis die Entwick lungsgeschichte des interessanten Pilzes eine vollstindigere Bearbeitung findet.

\section{Fruchtträger ron Elaphom çes und den Tuberaceen.}

Die reifenden Fruchtkörper von Elaphom y ces ${ }^{1}$ zeigen eine dem gleichnamigen Organe der Gastromyceten entsprechende uberall geschlossene Peridie, welche aus zwei mehr oder minder scharf hervortretenden, übrigens immer fest miteinander rerbundenen Schichten besteht. Die innere derselben (Peridium im engeren Sinne nach Vittadini ist ein machtiges, aus dicht verfilzten, manchmal sehr derbwandigen Hỵhen zusammengeflochtenes Ge-

1) Die sich hier anschliessende kleine Gattung Onygena sowie die ungenügend bekannten Formen, welche als Cenococcum und Endogone bezeichnet werden, lasse ich hier unberücksichtigt. 
webe. Die iussere (Cortex Vittad.) ist dünner, je nach den Arten von verschiedener Consistenz und entweder glatt oder warzig, haarig. stachelig. Ihr Bau wechselt gleichfalls nach den Species und ist für die meisten derselben noch nicht genauer beschricben. Bei E. granulatus ist sie hart, spröde und mit Warzen dicht besetzt; die Mitte einer jeden dieser besteht aus einer kegelförmigen Gruppe unregelmassig gestalteter und mit uberaus stark verdickten, lebhaft gelben Winden verschenen Zellen. Die Basen dieser Kegel sitzen der Innenschicht unmittelbar auf und berühren einander seitlich. Die Zwischenräume zwischen den Kegeln und die Gipfel derselben werden theilweise ausgefüllt, beziehungsweise bedeckt von einem lückenlosen, aus vielen zur Oberfliche concentrischen Lagen vierseitigy prismatischer Zellen bestehenden Gewche: imnerhalb einer jeden Lage sind die Zellen in Reihen geordnet. Welche von jedem Kegel aus strahlig divergiren und in den Zwischenriiumen mit den von benachbarten Kegeln ausstrahlenden zusammenstossen. Ein der Oberfliche paralleler Schnilt ist somit aus zierlichen, von strahlig̣en Zellreihen gebildeten rundlichen Facetten zusammengefiigrt, deren jede in ihrer Mitte eine Gruppe derber lebhaft gelber Zellen zeig̣t.

Von der Peridic entspring̣t allenthalben cin den Innenraum durchsetzendes, locker verfilztes Geflecht-dünner langghliederiger Hyphen; hie und da sind diese, zumal bei jüngeren Exemplaren, wohl zu grösseren. von der Peridie nach innen vorspringenden Platten oder stringen dichter vereing gavg eine in abgeschlossene Kammern getheilte Gleba ist jedoch nicht rorhanden. Die Luicken des

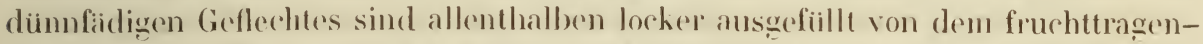
den Gewebe: Ilyphen, die zwoi-bis dreimal dicker als die ersterwihnten. kurzgliederig, vielfach geckinmmt zu knzimehn verflochten sind und an ihren

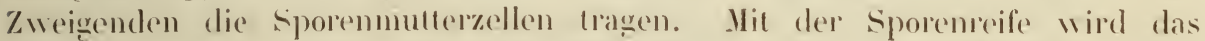

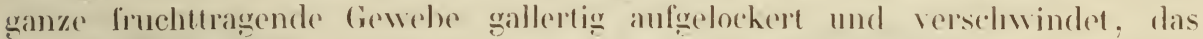
diumnfiidigge Geflecht bleibt als zartes Cappillitium zwischen dem trockenen, massigen sporenpulver zuriich.

Die Fruchthörper der t!pisehen Tuberaceen haben bekamtlich die Gestalt

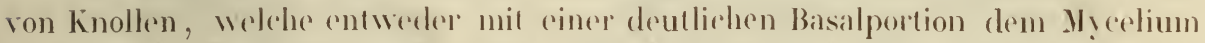
aufsitzen \%. B. Terfezial, Delastria obler \%. B. Tuber in der Jugend ringsum

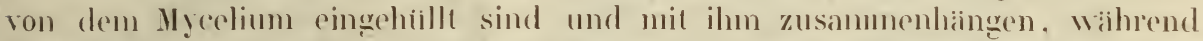
dasselbe zur Zeit der Reife versehwunden ist und der Fruchthörjere alsdamn nackt und frei im Boden liegrt.

Ihre Oberfliche ist entweder abgesehen von den vielfach vorkommenden Warzen und Rauhigheiten glatt und nur mit ganz unreg̣elmassig̣en, so zu sag̣en zulaillig̣en garösseren Inebenheiten verschen z. B. Tuber aestivum, melanospermum u. s. w., Terfezia) oler sie zeigen typische, grubigge Vertiefungen oder enge und tief rinspringende, ğgrös gewundene Furchen z. B. Ilỵdnobolites, Genabea . Der Fruchthörper besteht im einfachsten Falle, nimulich bei Hỵdnobolites, aus einem fleischigen, von dicht rerflochtenen It!phen gebildeten Gewebe, dem allenthalben zahlreiche, den Hyphenisten aufsitzende Sporenmutterzellen eingelagert sind; nur die oberflichlichste Gewebeschicht stellt eine Art Peridie dar, einen zarten, aus sterilen Hyphen bestehenden Flaum.

In einer zweiten Reihe von Formen unterscheidet nan eine sterile Grundmasse und zahhreiche dieser eingebettete Gruppen oder Nester fruchttragenden 
Gewebes. Letzteres besteht aus einem mehr oder minder dichten Hyphengeflechte, welchem die ron den Zweigenden entspringenden Sporenmutterzellen in grosser Zahl ordnungslos eingebettet sind. Jenes füllt die Räume zwischen den fertilen Gruppen aus in Form breiter, weitaus dic IIauptmasse des Körpers bildenden Streifen Genabea oder rolativ schmaler Platten, welche auf Durchschnitten das Bild reich und oft fein verzweigter Adern gewaihren (Terfezia, Delastria). Aussen wird der Körper von einer rerschieden dicken Lage sterilen Gewebes als ron siner Peridie umzogen, von der die Adern und Streifen im Innern entspringen: die Iyphen der fertilen Gruppen nehmen von den ang̣renzenden sterilen ihren Ursprung.

Ein dritter Typus wird dureh die Gattung Balsamia dargestellt. Die Oberfliche des Körper's wird hier ron einer dicken, überall geschlossenon Peridie umzogen, und der Innenraum ist in viele eng gewundene, luftührende Kammern getheilt mittelst dicker Gewebeplatten, welchè ron der Peridie entspringen gleich den Kammerwänden der Hymenogastreen. Wie bei diesen ist die Wand der Kammern mit einer Ilỵmenialschichte ausgagkleidet, deren Elemente ungefihr senkrecht auf jener stehen.

Eine ihnliche Structur wie die soeben beschriebene kommt der Gattung Tuber, oder doch weniggstens mehreren Arten derselben T. rufum, mesontericum, excavatum u. a., Tulasne f. hyp. Tab. XVII, XVIII in der Jugend zu, nur dass dio Kammern sehr eng und ungemein roichlich gewunden und rerzweight sind. Schon in frühen Stadien wachsen aber IIyphen des angrenzenden Gewebes in den Raum der Kammern hinein, um denselhen rollstindig auszufüllen in Form eines dichten, in den Interstitien lufthaltigen und daher weissen

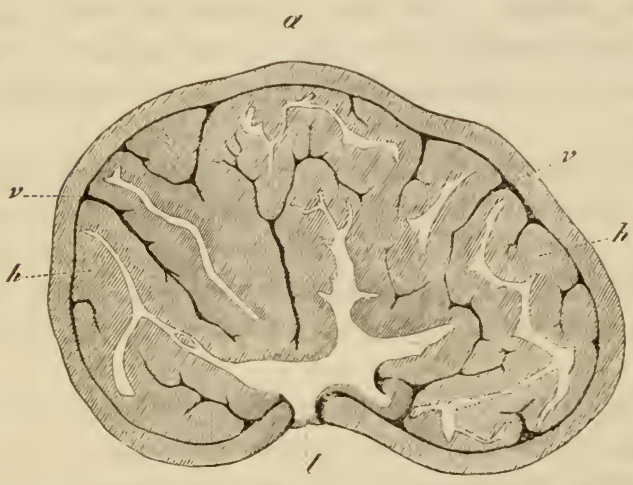

Fig. 36 .

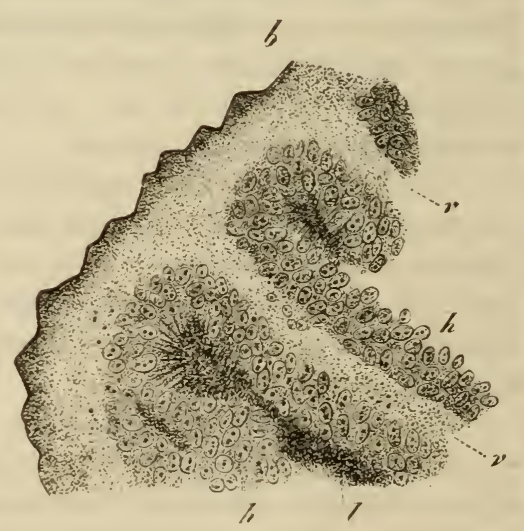

l,

Geflechtes. Gleichzeitig nimnt die Hymenialschichte der Kammerwände an Dicke betrichtlich zu und erhäl die Beschaffenheit eines massigen, allenthalben sporang̣ien trag̣enden, unordentlichen Geflechtes. Die Trama der Kammer-

Fiğ. 36. Tuber rufum Pico. Nach Tulasne fung. hỵpogr. a kleines Exemplar, halbirt, šmal vergr. in reflectirtem Lichte. Die weissen Adern, $l$, luftfihrend, die schwarzen, $v$, flussiğkeitfihrend. h Hymenialgewebe. $b$ diimer schnitt durch ein junges Exemplar, bei durchfallendem Licht, I omal rers. Buchstaben wie in $a$. 
wände behält bei manchen Arten ihre ursprügliche Beschaflenheit bei. Diese Verhälnisse bedingen das characteristische, marmorirte Aussehen des Durchschnittes oiner reifen oder reifenden Trüflel Fig. 36; : in einer dunkelfarbigen Grundmasse, dem fruchttagenden Geflechte, verlaufen zweierlei verzweigte Adern, dunkel gefiirbte und daher wenig aulfallende, welche der Trama entsprechen und keine Luft enthalten (Venae Iymphaticae, Veines aquiferes Tul., Venae internae Vittadini und weisse, luftführende Veines aerriferes, Venae externae. Erstere entspringen immer von der Innenfliche der Peridie. I.elztere und wahrscheinlich schon die Hohh:iume, durch deren Ausfülung sie entstehen, reichen an einzehnen Stellen bis zur Oberfliche der Peridie, münden dasellsst gleichsam nach aussen; und \%war geschieht dies an ordnungslos ïber die Oberdiache zerstreuten Orten, oder so. dass sich die Adern von allen Seiten her in einen an einem bestimmten Punkte des Lmfanges mündenden llauptstrang vereinigen. Manche Tuberarten \%. B. T. dryophilum, rapaeodorum lassen nur Luftadęrn in der überall gِleichmissigg von Sporemmutterzellen durchsetzten Grundmasse unterscheiden: wenigstens in ihren bis jetzt behannten Entwichelunğssitaclien.

Was den feineren anatomisehen Bau der Tuberaceen betriff, so ist dem Gesagten noch hinzuzufigen. dass die peripherische. als Peridie bezeichnete Sehichte eine meist mächtigye; dichte, pseudoparench!matische Gew ebemasse darstellt. Die iusseren Zellenlagen derselhen sind in den meisten Fiallen mit verdickten und der braunen bis schwarzen Farbe der Oberfliche entsprechend gefaiblen Winden versehen, seltner sind sic zarlwandigy und die Oberfliche von abstehenden Ilaten bedecht Tuher rapateodorum u. a.. Mit Ausnahme von Stephensia, deren Peridie scharf ron einander ahogesctze Schichten zeigrt. gehen die ausseren Zellenlag̣en wänz allmihlich in die inneren über und diese ebenso in die zwischen dem fruchthagenden Gewebe verbreiteten sterilen Adern und streifen. Letzlere zeigen entweder Genabea den galeichen, pseudoparenchymatiseden Bau wie die Peridie: oder. in den meisten Fallen. lassen sie, der Trama der Gastromyceten ihnlich, einen Verlauf ihrer Jlyphen erkennen, weleher dem der Adern folph.

Die Tuberaceengattung̣en Ilỵdnoc!stis, Ily dnotria und Genea sind hier unberioksichtigy geblieben. Woil ihre genauere Betrachtung zu sehr in deseriptive Einzelheiten führen wiurle: hier mag̣ die Benterkung genügen, dass sie in ihrem ganzen Bau die Mitte halten zwisehen Tuberaceen und den typischen Discom!ceten.

Leber die orsten Entwiekelungsstadien ron Elaphomsces und den Tuberaceen liegen nur wenigre Beobachtungen vor.

Die jügsten Fruchttrig̣er von Elaphomyces granulatus ${ }^{1}$, welche ich gefunden habe, sind 1\%/2 his 2 Mm. garosse, kugelige körjerchen, welehe im Innern eines dichten, sehmutrig gelben Myeoliums sitzen. Ihre Oberflache ist mit einer Corticalschichte überzogen, welche die gleiche Dicke, Farbe und warzige Oberfliche zeight. Wie bei erwachsenen Exemplaren, und aus einem zartwandig̣en, unordentlichen Pseudiparenchỵm besteht, dessen Elemente vielfach mit

1) Vielleicht besser E. asperulus Vitt., wenn zwischen beiden Arten überhaupt eine Grenze gezogen werden könnte. 
den Myceliumfäden in continuirlichem Zusammenhange stehen. Die Corticalschichte umgibt eine aus dicht verflochtenen, zarten Hyphen gebildete, den ganzen inneren Raum ausfüllende Gewebemasse, welche allenthalben den gleichen Bau, nur in verschiedenen Regionen verschiedene Farbe zeigt; eine kleine, centrale Portion ist weisslich, diese wird umgeben von einer schmutzig violetten Schichte, und eine zwischen letzterer und dem Cortex liegende schmale Zone hat wiederum weisse Farbe. Wie spätere Zustände zeigen, wird die weissliche Centralmasse zum fruchttragenden Gewebe oder der Gleba, das übrige zur Peridie. Die beschriebene Structúr und das Grössenverhailtniss der einzelnen Regionen bleiben die gleichen bis der Körper stark erbsengross ist. Noch grössere Exemplare zeiğen die Gleba in höherem Maasse als die Peridie vergrössert, zwischen den dünnen Fäden ihres ursprünglichen Geflechtes beginnt die Entwickelung des sporenbildenden Gewebes, und bald macht die Gleba weitaus die Hauptmasse des Körpers aus, der allmaihlich bis zu Nussgrösse heranwachsen kann. Während somit der Uinfang der Peridie gewaltig wächst, nimmt ihre absolute Dicke gleichzeitig noch zu, oder doch jedenfalls nicht ab. Die Structur der Innenschicht, insonderheit die Dicke ihrer Hỵphen, bleiben hierbei unverändert; auch die Zellen der Corticalschichte werden nur etwa um die Hälfte grösser, als in dem beobachteten ersten Stadium, die Warzen vermehren sich derart, dass sie bei wenig veränderter Grösse die Oberfliche stets dicht bedecken, und zwar geschieht ihre Vermehrung dadurch, dass sich eine in zwei oder inchrere spaltet. Alle diese Daten zeigen, dass das Wachsthum hier bis in späte Entwickelungsstadien durch eine in allen Theilen gleichzeitig dauernde Neubildung von Zellen geschehen muss.

Tulasne's Darstellungen stimmen mit dem eben Gesagten überein, bis auf die Angabe, dass die jungen Exemplare zuerst hohl sein sollen - eine Differenz, welche vielleicht in Verschiedenheiten der untersuchten Species ihren Grund hat.

Aelmlich wie bei Elaphomyces scheint sieh, nach den wenigen Daten welche wir Tulasne verdanken, das Wachsthum von Tuber zu verhalten. Die Fruchthörper entstehen, wie schon oben erwähnt wurde, im Innern eines Myceliumgeflechtes. Sehon in sehr frühlher Jugend sind an ihnen die verschiedenen Regionen und Gewebe von einander gesondert; bei lanfsamengrossen Exemplaren von Tuber mesenterieun zeigt die Oberflache schon den Bau und die schwarze Farbe erwachsener Exemplare.

Eine vollständig̣e Entwichelungageschichte dieser unterirdischen Gewächse wird wohl auf sich warten lassen, bis es gelungen ist, sie zu cultiviren.

\section{Litteratur}

der Gastromyceten und Tuberaceen.

Micheli, Nov. pl. gen. Phallus. Clathrus.

Vittadini, Monographia Tulueracearum. Mediol. 1831. Mir nur nach den Citaten bei Tulasne bekannt.

- Descr. dei funghi mangerecei etc. Milan. 183 .

- Monogr. Lycoperdineorum. Memoire delle Ac. Torino, Tom. Y, 1842.)

Berkeley, Annals and Mag. of Nat. Hist. 1839 u. Ann. sc. natur. 2e Série. Tom. XII, p. 160. 
Schmitz, Ueber Cyathus. Linnaea Bd. XVI 1842 .

Tulasne, De la fructification des scleroderma comparée à celle des Lycoperdon et des Bovista. Inn. sc. nat. 2e Ser. Tom. XVII.

— Sur les genres Polysaccum et reaster. Ibid. Tom. XVIII (1842).

- Rech. sur l'organis. des Nidulariées. Ibid. 3é Sér. Tom. I (18千4).

- Reclı. sur l'organis. des Onygena. Ibid.

— Description d'une nouvelle espèce de Secotium. Ibid. Tom. IV (1843).

— in d. Exploration scientif. d'Algérie, p. 434, Tab. 23. Entwickelung von Clathrus.) Ueber denselben Gegenstand s. Berkeley, Hookers Journ. of Bot. Vol. IV, p. 68.

v. Schlechtendal u. M̈̈ller, Mitremyces Junghuhnii, Bot. Ztg. 1844, 401.

Bonorden, Iycologische Beobachtungen. Bot. Zeitg. 1851, p. 18. Phallus, Spliaerobolus.)

— die Gattungen Lycoperdon u. Bovista. Ibid. 1857, p. 393.

Rossmann, Beitr. Zur Entw. des Plıallus impudicus. Ibid. 18э3, p. 183 .

Jul. Sachs, Morploologie des Crucibulum vulgare Tul. Ibid. 185 ว.

v. Schlechte indal, Phalloideen. Linnaea Bd. 31 1862). Enthält reiche Litteraturangahen über diesen Gegenstand.

Hoffmann, Icon. analyt. Fungor. II, p. 33 Hymenogaster).

de Bary, Beitr. zur Morphol. u. Phiysiol. d. Pilze, I 1864) Pliallus).

Haupt-Quellenw erke endlich sind:

Corda, Icon. fungorum Tom. II, Y, II und vor allen Tulasne, Fungi hypogaei. Paris 1831.

3. Py reurom cete ir.

Die Pyrenomyceten sind ron ihren nïchsten Verwandten den Discomyceten und Tuberaceen durch dio Conceptacula oder Perithecia Pyrenia nach Walloth ausagezelonet, kleine, krugformige oder rundliche und bei den meisten mit einer engen Oeffinung nach aussen miindende Behiblter, deren einfacher Hohlraum die fiur die Ordnung characteristischen Fortpflanzungsorgane Sporenschliuche enthailt. Diese bilden, oft mit aecessorischen Organen, eine von der Wand entspringende Ilymenialschichte und füllen sammt letzterer den Innenraum ziemlich! vollstiondigy aus, in Form einer weichen Masse, welche der Kern, Nucleus des Peritheciums gemamnt worden ist.

Bei einer Reihe von Formen z. B. Sphaeriae simplices Fries, Pleospora, Capnodium etc.) sitzen die Perithecien frei auf dem fidiggen, meist unscheinbaren Myeelium, einzeln oder gruppenweise, jedes stellt für sich allein einen besonderen Fruchtriger dar. In einer zweiten Reihe Sphaeriae compositae, X!laria, Cordyceps, Ilypoxylon u. s. w.) sind die Perithecien zu mehreren bis sehr vielen der Oberfliche eines gِemeinsanen Trügąers aufgesetzt oder eingesenkt, so zwar dass ihre Mindungen ins Freie sehen.

Der gemeinsame Trigger, Stroma genannt, hat in den meisten Fibllen polsterförmigge, in anderen aber auch die Gestalt einfacher oder verzweigter, stiel- und strauchförmiger Körper, Becher, u. s. f. Seine Structur und Entwichelung gleicht, wenn man von den Perithecien absicht, im Allgemeinen vollstiindig den g̣mnocarpen Fruchttriggern; das Spitzenwachsthum der stielförmigen Stromatia ron Xylaria ist schon 1843 Limnaea Bd. 17 ron Schmitz durch "renaue Messungen nachgewiesen worden; für die übrigen fehlt es noch an 
genauen Entersuchmoen ïber die Art ihres Wachsens. Was die Structur betrifit, so ist die Mehrzahl der Stromata fest, wasserarm, ihre Zellmembranen derb und entweder in dem ganzen Stroma oder nur in der Corticalschichte verholzt, spröde und lebhaft, meist braun oder schwarz gefirbt, kohlig, carbonaceae, nach dem üblichen Terminus. Fleischige Stromata kommen nur wenigen Genera (z. B. Cordyceps) zu.

Das Perithecium ist mit einer Wand rersehen, welche aus einer rerschieden grossen Anzahl zur Oberfliiche concentrischer, fest verbundener Zellenlagen besteht, entweder einem dichten Geflechte deutlich unterscheidbarer Hỵphen, oder anscheinend ordnungslosem Pseudoparenchym, Die freie, nicht einem Stroma ringesenkte Perithecienwand lisst zwei Schichten unterscheiden, die jedoch allmählich ineinander überzugehen pflegen: eine aussere, aus derbwandigen Zellen. welche je näher der Oberfliche um so grösser sind, und eine innere, aus meist kleineren und stets ibleraus zarten, farblosen Zellen gebildete, welcher die Bestandtheile des II!meniums unmittelbar aufsitzen. Von der freien Aussenfliche entspring̣en nicht selten abstehende Ilaare und, an der Basis der stromaIosen Perithecien, Wurzelhaare.

An den Perithecien, welche einem Stroma eingesenht sind, unterscheidet man meistens gloichfalls zwei von der Substanz des Stroma verschiedene eigene IVandschichten: die innere zartzellị, wie soeben beschrieben wurde, die iusscre derb, rerholzt. oft hohligy und, soweit Lntersuchumgen daruber vorlicgen, meistens ats concentrisch verlanfenden Ilyphen zusammengesetzt, deren einzelne Zellen sehr eng und zur Zeit der Reife oft schwer unterscheidbar sind Cylaria, Hyporylon. Istulina. In einer anderen Reihe von Fiallen z. B. Claviceps. Dothidea in Sinne ron Julasne Carpol. fehlt eine rom Stroma algegrenzte Aussenwand, das Peritheeium ist gleichsam eine in das Stroma cingegrahene Jlöhlung. welehe atsçehleided wirel von dre zartzellig̣en, hỵmeniumlragenden schichte, und diese geht ummittelbar in das Gewebe des Stroma über.

An der stelle, wo die Miindung liegrt, ist die Perithecienwand meistens. mehr oder minder nach aussen vorgetrieben, of zu einer Papille oder sellost zu rinem langen Halse ausgezogen, in anderen Faillen \%. B. Nectria ist die Vortreibung hamm bemerkbar. Jin stets iusserst enger Canal geht an der bezeichneten Siclle ron dem Innentaume zur Oberfliche und mindet an letzterer mit viner ebenfalls engen, unter der Lupe punktförmigen Oeffinung. Fon der Wand des Canals entspringen allenthalben dicht gedringte, schr zarte und kurze Fädchen oder Haare. welche schraig aufwirts gerichted sind und von allen Seiten her derart convergiren. dass ilne Enden einander in der Mittellinie des Canals bis zur Berührung genihert werden; der Canal ist also durch diese Auskleidung fist vollstimdigy verstopft. In der Grenze zwischen Mündungscanal und Perithecienhöhlung̣ wenden sich die Auskleidunğghate des ersteren mit ihren Enden immer mehr nach letzterer hin, die untersten ragen fast senkrecht in diese hinab. Diese Aushleidung des Canals hommt jedenfalls vielen Pyrenomỵecten zu, z. B. Xỵlaria, Ustulina, Stictosphaeria Tul., Sphaeria Iyphina, Ciaviceps, Nectria: ob allen, dariber crlauben die vorliegenden Daten noch kein sicheres Irtheil. Ieberhaupt griundet sich die hier gagegebene Darstellung der Peritheciumstructur auf eine nur geringe Zahl genauer Beobachtungen, und ob 
sie eine allgemein gültige ist, kann erst durch eine grössere Ausdehnung eingehender anatonischer Untersuchungen entschieden werden.

Bestimmt von den beschriebenen verschieden ist das stets mündungslose Perithecium der Erysipheen. Seine hauptsächlichen Eigenthümlichkeiten werden im šten Capitel besprochen werden.

Aus Gründen, welche gleichfalls in dem eben genannten Capitel auseinandergesetzt werden sollen, hat die Frage nach der ersten Entstehung und Entwickelung der Perithecien ein besonderes Interesse. Die älteren Beobachtungen geben auf dieselbe keine weitere Antwort als etwa die, dass die Perithecien erst klein und geschlossen sind, und die Mündung später entsteht; und dass die freien, nicht ins Stroma eingesenkten Perithecien als allmählich wachsende Erhebungen auf ihrer Unterlage hervortreten. Alle eingehenderen Untersuchungen beziehen sich auf die Entwickelung der Reproduktionsorgane in ilırem Innern. Auch die Versuche, welche Sollmann in neuester Zeit zur Lösung bezeichneter Frage gemacht hat, ergaben im Grunde kein anderes Resultat als das angeführte.

Janowitsch und ich selber haben versucht der Beantwortung jener Frage näher zu kommen. Die dahin gehenden Untersuchungen haben wegen der Kleinheit der ganz jungen Peritheeien und ihrer einzehen Fornelemente grosse Schwierigkeiten. Sie sind daher zur Zeit weder abgeschlossen noch ausgedehnt genug, und das folgende Resumé derselben kann nur als Andeutung für künftige Beobachter dienen.

Das keulenförmige Stroma von X ylaria pol ymorph a (Fig. 37) besteht in der Jugend aus einem weissen Marke, welches von einer festen, schwarzen Rindenschichte eingeschlossen wird. Jenes wird von einem lufthaltigen Geflechte farbloser IIyphen gebildet, die Rindenschichte des fruchtlragenden Theiles aus einem kleinzelligen, pseudoparenchymatischen Gewebe. Letztere wird aussen ïberzogen von dem später zu beschreibenden conidientragenden, zuletzt zerfallenden IIymenium. Die ersten Anlagen der Perithecien $(A, p)$ zeigen sich in Form kleiner, kugeliger Gewebeportionen, welche dicht unter der schwarzen Rinde in dem Marke liegen und sich ron dem Gewebe dieses dadurch sofort unterscheiden, dass sie luftrei, daher durchsichtig sind. Sie bestehen aus einem dichten Geflechte zarter Hyphen, welche weit geringere Dicke haben, als die des ursprunglich vorhandenen Markes, und daher als Neubildung in diesem entstanden sein müssen; nur in der Mitte der Kugel liegt ein kleiner, unregelmässiger Knäuel von weiteren Zellen. Die Kugeln vergrössern sich zunächst, unter gleichbleibender Gestalt, Structur und Lage, nach dem Marke hin. Dann erhebt sich von ihrer an die kinde grenzenden Portion ein dichtes, breit - und ahgugestutzt kegelförmiges Büschel zarter, gerader IIyphen, welches sich gegen die Rinde hin streckt, diese erst wenig vortreilst und dann allmählich durchbohrt, so dass die Enden seiner Elenente über die Oberfliche vorragen $(n)$. Die Peritheciumanlage hat somit die Gestalt eines Eies erhalten, dessen hreiterer Theil im Marke liegt und die Anlage des Grundtheils des Peritheciums ist, wahrend das schmale, in die Rincle eingekeilte Ende dic Anlage des llalses und der Mündung des Peritheciums bildet. Schon früh entsteht in der Mittellinie des letzteren, in nicht genau ermittelter Weise, der von den convergirenden Hairchen ausgekleidete Canal, wahrend die Elemente in seiner Peripherie verholzen, 
der Itals daher bald von einer schwarzen, mit der Rinde continuirlick zusammenhängenden Aussenwand umgeben ist $(q)$. Der Process des Verholzens und

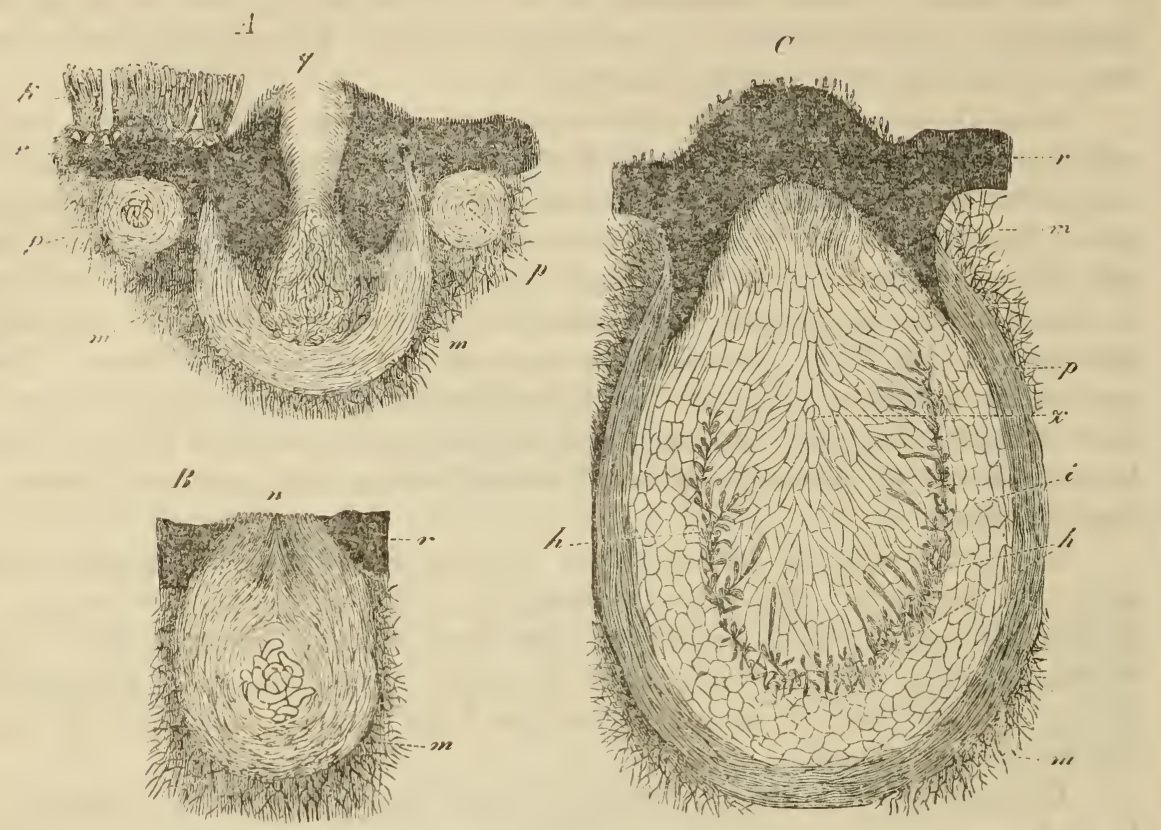

Fig. 37.

Schwarzwerdens schreitet gegen den Grund des Peritheciums sehr langsam fort und erreicht hier erst bei der Reife seine Vollendung. Nit der Anlegung des Halses dehnt sich der Grundtheil des Peritheeiums weiter in das Mark hinein aus. Sein Umfang wird dabei stets ron einer Schichte fest verflochtener, der Oberfliiche parallel laufender, dimner Hyphen eingenommen: der später verholzenden und schwarz werdenden, ïusseren Wandschicht. Diese umschliesst eine verworrene, kugelige und den ganzen Innenraum ausfüllende Fadenmasse, den Kern des Peritheciums, deren Hyphen zunïichst sehr zart und dünn bleiben, nur in der Mitte einige schon erwilhnte, weite Zellen umschliessen, und welehe in Wasser stărk aufquillt. Später $(C)$ dehnen sich die Zellen des Kerns beträchtlich aus, ihr Protoplasmainhalt rerschwindet, die Mitte des Kerns erseheint aus einem Geflecht gewundener, zartwandiger, hyaliner IIyphen mit gestreckt eylindrischen Zellen gebildet, sein Lmfang aus etwa sechs Schichten isodiametrischer Zellen. Letztere bilden die innere Lage der Peritheciumwand,

Fig. 37. Xylaria polymorpha Fr. Querschnilte durch junge Stromata, mit mehr oder minder genau halbirten Perithecien, alle drei $90 \mathrm{mal}$ vergr. $r$ Cortical-, $m$ Medullarschicht des Stroma. $k$ Conidienlager. $A: p$ schr junge Peritheciumanlage, mitten, $p^{\prime}$ ebensolche neben der Mittelebene durchschnitten. $q$ ältere Peritheciumanlage. $B$ Peritheciumanlage, deren Mündungstheil $n$ die Corticalschicht durchbricht. C Fast erwachsenes Perithecium. Der Schnitt ging neben der Mündung (die wie bei $q$ beschaffen ist) her, im Uebrigen genau durch die Mittelebene. $p$ äussere (noch nicht verholzte), $i$ innere Perithecienwand, $x$ grosszelliges, hyalines Gewebe der liernmitte, $h$ Anfänge des Hı̀neniums. 
und aus ihnen sprossen zuletzt die Bestandtheile des Hymeniums hervor, die Italinen Iyphen der Mitte mehr und mehr verdrängend (Fị̄. $37 \mathrm{C}, 38$ ). Das (iewebe des Kerns behält jederzeit eine hohe Quellbarkeit in Wasser. Die gleiche Entwickelung der Perithecien findet, soweit meine Untersuchungen reichen, bei Xylaria Hyporylon und Ustulina rulgaris Tul. statt.

Die Perithecien von Nectria cinnabarina entstehen als gewölbte Hervorragungen auf der Oberfliche des Stromas; ihre Mitte wird in den frühesten untersuchten Stadien ron einem Knäuel unregelmaissiger, farbloser, hyaliner Zellen eingenommen, ihrl'mfang von einigen Lagen pseudoparenchymatischer Zellen, deren Wiinde die rothe Farbe der Zellmembranen des Stroma besitzen. Die Hervorragungen vergrössern sich und zeigen in dem nächsten genauer untersuchten Stadium die rothen ZelIen ihrer Oberfliache vergrössert und vermehrt, miteinander die Aussenwand des Peritheciums bildend, welcher innen die zartzellige Innenwand anliegt. Der von letzterer umschlossene Raum wird erfült von einem lockeren Geflechte dicholon oder büsche-

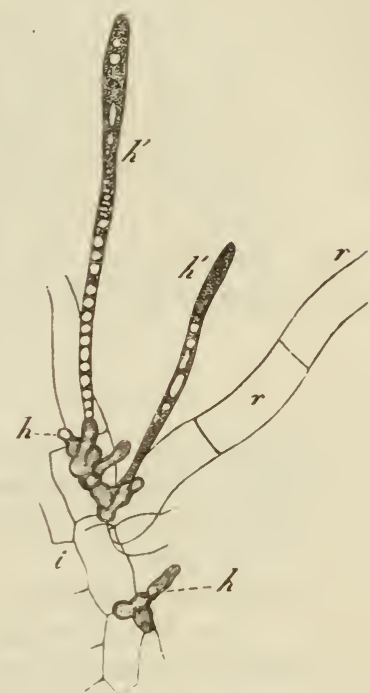

Fig. 35. lig verzweigler Fäden, die von allen Regionen der Innenwand entspringen, und wie Kugelradien convergirend, einander durchhreuzend und ihre Zweige verschrinkend bis zu der ihrer Lisprungsstelle gegenitberstehenden Seite der Wand reichen. Die Lucken des Geflechtes werden von wasserheller Gallerte erfullt. In Scheitel des Peritheciums wächst von der Innenwand aus ein dichtes, kurzes Fadenhusschel nach aussen, um, wie bei ly laria, die Aussenwand durehbohrend den kurzen Mundungseanal zu bilden. Zuletzt sprossen auch hier die Sporenschläuche aus den Zellen der Innenwand hervor und verdrängen die den Raum anfangs allein ausfullenden Fïden.

Während in diesen Fïllen die Prithecien ganz oder theilweise aus einer im Innern des Stromas stattfindenden Neubildung hervorgehen und ihr Nucleus von Anfang an aus einem gelatinösen, später mehr oder minder verschwindenden Fadengeflechte zusammengesetzt ist, erheben sich bei Sphaeria typhinaP. die Perithecien als Prominenzen auf der Oberfliche des Stroma und sind von Anfang an mit dem offenen Miundungscanal versehen. Die anfangs enge Höhlung, in welche dieser nach unten endigt, erweitert sich mit dem Wachsthum des PeriHheriums, und in sie sprossen von der Wand aus die Hymenialelemente. Nach einigen freilich litchenhaften Beobachtungen scheint den Perithecien von Clavie eps der gleiche Entwichelungsgang eigen zu sein.

Eine vollstindige Entwickelungsgeschichte von Perithecien, die nicht von einem Stroma getragen werden, liegt zur Zeit nicht vor, wenn man von Erysiphe, welche weiter unten besprochen werden soll, absieht.

Fïg. 3s. Xylaria polymorpha Fr. Kleines Stück des in Fig. $37 \mathrm{C}$ abgebildeten Schnittes, 390 mal vergr. $i$ Innere Perithecienwand, $r$ hyaline Zellen der Kernmitte. $h$ Anfänge der IIymeniumbestandtheile aus den Zellen der Inuenwand hervorsprossend. $h^{\prime}$ halberwachsene Asci. 
Viele Pyrenomyceten haben ausser den durch die Sporenschläuche, wclche sie erzeugen, ausgezeichneten Perithecien noch andere Conceptakeln, welche je nach den in ihnen entwickelten Fortpflanzungsorganen als Pyeniden und Spermogonien bezeichnet weṛden. Ueber die Entwickelung dieser Bchälter ist noch nichts Genaueres bekannt. Ihre Wand zeigt im ausgebildeten Zustande wesentlich den gleichen Bau wie die der Perithecien; sie ist in einer Reihe von Fällen mit viclfach gewundenen Faltungen versehen, die Höhlung, welche sie umschliesst, daher entsprechend ausgebuchtet.

Durch die bis jetzt unbekannte Entwickelungsgeschichte wird entschieden werden müssen, ob die Fruchtkörper der Hysterineen hier oder bei den gymnocarpen aufzuführen sind.

\section{Litteratur.}

Tulasne, Selecta fungorum Carpologia. Tom. II.

Corda, Icones fung. Tom. II-V (einzelne Analysen von Perithecien u. Stromata). Schmitz, Ueber d. Wachsth. der Sphacria carpophila Pers. Linnaea Bd. 17 (1843), p. 456 .

Bail, Mycolog. Studien. Nov. Act. Acad. Nat. Curios. Vol. 29 (1861). Misslungene Darstellung von Sphaer. typhina.

Sollmann, Beiträge zur Anatonie u. Physiologie der Sphaeriaceen. Bot. Ztg. 1863, p. 193 u. $1864, \mathrm{Nr} .36,37$.

de Bary, Ueber die Entwickelung von Sphacria typhina P. Flora 1863, p. 401.

$\Lambda$. Janowitsch, Ueber d. Entw. v. Nectria. Bot. Ztg. 1865, p. 149.

\section{Zweite Abtheilung.}

\section{Fortpflanzungsorgane.}

Man kennt gegenwärtig bei den Pilzen geschlechtslose und geschlechtliche Fortpflanzungsprocesse und bei einigen Copulationserscheinungen, welche sich den letzteren anschliessen.

Die Organe der Fortpflanzung sind in beiden Fällen einfache Zellen. Die der geschlechtlichen Zeugung dienenden sind zwechmässiger Weise mit den von Pringsheim (Jahrb. f. wiss. Bol. I) vorgeschlagenen Namen Oogonium, Oospore, Antheridium u. s. w. zu bezeichnen; sie werden weiter unten ihre ausführlichere Besprechung finden. Wie bei den übrigen Gewächsen kommt auch, soweit bekannt, bei den Pilzen jeder Species nur eine Form der geschlechtlichen Zeug̣ing zu.

Für die gesehlechtslosen Fortpflanzungszellen lisst sich zur Zeit eine auf sämmtliche Pilze gleichmaissig anwendbare Terminologic kaum mit Sicherheit 
begrüuden. Die neucren Forschungen haben gezeigt, dass in der grossen Mehrzahl der Fälle einer und derselben Pilzspecies mehrere Arten ungeschlechtlicher Fortpflanzungsorgane eigen sind. Für eine Anzahl von Familien und Gattungen sind alle diese Organe und die Stellung, welche sie in dem Entwickelungsgange der Species einnehmen, hinreichend genau bekannt, um eine klare und einfache Bezeichnungsweise leicht durchführbar zu machen; für eine sehr grosse Zahl von Pilzen sind dagegen die Kenntnisse noch überaus lückenhaft, man weiss nicht in wie weit ihre verschiedenen Fortpflanzungsorgane denen der genau erforschten Gruppen entsprechen. Es kann sich daher zur Zeit nur um Feststellung einer provisorischen Terminologic handeln, und diese wird am sichcrsten stehen und am brauchbarsten sein, wenn sic sich theils an die für die niichstverwandten Thallophỵten, die $\Lambda$ ggen, festgestellte, theils an den von Alters her überkommenen Sprachgebrauch anlehnt.

Von diesem Grundsatze ausgehend nenne ich in Folgenden jede einzelne geschlechtslose Fortpflanzungszelle, welche unter normalen Bedingungen in einen oder mehrere Pilzfiden auswaichst, Spore. Die Verschiedenheiten der Sporen nach Entstehung, Function, Bau u. s. w. können dabei theils durch Compositionen wie Schwarmspore, Stylospore, Ectospore u. s. f., theils für besondere Fälle durch besondere Worte ausgedrüickt werden, wie Gonidium, Sporidium.

Die Zellen, von welchen die Sporen er\%egat wreden, sind als Sporenmutferzellen, Sporangien und für besondere Falle wiederum mit besonderen Namen, wie Ascus, Basidium u. s. w. zu bezeichnen.

Eine ringehendere Besprechung der verschiedenen Bezeichnungsweisen wird erst nach Betrachtung der Fortpflanzungsprocesse selbst am Platze sein.

\section{Capitel 4.}

\section{Geschlechtslose Fortpflanzung.}

I. Lintwichelumg der Sporenmulterzellen und sporen.

Die Entstehumg der Pilzsporen findet in dreierlei verschiedenen Formen statt, nimlich durch fireir Zellbildung, durch Abschnürung, und durch eine der vegretativen grleiche oder iihnliche Zellheilung oder wandstindige Zellenbildung. Die Sporenumultrzellen werden herkömmlicher Weise für den ersten Fall mil den Namen Asci, Thecae, Sporenschlïuche, für den zweiten als Basidien, für den drilten einfach als Sporenmutterzellen, Sporangia bezeichnet; daher die Benemnungen Ascomyceten, thecaspore, basidiospore Pilze.

\section{Sporenbildung in Ascis.}

Fast alle Ascomyceten (Tuberaceen, Disco-Pyrenomyceten) sind mit einem zusammengesetzten Fruchttriger versehen, ihre Sporenschlituche in Molırzahl (3-10 bei kleineren P!renomyceten), oder meist in grosser Menge zu Iymenien 
vereinigt. Die Schlauche sitzen in diesen den Hyphen des sie tragenden Gewebes als Astzellen oder Endzellen von Aesten auf, einzeln (Tuberaceen) oder in Büscheln. Ihre Entstehung ist von der vegetativer Astzellen nicht wesentlich verschieden. Mit den Ascis entspringen von den hymeniumtragenden Hyphen in sehr vielen Fällen ein-oder mehrzellige, meistens, doch nicht immer, unverzweigte Haare, Paraphysen genannt, welche sich in gleicher Richtung wie die Asci auf die IIymenialfläche ordnen und meist in grosser Zahl zwischen jene eingeschoben sind. Zumal bei den typischen Discomyceten dürten diese Organe wohl kaum je fehlen. Sie treten hier in vielen Fällen (Peziza, Helvella) oder vielleicht immer früher auf als die Asci; letztere drängen sich erst nachträglich zwischen sie ein oder wachsen über sie hervor, so dass es zuletzt den Anschein hat, als sei das Iymenium aus Ascis allein, ohne Paraphysen gebildet (Morchella esculenta). Bei den Pyrenomyceten werden die Paraphysen häufig zwischen den Ascis gefunden; sie entstehen hier, wie die Darstellungen zeigen, mit den Ascis gleichzeitig und von denselben subhymenialen Trägern aus. Auf der anderen Seite fehlen sie aber bei vielen Arten und Gattungen ganz oder beinahe vollständig (z. B. Stictosphaeria Tul., Dothidea ribesia und andere Species, Polystigma; vgl. Tul. Carpol., auch bei Iysterium decipiens Dub., Hoffin. Icon. anal.) und es ist noch $\mathrm{zu}$ entscheiden, ob nicht bei den Pyrenomycet'n zweierlei Dinge bisher als Paraphysen beschrieben worden sind, nämlich einerseits die Ueberbleibsel des transitorischen Gewebes, aus welchem der Kern vieler Perithecien (s. Seite 99, Fig. 38) in der Jugend allein besteht, und andererseits ichte Paraphysen, welche mit den Ascis aus der Innenwand des Peritheciums hervorsprossen.

Von Pilzen einfacheren Baues mit Sporenschlauchen ist Exoascus pruni zu nennen, bei dem, wie oben schon erwähnt wurde, jede Zelle des einschichtigen Fruchtlagers einen Ascus erzeugt und trïgt, ohne Paraphysen; ferner die im 5ten Capitel genauer zu besprechenden Erysipheen; endlich Protomyces macrosporus, ein in Umbelliferen lebender Hyphomycet, bei welchem einzelne interstitielle Gliederzellen der Iyphen anschwellen und sich zu Ascis ausbilden.

Die Gestalt der Asci ist in den meisten Fillen schmal-keulenförmig, seltener breit - oval, oder gestielt - kugelig (Tuberaceen, Elaphomyces, Erysiphe, u. а.).

Abgesehen von den unten besonders zu besprechenden Eigenthumlichkeiten des Protomyces macrosporus entsteht der Ascus auf seinem Träger als eine zarte Zelle von der Form, welche ihm bei der Reife zukommt, wächst sofort, und of schnell zu seiner definitiven Grösse heran, worauf wiederum unverzüglich die Sporenbildung beginnt (vgl. Fig. 39, 40).

Ueber die speciellen Vorgänge, welche während und vor der letzteren stattfinden, kennt man zur Zeit Folgendes.

1. Bei der überwiegenden Mehrzahl der Ascomyceten werden in jedem Schlauche 8 Sporen simultan gebildet. Verfolgt man den Entwickelungsprocess genauer, so ist zunächst bei einer Anzahl von Pezizen (P. confluens P. [Fig. 39], P. pitya P.) der jugendliche Ascus mit feinkörnigem, einzelne Vacuolen umschliessendem Protoplasna erfüllt, in dessen Mitte, sobald der Schlauch etwa ein Drittel seiner definitiven Linge erreicht hat, ein Zellkern deutlich wird, in Form eines hellen, kugeligen Körpers, in welchem ein centraler, kleiner, stark licht- 
brechender, runder Nucleolus liegt. Mit dem ferneren Wachsthum des Schlauches rückt das Protoplasma in das obere Ende desselben ein; in dem unteren, bis Dreiviertel der ganzen Linge betragenden Theile des Schlauches bleibt nur mehr wiisserige Flüssigkeit und ein lünner, die Wand überziehender Protoplasmabeleg oder Primordialschlauch. Ilat der $\Lambda$ seus sein Längenwachsthum vollendet, so wird der Anfang der Sporenbildung dadurch angezeig̨t, dašs an der Stelle des ursprüglichen Zellkerns жwei kleinere auftreten. In einem ferneren Stadium

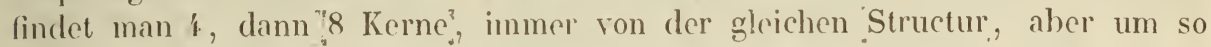
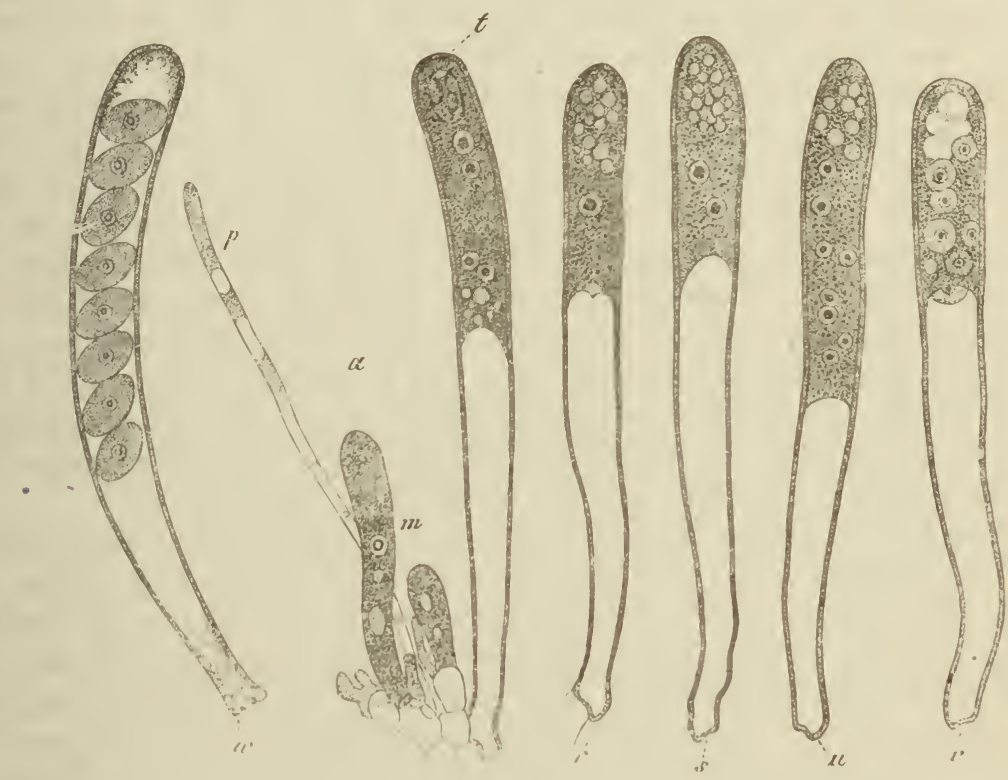

Fig. 39.

kleiner jo höher ihre Zahl ist. Die 8 Kerne letzler Ordnung gruppiren sich in ziemlich gleiche Entfermung ron cinander: endlich ist jeder derselben von einer rumden Protoplasmaportion umgehen, welche von dem ubrigen durch grössere Murchsichligkeil ausgereichnet und durch eine sehr zarte Linie abgegrenzt ist. Diese Protoplasmaportionen sind die Anfinge der Sporen, sie entstehen alle grleichzeitig, erhalten hald feste Mfembranen und wachsen im Innem des Ascus otwa aufs Doppello ihrer urspribg̣lichen Grösse heran. Das Protoplasma, welches sie zuerst umgibt, verschwindet wihrend ihres IIeranwachsens bei Pez. pitya rasch ; es wirt hier immer gleich dem in den Sporen enthaltenen durch Jod gelb gefirbt. Bei P. confluens zeight das Protoplasma des Ascus vor-der Sporenbildung die gleiche Jodeaction, und das nimliche gilt jederzeit von dem in den Sporen.

Dagegen nimmt nach Entstehung letzterer das Protoplasma die Eigensehaften einer Substanz an, fïr welche ich den Namen Epiplasma vorgeschlagen

Fig. 39. Peziza confluens P. a Kleines Fragment des Hymeniums, $p$ Paraphyse, mit drei Iscis von dem subhymenialen fewebe entspringend. $r-w$ erwachsene $\Lambda$ sci, Entwiçkelungsfolge nach den Buchstaben; in $r-u$ Vermehrung der Zellkerne, in $v$ Sporen angelegt, in w Sporen reif. m. junge Isci. Vergres 390. 
habe und welche sich von dem gewöhnlichen Protoplasma durch stärkeres Lichtbrechungsvermögen, eigenthümlich homogen-glinzcndes Aussehen und besonders durch die rothbraune oder violettbraune Farbe auszeichnet, welche sie bei Einwirkung selbst sehr verdünnter Jodlösung annimmt.

Bei einer Anzahl anderer mit grossen Ascis versehener Arten [Peziza conrexula, Acetabulum ${ }^{1}$ ), melaena, IIelvella esculenta, elastica, Morchella esculenta] tritt schon vor der Sporenbildung eine Sonderung des zuerst gleichförmigen Schlauchinhalts in Protoplasma und Epiplasma ein. Jenes sammelt sich zu einer in der Mitte des Schlauches liegenden Querzone (Pez. convexula) oder, in den meisten Fällen, zu einer das obere Drittel oder Viertel des Ascus füllenden Masse an; der übrige, zumal der untere Raum enthält nur Epiplasma, welches meist von zahlreichen Vacuolen verschiedener Grösse und Anordnung durchbrochen ist. Manchmal (Morchella, Pez. Acetabulum) wird auch das oberste Ende des Ascus, über dem Protoplasma, von einer Epiplasmaschichte eingenommen, jenes füllt gleichsam eine scharf umschricbene Höhlung in der Epiplasmamasse aus. Der Zellkern liegt immer in dem Protoplasma, central oder etwas excentrisch, die Sporenbildung findet gleichfalls in diesem Theile statt, und zwar jedenfalls im Wesentlichen auf die oben beschriebene Weise. Nur sind bei den genannten Arten meist bloss der primäre und dann die 8 Kerne vicrter Ordnung, um welche dic Sporenbildung unmittelbar erfolgt, gefunden worden, es ist ungewiss, ob die Bildung transitorischer secundärer und tertiärer Kerne übersprungen wird odler nur der Beobachtung entgangen ist.

Zahlreiche vereinzelte Beobachtungen haben zunächst für eine ziemliche Anzahl von Discomyceten mit 8 simultan entwickelten Sporen in einem Ascus das Vorhandensein des primären Zellkerns vor der Sporenbildung, das Auftreten der jungen Sporen in der oben beschriebenen Weise, und je nach den Arten das Stattfinden oder Unterbleiben einer Sonderung ron Epiplasma und Protoplasma nachgewiesen. Es ist daher nicht zu bezweifeln, dass der oben beschrichene Entwickelungsgang bei der genannten Ordnung (Peziza, Phacidium, Ascobolus, Leotia, Geoglossum) eine schr allgemeine Verbreitung hat. Seine genaue Verfolgung wird häufig auch bei grossen Ascis Leotia lubrica, Geoglossum hirsutum, Helvella u. s. w.) dadurch erschwert, dass zahlreiche grosse Oeltropfen in dem Protoplasma des jungen Schlauches und der Sporen suspendirt sind und dasselbe undurchsichtig machen. In anderen sehr zahlreichen Fällen lässt die Kkeinheit der Asci und Sporen eine genaue Verfolgung des Vorganges nicht oder nur schwer zu; doch findet man auch hier bei einiger Aufmerksamkeit leicht den primären Kern, das simultane Erscheinen der 8 Sporen als zartunschriebene Protoplasmaportionen, und manchmal (Pez. Sclerotiorum, Fuckeliana) in jeder derselben einen Zellkern. Der primaire Kern erscheint bei den kleinen Ascis (z. B. Pez. tubcrosa, Sclerotiorum, calycina, Phacidium Pinastri) in der Form, welche oben für den Nucleolus beschrieben wurde, d. h. als ein stark lichtbrechender, rundlicher, homogener oder in der Mitte hellerer und gleichsam ausgehöhlter Körper; der helle, durchscheinende, kugelige Raum in seinem Unkreise ist nicht oder nicht immer (Pez. Fuckeliana) zu beobachten.

1) Die in meiner schrift uber die Ascomyceten als Pez. sulcata? bezeichnete Form gehört zu P. Acetabulum. 
In den Schläuchen der Pyrenom yceten mit 8 simultan entstehenden Sporen ist die Beobachtung der Sporenbildung weit schwieriger, als bei den Discomyceten, theils wegen der-Kleinheit und Zartheit der Organe, theils wegen der in dem Protoplasma meist zahlreich vorhandenen Fetttröpfehen. Doch zeigt aufmerksame Beobachtung, dass die ganz jungen Sporen hier in dersolben Weise auftreten, wie oben beschrieben wurde, nur dass ich einen Zellkern in denselben nie wahrnehmen konnte. Die gegentheiligen Angaben, welche in dieser Bezichung neucrdings von Sollnann gemacht worden sind, beruhen unzweifelhaft auf einem Uebersehen der ersten, zarten Anlagen der Sporen und einer Verwechselung von Fetttöpfehen mit Zellkernen. Der primaire Kern ist dagegen vor der Sporenbildung in vielen Fillen deutlich vorhanden. Er hat die Besclraffenheit, welche soeben für Pez. calycina und tuberosa beschrichen worden ist, und liegt stets an der gleichen Stelle, etwas über der Mitte des Ascus. Ausser bei Xylaria polymorpha, wo ich ihn schon früher fand, wurde er von Janowitsch und mir gesehen bei Nectria, Sphaeria obducens, Cucurbitaria Laburni, Pleospora herbarum, Sordaria fimiseda deNot u. a. Der Inhalt der Pyrenomycetenschliuche zeigl in den meisten untersuchten Fällen nur die gelbe Jodfarbung des Protoplasma; bei Sphaeria obducens trill jedoch mit oder schon vor der Sporenbildung, bei Pleospora herbarum, Sordaria fimiseda, Sphacria Scirpi jedenfalls nachher, exquisite Epiplasmareaction ein. NHe diese Thatsachen lassen kaum einen Zweifel daran, dass die Entwickelung der 8sporig̣en Asci bei den Pyrenomyceten mit den I)iscomyeeten im Wesentlichen übereinstimmt und dass fernere Beobachtungen hierfür den dieceten Nichwois liefern werden.

Die 8sporigen Schliuche von Erısiphe Cichoracerum zeigen in der Jugend einen grossen Zellkern; in einem spiteren Stadium ist dieser versehwunden; die simultan auftetenden Sporen haben sehr deulliche centrale Kerne und sind einer glinzenden Epiplasmamasse eingebettet.

Bei dem ebenfalls hier anzuführenden Exoascus Pruni fand ich zu keiner Zeit weder in den Schliiuchen noch den Sporen Zellkerne: im Uebrigen schliesst sich seine sporenentwickelung vollkommen den epiplasmafreen Discomyceten an.

Die Zahl der in den typisch ssporigen Schliuchen angelegten sporen ist höchst bestandig, Ueberschreitungen derselben, wie z. B. 9 Sporen in Cirptospora Tul., Exoascus, und 1:3 norual entwickelte in einem rinzelnen Schlauche von Peziza melaena verhiiltnissmaissig selten. Haiufiger kommut. Weniggstens bei Pyrenomycelen, der Fall vor, dass von den 8 angeleg̣ten sporen einzelne unentwickelt bleiben; die Fiblle, in welchen man weniger als 8 Sporen bei typisch ssporigen Arten findet, mögen wohl meistens hierin ihren Grund haben. Der Abort einzelner Sporen gehört übrigens fast immer zu den sogenannten zufiilligen Erscheinungen.

2. Eine Anzahl Erysiphe-Arten, Pỵrenomyceten, IIysterineen, enthalten in ihren Aseis typisch zwei (Erysiphe gutlata), vier Erysiphe, Ag̣laospora pro[usi), sechzehn Ascoholus sexdecimsporus Crouan, Ann. sc. nat. 1838, Hy.pocrea rufa P., gelatinosa Tode, citrina Tode, lenta Tode u. a. nach Curres, Limn. Transactions, Vol. 22) Sporen, oder cine Anzahl, welche weit höher als 8 und nichl schanf bestimmt ist, 40, 50 und mehr (\%. B. Diatrype quereina, verrucactormis, Calosphaeria verrueosa Tul., Tympanis conspersa Fr., saligna 
Tode u. a.). Andere zeigen häufige Schwankungen zwischen 2 und 4 (Dothidea Sambuci Fr.), 4. und 6 (Erysiphe) u. s. w. Die Sporen erscheinen bei den hier in Rede stehenden Formen, soviel bekannt ist, simultan und in der nimlichen Weise wie bei den typisch ssporigen. (Ygl. Sollmann, Bol. Zeilung 1862, Taf. XII, Fig. 3- ̈), die nächsten Gattungsverwandten jener sind häufig (Erysiphe, Diatrype, Aglaospora, Calosphaeria) mit 8sporigen Asci versehen und bei Valsa ambiens, salicina, nivea kommen Perithecien mit nur 4sporigen, andere mit nur Ssporigen und solche mit beiderlei Arten von Ascis vor. Es darf nach diesen Daten wohl angenommen werden, dass die Sporenanlage in den erwähnten Fällen ebenso wie es oben beschrieben wurde geschieht. $\mathrm{Zu}$ untersuchen wäre, ob etwa in gewissen Fallen eine geringere Zahl als 8 durch typisches Abortiren einer Anzalıl der Anlage nach rorhandener Sporen zu Stande kommt.

3. Die Sporenbildung in den Ascis von Tuber und Elaphom yces, denen sich die Mehrzahl der Tuberaceen anschliessen werden, ist von der beschriebenen dadurch verschieden, dass die Sporen in jedem Ascus ungleichzeitig und bei jeder Species in unbeständiger Zahl gebildet werden, und dass Zellkerne bei derselben nicht beobachtet worden sind. Nach einer langen Reihe von Untersuchungen von Turpin, Corda, Tulasne, Schacht, Kützing, Hofmeister und mir sind die Asci von Tuber in frühester Jugend von körnigem Protoplasma gleichmässig erfüllt; ältere, halberwachsene enthalten eine dichte, glänzende Substanz, in welcher zahlreiche, schwach lichtbrechende, blasige Hohlriume eingeschlossen sind; Jod färbt diesen Inhalt braungelb. Erwachsene Schliuche (Fig. 4.0) enthalten einen dicken Wandbeleg aus homogenem, stark lichtbrechendem und durch Jod braumroth werdendem Epiplasma, in welchem sich oft heine Vacuolen befinden, und einen von diesem umschlossenen, excentrischen, meist genau kugeligen Hohlraum, der von schwach lichtbrechendem, feinhörnigem, durch Jod gelb werdendem Protoplasma angefüllt ist. Der Protoplasmaraum ist zuletzt sehr scharf umschrieben, die ihn umgebende innerste
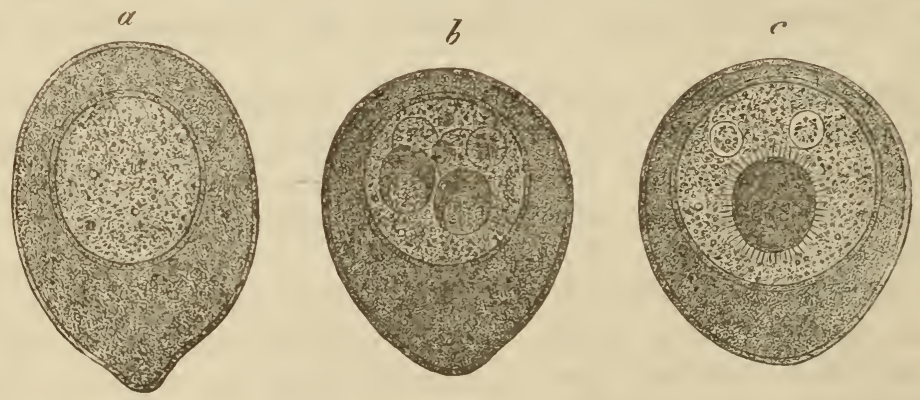

Fig. 10 .

Sehichte des Epiplasma offenbar - dichter als dessen uibrige Masse, manchmal doppelt contourirt, was Kïtzing und Schacht zu der irrigen Meinung veranlasste,

Fìg. 40. Tuber brumale Vitt. Erwachsene Asci, freigelegt, 390 fach vergr.

a Protoplasmaraum von dem Epiplasma gesondert.

$b$ In ersterem 6 oder 7 junge, ungleiche Sporen.

$c$ Eine halbreife und 2 ganz jugendliche Sporen angelegt. 
der Proloplasmaraum sei cine von besonderer Mombran umgebene in den Ascus eingeschachtelte Tochterzelle. Die Sporenbildung erfolgt in dem Protoplasmaraume; als erste Andeutung derselben sicht man in letzterem eine bis drei 1/30 Mm. bis 1/150 Mm. grosse runde Zellchen auftreten, welche ïbseraus zart umschrieben und von dem mugchenden Protoplasma durch etwas geringere Durchsichtigkeit ausgezeichnel sind. Die junge Spore nimmt nun zunächst an Grösse betriahtlich zu, orhäl schiirferen Lmriss und allmihlich derbe Membran. Während dor Aushildung der erstentstandenen treten hïufig̣ Anfiinge nener Sporen auf: bei den Arten mit typisch vier- bis sechssporigaen reifen Sehliuchen, \%. B. Tuher brumale, finden sich nicht selten die jüngsten Anfiinge der Sporen neben sclion betrichtlich vergrösserten in cinem $\Lambda$ scus, und niemals sind alle Sporen eines mehrsporigen Schlauches auf gyleicher jugendlicher Entwickelungsstufe; erst gegen die Reife hin werden die früher entstandenen ron den jiingeren eingeholt.

Aus diesen Erscheinmongen erkliirl sich, warum die Zahl der in einem Sehlatuche enthaltenen Sporen bei allen Trüfelarten grossen Schwankungen unterworfen ist, bei T. brumale, aestivum, melanospermum \%. B. in der Reged 4 bis 6 , daneben aher auch oft nur 1 bis 3 gefunden werden. Allerdings selieint hierzu noch der fermere Ĺmstand beizutragen, dass von den angelegten

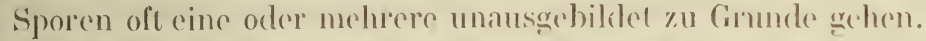

Ilie und da kommen zwisehen den beschriebonen. als nermal zu bezeichnenden $\Lambda$ seis solehe vor, welehe statl eines grossen, kugeligen Protoplasmaraumes mehreere kleinere enthaleen. Die Anlagen der Sporen sind alsdamn in diese vertheilt, sonst die Ersehoinungen die greochen wie bei den normal grestalteten.

Die Asci von Elaphom gees granulatus enthalten vor der Anlegung der Sporen sehr durchsichtiges, manchmal ganz wasserhelles, dureh Jod gell) werdendes Protoplasma, wolehes $u m$ rine oder wenigge grosse Vacuolen eine diunne wandstandige Schichte bildet. Epiphasma ist zu heiner Zeit vorhanden. In der Protoplasmaschichte treten die Anfiange der 1 bis 8 in der Regal 6 Sporen auf, welehe dem reifen Ascos zukommen, in Form höchst zarter, eine grosse Vacuole umsehliessender Bläschen, sucessive wie bei Tuber und erst bei der waileren Ausbildung cinander cinholend. -

In den meisten $\Lambda$ scis, zumal der D) is eom yeeten, nimmt das Protoplasma mand Epiplasma, welehes die nementstandenen Sporen mspriuglich mmgibt, in dem Massse ab, als letztere sich ausbilden. An dio Stelle beider Substanzen trilt wisserige Flüssigheit, und diese erfüllt \%uletzl den Raum des Ascus fast ausschliesslich, die reifen Sporen sind in ihr entweder regellos oder in eine bis zwei Reihen geordnet, suspendirt, bei linger gestreckten Ascis meistens in dem oberen Theile Fig. 39, ze). Von den protoplasmatischen Substanzen bleibt in dem reifen Ascus nul - aber auch ausnahmlos - der dimne, die Membran anskleidende hörnige Wandhelegr zurilek, weleher oben als Primordialschlauch bezedonet wurde. Es kann im Nlgemeinen wohl heinem Zweifel unterliogen, dass das Vorschwinden des Protoplasma und Ejpiplasma zu Gunsten der heranwachsenden Sporen geschicht. Ob beide Substanzen das Material zur Ernähromg letzlerer liefern oder ob das Epiplasma hierzu vielleicht nichts beitrigyt, muss nach den vorliogenden Beobachtungen dahingestellt bleiben. Für die 
naheliegende und durch Kützing für Tuber geäusserte Vermuthung, dass die protoplasmatischen Substanzen zur Bildung der Sporenmembranen dadurch beitragen, dass sie sich auf den jungèn Sporen gleichsam niederschlagen und erhärten, liegt gegenwärtig kein Grund vor; doch dürte die Sache, zumal bei Ascobolus, noch genauer zu untersuchen sein.

Bei Ascobolus Kerverni fanden die Brüler Grouan (Ann. sc. nat. 4e Sér. X 1858) p. 194; vgl. auch Coemans, Spicil. mycol. I, p. 14) die 8 Sporen zur Zeit der Reife miteinander in einen hyalinen, frei in der Flüssigkeit des Ascus schwebenden Sack eingeschlossen. Welcher Natur und Herkunft dieser ist, muss vorliufig dahingestellt bleiben.

Wie oben schon angedeutet wurde bleibt bei Erysiphe der ganze Ascus zu allen Zeiten von Protoplasına (oder Epiplasma) erfüllt und die Sporen diesem eingebettet. Desgleichen bleibt auch bei vielen Sphaeriaceen (ob viclleicht bei allen ist niher zu prüfen), z. B. Sphaeria Scirpi, Pleospora herbarum, Cucurbitaria Laburni, Sordaria fimiseda, auch in dem reifen $\Lambda$ scus eine reichliche, vacuolenhaltige Epi-oder Protoplasmamenge un die Sporen zurück.

Die Membran des $\Lambda$ seus tritt zur Zeit der Reife am deutlichsten hervor; sie wird darum erst hicr besprochen. Sie ist in allen Fillen eine farblose durchsichtige IIaut von ziher und dehnbarer oder, zumal bei vielen Pyrenomyceten, gallertartig weicher Beschaffenheit, in letzlerem Falle in Wasser mehr orler minder aufquellend. Gegen Reagentien zeigt sie meistens das Verhalten gewöhnlicher Pilzcellulose oder Gallertmembranen. Lis ist jedoch gegenwärtig eine ganze Reihe von Fïllen bekannt, in welchen die Ascusmembran, ihnlich der der meisten Lichenen, durch wisserige Jodlösung ganz oder theilweise blau grefaibl wird. Zuerst wurde dies ron Nylander (Ann. sc. nat. Ser. 4 Tom. 3, $18: 53$ und Syn. Lichen. p. 3) bei Sphaeria Desmazicrii Berk. und Xylaria pedunculata Dicks gefunden, für letztere nachher durch Tulasne bestätigt. Die Bläuung tritt hier in dem gallertig verdickten oberen Ende des Ascus ein. Sodann ist hier wohl Currey's Amylocarpus zu nennen (vgl. Ann. sc. nat. Ser. 4, X, 180̈8), bei welchem fast alle Zellnembranen durch Jod blau werden. Bei Peziza vesiculosa (II. Hoffmann Bot. ZIg. 1856), tuberosa, Sclerotiorum, Fuckeliana tritt besagte Jodfiiloung an dem verdickten oberen Ende ein, bei P. convesula, cupularis farbe sich die ganze Membran sowohl erwachsener als sehr juzger Schlauche, die Spitze ersterer an intensissten. Nahe verwandte Arten, z. B. Pe\%. confluens (auch P. pilya, melaena, coccinea, calycina u. s. W.j zeigen heine Bliuung. Nach Coenans werden die Asci von Ascobolus immersus P., glaber P., carneus P., Pelletieri Cr., cinereus Cr. durch Jod blau. Bei Asc. furfuraceus, den ich niiher untersucht habe, kann ich dieses für die Membran der jungen Asci bestitigen. Bei völlig erwachsenen wird die Membran nicht blau; dagecgen tritt auf Jodzusatz sofort schön blauvioleite Finbung ein in der die sporen umgebenden Flüssigkeit oder an zahlreichen Körnern oder Klümpehen, welche in dem dic jungen Sporen umgebenden Protoplasma suspendirt sind, und an der Membran der letzteren selbst, sobald sie der Reife nahe stehen.

Was die Structur der Membran anlangt, so ist diese in vielen Fällen durchaus einfach, ungeschichtet, mehr oder minder dick, je nach Grösse und speciescigenthimlichkeit. Sclbst bei vielen grossen Discomycetenschliachen (z. B. Peziza pilya, mclaena, Acclabulum, Morchella esculenta) ist eine Schich- 
tung an dem intacten Schlauche optisch nicht nachwoisbar. Zerschneidet man diesen aber unter Wasser, so trill an dem Rancle der Stücke eine Krümmung ein, bei welcher die Innenfliche convex wird, was eine Sonderung anzeigt in eine iussere und eine innere Schichte von verschiedener Quellharkeit oder Elasticitait.

Andere grössere Asci (z. B. Elaphomyces) lassen in ihrer derben Membran ringsum gleichförmige Schichtung erkennen. Der bemerkenswertheste hierher gehörende Fall ist der von Pringsheim für Sphacria scirpi genau beschriebene, welcher, wie aus Tulasne's, Currey's (Microsc. Journ. Vol. IV, p. 198) und Sollmanns Mittheilumgen hervorgeht, unter den Sphaeriaceen sehr verbreitet ist (Beispiele Sph. scirpi, Sph. Lemaneae Cohn, Sph. obducens Schm., Cucurbitar. Laburni, Pleosporae Species). Die Membran des Schlauches besteht hier aus einer dünneren, wenigg quellharen iusseren Schichte und einer inneren gallert-artig weichen, welche in Wasser ungemein stark aufquillt. Wird ein reifer Ascus in Wasser gehracht, so dehnt sich die innere und tritt aus der berstenden ausseren hervor, als ein Sack, dessen Liinge die urspriingliche 1 m mehr als das Doppelte übertrift, wie unten hei der Sporenentleerung ausführlicher beschrieben werden wird. In dem intacten Ascus ist die Innenschicht im Vergleich zu dem Lumen dünn, sie seheint fest zusanmengepresst zu sein zwischen der festen, wenig dehnbaren Aussenschicht und dem mit Inhaltsfliissigkeit strotzend angefiillten Primordialschlauche. Sobald der Druck, unter welchem sie steht, durch Verletzung des Ascus aufgehobon wird, quillt sie gegen die Lïngsachse des letzteren hin dergestalt auf, dass das Lumen zu einem schmalen Canal verengt und der Inhalt, seien es Sporen oder Protoplasma, aus der Verletzungsstelle ausgetrieben wird. Dies findet sowohl bei erwachsenen, der Reife nahen, als jungen, kaum hallow üchsigen Ascis stall, bei beiden ist die Membran im unverletzten Zustinde grleich diunn im Vergyleich zu dem weiten Innenraum. Die $\Lambda$ sci, Welche Hoffmann (Icon. anal. Ileft III) bei Sphacria obducens als junge beschreibt, sind jedenfalls verletzte, und seine Ansicht, dass die Membran des Schlanches in dem Maasse an Dicke abnehme als die Sporen heranwachsen, und dilher zur Aushildung der letzleren das Material liefere, enthehrt weniggstens fiir die genannte Sphaeria (sein Iysterium decipiens konnte ich nicht unfersuchen der Begriundung. Berkeley hat schon 1838 Magaz. of Zoology and Bot. Vol. II, P. 222: On the existence of a second membrane in the Asci of fungi) solehe Schliuche mit dicker, quellharer Wand gekannt; was er aber als second membrane heschreibt ist unzweifelhaft nichts anderes als der Primordialschlanth.

Bei zahlreichen Pyrenomyceten und Discomyceten ist die Membran im Scheitel des $\Lambda$ seus stiirker verdickt, als im übrigen, und dabei mit einem longitudinalen, aussen gạchlossenen Poreneanal rersehen. Das exquisiteste Beispiel hierfür liefern die oft beschriebenen schliuche von Cordyceps, Claviceps, Sphaeria Iyphina, deren Membran sonst iiherall sehr zart und diinn, an Ende aber zu ciner unregolmissig cylindrischen, von einem sche engen Porencanal durchzogenen Masse angeschwollen ist, welche fast so dick als der Schlauch breit und diesem wie ein Pfropl aufgesetzt ist. Bei einer Anzahl Pezizen, \%. B. P. Sclerotiormm und Verwandten, ist die Membran am Ende des Schlauches zweischichtig und mehr als doppelt so dick als an den Seiten. Die innere Schicht ist 
von einem breiten Porencanal durchbrochen, welcher aber von einer gallertigen Masse, die durch Jod dunkler blau wird als ihre Umgebung, ausgefüllt wird. Weitere Einzelheiten hier anzuführen ist umsoweniger thunlich, als es noch vielfach an genauen histiologischen Lntersuchungen uber die in Rede stehenden Verhaltnisse fehlt. Die Structurverhälnisse der Schlauchmembran, welche in directer Beziehung zur Entleerung der Sporen stehen, werden mit dieser besprochen werden.

Wie schon angedeutet wurde weichen die Asci des Protom yces macrosporus von allen anderen in mehrfacher Bezichung ab. Sie entstehen an den zarten, nicht zu Fruchtkörpern vereinigten Hyphen, indem einzelne interstitielle Glicterzellen zu meist breit ovalen, etwa 1/20 Mm. grossen Schliiuchen anschwellen. Ihre zuerst dünne Membran verdicht sich betrachtlich und besteht zuletzt aus drei IIauptschichten, Innen-, Mittel- und Aussenhaut, von denen die letztere wiederum reiche Schichtung und unter Einwirkung ron Jod und Schwefelsaure intensive Blaufärlung zeigt. Hhe Inhalt erhisilt allmählich die Beschaffenheit einer braunlichgelben, dicht- und grobkörnigen Masse, die aus einer geringen Menge von Profoplosma, hauptsachlich aus groben Fettkörnern besteht. Ein Zellkern ist zu keiner Zeit beobachtet worden. In dem beschriebenen Zustande bleiben die Asci, wïhrend die II!phen des Pilzes und die krautigen Organe der Lmbelliferen, in denen er sich entwickelt, absterben, unverandert den Winter ïher: ihre weitere Ausbildung geschicht im Frubling nach ihrer Entstehung. Unter dem Einfluss von Wasser beginnt jetzt das Fett vom Umfang nach der Mitte hin aufgelöst und durch feinkörniges Protoplasma ersetxt zu werden. Ist dieser Process vollendet, so delint sich die Innenhaut mit ihrem
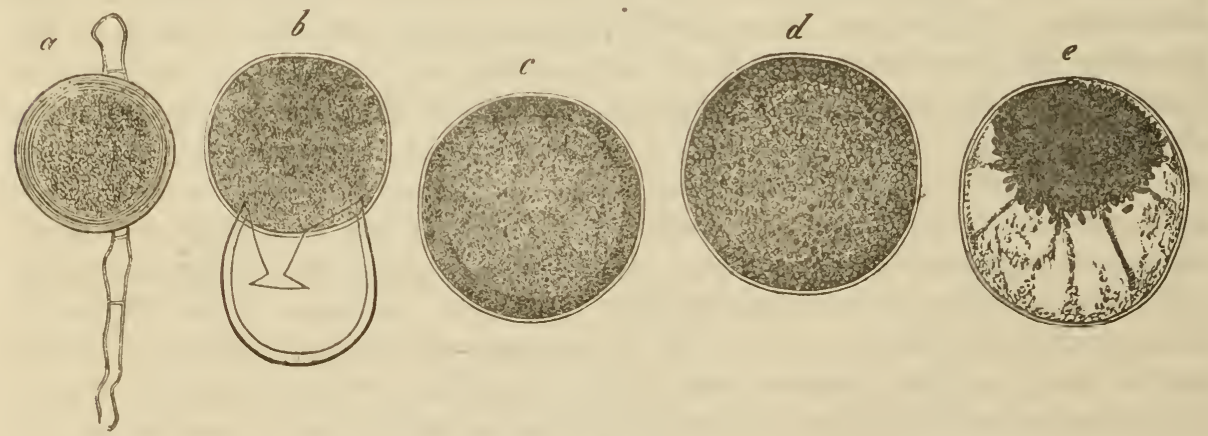

Fig. 41.

Inhalt, sprengt die iusseren Schichten und tritt ins Freic, in Form einer kugeligen, eine Zeit lang noch an Grösse zunchmenden Blase. Das Protoplasma, welches Anfangs in der Mitte dieser rol\%ugsweise angehäuft war, ordnet sich allmihlig \%u einer wandstindigen, eine grosse centrale Vacuole umgebenden Schichte, und in dieser antstehen endlich simultan Ihunderte von stab-

Fig. 41. Protomyces macrosporus Lnger. 390 fach vergr. a reifer Ascus, init den Resten der ihn tragenden Hyphe. $b$ Innenzelle aus der aufgerissenen Aussenhaut ausgeschliupt. $c-e$ Weiterentwickelung der Innenzelle, in $d$ sporen gebildet, in $e$ zusammengeballt. 
förmigen, 1/450 Mm. langen Sporen. Diese rücken nun mit dem sie umgebenden zu ihrer Bildung nicht verbrauchten Protoplasma zu einem dichten, runden, an der einen Seite der $\Lambda$ scuswand anliegenden Ballen zusammen, das Protoplasma verschwindet rasch, zuletzt ist der Sporenballen innerhall der vom Primordialschlauch bekleideten Membran in wässeriger Flüssigkeit suspendirt. (Fig. 41).

\section{Sporenabschnürung. Basidien.}

Bei der Sporenbildung durch Abschnürung gliedert sich das Ende der Mutterzelle oder der Fortsitze und Ausstiilpungen, wolche sie treibt, als Tochterzellen ab, um sich zur Spore zu entwickehn und zuletzt spontan loszulösen. Bis zur Lostrennung erscheinen die Sporen der Mutterzelle als einem Tr:igrer, einer Basis aufgesetzt, daher die Bezcichnung Basidie (Léveillé), Sporentriger (Sporophores), Stuitzschlituche, Asci suffultorii Corda) und die Benennungen gipfelstimdig̣e, acrogene Sporenbildung, Acrosporen, Ectosporen. Die Sporenabschnirrung ist eine iblhte Zellentheilung, von anderen Theilungsvorgiingen nur der Form nach ausgezeichnet, die Basidie ist nach vollendeter Abgliederung streng genommen die Schwesterzelle der Sporen, welehe die Gestalt, Grösse und Stellunğ der Mutterzelle beibehialt, nicht aber die Mutterzelle selbst, wenn es gyleich der Anschanlichkeit und Einfachlocit halber zwechmbissig ist, sie mil letzlerem Namen immer zu bezeichnen.

Es ist gleich hier zu elwihnon, dass in manchen Fillen (z. B. Cystopus, Peronospora) Sporangien, Sporenmulterzellen auf Basidien abgeschnürt werden, auf die nimliche Weise wie in der Regel sporen.

Nach der Art der Sporenbildung hat man zu unterscheiden zwischen solehen Basidien, welehe an einem oder an mohreren Punkten gleichzeitig die Sporen abschmitren, und dimn heine weiteren; und anderen, bei welchen an cinem Punkte mehrere bis viele $\Lambda$ bschmiirumgen, eine nach der anderen, erfolgen. Jene mögen simultan abschnuirende (das Wort monospore, einsporige passt nur auf wenige letztere sue ecdan abschnörende oder hury succedan ne Basidien genamnt werden.

Fiur die simultane $\Lambda$ bschnürung sind die Basidien simmtlicher II ymenomyceten und Gastromyeoten das wichligste und daher in erster Linie zu betrachtende Beispiel.

Wie in dem vorigen Capitel beschrieben wurde, stehen bei diesen P'ilzen die Basidien senkrecht und in grosser Zahl bei einander in der Hymenialschichte, oder sie füllen bei manchen Gastromyceten die Kammern der Glela gäröstentheils aus. Sie sind urspruinglich immer Endzellen der IIyphenzweige des subhymenialen Gewebes liegel reich biischelig verastelt, die Basidien auf ihnen daher gleichfalls

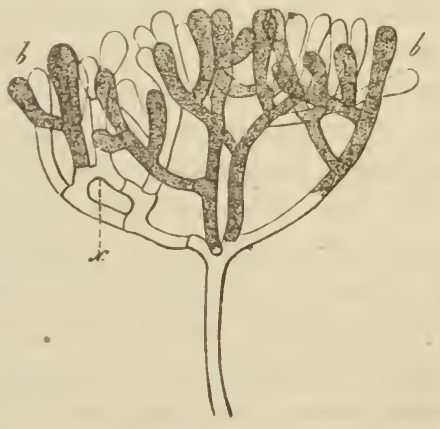

Fig. 42 .

Fig. 42. Hypochnus centrifugus Tul. $b, b$, jugendliche Basidien, als Endzellen von einer büschelig verästelten Hyphe entspringend; bei $x$ Hförmige Anastomose. Vergr. 390. 
büschelig angeordnet, die eines Büschels meist von verschiedenem Alter und Entwickelungsgrad. Bei den Pilzen, welche stets fiidige Structur behalten, ist diese Anordnung stets aufzufinden, wenngleich oft wegen dichter Verflechtung und Zartheit der subhymenialen Elemente mit einiger Mühe. Wo, wie bei Amanita, Russula, Coprinus (Fig. 4.3) auch das subhymeniale Gewebe zuletzi pseudoparenchymatische Structur anninmt, erscheinen die Basidien im ausgebildeten Hymenium einzeln oder zu einigen, den isodiametrischen Zellen der subhymenialen Schicht aufgesetzl. Von den in das Hymenium verlaufenden

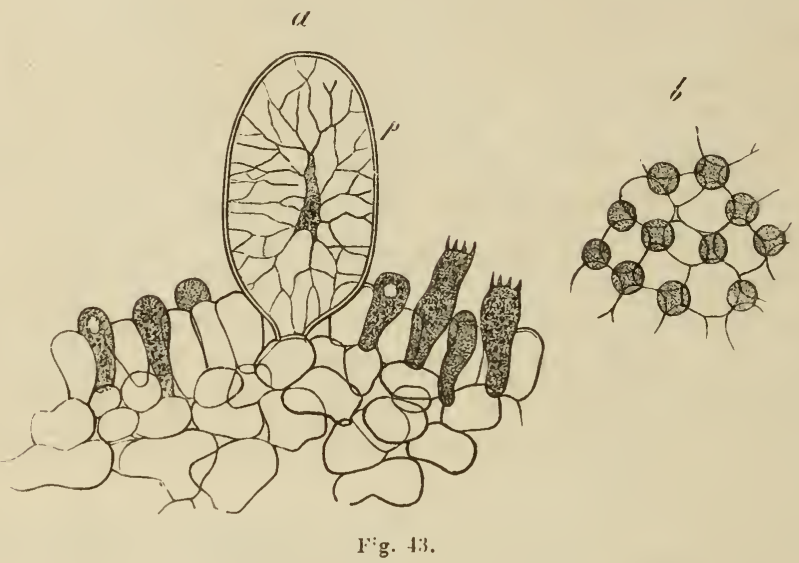

Endzweigen der fruchltragenden Hyphen ist oder tright in vielen Fällen nur ein Theil Basidien. Eine oft betrïchtliehe Anzahl derselben bleibt unfruchtbar und umgilıt die Basidien ähnlich den Paraphysen der Ascomyceten, mit welchen sie auch den gleichen Namen führen können. Sic sind entweder gleich letzteren schmale, meist mehr\%ellige, von den Basidien auch der Gestalt nach sehr verschiedene Haare (z. B. Tremellinen), oder ihre Form und Grösse ist denen der Basidien ïbnlich, sie unterscheiden sich von diesen nur durch ihre constante Sterilitiit, ilıren späilichen Protoplasmainhalt und oft dadurch, dass sie durch Querwinde in mehrere Zellen getheilt sind (Geaster hygrometricus, Octaviania (Fig. 44), Hymenogaster. Bei Coprinus (Fig. 43.) sind diese Organe kurze und unregelmìissig prismatische, wasserhelle Zellen, welche wie Pflastersteine den grössten Theil der Hymenialfliche bedecken, und zwischen welehen sich, in ziemlich weiten Abstiinden von einander, die Basidien nach aussen dräingen. Besondere Erwähnung verdient das schiisselförmig gestaltete Ilymenium von Corticium a!̣norphum Fr., weil bei ihu die lang keulenförmigen Basidien in relativ geringer Zahıl zwischen schr zahlreichen, fadenförmigen, verzweigten und oft rosenh'anzförmig eingeschnürten Paraphysen stehen, und weil es daher auf den ersten Blick weit weniger dem Fruchtlager eines Hymenonyceten, als viehmehr dem einer kleinen Peziza gleicht. Beispiele für das beständige Vorkommen

Fig. 43. Coprinus micaceus Fr. $a$ dünner Längsschnitt durch die Oberfläche einer Lamelle. Die durch trüb-hörnigen Inhalt ausgezeichneten Basidien zwischen wasserhellen blasigen Paraphysen von den subhymenialen Zellen entspringend. $p$ Cystide. $-b$ Oberflächenansicht des Hymeniums. Vergr 390 . 
zahlreicher Paraphysen zwischen den Basidien sind ausser den erwähnten noch die Genera Stereum Fr., Corticium Fr. Es ist wahrscheinlich und bei ferneren Lntersuchungen zu beachten, dass die gennanten accessorischen Organe unter den in Rede stehenden Pilzen vielleicht verbreiteter, als gewöhnlich angegeben wird, aber da, wo sie den Basidien in Gestalt und Grösse gleichen, ubersehen worden sind. Bei Coprinus sind sie lingst bekannt: bei den IInmenomyceten ïberhaupt scheint sie Léveille in seiner grundlegenden Arbeit als tissu hỵménial von den Basidien zu unterscheiden; Montagne Esy. or $\underline{\underline{g}}$. et phys.j erwiihnt und beschreilot
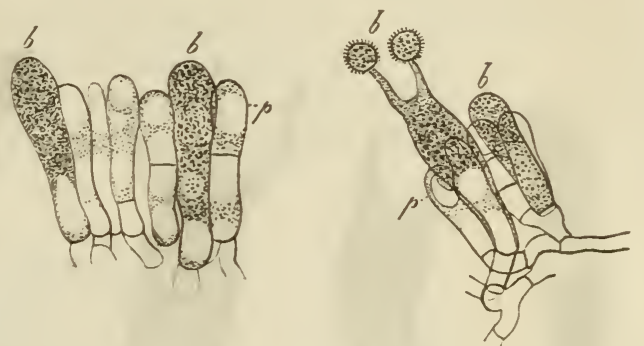

Fig. 44. sie sehr bestinmut als Paraphysen: allein in neuerer Zeit scheint man sie vielfach fiur noch unentwickelte Basidien gehalten oder mit solchen rerwechselt zu haben.

Die Basidie selhst ist eine Anfangas eylindrische Calocera. Dacrymyes oder in den allermoisten Fiallen kur\% keulenförmige Zelle. bei Corticium amolphum gestreckt keulenförmig und rnorm his 1/4 Mm. lang ghe Scheitel zunächst immer abgarerundet.

thre meist zarte. farblose Membran zeigat zu koiner Zeit bemerkenswerthe Eiggenthümlichkeiten. Sie enthiilt mehr oder minder kömig̣es, selten gefärbtes Protoplasma, welches entweder den ganzen Raum der Zelle gleichmaissig erfiillt, oder von Vacuolen, die manchmal reg̣ehuissige Anordnung zeigen, unterbrochen ist. In den Basidien einiger Pilze ist ein Zellkern enthalten. welcher dem für die Asci beschriebenen in jeder Bezichung aihnlich ist. Er wurde in dem hiesigen botanischen Laboratorium zuerst von J. Walz bei Dacrymyes deliquescens gefunden, wo er in ganz jungen Basidien nicht erkemnbar, in entwichelteren dagegen in der fiir Peziza confluens beschriebenen Form otwas unterlatb der Vitte constant vorhanden ist. Ferner fand ich ihm bei Corti('ium amorphum und Ilypochnus spec. ("Thelephora calcea auct. vet.). Bei anderen Arten Hymenogaster Klotzschii, Coprinus konnte ich ihn bis jetzt nicht finden, doch ist kaum zu bezweifeln, dass er sich allyemeiner nachweisen lassen wird.

Zum Behufe der Sporenbildung Fig. 403 treibt der Scheitel der Basidie meist zwoi oder mehr Ausstuilpungen, welche in der Regel die Gestalt aufrechter, pfrienenförmiger Stiele. Sterig̣men annehmen. Wemm diese ihre definitive Liange erreicht haben, schwilt ihre Spitze an zu einer Blase. welche allmihlich die Gestalt und Grösse der fertigen Spore erhält. In dem Maasse als dies fortschreitet rücht das Protoplasma aus der Basidie in die Anschwellungen hinauf, jene wird ron unten nach oben mehr und mehr entleert und enthiilt, nachdem die Sporen ihr Wachsthum rollendet haben; nur mehr spärliche Protoplasma-

Fig. 44. Octaviania carnea Corda. Dünne Schnitte durch das Hỵmenium, 390 fach vergr.

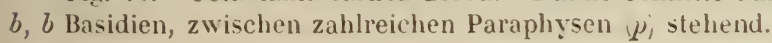

Handbuch d. physiol. Botanik. II. 
überbleibsel und Fettkörner. Von dem Beginn der Sterigmenbildung an fand ich den Zellkern in den Basidien der oben genannten Arten nicht mehr, er scheint zu verschwinden. In den jungen und frisch gereiften Sporen vieler
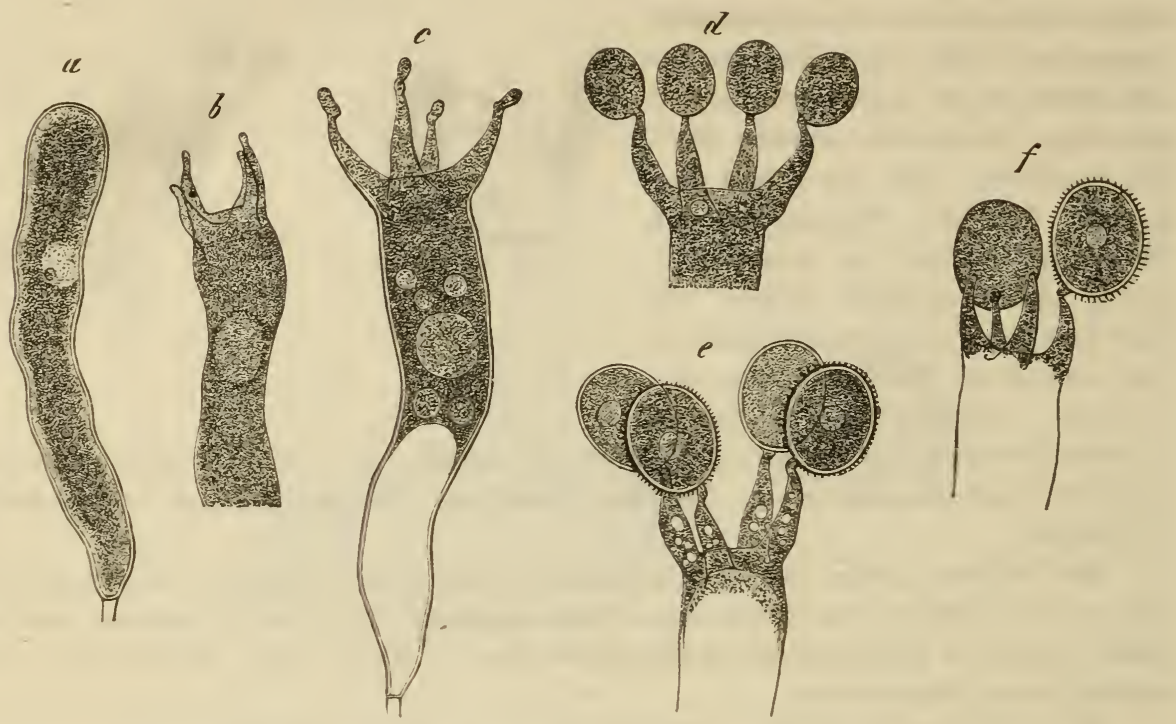

Fig. 45 .

Arten unterscheidet man einen centralen, hellen Kreis; ob derselbe ron einem Kern herriiht, lasse ich dahingestellt. Zuletzt, nachdem die Sporenanlagen ihre rolle Grösse erreicht und ihre Membranen nahezu rollstandigg a usgebildet und rerdickthaben, grenzt sich die Spore durch eine Querwand ron der Basidie ab, letztere geht allmïhlig zu Grunde, manchmal z. B. Dacrym len durch Querwinde getheilt hat. Die Abgliederungsstelle der Sporen liegt meistens rin hurzes Stüch unterhall) des Insertionspunhtes der Anschwellung, sie wird bei sehr vielen H!menomyceten durch eine leichte Knickung des Sterịma nach aussen von Anfang an bezeichnet. Die Spore ist daher zur Zeit der Reife an ihrem Anheftumgspunhte mit einem hurzen Stielchen versehen. Bei Borista und cinigen Lycoperdon-Arten geschieht die Abgliederung im unteren Theile des Sterigma, die Basis der Spore ist daher in einen langen stielartigen Anhang ausgezogen. Bei einer Inzahl ron Genera Geaster hygrometricus, Poḷsaccum, Scleroderma, Phalloideen sind die Sterigmen ganz kurz oder gar nicht entwickelt, im Tebrigen die Sporenbildung gleich der beschriebenen: die Sporen sitzen daher unmittelbar auf dem gewölbten Scheitel der Basidie. Eine ganz eigene Form haben die Basidien ron Geaster tunicatus Tulasne, fung. hyp.

Fig. 43. Corticium amorphum Fr. Sporenhildung. Entwickelungsfolge nach den Buchstaben $a-f$. " fast erwachsene Basidie mit Zellkern. $f$ Abgliederung einer reifen Spore; zwei der auf dieser Basidie gebildeten sind schon abgefallen. Verğr. 390. 
Tab. XXI, fig. IX). Sie sind oval-keulenförmig̣e Blasen, deren Scheitel in einen cylindrisch kegelförmigen, schmalen Hals auswichst; das obcre Ende des letzteren treibt dann etwa sechs strahlig divergirende, sporenabschnürende Sterigmen. Die Zahl der Sterigmen und Sporen auf einem Basidium ist bei der uberwiegenden Mehrzahl der basidiosporen Schwimme vier, bei anderen z. B. Calocera, Dacrsmyces, Arten ron IIymenogaster, Octaviania [Fig. 4t] typisch zwei, in noch anderen Fillon sechs bis neun, durchschnittlich etwa acht (Phalloideen, Rhizopogon, Geaster [Fig. 46] etc.). Schwankungen in der Zahl,
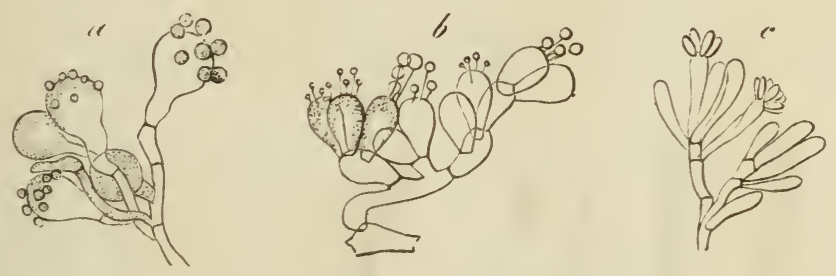

Fig. 46.

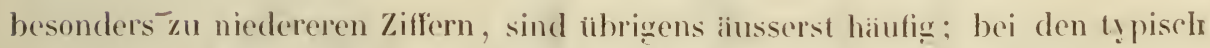
viersporig̣en Arten wird man z. B. selten vergobens nach zwei- und dreisporig̣en Basidien suchen. Typisch einsporige Basidien scheinen, abgesehen von den unten zu nemnenden Tremellinemgattunğen, lei Gastro- und H!menomyecten nicht volzuhommen; als Ausnahmsfiille finden sie sich nicht selten bei typisch zweisporiguen Arten, zumal Hymenogastreen z. B. Hymenogaster Klotzschii .

Abgeschen von zufiallig eintretenden. ïhrigens sehr seltenen Störungen, halten alle Sterigmen und Sporen einer Basidie in ilner Entwichelung genau gleichen Schritt. Die Basidien eines und desselben Il meniums dagegan fruetificiren heineswegs gleichzoitig und es ist behannt, dass man in nicht iiberalten Fruchttrigern immere ihre verschiedensten Entwichelungszustiande nelen einander finden kann. Diejenigen, welehe gerade in der Sporenbildung begriffen sind, strechen sich derat, dass ihr scheited oder wenigstens Tremellinen, ilıre

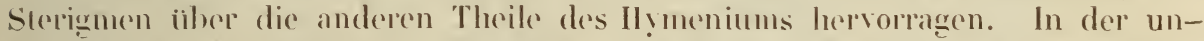
galeichzciliggen Ausbildung der Basiden, und nicht, wie Schnitz früher meinter, in der melermals wiederholten sporenbildung auf jeder derselben hat es seinen

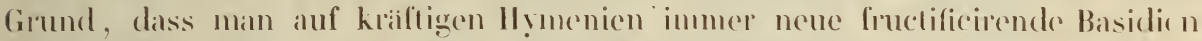
hervorteren sicht, wenn man die reifen syoren abewewischt hatte.

Wie Tulasne zuerst gezeigat hat, sind die Basidien von Exidia, Tremella und Ilỵdnum gedatinosum dureh ihe Entwichelung von allen anderen versehieden. Auf den Enden der zarten und diinnen subhymenialen Fiden finden sich zuerst zahleciche, gleich Basidien angeordnete, protoplasmareiche Zellen frimiire Basidien ron kugeliger oder hreit ovaler Gestalt. Diese theilen sich durch senkrechte Lingrswinde in vier wie Kugelquadranten geordnete Tochterzollen, vonfenenen jede eine einsporige Basidie ist. In der ursprünglichen Ver-

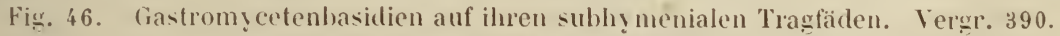

\footnotetext{
a ssporigre ron Geaster hygrometricus.

6 4iporige von Lycoperdon py riforme.

c 4-ssporige von Phallus caninus.
} 
einigung verbleibend oder ron den übrig̣en drei sich loslösend. treibt eine jede aus ihrem oberen Ende ein langes Sterig̣ma, dessen weiteres Verhalten den oben beschrichenen gleich ist. Die Zahl der aus einer Mutterzelle entstandenen Basidien ist ähnlichen Variationen unterworfen, wie die oben besprochenen Zahlenverhailtnisse. Bei Hirneola Auricula Judae Berk. (Exidia Auctor.) ist die primäre Basidie lang ç̣lindrisch, den Basidien von Dacrỵmces und Calocera sehr ähnlich. Sie theilt sich durch Querwände in eine Reihe von vier oder fünf Tochterzellen, von denen jede ein pfriemenförmiges aufrechtes Ste-

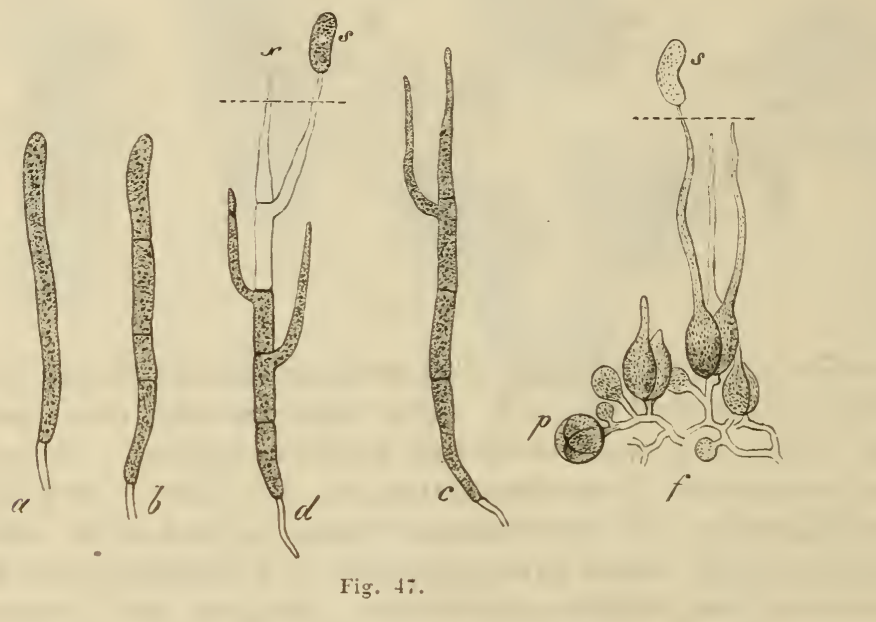

rig̣na treibt, welches über die Ilymenialfliche hervortritt und eine Spore abschniur. An der obersten Basidie einer Reihe tritt das Sterigma aus dem Scheitel, an den anderen seitlich dicht unter der oberen Wand herror; seine Bildung und die Sporenabsehnirung heginnt in der obersten Basidie einer Reihe, der dann die anderen, von oben nach unten fortsehreitend, folgen. Fig. 4i).

Simultane Basidien kommen, wie aus den Beschreibungen bekannt ist, bestimmten Fructificationsorganen zahlreicher anderer Pilzgruppen zu, als die soeben beschriebenen. Die Gestalt der Basidien ist je nach den einzelnen Arten höchst mamnigfaltigy, theils denen der Gastro- und Hymenomyceten ähnlich (z. B. Botrytis cinerea, Gonatobotrys, Botryosporium Corda, theils verschieden; hiiufig haben sie die Form fadenförmiger, im Verhiltniss zur Spore schmaler Stiele, sie gleichen dann den Sterị̣men der oben beschriebenen Pilze und werden hiaufig einfach mit diesem Namen bezeichnet. Die Zahl der Sporen auf einer Basidie wechselt auch hier nach Arten und Gattungen: typisch zwei- und

Fig̣. 4i. $a-d$ Hlirneola Auricula Judae Berk. (Exidia Auct.) Basidien; $a$ Primärzelle, $b-d$ Theilung derselben, Bildung der Sterigmen und Sporen. In $d: x$ Sterigma, dessen Spore ahgefallen. $s$ spore. Die punctirte Linie bezeichnet die Hymeniumoberfläche (die Spore ist nach einem anderen Präparat auf das Sterigma gezeichnet, alles Uebrige genau nach d. Natur; 390 fach vergr.).

$f$ Exidia spiculosa Sommerf. Basidien verschiedener Entwickelung. $p$ Primärzelle, in vier Tochterzellen Basidien) getheilt. $s$ und punktirte Linie wie bei $d$. Stark vergr. Nach Tulasne copirt. 
viersporige scheinen nicht ausserhalb der Hymeno- und Gastromyectenordnungen vorzukommen; mehrsporige sind z. B. den soeben genannten Hyphomycetenformen eigen. Auch die typisch einzelligen, dichotom verzweigten und an den Zweigenden je eine Conidie (Spore, Sporangium) abschnuirenden Fruchttriger ron Peronospora sind hier zu nemnen. Am häufigsten sind jedenfalls ausserhalb der Gastro- und Hỵmenomycetengruppe einsporigac, schmal stielförmige, in der Regel Steriğmen genannte Basidien. Sic kommen z. B. den sogenannten Uredohymenien vieler Uredineen \%. B. Puccinia, Phragmidium, Melampsorae spec.) zu, und wohl auch den conidien- und stylosporenbildenden Organen von Ascomyceten; doch ist es bei diesen vielfach ungewiss, ob die Basidien simultane, und nicht, wie für sehr vicle ausser Zweifel steht, succedan abschnürende sind.

Der Process der Sporenhildung ist, soviel bekannt, fiir alle Fille wesentlich der ggleiche, welcher oben beschrieben wurde. Nur die aine bemerkenswerthe Verschiedenheit kommt oft ror (z. B. Uredineen, dass sich die spore vor Vollendung ihrer Verg̣rösserunğ und Ausbildungِ dureh eine Querwand von ihrem Triiger abgrenzt und dann his zur Reife von letzlerem aus auf endosmotischem Wege ernibiht wirl.

Auf den suecedan abschnoirenden Basiden ist der Vorgang bei der Bildung jeder einzolnen Spore, wenn man von den tausenderlej Formdifferenzen absieht, wesentlich der oben beschriebene, er wiederholt sich aber mohrmals

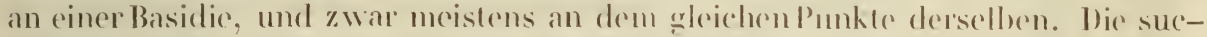
cedane Abschniirung kommt in drei Hauptformen vor, als Abschniarmeg von Sporenköpfehen, voneinfachenundron is sig̣en Sporenkeflen orler Reihen Bildung von Arthrosporen, wie Leveille die Gilieder soleher Keften genamnt hat .

Bei der arsten Form Fign. is entsteht auf dem spitzen Ende des schmalen, pfriemenförmiggen Basidiums oder sterig̣mas zuerst eine einzolne spore. Nach Mholiederung derselben sprosst dicht nobon ihrer Insertionsstelle eine neue Anschmellung aus dem Sterigma hervor, welehe die erstgebildete Spore zur Sorite driingt, 1101 bald ihrerseits das Ende des Sterigma cinzumehmen und sich num zur Spore ausbildet. Auf die zweite şpore folget in derselben Wreise pine sie verdraingende drille, und so weiter, oft wiederholt sich der Vorgang viele Male hintereinander. Die verdringten sporen bleiben entwerler unter der spitze des Sterigma eine Zeit lang
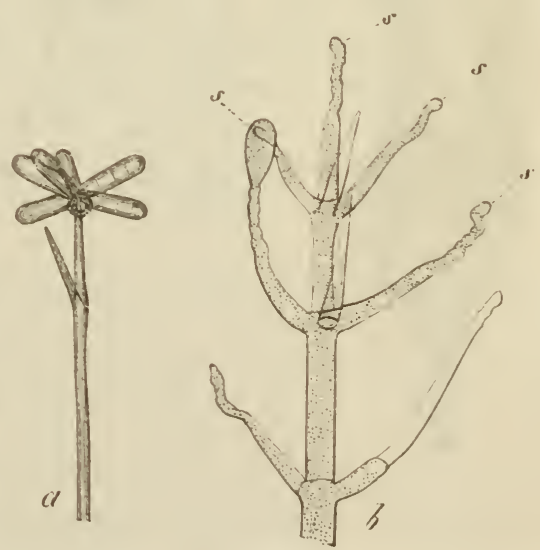

Fig. 45 . sitzen, indem letzleres zwischen je zwei Sporen ein wenn auch sehr kleines Stiick in die Länge wïchst und hierdurch

Fig. 4s. Dactylium macrosporum Fr. Enden von sperentragenden Hyplien, 300 ma vergr. " trocken, oben Sporenköpclien. $b$ in Wasser; auf den Zweigenden Anfänge der jünsten sporen $s$; die darunter stehenden kleinen Enebenheiten sind die Ansatzstellen der alteren, durch das Wasser abgelösten Sporen. Vergr. 300. 
ihren Anheftungrsunkten Raum gibt; sie sind strahlig zu einem köpfchen vereinigt, in dem sie einen um so höheren Platz einnehmen, je jünger sie sind. In anderen Fillen wird jede Spore durch ihre Nachfolgerin vollkommen von ihrem Träiger abgelöst, um abzufallen oder der jüngeren seitlich ankleben zu bleiben, letzteres nicht selten vermittelst gallertiger Aussenfliche. Beide Formen der Köpfchenbildung kommen häufig vor; für die erstere mögen Dactylium macrosporum Fr., die kleinen Conidien ron Hypomyces Tul. (Verticillium agaricinum Auct. und ihnliche Formen), Botrytis Bassiana als Beispiele genannt werden: für die zweite dic als Acrostalagmus Cord. bezeichneten Hyphomycetenformen, die Conidien ron Sphaeria typhina, Claviceps purpurea (s. Fig. 79 b, Kühn, Ber. d. Landw. Inst. zu IIalle). Es ist wahrscheinlich, dass zumal die letztere Form unter den conidienbildenden Organen der Ascomyceten eine grosse Verbreitung hat, sic ist aber schwer und nur an ganz frischen in der Luft befindlichen Exemplaren zu erkennen, weil die reifen Sporen durch Erschüterung oder Einwirkmog von Wasser sofort von dem Orte ihrer Entstehung losgetrennt werden.

Bei der succedanen Abschnurung einfacher Sporenketten sprosst

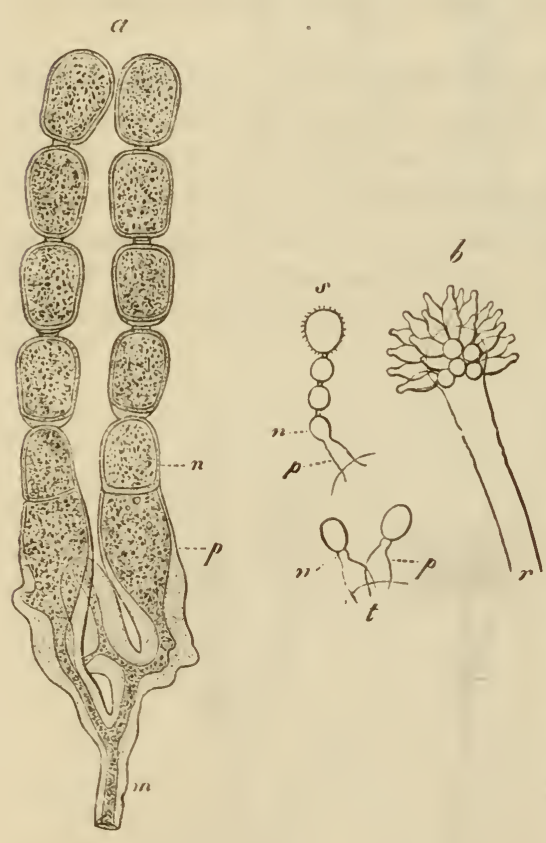

Fig. 49. unter der erstgebildeten Spore aus dem Gipfel des Sterigma oder der Basidie eine neue Ausstülpung hervor, welche die erste senkrecht emporhebt und fortschiebt und sich selbst zur Spore entwickelt. Der zweiten folgt eine dritte, und so fort, oft bis zu zwanzig und mehr (Fig. 49,. Die an jedem Bildungspunkte erzeugten Sporen bilden somit eine Kette, deren Glieder um so jünger sind, je naher sie dem genannten Punkte liegen. Sie bleiben oft lange locher mit cinander verbunden vermöge viner zarten, alle iiberziehenden aussersten Membranschichte, welche zwisehen je zweien tief eingeschnürt ist und laselbst eine schmale Bricke bildet. Yon den zahlreichen bekannten Fillen der einfachen kettenbildung seien hier die Conidien der meisten Erysiphe-Arten, Penicillium glaucum, Asperọillus Fig. 49, $b$, die Accidiumfrüichte der Eredineen, sowie die Conidien Sporang̣ien von Cystopus Fig. 49, a beispielsweise grenannt. In Beziehung auf die Form der Abschnurung kommt bei diesen und ähnlichen Beispielen eine Verschiedenheit in soferne vor, als bei den einen Aspergillus. Penicillium jede Sporenanlage aus dem bleiben-

Fig. 49. $a$ Conidienhildung von Cystopus Portulacae Lér. Verg̣r. 390.

6 Dieselbe von Eurotium herbariorum Lk. Aspergollus glaucus; Verğr. 300. r kopfiges Ende einer Fruchthyphe, dicht mit Basidien oder Sterigmen besetzt, auf denen die Bildung der ersten spore beginnt. In $s$ und $t$ einzelne Basidien. In $a$ und $b$ is $p=$ Basidie, $n$ jungste spore, m Mỵcelium. 
den Gipfel der Basidie hervorsprosst in Form einer mit schmaler, stielartiger Basis aufsitzenden Ausstülpung: während bei den anderen Erısiphe, Cystopus, Aecidien) nach jeder Sporenbildung das breite Ende des Basidiums ein Stïck in die Lainge wächst, sich dann durch eine horizontale, breite Querwand als Spore abgrenzt, und diese dann abgegliedert wird dadurch, dass sich die Querwand in eine der Sporenmembran und eine der Basidie angehörende Platte sondert, welche sich beide gegeneinander wöben und zuletzt trennen.

Die Bildung is tiger Sporenketten beginnt damit, dass auf der Basidie ein, oder meistens mehrere, selbst zahlreiche Sporenanfïnge auftreten. Nach oder vielleicht selbst schon vor ihrer Abgrenzuıg durch eine Scheidewand sprosst aus dem oberen Ende der jungen Spore der Anfang einer zweiten herror, aus dieser die dritte u. s.f. Neben den terminalen treten an den jungen Sporen auch seitliche Sprossungen auf, die sich den terminalen gleich verhalten. Es ist ohne Weileres klar, dass auf diese Weise eine verzweigete, rosenhranzförmigge Zellreihe zu Stande kommt, deren Glieder um so jünger sind, je ferner sie der Ursprungsstelle der Reihe liegen. Ob auch typisch einfache Reilıen durch diesen terminalen Sprossungsprocess gebildet werden hönnen, ist mir nicht behannt. Zuletzt, und in derselben Aufrinanderfolge wie sie entstanden sind. nehmen alle Glieder der Ketten gleichmissigy die Eigenselaften von sporen an und trennen sich ron einander. I)iese letzteren Erscheinungen rechtfertigen denn auch die Bezeichnung der einzelnen Glieder als Sporen, wiihrend der Entwickelungsgeschichte nach alle diejeniggen, von welchen neue sprossungen ausgehen, ebenso gut Basiolien als Sporen genannt werden hönnten: - es ist dies einer der bei niederen Gewachsen so hiufig̣ wiederhehrenden Falle, in denen eine strenge Classilication der Organe auf uniberwindbare Sehw ierig̣keiten stösst. Für die beschrielenen Bildungen liefern Beispiele die dichen Sporenhöpfe der Formen, welehe von Fresenius Beitr. und Riess Bot. Zeitg. 18:33, 139) Periconia genannt werden, die des II r rocephalum botryosporum Not. und die allenthalben so läiufigen Microconidientrigger von Pleospora herbartum 1g̣l. Tulasne, Carp. II.), welche den Xamen Dematium vulgarere, Dem. herbarum Pers. fiihren. sowie viele ihnliche, schwer zu benennende formen. (Vọl. auch Penieillium viride. P. chlorinum Fresenius, Beitr. Taf. III, P. olivaceum Corda, Ie. III, fig.. 3. .).

Eine Menge dubiöser, den Pilzen beigesellter Organismen, zumal die Gattung der Hefenpilze. Il orm iscium kunze, mil ihrem bekanntesten Repriisentanten H. Cerevisiae, der Bierhefe Torula Cerevisiae Auet. plur., Creptococeus hiitzing besteht aus Zellen. welche erst einzeln gefunden werden. und aus welchen unter geeigneten Bedingungen istig̣e, rosenkranzlörmige Zellreihen hervorsprossen, genau wie die astigen Sporenketten aus ihren Anfang̣sgliedern. Olıne hier discutiren zu wollen ob diese Hefezellen ursprünglich von Fruchtträgern bestimmter Pilze erzeug̣t, oder Repräisentanten selbstiondig̣er Arten sind, ist es am Platze, sie an dieser Stelle zu erwihnen. Nach ihnen wird die sochen beschriebene Sprossung und Kettenbildung häufig kurzweg als hefeartige Sprossung bezeichnet, und ihre umstehende Nbbildung Fig. mögęe zur Erliiuterung der Bildung verzweigter Ketten dienen.

Es eriibrig̨t noch, die histiologischen Verinderungen zu betrachten, durch welche die Lostrennung der abgeschniirten sporen von ihren Trigern bewirkt 
wird. Am vollständigsten lassen sich dieselben beobachten bei den einfachen Conidien- Sporangien-) Reihen von Cystopus, zumal C. cubicus und C. Portulacae. Vgl. de Bary, $\mathrm{nnn}$. sc. nat. 4e

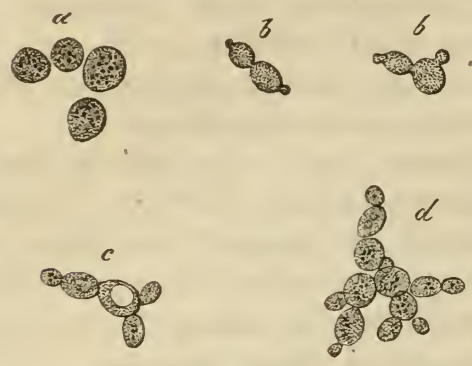

Fig. 50. sér. tom. XX, p. 133. Die Conidie (Fig. 49 , a) wird hier angelegt dadurch, dass sich der kuppelförmigae Scheitel der keulenförmigen Basidie mittelst einer dicken, gallertartigen, bläulich glänzenden Querwand von dem unteren Theile abgrenzı. Die Querwand entsteht wie die Scheidewände der Confervenzellen, sie setzt sich in die inneren Schichten der Seitenwand der Basidie fort, die äusserste Schicht letzterer zieht sich als eine düne Scheide continuirlich iber die Querwand und die ganze Conidie. Nach Bildung einer Conidie wiichst das obere Ende des Basidium ein Stück in die Lỉnge und nimmt wiederum Kuppelform an. Die Querwand behiilt ihre ursprüngliche Gestalt und Grösse, sie sitzt daher bald auf dem Scheitel der Basidie als eine kreistunde, oben leicht concave, die Conidie tragende Platle, deren Rand anscheinend frei, jedoch von der scheide wie zu Anfang eingeschlossen ist. Auf der Innenflache der Querwand erscheint nun eine neue, in die Seitenwand der Conidie continuirlich abergehende Celluloseschicht, die Conidie ist somit von einer eigrenen Membran rings umgeben, unten von der ursprünglichen Querwand gestützt, seillich von der Scheide überzogen. Indem sich der gleiche Torgang nach den Regeln der einfach reihenweisen Abschnürung wiederholt, entsteht cine lange Kette ron Conidien. In dem Maasse als diese von den jüngeren vorgeschoben werden, nimmt die Grösse der primiiren Quewainde unter ihnen ab, letzlere erscheinen unter der drittoder viertjünǵsten Conidie einer Reihe nur mehr als kleine, dünne, kreisförmige Plittehen und sind an noch iilteren völlig̣ verschwunden. Die Scheide bleibt den hleiner werdenden Querwinden immer eng anliegen, sie wird daher mit dem Schwinden letzterer zwischen je zwei Conidien immer tiefer eingeschnür, nach dem völligen Verschwinden der Querwand bleiht sie zunächst erhalten als zarte, die Conidien verbindende Bricke, die endlich gleichfalls verschwindet. An der Abgrenzungsstelle der Conidien findet somit ein in entgegengesetztem Sinne erfolgendes Converwerden der einander berührenden Winde ron Conidie und Basidie statl. und eine allmähliche Resorption der primiren Querwand sowohl wie der scheidenartigen iusseren Portion der Mutterzellmembran. Beide Processe oder der letztere für sich allein muissen in allen Fällen die Loslösung der abgeschnürten Fortpflanzungszellen bewirken, wie sich meistens nachweisen lisst, wemn auch minder rollstindig wie in dem beschriebenen erquisiten Beispiele.

Fig. 30. Bichefe Hormiscium Cerevisiae). 390 mal verg̣r. a Zellen vor der Sprossung. $b-d$ sprosungen, in gährender Traubenzuckerlösung. Entwickelunğfolge nach den Buchstahen. 
3. Sporenbildung durch Zelltheilung.

Als Zellentheilung bezeichne ich im Gegensatz zur freien Zellbildung , bei welcher ein Theil des Protoplasmas einer Ifutterzelle zur Anlage von Tochterzellen wird denjenịgen Vorg̣ang , bei dem der ganze Protoplasmakörper der Mutterzelle in zwei oder mehrere Tochterzellen zerfiillt, sei es unter gleichzeitiger Bildung von der Innenschichte der Multerzellhaut ausgehender und mit dieser zusammenhängender Scheidewinde 'wandstindige Zelltheilung Nigeli, Theilung durch Scheidewände, sei es ohne unmittelbare Betheilig̣ung der Ifutterzellmembran.

Alle nicht in den beiden vorhergehenden Abschnitten besprochenen Sporenentwickelungsprocesse, sind unter der in der Leberschrift genannten Bezeichnung zusammenzufassen. Die in dem rorigen Abschnitte beschriebene Abschnürung ist ledig̣lich eine Form der Zelltheilung̣ mit Scheidewäinden, und sie ist, wie sich a priori erwarten liisst, mit den übriggen Theilungssormen durch so zahlreiche Leborgạngsformen verbunden, dass auf eince allg̣emein durchğreifende Trennung wohl stets wird rerzichtet werden missen. Immerhin wird die Enterscheidung für viele Fialle durchführbar und gevechtfertig̣t sein.

In der folgenden Eebersicht der Ilauptformen, unter welehen die Sporenentwickelung durch Zelltheilung auftritt, sollen, der Deutlichkeit wegen, die scharf characterisirten Fille vorangestellt werten. es ist daher zu beginnen mit der

1. Theilung ohne scheidewandbildung. Dieselbe findet statt in den Sporangeien der Mucorinen, den Zoosporangen der Saprolegnieen und Peronosporeen. Das ganze. entweder wandstimdige oder den ganzen Zellramm erfiillende Protoplasma der Sporemuntlerzelle zerfiillt bei diesen Pilzen simult a n in mehrere zwei, drei his zwölf und sechzehn bei den Peronosporeen oder selur viele Saprolegrnieen, den meisten Mucorinen Portionen, welche erst durch sehr zarte, dann schibfer hervortedende Grenzlinien umschrieben sind und ron denen jede alsbald die Eịgenschaften einer Spore annimmt, bei den Jucorinen eine derlue Zellmembran um ihre Oberfliche erzeugend, bei den anderen Gruppen zuniehst olne distincte Membran. Die Wand der Sporenmutterzelle ist bei dem Vorgang unbetheilig̣t, die sporen liegen abgesehen von der sogleich zu erwihnenden Besonderherit bei P’ythum ron dem Momente ihrer Bildung an frei in dem ron ihr unschlossenen Bamme. Man hat deshalb. aber wie ich glaube mit Enrecht. den in Rede stehenden Process den Erscheinungen der freien Zellbildung zug̣ezililt.

Der Theilung geht wohl immer für die Mucorinen fehlt es an genauen Lntersuchungen eine Verönderung in dem Ansehen des Protoplasma voraus, es

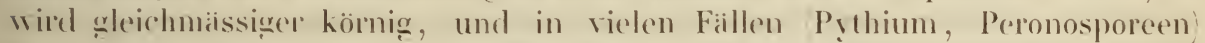
treten in ilım sovicle zartumschriebene, runde, körnerfreie, helle Flecken auf, als Sporen gebildet weiden; jeder Fleek nimmt nach der Theilung die Mitte einer spore ein. Ob es sich hier um Zellkerne oder Analogá derselben handelt, ist zweifellaft, nach vereinzelten Beobachtungen an Mucorinen Piloholus, folgend. Mbschn. nicht unwahıseheinlich.

Die sporemmatterzellen der in Rede stehenden Pilze entstehen einzeln oder 
reihenweise auf den Enden der fruchttragenden. Ilyphen; bei den Peronosporeen werden sie ror der Sporenbildung durch Abschnürung losgelöst: bei Achlyogeton und, wie es scheint, auch Pythium reptans wird schliesslich jede Gliederzelle des verästelten Thallusfadens zu einem Sporangium. Bei den letztgenannten Formen ist selbstrerständlich die Gestalt der Sporangien der der Thalluszellen gleich; bei den übrigen sind jene durch berondere Formen ausgezeichnet. Bemerkenswerth ist die für die Gattung Mucor characteristische: das Sporangium ist eine kugelige, endstindige Blase, deren untere, dem Fruchttriger angrenzende Wand hoch emporgewölbt ist, also in Gestalt eines kopflörmigen Körpers („Columella ins Innere der Kugel ragt.

Von dem Bau des Sporangiums sei hier nur eine Eigenthümlichkeit der Gattung Pythium hervorgehoben. Unmittelbar vor der Sporenbildung quillt plötzlich aus seiner Spitze eine kugeligge, rasch anschwellende Blase hervor, welche von einer höchst zarten, weichen, in die innerste Umrisslinie der Scitenwand sich fortsetzenden Membran umgeben ist, und in welche das ganze Protoplasma des Sporanğiums ron dem ersten Augenblicke ihres Erscheinens an rasch einströmt. Zuletzt lieğ alles Protoplasma zu einer regelmässigen hugel geformt in der Blase, vor der leeren ursprünglichen Sporangiummembran , und nun beginnt sofort die Sporenbilelung.

2. Theilung mit Scheidewandbildung. Soweit die vorhandenen Untersuchungen reichen, ist hier der Vorganga der Theilung selbst der nämliche, wie bei der regetativen Zeltentheilung sowohl der Pilze als der übrigen Gewähse, eine Beschreibung desselben unterbleibt daher hier. Was die Formèn, in denen der Vorgarang auftritt, betrifft, so schliesst sich die erste unmittelbar an die Abschnürungen an: der obere Theil einer eglindriseh - keulenförnigen Mutlerzelle Basidie grenzt sich friih durch eine Querwand von dem unteren ab und wichst, von letzterem als von einem Stiele getragen und ohne sich spontan von ihm loszulösen, zur Spore heran. Entweder wird auf diese Art eine einzelne Spore gebildet Teleutesporen der typischen Uromyces - Arten, Melampsora, Sepedonium chrysospermum Fr. und wohl auch die Stylosporen mancher Sphaeriaceen, bei welchen jedoch 1 bschniirung meistens stattzufinden scheint, oder der ersten Spore werden ron der Basidie aus andere nachạeschoben in derselben Weise wie bei der Abschnürung einfacher Sporenreihen. Die sogenannten Lig̣ula oder Columella ron Cronartium besteht aus zahlreichen und reichgliederigen sporenreihen, ron denen eine jede auf die oben angedeutete Weise entsteht und wächst, und welche simmtlich zu einem soliden Cy linder der Linge nach miteinander rerbunden sind.

Die zweite Form schliesst sich eng̣er an die vegetative Zellentheilung an. Die Sporenmutterzelle wird durch Scheidewinde getheilt in eine verschieden grrosse Anzahl ron Tochterzellen, die nach Art regetativer zu einem Körper verbunden bleiben. und von denen jede die Eig̣enschaften einer Spore annimmt. Die Zahl der Tochterzellen in einer Mutterzelle ist nach Gattungen und Arten sehr verschieden, ron zwei z. B. Puccinia bis zu sehr vielen, ihre Anordnung: wenn mehr als zwei rorhanden sind, entweder reihenweise oder flächenartig̣, oder nach den drei Raumesdimensionen. Wohl in den allermeisten Fällen. wenigstens den bisher untersuchten, entstehen auch die mehrund vielzellig̣en hier in Rede stehenden Körper durch wiellerholte Zweitheilung: 
und zwar theilt sich in der Regel die Mutterzelle in zwei nahezu gleiche Hiilften, die Tochterzellen der verschiedenen Generationen ebenfalls; bei den vielzelligen Körpern mit Anordnung der Zellen nach zwei und drei Dimensionen pfleğt die Theilung in der Mitte des Körpers durch eine girössere Anzahl von Generationen zu dauern, als an seinen Enden. Bei den braunen Teleutosporenreihen von Phragmidium (von welchen ich frïher, durch die dicke, gallertige Mutterzellmembran getiuscht, eine Entstehung durch freie Zellbildung annahm, welche Meinung Hoffmann neuerelings reproducirt hat beginnt die Abgrenzung der Sporen durch Querwinde in dem Scheitel der Mutterzelle und schreitet ron da zum Grunde fort, sie bedarf hier iibrigens nochmalig̣er Lntersuchung. Ob da, wo typisch drei Sporen in einer Mutterzelle entstehen, wie z. B. bei Triphragnium, die Scheidewinde simultan entstehen, ist gleichfalls noch zu ermitteln. Es ist eine jedenfalls sehr allgemeine, wenn auch nicht ausnahmslose Regecl hei der in Rede stehenden Bildunğ, dass die Mutterzelle zur Zeit wo die Theilumğ begrinnt, eine im Vergleich mit dem fertigen Theilung̣sproduct gageringe Grösse und meist hohe Zartheit zeiggt. Die Tochterzellen früherer Generationen wachsen nach ilner Anlegung bedeutend, um sich spaiter wiedler zu theilen oder ungetheilt zu bleiben.

Wie bei viclen vegretativen Zellen, zumal niederer Gewichse, sind die Zellmembramen spoiterer Generationen bei den in Rede stehenden Körpern oft deutlich in die der friiheren eingeschachtelt. Besonders umgribt die Mutterzellenmembran den ganzen Körper als ein mit diesen wachsender eng anschliessender Sack.

Durch den in seinen allg̣emeinen Lmrissen sochen gaveschilderten Theilung̣sprocess entsteht ein Zellhörper, dessen einzolne Glieder die Ëgenschaften ebensovieler sporen haben, der also, seinem Wesen nach als ein aus sporen bestehender, ein sporen-Kïrjer zu bezeichnen ist. Solehe Sporenkörper sind

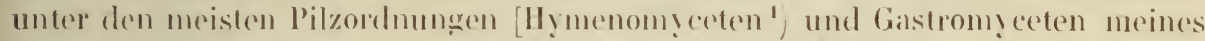

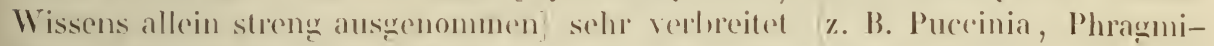
dium; viele Hyphom!ectenformen, deren șstematische Stellung noch nicht niher bestimmt ist, Trichotherium, Arthrobotr!s. Fusisporium u. s. f. ; andere. die wir jetzt als Conidientrigere on P’renom!celen hemnen, wie die Fries'schen Gruppen Aler Dematieen, Sporidesmiesen, z. B. Ilelminthosporium, Cladospo-

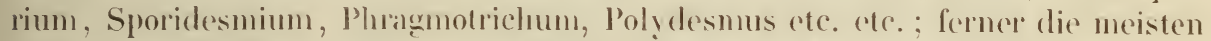
Stylosporen der Pyrenomyceten, wie die Formgenera Melaneonimm, Stilbospora, Coryneum, Exosporium, und sehr viele andere, Die Gestalt der Körper respe. ihrer Mutterzellen, die Anordnung - reihenweise, einzeln endstindig̣ oder interstitiell - ist nach Arten iiberaus verschiecten; ebenso ol der Körper oder seine Mutterzelle auf seinem Trägạer hefestig̣t bleibt oder sich durch Abschniurung loslöst.

Die in Rede stehenden Sporenhörper habe ich, in theilweisem Anschlusse an Fries, friber (Brandpilze mit dem Namen sporidien, der jetzl jedenfalls aufzuggeben ist, spiter Flora 1862 , p. 63 Sporenbiindel, Sporidesma genannt; allg̣emein gelten für sie die Bezeichnungen septirte. mehrfächeriğe, zu-

1) Bei Agaricus rutilus sollen nach Montagne Sporenkürper, rfuerwändiqge sporen vorkommen. S. Imn. sc. nat. 2e sér., t. s, p. 328. 
s a mmengesetzle Sporen, Sporae septatae, multiloculares compositae, auch Sporae cellulosae Corda', Semen multiplex (Tulasne carp.). Diesen Bezeichnungen liegt die Auffassung des ganzen Körpers als e in er Spore zu Grunde; der septirten oder mehrficherigen wird die unseptirte, cinfache Fortpflanzungszelle entgegengesetzt. Streng genommen sind diese Bezeichnungen unrichtig , denn wenn man von dem einzig̣en stichhaltiogen Gesichtspunkte ausgeht und die einzelne geschlechtslose Fortpflanzungszelle Spore nennt, so ist eben jedes einzelne Fach jener vielfächerigen Körper eine Spore, und nicht der ganze; und wenn man consequent sein und ron mehrficherigen, d. h. mehrzelligen Fortpflanzungszellen reden wollte, so würde dies widersinnnig sein. Yom histiologischen Standpunkte aus ist darum die oben gegchene Auffassung wie mir scheint die allein richtige. Behält man dieses im Auge, so mögen übrigens Ausdrücke wie septirte, querwindige Sporen heizubehalten sẹn, wie so manche andere einmal eingehürgerte in ihrer wörtlichen Bedeutung unpassende Kunstausdrücke; und am zweckmiissiq̣sten dürfte ron den überkommenen dic Bezcichnung z.u s a mmengesetzte Sporen sein; sie soll hier hinfort gebraucht, und das einzelne Glied einer zusammengesetzten als Einzel-oder Theilspore, Merispora, bezeichnet werden.

Dic altherkömmlichen Bezeichnungen, welche socben besprochen wurden, sind übrigens von anderen als streng histiologischen Gesichtspunkten aus darum

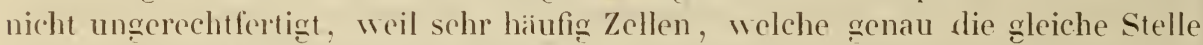
in dem Entwickelungs sange einnehmen, bei der cinen Gattung oder Species zur einfachen Spore werden, bei der anderen Mutterzellen zusammengesetzter Sporen sind. Ein bekanntes Beispiel hierfür liefern die Genera Lromsces Tul. und Puccinia, und das auffallendste jedenfalts die Ascomyceten, zumal Prrenomyceten. Dic Fortpflanzungszellen, wetche in den Ascis durch freie Zellhildung entstehen, und in dem früheren Abschnitte Sporen genannt worden sind, werden hier in riner Reihe von Fillen zu einfachen, in einer anderen zu zusamengesetzten Sporen. In letzteren beginnt die Theilung schon sehr frühe,

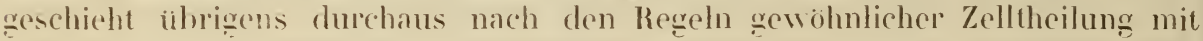

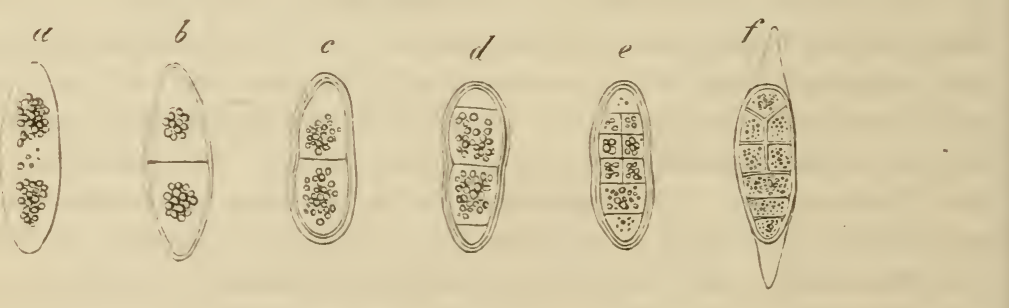

Fig. 51.

Scheidewandhildung, was nach den wenig̣ klaren Darstellungen von Sollmann Botan. Zeitung 1862,1863 zweifelhaft werden könnte. Tgl. Figg. äI .

Fị̣. з̆1. Sphaeria Scirpi DC. $a-e$ Entwickelungsstadien der Sporen, 390 fach vergr. Entwickelungsfolge nach den Buchstaben; alle nach Exemplaren gezeichnet, welche sich im Innern frisch freigeleg̣ter, unverschrter Asci befanden. $f$ reife, entleerte zusammengesetzte Spore, 330 mal verg̣., 
An die Zelltheilungen und reihenweise Abschniirung schliesst sich auch del Sporenbildungsprocess von Ĺstilago an, wie er von kühn und mir früher beschrieben worden ist. Die relativ dicke, weich gallertige Membran der buischelig reraistelten sporenbildenden Fiden und die kleinen gliinzenden früher ron mir fälschlich Zellkerne genannten Protoplasmakörper der ganz jungen Sporen sind der Grund, warum die jungen Sporengruppen auf den ersten Blick ein ganz absonderliches Ansehen haben. Ihre Bildung ausführlich zu beschreiben würde hier zu weit führen. Bei den anscheinend zusammengesetzten sporen der Ustilagineengattung Lroc!stis Rab. (Polyeystis Lev.) sind wenigstens die kleinen wasserhellen, den dunkeln Sporen selbst aussen aufsitzenden Zellen nicht Schwesterzellen der Sporen, sondern Glieder von kurzen Hỵpen, welche sich der jungen Spore aussen fest anlegen. Die vielgliederigen Sporenknauel der verwandten Gattung Sorisporium Rud. beginnen als kug̣elige Ballen dicht verflochtener, einzeln kaum unterscheidbarer Hyphen. In der Mitte des Ballens tritt dann die Anfangs sehr klein - und zartzellige sporengruppe auf, welche ohne weitere Theilung ihrer Glieder zu ihrer definitiven Grösse heranwichst, wahrend das peripherische Geflecht des Ballens allmählich durch Resorption) verschwindet. Wie die Sporen zuerst angelegt werden ist ganz unklar.

Schliesslich mag dem Sporenbildungsprocess durch Zelltheilung die Erseheinung angereilıt werden, bei welcher sich gewöhnliche regetative II!phen des Myceliums oder Fruchttrigers durch Querwinde in meist kurze Gliederzellen theilen, die sich dann meist ron einander trennen und ron denen jede einzehne unter güunstigen Beding̣ungen wieder zu einem Myceliumfaden auszuwachsen vermag. Die Produkte dieses Processes mögen als Brutzellen bezeichnet werden. Sie sind ron den vegetativen dergleichen species in der Regel durch derbere Membran, reichlichere Hengen hörnig̣en Inhalts oder reichlichere Fetttropfen ausgezeichnet. Den Sporen schliessen sieh diese Bildungen durch ihre Ahtrennung von der Jutterpflanze und ihre Keimfihligheit an: ron denselben zu unterscheiden sind sie aber darum, weil sie, veryleichbar den Brutzellen und Brutknospen nancher höheren Gewichse, nicht tỵpische Fortpflanzungasorgane der Species sind, sondern cher krankhafte Produkte, erzeugt in Folge ungainstiger Vegetationsbedingungen. In Reihen von Brutzellen zerfallen z. B. die Aeste des Myceliums von Mucor Mucedo bei ungeeigngeter Ernaihrung; bei Dacrymyces deliquescens zerlillt oft der ganze Fruchttriger, wenn er langsam austrocknet, in unregelnaissig gestaltete Brutzellen Tulasnej; die Pilzform. welche Caspary Monatsber. d. Berl. Acad. 18:3.) als Fusisporium melanochlorum beschrieben hat, gehört ohne Zweifel hierher, und zahlreiche Beispiele findet man an den Mycelien fidiger Pilzformen, zumal der Dematieen. Viele derselben mögen unter den Formen sein. die in der descriptiven Mycologie den Namen Torula fühıren. 


\section{B a u d e r s poren.}

Bei der Betrachtung der Structur reifer Sporen ist zunichst zu unterscheiden zwischen den beweglichen Sporen, Schwïrmsporen, Zoosporen und den bewegungslosen.

Die ersteren kommen verhältnissmässig wenigen Pilzen zu, nämlich den wasserbewohnenden Saprolegnieen und einer Anzahl, für die Sporenbildung gleichfalls auf das Vorhandensein tropfbar flïssigen Wassers angew iesener Peronosporeen (Cystopus, Arten von Peronospora, Fig. :3). Die Schwirmsporen der Pilze sind, abgesehen ron dem Mangel des Pigmentes in ihnen, den gleichnamigen Organen der Algen im Wesentlichen gleich gebaut: nackte, einer deut-

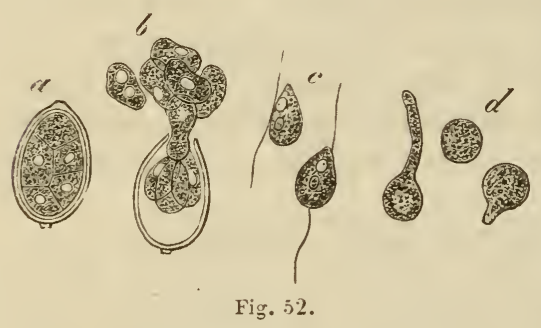
lichen Cellulosemembran meistens Saprolegnia ferax soll eine sehr zarte Membran besitzen) entbehrende Protoplasmakörper oder Primordialzellen. von deren Oberfliche meist zwei (eine bei Pythium entophytum und monospermum nach Pringsheim) schwingende Cilien entspringen. Diese sitzen seltener an dem spitzen Vorderende der eiförmigen Spore Saprolegnia ferax nach Thuret), und sind dann beide vorwäts gerichtet, gleich denen der Schwärmsporen von Llothrix, Chateophora u. s. f. Die meisten Pilzzoosporen sind vielmehr oval, oder rundlichlinsenförmig, zeigen an ihrer einen Seitenfläche einen rundlichen, einer an dic Oberfliche grenzenden Vacuole gleichenden hellen Fleck, und von zwei diametral entgegengesetzten Punkten des Randes dieses Fleckes entspringt je eine Cilie, von denen die eine nach rorne, die andere nach hinten gerichtet ist; eine Anordnung, welche an die für die Phaeosporen-Algen Thurets erinnert. Bei Peronospora infestans entspringen beide Cilien ron demselben Punkte. Im Lebrigen stimmen die Pilzzoosporen so sehr mit denen der Algen überein, dass eine ausführlichere Besprechung derselben hier unterbleiben kann. Wie bei den Algen konmen die Schwämsporen der Pilze zuletzt zur Ruhe, bilden eine zarte Cellulosehaut auf ihrer Oberfliche und beginnen dann sofort zu keimen.

Alle bekannten Pilzsporen ausser den eben erwähnten entbehren der schwingenden Cilien und der selbstindigen Bewegung. Sie haben zur Zeit der heife und meist schon lange vorher eine feste Zellmembran und diese lässt in sehr vielen Faillen zwei Lagen unterscheiden: Aussenhaut, Episporium oder Exosporium und Innenhaut, Endosporium, von denen die eine oder die andere wiederum geschichtet sein kann. Bei zarten oder kleinen Sporen ist diese Sonderung in zwei Lagen nur sehr schwer, oder vor der Keimung gar nicht zu erkennen z. B. Kleinsporige Pezizen, wie P. calycina, tuberosa, Scle-rotiorum; Acrostalagmus; Corticium quercinum und viele ihnliche: Conidien ron

Fig̣. 32. Peronospora infestans Mont. a Sporangium, in Wasser liegend, nach vollendeter Theilung. $b$ Austritt der 10 Zoosporen aus demselben. $c$ Zoosporen während der Bewegung. $d$ solche zur Ruhe gekommen und zu keimen beginnend. Vergr. 390. 
Xylaria, Claviceps etc. ; manchmal selbst zu keiner Zeit Exoascus). Die Sporenwand, alsdann oft schlechthin Episporium genannt, stellt in diesen Fillen eine einfache, farblose oder gefirbte Membran dar.

In den zahlreichen Fillen deutlicher Sonderung stellt die A ussenhaut meistens eine derbe Membran dar, welche meist in der verschiedensten Woise und Intensitiit gefirbt, selten ganz farblos ist, und von deren Färbung in den meisten Fällen die der ganzen Spore herriihrt. Die Oberfliche derselben ist entweder ganz glatt z. B. bei den meisten Puccinia-Teleutosporen, vielen Pezizen), oder hïufiger wohl mit nach aussen vorspringenden Verdickungen von der Gestalt von Warzen, Stacheln, Runzeln, netzförıniğ verbundenen Leisten versehen, deren Dicke und Höhe je nach den einzelnen Species wechselt, ron den zartesten punktförmiggen Erhebungen z. B. Lredosporen von Puccinia coronata, Aspergillus etc.) und Netzleistchen Peziza aurantia, Puccinia reticulata) an bis zu den dicksten Warzen (Genea), Stacheln (Tuber melanospermum, Octaviania, Triphrağmium echinatum oder netzörmig verbundenen Kimmen (Tuber aestivum). Die Aussenhaut ist dabei entweder homogen oder geschichtet. Bei den durch Abschnürung gebildeten Sporen ist solhr oft eine duinme ausserste Schichte ron dem Uebrigen unterscheidbar, von der durch die Entwickelungsgeschichte ziemlich unzweifelhaft wird, dass sie die urspringliche zarte Menbran der Sporenanlage darstellt, welche mit der Spore herangewachsen ist, und an deren Imnenseite sich die anderen Schichten gebildet haben. 1)ieser ausseren Cmkleidung, man kann sie die primire Schicht nennen, gehören oft z. B. Lredosporen, Corticium amorphum die Prominenzen der Aussenfliche ausschliesslich an. Dass die zusammengesetzlen oder septirten sporen in ahnlicher Weise von der mit ilmen Waldsenden Mutterzellhatut wie ron rinem knaply anliegenden Sacke Hunzogen werden, wurde schon ohen erwihnt. Einige Episporien, besonders schön die ron P'helonites strobilina, Peridermium Pini, Caeoma pinitorfumm und einigger anderer Credineen zeigen statt der Schichtung ein Gefügere, welches sie wie aus kleinen, auf der Sporenoberfliche senkrecht stehenten, prismatischem Stibchen zusammengesetzl erscheinen lisst. Die gewölbten äusseren Enden der Sibibehen lagen als Wäzchen nach aussen vor. Am schönsten sieht man diese Structur. Wenn die genannten Episporien dureh Einwirkung von Selnwefolsiure auffuellen.

Das Endosporium stellt eine meist farblose, oder doch weit blasser als die Aussenhaut gefirbte, glatte, homogene oder geschichtete Haut dar; es ist ron (lem Eprispor meist durch arössere Weichheit und Zartheit, doch keineswegs inmer durch geringere Dicke unterschieden.

Manche Pilzsporen lassen in ihrer Membran Poren oder Tiipfel erkennen, "elche meist in bestimmter, bei der einzelnen Species nur zwischen sehr engen Grenzen sellwankender Zahl und in regehnissiger stellung und Vertheilung̣ auf der Sporenoherfliche aufteten. Viele derselben dienen den schlaurhförmigen .lusstiilpungaren, welche beim Keimen aus der spore hervortreten, als lustrittsstelle und hönnen taher als Keimporen bezeichnet werden: anderen hommt diese Bodeutung nicht zu, sie möğen einfach Tüpfel oder Poren heissen. Die Lag̣e dieser Poren in der Membran. oder wenn man so sağen darf, die structur derselhen ist nach den Einzelfillen rerschieden. Die Sporen ron Sordaria fimiseda deNot. z. B. halen in ihrem Scheitel einen nur ron der äussersten 
Membranschicht geschlossenen Keimporus (vgl. unten Fig. :3:. Die Keimporen der Uredosporen, welche ich untersucht habe, z. B. derer von Puccinia und Uromyces, sind scharf umschriebene, runde Löcher in dem Endosporium: aussen werden sie von dem darüber hinziehenden Episporium geschlossen. Die in den sogenannten Teleutosporen derselben Genera befindlichen sind, soweit es entschieden werden konnte, Tüpfel im Epispor, welche jedoch dieses nicht bis in seine aussersten Schichten durchbrechen; auf der Innenseite scheinen sie durch das undurchbrochene Endosporium geschlossen zu sein. Einen für die Keimung bedeutungslosen Tüpfel zeigen manche,

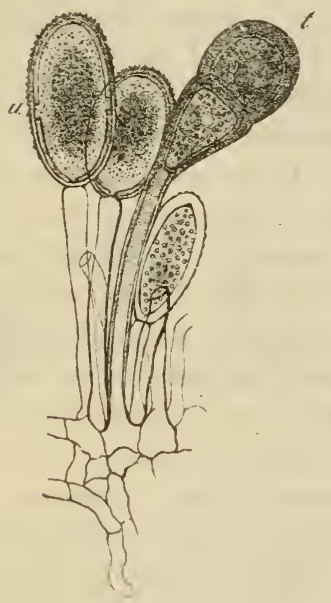

Fig. 53 . vielleicht viele Uredosporen (z. B. Puccinia graminis an ihrer Anheftungsstelle (s. Fiğ. 33 ). An der gleichen Stelle sind die Sporen mancher Hymeno- und Gastromyceten z. B. Hymenogaster Klotzschii und wohl noch andere, durch Abschnürung entstehende mit einem Tüpfel versehen, welcher dem Episporium anzug̣ehören scheint; Corda (Anleitg. p. XXXII) wirft diesen Tüpfel mit dem an dem Anheftungspunkte der meisten abgeschnúrten Sporen vorhandenen, oben erwihnten Stielchen unter dem Namen Hylus, Fensterchen, Nabel zusammen, den er als eine „Oeffnung, Spur einer Durchbohrung oder ein kurzes, durchbohrtes Wärzchen « beschreibt. Soviel ich wenigstens bei dem grosssporigen Corticium amorphum (vel. Fig. 4.j) erkennen konnte, ist das Stielchen der acrogenen Sporen der Hauptsache nach eine Fortsetzung oder Ausstülpung des Endosporiums, über welche sich das Epispor nicht oder nur als ungemein rerdiinntes Hiutchen fortsetzt: das Stichehen selbst zeigt ein enges Lumen, oder die Membran ist ihm bis zum Verschwinden des letzteren verdickt. Manche Ustilagineen. zumal Lstilago receptaculorum, zeigen ferner das Episporium mit einem breiten. oft $1 / 4$ bis $1 / 3$ des Sporenumfangs einnehmenden helleren Flecke versehen, welcher einer düneren, allmahlich in die starker verdickte und dunkler gefirbte übrig̣e Wand übergehenden Stelle entspricht.

Als letztes Beispiel seien hier noch die zierlichen Liangsstreifen auf den ovalen Sporen von Ascobolus furfuraceus und Verwandten erwähnt, welche Coemans als weisse Adern beschreibt. Sie sind enge, soviel ich erkennen konnte. völlig offene Liingsspalten in dem schön violetten Episporium : das farblose Endosporium ist glatt, homogen und undurchbrochen.

Die Fälle, in denen das Episporium ron der Innenhaut, schwer, kaum deutlich unterschieden werden kann, wegen der geringen Dicke beider Membranen oder einer derselben, bedürfen hier keiner ausführlicheren Besprechung.

Besondere Erwihnung dürfte die Structur der Sporen ron Nyctalis und ron Elaphomyces verdienen.

Fig. 53. Puccinia graminis, dünner Schnitt durch ein Sporenlager, $390 \mathrm{mal}$ vergr. $u$ Uredosporen, mit 4 Keimporen im Aequator. $t$ Teleutosporen, die obere mit einem Keimporus im Scheitel. 
Die ersteren (rgl. Bot. Ztğ. $18: 39$, p. 386 entstehen einzeln. als spindelförmige oder sternförmig ausgezweigte Zellen auf den Enden oder in der Continuität der fruchttragenden Hyphen. Nachdem sie ihre volle Grösse erreicht haben, zieht sich der ursprünglich der Membran überall anliegende Protoplasmakörper aus den Enden der Zelle und den sternförmigen Aussackungen zurück, nach der Mitte hin zusammen, und an seiner Oberflache tritt eine neue Membran auf. Letztere erhält doppelte Contouren; sie ist als Endosporium zu bezeichnen; die ursprügliche, ebenfalls doppelt contourirte ungeschichtete und der letztgenannten gleichdicke als Episporium. Das Endosporium steht nur mit der nittleren Reggion des Epispors in Berührung, die Enden und Aussackungen des letzteren stehen weit von ihm ah, es nimmt gleichsam die Vitte eines nut wässeriger Flussigkeit erfülten Sackes oder Mantels ein, weshalb ich die in Rede stehenden Sporen einstweilen Chlamydosporen genannt habe.

Die Sporen von Ela phom y ces (vgl. Tulasne, fung. lı̣pog.; de Bary, Fruchtentw. der Ascomỵe. sind durch die enorme Jicke des Endosporiums ausgezeichnet. Dasselbe bildet weitaus die Hauptnasse der grossen kugeligen Spore: es umschliesst den verhailtnissntissig̣ engen lnnenram in Form einer blaiulich glänzenden Masse von gallertartiger Beschaffenheit, gesondert in eine schmale, in Wasser, Siuren u. s. f. zu einem formlosen schlein aufquellende aussere. und rine breitere, durch die genannten Agentien unveräindert bleibende innere Lạ̧e: beide Lag̣en zeiggen meistens noch untergeordnete Schichtungen. Das Episporium ist eine dünne, aber feste und spöode dunhel geforithte llaut. welehe dem Endospor ('ng anliegl und meist wiederum in zwei sehr dünne Schichten gesondert werden hann, deren äussere bei manchen Arten feinstachelig ist Fig. ". í.

Die verschiedenen Schichten und Hitute der sporennembran, von denen bisher die Rede war. entwichehn sich, soweit die vorliegenden Beobachtungen reichèn, in derselben Weise und Aufeinanderfolge wie die pflanzlichen Zellmembranen und ihre Schichten überhaupt. Es lieget daher hein Grund ror, auf

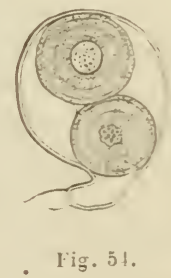
ihre Entstehungsgeschichte hier ausfiilndicher einzugehen, als dies in den vorigen Absehnitten schon geschehen ist.

Eine Menge von Pilzsporen zeiğ ausser den beschriebenen Membranen auf ihrer Oberfliche Luhüllungen oder Inhängsel, welche aus einer farblosen, durchsichtig̣en, unter Einwirkungr von Wasser stark fuellenden und meist rasch zerfliessenden und rerschwindenden, durch wasscrentziehende Reagentien schrum-

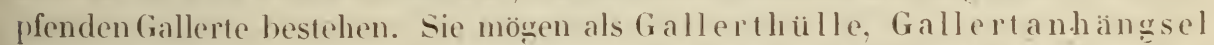
bezeichnet werden. Sie finden sich sowohl bei den in Ascis gebildeten, als bei acrogenen, bei einfachen und zusammengesetzten Sporen.

Yon Ascosporen sind die vieler sphaeriaceen z. B. Massaria, rgl. Fresenius Beitr., Tulasne, Carp., ferner Sphaeriae spec., rogl. Sollmann, Bot. Ztg̣. 1862,63, Iylaria pedunculata, zuerst erwähnt -von Berkeley, 1838, in Mag̣az. of Zool. and Bot. Vol. II, p. 22.t, vgl. Tul. Carp. II., mit einen verschieden breiten, sehr zart unschriebenen Gallerthof rings umgeben. Aehnlich rerhalten sich R hyt isma Andromedae, II ýsterium nervisequum und andere Hysterineen. Die

Fig. 54. Elaphomyces granulatus. Ascus mit 2 halbreifen, noch farblosen Sporen. Das relativ enge Lumeu derselben an dem hörnig trüben Inhalt kenntlich. Vergr. 390. 
zusammengesetzte Spore von Sphaeria Scirpi ist in einen zarten durchsichtigen Sack eingeschlossen, der den Seiten eng anliegt, an jedem Ende dagegen zu einem lang kegelförmigen Anhängsel ausgezogen ist. (Fig. .̆। . Pringsheim, Jahrb. I, Taf. 24 ). Anhingsel von pfriemenförmiger oder halbkugelig-buckeliger Gestalt zeigen die Enden der Sporen vieler anderer Sphaerien, z. B. Arten von Valsa, Melanconis (vgl. Tulasne, Carp. II, Fresen. Beitr. Taf. VII, 22, 21). Auf der einen Seite der kugeligen Sporen von Peziza melaena und der ovalen von Ascobolus albidus Coemans, A. furfuraceus P. liegt dem Episporium ein halblinsenförmiger, nach der Entleerung der Sporen in Wasser zu halb- und ganz kugeliger Form aufquellender Gallertanhang an; Peziza convexula und Ascob. immersus P. (Coemans l. c.) zeigen das ganze Epispor von einem breiten Gallerthof umzogen, die oben erwihhte gemeinsame Hülle der 8 Sporen von Asc. Kerverni dürfte wohl auch hierher gehören.

Von den acrogenen Sporen zeigt z. B. die als My xocyclus confluens Riess beschriebene Form (vgl. Tul. carp.; Fresenius Beitr.) einen breiten Gallerthof um die grossen zusammengesetzten Sporenkörper. Die Sporenköpfichen von Acrostala gom us, die aus dicht gehiuften istigen Sporenhetten gebildeten Köpfehen von Myriocephal u m botryosporum sind in eine massige Gallerthülle eingeschlossen, und so liessen sich viele Beisjoicle anführen. Auch die anscheinend homogene, meist sehr zerfliessliche Gallerte, ron welcher die Stylosporenlager unzahliger Ascomyceten bedecht und welcher die Sporen eingebettet sind, dürfte hier zu erwihnen sein.

Die morphologische Bedeutung der verschiedenen Anhängsel ist noch durch die Entwichelungsgeschichte genaner festzustellen. Die Gallerthöfe und massigen Gallertumhüillungen ganzer Hymenien dürften bei acrogenen Sporen wohl jedenfalls gallertige aussere Sporen- oder sporenmutterzellhiute scin, oder das Product des Zusammenfliessens solcher. Für viele in Ascis erzeugte Sporen ist es a priori wahrscheinlich, dass die Anhäingsel und Gallerthöfe gleichlalls partielle Verdichungen der aiussersten Membranschicht sind, oder in einer gelatinösen Beschaffenheit der ganzen iussersten Lage ihren Grund haben. Auch sprechen hierfür Sollmanns Angaben Bot. Ztg. 1862 und 1863, die aber wegen der in ihnen herrsehenden Verwirrung der ersten histiologischen Schulbegrifle unzuverlissig sind. Der sack, welcher die Spore ron Sph. Seirpi ungibt, ist entschieden die primaire iusserste Membranschicht, welche der Spore zuerst überall knaple anliegt und sich mit der Roife an den Enden zu den heggelförmigen Anhaingen ausdehnt. Es kommen aber auch Anhingsel anderen Lrsprungs vor. Tulasne Carpol. I. p. 80 beobachtete bei seiner sphaeria praecox fadenförmige Appendices, welehe dadurch entstelem, dass die Sporen innerhall, des Ascus zu heimen beginnen, indem sie an den Enden schliuche austreiben. Ein bemerkenswerthes Beispiel für das Vorkommen von Anluingsehn zweierlei Art sind die Sporen ron Sordaria fimiseda Not. In der ersten Anlage sind dieselben zarte, ovale, unten in einen ç lindrischen Stiel ausgezogene, protoplasmareiche Zellchen. Unter steter Verğeösserunğ aller ihrer Theile tritt nun zuerst an beiden Enden eine weich gallertige und fein lingsgestreifte Verdickung ihrer Membran auf, die in Form eines spitz conisclen, meist hakig gekrummten Fortsatzes nach aussen rorragt und mit dẹ ibbrigen Spore an Grösse zunimmt. Inat die Spore ihre Ausdelmung vollendet, so rickt alles Protoplasma aus dem cylindrischen 
unteren in den ovalen oberen Theil: letzlerer grenzt sich ron jenem dann durch eine Querwand ab, seine Membran erhält Verdickung̣sschichten und allmählich schwarzviolette Farbe, während jener unverundert als ein hỵaliner c!lindrischer Stiel mit der dunkeln Spore in Verbindung bleibt igl. Fig. $: 3.3$.

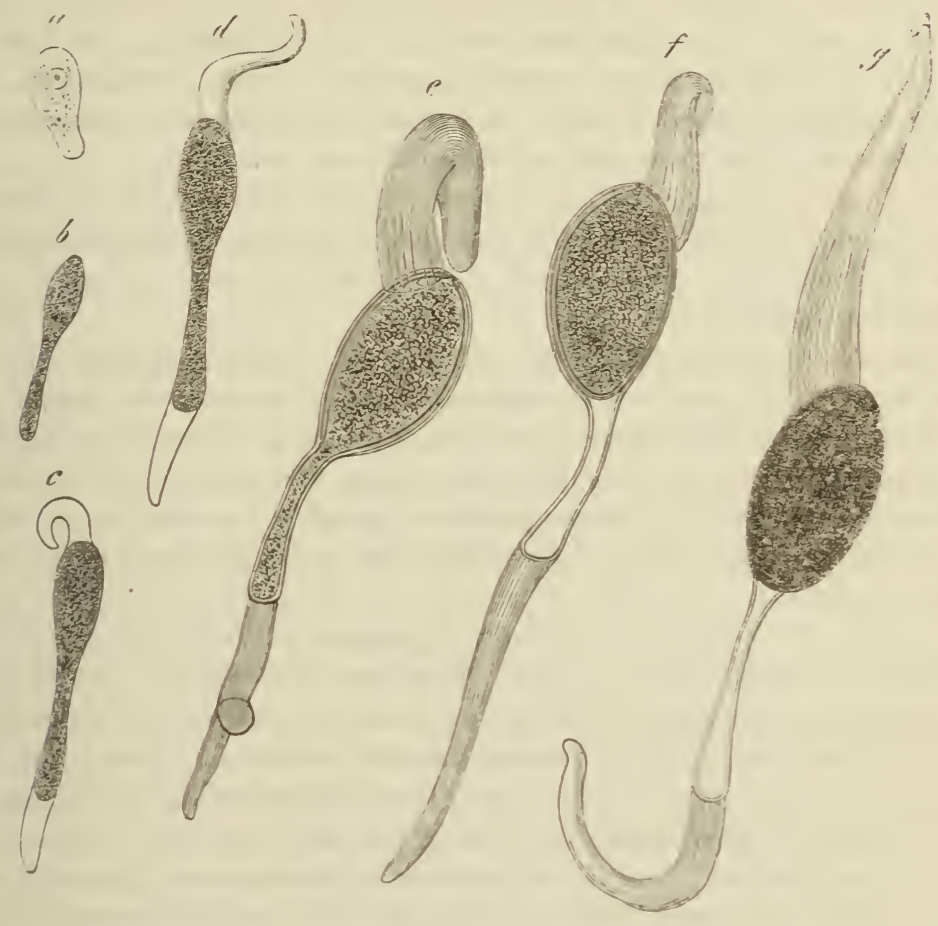

Fig. 5.5.

Von dem chemischen Verlatlen der sporenmembranen hennt man bis jetzt nur vereinzelte Thatsatehen, an einer unfassenderen Bearbeitung fohlt es noch. Vielerlei Details hat Hoffumm P'ringsheims Jihrb. 11. p. 308 zusimmmengestellt.

Die meisten Sporemmembranen sind nach der iblereinstimmenden Ingabe aller Beobacher durch ihre garosse Widerstandsfahigheit gegen Zersetzung und gegen heftig einwirkende Igentien. zumal concentrirte Jineralsiuren ausqezeichnet. Vicle werden selbst von coneentrirter schwefelsiiure nur wenig angegriffen, durehsehnilllich um so wenigere, je intensiver sie geforitht sind, uncl, was damit

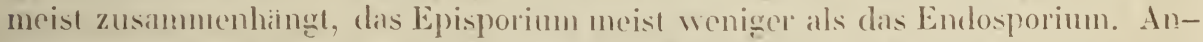
dere quellen in der genannten Siure mehr oder minder stark oder werschwinden

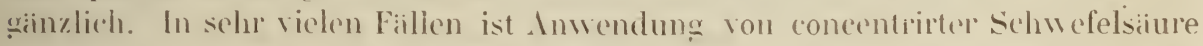

Fiğ. ว̆. Sordaria fimiseda de Not. Entwickelung der Sporen, Entwickelungsfolge den Buchstahen entsprechend. Alle Figuren gleich stark, nämlich 390 fach vergr. $a-f$ aus frisch frovizelegten unversehrten lscis; $f$ ausgew achsen, aber mit noch durchichtiger, gelbbrauner Membran, oben der heimporus deutlich. g reife, entleerte spore, Membran dunkel schwarzvinlett. 
ein vortreffliches Mittel. um feinere Structurverhälnisse des Epispors deutlich zu machen, theils weil dieses in derselben durchsichtiger, theils weil die anderen Theile zerstört werden oder aus dem spontan berstenden oder leicht zu sprengenden Epispor austreten.

Durch kochende Kalilösung werden die gefäbten Episporien in der Regel mehr oder minder zerstört, die netzförmig verdickte Aussenmembran von Tuber aestivum nach Schacht (Anat. und Phys. II, 193) vollstandig; ebenso die fein warzige điusserste Schicht vieler Uredineensporen (de Bary, Brandpilze). Die erwihnten Membranen gleichen daher in ihrem Verhalten gegen Reagentien den Cuticularschichten oder der Guticula höherer Gewichse.

Mit wenigen, nachher zu nennenden Ausnahmen werden die Membranen der Sporen auch nach Maceration mit Kali oder Schulze'scher Mischung durch Jod und Schwefelsiure gell) oder gar nicht, nicht blau gefairbt; sie gleichen hierin sler Mehrzahl der Pilzhyphen.

Das Cresagte gilt sowohl für die einzelnen, einfachen Sporen im strengen Sinne des Wortes, als für die Mutterzellmembranen zusammengesetzter.

Die Gallerthüllen und Anhiinge und die übrigen gelatiniösen Schichten, ron denen schon die Rede war, verhalten sich gegen Reagentien den gleichnamigen Körpern anderer Organe und Gewichsclassen gleich. Sie sind in der Regel sehr verganglich und werden raseh unkemntich, wenn die Sporen in oder auf Wassor gesiit werden.

Der Collulose höherer Gewichse vollkommen gleich, auch gegen Jod und schwefolsiure, verhalt sich die ganze Membran der Sporen von Peronospora. 1)ureh waisserige Jodlossung allein wird die ganze Sporenwand von Currey's A m ylocarpus intensir blaugefirbt, ebenso die Gallerthuille der Sporen ron Xy laria pedunculata (s. Tul. carp. u. Ann. Sc. nat.) Bei den Sporen ron Corticium am orphum Fr. Fig. fï) fäbt sich die der Cutieula anderer Sporen entspechende ausserste fein stachelig warzige Schichte des Episporiums durch wisserige Jodlösung schön hellblan, dureh Jod und Schwefelsaiure dunkelblau; ihre Stachelehen nehmen an der Farbung Theil, die innere, mähtigere Schichte des Episporiums und das Endospor bleiben ungefarbt.

Der In halt Kirm, Nueleus nach Corda und Tulasne der Pilzsporen besteht atus einer homogenen oder mit Körnern oder Fettropfen rerschieden reichlich durchsiiten Protoplasmamasse. Er erseheint bei Betrachtung der einzelnen Spore mit dem Mihroskope in der Regel farblos, seltener z. B. bei den meisten Uredineen rothg̣elh, bei Corticium amorphum rosa) gefirbt. Geg̣en Reagentien zeig̣t das Protoplasma, soweit die Untersuchungen reichen, das gleiche Verhatten wie anderwiils, eine ausführliche Beschreibung ist daher iiberfliissig.

Das Oel, welches es in vielen Fälen enthït, tritt hiiufig in Form grosser kuglig̣er Tropfen auf: bei Peziza Acetabuhum, llelvella elastica z. B. nimmt ein solcher, oft noch von hleineren umgeben die Mitte der Sporen ein. In vielen anderen Fillen sind kleinere Oeltröpfchen in dem Protoplasma regellos vertheilt, oder in ziemlich constanter Zahl an bestimmte Orte gestellt. Der bekannteste und auffallendste Fall dieser Art findet sich in den elliptischen Sporen von Peziza vesiculosa, Sclerotiorum, Helvella esculenta (Fig. 39) und anderen, welche in den Brennpunkten in der Regel je einen, seltner zwei Oeltropfen zeigen. (Bei P. tuberosa und hemisphaerica sah ich an denselben Punkten bei Anwendung ron Jod runde 
oder unregehmissige, vorher nicht sichtbare Körper auftreten, welche die rothbraune Epiplasmafarbe amnahmen, wihrend der iibrige Inhalt gelb wurde).

Von den foineren Körnchen, welche das Protoplasma oft dicht erfiillen, dürfte gleichfalls ein grosser Theil aus Fett oder Oel bestehen, das emulsionsartig in ter eigentlichen Protoplasmamasse vertheilt ist ( $\mathrm{rgl}$. Iloffmann, Pringsh. Jahrb. II, 308 u. f.).

Auch die Farbe der Uredineensporen fandere sind in dieser Hinsicht nicht genauer untersucht rührt von einem gefiubten Oele her, welches die schon auf Seite 11 erwihnte Eigenthiimlichkeit zeiğt, durch Schwefelsiure Zusatz von

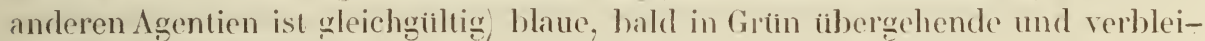
chende Farbe anzunchnon.

Ein Zellkern ist in den reifen frischen Sporen nur selten Eir siphe Cichoracearum, Pilobolus leicht und deullich zu unterseheiden, selbst nicht in denen, wo er in der Jugend sche in die Augen fïllt und das Protoplasma nicht durch Körner oder grosse Oeltropfen getriibt ist, wic bei Ascobolus furfuraceus und den meisten der auf S. 102-104 genammlen Discomyceten; allerding gedingt es hie und da, sein Vorhandensein anch in den viollig reifen Sporen dieser Pilze nachzuwcisen. Wie schon oben erwähnt wurde, sicht man in vielen acrogenenen sporen z. B. Hymenomiceten, Vredineen-Teleutosporen; in der Mille des Proloplasmas einen kugeligen hellen haum durehschimmern, von dem es noch unentschieden ist, ob er als Zellheru oder als Vacuole bezedomed werelen muss. Was hisher als Kern dere Pilzsporen beschrieben ist, sind mil Ausmahme riniexper ron mil Ascomye. untersuchter Faille, entweder Ocltröpfehen, deren wahre Vatur und Verschiedenheit vom Zellkern elwas Aether leichl ins Klare hringla oder es wird nach Corda's nenerdings von Tulasne adoptirter Terminologrie, der wanze Protoplasmakörper der Spore Kerm, nucleus grenannt, eine Be\%chohnum, die an sich recht gut, aber dal'um verwerflich ist, weil für die Zellen der Pil\%e doch nur die

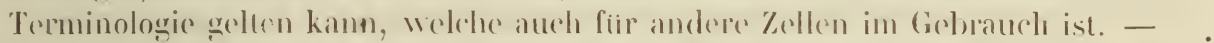

Der Inhalt der Sporen ist im frisehen Zustande wisserreich und saugu, wenn

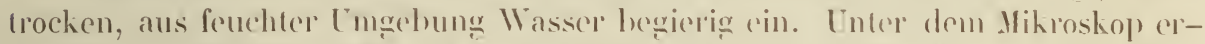
scheint eine frische im. Wasser liegende spore inn ihm strotzend angediulle. Beim

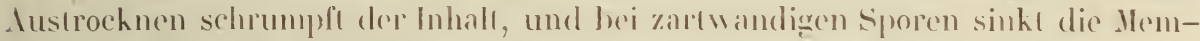

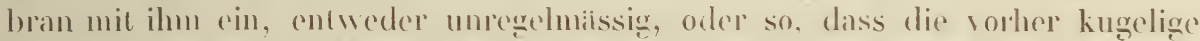

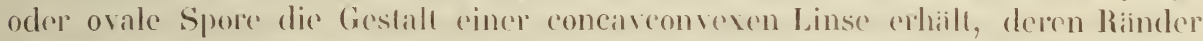
sich oft noch cintollen, 1 m dem Gimzen hahnförmige Gestalt zu geben. In manchen Fillen bei Pezizal abietina und in den Sporangen on Cystopus candidus nach IIoflmann, forner Pe\%. melacna, Soldaria emvula n. sp)., auch bei den in Ruhezustand abergegangenen Asci des Protomyees macrosporus tritt in dem Inhalt austrocknender sporen cine Lufthlase auf. J)ies ribet wenigstens in den drei letzgenannten von mir untersuchten Fiallen daher, dass irgend ein Gas in

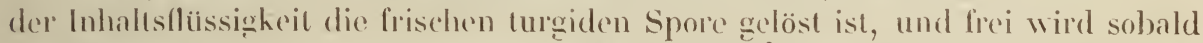
der Wassergehalt des Inhalts in gewissem Gande vermindert wird. Demn die Luftblase tritt auch auf, wemn man auf die unter Wasser liegenden Sporen wasserentziehende Reagentien Glycerin, Alkohol, Schwefelsiume einwirken liisst und wird rasch heiner, um baid zu verschwinden, wenn man genannte Reagentien wiederum durch Wasser ersetzt. 


\section{Litteratur.}

der Bildung und Entwicklung der Sporen.

Organe, welche den Samen der Phanerogamen ähnlich zu neuen Individuen heranwachsell, wurden bis zu Tournefort's und Micheli's Zeiten (1707, 1729) den Pilzen entweder abgesproclıen, oder man frug wenigstens nicht viel danach. Einzelne Stellen, welche von Pilzsamen reden, finden sich allerdings schon bei den Alten.

Man vergleiche hierüber besonders Ehrenherg, Ep. de Mycetogenesi. Tulasne, Sel. fung. carpologia. Prolegomena, Cap. I et IV.

Die Entwicklung der Sporen wurde zuerst vorzugsweise bei den grösseren Schwämmen untersucht. Micheli, Nov. plant. genera (1729) sah die tetradenweise Gruppirung der Sporen auf den Lamellen von Agaricis (I. c. p. 133. Tab. 73, 76), ohne jedoch ilıre Befestigungsart zu erkennen; daggegen erkannte er deutlich die Asci von Tuber und die Sporen in ihnen (l. c. p. 221, Tah. 102). Bulliard (Champ. de Fr. 1791) erkannte die Sterigmen (filets), denen die Sporen der Hymenomyceten aufsitzen, O. F. Müller (Flora Danica, Fasc. XIV) hatte schon 1780 die Sporentetraden von Coprinus comatus vortrefflich dargestellt; Hedwig, Descript. etc. Musc. frond. (1788) entdeckte die achtsporigen Isci der Discomyceten; er selbst und die Autoren der nächstfolg̣enden Zeit fanden diese Organe allmählich bei der Mohrzahl der Ascomycetenordnungen; insonderheit beschreibt sie Perso o n 1794 für Pe z i za, Helvella, Morchella, Ascobolus, Sphaeria, Geoglossum, in seinem epochemachenden Versuch einer ș̣tematischen Eintheilung der Schwämme, in Römer's neuem Magazin f. Bot. I, p. 62 u. f. lerğl. ferner l'ersoon, Icon. et descr. fungorum I. (1798) p. 6 u. p. 2 s. J. Hedwig, Theor. generat. et fructif. plant. Cryptog. El. 2. (1798); von Späteren Ditmar, in Sturmis D. FI. III, I U. s. W.

Raproducirt sind viele Darstellungen dieser älteren Autoren in Nees v. Esenbeck, system der Pilze und Schı̋ähme. Wiirzburg 1817.

Die Auffindung der Isci bei einer grösseren Anzahl von Pilzen führte zunächst zu' der irrigren Annahme, alle höheren schwämme, speciell die Hymenomyceten, seien mit solchen Organen versolıen. Sie findet sich ansgesprochen seit Persoons citirtem »ersuch" und besonders l, iuls olservationes in Ord. plant. naturales I (Magazin d. Ges. naturf. Freunde, Berlin, 4s09, bis in die netere Zeit (lies, syst. mycolog. Epierisis syst. mycolog.) : und sellst, wenngleich undeutlich, in Abhildungen darugestellt (Vọl. Nees syst. d. P.). Für aus-

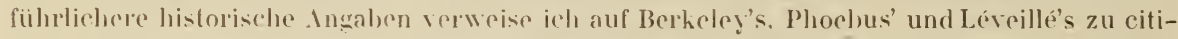
rende Irheiten.

Vittadini, Monogrr. Tuheracearum (nach Tulasne, mir fehlt das Buclij entdeckte 1831 die Basidien bei Boletus und llỵmenogaster, oder entelekte sie von neuem. Allgemeiner erhanmt und genauer studirt wurden sic aber erst, zunäclıst für die Hymenomyecten, seit dron classischen gleirhzeiliø̣en Arbeiten Leveille’s, Recherches sur l'Hỵménium des Champignons, Innales d. se. nat. 2. Sér. Tom. VIII. (1837) und Berkeley's, On the fructification of Iymenom ceet. fungi, in Ann. of Nat. Hist. Vol. I (4838) p. 80. Von diesen unabhäng̣ig erhielten Indere mit ilmen übereinstimmende Resultate, die jedoch später zur Veröffentlichung hamen :

Ascherson, in Wiegmanns Archiv 1838 und Frorieps Notizen, Band zo.

Phocbus, Leber den heimkörnerapparat d. Agaricinen u. IJelvellaceen. Nov. Act. Acarl. Natur. Cur. Vol. XIX, II. (1842).

Corda, Ieon. fungorum Tom. III. p. 40 (1839); frühere Beob. Corda's sind dasellst elwähnt. Die Basidien der Gastromỵceten lehrten zuerst Berkeley und Tulasne (s. pag. 94) genauer kennen; die der Trenellinen Tulasne erst in neuerer Zeit: Inn. Sc, nat. 3. Sér. Tom. XIX.

Von spateren Beobachtern der Basidien ist hier noch zu citiren Schmitz, Ueber Thelephora lirsuta etc. Linnaea Bd. 17 (1843. 
Die Asci wurden gleichfalls genauer behannt durch Léveillé und Phoebus (l. c.', ohne dass jedoch den Beohachtungen Früherer sehr Wesentliches hinzugefügt worden wäre. Mit der Structur des Hymenimms und dem Ursprung seiner Tlieile mussten sich die genannten Schriftsteller selbstverständlich auch heschäftigen; für die Gastromyceten wurde die Sache vorzugsweise durch Tulasne's neuere Arbeiten aufgeklärt (Fungi hypogaei). Bei den übrigen Schwämmen wurde jedoch bis in die neueste Zeit das zarte suhhymeniale Gewehe übersehen oder misskannt. Schacht (Pflanzenzelle), Hoffmanns und meine Arbeiten, welche auf S. 74 citirt sind, haben es vollständiger als frihere beschrieben.

Von den einfacheren Pilzformen, den Hyphomyceten, stellt schon Micheli $\mathbf{N}$. gen. Tab. 91; die acrogenen Sporen bei Botrytis und Aspergillus als auf den Enden der Hyphen sitzend dar. Spätere gechen lange Zeit hindnrclı theils ähnliche Darstellungen, theils konnte ihnen weder Uisprung noch Insertion der Sporen klar sein. Erst Corda's spätere Arheiten, Fresenius' Beiträge, Bonorden (s. dessen allgem. Mycologie) fassten die Fragen nach der Entstebung der Sporen schäıfer ins Auge. Auf diese Werke und auf die descriptive Litteratur muss hier verwiesen werden, hestimmte Wendepunkte traten in der Bearbeitung dieser Verlältnisse nicht ein.

Was die erst in neuerer Zeit hearbeitbar gewordenen feineren lristiologisclien und entwicklmngsgeschichtlichen Fragen betrifft, so ist die Sporenentwicklung in den Ascis, wie ich glaube, von mir am genauesten erforscht worden: Veher die Fruchtentwieklung der Ascoinyceten. Leipzị̂ 1863, nachdem zahlreiche Vorarbeiten eine präcisere Fragestellumg ermölicht hatten, nänlich :

Nägreli, In Linnaea Bd. XVI, p. 257. Zeitschr. f. wiss. Bot. Heft I, p. 43 , Heft III u. IV. p. 23.

Sclileiden, Grundziige, 3. Aull. II, p. 4 5ั.

Corda, lcon. fuń. Vol. III, $38 ; \mathrm{V}, 69,74,80$.

Fresenius, in Flora 1847 , p. 11.

Sclı clıt, Pllanzenzelle, p. ว̈. Inat. u. Plısiol. d. I’l. I, p. 71. 73, 170.

li ï $\mathrm{z}$ ing, Philosnph. Botanik, p. 236.

Tulasır, fungi h!̣pogaci. Selecta Funğor. Carpol. I.

Hofme ister, in Pringsheims Jalıl. Bel. II, p. 37s. Tuber aestivum.

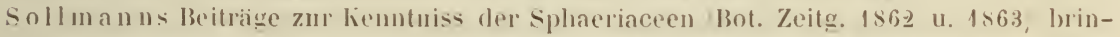
gen aus oben angegelenen Griuden heine wesentliche Bereicherung unserer lienntIIisse.

Die Beschreibungen der sporenbildung bei den Mucoriuen stellen diese älnulieh wie die in den . Iscis dar:

Corda, I'onn, fung. Il, p. 19.

Fresenius, Beitriegere, 1). 6.

Sclracht umt IInffmam (1. citand.) hetrachten die sporangien dieser Pilze geradezu als Asci. Cohn Eintw. des Pilolinlus, X. Act. Vol. Xill, Coemans, Monogar. du genre PiloboIns, in Mem. pres. de l'aread. Brux. Tom. IXX, und ich Beitr. zur Morph. u. Pligs. d. Pilze, p. 83) haben sie kurz beschrieben. Die Entwicklung der sporen der saprolegnieen und Peronosporeen fintet sich nelost ausführlicheren Citaten ter älteren Litteratur bei:

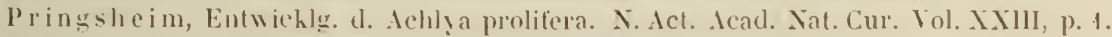

1. Braun, Verjüngung p. 287.

de 13 a ry, Bot. Zeitung, 1s32, p. 473.

Pringslı eim, Jalub. f. wiss. Bot. I, 290. II, 205.

de Bary, Ibid. II, 169.

Sclienk, Verhandl. d. plı̣s. Ges. in Würzlourğ, Bul. IX.

B. Privost, Mémoire sur la cause imméd. de la Carie ou charbon des hlés. Montauhan 1807. (Schwärmsporen von Cystopusi.

de Bary, Leber Schwärmsporenbildung bei Pilzen, Ber. d. Naturf. Ges. Freiburg. Bıl. IJ. p. 314. Inn. sc. nat. 4. Ser. Tom. MIII. Sur le développenent de quelques Champ. paras, Ibid. 4. Ser. Tom. XX. 
Auch die Sporenabschnürung wird von vielen neueren Autoren als ein Process freier Zellbildung aufgefasst, von dem in den typischen Ascis nur dadurch verschieden, dass die Tochterzellen in besonderen Ausstülpungen des Ascus entstehen. Vittadini (l. c.) lässt sogar die Spore der Hymeno- und Gastromyceten im Innern des Basidiums entstehen und zuletzt, in einer hernienartigen Ausstülpung der innern Membranschicht (Sterigma) eingeschlossen, nach aussen hervortreten; ähnlich ist die Ansicht von Montagne (Esq. org. etc.) Schleiden, Grundzüge, Band II, p. 38 (3. Aufl.). Sch acht, Pflanzenzelle, p. 54. Anat. u. Physs. d. Gew. I, p. 74, vertreten die oben genannte Meinung, und am schroffsten $\mathrm{H}$. H of fmann, Botan. Zeitg. 1856, p. 153 und in Pringsheims Jahrb. Band II, p. 303. Hier heisst es : „Ein Grundtypus, mannichfach variirend, kehrt immer wieder : die Sporen entstehen durch freie Zellenbildung im Innern von Mutterzellen (Schläuchen), welche bald mit ihnen verkleben (Phragmidium, Agaricus, Phallus) bald die Spore oder die Sporen nur locker unhüllen (Mucor, Peziza, Tuber etc.)." Nach den mitgetheillen Thatsachen und den hier nicht zu erörternden Grundbegriffen der Zellenlehre ist die Unhaltbarkeit dieser Ansicht unzweifelhaft. Berkeley (s. Inn. Mag. nat. Hist. vol. IX, 1842, p. 9, 283, Anm.) und Tulasne 11. cc.) haben die hier im Texte vorgetragene Auffassung des Abschnürungsprocesses ron jeher den entgegengesetzten Anschauungen gegenüber vertreten.

\section{Ausstreung der Sporen und Sporangien.}

Die durch $\Lambda$ bsehnürung frej werdenden Fortpflanzungszellen der Pilze lösen sich von ihren Trigern los, wie S. 120 beschrieben wurde; sie werden vollends frei, wo, wie z. B. bei den Lyeoperdaceen, Phalloideen, die Basidien nach vollendeter sporenhildung völlig resorbirt oder in Gallerte umgesetzt werden. Ihre Aussaat wird, bei Fruchtrigern, welche ganz oder grösstentheils geschlossen bleiben, wie bei den meisten Gastromyceten, nut durch zufillige Erschütterung, Zerstörung, Zersetzung u. s. w. des sie umschliessenden Behälters möglich; eine wichtige Rolle müssen bei derselben die den Pilzen nachstellenden Thiere, zumal Insecten spiclen. Von letzteren werden allerdings auch sehr oft die Sporen massenhaft gefressen und zerstört, ihre Iembranen gehen, zu Cylindern zusammengeballt, mit dem Kothe der Thiere ab, und solche Cylinder sind zu wiederholten Malen als die charakteristischen Fructificationsorgane von Pilzen heschrieben werden, weshalb sie hier zur Warnung erwahnt sein mögen ${ }^{1}$ ).

Wo die alogeschnürten Sporen auf offenen Fruchtlagern reichlicher Gallerte eingebettet sind, welche im Wasser his zum Zerfliessen quillt, beim Trocknen fest wird, haingt ihre Ausstreuung selbstverständlich von dem Wassergehalte der Ungebung, im Freien vorzugsweise von den atmosphärischen Niederschligen ab.

Auch bei nicht grelatinösen offenen Sporenlagern oder Behiiltern, in welchen die Sporen dicht gedriingt nebeneinander liegen, z. B. den Lredo-Lagern und Accidien übt die Feuchtigkeit der Lmgebung auf die Ausstreung der Sporen einen erheblichen Einfluss aus. Werden die genannten Fruchttriger zur Zeit der Reife in wasserdunstgesittigte Luft gehracht und die Pflanzentheile, von welchen sie getragen sind, feucht gehalten, ohne dass jedoch das Fruchtlager selbst mit dem tropfharen Wasser in Beruhrung kommt, so schwillt die reif Sporenmasse an und liingstens nach einigen Stunden sind eine Menge Sporen über den Rand

1) z. B. Ditmar, in Sturms Flora, III, 1, Tab. 38. Corda, Icon. fung. VI, Tab. III, 40 . Vgl. hierüber auch Tulasne, in Ann. sc. nat. 4. Sér. Tom. XI. p. 132. 
des Lagers oder Behäilters hinaus verbreitet. Der Grund dieser Erscheinung liegt wohl darin, dass die lufturockenen reifen Sporen dunstförmiges wie tropfbarflüssiges Wasser begierig aufsaugen und durch dasselbe hedeutend anschwellen. was leicht direet $\mathrm{zu}$ beobachten ist; dass daher, unter den oben genannten Bedingungen die ganze Sporenmasse an Volumen betrichtlich zunchmen, über den Rand des Lagers oder Behälters hinaus anschwellen und theilweise ausfallen muss. Die Turgescenz der Pflanzentheile, auf welchen sich die Uredineen entwickeln, mag fördernd mitwirken. In missig feuchter oder trockner Lmgeloung fallen fortwährend einzelne, doch verhältnissmissig wenige Sporen von den Lagern oder Behailtern ab.

Von den Fruchtlagern der Hymenomyceten und den Fruchthyphen der sporenabschnürenden II!phomỵceten lösen sich die reifen Sporen fortwährend los und fallen, falls sie nicht durch Gallerte festgechalten sind, ah. Es ist langst hekannt, dass das nach oben gekehrte II! menium eines Ilỵnenonyceten allmählich von freien Sporen hestiubt wird, und dass, wenn es nach unten grekehrt ist, die Sporen von ihm in Menge abfallen. Ihr Fall erfologt theilweise in genau senkrechter Richtung, wie aus der bekannten Thatsache hervorgeht, dass auf einem unter dem frei stelenden Iỵmenium eines Agaricus befindlichen Blatt Papier die abgefallene Sporenmasse eine radiale Streifung̣ zeigyt, welche dem radialen Verlaufe der Lamellen des Iegrieus genau entspricht.

Ausserdem findet aber bei den in Rede stehenden Pilzen oine Dispersion der Sporen in anderer Richtung̣ als der des freien Falls statt. Wie schon Bulliard Champ). de Fr. I, p. 引I) ang̣ibt und Itoflimann und de seynes I. e. nenerdings bestitigt haben, fallen von einem nach unten gehehrten Agaricushymenium viele Sporen weit über die dem IIutrande entsprechende Linie hinaus nach aussen. Hofmann sah yon Polyporus destructor in schwach heweger Luft ganze weisse Wolken von Sporen rauchatigy aufsteigen, nin vollstindig abgeschlossener und völig ruhender Luft grelangte dagegen heine Spore auf eine Gilasplatte, welehe nur $3 / 4$ Zoll ü ber dem Pilze schwehte, wihrend auf riner $21 / 2$ Zoll unterhalh des Pilzes befindlichen Gilistafel die Sporen ziber das Serehsfache des Pilzumfanges fast gyleichmissigy bis an den Rand bedechten." Andere I! menom ten sich im Wesentlichen ehenso.

Zur Erklarung dieser Erscheinungen dürte cine bei sporenabschnuirenden II! phomı̨eeten, zumal Peronospora, leicht zu w iederholende Beobachtung dienen. Die fruchteragenden Il! phen dieser Pilze sind im feuchten Zustande turọid, e! lindrisch, in trocknen collahiren sie, zumal zur Zeit der Sporenreife, zu bandförmigg-platter Gestalt und drehen sich dabei un so stirker um die eig̣ene Liingsachse. je stiirher die Austrochnung ist. Sie sind lıöchst lıg groscopisch, die geringste Aenderung in dem Dunstg̣ehalt der umgebenden Luft, wie sie z. B. dureh den Ilauch des Beobachters hervorgebracht wird, lasst sofort Wechsel ihrer Turgescenz und Torsionen eintreten. Dureh letztere worden die fruchttragenden Enden hin und her gerefuirlt und die darauf gereiften Sporen, wie sich leicht beobachten lässi, zur Seite gesehleudert.

Soweit bis jetzt ermittelt werden konnte, zeig̣en die Sterig̣men der Hỵmenom!ceten ahnliche h! groscopische Erscheinungen und Drehungen, wie die beschrielenen, und auch in ruhender al)geschlossener Luft werden solehe an den reifen Basidien immer auftreten, da ja in der Lmgebung dieser durch das Iler- 
vortreten neuer Basidien, Sterigmen und Sporen eine andauernde Bewegung herrscht. Allerdings ist diese Erklärung noch durch genaue Versuche zu prüfen.

Die durch Zelltheilung gebildeten Sporen werden bei der Mehrzahl der Mucorinen - von Pilobulus weiter unten - durch Zerfallen, Desorganisation der Mutterzellmembran frei. Die Schwiirmsporen der Saprolegnieen und Peronosporeen werden aus einer circumscripten Oeffnung, in der Regel am oberen Ende der Mutterzelle, ausgetrieben. Der Or't der Oeffnung ist in vielen Fiillen schon vor der Entleerung durch eine partielle Verdickung der Mutterzellmembran ausgezeichnet, welche oft papillenartig nach aussen vorspringt (Peronospora Fig. 32 ) : die Oeffnung entsteht, indem die erwähnte verdickte Membranstelle, oder bei anderen Formen Saprolegnia, Aphanomyces eine ihr entsprechende nicht verdickte, zur Zeit der Reife bis zur Unkenntlichkeit aufquillt. Die Zoosporen werden an dem zunïchst nur aufgelockerten Punkte der Sporangiummembran dadurch hervorgepresst, dass eine sie umgebende Gallertmasse gleichfalls aufyuillt sobald sie, nach entstandener Oeffnung, mit dem umgebenden Wasser in Berührung kommt. Die Vorgänge hierbei sind den bei den Algen stattfindenden in der Hauptsache gleich, es ist daher hier von einer ausführlichen Beschreibung derselben abzusehen. Die zarte Blase, in welcher bei Pythium die Sporenbildung stattfindet (s. p. 122), öffnet sich gleichfalls in der angegebenen Weise an einem bestimmten Punkte, oder scheint völlig zu zerfliessen, entschwindet wenigstens zuletzt der Beobachtung.

Eine eigenthümliche, anderwäts nicht vorkommende Erscheinung tritt bei der Entleerung der Zoosporangien von Achlya, Aphonomyces und Achlyogeton auf. Hier werden die Zoosporen, ohne bereits sellstindige Bewegung zu zeigen, aus der terminalen Oeffnung hervorgepresst; vor dieser angelangt nehmen sie Kugelform an und gruppiren sich, dicht neben einander, zu einem Köpfehen ron der Gestalt einer aus einer bis zwei Schichten von Sporen bestehenden Hohlkugel. Auf der Oberflache jeder Spore wird dabei eine vorher nicht nachweisbare zarte aber deutliche Cellulosemembran ausgeschieden. Nach mehrstindiger Ruhe schlüpfen endlich dir Sporen, eine nach der anderen, aus ihren Vembranen aus, die ausgeschlüpften Sporen zeigen alsbald die Cilien an ihrer Oberfliche und zerstrenen sich in dem ungebenden Wasser mit der gewöhnlichen Zoosporenbewegung. Zulet\% sind alle Membranen des Köpfelens leer, ein zartes, bald verschwindendes kuggeliges Zellnetz aul dem Gipfel des leeren Sporangiums bildend.

Ausführlicheres über die Zoosporenentleerung s. in den S. 13:3 angeführten Arbeiten. Leber Achlỵogeton: Schenk, in Bot. Zeitg. 18:39.

Von den durch Zelltheilung entstehenden, nicht von ihren Trigern sich lösenden Sporen ist hier nicht weiter zu reden. Ihre Verbreitung hängt ron den Zufälligkeiten ab, welche die Zerstörung oder Verschleppung ihrer Träger oder ilores Substrats bewirken.

Von den mit Ascis versehenen Pilzen verhalten sich die Tuberaeeen den Gastromyeeten, insonderheit den Hymenogastreen gleich; die Sporen werden erst durch Zerstörung der Peridie frei. Bei Elaphomyces ist dasselbe der Fall. nur mit dem Unterschiede, dass hier in ne r halb der geschlossenen Peridie die Membran der Asci gallertartig aufquillt und bald völlig verschwindet, wenn die Sporen erst etwa die Ilälfte ihrer definitiven Grösse erreicht haben. Letztere werden 
somit unreif aus den Ascis entleert und wachsen, frei im Innern der Peridie liegend noch etwa um's Doppelte. In der reifen Peridie stellen sie ein trocknes Pulver dar, dessen Aussaat wiederum erst nach Zersetzung oder gewaltsamer Zerstörung der Peridie erfolgt. Auch bei den Erısipheen werden die Sporen erst durch allmähliche Verwesung ihrer Lmhüllungen frei.

Bei der Mehrzahl der Ascomyceten werden die Sporen aus dem sich öffnenden Ascus zur Zeit der Reife ausgeleert. Der Mechanismus, durch welchen dieses geschicht, ist, soweit die Untersuchungen reichen, ein verschiedener bei ten mit offen liegender Hamenialflaiche versehenen Discomvceten, denen sich Protomyces macrosporus anschliesst einerseits, und den Pyrenomyceten denen sich vielleicht manche Hysterineen anreihen andrerseits.

Von den Discomyceten habe ich die Sporenentleerung untersucht bei Exoascus Beitr. z. Morph. u. Phys. d. Pilze I, Norchella eseulenta. Ascobolus furfuraceus und inehreren Aiten von Peziza, Helvella, Bhỵtisma.

Nach Bildung der Sporen verschwindet, wie oben beschrieben wurile, das Protoplasma und Epiplasma, sie werden durch wasserigge Flüssig̣keit ersetzt, die Sporen sind in letzterer suspendirt und gruppiren sich reihenweise oder umregelmässig in dem oberen freien Theil der Asci. Letztere hleiben stets auch bei Ascobolus mit ihrem unteren Ende an der Subhrmenialsehicht befestignt, sie nehmen von der Vollendung der Sporenhildung an stetig an Lumfang, und zwar besonders an Liange zu, ihre oberen Enden treten daher zur Zeit der Sporenreife

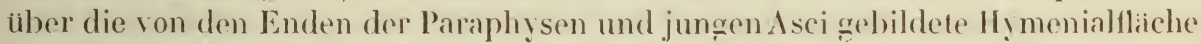
hervor, verschieden weit je nach den Arten, am weitesten bei Ascoloolus, wo die stumpf-kegelförmigen Enden der reifen Asci hoch über das übrige Hymenium hervorragen, fast mit blossem Ange erkennbar sind und zu der Fabel Anlass gegeben haben, die Asci wïrlen aus dem Hỵmenimm ausgeworfen. oder nach einer neueren Version Crouan, Cocmans sie lösten sich von der Subhymenialschicht los, um in die Oberfliche des II!menimm emporzurucken und, hier mit ihrer Basis zwischen die Paraphỵsen eingeklemmt. die sporen zu entleeren. in glei-

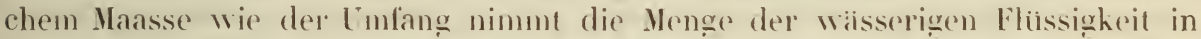
dem Ascus zu. Die in den in Rode stehenden Fillen mngeschichtete, ziemlieh dünne und wenig quellbare I/rmbran. Welehe stets von dem Primordialschlauch ausgekleidet bleibt, mağ der Vermehrung der Inhaltsflussig̣teit anfangs durch Flachenwachsthum folgen; jedenfalls wird sie aber durch die sich anhiufende

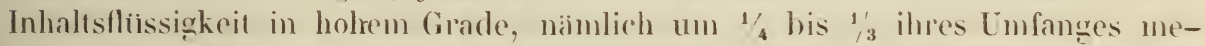
chanisch ausgedehnt. Sie behilt dabei eine hohe Elasticitit. Eine Stelle, die als die Rissstelle bezeichnet werden soll. ist ron der übrigen Wand dureh greringere behnbarkeit und Festiggent ansgezeichnet. Sie liegt in oder nahe dem Scheitel des Ascus. Eine Zeit lang widersteht die ganze Membran dem steigenden Drucke der Inhaltsflüssggkeit. Endlich wird dieser Widerstand in der Rissstelle überwunden, diese geoffinet und die Spannung aufggehohen. die clastische Wand des Ascus schnurrt daher in demsellyen Augenblick auf $3 /{ }_{4}$ bis $2 / 3$ ihres bisherigen Imlings zusammen, die Sporen werden hierdurch miteinander und mit einem Theile der Inhaltsfliissigkeit aus dem Risse hervorgespritzt. Der zusammenschnurrende Ascus zieht sich im Momente der Entleerung unter das Niveau des Ilymeniums zuriick und entschwindet somit der oberflachlichen Beobachtung Fig. $: 36$. Der Primordialschlauch folg̨t den besehriebenen Bewegungen 
passiv; im Augenblick der Ejaculation löst er sich oft theilweise ron der Membran los und wird manchmal ein Stück weit aus der Oeffnung hervorgestossen.

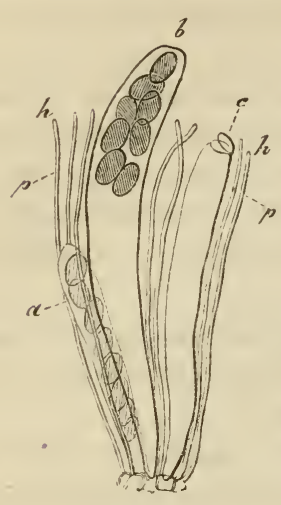

Fig. 5fi. Die Rissstelle selbst ist entweder der in Scheitel des Ascus vorgebildete, durch Gallerte verstopfte Porencanal Peziza Sclerotiorum, tuberosa und Verwandte, rgl. p. 110 , oder Rhytisna acerinum ein kurzes, das oberste Ende bildendes Spitzchen, oder der Scheitel des Ascus reisst mit einer zuvor nicht angedeuteten weiten und oft unregelmässigen Oeffnung auf (Pez. confluens, cupularis, Exoascus Pruni), oder der Riss erfolgt ringförmig dicht unter dem - Scheitel, dieser wird somit als ein kleiner Deckel Fig. 36) ron der runden Oeffnung abgehoben (Helvella crispa, Peziza convexula, pitya, melaena, Acetabulum, und ebenso, aber keineswegs ausschliesslich, wie Crouan, Coemans, Tulasne angeben, Ascobolus).

Man kann den beschriebenen Ejaculationsprocess direct beobachten, wenn nan Durchschnitte reifender IIymenien rasch in einen Wassertropfen unter das Mikroskop bringt, und der dargestellte Mechanismus desselben wird durch einige einfache Versuche und Beobachtungen erwiesen. Dass die Ascuswand elastisch und durch den Druck der Inhaltsflussigkeit mechanisch gedehnt und gespannt ist, zeig̣t sich am deutlichsten, wrnn man einen noch nicht geplatzten reifen oder nahezu reifen Ascus quer durehschneidet. Die dem Schnitt nähstliegenden Sporen werden alsdann aus diesem sofort ausgetrieben, die Wand des Schlauches zicht sich zu einem viel kleineren, den obigen Angaben entsprechenden Lmfanğzusammen; wahrend sie ursprünglich von den Sporen weit abgestanden hatte, legt sie sich diesen jetzt eng an oder schnürt sich selbst zwischen je zweien ein ; sie hleibt dibsig glatt und nimmt an Dicke deutlich zu, an dem oberen Ende der Asci von P. tuberosa, Selerotiorum und ähnlichen um mohr als das Doppelte, die Schichtung und der Porencanal werden bei diesen Arten erst nach der Oeffinung des $\Lambda$ seus oder der gِleich zu erwahnenden Manipulation deutlich. Vermindert man an intacten. Iscis die Jenge und Spannung der Inhaltsflissigkeit durch langsame Einwirkung wasserentziehender Reagentien, wie Alhohol, Glyeerin, so zicht sich der Ascus auf ein kleineres Volum zusammen, sein Scheitel trill unter das Niveau der H!̣menialflirche, die Dicke der Menbran steigt mit der Verminderung des Volumens bis zu dem bei der Durchschneidung sofort eintretenden Masimum. Umgehehrt wirl die Ejaculation dadurch beschleunig̣t, dass man die Asci in Wasser leg̣t, also die Möglichkeit endosmotíscher Wasseraufsaugung herstellt oder dass man den Druck auf die Membran ron aussen her durch Aullegen oder Aufpressen eines Deckglases/ steigert. Die Ejaculation tritt bei diesen Versuchen auch an Ascis oin, welche noch nicht die Ausdehnung völlig reifer erreicht haben; sie erfolgt um so rascher und energischer je niher die Asci dem Maximum der Spannung sind. Nach dem Gesagten muss

Fig. 36. Ascobolus furfuraceus P. Stiich eines Durchschnitts durch das Hymenium, 195 fach vergr. $h-h$ die durch die Enden der Paraphysen $(p)$ bezeichnete Hymeniumobertläche. $a$ junger Ascus. 6 fast reifer, über $h-h$ vorragend. $c$ eben solcher, der sich während der Beobachtung entleert und rerkiurzt hat, mit offenem Deckel an der spitze. 
auch in dem intacten frischen Hynenium die Ejaculation beschleuniggt werden durch Vermehrung des ron Aussen auf die Seiten der Isci einwirkenden Druckes, und dieser steigt mit der Einschiebung neuer Asci zwischen die erst vorhandenen und mit dem Wassergehalt der II!menien: wenigstens alle mit Paraphỵsen versehenen Discomycetenhymenien quellen in Wasser in der Richtung ihrer Fliche gewaltig und in weit höherem Maasse als das Gewcbe ihrer Triger auf.

Die Sporen von Protomyces macrosporus werden durch den gleichen Mechanisinus, welcher eben beschrieben wurde, ejaculirt. Die Rissstelle ist an der Membran des kugeligen Ascus nach der Bildung der Sporen in Form eines breiten Tüpfels oder einer verdünnten Stelle zu erkennen, und die Sporen rieken, indem sie sich, wie oben beschrieben wurde, zusammenballen, dicht unter diesolbe (igl. Fig. \&l.

In reifenden Hỵmenien von Peziza, Helvella, Morchella, Bulgaria, Exoascus und jedenfalls der Mehrzahl, wo nicht allen übrig̣en Discomyceten, werden fortwährend einzelne Asci suceessive entleert. Befindel sich der Pilz in abgeschlossener feuchter Luft, so findet man auf einer ibler oder neben das Hymenium gebrachten Glasplatte nach kurzer Zeit einzehne Sporen, meist zu je 8 in einem Fliissigheitströpfehen liegend, und allmihlich wird die Platte mil Sporen immer. dichter bestreut. Ausser dieser allmählichen Entleerung zeigen viele Discom!ceten die Eigenthïmlichkeit zu stii uben. d. h. plötzlich cine ganze Wolke von Sporen auszustossen, wenn man sie bew exgl. orler den Behailter öflnet, in dem sic aufbewahrt werden. Das stiuben hat sellostrerstindlich in der gleichzeitigen Entleerung zahlreicher Asci seinen Grund. Die Pilze, welche die Erscheinung zeigen - Peziza Acetabulum, Selerotiorum, Helvella crispa dienten mir vorzugiweise zu meinen Versuchen - stiuben nicht, wenn man sie feucht und in wasserreicher, ruhiger, durch eine Glasglocke abgeschlossener Luft cultivirt: es er-

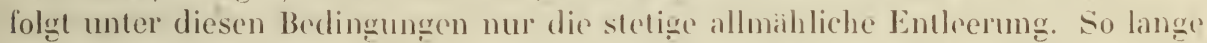
der Pilz von abgaschlossener wasserreicher Luft umgaben bleibt, tritt auch bei noch so starker Erschiitterung hein Stauben ein, mag der Pilz im Dunkeln oder im Tageslicht gehalten, oder aus der Dunhelheit pliotzlich in das difluse orler directe sommenlicht gebracht werelen. Dagegen stiubt der Pilz, sobald er aus dem feuchten Raum in die trockene Zimmerluft gebracht wird. Ist das Ilymenium nur missig feucht, so dass es von den vorstehenden reifen Sehlauchspitzen malt bereift oder fein flaumigg aussieht, so trill das stiuben wenigge secunden

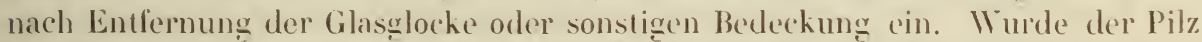
sehr nass gehalten, so ist das Ilymenium ron einer dimnen 1 asserschicht überzogen, daher mehr oder minder glinzend und dunkler gefirly als im missig feuchtem Zustand. Das Stiuben erfolgt an solchen Ilymenien erst dann, wenn die Wasserschicht abgedunstet und das matt-flaumige, hrller gefarbte Aussehen eingetreten ist. Mann kann es beschleunigen, wenn man die Verdunstung beschleunigat. Auch ohne Abschliessung in feuchter Luft stiuben nasse Hỵmenien nicht.

Aus diesen Thatsachen geht hervor, dass Austrocknung die bedingende Lrsache des Stiubens ist. Da letzleres bei nicht nassen Hymenien in dem Augenblicke eintritt, wo die trockne Luft mit dem Pilze in Berührung kommt, so kann die Austrocknung nicht dadurch das Stiuben verursachen, dass sie etwa ein Schrumpfen, eine Contraction des ganzen Pilzes oder Hymeniums und durch 
dieses eine Vermehrung des auf die Asci von aussen wirkenden Druckes hervorbringt. Es ist kaum denkbar, dass solches in irgend erheblichem Maasse in einer oder wenigen Secunden eintreten kann, und durch einfache Versuche und Messungen, uberzeugt man sich leicht, dass der von aussen wirkende Druck, unter welchen die Asci stehen, bei länger dauernder Austrocknung anfangs nicht rermehrt wird und spiter bedeutend abnimmt, dass er vielmehr in dem Maasse steigt, als das Hymenium Wasser aufsaugt.

Die Austrocknung kann daher nur dadurch das Stiuben verursachen, dass sie die Rissstellen der über die Hymenialfläche vorstehenden reifen Schlauchenden sprengt; sei es indem sie eine Verminderung des Lmfanges oder der Dehnbarkeit der Seitenwand bewirkt und somit den Druck der Inhaltsflüssigkeit auf die Rissstelle erhöht; sei es indem sie die Widerstandsfähigkeit der Rissstelle gegen den gleichbleibenden Druck aufhebt. Die Richtigkeit dieser Erklärung wird durch die Beobachtung erwiesen, dass die Ejaculation auch dann erfolgt, wenn man auf reife, freipriparirte, in wenig Wasser liegende Asci plötzlich wasserentziehende Reagentien (Alkohol, Glycerin) einwirken lasst.

Nach dem Gesagten ist es wohl unzweifelhaft, dass Bewegungen und Erschütterungen auf das Stauben nur insofern Einfluss haben, als sie das Nbtrocknen beschleunigen. Ilan kann ein IIymenium, wolches eben gestiubt hat, öfters zu abermaligem Stiuben bringen, wenn man den Pilz rasch hin und her berregt und hierdurch die noch minder vollkommen reifen Asci zum Platzen bringt. Dann aber, und oft schon nach dem ersten Stiuben, ist eine Ruhe von wenigstens melıreren Stunden nothwendig, um so viele neue Asci zur Reife kommen zu lassen, dass das Stiuben beobachlet werden kann.

Die Erscheinung des Stiubens fehlt manchen Discomyceten ganzlich; so konnte ich sie z. B. nicht hervorrufen bei Peziza pitya, 'onfluens, Morchella esculenta, Evoascus Pruni; bei den meisten tritt sie allerdings leicht cin, ausser bei den schon genannten Arten habe ich sie selbst beobachtet bei Peziza melaena, tuberosa, cyanoderma de Bary, Rab., Fung. Eur. 316 aurantia, cupularis, badia, Rhỵtisma acerinum. Viele andere Brobachtungen finden sich scit Micheli aufgezeichnet.

Bei Ascobolus finclet, soweit die Beobachtungen an $\Lambda$. furfuraceus reichen, heine successive, sondern nur gleichzeitigne Entleerung simmtlicher reifer Asci des Ilymeniums, also Stiuben statt. Sowohl der Mechanismus der Entleerung als die Bedingungen des Stiubens sind die gleichen, welche für die anderen Discomyceten angegeben wurden, nach Coemans soll ausserdem die Entleerung durch Lichtabschluss verzögert werden, was jedoch noch genauer festzustellen bleibt. Die Spitzen der reifen Asci ragen bei $\mathrm{A}$. furfuraceus weit uber die Hymenialfliche vor, sie cnthalten die dunkelvioletten Sporen und erscheinen dem blossen Auge als dunkle, fast schwarze über die IIymenialfliche zerstreute Punkte. Im Momente des stiubens verschwinden diese: die leeren Schlauchenden ziehen sich sofort unter das Nireau des Ilỵmeniums zurück, auf der Oberfliche dieses ist keine Spur der Asci mehr zu sehen: Diese Erscheinungen haben die oben schon erwihnte dugabe veranlasst, dass die ganzen Schläuche bei Ascobolus aus dem Ilymenium aufgeschleudert würden.

Sowohl bei der successiven Entleerung als beim sliuben werden die Spo- 
ren oft weit weg geschleudert, z. B. bei Bulgaria inquinans und Protomyces macrosporus 1-2 Cm. weit senkrecht nach oben, bei Exoascus Pruni $1 \mathrm{Cm}$. weil, bei den stark staubenden Pilzen, wie Peziza vesiculosa, acetabulum, Helvella crispa auf eine Entfernung ron $6 \mathrm{Cm}$. und dariber; hei Rhytisma acerinum nur auf einige Millimeter. Die Bewegungen des Stiubens verursachen bei grossen und stark stiubenden Hymenien ein Geriusch, was schon ron Desmazieres angegeben, neuerdings von Inderen bezweifelt worden ist. Bei kräftigen Exemplaren von Peziza Acetabulum und Helvella crispa habe ich es öfters als ein sehr vernehmliches Zischen gehört.

lch habe in obiger Darstellung die Fragen, welche Zusammensetzung die Inhaltsflüssigkeit des Ascus hat und auf welchem Wege ihre betrichtliche Vermehrung erfolgt, unberuhrt gelassen, weil ihre Beantwortung zur Zeit unsicher und jedenfalls nicht leicht ist.

Was den ersten Punkt betrifft, so ist bemerkenswerth, dass zur Entleerung reife $\Lambda$ sci, welche in $\Lambda$ lkohol oder Zurkerlösung oder Glycerin zur Zusammenziehung gebracht sind, sich nic auf das fribhere Volumen, und of uberhaupt kaum merklich wieder ausdehnen, wenn man sie wiederum in Wasser bringt. Hiernach kann zuncichst keine in Wasser quellende Substanz die Dilatation der Asci verursachen, der Juhalt inuss eine wirkliche Fliissigheit sein; und diese hann ferner keinen.Körper von hohem endosmotischen Aequivalent gelöst enthalten; wenigstens ergeben sich diese Folgerungen, wenn man die Annahme ausschliesst, dass durch die genannten wasserentziehenden Reagentien Permeabilitit oder Dehnharkeit der Schlanchwand veroindert werde, eine Annahme, für welehe in der That kein Grund vorliegt. Eiweiss oder Zucker, an die zuerst gedacht worden könnte, liessen sich auf mihrochemischem Wege bis jetzt im reifen Aseus nicht nachweisen, es scheint, als bestehe die Inhaltsfliissigxheit fast ausschlıesslich aus Wasser. Nach dem Mitg̣etheilen kann dieses nicht durch endosmotische Einsaugung in den Schlauch gedaugen; of es von dem subhỵmenialen Gewebe aus in den Schlauch eingepresst wird, oder als Vumselzungs- Ongdations- product des zur Sporenhildung nicht verbantehten P'rotoplasma und Epiplasma entsteht, bleibt zu untersuchen.

Von den beschriebenen Vorgaingen bei den biseonseden sind die hohannten Erscheinungen der Sporenentleerung bei den Pyrenonyceten verschieden. Es muss hier unterschieden werden zwischen der Befreiung der Sporen aus dem Schlauche und ihrer Auslecrung aus dem Perithecium.

Die erstere erfolgt in einer Reihe von Fällen darlureh, dass die reife Schlauchwand die Beschaffenheil einer in Wasser zerfliessenden Gallerte annimmt, und zwar entweder die ganze Wand Nectria oder zunachst der mittlere Theil derselben, wihrend die Spitze und Basis an der Desorganisation nicht oder erst spit Theil nehmen Cilaviceps, auch Lophium, nach 'Tulasne'.

Bei anderen, wie es scheint zahlreichen Sphatritceen mit fuellharer, zweischichtiger Schlauchwand (rgl. S. 109 zeigh der reife Aseus eigenthimliche Ver-

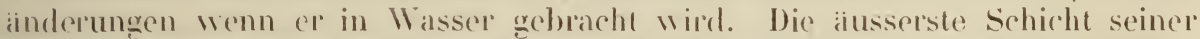
Hembran reisst plotzlich an dem Scheitel durch und die innere strecht sich, aus ihr hervortretend, auf etwa die doppelte bisherige Linge; die Breite des Aseus bleiht dabei unverindert oder nimmt in geringem Vaasse zu. die ums doppelte vergössierte Menıhran behält ohngefihr die grleiche Dicke wie vor der Streckung, 
sie muss daher in der Richtung ihrer Oberfliche aufquellen, unter gleichzeitiger Vermehrung der Inhaltsflüssigkeit. Die Sporen rücken wïhrend der Streckung in den oberen Theil des Schlauches. Bei einer Anzahl von Arten, wie Sphaeria Scirpi (Pringsheim, Jahrb. I, 189) Sph. inquinans Sollm. (Bot. Ztg. 1863, p. 202) Sph. Lemaneae Cohn u. a. reisst die Membran des gestreckten Schlauches alsbald im Scheitel auf, die oberste Spore wird in die enge Oeffnung eingepresst und alsbald weit weggeschleudert. In derselben Weise werden die übrigen Sporen, eine nach der anderen binnen wenigen Vinuten entleert. Nach jeder Ejaculation verkürzt sich der Schlauch etwas; ist eine neue Spore in die Oeffnung eingepresst, so folgt wiederum Aus-

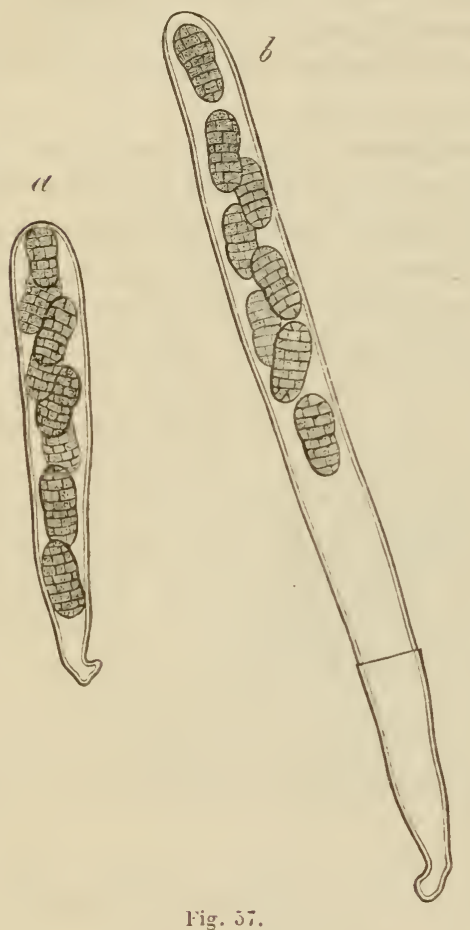
dehnung desselben, nach Auswerfung der letzten Spore verkürzt er sich um $1 / 3$ seiner Liinge unter bedeutender Quellung seines Membran in die Dicke. Es ist klar, dass dieser Process durch das Zusammenwirken endosnıtischer Vermehrung der wässerigen Inhaltsflüssigkeit und des Verkürıungsbestrebens der elastischen Schlauchwand zu Stande kommt. Bei ciner anderen Anzahl ron Arten (z. B. Pleospora herbarum, Fig. $3 \bar{i}$. Cucurbitaria Laburni erfolgt an dem ebenso gestreckten Ascus eine Ejaculation nicht oder nur seltén. Seine bran quillt vielmehr zu einer alsbald ganz rerschwommenen Gallerte auf, welche die Sporen und den collabirenden Primordialschlauch einhüllt. Die Quellung tritt um so rascher ein, je reifer der Ascus; bei völlig reifen oft schon wenige Minuten nach der Streckung. Innreife Iscis zeigen oft nur letztere Eischeinung, ohne dass selbst nach 2 $4-36$ stündigem Liegen im Wasser Quellung eintrite.

Wo die Asci in eine Gallertmasse zerfliessen, wird diese sammt den ihr vingebetteten Sporen in Form eines Gallerttropfens oder einer ziah gelatinösen Ranke aus der engen Perithecienmündung hervorgepresst, sobald der Pilz aus feuchter L'mgebung Wasser aufsaugt und die Gallerte hierdurch aufquillt. So z. B. bei Nectria cinnabarina; Pleurostoma Tul. Sph. fusca Hoffmann; bei anderen Formen, N. inaurata Berk., N. Lamyi Not. scheint selbst diese Form der Entleerung nur ausnahmsweise vorzukommen und die sporenführende Gallerte erst dureh allmihliches Zerfallen der reifen Perithecienwand frei gelegt zu werden Janowitsch, Bot. Ztg. 186ว̈). Der beschriebene Ent-

Fig. 57. Pleospora herbarum Tul. (grosse Form). a reifer Ascus (mit vielgliedrigen zusammengesetzten Sporen) frisch aus dem Perithecium genommen. $b$ derselbe nach Einwirkung des Wassers: Innenschicht gestrecht, Aussenschicht durchrissen. Bei diesem Exemplar erfolgte Ejaculation nach Art von Sph. Scirpi; meist unterbleibt dieselbe bei vorliegender Species. - Vergr. 19 ว. 
leerungsvorgang ist der gleiche wie der für solche Conceptakeln längst bekannte, in denen von Gallerte umhüllte Sporen durch Abschnürung frei werden (Spermogonien und Pycniden von Pyrenomyceten;.

Andere Pyrenomyceten ejaculiren ihre Ascosporen aus der Perithecienmündung auf eine Entfernung ron I Millim. und mehr und zeigen selbst in geringem Masse die Erscheinungen des Stäubens. Tulasne irwähnt dieses für Hypoxylon-Arten und Claviceps; es scheint auch bei anderen Sphaeriaceen vorzukommen. Die Erkliirung dieser Erscheinung findet in der geringen Weite der Perithecienmündungen Schwierigkeiten und bedarf jedenfalls noch genauerer Untersuchungen. Wo die Entleerung der Asci in der Art ron Sph. Scirpi ruckweise und mit einer gewissen Gewalt erfolgt, lässt sich die Sache erkliren, wenn man bedenkt, dass die Spitzen der reifen Schliuche dicht unter der Peritheciennüundung stehen und dass etwa in dem Mündungseanale hängen bleibende Sporen durch nachfolgende fortgestossen werden können.

Das Stauben beobachtete ich bei Claviceps, wo eine Ejaculation an den freipräparirten Ascis nicht beobachtet wird, diese sich vielmehr in ihrer Mitte gallertigr auflockern und somit der obere Theil sammt den zu einem Büindel vereinigten stabförnigen Sporen von dem subhymenialen Gewebe losagelöst wird. Bringt man reife Fruchttriger dieser Pilze aus der feuchten lmgebung, in der sie sich ausbilden, in trockene Luft, so sieht man alsbald dic Sporenbuindel wie zarte, ylit\%ernde Nidelehen aus den Perithecien hervorstiuben. Die Erscheinung dauert ziemlich lange. Man über\%eugt sich nun leicht, dass clas saftig̣e Gewebe der Perilheciumwinde an der trockenen Luft sofort stark zu schrumpfen und sich zusammenzuziehen anfiingt. Der der Luft nicht unmittelbar ausgeselzte gallertige Inhalt des Peritheciums wird dagegen langsamer seinen Wassergehalt vermindern und abschwellen, or muss daher durch die schrumpfende Wand einen steigenden Druck erleiden, und in diesem diurfte der Grund des gewaltsamen Lusworfens der losgelösten reifen Sporenbiindelchen zu suchen sein.

Eine kleine Anzahl von Pilzen, ron Tode fung. Meckl. fungi ejacuIatori genantit, zeichnet sich aus dadurch, dass zur Zeit der Reife der ganze sporenfiihrende Bohiilter wegageschleudert wird.

Ausser dem jetzl durch Fries S. veget. Scand. p. 4:39 von den Pilzen zu den Insecten verwiesenen Atractobolus Tode's gehort hierher zunichst die von Fries den Pyrenomyceten angereihte Gattung Thelebolus Th. stercoreus, Th. terrestris). Ein mohnsanengrosser, einem Sphaeria-Perithecium ähnlich sehender rundlicher Körper, von gelber Farbe bei Th. stercoreus, trigat auf seinem Scheitel einen kleinen kugeligen Sporenbehiilter, weleher zur Zeit der Reife mit Gewalt fortgeschlendert wird. Ueber die Structur des Pilzes und den Mechanismus der Ejaculation ist durchaus nichts Genaueres bekannt, und die getrockneten Exemplare welche ich untersucht habe, gaben keinen Aufschluss.

Die zweite hier zu erwahnende Gattung ist Pilobolus Tode, ron der Coemans Mém. cour. de l'Acad. roy. de Belg. Tom. XXX neuerdings eine gute Monographic geliefert und die umfangreiche Litteratur zusammengestellt hat. Der Fruchtriiger dieser den Mucorinen zugehörenden Pilze besteht aus einer gestreckten, in der Mitte eingeschnürten oder schmal-cylindrischen, oben und unten blasig aufgetriebenen, einige Millimeter langen Zelle, welche dem ver- 
kehrt kegelförmigen erweiterten Ende eines Myceliumzweiges aufsitzt und auf ihrem etwas verschmälerten Scheitel die abgeplattet-kugelige violettschwarze Sporenmutterzelle trägt. Letztere ist zur Zeit der Reife von der Tragzelle abgegrenzt durch eine Scheidewand, welche in Form eines stumpfen Kegelmantels oder Cỵlinders ins Innere des Sporangiums vorspringt ( $\mathbf{g} \mathbf{g} l$. Fig. 58). Die Wand des letzteren ist im Uebrigen geschichtet und in rerschiedenen Regionen verschieden gefïrbt, wie bei Coemans ausführlich beschrieben ist; sie lïsst sich vor der Reife unter Wasser von dem Trïger derart lostrennen, dass dieser durch die in seine Wand continuirlich übergehende untere Schichte der Scheidewand (die cloison sous-globulaire Coemans') geschlossen bleibt. Zur Zeit der völligen Reife wird endlich das ganze Sporangium plötzlich weğgeschleudert, und zwar auf eine Höhe, welche nach Coemans' Messungen 10 f Cm. erreichen kann. Der Mechanismus dieses Schleuderns ist dem für die Ejaculation der Discomycetensporen beschriebenen im Wesentlichen gleich. Die Tragzelle ist ror der Abwerfung des Sporangiums strotzend mit wässeriger Flüssigkeit (innerhalb einer mïchtigen Protoplasmaschichte) erfüllt, ihre Membran gedehnt und elastisch, wie Durchschneidungen leicht zeigen. Von dem Mycelium aus wird die Menge der Flüssigkeit in der Tragzzelle und hierdurch die Spannung der Theile fortwährend vermehrt, bis endlich die Membran dicht unter der Basis des Sporangiums ringförmig durchreisst. In demselben Augenblick wird, auf die nämliche Weise wie bei den Discomycetenascis, aus der Oeffnung ein Theil der Inhaltsfluissigkeit hervorgespritzt, und durch diese das Sporangium fortgetrieben. Das Sporangium bleibt wiihrend dieser Vorgänge geschlossen, die Sporen werden erst durch spätere Zerstörung seiner Wand frei. Die Tragzelle zieht sich, wie aus dem Mitgetheilten hervorgeht, im Momente der Ejaculation auf einen bedeutend kleineren Lmfang zusammen. Nicht selten behält sie dabei glatte Oberfliche und man sieht alsdann aus der weiten runden Oeffnung ihres oberen Endes einen immer grösser werdenden Wassertropfen hervortreten - cine Erscheinung, welche die oben ausgesprochene Behauptung, dass ron dem Mycelium aus Wasser in die Tragzelle eintritt, begrundet, und zeigt, dass dieses in die Tragzelle eingepresst wird. Sehr bald sinkt übrigens die geöffnete Zelle zusammen und geht zu Grunde. Die ringförmige Rissstelle des Sporangiumtrigers ist schon vor dem Platzen in Form einer zarten, scharfen Linie erkennbar. Das Abwerfen der Sporangien wird bestimmt oder doch in hohem Grade befördert durch die Einwirkung des Lichtes, wie Coemans ausführlich nachgewiesen hat. Im gewöhnlichen Entwickelungsverlauf beginnt die Eṇtwickelung der Traiger Mittags oder Nachmittags, wird sammt der Sporangien - und Sporenbildung Nachts vollendet, und das Abwerfen erfolğt am folgenden Morgen, um so eher, je heller die Beleuchtung. Pilobolus oedipus Mont. zeigt diese Periodi-

Fig. šs. Pilobolus crystallinus. Schematische Ansicht. $t$ oberes Ende der Tragzelle. $s$ Sporangium. $r$ die dicht unter der unteren Grenze des Sporangiums verlaufende ringförmige Rissstelle. 
cität minder regelmiissig, als P. crystallinus. Wärme und Trockenheit wirken ther hemmend als fördernd aul die Abwerfung ein. Die Sporangienträger ron Pilobolus zeigen überaus starke Lichtkrümmungen; nach dem was man über den Mechanisınus dieser Krümmungen überhaupt kennt, ist wohl anzunehmen, dass der Lichteinfluss das Abwerfen in sofern fördert, als er die Dehnbarkeit der Membran des Trägers vermindert.

Drittens ist hier zu nennen die seit Micheli viele Male beschriebene Gattung Sphaerobolus Tode, kleine, etwa senfkorngrosse Gastroinyceten, deren Bau ron Corda (Icon. V, 66 ) und Bonorden (Bot. Ztg. 1851, P. 22). deren Basidien durch Bonorden 1. c. und Tulasne (Fung. hypog. tab. XXI) beschrieben sind. Die ausgebildete Peridie von Sphaer. stellatus lässt eine aussere, eine mittlere und eine innere Schicht unterscheiden, letztere ist, als die Sporen unmittelhar umschliessend, Sporangie genannt worden. Der Beschreibung zufolge reissen zur Zeit der Reife die beiden iusseren aneinanderliegenden Schichten der Peridie an Scheitel sternförmig in sieben bis neun Lappen auf, einen Napf mit gezacktem Rande bildend, in dessen Grunde, so lange der Pilz hinreichend feucht ist, die kugelige braune sporangie lieğt. Wird aber die Feuchtigheit durch Verdunstung vermindert, so stiilpt sich die Mittelschicht der Peridie nach oben und aussen plötzlich einpor, wird glockenförmig und schleudert die sporangie oft einige Zoll weit fort. - Welche Verinderungen und mechanische Verhiltnisse hierbei stattfinden, ist nirgends genauer angegeben; die ganze Entwickelungsgeschichte dieses interessanten Pilzes bedarf dringend eincr neuen griundlichen Bearlocitung.

\section{K e im ung d e r s poren.}

Unter den spiiter zu besprechenden geergneten Bedingungen, von denen hier nur einstweilen das Vorhandensein einer Quantitit tropfbar flüssigen oder dunstförmigen Wassers erwihnt werden möge, tritt die Weiterentwickelung, Ke imung der reifen Spore ein. Dieselbe ist zur Zeit für zahlreiche Repräisentanten der meisten Ordnungen und Familien der Pilze bekannt, so dass nur diejenigen grösseren Gruppen hervorzuheben sind, deren Angehörig̣e bis jetzt den Keimungsversuchen beharrlich widerstanden haben; niinlich die Gastromyceten (mit Ausnahme von Lycoperdon constellatum Fr., verrucosum Rupp, Bovista plumbea P., Cyathus striatus W., wemn Iloffmanns Angaben, Bot. Ztg. 1859, p. 217 , zuverlassig sind, Elaphomyces, Onygena, die Tuberaceen nit Ausnahme von Balsamia ( $\mathrm{gl}$. Tulasne, fung. hypog.), die muthmasslichen Sporen gewisser Protomyees - und Physodermaformen (vgl. de Bary, Beitr. zur Morphol. (l. Pilze I). Von vielen einzelnen Species und Sporenformen honnte allerdings die Keimung noch nicht gefunden werden; ihre ausführliche Aufzählung wird jedoch durch die bekannte Keimung verwandter Formen überflüssig gemacht. Von den constant nicht keimenden Spernatien wird im nächsten Capitel die Rede sein.

Nach den morphologischen Vorgängen lasseg sich vier, allerdings vielfach durch Leberginge mit einander verbundene Hauptformen der Keimung unterscheiden : 
1) Austreibung ron Keimschliuchen oder Keimfäden.

2) Bildung eines Vorkeims (Prom ycelium Tulasne), welcher sofort secundäre sporen (Sporidia Tulasne) abschnürt;

3) Sporidienbildung durch hefeartige Sprossung;

4) Keimungen, welche durch Theilung der Spore mittelst Scheidewainden eingeleitet werden.

Die erste Form ist die häufigste und seit Prévosts Mémoire sur la carie und Ehrenbergs Epistola de Mycetogenesi unzählige Male mehr oder minder genau beschrieben worden. Sie findet sich zunächst bei allen Schwämsporen: sobald dieselben zur Ruhe gekommen und mit einer Membran versehen sind, treiben sie nach einer oder zwei Seiten hin einen Keimschlauch (s. oben Fig. 52), dessen Membran die unmittelbare Fortsetzung der Sporenmembran ist und der sich im Uebrigen denen der unbeweglichen Sporen gleich verhält. Diese (Fig. :39) schwellen bei der Keimung zuerst durch Wasseraufnahme an und treiben alsbald nach einer, oder

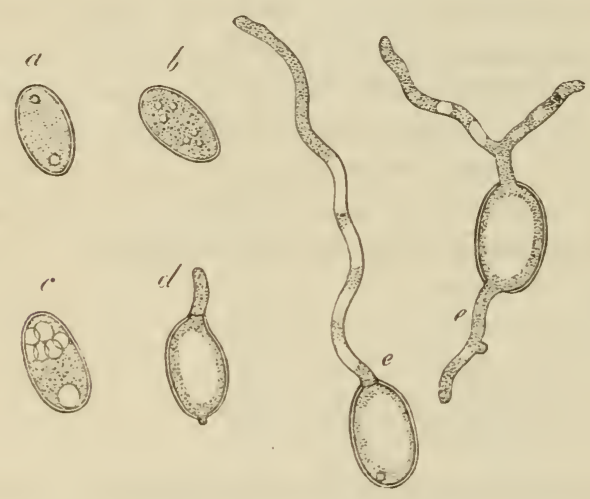

Fig. 5!). hiufig nach zwei entgegenge- setzten, manchmal nach mehreren Seiten eine schlauchförmige Ausstülpung - Ke i m s c h l a u ch, K e i m f d en, welche sich durch Spitzenwachsthum verlängert, häufig verzweigt, und bei geeigneter Ernährung continuirlich $\mathrm{zu}$ einem endlich wiederum fructificirenden Mycelium heranwaichst. Der Keinschlauch wird ron einer Fortsetzung der innersten Sporenmembranschicht bekleidet. Selbst da. wo die Sporenmembran ror der Keimung zart und ohne deutliche Sonderung in Endospor und Epispor ist, sieht man oft deutlich die zarte Wand des Keimschlauches sich in die Innenfliche der Sporenhaut fortsetzen, z. B. Acrostalagmus, lenicillium, etc. Auch derbere Endosporien stiilpen sich nicht ganz zur Keimschlauchmembran vor, sondern nur ihre innerste, die ausseren durchbrechende Schichte (z. B. Uredosporen). Bei deutlich entwickeltem Episporium bricht der heimschlauch aus diesem hervor, dasselbe entweder an vorher nicht besonders ausgezeichneten Punkten perforirend oder klappig sprengend: oder aber aus den vorgebildeten Tüjpeln austretend, welche oben als Keimporen bezeichnet worden sind. In dem Inhalte der Spore verschwinden mit dem Beginn der Keimung die grösseren Oeltropfen, indem sie entweder völlig aufgelöst werden, oder in kleine Körnchen zerfallen, die sich in dem Protoplasma vertheilen. Der Zellkern wird, wo er vorher sichtbar war, mit der Keimung stets unkenntlich. Von dem Beginne der letzteren an treten in dem Protoplasma der Spore Vacuolen

Fig. 59. Helvella esculenta P. $a$ reife Spore mit den zwei characteristischen Oeltröpfchen an den Enden. $b-e$ lieimung. Entwickelungsfolge nach den Buchstaben. Vergr. 390. 
auf oder die vorhandenen werden grösser; sobald die Austreibung der Keimschläuche beginnt, nehmen sie schnell gewaltiğ an Grössse zu, indem mindestens ein betrichtlicher Theil des Protoplasma aus dem Sporangium in den Schlauch tritt und mit der fortwachsenden Spitze des letzteren vorrückt, in dem sporenraume und dem älteren hinteren Theile des Schlauches zumeist nur wässerige Flüssigkeit zuruicklassend.

In der Mehrzahl der Fille nehmen die Theile der Spore, nach der in wenigen Minuten vollendeten ersten Wasseraufsaugung, bei der Keimung nicht mehr an Grösse zu; sie g̨eben das Protoplasma und die Reservenahrung ganz oder bis auf unbedeutende, zufiillig zurückbleibende Reste an den Koimschlauch ab und gehen bald nach der Keimung zu Grunde. Von unzihlig̣en Beispielen hierfuir sind die exquisitesten unter den ichten Schmarotzerpilzen zu finden, zumal den Peronosporen und Uredineen. Andererseits gibt es Sporen, welche sich wihrend des Keimens oft auf mehr als das Doppelte vergrössern, von einer betrichtlichen Protoplasmaschicht ausgekleidet bleiben und mit den Keimschlïuchen gleich einer Myceliumzelle wachsen; so \%. B. die Sporen ron Mucor Mueedo und Verwandten bei Aussaat in eine zur Ernihrung der Species geeignete Flüssigkeit, die Stylosporen von Erṣsiphe Tulasne, Carpol. I und andere, zumal auch zusammengesetzte z. B. Pleospora herharum .

Eigenthimlich ist die Keimung der Sporen Conidien ron Peronospora densa Rab. und P. pygurara Unger. Hier quillt plötzlich das ganze Protoplasma aus der sich öffnenden papillenförnigen spitze der Spore hervor, nimmt die Form eines kug̣egligen Körpers an, der alsbald auf seiner Oberfliche eine neue Cellulosemembran ausscheidet und dann rinen einfachen keimschılauch treibt.

Bei den zwei- bis vielgliederiggen Sporenkörpern oder zusammengesetsten Sporen keimt jede Theilspore gleich einer cinfachen oder besitzt doch die Fihigykeit hierzu. Vicht selten sieht man, auch bei selur vielgliederigen, von fast allen Theilsporen einen Keimschlauch ausstrahlen; z. B. Pleospora herbarumi, Cucurbitaria Laburni. In anderen fiallen keinten von den zusammengesetzten sporen der Regel nach nur einzelne Theilsporen, zumal da wo letztere eine cinfache Reihe bilden ein oder beide Endylieder der Reihe; z. B. Nelogranmua Bulliardii Tul., Melanconis Tul., Aglaospora profusa Not., Exosporium Tiliae, Stylosporen von Cucurbitaria nucrospora Tul. Carp. II. I) nicht keimenden Theilsporen eines Körpers geben dabei, nach Tulasne Carjol. I, p. 9:̈), ilıren Inhalt allmibilılig an die keimenden ab.

Jer Keimfaden hat in allen Fillen die Gestalt eines cylindrischen oder varicösen Schlauches, der im Mllgemeinen die Beschaflenheit eines Mỵceliumfadens und je nach Gattung und Art mannigfache Formdifferenzen, Krüumungen u. s. w. zeight, und zunaichst einfach bleibt oder sich schon früh rerzweigyt. Wurde die Aussaat in ein Medium gemacht, welches die zur Ernilırung der Spe(cies nöthiggen Materialien nicht enthailt, z. B. in reines Wasser, so bleibt sein Wachsthum bald stille stehen, die in der spore aufyespeicherte Reservenahrung reicht oflenbar nur für eine kurze Entwickelungszeit aus. Bei hinreichendem Nahrungsmaterial entwickelt sich dagegen der Keimschlauch sofort zu einem wiederum fruchthildenden Mycelium weiter. Dieses Gesetz ist jetzt durch directe Beobachtung für eine grosse Anzahl von Pilzen festgestellt; so die Saprolegnieen, Peronosporeen, Lredineen, Mucorinen, viele Schimmelformen, z. B- 
Penicillitum, Eurotium u. s. f., es gilt für Coprinus fimetarius, Peziza Sclerotiorum, P. Fuckeliana, und kann daher mit Sicherheit auf alle nicht sporidienbildende Keimschläuche ausgedehnt werden, auch wenn dieselben, wie bei den meisten zusammengesetzten Schwämmen, noch nicht über die in reinem Wasser oder Wasserdunst auftretenden Anfangsstadien hinaus verfolgt worden sind.

Nicht selten beobachtet man wenn zahlreiche Sporen einer Species miteinander ausgesiet werden, dass die Keimschlaiuche, welche von verschiedenen Sporen entspringen, da wo sie einander

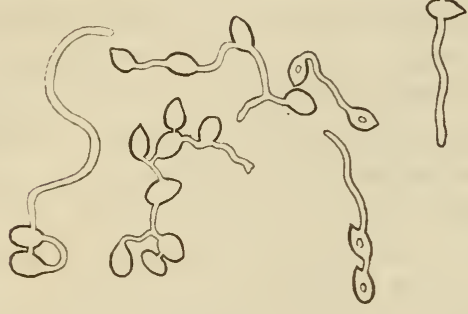

Fig. 60 . berühren fest mit einander verwachsen und zwar bis zum Verschwinden der Membran und Herstellung einer offenen Communication zwischen beiden verbundenen Zellen an der Verwachsungsstelle. Tulasne erwähnt dieser Erscheinung (Carpol. I, p. 98) als einer öfters vorkommenden, er stellt sie (Carpol. II, Tab. XVII) für Cryptospora aucta Berk. dar; Hoffmann (z. B. in Pringsh. Jahrb. II, p. 280) und ich sahen sie öfters bei Schimmelpilzen, z. B. Fusarium heterosporum, Spicaria Solani Hart. (Fig. 60). Sie findet sich auch bei erwachsenen Myceliumfiuden (s. Seite 17) und verleiht dem ganzen Mycelium eine oft engmaschig netzförmige Beschaffenheit.

Das characteristische der beschriebenen ersten Keimungsform liegt darin, dass der von der Spore ausgetriebene Keimschlauch die Fähigkeit besitzt, continuirlich zu dem Mycelium auszuwachsen. Bei der zweiten Form der Keimung treibt die Spore gleichfalls einen Schlauch; sein orstes Auftreten und die Veranderungen, welche diesem vorangehen, sind die gleichen, welche für die erste Form beschrieben wurden. Der Schlauch - Vorkeim, Promycelium zeigt aber ein typisch begrenztes Lingenwachsthum, or wird je nach dem Einzelfalle ein, zwei oder vicle Male liinger als die Spore und beginnt dann sofort Sporen zweiter Ordnung, Sporidien abzuschnüren. Das in der Spore enthaltene Protoplasma und die Reservenahrung werden zur Entwickelung des Promyecliums und der Sporidien verwendet, eine $\Lambda$ ssimilation findet von Seiten des Promyceliums nicht statt; dieses ist nach Abschnürung einer bestimmten Anzahl von Sporidien leer und geht dann zu Grunde; seine ganze Entwickelung liuft in kur\%er Zeit, manchmal in wenigen Stunden (z. B. Endophyllum Sempervivi) ab. In Beziehung auf Gestalt, Grösse, Zahl der Sporidien u. s. f. sind die Promycelien je nach Arten und Gruppen sehr mannigfaltig. Die besten Beispiele für ihre Entwickelung bieten unstreitig die Teleutosporen der Uredineen dar. Diese treihen bei der Koimung einen Schlauch, der mehrmals lïnger wird als die Spore. Bei Coleosporium bleibt er in der Regel ganz einfach, ungetheilt und schnürt auf seinem pfriemenförmig zugespitzten oberen Ende eine rundliche oder nierenförmige Sporidie ab, welche alles Protoplasma

Fig. 60. Spicaria Solani Harting. Keimende Sporen, 24 Stunden nach der Aussaat. $a$ treibt zwei unverbundene, die übrigen anastomosirende Keimschläuche. - Vergrösserung 390 . 
des Schlauches in sich aufnimmt. Bei den übrigen Lredineengattungen (Fig. 61 ) erhält das Promycelium die Gestalt eines dicken, stumpfen, mehr oder minder gekrummten Schlauches, dieser theilt sich nach vollendetem Längenwachsthum durch Querwände in drei bis fünf Zellen, von denen jede in ihrem oberen Theile eine kurze pfriemenförmige Ausstülpung - sterigma - treibt; auf dem Ende eines jeden Sterigma wird eine runde oder ovale oder nierenförmigge Sporidie abgeschnürt. Die Abweichungen von diesem typischen Entwickelungsgange, welche hier und da vorkommen., sind zu unbedeutend, um hier erwihnt zu werden. Unter der verwandten Ustilagi nee nfamilie zeigt Lstilago receptaculorum Fig. $62 \mathrm{~B}$ ihnliche Keimung, wie die zuletzt erwihhten Uredineen, nur dass die Sporidien an den Gliedern des Promyceliums ungestielt. manchmal zu mehreren neben einander und, wie es scheint, auch successive nach einander abgescbnürt werden. Das Promycelium ron L'st. Iongissima Fig. $62 A$ ist ein diinner cylindrischer Schlauch von der zwei- bis dreifachen Lange der Spore und schnürt auf seiner Spitze je eine spindelförmig-ẹlindrische Sporidie ab: ob überhaupt

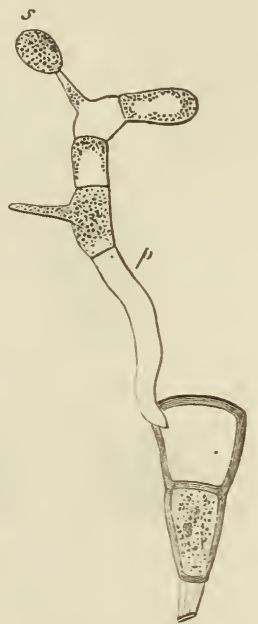

Fig. 61. nur eine einzige oder mehrere reihenweise nach einander, ist noch zu untersuchen. Von den anderen Arten abweichend verhält sich Ustil. Carbo DC. Fig. 6.2 $C$. Seine Sporen treiben einen kurzen, cylindrischen,
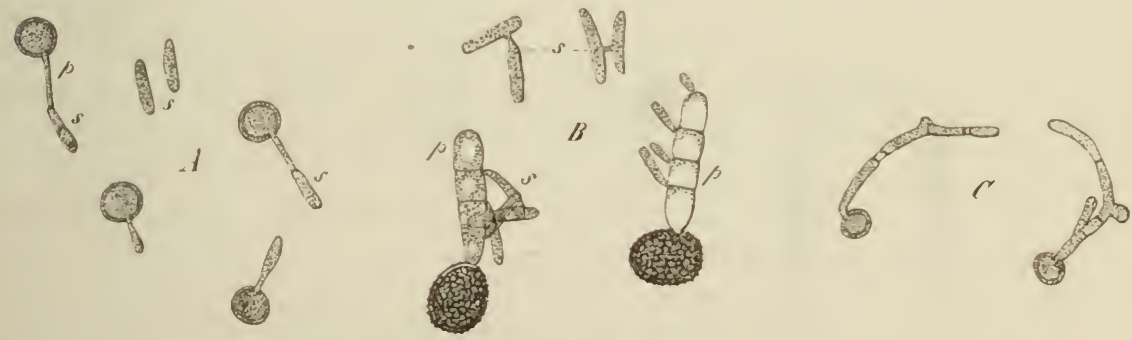

Fig. 62.

oft etwas gekrimmten und mit einem oder zwei Zweiglein versehenen Schlauch, und dieser bildet Sporidien theils auf den Enden kleiner Seitenzweiglein, theils dadurch, dass er der Quere nach in cylindrische Glieder zerfiillt. U. antherarum verhist sich ihnlich. Die detaillirtere Beschreibung seiner Keimung sowie der Promycelien der übrigen Estilagineen und der Uredineen findet sich bei Tulasne, Ann. sc. nat. 4e serr., tom. II, auch 3e sér., lom. VIl; und J. Küihn, Krankh. der Culturọewichse. Unter den daselbst beschriebenen Ustilag̣ineen

Fig. 61. Puccinia straminis Fuckel. Keimende Teleutospore. 390 fach verg̣. $s$ Sporidie. $p$ Promycelium.

Fig. 62. A Ustilago long̨issima Tul. Keimung. Verg̣r. gegen 700 .

$B$ Ust. receptaculorum. Desgl. Verg̣r. 390 .

$C$ Ust. Carbo DC. Desgl. Vergl. iiber 390. - p und $s$ wie in Fig. 61. 
ist Tilletia Caries Tul. (Fig. 63) durch ihr Promycelium besonders bemerkenswerth. Dasselbe ist ein kurzer, dicker, zuletzt oft septirter Schlauch, an dessen Anfangs stumpl abgerundetem Scheitel ein

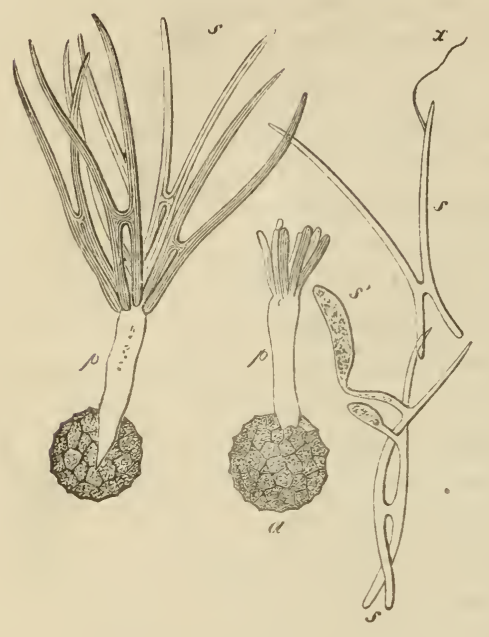

Fig. 63. Wirtel von meist acht bis zehn schmal cylindrischen, zuletzt stark verlingerten und pfriemenförmig zugespitzten Sporidien ()Kranzkörper( Kühn) hervorsprosst und abgeschnürt wird. Diese verbinden sich vor ihrer Lostrennung von dem Promycelium mittelst einer kurzen Querbrücke paarweise zu Doppelsporidien von der Form eines H. Achnlich wie Tilletia keimen Lrocyst is occulta und U. pompholygodes; doch sind die Sporidien minder zahlreich, von unregelmassiger und ungleicher For'm und ohne die Hlormige Verbindung.

Ausser bei den genannten Gruppen ist Promscelium und Sporidienbildung bei den Tremellinen, mehreren Dis comyceten Peziza bolaris Batsch., P. Cylichnium, P. tuberosa, rergol. Tulasne, Ann. sc. nat. 3e sér., tom. XX, p. 171; auch bei Rhytisma Andromedae Fig. 64 A bekannt. Der Vorgang besteht hier im Wesentlichen immer darin, dass die Spore an einem bis mehreren Punkten

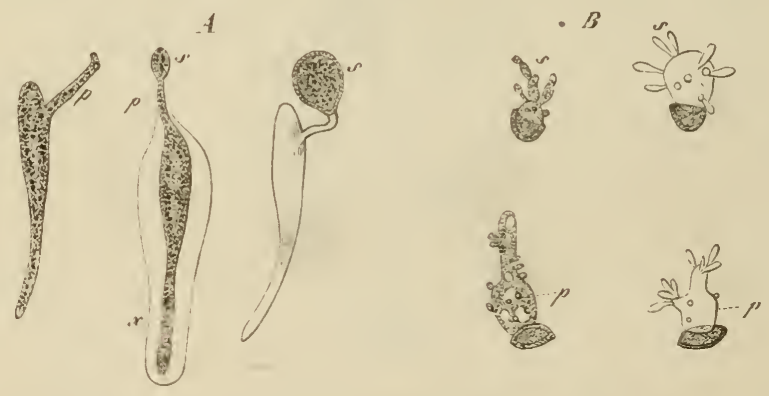

Fig. 64 .

"einfache kurze Sterigmen treibt, welche an ihrer Spitze eine Sporidie abschnüren. Bei Dacrymyces wird die leicht gekrümmte ç̣lindrische Spore vor der Keimung der Regel nach durch Querwände in zwei, vier oder acht Zellen

Fig. 63. Tilletia Caries Tul. Keimung. 460 fach vergr., nach Tulasne copirt. $p$ und $s$ wie in Fig. 61. $s^{\prime}$ secundäre Sporidie. $x$ zarter, von einer primären Sporidie getriebener Keimschlauch. $a$ Beginn der Sporidienbildung.

Fig. 64. A Rhỵtisma Andromedae Fr. Keimung, 390 fach vergr. $p$ und $s$ wie in Fig. 61 . Die Spore $x$ ist noch von dem ursprünglich vorhandenen Gallertsaum umgeben, der bei den zwei anderen verschwunden ist.

$B$ Bulgaria inquinans $\mathrm{Fr}$. Keimung. Vergr. 300 . Buchstaben wie oben. 
getheilt, von denen jede ein oder mehrere kurze, sporidienabschnürende Sterigmen treibt.

An die letztbeschriebenen Fälle, in welchen das Promycelium auf ein kurzes Sterigma reducirt ist, schliessen sich die Sporidienbildungen durch hefeartige Sprossung, welche oben als die dritte Keinungsform bezeichnet wurden, unmittelbar an. Sie sind, abgesehen von den dubiösen Hefebildungen, bei rereinzelten Genera und Arten bekannt: Exoascus (de Bary, Beitr. I), Dothidea Ribesia Fr. Tulasne, Carpol. II, Tab. IX, Nectria Janowitsch, Bot. Ztg. 186:3). Auch die erwähnten sporidienbildenden Pezizen schliessen sich zum Theil hier an. Aus der Oberfliche der Spore sprossen, nach Art beginnender Keimschläuche, Fortsätzchen mit sehr schmaler Basis hervor, erhalten meist laingliche oder cylindrische Form und gliedern sich zuletzt ab, wie es oben (Seite II!) für die hefeartige Abschnürung beschrichen wurde. In demselben Punkte kann der ersten Sporidie eine zweite, dritte u. s. f. folggen, bis das Protoplasma der Spore verbraucht ist. Dic Sprossung findet entweder an einzelnen belicbigen Punkten der Spore statt Exoascus, Dothidea, oder an bestimmten Punkten z. B. den beiden Enden der spindelförmigen, zweiğgliedriğ zusammengesetzten Spore von Nectria inaurata), oder auf der ganzen Sporenoberfliche, so dass diese von senkrecht abstehenden sporidien dicht eingehüllt ist z. B. Nectria Lamyi).

Was die Sporidien selbst betrifrt, so haben dieselben im Allgemeinen die Eigenschaften zarter diunnwandiger Pilzsporen. Bei den Tredineen, wo sie bis jetzt am genauesten studirt sind, treiben sie unmittelbar nach ihrer Entstehung einen kurzen Schlauch, welchor nach kurzem Lingenwachsthum an seiner Spitze eine der ersten grleiche sporidie zweiter Ordnung erzeugen kann,

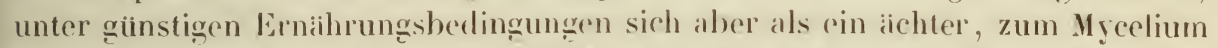
auswachsender Keimfaden rerhiilt. Die IIförmigg verbundenen Sporidien von Tilletia treiben entweder feine Keimschliuche. oder schniiren auf dem Ende eines kurzen, seillich vortretenden sterigma eine gekrümmt - eglindrische, stumpfendige secundäre Sporidie ab, die dann ihrerseits einen Keimschlauch erzeugt. An den Sporidien von Estilag̣o Carbo hat Kühn Koimschliutuche beobachtet; von denen der ührigen Lstilagineen, der Discomyceten, Tremellinen, Vectrien konnte bis jetzt keine Keimung erhalten werden.

Die durch hefearlige Sprossung erzeugten Sporidien von Dothidea ribesia entwickeln durch den gleichen Process Sporidien zweiter Ordnung; bei Exoascus setzt sich die Sprossung durch fünf his sichen, vielleicht noch inehr Generationen fort, die sprossen verschiedener Ordnumgen sind zu ästigen, rosenkranzförmigen Reihen vereinig̨t, welehe zuletzt in ihre Glieder zerfallen. Weitere Keimungserscheinungen sind hier von den Sporidien nicht bekannt.

Ueberginge oder Zwischenformen zwischen der keimfaden- und Promycelien-nebst Sporidienbildung finden sich hie und da. Bei Bulgaria inquinans Fig. 6 i $B$ ) lricht das Endosporium der keimenden spore aus dem aufreissenden Epispor hervor, schwillt zu ciner weiten, oft ovalen oder rundlichen Blase an, die auf ihrer Oberfliche zahlreiche stabförmig̣e Sporidien hefeartig abschniirt; zuletzt wächst das eine Ende der Blase ohne weitere Sporidienbildung nach Art eines Keimfadens weiter. Andere Sporen derselben Species treiben nur Keimschliuche Tulasne). Yon den Sporen von Nectria cinnabarina, Do- 
thidea ribesia schnüren die einen nur auf ihrer Oberfliiche Sporidien ab, andere treiben einen cylindrischen, dicken Schlauch, der seinerseits Sporidien abschnürt, bei noch anderen endlich findet beides zugleich statt. Bei Peziza tıberosa, P. bolaris und bei Dacrymyces deliquescens (Tulasne) zeigen von sonst gleichwerthigen Sporen die einen Sporidien-, die anderen nur Keimschlauchbildung. Bei den Ustilagineen und bestimmten (Teleuto-) Sporen der Uredineen ist dagegen die Entwickelung des Promyceliums und der Sporidien immer die gleiche - geeignete Entwickelungsberlingungen vorausgesetzt. Ungeeignete Bedingungen haben hier wie bei anderen Fortpflanzungszellen immer Austreibung eines oder mehrerer Keimschläuche zur Folge; dieselbe findet z. B. auch bei den Sporangien von Peronospora statt der Zoosporenbildung statt, bei Zoosporen, welche im Ausschwämen gehindert sind, u. s. f. Solche anormale Keimschläuche können sich, wie für Peronospora infestans bekannt ist, gleich normalen weiterentwickeln; in anderen Fällen schwellen sie bei der genannten Art nach kurzem Längenwachsthum an ihrer Spitze an, um ein neues, secundaires Sporangium zu bilden, das dann auf die normale Weise Sporen zu erzeugen vermag.

Was die vie r te oben in der Uebersicht bezeichnete K e i m u $\mathrm{n}$ g f $\mathrm{for} \mathrm{m}$ betrifft, so wird in manchen Fällen die Spore reif und ron ihrem Träger losgelöst als eine einfache Zelle, mit dem Beginn der Keimung aber theilt sich diese durch Querwinde in zwei oder mehrere, von denen dann jede einzelne Keimschläuche oder ein Promycelium zu treiben vermag. Wie schon oben angegeben wurde, findet dies bei Dacrymyces, und zwar bei beiden beschricbenen Keimungsformen dieser Gattung statt; ihnliches ist bei Peziza tuberosa, P. bolaris, P. Cylichnium Tul. (Ann. sc. nat. 3e sér. XX, p. IFi), und zwar bei den aus den Ascis entleerten reifen Sporen beobachtet worden.

Diese Erscheinung liefert wie mir scheint einen guten Anhaltspunkt für die Auffassung der morphologischen Bezichungen, welche zwischen den hinsichtlich ihrer ersten Entstehung gyleichwerthigen, zur Zeit der Reife aber so sehr von einander verschiedenen einfachen und vielzelligy-zusammengesetzten Sporen nahe verwandter $\Lambda$ scomycetenarten bestehen. Es muss hierbei noch die andere Thatsache erwihnt und berücksichtigrt werden, dass eine ganze Anzahl von Faillen bekannt ist, in denen die Sporen von Ascomyceten schon innerhalb des frisch reifen Ascus keimen, sowohl einfache Keinschläuche treibend (Sphacria praecox Tul., Peziza tuberosa), als Sporidien bildend (Exoascús, Pez. Cỵlichnium, Pez. bolaris, und besonders Nectria, wo bei manchen Arten, wie X. Lanıi, N. inaurata u. s. f. der reife Ascus von den Sporidien dicht erfüllt, die Sporen selbst verdeckt sind, was zu allerlei Vissverständnissen Anlass gegeben hat). Die septirten oder zusammengesetzten Ascosporen dürften hiernach als Keimungsprodukte eirfacher Sporen zu betrachten sein, welche gleich den Sporidien genanntei-Nectrien typisch innerhalb der Asci entstehen, um dann erst nach der Entleerung die begonnene Keimung fortzusetzen.

Nach dieser Aulfassung, auf welche schon oben hingedeutet wurde, sind hier auch die eigenthümlichen Sporen von Cordỵceps und Torrubia (Léveillé mspt., rgl. Tulasne, Ann. sc. nat. 3e sér., tom. XX, p. 43) zu erwähnen. In den Ascis dieser Pilze werden acht schmale, nadelförmige Sporen gebildet, welche sich mit der Reife durch Querwände in unzählige kurz-cylindrische 
Glieder, Theilsporen oder Sporidien theilen, die sich oft noch innerbalb des Ascus spontan von einander trennen. Bei nächstverwandten Genera (z. B. Claviceps, nach Kühn bleiben die nadelförmigen Sporen bis zu und nach der Keimung ungetheilt und treiben Keimschläuche. Auch die Sporen von Cenangium fuliginosum Fr. verhalten sich wie die von Cordyceps, wähend die verwandten Cenangien nicht in Glieder zerfallen (Tulasne, Anṇ. sc. nat. Tom. XX, 3e Sér., p. 130). De Notaris (Microm. ital. Dec. V, in Mem. R. Acad. d. Torino stellt das Zerfallen auch bei Sporormia fimetaria Not. dar.

\section{Capitel 5.}

\section{Geschlechtliche Fortpfinzung und Copulation.}

Bei einer Anzahl von Pilzgattungen ist in neuerer Zeit ein geschlechtlicher Zeugungsprocess nachgewiesen worden: bei alen Mucorinen findet eine Copulation statl, also ein Vorgang, der sich, nach meiner und Hofmeister's Ansicht, an die sexuelle Zeugung, als eine besondere Form derselben unmittelbar anschliesst. Für sehr zahlreiche Pilze hat man ferner: seit Micheli und Bulliard, das Vorkoumnen geschlechtlicher Zeugung Blithen, Antheren u.s.f.) wenigstens vermuthet.

Beginnen wir mit der Beschreibung der sicher ermittelten Fille. Zunichst gehören hierlıer die Sapro leğn i e en, deren Befruchıtungsprocess und Geschlechtsorgane von Pringsheim entdeckt und in seinen Jahrbiichern für wiss. Botanik 1, p. 28\%, II, 1). 20:3) beschrieben worden sind. Bei denjenig̣en Formen, die als monöcische \%usammeng̣efasst werden hönnen /Saproleg̣nia monoica, Pṛthium, Aphanomyes dBy. in Pringsh. Jahrb. II. 169 stellen die weiblichen Geschlechtsorgane, Ooğonien, zuerst kugelig anschwollende, protoplasmareiche Zellen dar, welche meistens auf den Enden kurzer Aeste der Thallusschlizuche stehen, selten interstitiell gestellt sind. Bei Saprolegnia monoica wird an dem erwachsenen Oogonium die M('mbran an zahlreichen kreisförmigen Stellen resorbirt, durchlöchert. Zuğleich zerfiillt das Protoplasma allmiahlich in mehrere bis viele Portionen, die sich zu Kugeln abrunden und von der Wand zuruekziehen, um, in der Mitte des Ooğoniums zusammengehäuft, innerhall waisseriger Fliissiğkeit zu schwimmen. Diese Befruchtungskugeln sind zunaichst mit glatter, nackter, d. h. einer Cellulosemembran entbehrender Oberfliche versehen. Bei Pythium, Aphanomyees und einzelnen Saprolegnieen zieht sich die ganze Protoplasmannasse des Oogoniums zu einer einzigen Befruchtunğskugel zusammen, welehe, von wisseriger Flissigkeit umgeben, die Mitte des Oogoniums einnimmt.

Wihrend der Bildung des Oogoniums wachsen von dem Träger desselben oder von benachbarten Thallusschliuchen aus dünne cylindrische, gekrümmte, manchmal um den Oogoniumtriger gewundene Zweige gegen das Oogonium hin. Ihr oberes Ende schmiegt sich der Oogoniumwand fest an, hört hiermit auf in die Länge zu wachsen, schwillt alsdann etwas an und grenzt sich durch eine Querwand zu einer besonderen, gekrümmt linglichen und dem Oogonium fest 
anliegenden protoplasmareichen Zelle ab, dem minnlichen Geschlechtsorgan oder Antheridium. Einem Oogonium liegen ein oder mehrere Antheridien an. Zur Zeit wo die Bildung der Befruchtungskugeln stattfindet, bemerkt inan, dass jede Antheridie einen oder mehrere schlauchförmige, die Wand durchbohrende Fortsätze ins Innere des Oogoniums treibt, welche sich an der Spitze öffnen und ihren Inhalt austreten lassen. In diesem sieht man wihrend des Austretens lebhaft bewegliche Körperchen, kaum 1/500 Mm. gross, welche auf Grund der Aehnlichkeit der in Rede stehenden Organe mit den gyleichnamigen von Vaucheria, für die befruchtenden Formelemente, Samenkörperchen, Spermatoz oiden, zu halten sind. Nach Entleerung der Antheridien findet man die Befruchtungskugeln mit einer Cellulosemembran umgeben; sie bilden sich sofort zu derbwandigen Oosporen, nach Pringsheim's für die Algen eingeführter Terminologie aus. Theils nach den in vieler Beziehung analogen Erscheinungen, welche man für Vaucheria und andere Conferven kennt, theils nach Pringsheim's directen Beobachtungen ist es nicht zweifelhaft, dass die Cellulosemembran in Folge einer sexuellen Bofruchtung an der Oberfläche der Befruchtungskugeln entsteht, und dass die Befruchtung dadurch geschieht, dass die aus der Antheridlie entleerten Samenkörper in die Befruchtungskugeln eindringen und mit der Substanz derselben verschmelzen.

Bei Saprolegnia dioica und Achlỵa dioica bilden sich die Befruchtungskug̣eln und Oogonien auf die beschriebene Weise, die Membran der letzteren wird durchlöchert, es legen sich aber keine dünnen antheridientragenden Zweige an sie an. Pringsheim fand bei diesen Arten anderwärts Organe, welche mit grosser Wahrscheinlichkeit für Antheridien zu halten sind. Dicke, den zoosporenbildenden ïhnliche Schliuche erhehen sich zu bestimmter Zeit von dem Mycolium und theilen sich durch Querwinde in eine Reihe cylindrischer Zellen, welehe die Antheridien darstellen. Bei Saprolegnia dioica zerfillt das ganze Protoplasma der Antheridie in unzïhlig̣e sehr kleine stabförmige Samenkörperehen, die zuletzt in lebhafter Bewegung aus einer sich öffnenden, kurzen halsartigen Ausstülpung der Antheridienwand entleert werden. Bei Achlya dioica theilt sich der Inhalt der ẹlindrisehen Antheridie zunichst in eine Anzahl von Portionen, welehe ung̣efihr die Grösse der Schwämsporen der Species haben und sich zu kuggelig̣en, in der Mitte der Antheridie zusammengehäuften Zellen ausbilden. In diesen theilt sich dann das Protoplasma in eine Anzahl stabförmiger Samenhörperchen, welche erst aus der Membran ihrer Specialmutterzelle, damn aus der Antheridic ausschwirmen, auf demselben Wege wie bei Saproleğnia dioica. Die Samenhörper beider Arten gleichen denen der Vaucherien, sie sind stabförmigy und mit IIiilfe einer langen Cilie lebhaft beweglich. Es ist, zumal nach den ron den Algen sicher bekannten Thatsachen, wohl anzunehmen, dass die Samenkörper in die Löcher der Oogonien eintreten und sich mit den Befruchtungِskugehn rereinigen. Beobachtungen hierüber liegen jedoch noch nicht vor, die Deutung der beschricbenen Organe kann daher noch nicht für vollkommen sicher gelten. Zweifelhafter Natur und jedenfalls fernerer Untersuchung werth sind die zuerst ron Nigeli, später von A. Braun und Cienkowski untersuchten, neuerdings von Pringsheim genau beschricbenen und wenigstens für muthmassliche Antheridien einer besonderen Achlya- oder Saprolegñiaspecies gehaltenen Organe. Dieselben entstehen nach Pringsheims Darstellung 
in dicken, den Zoosporangien bildenden ähnlichen Schläuchen, zunächst als Protoplasmaklumpen, welche innerhalb des sonst unveränderten wandständigen Protoplasmas liegen. Sie erhalten bald schärferen Umriss, in ihrem Innern einige homogene kugeligge, spiiter ovale Körner, und rüchen zuletzt in die blasig erweiterte Spitze des Schlauches. Hier wachsen sie zu runden oder ovalen Zellen heran, bilden eine Cellulosemembran an ihver Oberfliche und treiben an einer oder an mehreren Stellen eine cylindrische Ausstiilpung, welche gegen die Membran des Schlauches wiachst, diese durchbohrt, jedoch immer nur sehr wenig nach aussen vortritt. Das von Vacuolen durchsetzte Protoplasma der Zellen zerfällt zuletzt simultan in zahlreiche, 1/250 Mm. grosse Körperchen, welche aus der sich öfhenden Spitze der cylindrischen Ausstiilpung ausschw:irmen und, was Bau und Beweglichkeit betrifft, den Samenkörpern der Aglya dioica ahnlich sind. Im Wasser werden diese Körperehen bald ruhig g ohne zu keimen. Wïhrend der Entwickelung beschriebener Oroane behiilt das Protoplasma des Schlauches, in dem sie liegen, Anfangs durchaus normale Beschaffenheit; erst bei ihrem späteren Wachsthum rersehwindet es allmiblich vollstiandig. Dass die beschrichenen Organe der Saprolegnia, in welcher sie vorkommen, angehören und die Antheridien derselben darstellen, dafïr spricht eine Anzahl von Grüden, welche Pringsheim l. c. klar dargeleğt hat. Eine andere Ansicht, welche gleichfalls ron Pringsheim besprochen wird, dass nämlich die beschriebrnen Körper Parasiten seien, welche in die Saprolegnia eindringen und dasellost auf Kosten des Protoplasma fructificiren, gründet sich vorzugsweise auf die grosse Achnlichkeit jener Körper mit unzweifelhaften Parasiten, nämlich Chytridien. Fermer sprocht fiir dieselbe Pring̣heims Beobachtung, dass neben den beschriebenen Körpern in den angeschwollenen Schlauchenden zuweilen feinstacheligge kuggeh vorkommen, welche denjenigen gleichen, die offers in Spirogyren, Vaucherien u. s. l. gefumden werden und ohme Frage Organe von Sehmarotzern sind. Die Gruinde. Welehe Pringsheim gegen diese Ansicht geltend macht und wolehe hier nicht ausliihrlich wiedergageben werden können, dürften mittlerweile durch newere Beobachtungen über die Biolog̣ie der nikroskopisehen Parasiten an Gewieht verloren haben, die ganze Frage neu zu bearbeiten sein. Für weitere Details über die Sexualorgane der Saproleg̣nieen muss hier auf Pringsheims genannte Arbeiten rerwiesen werden.

Die bis jetzt bekannten reifen Oosporen der Saprolegnieen zeigen gleich vielen Sporen eine mässig diche, in Epi- und Endosporium gesonderte Menbran und keimen nach lingerer Ruhezeit mit Keimschlauchen. Ausnahmsweise entwickeln letztere schon nach geringer Verlängerung Zoosporen.

Ein directer experimenteller Nachweis ron dem Stattfinden eines Befruchtungsprocesses hat bei den Saprolegnieen bis jetzt nicht geliefert werden können, wenn nicht ein von Pringsheim beschriebener Fall dafür angesehen werden darf, in welehem die zahlreichen Befruchtungskugeln einer Saprolegnia, bei zufälligem Fehlen von Antheridien, simmtlich zu Grunde gingen. Bei der Uebereinstimmung aber, welehe die beschriebenen Organe der Saprolegnieen mit den genauer bekannten und theilweise experimentell untersuchten Sexualorganen der Algen zeigen, ist ihnen die gleiche Bedeutung wie diesen ohne Zweifel zuzusprechen. Für die übrigen geschlechtlichen Fortpflanzungsprocesse und Organe bei den Pilzen ist eine experimentelle Untersuchung gar nicht möglich. Die Deutung der 
betreffenden Organe als Geschlechtsorgane gründet sich auf die Beständigkeit ihrer Wechselwirkung und auf ihre Aehnlichkeit mit denen der Saproleğnieen.

Den monöcischen Formen letzterer sind der Gestalt und ersten Entwickelung der Sexualorgane nach durchaus ähnlich die Peronosporeen (Fig. 6̈̈). In den Intercellularr:iumen des Parenchyms lebender phanerogamer Pflanzen, welches diese Parasiten bewohnen, entstehen die Oogonien als grosse kugelige, von Protoplasma dicht erfüllte Zellen meist auf den Enden der Myceliumzweige, seltener interstitiell. Lange bevor das Oogonium seine volle Grösse erreicht hat, wächst entweder von dem Mỵceliumzweige, der es trägt, oder ron einem anderen, benachbarten ein dünner Ast gegen dasselbe hin und legt sich mit seinem freien Ende fest an die Wand desselben an. Das Längenwachsthum des Astes hört hiermit auf, sein Ende schwillt etwas an und grenzt sich durch eine Querwand zur selbständigen Zelle, Antheridie, ab, welche gekrümmt-keu-

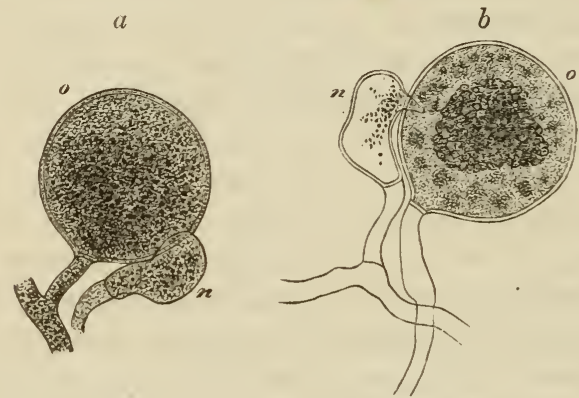

Fig. 65 .

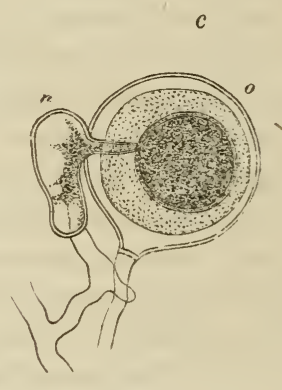

lige orler ovale Form, bedeutend geringere Grösse als das Oogonium besitzt und letzterem in einer relativ grossen Berührungsfläche fest angepresst ist. Niemals fand ich ausgebildete Oogonien, an denen die Antheridie unzweifelhaft gefehlt hätte, und nur höchst selten solche, denen zwei Antheridien anlagen.

Haben beide Geschlechtsorgane ihre volle Grösse erreicht, so sondert sich das Protoplasma des Oogoniums in eine peripherische, fast homogene, körnerarme Lage und eine die Mitte einnehmende, durch dicht gehäufte Fettkörner undurchsichtige und dunkele, kugelige Masse: Befruchtungskugel. Sobald diese gebildet ist, treibt die Antheridie von der Berülrungsfläche aus eine schmale, einem dünnen Schnabel gleichende, schlauchförmige Ausstülpung, Befruchtungschlauch, welcher die Oogoniumwand durchbohrt und durch das peripherische Protoplasma direct auf die Befruchtungskugel los wächst. Sobald er die Oberfläche letzterer berührt, steht sein Längenwachsthum still, die Befruchtungshugel aber ist von einer zarten Cellulosemembran rings umgeben und somit zur Oospore geworden.

Fig. 63. Peronospora Alsinearum Casp. Vergr. gegen 350 mal. Geschlechtsorgane. a jugendlicher Zustand. $b$ Bildung der Befruchtungskugel und des Befruchtungschlauches. $c$ nach der Befruchtung; peripherisches Protoplasma durch die Präparation etwas zusammengezogen, Befruchtungsschlauch in diesem Exemplar besonders dick. $-n$ Antheridie. o Oogonium. 
Die Antheridie ist von Anfang an mit mässig dichtem Protoplasma erfüllt, welches zur Zeit der Befruchtung häufig einen centralen rundlichen Ballen darstelllt, von dem schmale Fortsiitze nach allen Seiten ausstrahlen. Diese Beschaffenheit bleibt unverindert wihrend und nach der Befruchtung, oft bis zur völligen Reife der Oospore. Das Ende des Befruchtungsschlauches bleibt stets geschlossen, er wächst der jungen Oosporenmembran fest an, von Spermatozoiden ist keine Andeutung vorhanden; die Art der Einwirkung des Schlauches auf die Befruchtungskugel ist daher der des Pollenschlauches der Phanerogamen vergleichbar. Die Cellulosemembran der Oospore ninmt nun an Mächtigkeit zu und entwickelt sich zu der zuletzt derben und geschichteten Innenhaut der Oospore. Zugleich bildet sich aussen um diese eine zweite, allmihlich gelhbis dunkelbraune Farbe annehmende Membran, Aussenhaut, Episporium, welche meist derb und sehr fest, und je nach der Species auf ihrer Oberfliche mit Warzen, Runzeln, netzförmig verbundenen Leisten u. s. W. rersehen ist. Bei Cystopus besteht sie aus incrustirter Cellulose, bei Peronospora zeigrt sie nie Cellulosereaction. Diese Aussenhaut bildet sich aus dem peripherisehen Protoplasma, indem sich dieses allubihlich um die Oospore gleichsam niederschlight und erhïrtet. Die reife Oospore liegt, in wisseriger, nur spibliche Körner führender Flüssigkeit suspendirt, innerhalb des Oogoniums, dessen Wand je nach den Arten zur Reifezeit stark verdickt und rigid ist, oder zart bleibt und collabirt. Das reife Endosporium ungibt cine feinkörnigge, rings um eine grosse centrale Vaeuole wandstimdige Protoplasmaschichte. Der Befruchtungssehlauch bleibt bis zur Reife deutlich und ist meistens von einer derben bis zur Oogoniumwand reichenden Fortsetzung des Episporiums scheidenartig ungeben.

I) Oosporen der Peronosporeen keimen nach lingerem, den Winter über dauerndem Rulezustand. Es sind his jetzt zwei Fille und Formen der Keimung bekannt. Bei Cystopus candidus sehwillt das Endosporium mit seinem Inhalt unter Einwirkung ron Wasser an, sprenge das Epispor an einer Seite und treibt cine breite, kurze, stumpfe Ausstiilpung aus dem Riss hervor. In dem Protoplasma treten damn grosse, weehschnde Vacuolen auf, und alsbald eine simultane Theilung in zahlreiche gleichgrosse Portionen, welche sich rasch zu ebensovielen, den in den geschlechtslosen sporangien entwichelten völlig gleichen Zoosporen ausbilden. Lnmiltelhar nach der Theilung schwillt die aus dem Epispor vorgetretene Ausstülpung zu einer hugeligen zarten Blase an, in welche die Zoosporen sofort hineinrüchen, un ihre lebhafte Bewegung zu beginnen und alsbald aus der aufg̣celockerten Blase auszuschwärmen.

Bei Peronospora Valerianellae, und wohl auch den mit dieser zunichst verwandten Arten treiht die heimende Oospore auf feuchtem Boden (nicht unter Wasser) einen Keimschlauch, dessen Membran von der innersten Schichte des Endospors entspringt und die ausserhalb befindlichen Membranschichten durchbricht. Der Schlauch wichst zu bedeutender Liinge heran, verzweigt sich reichlich und nimmt ganz das Ansehen ron Peronospora-Iyceliun an. Sein Eindring̣en in die Nährpflanze wurde nicht beobachtet.

Ausführlichere Beschreibungen finden sich Bot. Ztg. 1861, p. 89 und Ann. sc. nat. ie Sér. Tomi. MI. 
Den beschriebenen Befruchtungen schliesst sich zunächst die Copulation der Mucorinen an, welche erst bei zwei Arten dieser Familie bekannt ist. Die copulirenden Fäden von Rhizopus nigricans Ehrbg. (Fig. 66) sind derbe, niederliegende, ordnungslos verzweigte und durcheinander geschobene Schliuche. Wo sich zwei derselben berühren, treibt jeder gegen den anderen eine erst cylindrische, dem Schlauche selbst gleichdicke Aussackung. Beide Aussackungen sind ron Anfang an mit ihren Enden fest aneinandergepresst und wachsen nun zu keulenförmigen Körpern, Fruchtkeulen, von bedeutender Grösse heran, miteinander einen spindelförmigen, quer zwischen den zwei copulirenden Schläuchen stehenden Körper darstellend. Zwischen den Keulen eines
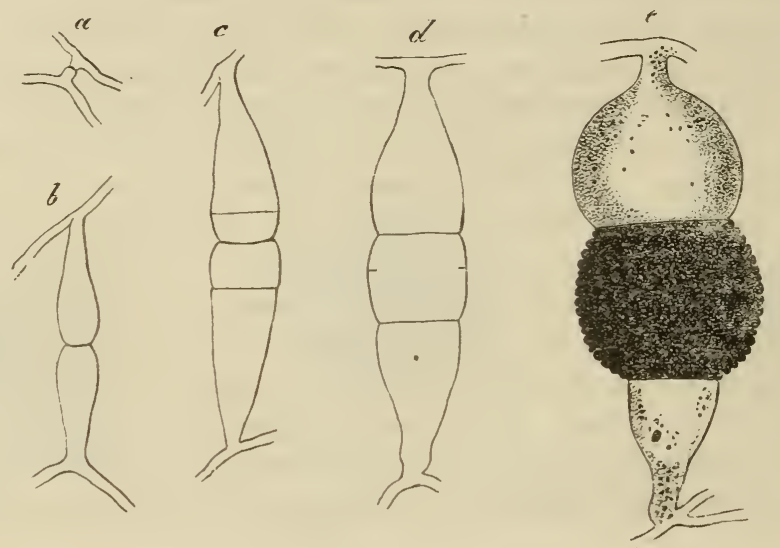

Fig. 6i.

Paares besteht zunachst kein constanter Grössenunterschied, oft sind sie einander ganz gleich. In beiden sammelt sich reichliches Protoplasma an, und wenn sie eine bestimmte Grösse erreicht haben, grenzt sich das der anderen zugckehrte breite Ende einer jeden durch eine ebene Querwand als besondere Zelle, Copulationszelle, von dem iibrigen Theil der Keule, dem Triger, Suspensor, ab. Die Copulationszellen eines Paares sind der Regel ron rerschiedener Grösse: die eine ein Cylinder, der so hoch als breit ist, die andere scheibenförmigg, nur halh so lang als breit. Die ursprüngliche Nembran der Fruchtheulen bildet zunaichst noch zwischen den beiden Copulationszellen eine feste, aus zwei Lamellen bestehende Scheidewànd; bald nach Abgrenzung beider Zellen wird diese zuerst in der Mitte durchlöchert, um alsbald gänzlich zu rerschwinden, die beiden Zellen verschmelzen somit zu einer Zygospore, d. h. einer Fortpflanzungszelle, welche durch Vereinigung zweier mehr oder minder gleichartiger Zellen gebildet wird. (S. de Bary, Lnters. über d. Conjugaten.) Die Zygospore nimmt nach ihrer Anlegung noch gewaltig an Grösse zu, erreicht einen Durchmesser von über $1 / 5 \mathrm{Mm}$. Ihre Gestalt wird dabei in der Regel die einer an den Berührungsflächen mit den Suspensoren abgeplatteten

Fig. 66. Rhizopus nigricans Ehr. (Mucorstolonifer, Ehr. Silv. myc.) Bildung der Zygospore. Entwickelungsfolge nach den Buchstaben. $e$ fast reife $Z$ ygospore, 90 fach vergr. Die anderen Figuren nach grösseren Zeichnungen ungefähr auf den Massstab von $e$ verkleinert. 
Kugel, oder einer kurzen Tonne. Ihre Membran verdickt sich gewaltig, sie besteht zur Zeit der Reife aus einem derben, dunkel blauschwarzen Episporium, welches auf den ebenen Berührungsflichen glatt, auf der freien Fläche mit dicken, innen ausgehöhlten Warzen bedeckt ist; und aus einenı dicken, geschichteten, farblosen Endosporium, das aussen mit derben, soliden, in die des Epispors eingepassten Warzen besetzt ist. Der Inhalt ist grobkörniges, oft mit grossen Oeltropfen durchsetztes Protoplasma. Mit der Zygospore wiichst der Suspensor der kleineren Copulationszelle zu einer gestielt-kugeligen, oft durch eine Querwand getheilten Blase heran, welche oft nahezu die Grösse der Zygospore erreicht; der Suspensor der grösseren Copulationszelle behialt seine ursprüngliche Form und ver⿳reössert sich nicht oder wenig mehr. Selten ist zwischen den beiden Copulationszellen und Suspensoren ein erheblicher Grössenunterschied nicht vorhanden.

Die Copulation von Ehrenbergs berihntem sy z g gites megalocarpus ist, wie ich ausfïhrlich beschrichen habe (Beitr. z. Morphol. d. Pilzel, der von Rhizopus im Wesentlichen gleich; ebenso der Bau der reifen Zygrosporen. Nur ist bei Syzygites ein constanter erheblicher Grössenunterschied zwischen den Copulationszellen und Suspensoren cines P'aares nicht vorhanden, und die Fruchtkeulen bilden sich zwischen den Aesten aufechter, regelunissig drei- und zweigabeligy verzweigter Fruchträger. Ferner ist bei syzygites ein Verhiltniss, welehes nir

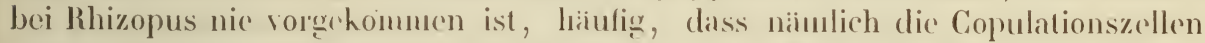
ohne miteinander zu verschunelzen die Structur von Zy gosporen annehmen oder, wie dies genannt werden hamn, zu $\backslash z$ ygosporen werden. Die keimung der

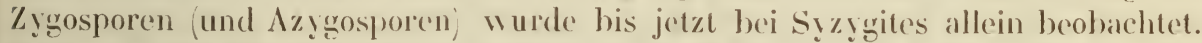
Nach Ablauf cines Ruhezuslandes auf feuchtes Substrat gebracht, treiben sie wie derbwandige Sporen einen Koimschlanch, und dieser entwichelt sich sofort, ohne Myecliumbildung, auf liosten der in der Zygospore aufgespeicherten Reservenahrung zu dent für die Speceies chantacteristisehen, reich diehotomen, endstiandige Sporangien bildenden, ungesehlechllichen Fruchttriger.

Es mag erlaubt sein, hier cinige Fille anzureihen, welche sich den Copulationsprocessen in sofern anschliessen, als bei ihmen je zwei unzweifulhafte fortpflanzungszellen zu einer versehmelzen. Ich meine erstlich die oben (S. 1:32, Fig. 63) beschriebene paarweise Ilförmige Verbindung, welche constant zwischen den primbiren Sporidien von Tilletia cintritt. Ferner findet man die Sporidien von L'stilago receptaculorum Fig. 62, S. I ̈̈1) meistens mittelst ciner engen, offenen Querbruiche paarweise, selten selbst zu dreien verbunden, und ich irre wohl nicht wenn ich angebe, dass sich dic Querbrücke zwischen den anfinglich getrennten Sporidien bildet, so lange sie noch dem Promycelium ansitzen. Endlich muss hier der Sporen von Protomy ces macrosporus gedacht werden. Dieselben werden, wie auf S. 110 beschrieben worden ist, in grosser Anzahl in den Ascis gebildet und, in Form kleiner cylindrischer Stibehen, ejaculirt. Feucht gehalten sind sie bald nach der Ejaculation einander paarweise genähert auf eine ilmem Querdurchmesser etwa gleichkommende Strecke; nach einigger Zeit ist jedes P'alr durch einen sehr feinen Streifen rerbunden, dessen Entstehung aus zwei von den beiden Sporen gegeneinander getriebenen Fortsitzen wahrscheinlich ist, aber wegen seiner Zartheit nicht bestimmt erkannt werden konnte. Der streifen wird nun breiter und erscheint schon drei bis 
vier Stunden nach der Ejaculation als ein Canal, der so breit ist wie die Sporen selbst und die Lumina beider mit einander verbindet.

Die Keimung der Sporidienpaare von Tilletia ist oben beschrieben worden, die von Ust. receptaculorum nicht bekannt. Von den Sporenpaaren des Protoinyces steht wenigstens sovicl fest, dass sich aus ihnen auf dem geeigneten Substrat ein fruchtbares Protomycesmycelium, allerdings auf nicht völlig aufgeklärte Weise, entwickelt. (S. meine Beiträge zur Morph. d. Pilze I, p. 14).

In wieweit sich die drei letztbeschriebenen Fälle den Copulationserscheinungen der Conjugaten, Mucorinen und mit diesen den sexuellen Zeugungen anschliessen, muss vorläufig dahingestellt bleiben. Ob vielleicht die brückenartigen Verbindungen und Verschmelzungen, welche man zwischen Keimschläuchen öfters findet, und von denen oben mehrfach die Rede war, zum Theil hierher gehören, ist eine völlig zweifelhafte, bei späteren Untersuchungen aber vielleicht zu berüchsichtigende Frage.

$\mathrm{Zu}$ den Pilzen deren Geschlechtsorgane bekannt sind, darf wohl nach meinen Untersuchungen Fruchtentw. d. Ascomyceten, Lpz. 1863) die Gattung Erysiphe gerechnet werden. Bei diesen Pilzen entwickelt sich aber das befruchtete Oogonium oder die Eizelle nicht zur einfachen Oospore, sondern zu einem vielzelligen, sporenbildende Asci enthaltenden Perithecium. Das Mycelium der Erys. Cichoracearum (Fig. 67) besteht, gleich dem der anderen Arten der Gat-

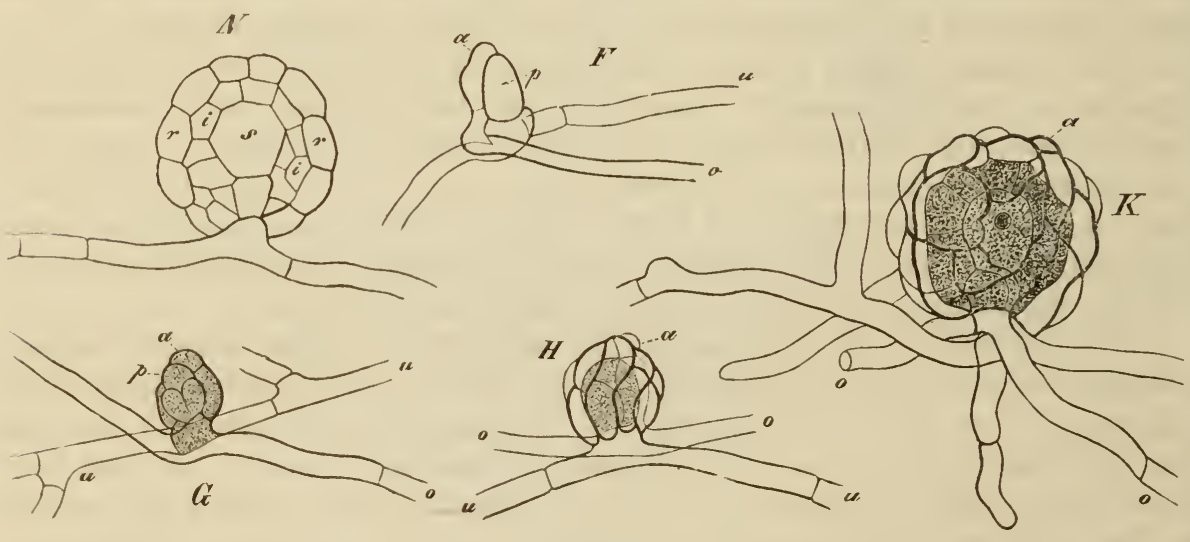

Fig. 67.

tung, aus verzweigten Fiden, welche der Oberhaut des Pflanzentheils, auf welchem der Pilz schmarotzt, fest angeschmiegt sind und einander vielfach durchkreuzen. An den Kreuzungsstellen zweier Fäden heginnt die Bildung der Perithecien. Beide Fiden schwellen etwas an, und jeder treibt eine senkrecht zur Oberhautfliche gestellte, dem Anfange eines Zweiges gleichsehende Aussackung. Die von dem unteren Faden entspringende erhält bald ovale Form, etwa die

Fig. 67. Erysiphe Cichoracearum DC. $F-K$ Entwickelung des Peritheciums, 390 fach vergr. o oberer, $u$ unterer Myceliumfaden. a Antheridie (in $F$ der sich später zur Antheridie abgrenzende Theil). $p$ Eizelle. $N$ Optischer Längsschnitt durch ein Exemplar vom ungefähren Alter von $K$. $s$ Ascus. $i$ innere, $r$ äussere Wand des Peritheciums. 
doppelte Dicke wie der Myceliumfaden und grenzt sich von diesem durch eine Querwand ab als besondere Zelle: E i z e lle ( $p$ ). Die Aussackung des oben liegenden Fadens wächst, der Eizelle immer innig angeschmiegt, zu einem schmalen eylindrischen Schlauche heran, der an dem Scheitel der Eizelle stumpf endigt. An seiner Basis grenzt er sich gleichfalls durch eine Querwand ab, und bald darauf entsteht nahe unter seiner Spitze an einer schon vorher durch eine leichte Einschnürung bezeicheten Stelle eine zweite Querwand; diese grenzt eine kurze, stumpfe terminale Zelle, die $\Lambda \mathrm{n}$ the ridie $(a)$, von ihrer schmal cylindrischen Stielzelle ab. Bald nach Bildung der Antheridie beginnen Neubildungen in der Umgebung der Eizelle und in letzterer selbst. Zunächst wachsen unter derselben, aus dem Tragfaden, acht bis neun stumpfe Schliuche hervor, welche, seitlich fest aneinander und an die Stielzelle der Antheridie schliessend und mit ihrer Innenfliche der Eizelle angeschmiegt, an dieser emporwachsen bis ihre Spitzen über dem Scheitel der Eizelle zusammenstossen. Jeder der Schl:auche theilt sich damn durch Querwände in zwei bis drei Zellen, und hiermil ist die vielzellige Aussenwand des Peritheciums gebildet. Die Eizelle wird mittlerweile grösser und theilt sich bald - auf nicht genau ermittelte Weise in eine centrale Zelle, welche von einer meist einfachen Lage kleiner, der Aussenwand anliegender rings umgeben wird. Die centrale Zelle wähst zu dem, bei in Rede stehender $\Lambda \mathrm{rt}$ einzigen $\Lambda$ seus heran, die sie ungebende Schicht zur Innenwand des kugeligen Peritheciums. Die weiteren Veründerungen bestehen lediglich in einer bedeutenden Vergrösserung des Peritheciums durch Ausdehnung seiner sämmtlichen Zellen, in dem Ilervorwachsen von Wurzelhataren aus der Aussenwand, dem Braunwerden letzterer und endlich der Sporenbildung in dem Ascus. Yon letzterer ist oben die Rede gewesen. Die Antheridie bleibt lange erkennbar, olme sich wesentlich zu veräinderm, mit der Brïunung des Peritheciums wird sie undeutlich.

Andere Erysiphe-Arten zeigen Eizelle und Antheridie in der beschriebenen Weise, nur mit unwesentlichen Formwerschiedenheiten. Der Bau ihrer reifen Perithecien stimmt mit dem beschriebenen in der Ilauptsache überein, nur ist meist eine Mehrzahl von Asci vorhanden, zwischen denen zahlreiche Reihen und Gruppen steriler Zellen stehen. Die Theilungen der Eizelle müssen daher weit complicirter sein, als bei E. Cichoracearum; der Beobachtung haben sie sich bis jetzt, wegen der Undurchsichtigkeit der jungen Perithecien, entzogen. Ueber die Structur der reifen Perithecien vergleiche man Tulasne, Selecta fung. Carpol. I. und Ann. sc. nat. Le sér., tom. VI, p. 299.

Der Perithecienbildung von Erysiphe schliesst sich vielleicht die von Eurotium an. Wie ich früher beschrieben habe (Bot. Ztg. 1834) rollen sich die perithecienbildenden Fiaden dieses Pilzes an ihrer Spitze horkzieherartig zusammen, in meistens sechs Windungen, welche sich zu einem hohlen, schraubenahnnlichen Körper fest aneinander legen. In dem nächsten beobachteten Stadium ist dieser Körper etwas angeschwollen und aus zahlreichen runden Zellen zusammengesetzt, welche auch die frühere llöhlung in seiner Mitte ausfüllen. Die oberflächlichen derselben sind zunächst noch deutlich zu einer schraubenförmigen Reihe angeordnet. In welcher Weise die Verinderungen und Zelltheilungen vor sich gehen, durch welche dieses zweite Entwickelungsstadium hergestellt wird, konnte bis jetzt nicht ermittelt werden; dass ein hierher gehörender 
Vorgang (Befruchtung, Copulation) dabei stattfindet, ist jedoch nicht unwahrscheinlich. Der vielzellige Körper vergrössert sich unter Theilung seiner Zellen und nimmt alsbald Kugelform an. Die Zellen der oberflichlichsten Schichte (oder nur ihre äusseren Winde, was von neuem zu untersuchen ist) erhalten bald polygonale Form, gelbe Farbe, und werden zu der dünnen Wand des Peritheciums. Im Inneren dieses dauert die Theilung lange an, zuletzt werden simmtliche Zellen zu typisch 8sporigen rundlich eiförmigen Ascis.

Nach den Erscheinungen bei Erysiphe liegt die Vermuthung nahe, dass auch bei anderen Ascomyceten entweder das einzche Perithecium, oder das mehrere Perithecien tragende Stroma, oder die entsprechenden Organe der Discomyceten, Tuberaceen u. s. w. Producte einer geschlechtlichen Zeugung sind. Beweise hierfür konnten jedoch bisher nicht gefunden werden. Was über die Entwickelung der Perithecien in dem Stroma ermittelt und oben (S. 98) mitgetheilt wurde, zeigt von einer Befruchtung nichts. Sollmann's Beobachtungen an )Sphaerella Plantaginis ( Bot. Zlg. 186i, p. 281) zeigen im besten Falle, dass ein Perithecium in der ersten Jugend aus wenigen, einander berührenden und von einem Myceliumfaden entspringenden Zellen besteht; wie sie die Vermuthung eines sexuellen Zeugungsprocesses begründen sollen, ist schwer abzusehen. Bei Peziza confluens P. habe ich (Fruchtentw. d. Ascomyeeten p. 11) gefunden, dass die erste Anlage des Fruchttrigers aus cigenthümlichen paarigen, protoplasmareichen Körpern besteht, die, in eine Rosette zusammengruppirt, von einem oder wenigen Myceliumfaiden entspringen. Jedes Par ist zusammengesetzt aus einer kleineren keulenförmig̣en, einzelligen Hälfte und einer grösseren, die gekrümmt ei- oder keulenförmig ist und aus zwei breiten, überein-
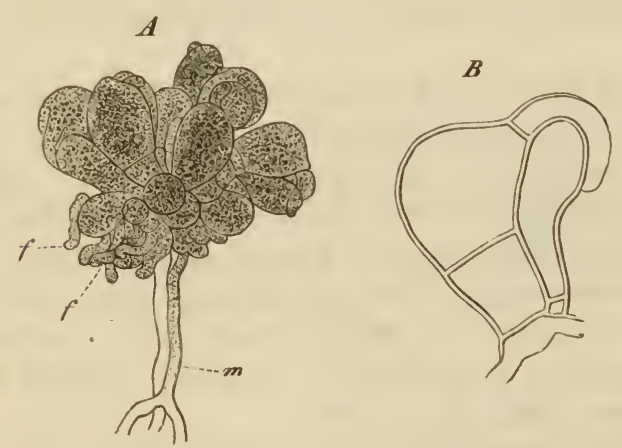

Fig. 68. anderstehienden Zellen besteht, deren obere auf ihrem Scheitel aine dritte cylindrische und hakigg gekliummte trigt (Fig. 68). Beide Hialften sind der Linge nach fest aneinder geschmiegt und die hakige Zelle um den Scheitel der kleineren Hälfte geschlungen. Am Grunde der Roselte sprossen cylindrisehe Hyphen $\left(f^{\prime}\right)$ hervor, welche die Paare rasch völlig umwachsen und umspinmen und sich ihrerseits zu dem hymeniumtragenden Fruchtkörper weiter

entwickeln. An den Paaren ist keine weitere Veranderung, als starke Ausdehnung ihrer Zellen zu bemerken, zuletzt werden sie unkenntlich; ob und wie sie einer Befruchtung dienen, ist cine durchaus unentschiedene Frage.

Von den sicher ermittelten Fallen geschlechtlicher Zeugung bei den Pilzen sind wir somil auf die zweifelhaften und dic Vermuthungen gekommen. Zu

Fig. 68. Peziza coufluens P. A Rosettenförmige Anlage des Fruchtträgers, oben aus den beschriebenen Paaren bestehend, $f$ Infänge der später die Paare iiberwachsenden Fäden. $m$ Iycelium. Vergr. 190. $-Z$ Curisse eines einzelnen Paares, 390 fach vergr. 
solchen haben gerade die Ascomyceten mehrfach Anlass gegehen. Es ist nicht zu läugnen, dass die Asci mit den Oogonien, zumal der Peronosporeen, Inancherlei Aehnlichkeit zeigen, und hierin mag der Grund liegen, warum man in ihnen mehrfach weibliche Geschlechtsorgane suchte und zu finden glaubte. Bei Tuber aestivum fand Hofmeister Jahrb. f. wiss. Bot. II, p. 378 die Endzellen eines oder mehrerer dünner Fäden, welche oft von den dickeren, denen die Asci aufsitzen, als Zweige entspringen, an verschiedenen Stellen der Aussenfliache des Ascus fest angewachsen. An der Vorwachsungsstelle war oft ein Tüpfel in der Membran des Ascus, und an jüngeren Asci fanden sich solche Tuipfel, ohne dass sich ein Faden angelegt hätte. Das Anwachsen fand statt zur Zeit, wo die Sporen oder ihre Aussenlaut angelegt wurden. Nach diesen, an Saprolegnia monoica erinnernden Thatsachen vermulhet Hofmeister in den Endzellen der anliegenden Fäden Antheridien, in den Ascis der Trüffeln Oogonien. Ich habe spïter Fruchtentw. der $\Lambda$ scom. p. 2f) gezeigt, dass bei Tuber-Species, welche wegen ihres grosszelligen und lockeren Gewebes zur Beobachtung geeigneter sind als T. aestivum, solche Antheridien nicht vorhanden sind, dass die Sporenentwickelung in den Ascis der Trüfleln der von anderen Ascomyceten in Wesentlichen gleich ist s. oben S. 106) und dass in dem sehr dichten Gewebe von Tub. aestivum ein festes Aneinanderhaften der Asci und der dünnen Faiden, zwischen welche sie eingedringt sind, eine leicht crklirliche, fast unvermeidliche Erscheinung ist, welche, zumal dem Verhalten der anderen Arten gegenüber, zu den von Hofmeister gezogenen Schlüssen nicht berechtigt.

Sollmann hat kürzlich Bot. Zt⿳. 186 k, p. 263 behauptet, diass in den Ascis von Nectria die Sporen in Folge einer von eingedrungenen Samenkörperchen (Spermatien) ausgeubten Befruchtung gebildet werden. Diese Angabe beruht auf einer T:iuschung, indem die angeblich eingedrungenen Körperchen Sporidien, Keimungsprodukte der vorher in der gewöhnlichen Weise gebildeten Sporen sind. Vergl. oben S. 1:53 u. 15 i und Janowitsch, Bot. Ztg. I 86.5. Was Ciorda, Icon. fung. ItI, $\mathrm{V}$, ete. bei den Ascomyceten Antheridien nennt, sind unweifelhaft nur jung̣e Asci.

Nach allen diesen Thatschen werden die $\Lambda$ sci der $A$ scom receten allg̣emein für geschlechtslose Fortpflanzungsorgane zu halten sein.

Wiederum sind es volzugasweise Asentuyeeten, bei denen Tulasne die mit dem Nanen Spermatien bezeichneten Organe und ihre Pehälter oder Träger die Spermogonien Spermogrmia oder spermegonimm entelecht hat, in wetrhen man nicht ohne Grund minnliche Sevualorgane vermuthete oder noch vermuthet. Dieselben konimen jedoch nicht den Aseomrecten allein zu, sondern sind auch bei den lredineen und Tremellinen /und Lichenen gefunden worden.

Die Spermatien sind hleine, ovale oder meistens sclimal-stabförmige, haiufig auch \%. B. Rhytisma, Diatrype - Fig. in - Polystig̣mal gekrummte hörperchen. Ihre absolute Grösse ist nach speeies sehr verschicden; bei schmaler Stibehenforn sind sie \% B. bei Tympanis conspersa ${ }^{1 / 330} \mathbf{M}$. Dermatea carpinea 1/100 Mm., bei Peziza arduennensis Mont. his 1/69 Mm. lang Tulasne, Ihr Bau ist, soweit unterscheidhar, der von sehr kleinen, zarten Sporen mit homngenem Protoplasma, ihre Entstehung der von acrogenen Sporen gleich: sic werden cinzeln oder reihenweise Uredineen) abgeschnuirt auf der spitze einlarher kurzer und schmaler Fïden - Sterigmen, Basidien - oder auf 
ebenfalls sehr schmalen und zarten verzweigten Hyphen, und zwar theils auf den Zweigenden, theils auch nicht selten (z. B. Triblidium quercinum, Tympanis, Peziza benesuada) an den oberen Enden der Zellen, welche die Fäden zusammensetzen, also in Beziehung auf den ganzen abschniirenden Faden seitlich. Die Spermatien werden, mit kaum nennenswerthen Ausnahmen, immer in grosser Menge bei einander gebildet. Sic sind dann einer beim Austrocknen hart und spröde werdenden, bei Ueberschuss von Wasser bis zur Unkenntlichkeit zerfliessenden Gallerte eingebettet. Bringt man sie mit dieser in eine relativ grosse Menge Wasser, so zeigen sie eine leicht wackelnde, oscillirende Bewegung, welche kleineren in Gallerte eingebetteten Sporen ebenfalls unter den gleichen Bedingungen zukommt, den durch Kochen, Einwirkung von absolutem Alkohol getödteten Spermatien ebensowohl wie den frischen lebenden eigen, und daher für eine rein physikalische Erscheinung zu halten ist, hervorgebracht durch die Bewegung, welche bei der Quellung und theilweisen Lösung der Gallerte im Wasser entsteht, und so kleinen und leichten Körperchen, wie die Spermatien sind, mitgetheilt werden muss.

Was ihre Bildungsstatte anlangt, so entstehen die Spermatien in relativ seltenen Fällen in denselben Hymenien wie die Asci. Bei Tulasne's Peziza benesuada (Fig. 69) finden sich in einzelnen, keineswegs in allen Becherchen zwischen den Ascis, an den Orten, wo sonst die

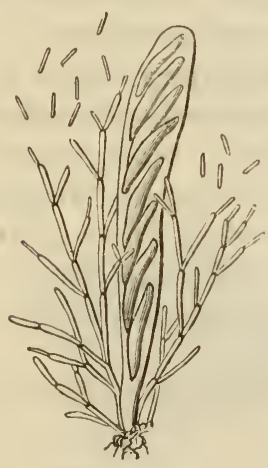

Fig. 69. Paraphysen stehen, duinne verzweigte Fäden, welche unzählige stäbchenförmige Spermatien abschnüren. Ebensolche Organe nehmen den Rand der schüsselförmigen schlauchführenden Hymenien von Cenang i um Frangulae Tul. ein.

Zweitens besitzen, wie im folgenden Capitel genauer beschrieben werden wird, die Ascomyceten vielfach neben den schlauchbildenden solche Hymenien (Pycniden Tul.), in welchen besondere Sporen (Stylosporen Tul.) durch Abschnürung oder einfache Theilung auf stielförmigen Basidien erzeugt werden. Nicht selten werden in diesen Pycniden ausser den Stylosporen Spermatien abgeschnürt; so, nach Tulasne, bei Cenangium Fraxini Tul., De r mate a carpinea Fr., D. Coryli Tul., D. dissepta Tul., wo die spermatienbildenden Fäden ebenfalls vorzugsweise den Rand der Hymenien einnehmen; ferner bei Dermatea amoena Tul., Peziza arduennensis Mont., Aglaospora. Von Nicht-Ascomyceten ist hier Tremella mesenterica anzuführen, in deren Hymenien Tulasne neben den typischen Basidien reichverzweigte spermatienabschnürende Fäden gefunden hat.

Drittens sind als Spermatien von Tulasne wenigstens in früherer Zeit bezeichnet worden die kleinen Zellchen, welche von den keimenden Tremellinenund manchen Pezizasporen abgeschnürt werden und oben (S. 154). bei den Sporidien Erwähnung gefunden haben.

Fig. 69. Peziza benesuada Tul. Ascus, umgeben von spermatienabschnürenden Paraphysen. Stark vergr., nach Tulasne copirt. 
In der weitaus überwiegenden Mehrzahl der Fälle endlich findet die Entwickelung der Spermatien in jenen besonderen Körpern statt, welche von Tulasne den Namen Spermogonien erhalten haben. Diese besitzen in einer Anzahl von Fällen die Form von convexen, polster-knoten-hornförmigen Körpern, deren Oberfläche mit dem spermatienabschnürenden Ilymenium bedeckt ist, und dabei entweder glatt oder nur wenig uncben (Peziza fusarioides Berk., "Dacryomyces Urticae Fr.«, Bulgaria sarcoides Fr., "Coryne sarcoides Fr.«, Calosphaeria princeps Tul.) oder von tiefen gyrös gewundenen und mit dem Sper-
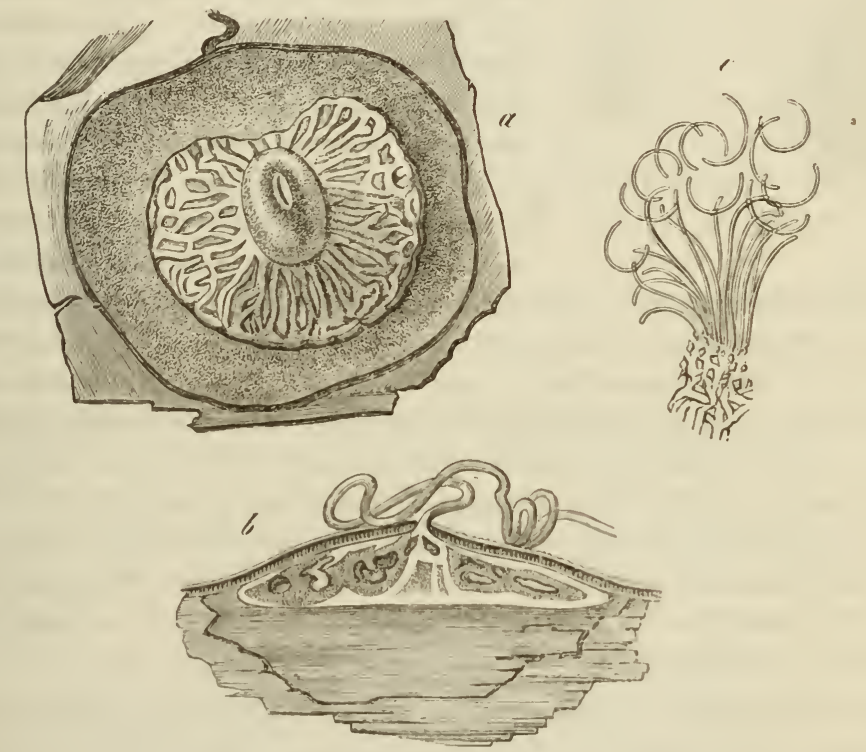

Fig. 70 .

matienhymenium ausgekleideten Furchen durchzogen (Stictosphaeria Iloffmanni Tul., "Myxosporium crocenm L.k.", Diatrype Tul. Q Quaternaria Tul., "Nacmasporae, Libertellae spee.(, s. Fig. 70). J)ie weitaus grösste Menge von Spermogonien stellt dagegen, den Peritheeien ähnlich, hohle Behiilter dar, mit glatter, krugförmiger oder sehr oft reichlich und aufs unregehmaissigste gyrös-faltiger llöhlung. Letztere erscheint, bei enger Faltung, auf Durchschnitten vielficherig. Sis ist allenthallen mit dem spermatienbildenden IIymenium bekleidet, die fertigen Spermatien, von Gallerte umhüllt, erfüllen die enge Höhlung vollstandig und treten, wenn die Gallerte durch Feuchtig̣keil aufquillt, zu Gallerttropfen oder langen Ranken zusammengeballt, in Unzahl aus der engen

Fig. 70. Diatrype quereina Fr. a Spermogonium, auf einem Stück Rinde, dureh Entfernung des Periderma frei gelegt. Die gy rös faltige, kegelförmig zulaufende Oberfläche träğt das Spermatienhymenium, $b$ senkrechter Längsschnitt durch ein Spermogonium; aus einer Deffnung in dem bedechenden Periderma quillt eine rankenförmige Spermatienmasse hervor. a und $b$ schwach-vergr. $c$ Fragment eines dünnen Durchschnittes durch die Oberfläche des Spermogonium, mit sichelförmigen Spermatien und ihren Sterigmen, 360 fach vergr. Alle Figg. nach Tulasne copirt. 
Oeffnung hervor, mit welcher der Behiilter nach aussen mündet. Krugförmige Spermogonien dieser Art, mit glatter Wand und einer bei den meisten Arten von pfriemenförmigen, nach aussen vorragenden Paraphysen eingefassten Mündung besitzen die Uredineen ("Accidiolum exanthematum Unger " [Fig. 71]). Von

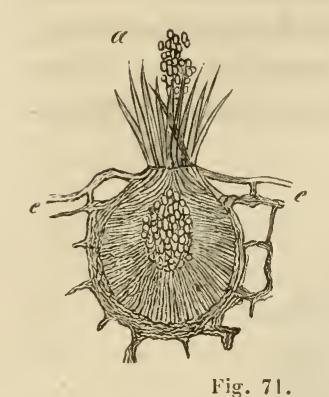

Fig. 71 . demselhen Bau, jedoch der Mündungsparaphysen entbehrend, meist weit stattlicher und oft gyrös vielficherig sind diejenigen, welche Tulasne für eine grosse Zahl Pyrenomyceten und kleinere Discomyecten nachgewiesen hat.

Die Spermogonien sind, wie sich nach dem Gesagten erwarten lisst, den Beobachtern vor Tulasne vielfach bekannt gewesen, aber nicht für Organe der Ascomyceten, Uredineen u. s. w. , sondern für besondere Pilzspecies, bezichungsweise Genera gehalten und benannt worden; die Namen dieser sind in den oben erwähnten Beispielen mit » bezeichnet; andere nur Spermogonien bedeutende bekanntere Gattungsnamen sind z. B. Cytispora, Naemaspora, Libertella, Melasmia, u. s. f. Das Wesentliche von Tulasne's Entdechung besteht in dem Nachweis, dass eben die Spermogonien nur Organe anderweitig fructificirender Pilze sind; einem Nachweis, welcher jotzt für eine schr grosse Reihe von Fïllen durch anatomische und entwickelungsgeschichtliche Untersuchungen vollständig gelicfert ist, so dass zwar hier und da noch Zweifel bestehen können, welcher Species ein bestimmtes Spermogonium angehört, aber jeder Streit mit Denjenigen, die wie z. B. Bonorden in den Spermogonien immer nur besondere Pilzarten sehen wollen, üherflüssig ist.

Tulasne vermuthete in den Spermogonien mainnliche Geschlechtsorgane, in den Spermatien die Analoga der Spermatozoiden und stülzte sich hierfür auf zwei Wahrseheinlichkeitsgründe, naimlich dass die Spermatien nicht keimten und dass die Spermogonienentwickelung meistentheils der Entstehung der sporenbildenden Organe vorangeht, - Verhälnisse, welehe allerdings an die von den Spermatozoiden und Antheridien anderer Gewiehse bekannten erinnern. Welches die zu befruchtenden weiblichen Organe speciell seien, blicb unentschieden. Für viele anfinglich den Spermatien zugezihlte Organe ist nun in neuerer Zeit, wiederum besonders durch Tulasne, nachgewiesen worden, dass sie keimen und hiernach zu den Sporen zu rechnen sind. Ferner ist zu beachten, dass manche Sporen nur unter ganz bestimmten Bedingungen keimen. Es ist daher zur Zeit zweifelhaft, ob es wirklich absolut keimungsunfiahige Spermatien gibt, oder ob nicht das Ausbleiben der Keimung darin seinen Grund hat, dass in den bisherigen Versuchen nicht die richtigen Bedingungen hergestellt waren. Es ist ferner bis jetzt immer noch keine Spur von weiblichen Geschlechtsorganen gefunden worden, die etwa durch Spermatien befruchtet würden; und endlich kommen bei den Ascomyeeten vielfach unzweifelhafte sporenabschnïrende, in

Fig. 71. Puccinia graminis. $a$ Spermogonium dem Parenchym der Nährpflanze (Berheris vulgaris) eingesenkt, aus der Epidermis $e-e$ vorbrechend. Vergr. 200. $b$ Sterigmen mit jungen Spermatien. Veror. etwa 350 . 
dem folgenden Capitel zu besprechende Orạane (Pỵcniden u. s. f.) gleich den Spermogonien als Vorläufer der Schlauchfructification vor. Die Bedeutung der Spermogonien und Spermatien muss daher zur Zeit als völlig zweifelhaft bezeichnet werden; für diejeniggen der letzteren, bei welchen keine Keimung beobachtet ist, ist jedoch die ursprüngliche Vermuthung, oder vielleicht die, dass sie die Rolle von Indrosporen (in der ron Pringsheim bei den Conferven gebrauchten Bedeutung des Wortes spielen, immerhin nicht gan\% von der Hand zu weisen. Beobachtungen, welche ich an den bis jetzt nie keimenden Spermatien und den Spermogonien der Uredineen angestellt habe, sind allerdings einer solchen Annahme nicht gainstig. Wie spiiter zu beschreiben ist, sind hier die Spermogonien constante Beg̣leiter und Vorliufer der sog̣enannten Aecidiumfrucht, und die Vermuthung liegt nahe, dass sie zu dieser in irgend einer sexuellen Beziehıng stehen. Bei Culturen von Endophyllum Sempervivi erhielt ich nun aber auf einigen von anderen völlig isolirten Sempervivumstöcken lecidien mit normal keimenden Sporen in reicher Menge, ohne eine Spur von Spermogonien oder Spermatien.

Die Spermatien und Spermogonien wurden von Tulasne entdecht wenn sie auch Friiheren schon als besondere formen, Species bekannt waren! und für vicle Fälle genan beschrieben :

Note sur l'appareil reproduct. d. I. Lirhens et les Champignnns. Compt..rend. Tom. XXXII, p. 470. Inn. se. nat. 3e Ser., Tom. sl, p. 370 (1851,. Ferner :

Ann. sc. nat. 3e Sér., Tom. XIX (Tremellinen, Hid. 4o serr., Tom. Il Ureclinei). Ibicl. 4e sér., Tom. Y Pırenomycetes, Ibicl. 3e ser., Tom. XX (Discomycetes).

Ferner:

Tulasne, Selecta fung. Carpol. Vol. II et I, p. 180.

Berkeley and Bronme, in Hooker's Journ. of Bot. 1851 , Tom. III, p. 319.

de Bary, Brandpilze, p. 61, 78 .

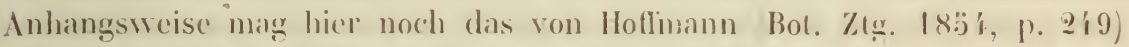
angegebene Vorkonmen von mSpermatien bei einem Fadenpilzex erwihnt werden. Von dem Mycelium des schwerlich eine sellostindige Art reprisentirenden) Trich of he ci um rose u m Lh. sollen, nach lloflimanns Angabe, die quirlig verastelten, selten einfachen I!̣phen mit aerogenen, von Gallerte umhillten Sporenköpfchen entspringen, welche Corda $\lambda$ erostalagmus cinnabarinus, Bonorden Vertieillium ruberrimum genannt hat. Bie liag̣lich cylindrischen, selır kleinen und im Wasser oscillirenden Sporen letzegenannter Form haben mit Spermation von Pyrenomyceten, Eredineen u. s. f. grosse Achnlichkeit und werden diesen ron Hoffmann angereiht, zumal da er sie nicht keimen sah. Da das Mycelium des Acrostalagmus manchmal sehr zart und unscheinbar, andere Vale dem des Trichothecium schr ihnlich ist, da es mir nie gelang, beide Formen aus demselben Mỵcelium entspringen zu schen, wohl aber, den Acrostalag̣mus mehrere Generationen hindurch aus seinen eigenen leicht keimenden Sporen zu erzichen, so ist die Vermuthung verzeihlich, dass eine Verwerhselung der Myeelien zweier verbreiteter und oft geselliger Schimmelformen den Angaben Iloflimanns zum Grunde liegt, und zur Aufkliarung der Sache neue Untersuchung nothwendig.

An die Spermatienfrage schliesst sich umnittelbar an die von ilteren Beobachtern, Bulliard, Fr. Iloffmann, Tode, IIolmskiold discutirte Ansicht, nach 
welcher das dem blossen Auge auffallende Pulver oder Mehl auf der Oberfläche der Xylarien und verwandter Sphaeriaceen den männlichen Geschlechtsapparat darstellen sollte. Es ist heutzutage unzweifelhaft, dass dieses, soweit es den betreffenden Pilzen wirklich angehört, theils aus besonderen acrogenen Sporen (Conidien, Stylosporen) theils aus Spermatien in dem oben bezeichneten Sinne des Wortes besteht. Ausführlicheres hierüber findet man bei Tulasne, Fung. carp. I, p. 172, seq.

Bei denjenigen Pilzen endlich, welche noch von Vielen für die höchstorganisirten gehalten werden, den H y me n o m y c e t e n, sind männliche Geschlechtsorgane vielfach gesucht worden. J. Hedwig (Theor. generat. et fructif. plant. crypt. Ed. 2) glaubte in dem Ringe oder den Streifen und Schuppen am Stiele der Hutpilze die Träiger der männlichen Geschlechtsorgane gefunden zu haben, für letztere selbst aber sieht er Körnchen an, welche sich auf genannten Theilen anhäufen, und welche seiner Darstellung nach nichts anderes sein können, als die von dem Hymenium abgefallenen Sporen. Schon viel früher hatte Micheli auf dem Hyimenium von Coprinus eigenthümliche blasenförmige Organe beschrieben und vielleicht (doch scheint mir dieses nicht ausgemacht) die nämlichen Organe von anderen Agaricinen als flores apetali, nudi, ex mero constantes filamento bezeichnet. Bulliard (Champ. de France T. I, p. 39-50) hat wohl jene nämlichen blasenförmigen Organe für vésicules spermatiques gehalten, also für männliche Sexualorgane; dieselben viurden später von den Bearbeitern des AgaricinenHymeniums vielfach beschrjeben und von Léveillé $\mathrm{G}$ ystiden, von Phoebus $\mathrm{Pa}-$ raph ysen genannt, von Klotzsch, Corda aber (Icon. Fung. III, p. 44) geradezu Antheridien, Antheren oder Pollinarien. Eine besondere Abhandlung hat ilınen neuerdings II. Hoffmann gewidmet (Bot. Zeitg. 18ว̈6, p. 137). Besagte Organe kommen bei der Mehrzahl fleischiger Hymenomyceten vor (Agaricus, Boletus, Polyporus), bei manchen (Agar. lateritius, A. geophyllus, Cantharellus aurantiacus) inconstant nach Phoebus; bei Hỵdnum, Clavaria scheinen sie bis jetzt nicht gefunden zu sein. Auch in dem Ilymenium der Hymenogastreen ( $\mathrm{Hy}-$ menogaster, Octaviania carnea) finden sie sich hie und da, und ihnen schliessen sich ohne $Z$ weifel die oben erwähnten Paraphysen von Geaster hygrometricus an. Die Cystiden sind grosse Zellen, welche dadurch besonders auffallen, dass sie mehr oder minder weit über die Hymenialfläche vorragen. Sie haben im Uebrigen die gleiche Richtung und Befestigung wie die Basidien. Ihre Gestalt und Grösse ist nach den Species sehr verschieden; meist constant und charakteristisch für die einzelnen Arten, weniger für Genera und Subgenera. Als bemerkenswerthe Formen sind zu crwähnen vor allen die grossen, dem blossen Auge schon auffatlenden, ovalen oder längtichen, stumpfen Blasen, welche, soweit die Angaben reichen, sämmtlichen Coprin is eigen sind (Fig. 43). In einer Reihe anderer Fälle ist ihre Gestalt cy lindrisch, keulen- oder flaschenförmig, mit stumpfen (Polyporus umbellatus nach Corda, Agar. viscidus L. nach Phoebus) oder gespitzten, oder geknöpften Enden (Lactarius, Russula, Boletus nach Corda) einfache oder verzweigte cylindrisch-haarförmige Cystiden haben z. B. A. fumosus P. A. laceatus Scop. (Hoffmann) u. s. w. Bei A. Pluteus P. sind sie flaschenförmig und am oberen Ende mit mehreren hurzen, spitzen etwas zurückgekrümmten Aussackungen mir mit Widerhikchen versehen (Ditmar, in Sturm D. fl. III, 1, 
Tab. 28). Speciellere Formbeschreibungen findet man bei den citirten Schriftstellern.

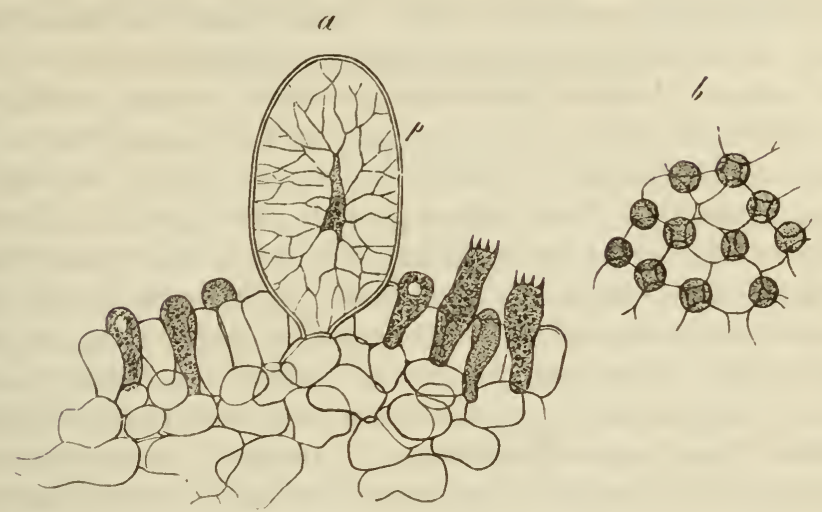

Fig. 43 (vgl. S. 112).

Die Structur der Cystiden zeigt wenig eigenthiumliches: eine zarte, farblose Membran umgibt in den meisten Fillen einen farblosen Inhalt, der entweder von einem vacuolendurehsetzten Protoplasmakörper gebildet oder ganz wasserhell ist. Bei Coprinus micaceus (Fig. 13, pj fand ich an lablbreifen II!menien im Innern der Gystiden einen centralen unregelmäissig länglichen Protoplasmakörper, von dem zahlreiche verzweigte und anastomosirende fadenförmige Fortsaitze zur Wand hin ausstrahlten. Diese zeigten einen erstaunlich lebhaften amöbenartigen Gestaltwechsel; : iltere Cystiden dieses Pilzes sind fast ganz wasserhell. Bei Lactarius deliciosus und auch wohl den verwandten Arten sind die Cystiden mit dicht körnigem, undurehsichtigem Inhalt erfüllt. Sie gleichen hierin den Milchröhren, uncl es sielıt auf dicken Schnitten oft aus, als scien sie Zweige dieser, zumal da sie hier tief unter das subhymeniale Gewebe ins Innere der Trama ragen. Ich sah sie jedoch immer nur von nicht milchführenden Tramahyphen als Zweige entspringen. - Bei $\Lambda$ gar. balanimus Berk. sind die Cystiden von tief purpurrother Farbe (Montagne, Esq. Org. el phys. de la classe des Champign.).

Nach Corda, und schon nach zweifelhaften Angaben Früherer, entleeren die Gystiden zuletzt ihren Inhalt in Tropfenform durch die der Abbildung nach geöffnete Spitze. Datss dieses spontan erfolge, davon konnte ich mich so wenig als Hoffmann uberzeugen; selbst das Platzen der in Wasser gebrachten Cystiden, das nach IIoffimann ganz regellos erfolø̄t, salf ich nur selten. Dass ihre Oberflaiche feucht ist, und oft Flüssigkeittröpfchen trägt, ist eine Erscheinung, welche sie mit allen saftreichen Pilzzellen gemein haben.

Die Gystiden entwicheln sich ohngefihr zu gleicher Zeit mit den Basidien. Sie stehen theils ordnungslos zwischen diesen zerstreut, theils und vorzugsweise findet man sie am freien Rande der Hymenialfortsitze, zumal an der Lamellenschneide der $\Lambda$ garicinen. Ihre Zahl ist im Vergleich zu der der Basidien immer gering, oft überaus spärlich.

Diejenigen, welche die Gystiden für männliche Sexualorgane hielten, stellten sich vor, die reifen, abgefallenen Sporen blieben an der feuchten Oberfläche 
haften und würden von der dort befindlichen Flüssigkeit befruchtet (Corda, I. e. und besonders Klotzsch, in Dietrichs flor. boruss. Bd. 6 bei Coprinus deliquescens); die Befruchtung hätte eine Erhöhung oder vielleicht erst Herstellung der Keimfähigkeit der reifen Spore zur Folge. Wäre diese durchaus unerwiesene Angabe richtig, so würde man es eher mit einer Art Düngung als mit Befruchtung zu thun haben. Andere Brobachtungen über etwaige weibliche, zu befruchtende Sexualorgane liegen nicht vor, und nach den mitgetheilten Thatsachen ist aller Grund vorhanden, die Cystiden für nichts weiter als eigenthümliche Haarbildungen zu halten. Viele haben geradezu die Gestalt cylindrischer gewöhnlicher llaare, die der Coprini hahen mit den Gliedern der Haare auf der sterilen Oberfläche des Fruchtträgers die grösste Aehnlichkeit, und bei manchen Pilzen findet man unzweifelhafte Haarbildungen an den Stellen, wo bei anderen die Cystiden stehen; so an dem Rande der Tubuli von Fistulina, so die über Hymenialfliche vorragenden, den Pollinarien sehr ähnlichen, aber mit überall derber verdickter Wand versehenen Borsten mancher Thelephoren, wie des Corticium quercinum und besonders der Gruppe, welche Léveillé Hymenochaete genannt hat (Theleph. tabacina, Th. rubiginosa u. a. Vgl. Léveillé, Ann. sc. nat. 3. Sér. tom. V, 1846, p. 1 30$)$.

Eine ausführliche Aufzählung dessen, was zumal von älteren Autoren über die Pollinarien gesagt ist, wäre hier zwechlos. Man vergleiche hierüber die citirten Arbeiten, zumal Phoebus und Tulasne's Fung. Carpol. I, p. 163 seq.; die im Texte kurz citirten Arbeiten sind dieselben, welche sich mil den Hymenium und den Basidien beschäftigen und auf S. 134 ausführlich angegeben sind.

In neuester Zeit ist A. S. Oersted Verhandl. d. K. Dän. Ges. d. Wiss. 1. Jan. 186:3) den Geschlechtsorganen der Hymenomyceten vielleicht an einem anderen Orte als wo man sie früher suchte auf die Spurgekommen. An dem Mycelium von $A$ garicus (Crepidotus) variabilis P. nämlich fand er Zellen (nEizellen(s), wolche an den IIyphen wie Zweiganlagen entstehen, länglich-nierenförmige Gestalt haben, reichliches Proloplasma und vielleicht einen Zellkern enthalten. An der Basis der Eizellen entspringen die muthmasslichen Antheridien: 1-2 diinne schlanke Fiaden, die mit ihren Enden den Oogonien meistens abgewendel, selten angelegt sind. Die Eizelle wird nun, ohne weitere bemerkbare Verinderungen zu erleiden, ron einem Geflechte Myceliumhyphen umwachsen, welehe von dem sie trag̣enden Faden entspringen, und dieseś Geflecht ist die Anlage des Fruchttriger's Hutes). Ob und wie hier eine Befruchtung wirklich stattfindet, ist vorliutig zweifelhaft. Lirweist sich Oersted's Ansicht als richtig, so ist naturlich der ganze•Fruchttriger ein Product der Befruchtung.

Schon 1860 hat Karsten eine Vermmhung in diesem Sinne ausgesprochen (Geschlechtlskeleen d. Pfl. p. \$0). Seine Beoharhtungen der ersten Entwickelung des llutes von Mgaricus campestris scheinen, soweit aus dem unklaren Bericht darüber Bonplandia 186?, p. 633) arsehen werden kann, mit denen Oersted's iibcreinzustimmen.

Inverkennbar ist die Achnlichkeit der von Oersted beobachteten Erscheinungen mil den oben für Peziza confluens beschriebenen. 


\title{
Dritte Abtheilung.
}

\section{Entwickelungsgang der Pilze. Pleomorphie. Generationswechsel.}

\author{
Capitel 6.
}

Bis vor l' Jahren galt es als eine ausgemachte Sache, dass jede Pilzspecies nur einc bestimmte Form von Fructifieationsorganen entwickele. Einsichtsvollen Beobachtern, wie schon Link, Jos. Banks, Albertini und Schwoinitz, Fries, Berkeley, war es zwar lingst aufgefallen, dass gewisse Pilzfructificationen constant gesellig mit einander und in bestimmter Reihenfolge auftreten, wie die Formen der Uredineen, die weissen Oidien auf lebenden Phaneroganamen und die Erysiphen, die Tubercularien, Gylisporen und Sphaerien u. s. f. Die eine, fruber auftretende Fruchtform wurde mehrfach für einen niederen Entwichelungsizustand der anderen, spiteren gehallen und Fries unterschied sogar schon im S!stema mycologicum zwischen Sporen (sporidia) und einer zweilen, manchen Pilzen zukommenden Form von Fortpflanzungsorganenen, die er Conidia, organa gonidiis algarum respondentia nannte. Er fügl allerelings (Syst. mye. HI, 3633) hinzu: duplex esse sporidiorum in eadem planta genus ommino denegamus. de mehr aber die Formen der Pilze genauer mit dem Mlikroskop untersucht wurden, um so hestimmter lernte man in den vermeintlichen niederen Entwichelungsstadien und den Conidien wohlausçebildete typische Forlpflanzungsorgane kennen; und da es firr selbstrerslandlich galt, dass vine Pilzspecies nur eine form von Sporen haben könne, wie eine phanerogame Pflanze nur cinerlei Samen, so hielt man die angedeutete Geselliggkeit mancher Fruchtlormen für eine zufïllige Eirseheinung oder für eine Folge des Schmarotzens eines Pilzes auf dem andern, jerle besondere Sporenform aber repriisentirte immer eine besondere species. Finzelne Faille, in welchen es unzweifelhaft 1 ar oder schien, dass auf demselben Pilzfaden zweierlei Sporen gebiledet wereten, wie der hei Corda dargesiellte von Ascophora elegams (Ie. fung. III, p. 14) und der andere, zweifelhafte, von Penicillium glaucum (Corda, lcon. 1, p. 21) erschienen nur als sonderbare Ausnahmen und komnten die herrschende Veberzeugumg zunichst nicht im mindesten erschïllern.

Da trat 1851 Tulasno (Cpt. rend. 24 et 31 Mars; Ann. se. nat. XV.) mil der Entdeckung zuerst auf, dass eine Pilzspecies nicht nur in cinzelnen Fälen mehrerlei Sporenformen haben kïnne, sondern dass sich zunäichst bei der grossen Familie der Pyrenomyecten mehrerlei Fortpflanzungsorgane constant und in bestimmter Succession entwickeln, nimlich Spermogonion mil Spermatien, P'y coniden mit Stylosporen, Gonidien und endlich die ascusbildenden Perithecien. Eir zeigte, lass cine Reihe von Galtungen, welche bisher auf Grund einer cinzelnen Form von Sporen aufgestellt worden waren, nur Formengruppen, Fo rmgenera kann man sagen, sind, dass z. B. die Lormgenera Cytispora, Naemaspora, Micropera, Ascochyta, Sporocadus, Melanconium, als Spermogonien, Pycniden und conidientragende. Organe in den Entwickelungskreis achter, schlauchbildender Sphaerien gehören; er wies gleichzeitig eine ähnliche Multiplicitit der Reproductionsorgane 
für die Lichenen nach. Zahlreiche weitere unten anzuführende Arbeiten Tulasne's zeigten alsbald die typische Pleomorphie der Reproductionsorgane für fernere Gattungen, Familien und Ordnungen der Pilze, und sein unter dem Titel Selecta fungorum carpologia begonnenes Werk hat speciell die Aufgabe seine Entdeckungen in der bezeichneten Richtung in der sorgfältigst ausgearbeiteten Form darzustellen. Tulasne's Entdeckungen wurden bald von Anderen bestatigt und theilweise erweitert. Auch an Widersachern fehlte es, wie natürlich, anfangs nicht, doch muss jeder sorgfailtige Beobachter bald zur Anerkennung des Pleomorphismus der Pilze kommen, urid wer ihn, wie Bonorden noch heute, überall in Abrede stellt, dem kann nur das entgegnet werden, dass er nit grösserer Sorgfalt untersuchen möge. Weit grösser als die Schwierigkeit des Auffindens der verschiedenen Fruchtformen ist die Gefahr, nicht zusammengehörende Organe in den Entwickelungskreis einer und derselben Species zusammenzustellen. Tulasne hat sich selber in dieser Beziehung schon Irrungen nachgewiesen, für eine Reihe von Einzelfällen bestehen noch ungelöste Zweifel und Controversen. Dem Anfänger ist daher für seine Untersuchungen und Schlussfolgerungen die grösste Behutsamkeit anzuempfehlen.

Zur Nachweisung des Pleomorphismus der Pilze sind zwei Methoden möglich. Die erste, von Tulasne vorzugsweise angewendete, besteht in der genauen anatomischen Untersuchung des fertigen Pilzes, des Ursprunges der verschiedenen Fruchtformen von dem Mycelium und Fruchttrigger. Die zweite, von mir mehrfach in Anwendung gebrachte besteht in sorgfailtig geleiteten Aussaatversuchen, welche die Entwickelungsproducte der verschiedenen Sporenformen unter geeigneten Bedingungen durch alle Stadien zu verfolgen haben. Die Anwendung dieser zweiten Methode hat nicht nur für die Lehre vom Pleomorphismus Bestiatigungen geliefert, sondern auch für eine Reihe von Pilzgruppen die Bedeutung der verschiedenen Fortpflanzungsorgane in dem Entwickelungsgang der Species, und mehrfach eine gesetzmässige A b w e ch s e lung, einen Generationsw ech sel näher kennen gelehrt, welcher zwischen denselben besteht.

Zur Zeit sind unsere Kenntnisse von der Gesammtentwickelung der Arten allerdings noch lückenhaft. Hier ist es zunächst nothwendig, eine Uebersicht der Thatsachen und Ansichten zu geben, welche bis jetzt von den einzelnen Genera und Ordnungen bekannt sind, und erst am Schlusse die Feststellung allgemeiner Gesichtspunkte zu versuchen.

Für die

\section{Saprolegnieen}

ist zuerst durch Schleiden (Grundz. 3. Aufl. 1, 314) und A. Braun (Verjüngg. p. 286) später besonders genau durch Pringsheim (l. c.) das Vorhandensein der Geschlechtsorgane neben den geschlechtslosen Schwärmsporangien nachgewiesen worden. An der Zusammengehörigkeit von beiderlei Organen wurde bei den in Rede stehenden Gewiichsen ebenso wenig wie bei den Conferven jemals ernstlich gezweifelt. Soweit die vorhandenen Untersuchungen reichen, entwickelt sich bei den Saprolegnieen aus der keimenden Schwärmspore sowohl wie der Oospore ein Mycelium, welches zuerst Zoosporangien, später Sexualorgane entwickelt. Bei den Formen, welche Pringsheim monöcische nennt, entstehen Oogonien und Antheridien gleichzeitig; bei den anderen zuerst die Zoosporangien, dann die antheridien- oder androsporenbildenden Zweige, zuletzt die Oogonien. 
Vergl. oben, S. 156. Bei cinigen Saprolegnieen, Sapr. ferax und Aphanomyces besonders, ist der ganze Kreislauf der Entwickelung anscheinend liickenlos wiederholt beobachtet, und an ihnen nur die Bildung und Keimung der beschriebenen, im Wasser sich ausbildenden Organe gefunden worden. Es ist jedoch möglich, dass vielleicht besondere Arten, vielleicht auch alle Saprolegnieen noch ein nicht genau aufgeklartes Entwickelungsstadium a us serhalb des Wassers durchlaufen. Bekanntlich entwickeln sich die meisten der in Rede stehenden Gewaichse besonders häufig auf ins Wasser gefallenen lnsecten, zumal Fliegen. Viele dieser Thiere, vor allen die Slubenfliege, sind einer Erkrankung ausgeselzt, welche seit Göthe bekannt, neuerdings von Cohn (Nov. act. Ac. Nat. curios. vol. 2:3 P. I) und Lebert (Verhandl. d. naturf. Ges. Zürich 18.36) ausführlich beschrieben worden ist. Die Krankheil wird durch das Auftreten von Pilzbildungen charakterisirt, welche von Cohn den Gattungsnamen Empusa, von Lebert My ioph yto n, von Fresenius Bot. Ztg. 18.36 und Abhandl. d. Senchenb. Ges. Frankfurt II, p. 201 En $t$ om oph th or a erhalten hat. Die Entwickelung dieser Pilze, wie sie bei der Entomophthora der Stubenfliege verfolgt ist, beginnt mit dem Auftreten zahlreicher kleiner farbloser Zellchen in dem Blute des Thieres. Die Zellchen wachsen rasch zu einer bedeutenden Grösse heran und behalten dabei die ursprüungliche Kugel- oder Eiform, oder nehmen die Gestalt gestreckter Schliiuche an. Mit dieser Entwickelung schreitet die Erkrankung der Thiere gleichmiissig fort, der Hinterleib schwillt betrichtlich an, die Bewegung wird triige, zuletzt stirbt die Fliege unter eigenthümlichen Streckungen und Verkrümmungen der Gliedmassen. Schon vor dem Tode haben sich die Zellen im Innern gestreckt und blindendigende Schliuche getrieben, die sich wurzelahnlich verlingern und verasteln und Blut und Eingeweide allmählich verdringen und aufzehren. Acht bis zehn Stunden nach dem Tode wird die die Körpersegenente verbindende Haut von den Enden der Entomophthora-Schliuche durchbohrt, diese strecken sich und schnüren auf ihrer Spitze eine grosse, rundliche, oben etwas zugespitzte, oft von einer weiten hyalinen, sackartigen Aussenhaut umgebene Spore ab, welche bis auf 3 Cum. Entfernung weggeschleudert wird; die todte Fliege ist daher bald von einem weissstaubigen Hofe umgeben. Die Entwickelung des Pilzes in dem Insect ist hiermit abgeschlossen. Die frischen Sporen, welche die genannten Autoren nicht zur Keimung bringen konnten, treiben auf Wasser lange, dicke Keimschliuche. Gesunde Thiere durch die Sporen zu inficiren ist stets tolal misslungen, die Entstehung der ersten zarten Zellchen in Blute zweifelhaft: Cohn lasst sie durch freie Zellbildung, durch eine Art Generatio spontanea oder Ileterogenie entstehen, Lebert möchte, und wohl mit Recht, lieber von Generatio incognita reden. Nach einer Notiz ron Cienkowski Bol. Ztg. 183̈.̈, p. 80:3) und nach Bails bestimmter Versicherung Bericht d. Vers. d. Naturforscher in Königsberg) vermögen aber die Entomophthora-Zellen zu »Achlya-Schläuchen«, d. h. zu Zoosporangien tragenden Schliuchen von wie es scheint verschiedenen grösseren Saprolegnieen auszuwachsen, wenn sie in noch jugendlichem Entwickelungszustand, jedenfalls bevor sie nach aussen hervorgetreten sind, ins Wasser gebracht werden. Sind diese, allerdings noch genauer Prüfung bedürftigen Angaben richtig, so ist jedenfalls eine wesentliche Erweiterung des Entwickelungskreises der Saprolegnieen zu erwarten. 


\section{Peronosporeen.}

Der Entwickelungsgang dieser in lebenden Phanerogamen schmarotzenden Pilze hat mit dem der Saprolegnieen viele Aehnlichkeit. Das Mycelium erzeugt zuerst auf baumförmig verzweigten (Peronospora) oder kurz keulenförmigen, zu dichten Hymenien vereinigten (Cystopus), immer an die Oberfliche des befallenen Pflanzentheils tretenden Fruchttriggern geschlechtslose, einzeln (Peronospora) oder reihenweise (Cystopus) abgeschnüte Fortpflanzungszellen, die passend als $\mathrm{C}_{0-}$ nidien zu bezeichnen sind (Vgl. oben, Fig. 19, 49, 52). Je nach den Species sind diese entweder einfache Sporen, die einen zu einem neuen Mycelium auswachsenden Keimschlauch treiben; oder, bei Peronosp. infestans und anderen Arten, und bei Cystopus sind die Conidien Zoosporangien, aus der keimenden Zoospore wird dann ein neues Ilycelium. Die Cystopusarten, vielleicht mit Ausnahme von C. candidus, haben zweierlei Conidien: Das Endglied einer jeden Reihe ist derbwandiger und meist etwas grösser als die übrigen, oft gelblichbraun gefarbt und mit sparlichem Protoplasma rersehen. Ich fand es immer glatt und keimungsunfiahig; Tulasne sah die Oberfliche bei C. Portulacae mit drei gleichweit von einander entfernten Längsfurchen versehen und beobachtete nach Aussaat auf Wasser das Austreiben eines einfachen Keimschlauchs (Second Mém. s. l. Urédinées p. 110). Die übrigen Conidien jeder Reihe sind farblos und bilden Zoosporen. Das conidienbildende Mycelium erzeugt später die von Tulasne (Cpt. rend. 26. Juin 18̈34) zuerst aufgefundenen, oben, S. 158 beschriebenen Sexualorgane. Die keimende Oospore entwickelt, wic S. 159 beschrieben ist, bei Cistopus candidus direct Schwarmsporen, welche dann gleich den aus den Conidien stammenden ein fruchtbares Mycelium erzeugen; bei Peronosp. Valerianellae treih)t sie einen ohne Zw eife] zum Mycclium heranwachsenden Keimschlauch.

Vgl. de Bar!, Recherches s. J. développement de quelques Champ. parasites. Ann. Sc. nat. 4. Sér. Tom. XX. und Beitr. z. Morph. d. Pilze, II.

Caspary (Ceber zwei- und dreierlei Früchte einiger Schimmelpilze, Monatsber. d. Berl. Acad. Mai 18\%5) gibt für einige Peronosporen noch eine dritte Art von Früchten an, die er Sporidangia nennt, grosse blasenförmige Behailter, welche in dem Parenchym der Nihrpflanze sitzen und sehr zahlreiche elliptische oder cylindrische „Sporidien« enthalten. Ich habe früher diese Organe nicht finden können und (1. c.) die Vermuthung ausgesprochen, besagte Sporidangien seien vielleicht unreife Oogonien. Nach den von Caspary selbst mir freundlichst mitgethcilten Prijparaten aber sind es Pycniden von Pleospora, Stigmatea oder einem anderen kleinen Pyrenomyeeten, die mit der Entwickelung der Peronosporen nicht zusammengehören, wohl aber sich hïufig in dem von diesen getödteten Parenchym ansiedeln.

\section{Mucorini.}

Bei den Pilzen dieser Gruppe treten, wie seit lange bekannt ist, aus einem reichverzweigten Mycelium aufrechte Fruchthyphen hervor, welche auf ihren Enden kugelige, durch eine ebene (Hỵdrophora Bonord.) oder hochgewölbte, mit dem Namen Columella bezeichnete Querwand von dem Trager abgegrenzte Sporangien mit bewegungslosen Sporen tragen, die auf S. 121 besprochen worden sind. Mycelium und Fruchttriger sind bis zur Sporenbildung unseptirte Schläuche; mit der Fruchtentwickelung oder Kurz vorher treten Querwände auf. Die angegebene geschlechtslose Sporangien- und Sporenbildung ist jedenfalls für die Mucorinen 
charakteristisch und galt lange für ihre einzige Fortpflanzungsweise. Bei vielen Formen und guten Arten (z. B. Mucor fusiger Lk., M. macrocarpus Cd.) ist sie auch heute die allein bekannte. Für andere haben neue Untersuchungen eine grosse Vielgestaltigkeit der Fructificationsorgane theils nachgewiesen, theils mit mehr oder weniger Grund vermuthen lassen.

An vollständigsten ist der Entwickelungsgang bekannt für Syzygites megalocarpus: Vergl. de Bary, Beitr. z. Morphol. u. Phys. d. Pilze I, wo auch die Litteratur über diesen Pilz verzeichnet ist. Das in fleischigen Schwaimmen wachsende Mrcelium dieses Pilzes treibt zweierlei Fruchtträger: Geschlechtslose, aus langgestrecktem Stamme wiederholt gabelig verzweigte, auf den Enddichotomien kugelige mit einer Columella versehene Mucorsporangien bildende Sporenträger; sie sind unter den Namen Aspergillus maximus und Sporodinia grandis Link längt bekannt. Zweitens drei- oder zweigabeligy verzweigte, durch Ehrenberg 1829 als Syzygites beschriehene $Z$ y gospore $n \mathrm{tr}$ ig e r, welche die auf S. 160 dargestellten grossen Zygosporen und Azygosporen entwickeln. Der keimenden Zygospore entsprosst eim Keimschlauch, welcher direct, ohne Myeolim zu bilden, zu einem, oder, sich verzweigend, zu eingen Sporentrigern auswichst. Aus der keimenden Spore entwickelt sich auf geedgnetem substrat rin Mycelium, das zuerst Zygosporentriger und nachher, rings um diese, Sjorenträger erzeugt. Anomalien in diesem regelmassigen Generationswechsel kommen insofern vor, als das Mycelium die zweierlei Fruchttäger auch in umgehehrter Reihenfolge, oder geschlechtslose allein bilden kann. Nach Tulasne Cpt. rend. Tom. 4, p. 617 und einer in der Vignelte vor den Tafeln der Sel. fung. carpol. befindlichen Zeichnung kommt es auch vor, dass beiderlei Fuchtformen auf verschiedenen Zweigen eines und desselben Fruchttrigers gebildet werden.

Ein jedenfalls : ihnlicher Entwickelungsgang kommt Ehrenbergs Mucor stolonifer oder Rhizopus nigricans (Epist. de Mreetogenesi Tab. I' zu. An derben niederliegenden Schläuchen entwickeln sich einerseits die S. 160 beschriebenen Zygosporen, andrerseits, auf kurzen, aufrechten, einzeln oder büschelig beisammenstehenden Trigern geschlechtslose Sporangien. Das aus den Sporen elwachsene Mycelium entwickelt oft immer nur geschlechtslose Reproductionsorgane. Wo beiderlei Organe gebildet werden, ist keine strenge und regelmaissige Succession derselben vorhanden. Die Z ygosporenkeimung von Rhizopus ist noch nicht beobachtet.

Eine anscheinend regellose Pleomorphie der Fortpllanzungsorgane findet sich bei einer Art, die ich M u cor II u ce do nennen will, und welche von den Autoren unter diesem und wohl auch vielen anderen Nämen beschrieben ist. Sie wächst spontan und in den Culturen auf faulenden Früchten, Speisen, Zuckerlösungen und besonders üppig auf Mist. Ihre genauere Kenntniss ist den Arbeiten von $\mathrm{Wo}_{0}$ ronin zu danken (vgl. Beitr. z. Morph. u. Phys. d. Pilze II). Zygosporen sind bei Mucor Mucedo noch nicht sicher gefunden worden. Aus seinem Mycelium erheben sich zuerst einfache oder mil einigen zerstreuten $\mathrm{Z}$ weigen versehene, verschieden starke Fruchttriger mil terminalen kugeligen Sporangien, die eine grosse Columella besitzen und ovale farblose Sporen bilden. Sehr oft bleibt es bei dieser Bildung. In anderen Fällen aberi treten später aus dem Mycelium Fruchthyphen liervor, welche kurze, überaus reich dichotom verzweigte Aestchen treiben und auf den Enddichotomien dieser wiederum kleine kugelige, der Colu- 
mella entbehrende Sporangien, Sporangiolen, nit 2 bis wenigen Sporen entwickeln. Die sporangiolentragenden Zweige entspringen entweder an den Seiten eines Fruchtfadens, der mit einem gewöhnlichen grossen Sporangium endigt, einzeln oder in Wirteln, die dem blossen Auge als weisse, kaum stecknadelkopfgrosse Kügelchen erscheinen; seltener nehmen sie das Ende der Fruchthyphe ein und diese entbehrt dann des grossen Sporangiums. Die sporangiolentragende Form ist unter den Namen Thamnidium elegans Lk. und Ascophora elegans Corda (Icon. III, 14) beschrieben und abgebildet. Zwischenformen zwischen ihr und dem nicht sporangiolentragenden Pilze finden sich nicht selten unter den typischen. Bei dem auf Mist wachsenden Mucor Mucedo tritt zuletzt, wenn die Sporangien- und Sporangiolenbildung nachlässt, eine drilte Form von Fruchtträgern aus dem Mycelium hervor, die als Conidienträger bezeichnet werden soll und von Berkeley und Broome (Ann. Magaz. nat. hist. 2d Ser., Vol. 13) zuerst als Botrytis Jonesii, von Fresenius (Beitr. z. Mycol. p. 97) unter dem Namen Chatocladium beschrieben worden ist. Es sind aufrechte, schlanke Schlauche, die auf einer Iöhe von etwa ö-6 Millim. einen oder einige in geringen Abstïnden übereinander stehende Wirtel von zwei bis sechs

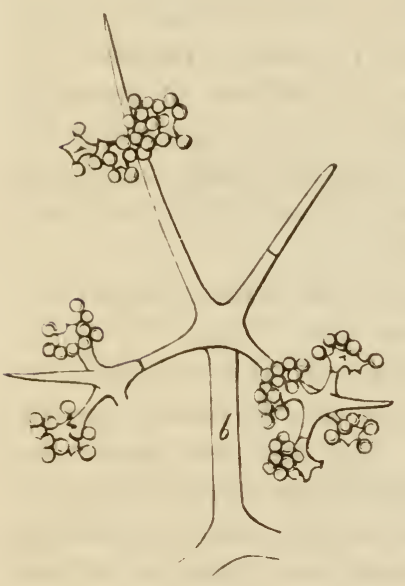

Fig. 72 .

abstehenden Aesten tragen. Diese Aeste erster Ordnung tragen etwa in ihrer Mitte durchschnittlich drei wiederum wirtelig gestellte secundiare Zweige, deren jeder in seiner Mitte abermals zwei bis drei Wirtelistchen triggt. Die Enden der Zweige zweiter und dritter Ordnung laufen meistens in pfriemenförmige Spitzen aus, die Zweige der dritten Ordnung aber tragen wiederum unter der Spitze einen Wirtel von drei und mehr kurzen Aestchen, deren jedes drei bis funfzehn und zwanzig kugelige Sporen - Conidien - simultan abschnüt. Die Enden der tertiaren Zweige tragen öfters gleichfalls statt der pfriemenförmigen Spitze einen ebensolchen Sporenstand. Einzelne Abweichungen von dem angegebenen Verzweigungsschema finden sich nicht selten Fig. 72). Sporangien oder Sporangiolen sind auf den Conidientrigern nie gefunden worden.

Die Keimung aller drei Sporenformen erfolgt leicht nach Aussaat in eiweisshaltige Zuckerlösung, Fruchtsäfte, schwer und bei den Conidien gar nicht in destillirtem oder Trinkwasser. Bei genau controlirten, auf dem Objectträger lückenlos beobachteten Aussaatversuchen keimten alle drei Sporenformen mit Schliuchen, die sich rasch zu einem reichästigen Mycelium entwickelten, und dieses trieb alsbald Fruchthyphen mit Sporangien, Sporangiolen oder intermediaren Formen. Auch aus den Conidien erwuchs nur sporangientragendes Mycelium. Diese Culturresultate setzen somit ausser Zweifel, dass die drei beschriebenen Fruchtformen dem Entwickelungskreise der nämlichen Species

Fig. 7z. Mucor Mucedo, Stück eines Conidienträgers, 200 fach vergr., nach einer Zeichnung von M. Woronin. $b$ Ast zweiter Ordnung. 
angehören. Mucor Mucedo besitzt noch eine vierte Form hier zu erwihnender Organe, welche schon 1838 von Berhele! Magaz. of Zoolog! and Botany Yol. II, p. 310), neuerding von Bail Flora 18:5, p. 117) und Zabel Mélanges biol. Acad. St.-Pétershourge, Tom. III beschrieben sind, und lier Brutzellen heissen mögen. An alten Mỵcelien nämlich, oder an solchen, wo durch mangelhafte Ernihrung, Luftabsperrung und dergleichen die sporenbildung gehindert wircl, grenzen sich kurz-crlindrische, mit homog̣enem Protoplasma dicht erfuillte Stücke durch Querwände zu besonderen Zellen ab. Diese behalten cylindrische Gestalt oder schwellen zu Ei- oder fast Kugelform an. Sie entstehen einzeln oder reihenweise entweder in der Continuitiat der Fiden oder den Zweigenden: wo letzteres der Fall ist, stellen sie oft lange, einfache oder verästelte rosenkranzförmige Reihen dar, deren Glieder verbunden bleiben oder sich schliesslich von einander trennen. In eine geeignete Flussigkeit, z. B. Zuckerlösung gebracht, waclısen diese Zellen, keimenden Sporen gleich, sofort zu einem normal fructificirenden Ifycelium aus. Ebensolche, und zwar interstitielle Brutzellen hat Coemans bei Jueor Yucedo M. vulgaris Coem.) und Rhizopus nigricans gefunden und Chlamỵdosporen genannt. Spicilige mycologique Nr. i, ex Bullet. acad. Belg̣. 2e Sir.. Tom. XYi, Mr. 8.

Zu den unzweifolhaft mit mehrerlei Fruchtformen versehenen Mucorinen gehört ferner der von Tulasne, Sel. Fungor. Carjol. I, p. 6ł kurz erwähnte Az!gites, dessen ausführlichere Beschreibung abzuwarten ist; und vielleicht auch die wunderbare Kickxella alabastrina Coemans spicil. mycol. Nr. 3, welche jedoch noch nicht genau genu untersucht ist um ein sicheres Lrtheil zu gestatten.

Bei Pilobolus sind Organe, welehe den Brutzelien von Mucor zu entsprechen scheinen, derbwandiğe, ovale Zellen, die den Enden kurzer Irsceliumzweige aufsitzen, ron Cocmans Spicil. m!col. Ar. 6, und Woronin gefunden worden. Coemans fand ferner bei alten Culturen von Pilob. oedipus

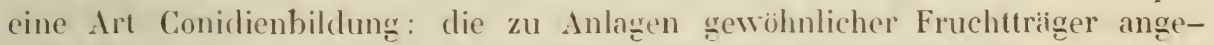
schwollenen Zweigenden des Myceliums trieben, statt zu Fruchttriggern auszuwachsen, aus ihrer Spitze mehrere faclenförmige, reich und wrederholt verzweigte Schliuche, die sich durch Querwinde in cy lindrisch-eiförmige, zulezt sich von einander trennende Glieder, Conidien, theilten Monoğr. du genre Pilobolus, p. : i . Ceber die heimung oder sonstige Weiterentwichelung dieser Organe liegen keine Entersuchungen vor. Zygosporen von Pilobolus hat vielleicht Woronin beobachtet. Auf einer über Winter eingetrockneten Cultur von P. crı stallinus auf Kulımist fanden sich kugelige grosse Zellen mit derber gelbbramer, runzeliger Aussenhaut und farbloser Innenhaut. Sic sassen auf einer blasig-obconischen Erweitcrung rertrochneter Myceliumfiden, wie die Azrgosporen von Syzggites auf ihren Suspensor, von einen zweiten Suspensor war nichts zu bemerken. Wieclerangefeuchtet tricben diese Orwane einen dicken aufrechten Keimschlauch, der sich, olıne Mrcelium zu entwickeln, direct zu (rinem typischen Sporangiumtrigger aushildete. Bei aller Achnlichkeit dieser Erscheinungen mit den von syzggites beschriebenen ist es zweifelhaft, ob es sich hier um Analoga der Zygosporen oder um derbwandige Loberwinterungsformen einfacher Sporenträger handelte. Die in den Sporangien entwickelten Sporen von Pilobolus trieben auf geeignetem Substrat zumal Mist oder dessen 
Decoct Keimschläuche, die sich direct zu einem sporangienbildenden Mṣcelium entwickeln. Man kann solche Culturen viele Generationen hindurch auf dem Objectträger machen, und Coemans hat (Monogr. p. 53) gezeigt, wie die Sporen durch Herbivoren zufällig verschluckt, noch im Darm des Thieres zu keimen beginnen, so dass auf den Excrementen alsbald die Sporangiumtriiger erscheinen. -

Für eine Reihe von Mucorinen liegt ferner eine Anzahl ganz zweifelhafter, auf Pleomorphie der Fructification bezüglicher Angaben vor. Bei Pilobolus fand Cocmans (Spicilège Nr. 6) ausser den schon erwähnten Organen erstlich »eine zweite Art von Sporangien «, relativ kleine, zuletzt morgensternförmig-stachelige endständige Zellen. Sie lösen sich zuletzt rom Mycelium los, und »bedecken sich entweder mit einem fädigen, mehr oder minder dichten Filze, scheinen jedoch dabei nicht zu keimen; oder sie treiben eine Unzahl gestielter Knöspchen, die zu farblosen Sporen heranwachsen; oder, am häufigsten, erzeugen sie endogene' Sporen " durch Theilung des Protoplasma. Die Erkliirung dieser Angaben ist von ferneren Untersuchungen zu erwarten; ich habe morgersternförmige Zellen, welche auf Coemans' Beschreibung und Abbildung zienlich gut passen, auf Mist oft beobachtet, mit und ohne Pilobolus, aber auf einem zartfädigen, farblosen Mycelium, das mit dem vom Pilobolus nur den Standort gemein hatte. Zweitens beschreibt Coemans eine zweite Form von Conidien des Pil. oedipus; sie werden auf den Astenden fächerförmig verzweigter (penicilliumähnlicher) Mṿceliunı̈ste abgeschnürt. Auch über sie sind genauere Angaben alozuwarten.

Bei Rhizopus nigricans fand Coemans eine ganze Anzahl verschiedener Organe. Erstlich neben den gewöhnlichen Sporang̣ien kleinere, - vielleicht Krüppelformen, wie solche häufig sind, oder Organe, welche den Sporangiolen von Thamnidium entsprechen. Zweitens proliferirende Sporangien, deren Beschreibung hier unterbleibt, weil sie ohne Zweifel nur alte, von einem kleinen Fadenpilze überwucherte oder durchwachsene Sporangien oder Columellen sind. Drittens Conidien, deren flüchtige Beschreibung ebenfalls vermuthen lässt, dass sie dem Rhizopus fremd sind. Viertens die schon oben erwähnten Chlamydosporen. Fünftens Pỵcniden: Spindelförmige, 1- $5 \mathrm{Mm}$. lange und bis 1/2 $\mathrm{Mm}$. dicke, manchmal auch unregelnässig gestaltete Körper, welche meist einzeln von den derberen Mrceliumfäden entspringen, mit einer vielzelligen Wand und einer axilen, conisch-cylindrischen Columella versehen und von zahlreichen kleinen Sporen (DStylosporen () erfüllt sind. Diese Organe entwickeln sich, wenn die Sporangienbildung aufgehört hat. Ihre Bedeutung muss zweifelhaft bleiben, so lange über ihre Entwickelung nichts näheres bekannt ist.

Ansichten über den Pleomorphismus der Mucorinen, welche viel weiter gehen, als die bisher angeführten, hat B a il ausgesprochen. (Ueber Krankheiten der Insecten durch Pilze. In d. Bericht der Vers. D. Naturforscher zu Königsberg. Die wichtigsten Sätze der neueren Mykologie. Nov. Act. Acad. Natur. Curios. Band 28.) Nach ihm sind Entomophthora, Achlya prolifera und Mucor Mucedo nur Formen einer Species. In Bierwürze entwickelt sich aus Mucor Mucedo Bierhefe, Hormiscium Cerevisiae, und die oben (S. 175) unbeantwortet gebliebene Frage nach dem Ursprung der Entomophthora in den Fliegen beantwortet er: wenn Hefe von Fliegen gefressen wird, bilden sich die Hefezellen im Innern 
des Thieres zu den Anfängen ron Entomophthora aus. Was die erste dieser Angaben betriff, so ist von dem vermuthlichen Zusammenhange zwischen Entomophthora und Saprolegnia oben (S. 175) die Rede gewesen. Die a priori nicht wahrscheinliche Ansicht, dass Mucor Mucedo nur eine Form von Achlya sei, gründet Bail auf die Beobachtung einer Portion Mücken, die von Entomophthora erfüllt waren, und aus denen, bei Cultur auf feuchtem Moose, überall Mucor Mucedo hervorbrach. Da die Entomophthora vor Erscheinen des Mucor schon fructificirt hatte, und letzterer ein allverbreiteter Schimmelpilz ist, berechtigt die eine Beobachtung Bails zu nichts weniger als seiner Behauptung. Mir haben viele mannigfach variirte Versuche, einen genetischen Zusammenhang zwischen Mucor und Saprolegnieen nachzuweisen, nur verneinende Resultate ergeben.

Die zweite Ansicht Bails führt auf die Frage nach der Natur und Entstehung der Alkoholg̣ilurung erregenden Formentorganismen oder He fe p il ze, eine Frage. die hicr ihre Besprechung finden mağ, da wir über den Ort, wo sie wirklich hingehört, noch im Enklaren sind. Die Bierhefe, Hormiscium Cerevisiat Bail,

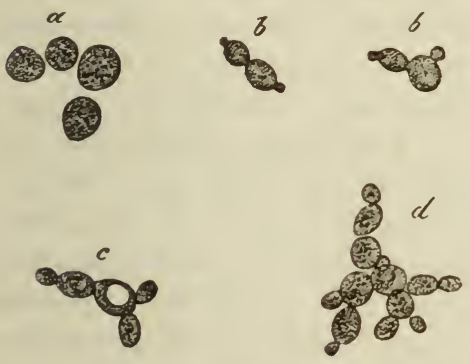

Figr. 50 (rgl. Seite 120). Cryptococeus Cerevisiae Kützing (s. Fìg. 亏̈0 besteht nach vollendeter Gïhrung aus rundlichen, mit einzelnen linglich ovalen untermischiten Zellen ron durchischnittlich 1/95 Mnt. Durchmesser, dunkelm Contour, lınnggenem, einzelne kleine Körnchen enthaltendem und oft eine grössere oder zwei bis drei kleine Vacuolen unschliessendem

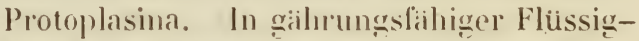
keit begrinnt an diesen Zellen die oben beschriebene "hefeartige Sprossungu und wiederholt sich eine Anzahl von Generationen hindurch. Die neu entstandenen Sprosszellen sind anfangs zirter contoururt, bliisser und zu rosenkranzförmigen, istigen Kettchen verbunden; sie nehmen allmählich das erwihnte Ansehen der älteren an und trennen sich mit dem Ende der Gährung von einander. Eine erhebliche Verschiedenheit zwischen Oberhefe und Enterhefe, und die Angabe Mitscherlichs Pogagend. Ann. Bd. ə̈9), dass sich bei ersterer die Zellen durch Bildung endogener, zuletzt aus der aufreissenden Membran austretender Tochterzellen vermehren, hat sich in neuerer Zeit nicht bestatigt. - Die Hefe des gahrenden Weinmostes (Crypt. vini Kig.) finde ich durch kleinere, zartere, ovale und an beiden Enden fast spitze Zellen von der Bierhefe verschieden. Aehnliche Bildungen wie die beiden genannten, durch Gestalt und Grösse der Zellen von einander verschieden, finden sich bekanntlich in organischen Flüssigkeiten sehr verbreitet und sind unter den Gattungsnamen Torula, Hormiscium, Crỵptococcus (Kützing spec. algar.) u. s. w. beschrieben. Auch die Mycodermen Pasteur's schliessen sich hier an.

Ueber die Natur und Entstehung dieser Organismen herrschen zweierlei Ansichten, welche vorzugsweise für die Bier- und die Mosthefe discutirt worden sind. Die Einen betrachten die Hefepilze als Organismen sui generis, welche in den gährungsfihigen Flüssigkeiten aus ihren eigenen, specifischen Keimen entstehen (Schwann, Pasteur). Die ailtere, unter den Phytotomen noch ron 
Schleiden und v. Mohl vertretene Ansicht, nach welcher die Hefezellen durch freie Zellbildung elternlos in den gaihrungsfihigen Flüssigheiten entstehen sollen. ist nach dem heutigen Stande der Kenntnisse so lange für widerlegt zu betrachten, bis jene freie Zellbildung unter dem Mikroskop direct verfolgt worden ist. Nach der anderen Ansicht, welche Bail, H. Hoffmann, Berkeley vertreten, sind die Hefepilze nur Zustainde, besondere in den gạhrungsfähigen Flüssighkeiten entstehende Sporenformen oder Sprossungen von Pilzen, zumal Schimmelpilzen, welche an der Luft in anderer Gestalt fructificiren. Sie entstehen nach diesen Autoren gleichfalls aus Sporen oder keimen, sei es aus Hefezellen selbst, sei es aus den anderen, an der Luft gebildeten Formen, wenn diese in die Flüsigkeit gelangen. Eine dritte von Karsten (Bot. Zlg. 1848, p. 4ä ) vertretene Ansicht, nach welcher die Hefezellen aus Blischen entstehen, welche als normale Bestandtheile in den Zellen des Fleisches saftiger Früchte gebildet werden, hat von keiner Seite Bestaitigung gefunden.

Die Bail-Hoffmann'sche Ansicht wird von ihren Vertretern in rerschiedener Weise ausgeführt. Nach Bail »keint Mucor Mucedo in Bierwürze zu Bierhefe aus, die Weinhefe aber ist hauptsichlich das Keimungsproduct ron Botrytis acinorum Pers. ( $(=\mathrm{B}$. cinerea P.). Berkeley erklärt )die Hefe für nichts weiter, als einen besonderen Zustand einer Penicillium-Species, welcher einer fast unendlichen Vermehrung fähig ist, ohne je vollkommene Frucht zu tragen.« H. Hoffmann nimmt an, dass sehr vielerlei Pilze in Flüssigkeiten Hefezellen bilden können, Penicillium glaucum aber und Mucor Mucedo sind ihm rorzugsweise Hefeerzeuger. Zweierlei Versuche wurden zum Beweise dieser Ansichten angestellt. Erstlich Aussaat der typischen Sporen genannter Pilze in gailırungsfähige. Flüssigkeit unter möglichstem Abschluss der Luft: nach Bail sprossen hierbei aus den Brutzellen von Mucor Mucedo, nach Iloffnann aus den Keimschläuchen von Penicillium gährungerregende Hefezellen hervor. Ich habe mir viele Mithe gegeben, diese Versuche zu wiederholen, konnte aber niemals eine Bestitigung der genannten Resultate erhalten; weder bei Culturen auf dem Objectläger, noch bei solchen, die in grösserem Maassstabe, in Reagenzröhrchen, nit möglichst reinem Material künstlich dargestellten Lösungen und Weinmost, Sporen von Penicillium, Incor Mucedo, Botrytis cinerea u. a.) angestellt wurden. In fast allen diesen Versuchen erfolgte normale Keimung, ohne Hefebildung und ohne Gährung, bei Luftabschluss auch ohne Fructification. In einigen Fällen wo Hefezellen aufraten war es nicht möglich, einen genetischen Zusammenhang derselben mit dem ausgesieten Pilze nachzuweisen. Ich muss daher die Richtigkeit der in Rede stehenden Angaben bezweifeln, um so mehr, als bei solchen Intersuchungen zweierlei Fehlerquellen schwer zu beseitigen sind. Einmal ist es nämlich unbestritten, dass wirkliche gährungerzeugende Hefezellen überall verbreitet sind, daher leicht mit den gesäeten Sporen in die Versuchsflüssigkeit gelangen und Täuschungen reranlassen können. Zweitens gibt es, wie oben (Seite 119) theilweise erwahnt wurde, eine Anzahl von Pilzen, welche hefeähnliche, aber nicht Gährung erregende Sprossungen treiben, theils aus ihren Sporen, wie besonders Exoascus, theils aus dem Mycelium. Letzteres gilt besonders von einer ungemein häufigen, an die Dematieen respective Sphaeriaceen sich anschliessenden Pilzform, die ich, um einen Namen zu haben, Dematium pullulans nennen will (Fig. 73). In 
Zuckerlösung, auch in Wasser, sprossen aus den farblosen, ästigen und septirten Myceliumfäden dieses Pilzes ovale Zellchen in Menge hervor, theils auf den Enden kurzer Zweige, theils an den Seiten. Sie schnüren sich ab und vermehren sich genau wie Hefezellen. Zuletzt, wohl nach Verbrauch des vorhandenen Nahrungsmaterials, theilen sich die Myceliumfiden durch Querwinde in Glieder, welche so lang als breit sind, zu rundlicher Form anschwellen, eine dicke zweischichtige, braune Membran erhalten und im Innern Oeltröpfchen aussondern. Die frei liegenden Sprosszellen zeigen unter den gleichen Bedingungen die gleichen Verïnderungen. Wiedterum in geeignete Fluissigkeit gebracht, treibt jede cinzelne bráunhiutige Zelie, auch nach langem Ruhezustande, einen Keimschlauch, der sofort, oder nachdem er wiederum zu einem verzweigten Faden ausạcwachsen
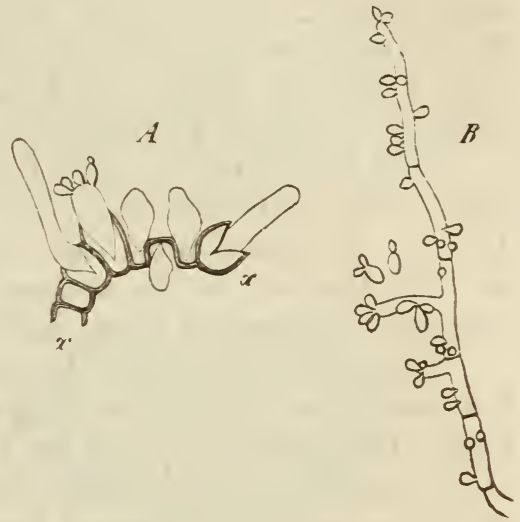

Fig. 73 . ist. die Abschnürung ron neuem beginnt. Jie hefeartigen Zellen des Dematium erreichen bedeutende Grösse und nehmen dann cylindrisch-lingliche Form an; oft wachsen sie selbst zu langen septirten IIyphen aus. Viele bleiben jedoch kleiner, und solche sammt ihren secundïren Sprossen sehen ïchter llefe tiuschend ähnlich. Alkoholgährung wird durch das Dematium nicht erregt. Die farblosen, abschnürenden Fiaden des Dematium sehen Mrcelfaden von Penicillium oder Botrytis cinerea so ihnlich, dass sie, zumal bei geselligem Vorkommen, leicht mit ihnen verwechselt werden können, und bei der grossen Häufigkeit des in Rede stehenden, bisher nicht klar unterschiedenen Pilzes dürfte eine solche Verwechselung den Angaben von Hefeabschnürung durch Penicillium u. s. f. zum Grunde liegen. Nach den hefeahnlichen Gebilden und Pilzsporen zu urtheilen, welche man auf der Oberfliche lebender Pflanzen, vielfach findet, ist es wahrscheinlich, dass die beschriebenen Erscheinungen nicht dem Dematium pullulans allein, sondern auch anderen, mit ihm rerwandten Formen zukommen.

Die Sprossungen, welche Bail an den Mucor-Brutzellen entstehen und sich abgliedern sah, haben nach seinen eigenen naturgetreuen Darstellungen mit ächter Bierhefe nur geringe Aehnlichkeit und sprechen nicht für die Ahkunft der letzteren von Mucor Mucedo.

Dic zweite Reihe von Versuchen prift, in umgekehrter Richtung wie die bisher erwihnten, die Frage, was aus den Hefezellen wird, wenn sie in anderen Medien als einer gährungsfihigen, von der Luft abgesperten Flüssigkeit cultivirt werden. Sie haben znmeist kein sicheres positives Resultat ergeben, besonders wenn man bedenkt, dass die oft beobachtete anscheinende Streckung

Fig. 73. Dematium pullulans. $A x x$ Stiick einer Reihe braunhäutiger Zellen, in Zuckerlösung Schläuche und zum Theil hefeartige Sprossungen treibend. Vergr. 390 .

$B$ Stuick eines mit hefeartigen Sprossen bedeckten in Zuckerlösung vegetirenden Fadens. Vergr. gegen 200 . 
der Hefezellen zu cylindrischen, den Anfängen von Myceliumfiden ähnlichen Schläuchen gar zu leicht auf einer Verwechselung ächter IIefe mit beigemengten hefeähnlichen Zellen beruhen kann. Berkeley gibt an, er hahe Hefezellen an der Luft direct zu fructificirendem Penicillium glaucum auswachsen sehen; Anderen und mir selbst ist dies nicht gelungen, und bei der Allverbreitung des Penicilliunı glaucum einerseits und andererseits der Leichtigheit, mit welcher seine keimenden Sporen mit Hefezellen verwechselt werden können, hat eine derartige vereinzelte Beobachtung wenig Beweiskraft.

Nach Bail würden sich die llefezellen, wenn sie von Fliegen gefressen werden, weiter ausbilden, und zwar entweder zu Mucor oder Entomophthora oder Achlya. Die Beobachtung eines derartigen Entwickelungsganges begegnet aber zu vielen Quellen von Täuschungen und Irrthümern, als dass derselbe nach den dermalen vorliegenden Thatsachen für erwiesen betrachtet werden dürfte.

Nach allem dem bedarf die Frage nach der morphologischen Bedeutung der Hefe und vieler hefeähnlicher Zellen zu ihrer hlaren Lösung noch fernerer sorgfaltiger Untersuchungen, und zur Zeit ist es geboten, diese Gebilde für Organïsmen sui generis zu betrachten. Ihr Zusammenhang mit typischen Pilzen bleibt allerdings nach den bekannten Thatsachen ron hefeartiger Sprossung an solchen (Dematium, Exoascus) in hohem Grade wahrscheinlich.

\section{Litteratur}

über Entstehung und Morphologie der Hefe.

Die ältere Litteratur findet sich in den zu nennenden Arbeiten.

Bail, Ueber Hefe. Flora 1857, p. 417; und in den oben (pag. 180) citirten Arbeiten.

Berkeley, Introduction to crypt. Botany, p. 242 u. 299. Berkeley u. Hoffmann, in Morton's Cyclopaedia of Agriculture, Art. Yeast (nach Berkeley's Citat).

H. Hof fman n, Mycolog. Studien über die Gährung. Bot. Ztg. 1860, p. 41. Idem, in Comptes rendus, Tom. LX (1865).

L. Pasteur, Mémoire sur la fermentation alcoolique. Ann. Chim. et Phys. Tome

- LVIII (1860).

Vgl. auch Tulasne, Fungor. carpol. 1, p. 154 und meine oben (S. 75) citirte Arbeit uber Exoascus.

John Lowe, Development of the Yeast plant. Ann. Mag̣. Nat. hist. 2d Ser. Vol. XX, p. 304.

\section{Uredineen.}

Einen reichen und jedenfalls unter allen Pilzen den bestbekannten Pleomorphismus und Generationswechsel zeigen die Uredineengattungen Puccinia und Urom yces oder doch die Mehrzahl ihrer Arten, wie Puccinia graminis P., P. Tragopogonis Gd., Uromyces appendiculatus, U. Phaseolorum u. a. In. Die Entwickelung dieser pflanzenbewohnenden Parasiten schliesst im Spätjahr ab mit der Bildung derbwandiger Sporen, die ich T ele u to s p ore n nenne, welche auf dem Ende fadenförmiger Sterigmen einzeln (Uromyces) oder paarweise übereinander Puccinia) gebildet werden und sich von den Sterigmen nie spontan lostrennen. Nach Ueberwinterung keimen die Teleutosporen, indem jede ein Promycelium treibt, welches meist drei his vier Sporidien bildet. (Vgl. S. 151, 
Fig. 61). Die Sporidien treiben sofort kurze Keimschläuche, und diese dringen, auf eine geeignete Nähpflanze gelanğt, die Wände der Epidermiszellen durchbohrend in das Parenchym ein, um hier sofort zu einem Mycelium heranzuwachsen. Nach durchschnittlich acht bis zehn Tagen beginnt an diesem die Bildung neuer, unter der Epidermis des Wirthes entstehender und durch diese zuletzt nach aussen hervorbrechender Fructificationsorgane: der A e c i di e n und ihrer constanten Begleiter, der Spermogonien. Dic letzteren, von deren Bau oben S. 168, Fig. 7 I die Rede war, erscheinen zuerst. Rings um eine Gruppe von Spermogonien oder ordnungslos zwischen diesen zerstreut treten später die Aecidien auf. Als erste Anfinge dieser findet man in den Intercellularriumen des subepidermalen Parenchyms dichte, aus verfilzten Myceliumfaden gebildete Geflechte mit lufthaltigen Interstitien, anfangs kaum grösser als eine Parenchymzelle, allmählich an Lmfang zunehmend und die umgebenden Elemente des Parenchỵms verdraingend. Von dem Centrum gegen den Lnfang hin fortschreitend nehmen die einzelnen Zellen der anfangs schmal erlindrischen Fäden, aus denen das Gefleclit besteht, an Umfang derart zu, dass dieses allmählich das Ansehen vines Pseudoparenchỵms oder Merenchyms erhält mit runden oder ovalen, zartwandigen wasserhellen Zellen und engen lufthaltigen Interstitien. Dieser Merenchymkörper im $\mathrm{We}_{\mathrm{C}}$ sentlichen das von mir früher so genannte Perithecium darstellend bleibt ring̣s umgeben von cinem (ioflechle gewöhnlicher und in seine iusseren Elemente continuirlich übergehender Iỵceliumfaiden. Es liegt mit seiner einen Seite Scheitel nahe unter der Epidermis des Wirthes. seine entgeggengesetzte Seite Grund ragt tief in das Parenchỵm hinein Fig. it. A. Seine Gestalt ist kugelig oder von dem Scheitel nach dem Grunde hin abgeplattet. In dem Grunde des Merenchỵmkörpers, und zwar in der Fläche wo dieser an das umgebende Mycelium grenzt, tritt nun das Hrmenium

Fig. 74. Aecidium. A (Vergr. 100) Aecid. der Puccinia Tragopogonis Cord. Jugendlicher Entwickelungszustand: Herenchymkörper, der dunkle Streif in seinem Grunde bezeichnet die Region, in der später das Hymenium auftritt. $B$ (Vergr. 90) Aecidium von Lromyces (appendiculatus?) auf Trifolium repens, dünner Längsschnitt durch einen reifen offenen Becher. $h$ Hülle oder Pseudoperidie. In $A$ u. $B$ ist $e$ Epidermis, $p$ Parenchymzellen der Nährpflanze. $C$ Von Puccinia graminis, 390 fach verg̣r. Umrisse von 3 Basidien $(s)$ aus dem Grunde eines Bechers, mit Sporenketten auf ihrem Scheitel. 
auf: eine kreisförmige, seltner unregelmässig gestaltete, lückenlose Schichte kurz cỵlindrisch-keulenförmiger, senkrecht geqen den Scheitel gerichteter Basidien, deren jede eine einfache lange Reihe von Sporen in basipetaler Folge abschnürt (Fig. 74, $C_{j}$. Die Sporen sind rundlich-polyedrisch, seltner oval, und von dichtem, durch rothgelbes Oel gefärbtem, seltner farblosem Protoplasma erfüllt.

Das Hymenium und die von ihm ausgehenden Sporenreihen werden umgeben von einer häutigen, aus einer einfachen Zellschicht bestehenden Hülle (Peridie, Pseudoperidie, Paraphysenhülle), deren Zellen reihenweise geordnet sind, wie die Sporen, und welche gleich den Ketten der letzteren und mit denselben Schritt haltend dadurch wächst, dass ihr vom Grunde aus fortwihrend neue Elemente hinzugefügt werden. Eine den Rand des Hymenium einnehmende ringförmige Reihe von Bildungszellen, gleichsam Basidien, vermittelt dieses Wachsthum. Die Zellen der Hülle stehen seitlich mit einander in lückenloser Verbindung, die obersten neigen und schliessen iber dem Scheitel der Sporenketten zusammen. Alle haben polyedrische Form und sind von den Sporen unterschieden durch betrichtlichere Grösse, stärker verdickte, oft sehr zierliches Stäbchẻngefïge $(\mathrm{rgl}$. Seite 127) zeigende Wand und spärlich körnigen oder ganz wasserhellen, zuletzt oft luftführenden Inhalt. Schon aus dem Mitgetheilten geht hervor, dass die Hülle ein Theil des Sporenlagers ist, gleichsam aus einer peripherischen Schichte steriler Sporen gebildet wird. Sie tritt ğleichzeitig unit dem Hỵmenium oder vielleicht schon kurz vorher auf. Durch die stete Nachschiebung neuer Elemente vom Grunde aus und die Vergerösserung der angelegten nịmmt das Sporenlager mit seiner Hülle an Unfang zu und drängt sich in den Merenchymkörper ein. Sein Wachsthum in die Dicke drückt die Zellen des letzteren oft bis zur Unkenntlichkeit zusammen. In Folge seiner Verlängerung wird erst der Scheitel des Merenchỵkörpers durchbohrt, dann die Epidermis der Nihrpflanze durchrissen, das Lager tritt iber diese hervor und wïhst. wenn es vor Verletzung geschützt ist, durch stete Yeubildung rom Grunde aus, zu einer bis I Mm. langen, sporenerfüllten Röhre heran. Nach Durchbrechung der Epidermis trennen sich die Zellen der Ilülle im Scheitel von einander, diese wird becherförmig geöflnet Fig. $74, B$, die obersten reifen Sporen fallen aus, und dieses Zerfallen der Hülle und der Sporenketten schreitet gegen den Grund des Lagers fort, rascher im Freien und bei wechselnder Feuchtigkeit der Umgebung als an sorgfillig geschützten Culturexemplaren.

Die Accidiumsporen sind rom Augenblick der Abschnürung oder Reife an keimfihig und treiben bei der Keimung gekrummte, einfache oder ästige Schliiuche, welche in die Spaltöfnungen der Nährpflanze eintreten, um in deren Intercellularriumen rasch zu einem Mycelium heranzuwachsen. Nach wiederum sechs bis zehn Tagen bildet dieses von neuem Fruchtlager, welche als Uredo bezeichnet werden: flache, rundliche, aus verfilzten Hỵhen bestehende Polster, dicht unter der Epidermis liegend, und auf ihrer ganzen dieser letzteren zugekehrten Oberfläche mit fadenförmigen Basidien bedeckt, welche je eine runde oder längliche Spore abschnüren (Fig. 53, u). Mit der Sporenbildung durchbrechen die Lager die Epidermis. Die Uredosporen (Stylosporen Tulasne) keimen wie die Aecidiumsporen, und ihre Keimschläuche treten gleichfalls durch die Spaltöffnungen in die Nährpflanze. Das aus ihnen entstandene Mỵcelium 
bildet wiederum nach sechs bis zehn Tagen Fruchtlager und zwar immer nur wieder Lredo: sie reproduciren also immer wieder die gleiche Form der Species. Die Uredosporen nehmen daher in geometrischer Progression an Menge zu, und vermöge ihrer hierdurch bald ins Lngeheure wachsenden Anzahl sowie ihrer hohen Keimfihigkeit sind sie vorzugsweise die Organe, durch welche die massenhafte. und schnelle Verbreitung der Lredincen erfolght. Das nämliche Mycelium, welches die Credo er'zeuğt, bildet zuletzt wiederum Teleutosporen, entweder

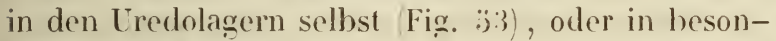
deren Hymenien. Bei den beschriebenen Arten treten somit, abgesehen von den Spermoyonien, vicrerlei Fortpflanzungsorgane und Sporenformen theils in regelmassiger sucersion, theils in strengem Generationswechsel auf. Manchmal, aber keineswegs constant, kommt dabei noch der Fall vor, dass das aus den Sporidien entstandene $\mathbf{H y -}$ celium nach Reifung der Aecidien noch Lredo- und Teleutosporenlager erzeugt.

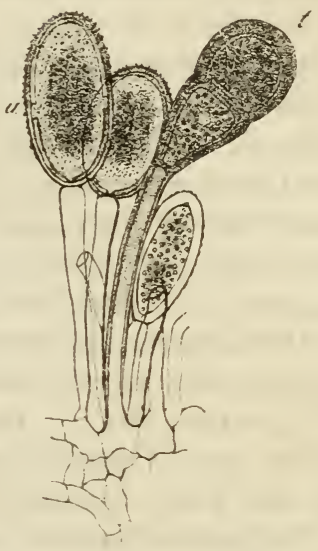

Fig. 53 ( $r g l$. Seite 12 $\checkmark$ ).

Es braucht kaum bemerkt zu werden, dass die Orọane, welche dermalen Uredo, Aecidium genannt werden, fruherhin für Reprisentanten besonderer Arten, resp. Gatlungen betrachted wurden, und dass ihre Namen ursprünglich zur Bezeichnunğ dieser Formgenera dienten, wihrend die Benennungen Puccinia, Lromsces für die Teleutosporen allein galten. Der Höhepunkt des beschriebenen Entwickelungsganges wird unstreitig durch das Arecidium bezeichnet, da dieses Organ, auch abgesehen von der steten Beggleitunğ der Spemogonien, von allen anderen durch Complication des Banes und der Bildungageschichte ausgeroichnet ist.

Fiur die meisten Genera der Uredincen sind durch Tulasne's C'ntersuchungen Uredo, Teleutosporen und Sporidien nachgewiesen, welche, bei aller Mannigfaltigheit der ainzelnen morphologischen Verhiltnisse, mit den oben beschriebenen in ihren wesentlichen Ëigenschaften, besonder's auch den Keimungserscheinungen, vollkommen ibbereinstimmen. Forner ist eine nicht unbetrichtliche Anzahl von Aecidien behannt (den früheren Formgenera Aecidium, Roestelia, Peridermium ang̣ehörend), deren Entwickelungszusanmenhang zwar noch nicht sicher ermittelt, aber, nach dem durchaus ubereinstimmenden Bau und der gleichen Keimungsart zu urtheilen, gewiss ein ähnlicher ist, wie bei den beschriebenen Puccinien. Es ist daher kaum zu bezwoifeln, dass den meisten Uredineengattungen der für die letztğenannten dargestellte Entwickelungsgang weleher seinen Gipfelpunkt mit den Aecidium erreicht, eigen ist. Bei der grossen Anzahl und Mannigfaltigkeit der einzelnen Arten ist allerdings schon von vornherein zu vermuthen, dass in dem Verlaufe dieses Entwickelungsganges mancherlei Modificationen und Variationen vorkommen werden, und eine Anzahl solcher kennt man bereits. So erstlich das Vorkommen von Spermogonien als Beggleiter der Lredo- und Teleutosporenlager, z. B. bei Puccinia Compositarum (Credo suaveolens . P. Anemones u. a. Das Vorkommen von Teleutosporen- 
lagern ohne Uredo bei bestimmten Arten (z. B. Puccinia compacta, P. Dianthi u. s. f.). Ferner ist durch Tulasne bekannt, dass die Teleutosporen sowohl bestimmter Genera (Coleosporium, Podisoma, Cronartium), als auch einer Anzahl von Puccinia-Arten, unmittelbar nach der Reife und ohne zu uiberwintern ein sporidienbildendes Promycelium trieben. Bei einer dieser Arten, der Puccinia Dianthi DC. , treten die Sporidienkeime durch die Spaltöffinungen in die Nährpflanze ein und wachsen sofort zu einem Mycelium heran, welches wiederum neue Teleutosporenlager erzeugt. Weder Uredo noch andere Entwickelungsglieder konnten bei dieser Art bis jetzt aufgefunden werden. Podisoma Juniperi Sabinae hat nach Oersteds Untersuchungen den oben beschriebenen Entwickelungsgang (sein Aecidium ist die Roestelia cancellata Rebent.j, aber ohne Uredo.

Die bemerkenswertheste Ausnahme von dem oben beschriebenen Entwickelungsgange macht jedenfalls die Gattung Endophỵllum (E. Sempervivi Lév. und E. Euphorbiae (B!.). Die Aecidien dieser Pilze, denen der übrigen Genera in Structur und Entwickelung völlig gleich, bilden Sporen, welche unmittelbar nach der Reife keimfähig, ein sporidientragendes Promycelium treiben. Aus den die Epidermiszellen der Nährpflanzen durchbohrenden Keimschliuchen der Sporidien entwickelt sich ein Mycelium, das nach Jahresfrist wiederum Spermogonien und Aecidien bildet. Die Entwickelung der Uredo - und Teleutosporen fehlt gïnzlich, sie wird gleichsam übersprungen.

\section{Litteratur.}

Unger, Die Exantheme d. Pflanzen. Wien 1833.

Die übrigen älteren Arbeiten sind in den sogleich zu nennenden aufgezählt.

Lé veillé, Sur la dispos. des trédinées, Ann. sc. nat. 3e Sér. Tom. Ylll. u. Artikel Urédinées in d'Orbig̣ny, Dict. hist. nat.

Tulasne, Mém. sur les Lstilaginées et les Lrédinées. Ann. sc. nat. 3e Sér. Tom. VII. u. besonders Second Mémoire s. I. Urédinées et les Ustilaginées. Ann. sc. nat. 4e Sér. Tom. II.

K üh $\mathrm{l}$, hrankheiten d. Culturgewächse. Berlin 1859.

de Bary, Rech. sur les Champignons parasites. Ann. sc. nat. 4e Sér. Tom. XX. (pag. 64).

_- Inters. über d. Brandpilze. Berlin 1853.

- Ceber Caeoma pinitorquum. Monatsber. d. Berl. Acad. Decbr. 1863.

— Neue Lnters. über Uredineen. Ilbid. 1865.

\section{̈̈. Ustilagineen.}

Tilletia Caries Tul., Ustil. destruens, U. Carbo sind die einzigen Arten dieser Endophyten, bei welchen der Entwickelungsverlauf einigermassen bekannt ist. Die derbwandige Spore treibt beim Keimen ein Promycelium, welches, wie auf Seite 130 (Fig. 62, 63, beschrieben wurde, Sporidien bildet. Die feinen Keimschläuche, welche von diesen oder den durch sie abgeschnürten secundären Sporidien getrieben werden, dringen nach Kühn's und Hoffimann's Untersuchungen in die Axen der keimenden Getreidepflainzchen ein, entwickeln sich im Innern derselben zu einem Mycelium und dieses wächst mit der Getreidepflanze empor, un zuletzt in die Fruchthnoten einzutreten und hier von neuem Sporen zu bilden. 
suchungen Erfolge erwarten lassen, habe ich bei Aussaatversuchen von Coprinus erhalten. In eine kleine, in ein Uhrschälchen gebrachte, vorher längere Zeit gekochte Portion Kaninchenmist, der auch sich selbst übcrlassen nur einzelne Exemplare von Coprinus stercorarius Fr. trug, wurden Sporen des leicht erkennbaren Copr. fimetarius Fr. gesät. Schon zehn Stunden nach der Aussaat keimten sie, nach vierundzwanzig Stunden waren die Keimschliuche mit sehr zahlreichen feinen Aesten versehen, und diese durchwucherten nun reichlich den Mist, ein sehr zartes, nur mit dem Mikroskop nachweishares Mycelium bildend. Von 19ten Tage nach der Aussaat an traten die ersten Anfänge neuer Fruchtträger auf, und allmählich wurden diese sehr zahlreich und erreichten eine sehr bedeutende Grösse. Mucor Mucedo und Pilobolus, deren Sporen nachweislich mit denen des Coprinus in die Aussaat gelangten, waren die einzigen Pilzformen, die ausser der genannten Species in geringer Entwickelung in der Cultur auftraten. Von anderen Fortpflanzungsorganen als den typischen gestielten Hüten trat an dem Coprinus-Mycelium keine Spur auf. Die Versuche wurden im December und Januar im Zimmer angestellt. Spätere, zu verschiedenen Zeiten selbst auf dem Objecttriger gemachte ahnliche Culturen von Copr. fimetarius und stercorarius ergaben immer die gleichen Resultate.

Ueber das Vorkommen von anderen Reproductionsorganen als den typischen Basidien S. 111 ff.) an den ausgebildeten Fruchtttrigern sowohl als dem Mycelium liegt liur die Hymenomyceten eine Anzahl von Angaben vor. In erster Linie sind hier zu nennen die Tremellinen nit den schon oben beschriebenen Spermatien in dem Hymenium und der Promycelium- und Sporidienbildung an den keimenden Sporen, deren Entdeckung wir Tulasne verdanken (vergl. oben S. 10̈4, 16.3. O Oersted hat kürzlich „Oversigten « d. Verhandl. d. K. D. Ges. d. Wissensch. Jan. 186.3) eine schöne Darstellung von Conidien gegeben, dic - seiner Ansicht nach unzweifelhaft - dem Agaricus variabilis P. zukonmen. Kurze, unseptirte, aufrechte Fruchthyphen erheben sich von den Myceliumfiiden dieses Pilzes und schnüren auf ihrer Spitze simultan ein Köpfchen ovaler Sporen ab, nach Art ron Corda's Formgenus Cephalosporium.

Ferner ist hier zu nennen Agaricus racemosus Pers. Der aus einem Sclerolium entspringende schlanke Stiel dieses Pilzes endigt an völlig entwickelten Exemplaren in einen schirmförmigen Hut, der, den vorhandenen älteren Beschreibungen und Abbildungen zufolge, die typische Agaricinenstructur besitzt. Der Stiel ist seiner ganzen Lïnge nach mit kurzen haardünnen, abstehenden Aestchen besetzt, welche ron Fries (Epicris. p. 90) und Berkeley (Crypt. Bot. p. 36วั) mit den Fruchtträgern der Formgattung Stilbum verglichen werden, d.h. gleich diesen an ihren Enden zahlreiche, reihenweise geordnete Sporen (Coni(lien) abschnüren, die miteinander ein weich gallertiges Köpfchen bilden. An anderen Exemplaren ist die Verzweigung unregelmässiger und auch der Hauptstiel mit einem Conidienköpfchen geendigt. Die Conidien haben nach Tulasne's Untersuchung (Fung. Carpol. I, p. 110 ) ovale oder langliche Form und treiben nach Aussaat in Wasser lange Keimschläuche.

Auf den Enden kurzer Myceliumstränge ron Agaricus vu!garis Fr. sah Hoffmann Bot. Ztg. 1856, p. I 58 ) hier und da kleine cylindrische Zellchen reihenweise abgeschnürt werden, die er Spermatien nennt. Aehnliches gibt Coemans für das Mycelium von Coprinus ephemerus an (Spicilège mỹcol. Nr. ö. Bull. 
Acad. Belg. 2e Sér., T. XT, Nr. כ̈), während er gleichzeitiğ die Glieder der rosenkranzförmigen Haare anderer Coprini olıne irgend zureichenden Grund als „Conidien « beschreibt.

Ich habe Botan. Zeitg. 18\%9, p. 38\%) das Vorkommen von zweierlei Sporen in den Fruchtträgern der Fries'schen Agaricinenspecies Nictalis asterophora angegeben. Die Fruchtriger dieses Pilzes entwickeln sich nach Art der typischen gymnocarpen Agaricinen. Das lockere lufthaltige Geflecht radial divergirender zarter Fäden, welches die ganze obere Seite des Hutes bildet, entwickelt schon früh allenthalben zahlreiche sternförmige Chlamydosporen (vgl. S. 129 u. Fig. 7:3) oder Macroconidien von gelbbrauner Farbe, es stellt bei völliger Ausbildung eine bis $1 \mathrm{Mm}$. dicke, gelbbraune, endlich zerfallende Schicht dar. Auf der Lnterflïche kräftiger llüte entwickeln sich Lamellen und in diesen meist spärliche viersporige Basidien. Das Gewebe der unteren Hutseite, welches die Lamellen trägt, ist im ausgebildeten Zustande von dem des Chlangdosporenlagers durch Gestalt und Grösse seiner Zellen wesentlich verschieden. An jụngen Exemplaren dagegen besteht der Pilz aus lauter gleigchartigen II!phen, und zwischen denen der Hutunterseite und des Chlam! dosporenlagers ein continuirlicher Zusammenhang, die letzteren sind Zweige der ersteren. An anderen Exemplaren kommt dic Entwiekelung der Lamellen und Basidien gar nicht zu Stande. Tulasne gilst in den Chlamydosporenlagern noch eine dritte Form von Sporen, Microconidien, an, kleine farblose, cylindrische Zellen, welehe in langen Reihen abgeschnuirtwerden. Eine zwrite, gleich der $\mathrm{X}$. asterophora auf grösseren Igaricis, zumal Russula adusta Fr. wachsende Art, X. parasitica Fr. bildet elliptische,

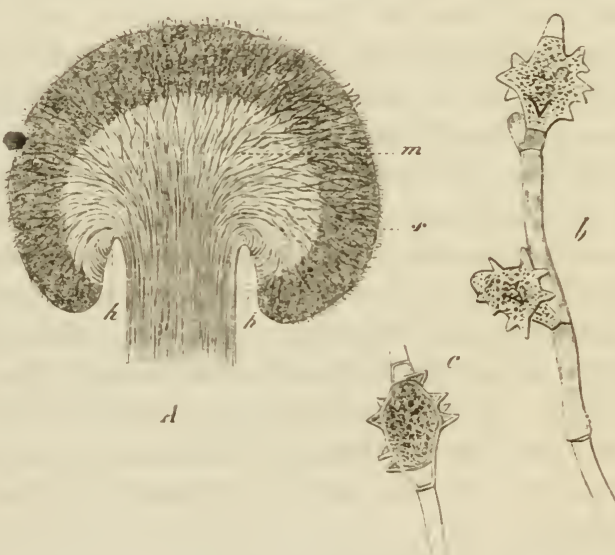

Fig. $: 5$. glatte Chlamydosporen in dem

ganzen Gewebe der dickangeschwollenen Lamellen, die ïbrigen Theile des Huts sind frei davon. Typische viersporige Basidien fand Tulasne ofters vereinzelt in denselben Lamellen mit den Chlamydosporen, in meinen Exemplaren waren sie nie vorhanden. Die Ansicht, nach welcher die Chlamydosporen Organe der Nyctalis sind, gründet sich bei beiden Arten darauf, dass die Färlen, von welchen sie erzeugt werden, ron denen des übrigen Gewebes deutlich als Zweige entspringen, was zumal an jüngeren Exemplaren unzweifelhaft zu sein scheint.

Tulasne ist (Ann. sc. nat. te Sér., Tom. XIII, p. 5) dieser Ansicht ent-

Fig. 73. Nyctalis asterophora Fr. $A$ junges Exemplar, senhrechter Durchschnitt, in durchfallendem Licht, schwach vergr. m Hymenophorum. s Chlamydosporenlager, $h \mathrm{Hy}$ meniumanlage. $b$ Hyphe mit 2 halbreifen, $c$ reife Chlamỵdospore (s. oben S. 129), beide $390 \mathrm{mal}$ vergr. 
gegengetreten. Er häl, wie schon vor ihm Corda, Bonorden und Andere (rgl. Bot. Ztg. l. c.) gethan hatten, die Chlamydosporen (nebst den Microconidien ron N. asterophora) für Organe zweier Schmarotzerpilze, welche eine besondere auf Russula u. s. f. wachsende Agaricus-Species, Ag. parasiticus, bewohnen und mehr oder minder entarten machen, und stellt diese Schmarotzer in die pilzbewohnende Sphaeriaceengattung Hypomyces, als H. asterophorus und H. Baryanus. Die Gründe für seine Meinung nimmt Tulasne von der Aehnlichkeit der beschriebenen Organe mit den gleichnamigen anderer Hypomyces-Arten her, deren Parasitismus auf Agaricinen unzweifelhaft ist; ferner von der Thatsache, welche ich bestitigen kann, dass die Chlamydosporen zuweilen auch vereinzelt auf dem Mycelium der Nyctalis entstehen, welches in oder auf der Russula wichst; und endlich von dem Vorkommen unzweifelhafter Perithecien in Gemeinschaft mit den Chlanydosporen 'auf Nyctalis asterophora. Einen Fehler in der anatomisch-entwickelungsgeschichtlichen Untersuchung, auf welche ich meine Ansicht griundete, hat er nicht nachgewiesen.

Tulasne's Ansicht hat so grosse Wahrscheinlichkeit, dass ich mir selbst viele Hühe gegeben habe, meinen Fehler zu finden, allein neuere Untersuchungen haben mir ganz dasselbe Resultat ergeben, wie die früheren. Ich ziche daher vor, mich einfach an die Thatsachen zu halten und bei meiner früheren Ansicht zu bleiben, um so melır, als ein Agaricus parasiticus, welcher nicht den einen oder den anderen Chlanydosporenapparat besässe, meines Wissens Niemandem bekannt ist; als ferner der Bau des Fruchtträgers von $\mathrm{N}$. parasitica von dem der N. asterophora so sehr rerschieden ist, dass mir die Hypothese, beide Nyctalisformen seien derselbe Ag. parasiticus, welcher durch verschiedene Parasiten verschiedene Degenerationen erlitten hat, weit gewagter vorkommt, als meine oben ausgesprochene Meinung; und als endlich diese letztere in dem oben beschriebenen Krombholz'schen Culturversuch rine entschiedene Bestätigung zu finden scheint. Wer hier Recht hat, muissen fernere Untersuchungen, zumal Culturrersuche, lehren. Möglich, dass beide Ansichten richtig sind, und die Entwickelung von Nyctalis mit der Bildung ron Perithecien und Ascis ihren Gipfelpunkt erreicht.

Einen weiteren hier zu erwähnenden Fall habe ich (Bot. Ztg. 1859, p. 401) für Agaricus melleus Fl. dan. beschrieben. An alten Exemplaren dieses Pilzes, deren Sporen grösstentheils abgefallen sind, treten auf den Lamellen sehr häufig zahlreiche, oft unregelmissig gefurchte, fein flaumige Pusteln auf, die zuletzt die ganze Lamelle bedecken und den ganzen Ilut verunstalten können. In den Pusteln findet man zwischen den ursprünglichen Gewebselementen der Lamelle zahlreiche, reich verästelte, protoplasmareiche dünne Hyphen, an denen allenthalben kleine, verkehrt eiförmige, ungestielte Asci einzeln oder gruppenweise beisammenstehend hervorsprossen. In jedem Ascus entstehen durch freie Zellenbildung vier halbkugelige Sporen mit dünner farbloser Wand, die rings um die ebene Grundflache der Spore leistenförmig vorspringt. In Wasser gesäet treiben die Sporen zwei bis vier radial divergirende kurze Keimschläuche. Die anatomische Untersuchung junger Pusteln macht es wahrscheinlich, dass die ascustragenden Hyphen als Zweige von den primären Elementen der Lamelle entspringen. Würde sich dies bestätigen, so wären die Asci unzweifelhaft eine zweite Fruchtform ron A. melleus. Nach den vorliegenden Thatsachen ist die 
Möglichkeit, dass sie einem Parasiten angehören, allerdings nicht ganz ausgeschlossen.

Kaum bezweifeln möchte ich endlich, dass die Organe, welche J. de Seynes (Ann. sc. nat. 5e Sér., Tom. I, p. 269) auf F is tulina hepatica fand und die Conidien dieses Pilzes nennt, die Sporen eines Parasiten darstellen. Dieselben werden einzeln oder in Köpfchen nebeneinander gestellt auf den Zweigenden dünner, septirter, überaus reich verisstelter Ilyphen abgeschnürt, welche nicht nur auf der oberen, wie de Seynes angibt, sondern auch auf der unteren, hymeniumtragenden Seite des Fistulina - Hutes theils oberflächlich verbreitet sind, auf und zwischen den Tubuli, theils das grosszellige Gewebe der Fistulina mehrere Millimeter tief durchwuchern. Diese Bildungen finden sich keineswegs an allen Exemplaren. Die Iyphen sind von den grossen Zellen des Fistulina-Gewehes stets durch ihre Feinheit und Verzweigungsweise ausgezeichnet, ein genetischer Zusammenhang derselben mit den letzteren liess sich an meinen Exemplaren nicht nachweisen, sie nehmen in Weingeist nicht die Missfarbe an, welche an den Elementen der Fistulina alsbald eintritt, es scheint mir somit vorläufig kein zureichender Grund vorzuliegen, sie für Organe der Fistulina zu halten.

Bei den G a strom y ceten ist der $A$ nfang der Keimung höchstens fur einzelne Fälle beobachtet (Iloffinann, Bot. Ztg. 1859 , p. 217) und von dem Entwickelungsgange nur die Bildungsgeschichte des Peridiums einigermassen bekannt. Eine Duplicitat der Fructificationsorgane nimmt Itoffmann für eine hierher gehörige Species an, insofern er die Endogone macrocarpa Tul. in den Formenkreis des Hymenogaster Klotzschii Tul. zieht (Ic. anal. fung. II, p. 33). Von den Grïnden, welehe er für die Zusammengehörigkeit beider Formen anführt, sind ihr - jedoch nur zuweilen - geselliges Vorkommen und die Aehnlichkeit des beiderseitigen Myceliums vorzugsweise zu erwähnen, jedoch noch sehr einer sorgfiiltigeren Prüfung bedürftig.

Von den

\section{Tuberaceen, On ygena}

sind nur die in früheren Capiteln beschriebenen einzelnen Entwickelungsstadien bekannt. Von dem eigenthümlichen, einfachsten Ascomyceten, dem

\section{Protomrces macrosporus}

habe ich (Beitr. z. Morph. d. P. I die Entwickelung ziemlich vollstindig verfolgen können: Die in den überwinterten $\Lambda$ scis gebildeten ejaculirten Sporen verbinden sich paarweise (vgl. oben S. $110 \mathrm{u} .161$, Fig. 41); an den Puncten der Nïhrpflanze (Umbelliferen), auf welche sie gesïet werden, findet man in die Epidermis eingedrungene Myceliumfäden, und diese bilden von neuem Asci. Eine weitere Fruchtform ist nicht bekannt.

\section{Pyrenom yceten.}

Die mannigfaltigste Reihe von Beispielen der Mehrfältigkeit der Fortpflanzungsorgane bietet, Dank den Arbeiten Tulasne's, die in der Ueberschrift genannte Gruppe dar. Erstlich findet man nicht selten, z. B. hei Cucurbitaria, Cryptospora Betulae, Pleospora, an derselben Species in verschiedenen Ascis desselben Peritheciums reife Sporen, welche bei gleicher Zahl auffallende 
Grössenverschiedenheit zeigen. Ferner wie schon oben erwähnt wurde (S. 106) in verschiedenen Ascis derselben Species eine verschiedene Zahl von Sporen, wobei gleichfalls Unterschiede in der Grösse auftreten (Valsa salicina, nivea u. a. 4, 6, selten 8 Sporen u. s. f.). Calosphaeria biformis Tul. und Cryptospora suffusa Tul. haben zweierlei Perithecien, von denen die einen Asci mit sehr zahlreichen kleinen Sporen enthalten, die anderen Asci mit vier bis sechs und acht weit stattlicheren Sporen.

Nach Berkeley (Ann. mag. nat. hist. Ser. III, Vol. 3, p. 373, pl. XI, fig. 32) finden sich bei Sphaeria oblitescens B. et Br. zwischen den Ascis einzelne Paraphysen, von denen 1 bis 2 Glieder 'zu länglichen septirten Sporen (Stylosporen im Sinne Tulasne's) angeschwollen sind, und bei Dothidea Zollingeri Berk. (Hooker's Journ. Vol. III, 1844, p. 336) solche, deren Endzellen ovalen einfachen Sporen gleichen. .Aehnliches gibt Berkeley (Introd. Crypt. Bot. p. 244) für eine Species von Tympanis an.

Ausser diesen hier und da vorkommenden Variationen in dem Inhalte der Perithecien und Hymenien sind aber, nach Tulasne's Entdeckungen, vier Arten von Reproductionsorganen zu unterscheiden, welche der Regel nach in verschiedene Behälter, Träger oder Lager vertheilt vorkommen; nämlich:

1) Conidien, acrogene, auf fadenförmigen Trägern entweder abgeschnürte oder durch Theilung ohne Abschnürung entstehende Sporen (auch zusammengesetzte Sporen), deren Träger entweder direct ron dem Mycelium oder von der Oberfliache eines Fruchtkörpers (Stroma) entspringen, sei es als freie Fruchthỵphen, sei es dass sie zu einem oberflächlichen dichten Hymenium zusammengestellt sind.

2) Stylosporen, ebenfalls acrogene, den Conidien im Wesentlichen gleiche Sporen oder Sporenkörper, gebildet im Inneren von besonderen Conceptakeln, die als Pycniden unterschieden werden. Die acrogene Bildung der Stylosporen ist meistens unzweifelhaft, für einzelne Fälle jedoch, z. B. Erysiphe, noch nicht bestimmt nachgewiesen.

3 Spermatien, in Spermogonien gebildet, von den Stylosporen und Conidien durch die anscheinende Lnfähigkeit zu keimen ausgezeichnet. Sie sind im 5̈ten Capitel genauer besprochen worden.

4) Sporen, welche in $A \mathrm{sc}$ is erzeugt werden, in Innern von Perithecien (vgl. S. 9艹, 101), als Ascosporen, Thecasporen, Endospoir non den übrigen zu unterscheiden.

Die Perithecien bezeichnen den Höhepunkt der Entwickelung, sie fehlen keiner Species, die Beobachtungen an Erysiphe (Seite 162) machen es wahrscheindass sie direct oder mittelbar aus geschlechtlicher Zeugung hervorgehen.

Von den übrigen drei Arten der Fortpflanzungsorgane ist bei manchen Species und Gattungen nur eine oder die andere beobachtet, bei anderen alle. Nicht selten kommen sogar Conidien und Stylosporen bei derselben Species in zweierlei Formen vor, die nach der Grösse als Micro- und Macroconidia etc. unterschieden werden.

Ein scharfe Sonderung von Spermatien, Stylosporen und Conidien ist, wie zum Theil schon oben angedeutet wurdé, oft schwer durchführbar und zur Zeit. nur auf Grund der angegebenen oberflächlichen Merkmale möglich.

$\mathrm{Ob}$ es Pyrenomycetenspecies gibt, bei denen immer oder in der Regel nur 
Perithecien vorkommen, bedarf noch fernerer Untersuchung; einige unten zu erwähnende Thatsachen sprechen dafür. Sicher ist es, dass auf der anderen Seite bei manchen Arten und Genera z. B. Hypomyces die Perithecien im Vergleich zu den anderen Reproductionsorganen höchst selten sind.

Die Pycniden, Spermogonien und Conidienträger der Pyrenomyceten sind vielfach seit lange bekannt und als besondere Species und Formgenera beschrieben. Die Formen, welche Fries' (Sumnia Veg. Scand.) Gruppen der Critisporacei, Sphacropsidei, Phyllostictei bilden, sind, wenn nicht alle, doch zum grössten Theile Pצ̣cniden und Spermogonien (so Naemaspora, Cỵtispora, Libertella, Septoria, Leptothyrium, Phyllosticta, Cheilaria, Gloeosporium, Spilosphaeria, Ascochyta; Phoma, Diplodia, Myxocyclus, Hendersonia, Sporocadus, Spaeropsis, Cicinobolus Ehr., Ampelomyces Ces., Byssocystis Riess u. s. f.); und was nach Abzug der Mucorini, Peronosporei und vielleicht weniger anderer Formen von den Hyphonyceten der seitherigen Systeme übrig bleibt, nebst einer grossen Zahl Gymnomyceten Fries' stellt, wie nach den vorliegenden Thatsachen mit Bestimmtheit behauptet werden kann, die conidientragen Apparate von Pyrenomyceten (und den nichstverwandten Discomyceten) vor. Bestimmt nachgewiesen ist dieses für Arten der Formgenera Gylindrosporium, Oidium, Dematium, Conoplea, Periconia, Cladosporium,--Helıninthosporium, Macrosporium, Dendryphium, Mystrosporium, Brachycladium, Sepedonium, Mycogone, Aspergillus. Verticillium, Botrytis, Antennaria, Torula, Isaria, Stilbum, Atractium, Graphium, Melanconium, Stilbospora, Steganosporium, Coryneum, Exosporium, Vermicularia, Tubercularia, Sphacelia.

Was den Entwickelungsgang betrifft, so steht zunaichst fest, dass die verschiedenen Fruchtformen auf demselben Mycelium oder sogar denselben Fruchttriger auftreten, der Regel nach in der Reihenfolge: Conidien, Spermogonien oder Microstylosporen, Pycniden und Macrostylosporen, endlich Perithecien; sei es dass alle Glieder dieser Reihe zur Entwickelung kommen (z. B. Stigmatea Tul., Fumago Tul.) oder dass eines oder mehrere fehlen (so z. B. Conidien und Perithecien einander folgen bei Nectria, Xylaria, Ustulina, Poronia, Torrubia, Claviceps Tulasne, Spermogonien oder Microstylosporen und Perithecien bei Stictosphaeria Tul., Diatr!pe Tul., Calosphaeria Tul. u. s. w.).

Die Bildung der relativen Vorformen, mit welcher die Fruchtentwickelung auf dem Mycelium beginnt, dauert in einer Anzahl ron Fällen auch wihrend der Entwickelung der spaiter auftretenden Organe ungeschwächt oder nur allmählich nachlassend fort. So findet man \%. B. auf dem Mycelium von Erysiphe anfainglich nur die reihenweise (selten einzeln) auf kurzen aufrechten Fruchthyphen stehenden ovalen Conidien, und wahrend die Bildung solcher fortwährt, treten allınihlich Pycniden Organe, deren Entwickelung hier noch unklar ist und welche sich theilweise wonigstens aus einer den Conidien gleichwerthigen Mutterzelle zu bilden scheinen) und meist fast gleichzeitig Perithecien (vergl. Seite 162$)$ auf. Mit der Vermehrung der letzteren nimmt die Conidienbildung ah. So stehen bei Pleospora herbarum, pellita, Fumago salicina reifende Conidien, Spermogonien, Pycniden und Perithecien auf demselben Mycelium, bei Valsa-Arten und Anderen Spermogonien und Perithecien (Fig. 78), bei Cucurhitaria macrospora Fig. 77), Conidien und reifende Perithecien auf demselben Stroına dicht_nebeneinander, bei Pleospora polytricha (Fig. 76), Clavariarum, 
pellita wachsen selbst die oberflächlichen Zellen der reifenden Perithecienwand zu conidientragenden Fäden aus. (Tulasne, Fung. Carpol. I, II., Tab. 26, 29, $30,31,34$ u. а.)

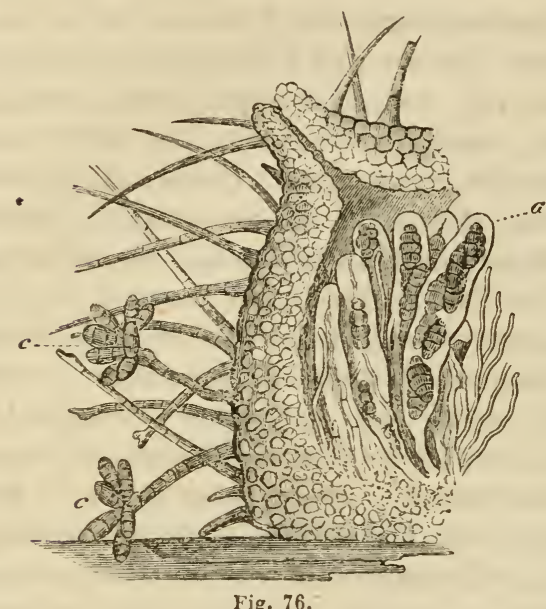

Fig. 76.

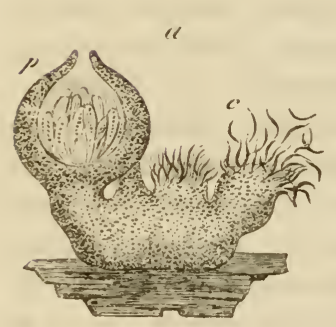

Fig. 77.

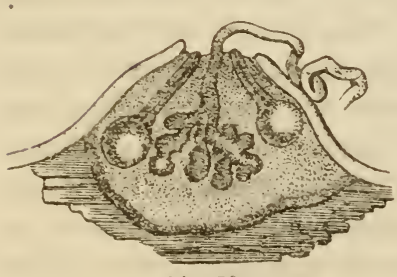

Fig. 78 .

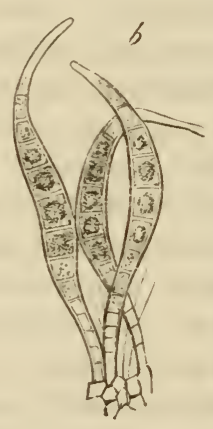
the mether Weise treten als Wortater der Perithecien und um ron diesen später verdrïngt zu werden oder mit der Ausbildung derselben zu vertrocknen, circumscripte Spermogonien von verschiedener Gestalt auf bei Tulasne's Genera Diatrype, Stictosphaeria, Calosphaeria und anderen.

Fig. 76. Pleospora polytricha (Wallr.) Tul. Dünner Durchschnitt durch ein Perithecium. a Asci. Auf der Aussenwand septirte haarähnliche Fäden, bei $c$ Conidien tragend. Vergr. etwa 125. Verkleinerte Copie nach Tulasne.

Fig. 77. Cucurbitaria macrospora Ces. u. de Not. a Stroma im Längsschnitt, schwach vergr. $p$ entwickeltes Perithecium, $c$ Conidienlager. $b$ Conidien auf ihrem Träger. Vergr. etwa 200. Copic nach Tulasne.

Fig. 78. Valsa nivea Tul. Senkrechter Durchschnitt durch ein Stroma, mitten ein Spermogonium, spermatien entleerend, beiderseits ein Perithecium. schwach vergr., nach Tulasne copirt. 
Auch Torrubia militaris ist hier zu erwähnen, bei welcher die Entwickelung der keulenförmigen Conidienträger (ssaria farinosa) auf dem Mycelium aufhört, sobald die der anderen, perithecientragenden beginnt. Und ron den einfachsten Pyrenomycetenformen möge Eurotium herbariorum mit seinen unter dem Namen Aspergillus glaucus bekannten conidientragenden Hyphen genannt werden.

In einer dritten Reihe von Fällen endlich fällt die Entwickelung der Perithecien typisch erst in die nächste Vegetationsperiode, welche auf die in welcher dic Vorformen erzeugt wurden folgt. Nachdem diese letzteren in der ersten Periode ausgebildet worden und abgestorben sind, entwickelt sich das Mrcelium weiter, bildet in der Regel Sclerotien oder ein massigges Stroma, um in der folgenden Periode Perithecien zu bilden. Dieses Verhalten findet bei solchen Arten statt, die in ter ersten Zeit ihres Lebens als ächte Parasiten in oder auf einjahrigen Pflanzentheilen leben. Polystigma rubrum bildet im Spätsommer runde rothe Flecke auf den Laubblittern von Prunus spinosa, Pr. domestica; sein Mycelium wuchert innerhalb des Blattparenchyms und erzeugt zahlreiche diesem eingesenkte, kugelig-flaschenförmige Spermogonien mit gekrümmt fadenförmigen Spermatien. An den im Herlsste abgefallenen Blaittern hat die Entwickelung letzterer Organe aufgehört, die rothen Flecke sind etwas angeschwollen und haben mit den abgestorbenen Blatt braune Farbe angenommen. Tom Ende des Winters an heginnt dann in den Flecken der auf feuchtem Boden liegenden Bliitter die Perithecienbildung. Einen ähnlichen Gang befolgat, nach Tulasne, die Entwickelung von Arten der Gattung Stigmatea Tul. Lnd unter den bekannten Fillen der exquisiteste wird von der unten zu besprechenden Gattung Claviceps geliefert.

Es braucht kaun gesagt zu werden, dass das Verhalten vieler Arten sich nicht mit aller Strenge an eines von den drei hier aufgestellten Sehemata, sondern öfters zwischen ihnen die Nitte hiilt. Auf weitere Einzelnheiten einzugehen würde aber zur Ueberschreitung der hier schicklichen Grenzen führen, es muss daher auf die anzuführende Litteratur, in erster Linie auf Tulasne's Carpologie verwiesen werden.

Der vollstandige Kreislauf der Entwickelung und die Bedeutung, welehe die verschiedenen Sporenarten in demselben haben, ist erst für iusserst wenige Pyrenomyceten bekannt. Ton etwa füfunddreissig Gattungen (die neuen Tulasne'schen mitgerechnet), welche bis jetzt genauer untersucht sind, kennt nıan, zumal durch Tulasne's Arbeiten, die Keimung aller Sporenformen Spermatien ausgenommen) und zwar meistens als ein Austreiben langer, sich verzweigender Keimschlaiuche, seltener (vgl. Seite 1:33) in Form von Promyceliumund Sporidienbildung. Ueber das weitere Schicksal der Keimschlauche sind nur die folgenden Facta bekannt.

Bei Erysiphe findet man öfters Conidien, deren Keimschlïuche sich zu cinem wiederum conidientragenden Mycelium entwickelt haben; dass dieses auch die anderen Fructificationsorgane erzeugt, ist nach dem oben Gesagten wenigstens sehr wahrscheinlich.

Aussaaten von Schlauchsporen sowohl als Conidien des Eurotium herbariorum lieferten sämmtlich wiederum ein conidientragendes Mỵcelium (Aspergillus). Perithecien kamen zwar in den Culturen nicht zur Ausbildung, entstehen aber 
spontan mit den Conidienträgern auf dèmselben Mycelium und später als diese.

Das Mycelium, welches sich aus den Conidien von Pleos por a selbst auf dem Objectträger erziehen lässt, trägt, nach Tulasne's leicht zu bestätigender Beobachtung, wiederum Conidien, und zwar dieselben zweierlei Formen, welche auf dem spontanen, perithecienbildenden Mycelium gefunden werden. Das aus den Ascosporen der Pl. herbarum erwachsende verhält sich ebenso, nur dass an ihm bis jetzt die grössere Conidienform (Macroconidia) allein gefunden wurde.

Die Conidien von Sphaeria typhina treiben in Zuckerwasser Hyphen, deren kurze aufrechte Aeste wiederum Conidien erzeugen, welche den ausgesäeten nach Entstehung, Gestalt und Grösse gleich sind.

Reine und sorgfältig gehaltene Aussaaten der Schlauchsporen von Sor daria curvula entwickelten mir zu wiederholten Malen auf dem geeigneten Substrat aus ihren sehr verästelten Keimschläuchen ein reichlich perithecientragendes Mycelium. Von Fortpflanzungsorganen anderer Art konnte ich an diesem nichts, oder höchstens sehr vereinzelte und daher zweifelhafte Conidien finden.

Eine vollstindige Entwickelungsgeschichte endlich besitzen wir, Dank den durch Durieu (vergl. Tulasne, Carpol. I, p. 144) und J. Kühn ergänzten Untersuchungen Tulasne's, für den Pilz des Mutterkorns, Claviceps purpurea und seine nächsten Verwandten. Aus den im Sommer gereiften und überwinterten Sclerotien, welche als Mutterkorn, Ergot (Sclerot. Clavus der Aelteren) bekannt sind, wachsen im kommenden Frühling auf feuchtem Boden meist je mehrere gestielt-kugelige Fruchtkörper hervor (s. Fig. 16, S. 39), deren kugeliger oberer Theil sich dicht mit halbeingesenkten Perithecien bedeckt. Die fadenförmigen Sporen, welche in diesen gebildet werden, schwellen bei Einwirkung von Wasser stellenweise an und treiben Keimschliiuche an mehreren Punkten. Bei hinreichender Feuchtigkeit in die jungen Blüthen von Granineen (Secale bei den Culturversuchen) gelangt, erzeugen die in Rede stehenden Sporen nach Kühns Untersuchungen die Mutterkornbildung,

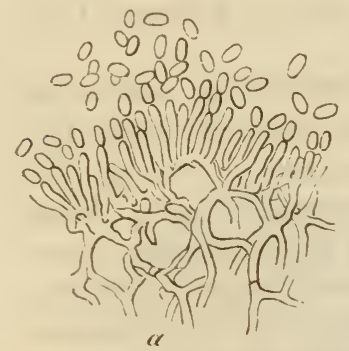

Fig. 79.

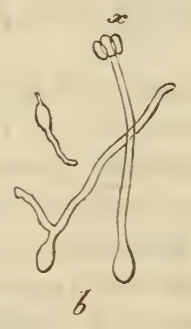
wie solche durch Tulasne's Arbeit bekannt ist; und zwar ohne Zweifel indem ihre Keimschlauche in das junge Pistill eindringen, wenn dieses auch noch nicht direct beobachtet wurde. Das vom Pilze befallene junge, zwischen den Spelzen verborgene Pistill wird zunächst iiberall durch- und überwuchert von den Hyphen des Pilzes. wie oben beschrieben wurde (S. 37, Fig. 14) und dieser bildet auf der ganzen Oberfläche ein weisses, von zahlreichen unregelmässigen Furchen und Gyri durchzogenes Hymenium (Léveillé's Sphacelia), in welchem auf cylindrischen Sterigmen Conidien abgeschnuirt werden (Fig. 79, a). Gleichzeitig mit der Bildung dieser

Fig. 79. Claviceps purpurea Tul. a Dünner Querschnitt durch das Conidien abschnürende Lager (Sphacelia), stark vergr. nach Tulasne copirt. Kühn.

$b$ Conidien keimend und bei $x$ ein Köpfchen secundärer Conidien abschnürend. Nach 
wird ein zuckerhaltiger klebriger Saft abgesondert, der in dicken, von unzähligen Conidien getrübten Tropfẹn zwischen den Spelzen hervorquillt und das Vorhandensein den Parasiten hierdurch verräth. In dem Grunde des vom Mycelium durchwucherten Pistillrudimentes beginnt nun die Bildung des Sclerotiums, welches, wie oben beschrieben wurde (Fig. 15, S. 37), zu dem bekannten hornförmigen, die Spelzen überragenden Körper heranwächst und die vertrocknende Sphacelia als eine leicht ablösbare Kappe auf seinem Scheitel trägt. Mit der Fruchtreife des Grases erreicht auch das Sclerotium seine Reife und geht in einen bis zum kommenden Frühling dauernden Ruhezustand über. Die Conidien (von Tulasne früher Spermatien, von Kühn Stylosporen genannt) treiben leicht sofort nach dem Freiwerden Keimschläuche und diese bilden auf dem Objectträger zuweilen aufrechte Zweiglein, welche von neuem Conidien abschnüren (Fig. $79, b$ ). Nach Kühn's vielleicht noch einmal zu prüfenden Angaben entwickelt sich aus den Keimen der Conidien, welche in junge Grasbliuthen gelangen, Sphacelia und Sclerotium. Wenn Westendorp Bull. Acad. Belg. 2e Sér., VII, Nr. 5゙, vgl. Bot. Ztg. 1862 , p. 266) ausser Claviceps-Fruchtträgern noch Coprinus papillatus, Trichothecium, Aspergillus angeblich aus dem Mutterkorn hervorkommen sah, so macht dies eine mangelhafte Reinheit seiner Culturen, nicht aber einen genetischen Zusammenhang zwischen diesen Bewohnern zersetzler organischer Körper und Claviceps wahrscheinlich.

\section{Litteratur.}

Tulasne, Selecta fungorum Carpologia, Tom. I, p. 46 ff. , 130, 191 ff. und Tom. II. und desselben Verfassers:

Note sur l'appareil reprod. des Lichens et des Champ. Ann. sc. nat. 3e Sér., Tom. XV (1851) p. 370.

Mém. sur l'ergot des Glumacées. Ibid. Tom. XX, p. วั.

Note sur l'appareil reprod. multiple des Hỵpoxỵlées ou Pyrénomỵcètes. Ibid. 4e Sér., Tom. V, p. 108.

Nouvelles observations sur les Erysiphes. Ibid. 4 e Sér., Tom. VI, p. 299. Bot. Ztg. 18.53, p. 257.

Note sur les Isaria et Sphaeria entomogènes. Ibd. 4e Sér., Tom. VIII, p. 44.

De quelques Sphéries fongicoles. Ibid. Tom. XIII, p. š (vgl. auch Cpt. rend. Tom. 41, p. 615 . Tom. 50, p. 16 .

v. Mohl, Ueber d. Traubenkrankheit. III. Bot. Ztg. 1854, p. 137.

B a il, Mycolog. Studien. (Nov. Act. Acad. Leop. Nat. Cur. Vol. XXIX) und de Bary, Flora 1863, p. 401 . (Sphaeria tỵhina, Poronia, Torrubia etc.)

Kü $\mathrm{h} n$, Mittheilgn. d. Landw. Inst. Halle I, 1863 (Claviceps).

Janow itsch, üb. Nectria. Bot. Ztg. 1865, Nr. 19.

J. Koch, Votum gegen das Genus Tubercularia. Bot. Ztg. 1843, p. 1 วั3.

de Bary, Ueber Eurotium u. Aspergillus glaucus. Bot. Ztg. 1854, p. 425.

Berkeley and Broome, On some facts tending to show the probability of the conversion of Asci into spores in certain Fungi. Hooker's Journ. of Bot. 1851, p. 323.

Currey, On the fructification of certain Spheriaceous fungi. Philos. Transact. Roy. Soc. Lond. Vol. 147 (1858), p. 543, pl. 24-26. 


\section{Discom yceten.}

Die Gruppen der Discomyceten, welche Fries (S. veg. Scand.) als Patellariacei, Phacidiacei und Stictei bezeichnet, stimmen, soweit unsere Kenntnisse reichen, mit den ihnen in jeder Hinsicht nahe verwandten Pyrenomyceten auch in Beziehung auf die Mehrfaltigkeit und die Succession der Reproductionsorgane so sehr überein, dass sie hier nur ganz kurz berührt zu werden brauchen. Tulasne (Ann. sc. nat. 3e Sér., XX, p. 128) hat für die Genera Tympanis, Cenangium, Dermatea, Stictis, Triblidium, Rhytisma, Hysterium, Heterosphaeria
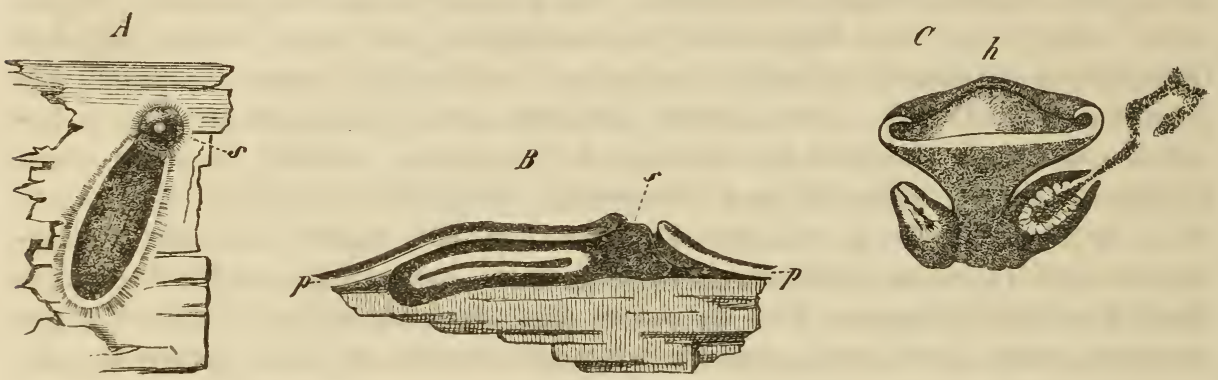

gezeigt, dass auf dem Mycelium oder Stroma successive dieselben verschiedenen Organe auftreten, wie sie für die Sphaeriaceen beschrieben wurden (vgl. Fig. 80 ), und dass die Fructification auch hier mit der Bildung des ascustragenden Hymeniums abschliesst. Als Vorliufer des letzteren sind zur Zeil für die meisten untersuchten Arten nur Spermogonien und Spermatien bekannt, von denen oben (S. 165) die Rede war, Pycniden und Stylosporen bei Cenangium, Dermatea, Stictis, Ileterosphaeria Patella. Für das Vorkommen von Ascis mit acht, und anderen, in besonderen Hymenien auftretenden, mit sehr zahlreichen viel kleineren Sporen bei der nämlichen Species liefert Stictis cinerascens P. ein Beispiel (Tulasne, Carpol. 1, p. 222). Auch für Bulgaria hat Tulasne Spermogonien und Spermatien als Vorliufer der schlauchtragenden Ilymenien nachgewiesen. Der Kreislauf der Entwickelung ist noch für keine Species der genannten Genera vollständig bekannt; ausser den Productionen des ausgebildeten Myceliums kennt man nur die ersten Keimungsanfiinge der Sjoren.

Von den stattlichsten Repräisentanten der Discomycetengruppe, den Helvellacei Fries, kennt man einen Pleomorphismus der Fruchtbildung bis jetzt nur für eine Anzahl von Pezizen. Spermatien - vielleicht mit der Zeit in Conidien umzutaufen - bei P. benesuada Tul. (s. Fig. 69, S. 166), P. fusarioides Berk., Stylosporen und Spermatien bei P. arduennensis Mont., Stylosporen bei P. graminis (vgl. oben S. 166). Sporidienabschnürendes Promycelium bei P. tuberosa, P. bolaris u. a., (vgl. S. 15\%). Zweierlei Fruchtträger, die einen mit grösseren,

Fig. so. $A$ und $B$ Triblidium quercinum P. $A$ Rindenstück eines Eichenzweiges nach Entfernung des Periderma; $s$ Spermogonium, daneben das längliche Fruchtlager. $B$ Längsschnitt durch die Triblidium tragende Rinde. $s$ Spermogonium, daneben Fruchtlager. $p$ Periderma. $C$ Tympanis conspersa Fr. $h$ Fruchtlager, unten jederseits ein Spermogonium, das eine Spermatien entleerend. Alle schwach vergr., nach Tulasne copirt. 
Keimschläuche treibenden Ascosporen, die anderen ebenfalls mit Ascis, welche kleinere und beim Keimen ein sporidienabschnürendes Promycelium treibende Sporen enthalten, bei P. Duriaeana Tul. Carpol. I, p. 104). Bei P. confluens P. Pyronema marianum Carus) beobachtete Tulasne Carpol. I, p. 74j einzelne Fruchtträger, welche statt der Asci mit reihenweise abgeschnürten cylindrischen Conidien dicht bedeckt waren - ein jedenfalls seltener, nir bei sehr zahlreichen Untersuchungen genannter Species nie vorgekommener Fall. Regelmässig kommen Conidien auf den Enden stielförmiger Träger, die sich den Stilbumformen anschliessen, bei Helotium aureum P. und Verwandten vor (Tulasne, Carpol. I, p. 130j. Eine Mehrzahl von Pezizen - P. Curreyana Berk., P. Duriaeana Tul., P. tuberosa Bull., P. Candollei Lév., P. Sclerotiorum Lib., P. Fuckeliana mihi u. a. entwickelt ihre Fruchttriger aus Sclerotien. P. Duriaeana führt in den ersten Entwickelungsstadien ein ächt parasitisches Leben; ihr Mycelium befillt lebende Carex arenaria, bildet im Innern der Halme dieser ihre Sclerotien und treibt aus diesen nach längerem Ruhezustand die Fruchtträger. P. Curreyana, welche ihre Sclerotien im Innern von Scirpus - und Juncus-Halmen entwickelt, scheint sich ahnlich zu verhalten. Dies deutet auf einen der Claviceps purpurea analogen Entwickelungskreislauf hin. Durieu vermuthet in dem Epidochium ambiens Desm. die conidientragende Form der P. Duriaeana. Für zwei andere sclerotienbildende Arten ist es mir gelungen, den Entwickelungsgang vollstiandig zu verfolgen. Bei P. Sclerotiorum ist derselbe höchst einfach. Aus den Keimschliuchen der Ascosporen entwichelt sich ein massig̣es Mycelium, welches sofort und so lange es Vahrung findet Sclerotien (Scl. compactum, varium Auctor. bildet; aus letzteren sprossen dann nach überstandener Ruhezeit wiederum neue aseustragende Fruchthörper lervor. Von Bildung anderer Fortpflanzungsorgane habe ich bei zahlreichen sorgefiltigg gehaltenen Culturen keine Spur bemerkt und hann hiernach jedenfalls bestimmt behaupten, dass solche, wenn überhaupt, dann höchst selten rorkommen.

Anders verhält sich die nahe verwandte kleine P. Fuckeliana. Ihr Sclerotium (von Fuckel als Sel. echinatum beschrieben, vergl. S. 30) bildet sich im Gewebe absterbender Blatter der Weinrebe im Spaitjahr und Winter. Bringt man es im frisch reifen Zustande oder nach einige Monate dauernder trockner Aufhewahrung auf die Oberfliche feuchten Bodess, so beginnt schon nach 24 Stunden das Austreiben conidientragender Fidlen, welche alle Eigenschaften der allbekannten und viehamigen Botrytis c incerea Pers. Botr. plebeja Fresen. Beitr. Polyactis Auctor. plurim. u. s. f.) besitzen. Säet man das Sclerotium, sei es im frisch gereiften Zustande, sei es nach mehrmonatlicher trockener Aufbewahrung einige Millimeter bis etwa $1 \mathrm{Cm}$. unter die Bodenoberfliche, so treibt es keine Conidienträger, dagegèn in dem Sommer, der auf seine Entstehungszeit folght, ascustragende, gestielt tellerförmige Becherchen. Die Fähigkeit letztere zu erzeugen dauert an :ilteren Exemplaren länger als die der Conidienbildung.

Aus den Keimschliuchen der Ascosporen erhielt ich in manchen Culturen wiederum nur Sclerotien, ohne Conidienbildung. Die letztere kann daher völlig übersprungen werden, insofern die Sclerotien direct wiederum die Ascusträger zu erzeugen vermögen. In anderen Fällen treibt das in dem Rebenblatte wuchernde Mycelium gleichzeitig mit der Sclerotienbildung oder vor und nach derselben zahlreiche aufrechte conidientragende Botrytisfiiden. Aus den Keim- 
schläuchen der Conidien sah ich, sowohl auf Rebenblätern als auf anderen pflanzlichen Organen und Substanzen, zunächst immer reichlich botrytistragendes Mycelium hervorgehen. Dass dieses, wenigstens auf den Blättern der Rebe, auch Sclerotien zu erzeugen vermag, ist kaum zweifelhaft, obgleich sichere directe Beobachtungen darüber fehlen. Es ist bekannt (vergl. S. 29), dass mehrere ungemein häufige Sclerotienformen, wie die als Scl. durum, Scl. bullatum beschriebenen, gleichfalls sowohl Botrytisfaden austreiben, als von einem botrytistragenden Mycelium ihren Ursprung nehmen, und diese Botrytis ist von dem conidientragenden Apparat der Peziza Fuckeliana nicht zu unterscheiden. Ob letztgenannte Sclerotien dem Formenkreise dieser nämlichen Species oder anderer nahe verwandter angehören, ist noch zu entscheiden. Auf den genetischen Zusammenhang der sogenannten Botrytis cinerea nit sclerotienbildenden Pezizen hat Münter, auf der deutschen Naturforscherversammlung zu Speier, zuerst in mündlichem Vortrage aufmerksam gemacht; nur hat er, irregeleitet durch die Aehnlichkeit, welche die verschiedenen hierher gehörenden Sclerotien mit einander zeigen, die Botrytis cinerea zu Peziza Sclerotiorum Lib. gezogen.

Dem Ascobolus - Mycelium werden von Coemans (Bull. Soc. Bot. Belg. I, $\mathrm{Nr}$. 1) reichliche, reihenweise abgeschnürte Conidien zugeschrieben, wovon, bei der Kürze der betreffenden Notiz und der Freigebigkeit des Verfassers mit Conidien, die Bestätigung noch abzurarten ist.

Will man auf Grund der bekannten Thatsachen allgemeine Regeln für den Entwickelungsgang der Pilze und die Bedeutung der verschiedenen Reproductionsorgane in demselben auffinden, so ist es zur Zeit geboten, sich an die genau ermittelten Fälle allein, also die Saprolegnieen, Mucorinen, Peronosporeen, Uredineen, Protomyces, Tilletia und eine Anzahl Pyreno- und Discomyceten $\mathrm{zu}$ halten, die ninder bekannten aber vorläufig ausser $\Lambda$ cht zu lassen. Fernere Untersuchungen werden dann zu entscheiden haben, ob die gegenwärtig festzustellenden Regeln allgemein anwendbar sind.

Bei den genauer bekannten Gruppen finden wir überall e i ne Form der Fortpflanzung, welche unstreitig den complicirtesten Bildungsprocess in dem Entwickelungsgange der Species darstellt, morphologisch betrachtet also als der Höhepunkt des letzteren angesehen werden muss. Diese Form der Fortpflanzung sei, zum Unterschiede von den übrigen, Fruetification genannt, die anderen Formen, wie dies anderweitig Brauch ist, als Propagation bezeichnet. Bei den Saprolegnieen, Peronosporeen, Mucorinen besteht die Fructification in dem geschlechtlichen Zeugumgs - und Copulationsprocess; bei den Uredineen stellt das Aecidium, bei den Ascomyceten das schlauchführende Hymenium oder Perithecium die Fructificationsorgane dar, Organe, welche nach Erysiphe zu urtheilen, zu einen sexuellen Zeugungsacte gleichfalls in Beziehung zu stehen scheinen. Wenige, noch unverstandene Ausnahmsfalle abgerechnet, kommt jeder Species nur e in e Fructificationsform zu, und der Typus dieser ist innerhalb der einzelnen Familien, Ordnungen, Genera höchst gleichförmig.

Wenige Arten scheinen zu existiren, bei welchen die Fructification die einzige Form der Fortpflanzung ist. Doch kommt dieses nach den bekannten Thatsachen vor bei Peziza Sclerotiorum. Andere Arten - und vielleicht wird 
die eben genannte durch fernere Untersuchungen auch noch zu diesen gestellt - haben ausśer den Fructificationsorganen noch Propagationsorgane (z. B. Conidien), aber diese erscheinen nicht als absolut nothwendige Entwickelungsglieder der Species, ihre Bildung kann, ohne den Entwickelungsverlauf zu stören, ausbleiben: so Peziza Fuckeliana, Sordaria curvula. Eine dritte Reihe von Arten - die meisten beschriebenen Pyrenomyceten, die Saprolegnieen, Peronosporeen - zeigt Propagationsorgane, welche nothwe ndige Entwickelungsglieder genannt werden müssen, weil ihre Bildung nie ausbleibt. Sie treten als constante Vorformen an dem Mycelium auf, dessen Entwickelung mit Fructification abschliesst; und das aus ihren Keimen erwachsene Mrcelium hat die gleichen Eigenschaften wie dasjenige, welches sie erzeugt hat. Sie sind im eigentlichen Sinne Vermehrungs-, Multiplicationsorgane.

Viertens endlich sind die Fälle zu nennen, in denen Propagationsorgane nothwendige Glieder der Speciesentwickelung sind, weil sie den Generationswechsel vermitteln, der für letztere charakteristisch ist. Hierher gehört Syzygites, Tilletia und vor allen die Lredineen, letztere entweder mit einfachem Generationswechsel Endophỵllum), oder dreifachem (Puccinia), welcher durch das alternirende Auftreten von Aecidium, Teleutosporen, Sporidien bezeichnet wird, und welchem ausserdem die constante Bildung von Multiplicationsorganen (Credo, meistens angefügt ist. Die Multiplicationsorgane sind bei den genauer bekannten Lredineen durchaus eigenartige und stehen zu dem Generationswechsel in keiner directen Beziehung. Sie fehlen bei Podisoma. In anderen Fällen (Sỵgagites) treten dieselben Projagationsorgane, welche integrrirende Glieder des Generationswechsels bilden, auch gleichsam überzählig. nur der Vervielfälligung dienend auf.

Es ist bemerkenswerth, dass das aus Propagationszellen erzogene Mycelium oft viele Generationen hindureh nur inmer Propagationsorgane erzeugt (Peziza Fuckeliana, Hypomyces, Mucorini u. s. f.), was theilweise wohl in äusseren Bedingungen begriindet, theilweise noeh unerklät ist. Für die Beurtheilung mancher zweifelhafter Fille ist es wichtig, diese Thatsache im Auge zu behalten. Speciell darf hiernach z. B. aus dem Lmstande, dass aus den Sporen von Coprinus neue sporentragende llite erzogen werden können, noch nicht geschlossen werden, dass letztere, sammt den lomologen Organen der Hymenomyceten überhaupt und der Gastromyceten die Fructification darstellen. Hierüber haben erst ausgedehntere Untersuchungen zu entscheiden, für welche einige Winke enthalten sind in den bekannten Fortpflanzungserscheinungen der Tremellinen, - der nahen Verwandtschaft dieser mit den typischen Hymenomyceten einerseits und andererseits der vielfachen Aehnlichkeit ihrer Basidien mit den Teleutosporen der Tredineen. Die noch streitigen Fälle, wie der von Nyctalis, sind hier natürlich nicht heranzuziehen.

Es ist ohne Weiteres einleuchtend, dass die Organe und Processe der Fortpflanzung bei den Pilzen sich ummittelbar an die der Conferven anschliessen. Der Lebergang von diesen zu den entfernter verwandten Pilzformen wird vermittelt durch die Reihe der Saprolegnieen, Mucorinen und Peronosporeen, und da bei den Conferven eine Pleomorphie der Fortpflanzung seit Jahrzehnten bekannt und unbestritten ist, so erscheint es doppelt wunderbar, dass letztere für die Pilze von mancher Seite immer noch sehlechthin in Abrede gestellt wird. 
Die Terminologie der Reproductionsorgane muss, so lange die Entwickelung der verschiedenen Pilzgruppen ungleich bekannt ist, an einer gewissen Ueberladung leiden; ihre Vereinfachung ist von fortgesetzten Untersuchungen zu erwarten. Zur Zeit scheint sie mir am einfachsten nach folgeriden zum Theil schon angegebenen Gesichtspunkten geregelt zu werden. Erstlich sind die Geschlechtsorgane und ihre unmittelbaren Producte mit besonderen Namen zu unterscheiden - Antheridium, Oogonium, Oospore, Zygospore, vergl. S. 101 und Capitel 5.

Zweitens sind, wie bei den verwandten Thallophyten, alle Fortpflanzungszellen, die nicht unmittelbares Product geschlechtlicher Zeugung sind und welche Keimschläuche oder Promỵcelien erzeugen, unter dem Namen Sporen zusammenzufassen, und nicht minder die von zweifelhafter Entwickelung und Bedeutung. Die verschiedenerlei Arten von Sporen können nach Bedürfniss und Ueberlieferung durch Zusammensetzungen (Ectosporen, Endosporen u. s. f.) oder besondere Worte unterschieden werden, wie in den vorausgehenden $\mathrm{Ab}$ schnitten geschehen ist. Nach dem gegenwärtigen Stande der Dinge sind hier theils eigene Namen für bestimmte Einzelfalle nothwendig (z. B. Aecidium); andere lassen sich schon jetzt für Organe, welche bei sehr verschiedeneri Gruppen oder Genera rorkommen, gleichmässig anwenden. So nenne ich, nach Tulasne's Vorgang, die von Promycelien oder von Sporen direct abgeschnürten Propagationszellen Sporidien ${ }^{i}$ ). So ist der Ausdruck Stylosporen in dem S. 194 bezeichneten Sinne für Pyreno- und Discomyceten allgemein anwendbar; und der Ausdruck Con idien ganz besonders für alle solche Propagat i o n s zellen, welche auf der freien Oberfliche besonderer, dem Mycelium entsprossender Träger a bgeschnürt werden. Ihrer weiteren Entwickelung nach sind die Conidien theils einfache, theils zusammengesetzte Sporen (z. B. Xylaria, Claviceps, Peronosporae pleuroblastae, auch Uredo, Pleospora, Hỵpomyces u. s. f.), theils Zoosporangien (Peronosporae zoosporiparae, Cystopus).

Die in Obigem kurz recapitulirten terminologischen Regeln weichen von den durch Tulasne befolgten insofern ab, als dieser überall dazu geneigt ist, das Wort Sporen für die der typischen Fruct ific a tion angehörenden geschlechtslosen Fortpflanzungszellen zu reserviren. Ich habe dieses Verfahren verlassen, weil es im Widerspruch steht mit dem für andere Thallophyten, speciell die Algen, eingeführten und weil die Erfahrung gelehrt hat, dass es practisch schwer durchführbar ist. Ob es sich in Zukunft wird einführen lassen, muss abgewartet werden.

1) Currey (Nat. hist. review XV, p. 394) meint, diese Anwendung des Wortes Sporidie führe zu einer Confusion der Terminologie, weil das Wort schon für die Ascosporen in Anwendung sei. Das ist nicht richtig, denn das Wort ist bisher für alles mögliche angewendet worden, und selbst von Berkeley, der es für die Ascosporen einführte, nicht consequent für diese. Zur Vermeidung der Confusion gibt es hier meines Erachtens überhaupt keinen anderen Weg als den, dass man die Standpunkte, von denen die mycologische Terminologie vor Tulasne ausging, völlig bei Seite lässt. 


\title{
Vierte Abtheilung.
}

\section{Physiologische Eigenthümlichkeiten der Pilze.}

\author{
Capitel 7.
}

Yon der Physiologie sind hier nur diejenigen Puncte zu erwähnen, in denen die Pilze von anderen Gewächsen abweichen oder irgend ein besonderes Interesse gewihren. Die Darstellung wird aus diesem Grunde und noch mehr weil die Untersuchungen über das physiologische Verhalten der Pilze erst in neuester Zeit wieder ernstlich aufgenommen worden sind, eine ungleichmässige und bruchstückweise sein müssen. Vorausgeschickt sei eine kurze Uebersicht der Ansichten über

\section{Entstehung der Pilze.}

Es ist bekannt, dass die ilteren Ansichten, wiê sie in Ehrenberg̣s Epistola de Mycetogenesi zusammengestellt sind, die Pilze nicht einmal für Pflanzen, sondern für Naturspiele, Excrescenzen fauler organischer Körper und dergleichen betrachteten, wenngleich schon einzelne alte Stellen auch von den Semina derselben reden. Nachdem man ihre Keime sowohl als deren Keimung seit Micheli wirklich kennen gelernt hatte, blieb doch die Meinung vielfach geltend, die Pilze entstinden, ausser aus ihren Sporen, auch durch Generatio spontanea, Urzeugung oder Heterogenie, aus zersetzter oder krankhaft verinderter organischer Substanz. Die Fälle aus dean Pflanzenreich, auf welche sich die Anhinger der spontanen oder heteromorphen Zeugung stiitzten, sind fast ausschliesslich von den Pilzen hergenommen. Bei der Besprechung derselben können wir uns füglich auf dasjenige beschräken, was in neuerer Zeit vorgebracht worden ist, und die :ilteren Angaben und Ansichten ausser Acht lassen, welche auf einer Lnbekamntschaft mit der Art und Weise wie und daher einer Unsicherheit darüiber, ob sich die Pilze aus ihren Sporen entwickeln, beruhen. In Beziehung auf jene Angaben und Ansichten ist auf die Arbeiten zu verweisen, welche sich speciell init der Lehre von der Generatio spontanea und ihrer Geschichte beschiftigen, insonderheit auf Pasteur, Examen de la doctrine des gén. spontanées Ann. Chim. 3e Sér., Tom. 64. Ann. sc. natur. Zoologie. 4e Sér., Tom. 16; im Auszug Flora 1862, p. 355), Pouchet, Hétérogénie, Paris 18.39 und die zahlreichen kleineren Arbeiten, welche sich in Kefersteins Bericht über die Fortschr. d. Generationslehre in d. Jahren 18.58-60 (Jahresber. über Anat. und Physiol. von Henle u. Meissner, 1860) und zum Theil in der Flora, 1862, p. 35\%, angeführt finden.

Bei der Frage, welche hier zu besprechen ist, muss unterschieden werden zwischen solchen Pilzen, die sich auf todter organischer Substanz ansiedeln und als Saproph ̣ten, Fäulnissbewohner bezeichnet werden können, und 
anderen, die sich als Schmarotzer, Parasiten auf lebenden, oder höchstens im Absterben begriffenen Organismen entwickeln.

Die ersteren werden bemerklich, wenn die von ihnen bewohnten Körper in Zersetzung oder Gührung übergehen; daher die Annahme, dass sie, d. h. wenigstens die ersten Zellen, aus denen sie sich entwickeln, aus den Bestandtheilen des faulenden oder gährenden Körpers gebildet werden wie aus einer Mutterlauge. Ob eine solche spontane Entstehung der Pilze in unserer Schöpfungsperiode wirklich stattfindet oder nicht, darüber haben jedenfalls zunächst allein die Beobachtung und das Experiment zu entscheiden.

Nun fehlt es erstlich durchaus an jeder directen Beobachtung darüber, dass eine Zelle irgend welcher Art ausserhalb eines lebenden Organismus entstände, und in Folge davon auch an einer präcisen Yorstellung darüber, wie sie entstehen könnte. Die älteren Angaben über die Entstehung von Hefezellen in Fruchtsäften (S. 182), welche sich auf directe Beobachtungen beriefen, werden zur Zeit wohl von niemandem mehr für genügend angesehen. Wir wissen dagegen dass und wie die Pilze sich aus ihren Keimen zu entwickeln vermögen, und dass nach Aussaat von Hefezellen oder Pilzsporen in eine zu ihrer Weiterentwickelung geeignete Substanz die letztere in dem Maasse in Gährung und Zersetzung übergeht, als die Entwickelung des Pilzes fortschreitet. Zumal durch die unten noch zu besprechenden Arbeiten Pasteur's ist dargethan, dass der Vegetationsprocess des Pilzes die Ursache der Zerselzung ist. Die mikroskopische Untersuchung des Staubes, atmosphärischer Niederschläge und insonderheit die von Pasteur (l. c.) neuerdings angestellten Luftfiltrationsversuche haben nachgewiesen, dass entwickelungsfähige Pilzsporen, Hefezellen u. s. f. allenthalben verbreitet und in der Luft suspendirt sind und auf die zersetzungsfähigen Körper gelangen können und wirklich gelangen. Versuche, welche seit Spallanzani vielfach, neuerdings besonders von Schwann, Schröder und v. Dusch, H. Iloffmann, in der vollkommensten Weise aber von Pasteur angestellt wurden, haben ferner gezeigt, dass organische Substanzen, welche, sich selbst überlasen, leicht in Zersetzung übergehen unter gleichzeitigem Auftreten von Pilzen oder anderen Organismen, dann intact und von Pilzbildung frei bleiben, wenn sie einer Temperatur ausgesetzt waren, welche die etwa in ihnen vorhandenen Pilzsporen u. s. w. tödtet, und wenn ihnen nur solche Luft zugeleitet wird, aus welcher die organischen Keime entfernt worden sind, indem sie durch Schwefelsïure, Kalilösung geleitet, oder geglüht, oder durch dichte Baumwollenpfropfe, trockene Thierblase filtrirt wurde. Bringt man eine sehr zersetzungsfähige Flüssigkeit in einen Kolben mit sehr fein ausgezogenem Ilals, welcher offen, aber derart hin und her oder abwïts gebogen ist, dass etwa durch die Luft zugeführte Keime nicht in die Flüssigkeit fallen können, sondern in dem Halse hängen bleiben müssen, kocht die Flüssigkeit einige Minuten lang und lïsst dann das Gefäss offen stehen; so bleibt die Flüssigkeit (18 Monate nach directer Beobachtung) intact und frei von Organismen. Bricht man den Hals ab, so sind letztere und Zersetzungserscheinungen nach 18-24 Stunden vorhanden. Wenn man eine zersetzungsfähige Substanz nicht frei an der Luft stehen, sondern nur eine limitirte kleine Menge gewöhnlicher Luft zutreten lässt, erfolgt häufig, aber keineswegs immer Zersetzung und Auftreten von Pilzen oder anderen Organismen; und zwar bleibt die Substanz um so häufiger intact und 
pilzfrei, je mehr die Luft von Staub rein und von menschlichen Wohnungen und sonstigen pilzführenden Orten entfernt aufgefangen worden ist. - Bei unbeschränktem Luftzutritt erscheinen die Pilze binnen kurzer Zeit, und meist immer die nämlichen, alverbreiteten Formen - z. B. Penicillium glaucum in den zum Experiment in der Regel angewendeten Zuckerlösungen. Bei limitirter Luftmenge treten die Pilzbildungen weit langsamer auf, und oft in verschiedenen Versuchen verschiedene Arten.

Ganz dieselben Resultate, welche an Substanzen beobachtet werden, die direct von einem Organismus hergenommen sind, und in denen frühere Vertheidiger der Generatio spontanea einen » Rest von Vitalität « oder Organisation annahmen, erhielt Pasteur mit einer künstlichen Flüssigkeit, welche keinen organisationsfähigen Körper enthält ( 10 Th. Candiszucker, 0,2 bis 0,5 weinsteinsaures Ammoniak, 0,1 Asche von Hefe auf 100 Wasser). Diese Erfahrungen und Versuche erklären jegliches Auftreten von Pilzen auf todter organischer Substanz aus der Entwickelung ihrer von Eltern erzeugten, allverbreiteten und leicht durch Luftzug und dergleichen verbreitbaren Keime oder Sporen. Es ist keine Thatsache bekannt, welche zur Zeit die Annahme einer elternlosen Entstehung forderte. Viehmehr findet diese Annahme darin eine erhebliche Schwierigkeit, dass viele der gerade für die Generatio spontanea angeführten Pilze und verwandten Organismen durch ihre Vegetation die bestimmten, specifischen Zersetzungsformen, als deren Begleiter sie gefunden werden, nachweislich e r regen, also die Ursache desjenigen Processes abgeben, dessen Product sie sein sollten. Dies alles führt dahin, das Stattfinden einer spontanen Generation unter den gegenwärtig bekannten und im natürlichen Verlaufe der Dinge stattfindenden Bedingungen zu läugnen, zunächst für die Pilze; für die übrigen Organismen gilt in dieser Bezichung wesentlich das Gleiche. Allerdings ist zuzugeben, dass in Anfang eimmal Organismen von selbst entstanden sind und unter ähnlichen Verhältnissen wie früher auch jetzt noch von selbst entstehen müssen (Nigeli, Rede üb. d. Naturhistor. Art. 186:3, p. 43). So lange jene Verhältnisse und Bedingungen aber nicht näher bekannt sind, ist man, wie ich glaube, genöthigt, obige Negation aufrecht zu erhalten, ohne dabei zum Wunderglauben seine Zuflucht nehmen zu muissen.

Anders als für die Bewohner todter Körper könnte sich die Sache bei den Parasiten verhalten, welche lebende oder absterbende Organismen bewohnen. Hier finden sich die parasitischen Pilze im Innern der Gewebe und häufig geschlossener, noch lebender Zellen, also an Orten, wo Zellbildung erfahrungsgemäss stattfinden kann; die Organismen aber, welche man von Schmarotzerpilzen befallen findel, sind mehr oder minder krank, und es liegt daher die Annahme eines Hervorgehens der Parasiten aus krankhafter Zellbildung ihres Wirthes nahe. In der That ist für viele endophytische Schmarotzerpilze behauptet worden, dass sie aus einer krankhaften Zellbildung ihres Wirthes hervorgehen, den pathologischen Gewebselementen des Thierkörpers vergleichbar; und unter den thierbewohnenden Arten wurde für Entomophthora museae (vergl. Seite 170) ähnliches angegeben. Ein unumstösslicher Beweis für diese Anschauungsweise schien in dem Vorkommen jugendlicher Schmarotzerpilze im Innern ringsum geschlossener Pflanzenzellen gefunden zu sein. Vergl. besonders Unger, die Exantheme der Pfl. 1833. Beitraige z. vergl. Pathologie. 1840. 
Anatomie u. Physiol. d. Pfl. (1855), p. 159. M eyen, in Wiegmann's Archiv 1837, p. 419. Pflanzenpathologie (1841), p. 98, 154. Nägeli, Algensysteme, p. 118. Die Stärkekörner (185\%), p. 135̆. Auch Reissek's Arbeiten über Entstehung der Pilze (Haidinger's Samml. Naturw. Abh. I, 1847 und Nov. Act. Nat. Curios. Vol. XXI, pars II, 469) schliessen sich hier an, nebst einer Arbeit Karsten's, Bot. Ztg. 1849, p. 361. Neuere Untersuchungen haben nun aber die erwahnten Ansichten als unhalthar erwiesen und zu den von B. Prévost, Jos. Banks, De Candolle früher vertretenen Anschauungen zurückgeführt, indem sie die Beobachtungsfehler der oben genannten Schriftsteller bestimmt nachwiesen, die Unmöglichkeit, die Entstehung eines Parasiten a us den Organen seines Wirthes zu beobachten constatirten, und direct zeigten, wie das Vorkommen jenes im Innern geschlossener Gewebe und Zellen immer nur die Folge eines Eindringens von aussen her ist. Wenn auch, der Natur der Objecte zufolge, keine Versuche wie mit todter organischer Substanz angestellt werden konnten, so haben doch die vorhandenen Untersuchungen für jeden Einzelfall die Möglichkeit dargethan, das Auftreten des Parasiten aus der Entwickelung seiner elternerzeugten Keime zu erklären, und die Nothwendigkeit, auf Grund der bekannten That sachen diese Erklärung und keine andere zuzulassen. Die betreffenden Arbeiten sind meist oben (S. 188) bei den Uredineen citirt; über das Eindringen der Parasiten ins Innere von lebenden Zellen und Geweben habe ich in meiner dort angeführten Arbeit über die Champignonș parasites Ausführliches mitgetheilt, nachdem diese Erscheinungen früher schon für Ustilagineen, Pythium und die Chytridien bekannt waren. Das Eindringen von Pilzen in todte Zellen war schon früher ron Unger (Botan. Zeitg. 1847) und Schacht (Pflanzenzelle) beobachtet worden.

Die Allverbreitung der Sporen und Keime der Pilze, auf welche sich die ausgeführte Erklïrung ihres Auftretens grüdet, begreift sich leicht, wenn man bedenkt, welche immense Mengen dieser Organe von einen Mycelium oder Fruchtkörper producirt werden; statt der Ausrechnung ungeheurer Ziffern wird es genügen, hierfür auf die von den Hymenien und Sporen handelnden Capitel zu verweisen. Nach den bekannten Eigenschaften der Sporen bedarf es keiner besonderen Ausführung, dass dieselben in den meisten Fällen leicht bewegt und verbreitet werden; und ebenso ist es selbstverständlich, dass unter günstigen Entwickelungshedingungen die Sporenmenge eines Pilzes in geometrischer Progression wachsen muss.

Es stellt sich hier die Frage, ob denn eine einzige Spore zur Erzeugung eines neuen fruchtbaren Myceliums genügt. Einfache sehr schnell wachsende Pilzformen, wie Mucorinen, Penicillium, Dematieenformen u. a. lassen leicht bei Aussaten auf den Objecttriger eine bestimmt bejahende Antwort auf diese Frage erhalten. Grössere Formen setzen der Untersuchung viele Schwierigkeiten entgegen, weil es meist kaum möglich ist, eine Spore für sich allein auf geeigneten Boden auszusäen, und weil es sich nach Aussaat vieler Sporen kaum je entscheiden lisst, ob ein Fruchttrïger aus dem Keimungsproducte einer oder mehrerer entspringt.

Culturversuche (auf dem Objectträger) mit Sordaria curvula haben mir jedoch wenigstens für diese gezeigt, dass sich aus einer einzigen Spore ein reich wucherndes Mycelium mit zahlreichen Peritheciumanfängen (die wegen unzu- 
reichender Ernährung allerdings nicht zur völligen Ausbildung kamen' zu entwickeln vermag. Hiermit steht die Erfahrung im Einklang, dass die Cultur von Pilzen sehr oft weit besser gelingt wenn eine sehr kleine, als wenn eine grosse Menge Sporen ausgesäet wird.

\section{K e i m ung s b e d i $\mathrm{ng} u \mathrm{ng}$ e $n$.}

1. Keimfähigkeit.

Die meisten bekannten Fortpflanzungszellen der Pilze (sie seien hier der Kürze halber alle als Sporen bezeichnet) sind rom Augenblick ihrer Reife an keimfähig. Verhältnissmässig wenige treten zunächst in einen Ruhezustand ein, der im Freien bis zum Ende des auf ihre Bildungszeit folgenden Winters dauert, in der Cultur schon wihrend des letzteren beendigt werden kann. Hierher gehören die Teleutosporen der meisten Puccinien (z. B. P. graninis, von Uromyces, Phragnidium, Melampsora, die Schlauchsporen von Erısiphe, „denen sich die Oosporen der Peronosporeen, Sỵzggites, die Asci von Protomỵces macrosporus anschliessen. Die Oosporen der Saprolegnieen lıaben eine kürzere Ruhezeit. Das Misslingen der Keimungsversuche hat öfters in der Nichtberücksichtigung des nothwendigen Ruhezustandes seinen Grund gehabt, letzterer ist daher bei solchen Versuchen nicht ausser Acht zu lassen. Zur Erklairung des nothwendigen Ruhezustandes müssen dieselben Hypothesen, wie für Phanerogamensamen, Algensporen u. s. w: vorläufig dienen.

Die Dauer der Keimfiahigkeit ist je nach der Species und Sporenart verschieden. Beschränht ist sie, soweit die vorhandenen Untersuchungen reichen, bei sämmtlichen Lredineen, und zwar für die verschiedenen Sporenarten in verschiedener Weise. Die mit dem Moment der Reife keimbaren Uredo- und Aecidiumsporen können einige Wochen, selten Monate lang ilıre Keimfähigkeit behalten. Diese erlischt jedoch, nach allen sicheren Beobachtungen, spätestens mit dem Ende des Sonmer's in welchem sie entstanden. Die überwinterten Teleutosporen von Pucc. graminis keimen ungemein leicht im Frühling, lanğsamer und seltener während des folgenden Sommers, vom August an konnte ich sie nicht mehr zur Keimung bringen. Teleutosporen mehrerer überwinternder Puccinien und Uromyceten, die eigens hierfür aufbewahrt waren, keimten im zweiten Sommer nach ihrer Entstehung nicht mehr.

Den Uredosporen :̈hnlich verhalten sich die Conidien (auch die Zoosporangien) der Peronosporeen. Ihre Entwickelungsfähigkeit erlischt nach einigen Wochen, z. B. nach $6-8$ bei $\mathrm{C}$. candidus, nach etwa 3 bei nicht völlig ausgetrockneten Conidien von Per. infestans; vollkommen lufttrockene hatten bei der letztgenannten Species ihre Entwickelungsfähigkeit schon nach 24 Stunden verloren.

Bei der Mehrzahl der Pilzsporen scheint die Dauer der Keimfähigkeit allerdings weit weniger eingeschränkt zu sein. Hoffmann fand die Sporen von Ustilago Carbo 11, 12, 31 Monate nach der Einsammlung keimfahig; Ustilago destruens nach 1 und nach $3 \frac{1}{2}$ Jahren; Ustilago Maidis nach 2 Jahren. Tilletia Caries ist noch im Laufe des zweiten Jahres keimfahig. Die gleich den genannten und den folgenden rom Augenblick der Reife an keimfähigen Ascosporen von Sordaria curvula zeigten mir nach 28 monatlicher Aufbewahrung alle sofort Keimung. Die 
Sporen von Botrytis Bassiana bleiben, nach Robin's und eigenen Erfahrungen, 1-2 Jahre keimfähig, jedoch nicht viel länger. Die von Rhizopus nigricans Ehr. keimten mir ein Jahr nach ihrer Reife theilweise, nicht alle.

Hohe Temperaturgrade tödten die Sporen, und zwar in Wasser oder Wasserdunst eher als in trockener Umgebung. Der Tödtungpunkt ist erst für wenige Fälle bestimmt worden. In dem oben erwähnten Fall der ausgetrockneten Conidien von Peronosp. infestans erfolgte das Absterben schon bei $22^{0}$.

Nach H. Hoffmann ertragen die Sporen von Ustilago Carbo und U. destruens eine Temperatur von $104^{\circ}$ bis $120^{\circ}$ im Trockenen; im dunstgesättigten Raume liegt der Tödtungspunkt für U. carbo zwischen $58,5^{\circ}$ und $62{ }^{\circ}$, für U. destruens bei einstündiger Erwärmung zwischen $74^{\circ}$ und $78^{\circ}$, bei zweistündiger zwischen $70^{0}$ und $73^{\circ}$. Nach Payen (Cpt. rend. Tom. 27, p. 4) ertragen die Sporen eines im Innern von Brod gefundenen Schimmels, Oidium aurantiacum, eine Temperatur von $120^{\circ}$; auf $140^{\circ}$ erhitzt waren sie verfärbt und todt.

Pasteur's genaue Versuche zeigten, dass die Sporen von Penicillium glaucum in trockner Luft bei $108^{\circ}$ unverändert bleiben. Bei $119^{\circ}-121^{\circ}$ verlieren viele, doch nicht alle ihre Keimfähigkeit, bei $127^{\circ}-132^{\circ}$ alle sehr schnell. Ascophora elegans (= Mucor Mucedo?) hat den gleichen Tödtungspunkt. Aehnliche Resultate ergaben Versuche mit unbestimmten, im Staube enthaltenen Sporen, unter denen Botrytis cinerea P. (Peziza-Conidien) oder eine nahe verwandte Form deutlich bestimmbar ist, welche $121^{\circ}$ ertrug. Erwärmung der in Flüssigkeit suspendirten Sporen auf $100^{\circ}$ war in den Pasteur'schen Versuchen immer tödtlich. Es darf jedoch hier hinzugefügt werden, dass, nach einer andern Versuchsreihe Pasteur's zu schliessen, die Keime bestimmter Vibrionen in einer schwach saueren Flüssigkeit bei $100^{\circ}$, in einer neutralen oder leicht alkalischen dagegen erst bei $103^{0}$ absterben.

Nach Schmitz ertragen die Sporen von Penicillium glaucum im Wasser eine Erwärmung auf höchstens $61^{\circ}$; die von Trichothecium roseum nur 12, $5^{0}$ (??), trocken aber $68^{\circ}-75^{\circ}$; die von Peziza repanda im Wasser $63,75^{\circ}$, trocken $137,5^{0}(?)$.

Dass die Keime bei höchstens $100^{\circ}$ im Wasser fast immer getödtet werden müssen geht schon aus der Gerinnung der Proteinkörper bei dieser Temperatur hervor. Für die verschiedene Resistenz verschiedener Arten ergibt sich aus der Differenz des Gerinnungspunktes verschiedener Eiweisskörper einige, jedoch nach den mitgetheilten Angaben keine ausreichende Erklärung. Die Angabe Spallanzani's (Opusc. trad. par Sénébier II, p. 398), nach welcher Sporen von Rhizopus nigricans, und Meyen's, nach welcher frische Bierhefe im Wasser durch die Siedhitze nicht getödtet werden sollen, sind unrichtig.

Durch Erniedrigung der Temperatur unter den Gefrierpunkt wird die Keimfaihigkeit vieler Pilzsporen in keiner Weise beeinträchtigt. Die überwinternden Teleutosporen der Uredineen ertragen die kältesten Winter ihrer Heimathländer im Freien : z. B. Puccinia graminis und Verwandte, Uromyces appendiculatus bei uns jedenfalls mindestens $-15^{\circ}$ bis $-20^{\circ}$. Ebenso die Asci von Protomyces. Nach Hoffmann widerstehen dem Froste die Sporen von Ustilago Carbo, destruens, Trichothecium roseum, Fusarium heterosporum, Penicillium glaucum, Botrytis cinerea, sowohl im Wasser als trocken. Die Bierhefe bleibt, nach CagniardLatour, selbst bei $-90^{\circ}$ lebensfähig. 
Aus den mitgetheilten, wenn auch noch dürftigen Daten geht jedenfalls das Eine mit Sicherheit hervor, dass sich über die Dauer der Keimfaihigkeit der Pilzsporen, ihre Widerstandsfähigkeit gegen extreme Temperaturerhöhung u. s. w. kein für alle gleichmässig gültiges Gesetz aufstellen lässt, sondern, dass jede einzelne Sporenform und Species besonders untersucht werden muss, wenn man uber sie ein sicheres Urtheil erhalten will.

\section{Lit teratur.}

H. Hoffmann, üher die Keimung der Pilzsporen, in Pringsheim's Jahrb. II, 267.

Pasteur, Examen de la doctrine des gén. spontan. Chap. VIII. I. l. c. c.

de Bary, Rech. sur les Champ. parasites, 1. c.

Schmitz, Verhandl. d. naturhist. Vereins f. Rheinlande etc. II. (1843.)

Me yen, Jahresbericht, in Wiegm. Arch. IV, 2 (1838) p. 98.

Vgl. auch Tulasne, Carpolog. I. pag. 90.

2. Die äusseren Bedingungen des Keimungsprocesses

sind nach den vorhandenen Daten für die meisten Pilze dieselben, oder doch ganz ihnliche wie für Keime und Samen anderer Gewichse. Von der Temperatur, welche zum Keimen erforderlich ist, scheint allgemein zu gelten, dass ihr Minimum sehr niedrig liegt. Nach Ifoffmann (1. c.) keint Ustilago Carbo schon bei $+0,5^{0}-1^{0} ;$ Botrytis cinerea bei $+1,6^{0}-2,1^{0}$; Penicillium glancum bei 6, $2^{0}$ u. s. w. ${ }^{1}$ ) Allerdings gehen bei solch niedern Graden die Keimungen langsamer und schwacher als bei höherer Temperatur; das Optimum liegt wohl für alle Pilze innerhalb der mittleren Frühlings- und Sommertenperatur, ist iibrigens für keinen genau bestimmt. Cystopus candidus fand ich bei $+5^{0}$ ebensogut Zoosporen und Zoosporenkeime bildend als bei $+25^{0}$. Für das Maximum der Keimungstemperatur fehlen gleichfalls noch genaue Bestimmmngen. Ustilago destruens keimt, nach Iloffinann, noch bei $38,7: 3^{0}$ (Minimum nach Hoffinann höher als $+5^{0}$.

Nach Beginn der Keimung werden viele ob alle? Sporen durch Frost getödtet (Hoflinann).

Alle Pilzsporen erfordern zur Keimung Vorhandensein von Wasser in ilırer Ungebung; wie an dem Anschwellen und dem Auftreten von Vacuolen direct sichtbar ist, beginnt der Keimungsprocess mit Wasseraufsaugung. Ausser den Zoosporenbildenden, den Peronosporae plasmatoparae und den nachher zu nennenden besonderen Ausnahmen keimen die bisher beobachteten Sporen mindestens ebensowohl in einer an Wasserdunst reichen Luft (aus welcher allerdings, wie Hoffinann bemerkt, immer kleine tropfbare Niederschlige erfolgen) oder auf Wassertropfen schwimmend, als wenn sie unter Wasser getaucht sind. Bei vielen, z. B. bei allen Uredineensporen nach Tulasne's und meinen Erfahrungen, bei den Tremellinen u. s. f. wirl sogar durch Untertauchen die Keimung stark beeintrichtigt oder völlig verhindert. Andere, z. B. die meisten Schimmelpilze (Penicillium, Botrytis cinerea u. s.f.) keimen auf beide Arten ziemlich gleich gut.

1) Ich gebe imıner Centigrade an; Hoffmann hat es manchmal zweifelhaft gelassen, ob er solche oder Réaumur meint. 
Leber die Einwirkung und Nothwendigkeit des Sauerstoffs fehlt es an Untersuchungen.

Für die meisten Sporen, jedenfalls alle in Wasserdunst keimenden (Uredineen, Ustilagineen, Peronospora, Rhytisma etc.) ist, abgesehen vom Sauerstoff; Wasser die einzige Substanz, deren Aufnahme zur Keimung erforderlich ist. Die Ausbildung des Keimschlauchs, des Promyceliums, der Sporidien geschieht im Uebrigen auf Kosten der in der Spore aufgespeicherten assimilirten Stoffe; diese werden, wie die directe Beobachtung lehrt, für die Neubildungen verbraucht; Wägungen würden, wenn sie ausführbar wären, eine Abnahme oder jedenfalls keine Zunahme der organischen Trockensubstanz ergeben. Das Verhailtniss ist also das gleiche wie in den ersten Keimungsstadien phanerogamer Samen.

Anders verhält sich eine bis jetzt kleine, durch fernere Untersuchungen aber jedenfalls zu vermehrende Anzahl von Sporen. Ihre Keimung erfolgt nur in solchen Medien, welche die zur Ernährung des Myceliums der Species erforderlicben Stoffe enthalten; ihr Protoplasmagehalt vermindert sich dabei nicht zu Gunsten der Keimungsproducte, sondern bleibt wenigstens längere Zeit hindurch erhalten oder nimmt sammt dem Volumen der Spore zu; es ist also wenigstens in hohem Grade wahrscheinlich, dass hier mit dem Beginn der Keimung auch der Assimilationsprocess beginnt, und dass jene von letzterem abhängig ist. In reinem Wasser oder ungeeigneten Lösungen keimen solche Sporen entweder gar nicht, oder bleiben bei kümmerlichen Anfängen stehen. Hierher gehören die Sporen von Rhizopus nigricans; sie keimen nicht in reinem Wasser, leicht in Fruchtsaften, Zuckerlösungen u. s. w., auf denen das fruchttragende Mycelium gefunden wird. Ferner Mucor Mucedo, von welchem ganz besonders die Conidien (Botrytis Jonesii Berk.) in reinem IVasser nie keimen. Ferner Peziza_Fuckeliana : die Ascosporen keimen in reinem Wasser absolut nicht, in Rohrzuckerlösung kaum, sofort in Weintraubensaft oder entsprechend componirten Traubenzuckerlösungen. Dic Ascosporen der nahe verwandten P. Sclerotiorum beginnen dagegen leicht ihre Keimung in Wasser und Wasserdunst.

Diese Thatsachen dürften den Schlïssel zur Erklärung des Misslingens mancher bisherigen Keimversuche enthalten.

Gewisse hicrher gehörende Eigenthümlichkeiten parasitischer Pilze werden im nachsten Abschnitte besprochen werden.

\section{E r n äh r u ng d e r P i l z e.}

\section{Nahrungsmittel. Aufnahme der Nahrung.}

Die chemische Analyse ergieht, dass die Pilze ähnliche Zusammensetzung hahen, wie die übrigen Pflanzen, und dass sie gleich diesen Stoffe, die ihnen C, II, O, Y liefern und eine gewisse Menge -Mineralstoffe als Nahrung aufnehmen müssen. Aus denselben, in ihrer Organisation gegebenen Gründen wie die ïbrigen Pflanzen, müssen sie die Nahrung zum Behufe der Assimilation ins Innere der Zellen aufnehmen, also in gasförmigem oder tropfbar flüssigem, resp. gelöstem Zustande. Was die Pilze von den meisten andern, speciell von allen mil Chlorophyll und verwandten Pigmenten versehenen Pflanzen auszeichnet, ist 
ihre durch den Chlorophyllnnangel angezeigte Ernährung von vorgebildeter organischer Substanz, die Unfähigkeit, ihre sämmtlichen organischen Bestandtheile aus unorganischem Rohmaterial zu bilden. Nach ihrem Nahrungsbedürnniss sondern sich die Pilze in zwei schon mehrfach angedeutete Gruppen: Schmarotzer, Parasiten, welche auf lebende Organismen, Thiere und Pflanzen, angewiesen sind; und Bewohner todter, sich zersetzender organischer Körper, welche oben Fäulnissbewohner, Saprophyten genannt worden sind. Eine Anzahl von Pilzen scheint in rerschiedenen Lebensstadien beiderlei Ernïhrungsweisen zu erfordern, nämlich ihre Entwickelung als echte Parasiten zu beginnen und als Saprophryten zu endigen. So die zahlreichen Pyreno- und Discomyceten, welche lebende Pflanzentheile befallen, auf diesen aber erst dann ihre Entwicklungshöhe erreichen, wenn dieselben abgestorben und theilweise zersetzt sind (z. B. die blattbewohnenden Rhytismen, Phacidium, Polystigma Tul., Stig̣matea Tul,; ; ferner die insectentödtenden Parasiten (Torrubia mit ihren Vorformen, Botrytis Bassiana, Entomophthora). Es ist jedoch zweifelhaft, oh bei diesen Pilzen nach dem Absterben ihres Wirthes noch eine Assimilation stattfindet, oder nur, wie bei den Sclerotien, eine Uinsetzung und Verbrauchung der während des parasitischen Stadiums aufgespeicherten Reservestoffe.

Im Einzelnen scheint das Nahrungsbedürniss bei beiden Reihen fast ebenso mannigfaltig zu sein, wie die Pilzspecies selbst. Dies wird angezeigt durch die bekannte Thatsache, dass viele Pilzarten nur auf einem oder einer geringen Anzahl organischer Körper, lebender oder todter, überhaupt zur Entwicklung kommen oder ihre völlige Ausbildung erreichen. Nur eine verhältnissmiissigkleine Anzahl von Saprophỵten kommt auf sehr verschiedenartigen Substanzen vor, wie Penicillium glaucum, Mucor Mucedo und die Arten, welche faule Hölzer, Pflanzentheile, thierische Excremente verschiedenartiger Herhunft hewohnen.

Welches speciell die Nahrungsmittel sind, deren die einzelne Pilzspecies bedarf, ist nur für wenige, den Saprophỵ te n angehörende Fälle genau behannt.

Eine Anzahl von Schimmel- und Fermentpilzen, nämlich Penicillium glaucum, Hormiscium Cerevisiae, Rhizopus nị̣ricans ninmm ihren ganzen Bedarf von Kohlenstoff, Wasserstoff, Stickstoff und mineralischen Bestandtheilen aus den Boden, in welchem das Mỵeelium ausgebreitet ist, oder der Flüssigkeit, in welche sie untergetaucht sind. Für Penicillium glaucum und Hormisc. Cerevisiae hat Pasteur gezeight, dass sie veğetiren und assimiliren, wenn ihnen die nöthigen löslichen Mineralstoffe, stichstoflhaltige Nahrung in Form eines anorganischen Ammoniaksalzes oder einer organischen Verbindung, stickstofffreie Vahrung in Form von Zucker geboten wird. Zusammensetzung der Versuchsflüssigkeit z. B. 10 Th. Zucker, 0,5 Ammoniaksalz, 0,1 Aschenbestandth. auf 100 Wasser.) Und zwar nimmt der Pilz seinen Kohle ns toff nur als vorgebildete organische Substanz auf; durch Kohlensïure kann ihm der Zucker nicht ersetzt werden. Dagegen können andere organ ische Substanzen statt desselben dem Penicillium als Nahrung dienen. Pasteur fand, dass dieser Pilz sich gut entwickelt auf einer Flüssigkeit, welche ihm Kohlenstoff und Stickstoff in Form von saurem traubensaurem Ammoniak darbietet. Die Traubensiure ist nach Pasteur's fruiherer Entdeckung zusammengesetzt aus optisch rechtsdrehender und linksdrehender Weinsäure, und gegen diese beiden zeigt Penicillium das merkwür- 
dige Verhalten, dass es allmählich alle rechtsdrehende aufnimmt, während alle linksdrehende in der Flüssigkeit zurückbleibt.

Ueber die mineralische Nahrung hat Raulin für Rhizopus nigricans genauere Untersuchungen angestellt und gefunden, dass dieser Pilz, bei einem Aschengehalt von weniger als 2 Procent, folgende Stoffe, nach ihrer relativen Menge in der Asche und dem Grade der Wichtigkeit für die Entwickelung des Pilzes geordnet, nothwendig erfordert: P. K. Mg. S. Mn.

Die in Rede stehenden Schimmel und die Hefe nehmen aus der L u f t Sauerstoff in reichlicher Menge auf, wie dies für a lle untersuchten Pilze längst bekannt ist; Stickstoff wird von ihnen in keiner Form aus der Luft aufgenommen.

Dagegen fand Jodin, dass andere, leider nicht näher bezeichnete Schimmelpilze, deren Substanz bis zu 6 Procent Stickstoff enthält, auf stickstofffreien organischen Körpern, wie Lösungen von Zucker, Glycerin, Dextrin, organischen Säuren, wenn sie die nöthigen Aschenbestandtheile aber keine Spur Stickstoff enthalten, gut gedeihen, und dass sie, in einer abgeschlossenen Atmosphäre von $\mathbf{N}$ und $\mathbf{O}$ cultivirt, eine betrachtliche Menge von N, und zwar bis zu T Volumprocente des aufgenommenen $\mathrm{O}$, absorbiren. Ob $\mathrm{N}$ als solcher, oder vielleicht nach vorheriger Bildung von salpetrigsaurem Ammoniak (Schönbein) absorbirt wird; ob direct durch den Pilz oder etwa zunächst durch die Versuchsflüssigkeit ist nach den bis jetzt vorliegenden Mittheilungen unentschieden. Aehnliche, jedoch weniger präcise Resultate wie Jodin erhielt Vogel. Er ist vorläufig geneigt, den in die Flüssigkeiten gelangten Staub für die Quelle des Stickstoffs anzusehen.

Vergl. uiber das Angegebene:

Pasteur, Comptes rend. Tom. 51, p. 298.

Pasteur, Mém. s. l. fermentation alcoolique. Ann. Chim. et Physs. 3e Sér. Tom. 58. Boussingault, Cpt. rend. Tom. 51, p. 571. Ann. Chim. 3e Sér. Tom. 61 p. 363.

Raulin, Eludes chim. sur la végét. des Mucédinées. Cpt. rend. Tom. 537, p. 228.

Jodin, Du rôle physiol. de l'azote. Cpt. rend. Tom. 55, p. 612.

Vogel, Sitzungsber. d. K. Bayr. Acad. 1862, p. 39.

Normale und üppigge Entwicklung von Schimmel - Penicillium glaucum wurde mehrfach beobachtet auf Lösungen von arseniger Säure, und oft ziemlich concentrirten Hoffmann, in Pringsh. Jahrb. l. c. : Jäger, Wirkg. d. Arseniks auf Pflanzen, Stultg. 1864); desğleichen auf Lösungen von Kupfervitriol, Eisenvitriol (Berkeley, Outlines p. 30). Ich habe selbst fussgrosse Haiute von Pen. glaucum untersucht, welche sich auf Kupfervitriollösung, die zu galvanoplastischen Zwecken benutzt wurde, gebildet hatten. Es ist wohl unzweifelhaft, dass in diesen Fällen der Pilz von der jedem Organismus unbedingt giftigen gelösten Substanz nichts aufnimmt; ob er aus der Kupferlösung Schwefelsäure assimilirt, ist auch nicht so sicher wie Harvey und Berkeley (l. c.) anzunehmen scheinen.

Nach einer Anzahl bekannter, aber noch genauer zu analysirender und in den soeben mitgetheilten Untersuchungen nicht berücksichtigter Daten ist es gewiss, dass viele Pilze auf verschiedenerlei Substanzen vegetiren, sich selbst üppig entwickeln und Sporen bilden können, aber zur völligen Ausbildung, insonderheit zur Erzeugung der vollkommenen Fructification, eines ganz bestimmten Substrats bedürfen. Rhizopus nigricans z. B. bildet Zygosporen und Sporangien, wenn er auf säuerlichen Früchten (Stachelbeeren, Vogelbeeren, Johannis- 
beeren, auch auf Brot) wächst. Auf den ausgepressten Säften jener Früchte, auf Zuckerlösungen u. s. w. wurden, bei sonst oft üppiger Vegetation, nie Zygosporen beobachtet. Syzygites megalocarpus entwickelt seine Sporangien, nach Schacht, auf vielerlei todten organischen Substanzen, wie Brot u. s. f. , Zygosporen nur auf fleischigen und zwar, wie es scheint, noch lebenden Schwämmen. Von Peziza Fuckeliana erhält man in ausgepresstem Traubensafte ein überaus massenhaftes, aber immer steriles Mycelium, die später fruchtbildenden Sclerotien nur in den Blättern der Rebe.

Ferner ist hier eine Thatsache zu erwihnen, welche zeigt, dass es Pilze giebt, deren Mycelium zu seiner ersten Ausbildung andere Nahrung erfordert, als zu seiner Weiterentwickelung wenn es einınal ausgebildet ist. Peziza Sclerotiorum findet sich oft üppig und massenlıaft Sclerotien bildend auf Rüben (Daucus, Brassica). Ihre Sporen keimen auf jeglichem feuchten Substrat. Die Keimschliuuche sterben aber bald ab und entwickeln sich nie zum Mycelium, wenn sie auf Rüben gesit werden; reichliche Mycelium- und Sclerotienbildung findet dagegen auf saftigen Früchten (Weinbeeren, Stachelbeeren, Melonen, Gurken) oder deren ausgepresstem Safte statt; und das hier entwickelte flockige Primärmycelium setzt seine Vegetation und Sclerotienbildung kraftig fort, wenn es auf Rüben übertragen wird.

Für die Schmarotzerpilze ist zwar noch nicht genau bekannt, welches die Stoffe sind, die sie für ihre Ernährung aus lebenden Organismen aufnehmen. Wohl aber kennt man von ihnen eine Reihe bemerkenswerther, zu dem Ernährungsprocess in unmittelbarer Bezichung stehender Thatsachen.

Zuniichst gilt dieses für die Pflanzen bewohnenden Parasiten. Bei diesen ist zu unterscheiden zwischen solchen, die ganz oder theilweise im Innern des von ihnen bewohnten Gewichses - ihres Wirthes oder ihrer Nihrpflanze - leben, als Endophyten, und anderen (wenigen), welche nur die Oberfliche des Wirthes, als epiph yte Schmarotzer, bewohnen.

Bei simmulichen bis jetzt untersuchten Pflanzenparasiten beginnt die Keimung der Sporen ausserhalb der Nihrpflanze. Auch von den Endophyten dringen nie die Sporen in jene ein, um erst im Innern zu keimen wiè bis vor kurzem allgemein angenommen wurde), sondern immer die Keimschliuche. Die Bildung dieser beginnt unter alleiniger Einwirkung von Wasser oder feuchter Luft; sie erreichen hier, auf Kosten der in der Spore aufgespeicherten Reservestoffe, eine für jede Art bestimmte Grösse und Form. Finden sie keine geeignete Nährpflanze, so sterben sie rasch ab, sind sie auf eine solche gelangt, so entwickelt sich der Keimschlauch zum Mycelium.

Bei den Endophyten beginnt diese Entwickelung mit dem Eindringen ins Innere des Wirthes und dieses erfolgt, je nach den Species und Sporenformen in verschiedener Weise. Eine erste Reihe von Keimschliuchen tritt nur in die Spaltöffnungen der Nïhrpflanze ein. Dies gilt zunächst von denen sämmtlicher Uredo- und Aecidiumsporen der Uredineen. Der lange, gekrimmte Keimschlauch wächst über die Epidermis hin; sobald seine Spitze eine Spaltöffnung trifft, senkt sie sich in diese ein, meistens nachdem sie vorher ausserhalb der Spaltöffnung blasig angeschwollen war. Das eingetretene, in der Athemhöhle liegende Ende nimmt rasch an Umfang zu, alles Protoplasma des Keimschlauches wandert in dasselbe ein, dieser stirbt, soweit er sich ausserhalb befindet, sammt der Sporen- 
membran ab. Das eingetretene Ende des Keimschlauches treibt sofort Zweige, welche sich zu Myceliumfälen entwickeln (Fig. 81). Es ist eine eigenthümliche
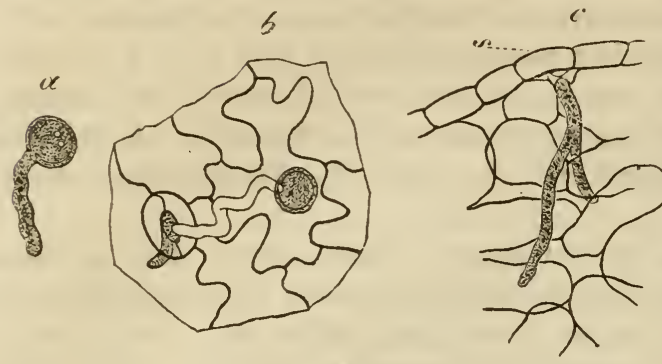

Fig. 81 . Erscheinung, dass die in Rede stehenden Keimschläuche in die Stomata jeder beliebigen phanerogamen Pflanze eintreten, um sich jedoch nur in bestimmten Nährspecies des Parasiten weiter zu entwickeln, in allen anderen dagegen noch innerhalb der Athemhöhle abzusterben. Hierher gehören ferner die kurzen Keime der Sporidien von Puccinia Dian-

thi DG. Keimt eine Sporidie in der Nähe einer Spaltöffnung, so richtet sich ihr Keimschlauch sofort nach dieser hin, tritt ein und wächst zum Mycelium heran. Findet die Keimung, die in feuchter Luft überall leicht geschieht, an irgend einem anderen Orte statt, so richten sich die Schläuche. ordnungslos nach allen Seiten und gehen nach kurzem Lïngenwachsthum zu Grunde.

Die Schwärmsporen von Gystopus und Peronospora nivea (Cmbelliferarum) treiben im Wasser schnell absterbende Keimschlauche. In Wassertropfen auf der Oberfläche ihrer Nährpflanzen kommen sie vorzugsweise auf oder dicht neben den Stomata letzterer zur Ruhe und treiben ihre Keimschlauche in diese hinein. Für sämmtliche aufgezählte Keime gibt es keinen anderen Weg, um ins Innere ihres Wirthes zu gelangen, als den angegebenen. Ueber die Ursache für die Fixirung der Zoosporen auf und für die Krümmung der Keimschläuche gegen oder in die Spaltöffnungen ist schwer ins Klare zu kommen; ihre Ermittelung bildet einen dankbaren Gegenstand für fernere Untersuchungen.

Den aufgezählten Fällen scheint sich noch Polydesmus exitiosus (Kühn, Krankh. d. Culturgew.) anzuschliessen; und ferner dürften fortgesetzte Lntersuchungen ergeben, dass die Keimschläuche der verschiedenen Sporenformen von Sphaeriaceen, welche auf lebenden oder abgestorbenen grünen Pflanzentheilen gefunden werden (Pleospora, Stignatea u. s. f.) in die Stomata der lebenden Pflanze eindringen, um sofort oder nach dem Absterben letzterer die Weiterentwicklung zu beginnen. Wenigstens spricht hierfür eine Anzahl gelegentlicher Beobachtungen.

Bei einer zweiten Reihe von Schmarotzerpilzen und Sporenformen dringen die Keime nie in eine Spaltöffnung, selbst wenn die Spore auf einer solchen liegt, sondern bohren sich durch die Epidermiszellen ins Innere der Nährpflanze ein. Hierher gehören die gegenwärtig bekannten Sporidienkeime der Uredineen und Peronosporen (Fig. 82) mit den oben angeführten Ausnahmen, und, nach J. Kühn die Keime von Tilletia Caries, wahrscheinlich auch die von Claviceps und Protomyces. Der Keimschlauch dieser Sporen (er entsteht überall leicht unter allei-

Fig. 81. Urom yces a p pendiculatus. Vergr. 195. $a$ Uredospore, keimend. $b$ Ebensolche, Keimschlauch eindringend in eine Spaltöffnung der Blattunterfläche von Faba vulgaris $\mathbf{M c h}$.

$c$ Querschnitt durch ein Blatt von Faba vulgaris. Von der Spaltöffnung $s$ aus ein verzweigter Keimschlauch in das Parenchym eintretend. 
niger Gegenwart von Wasserdunst) wendet sich nach meist kurzem Verlaufe gegen die Aussenwand der Oberhautzelle, stemmt sein Ende fest auf diese und treibt dann durch die Zellenwand hindurch einen dünnen, auch bei starker Vergrösserung meist nur als einfacher Strich erscheinenden Fortsatz; die Spitze dieses schwillt, sowie sie in den Innenraum der Zelle getreten ist, zu einer erst rund-

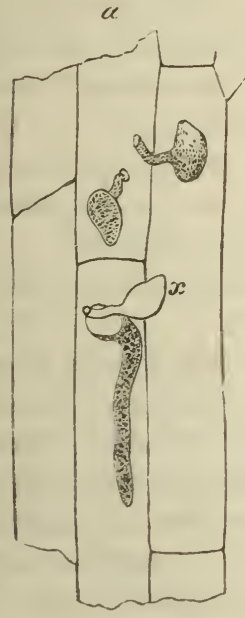

Fig. 82.

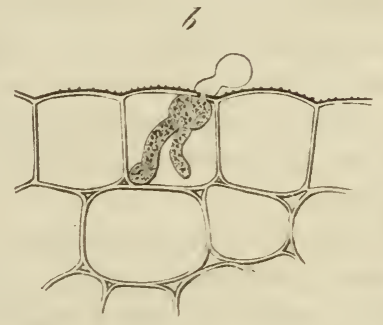
befindliche Schlauch an der Eintrittsstelle befestigt ist. Der eingedrungene Schlauch wächst nun beträchtlich, verzweigt sich oft noch innerhalb der Epidermiszelle und durchbohrt endlich die Innenwand dieser, um sich in dem darunter liegenden Gewebe zum Mycelium zu entwickeln.

Wenig von dem beschriebenen Vorgange verschieden ist das Eindringen der Pythien und Chytridieen. Die zu Ruhe kommende Schwämspore setzt sich hier auf die Zellen der Nihrpflanze fest und treibt meist unmittelbar jenen oben beschriebenen feinen, die Zellwand durchbohrenden Fortsalz. Das eingedrungene Ende dieses verhailt sich im Wesentlichen wie oben beschrieben wurde.

Bei wenigen Parasiten endlich - Peronospora infestans und parasitica treten die Keimschliuche ohne Unterschied sowohl in die Spaltöffinungen als durch die Zellwiinde ein.

Sämmtliche in die Oberhautzellen eindringenden Keime durchbohren nur die Zellwände bestimmter Nährspecies; auf der Epidermis jeder anderen Pflanzenart verhatten sie sich wie auf Glasplatten: sie treiben Keimschliuche nach beliebiger Richtung und gehen sammt letzteren bald zu Grunde (die der Chytridieen ohne Keimschlïuche getrichen zu haben). Bei sehr zahlreichen Untersuchungen habe ich von dieser Regel nur die einzige Ausnahme gefunden, dass die Keime

Fig. 82. Vergi. 390. $a$ Uromyces appendiculatus, Sporidien keimend auf der Stengelepidermis von Faba vulgaris Mch.; der Keimschlauch der einen $(x)$ in eine Epidermiszelle eingedrungen und bedeutend gewachsen.

$\checkmark$ Peronospora infestans Mont. Zoospore keimend und Keimschlauch eindringend in eine (quer durchschnittene) Epidermiszelle von einem Kartoffelstengel. Das Präparat 17 Stunden nach der Aussaat gemacht. 
der auf Anemonen schmarotzenden Peronospora pygmaea Lnger einmal in die Epidermis von Ficaria ranunculoides eindrangen, um jedoch sofort abzusterben. Die meisten der in Rede stehenden Keimschläuche durchbohren sowohl zarte, jugendliche Epidermismembranen, als auch stark verdickte und cuticularisirte, wenn auch an jenen das Eindringen augenscheinlich leichter und schneller stattfindet. Ein hiervon verschiedenes Verhalten ist bis jetzt nur für die Sporidienkeime ron Endophyllum Euphorbiae (und für Synchytrium) bekannt. Erstere dringen nur in die Epidermis der jungen, mit den Sporidien in demselben Frühling entwickelten Blätter der Nährpflanze - Euphorbia amygdaloides L. - ein, in die überwinterten nicht. Synchytrium Taraxaci und ohne Zweifel auch die ihm verwandten Formen dringt nur in junge unentwickelte Organe seiner Nährpflanze, in völlig entfaltete, wenn auch noch jugendliche, dagegen niemals.

Von den Kräften, welche bei der Einbohrung in die Oberhaut wirksam sind, haben wir noch keine nähere Kenntniss.

Alle pflanzenbewohnenden ächten Parasiten kommen nur auf jeweils ganz bestimmten Species von Nihrpflanzen zur Entwickelung, sei es, dass eine Schmarotzerspecies nur auf einer einzigen, oder auf einer Anzahl verwandter Nährpflanzenarten wohnt. Jeder Blick in die beschreibende Pilzlitteratur liefert hierfür eine Fülle von Beispielen. Hier seien nur Peronospora Radii, Cýstopus Bliti, Rhytisma Andromedae, dem sich viele verwandte Formen anschliessen, Triphragmium Ulmariae, Tr. echinatum beispielsweise als Species genannt, welche erst auf einer Nährpflanzenart gefunden wurden, ferner die WeintraubenErysiphe, welche bei uns wenigstens nur Vitis vinifera befällt; und von solchen, die eine Reihe von Species bewohnen, z. B. Cystopus candidus auf vielen Cruciferenarten; Peronospora infestans Mont. auf Solanum tuberosum L., seinen knollenbildenden nächsten Verwandten und S. Dulcamara, S. laciniatum, S. Lycopersicum L.; Sphaeria typhina auf Gramineen: Rhytisma acerinum u. s. w. Bei den Parasiten, welche mehrere Nahrspecies bewohnen, sind diese fast immer Angehörige derselben Gattung oder wenigstens natürlichen Familie. Manchmal sind einzelne Arten einer Familic zur Ernährung eines Parasiten geeignet, andere nicht; so entwickelt sich Puccinia Compositarum Schl. z. B. auf Taraxacum, Cirsium arvense, aber nicht auf Tragopogon. Das von Berkeley angegebene Vorkommen von Peronospora infestans Mont. auf Anthocercis viscosa, einer neuholliindischen Scrophularinee, das von mir angegebene Vorkommen der Cruciferen bewohnenden P. parasitica auf Reseda luteola sind unter den endophyten Schmarotzern jedenfalls seltene, noch der Prüfung bedürftige Ausnahmefialle. Grösser scheint die Mannigfaltigkeit der Nährpflanzen bei der jedenfalls vorwiegend epiphytischen Gattung Erysiphe, wenigstens bei manchen Arten derselben, zu sein. E. guttata z. B. bewohnt (nach Tulasne, Capol. I, p. 159) die Bläter von Corylus, Carpinus, Fagus, Betula, Crataegus, Fraxinus; auch E. communis scheint über vielerlei Phanerogamen verbreitet $\mathrm{zu}$ sein; doch haben hier erst ausfühilichere Untersuchungen die Grenzen dieser Species sicherzustellen. Ueberhaupt ist zu erwarten, dass genauere mikroskopische Untersuchungen die Zahl der Schmarotzerspecies vielfach vermehren und gleichzeitig die Anzahl der Nährspecies, welche die einzelne Art bewohnt, vermindern werden.

$\mathrm{Zu}$ den einzelnen Organen und Geweben ihrer Nährpflanzen zeigen die verschiedenen Arten von Parasiten verschiedenes Verhalten. Es ist seit lange be- 
kannt, dass die Fructification vieler Parasiten nur auf bestimmten Organen, Wurzeln, Blättern, Früchten u. s. w. ihres Wirthes gefunden wird. Genauere Untersuchung zeigt ferner, dass die einzelnen Arten der Endophyten ihre verschiedenen Fortpflanzungsorgane constant in oder auf bestimmten Geweben der befallenen Theile bilden: Im Innern des Parenchyms, inter- oder intracellulär (z. B. Ustilagineen, Protomyces, Sexualorgane der Peronosporeen); sehr oft unter der entweder unverletzten, oder zuletzt aufreissenden Epidermis $\mathbf{z}$. B. Credineen, viele Pyreno- und Discomyceten); in manchen Fällen bilden sich die Fruchtlager selbst zwichen den Epidermiszellen und der Cuticula oder den Cuticularschichten. letztere abhebend und zuletzt oft in verschiedener Weise perforirend (Rhỵtisma Andromedae, Exoascus Pruni, Spermogonien von Puccinia Anemones u. a. m. : endlich treten viele endophyte Pilze zum Behufe der Fruchtbildung an die Aussenfläche, theils durch die Stomata, theils indem sie die Hyphen die Oberhautzellen perforiren und aussen die Fruchtträger entwickeln (Conidientriger von Peronospora, Ustilago hypodỵtes, Sorisporium Saponariae, Sphacria typhina u. s. f.) Auch die in Algenzellen lebenden Pythien sind hier zu nennen, und es ist die Frage, ob niçht selbst das epiphỵtische Mỵcelium von Eṛ̣siphe (soweit es sich nicht aus den Conidien entwickelt) urspriinglich aus dem Innern der befallenen. Pflanze auf ihre Oberfliche tritt. Nicht minder verschieden ist die Verbreitung des Myceliums und selbst das Verhalten der eindringenden Keime. Bei den Parasiten, welche phanerogame P'llanzen bewohnen, kennt man in dieser Beziehung hauptsiichlich für vielerlei Einzelheiten ist auf die Monographien zu verweisen folgende Fialle.

1) Die Keime dringen in Stengel, Blitter und Blithentheile an jeder beliebigen oder, für die oben bezeichneten Fälle, an jeder mit Spaltöffnungen versehenen Stelle ein, das Mycelium entwickelt sich und fructificirt hier; und überschreitet nicht die nïhste Umgebung des Ortes, wo das Eindringen stattfand, es geht z. B. nicht über das Foliohum, wo es sich entwickelte, hinaus. Hierher viele Lredineen, z. B. l'uccinia graminis, P. straminis, Lromyces Phascolorum, U. appendiculatus u. s. f.

2) Die Keime dringen uiberall ein, wie in dem ersten Falle, oder entwicheln sich (bei Epiphyten) auf jedem Punkte der Oberflïche, das Mycelium überwuchert oder durchwuchert von den Punkten seiner ersten Entwickelung aus die ganze Pflanze oder doch weite Strecken derselhen und fructificirt allerwirts. Hierher viele Erysiphen, z. B. E. communis, Peronospora-Arten, z. B. P. Alsinearum, P. Ficariae, auch wohl P. infestans u. a.

3) Eindringen und Verbreitung des Myceliums wie bei dem zweiten Fall, aber Fruchtbildung nur oder ganz vorzugsweise in bestimmten Organen. Endophỵllum Sempervivi dringt im Frühling in jedes beliebige Blatt der Nährpflanze ein, durchwuchert alle Theile letzterer und fructificirt im nächsten Frübling in den juingeren der überwinterten Bläter.

4) Eindringen, Myceliumentwickelung und Fructification erfolgt nur an einem bestimmten Organe ( $z$. B. Fruchtknoten) der Nïhrpflanze, die ganze parasitische Entwickelung des Pilzes verliuft in diesem Organe: Claviceps (S. 36 u. 198).

5) Das Eindringen geschieht an bestimmten Punkten, das Mycelium durchwächst von diesem aus die ganze Nährpflanze, um fern von der Eintrittsstelle, aber wiederum in bestimmten Organen zu fructificiren. Für Endopḥ̣llum 
Euphorbiae ist der Ort des Eindringens oben angegeben worden; das durch die ganze Nährpflanze verbreitete Mycelium fructificirt nur in den Blättern der jungen (durch den Pilz verunstalteten) Blüthenstengel. Tilletia Caries dringt in die Achse (vielleicht auch die Würzelchen) der keimenden Weizenpflanze ein, das Mycelium wächst mit dem Stengel dieser empor, um in den Fruchtknoten zu fructificiren. Aehnlich verhält sich Ustilago destruens, U. Carbo Tul. (nach Hoffmann) und wohl die meisten in Blüthen und Früchten sporenbildenden Ustilagineen. Cystopus candidus treibt, auf Capsella und Lepidium sativum, zwar in sämmtliche Spaltöffnungen seine Keimschläuche, diese entwickeln sich aber nur dann weiter, wenn sie in die Cotyledonen eingetreten waren. Das Mycelium durchwächst von hier aus die ganze oberirdische Pflanze, um sowohl in allen grünen Organen, als vorzugsweise den Blüthen und Inflorescenzen zu fructificiren. An manchen Cruciferen, z. B. der saftigen Heliophila crithmifolia, vermögen die eingedrungenen Keime sich auch in den anderen Blittern zum Mycelium zu entwickeln, hier verhalt sich der Parasit wie unter 2) angegeben wurde.

Für viele Schmarotzerpilze wissen wir zur Zeit, dass ihr Mycelium durch die ganze Nährpflanze, oder doch weite Strecken derselben verbreitet ist und nur in bestimmlen Organen fructificirt, ohne von dem Eindringen Kenntniss zu haben; ob sie unter ä) oder 3) gehören ist daher zweifelhaft. ¡Beispiele: Sphaeria typhina, Uromyces scutellatus (Aecidium Euphorbiae Cyparissiae), Puccinia Anemones, Aecidiumforn ron Pucc. Tragopogonis, Ustilagineen, Peronospora Radii dBy u. s. f.

Von dem Perenniren endophyter Mycelien ist im zweiten Capitel (Seite 42) die Rede gewesen.

Eine weitere Eigenthümlichkeit mancher Endophyten mit pleomorpher Fortpllanzung besteht darin, dass sie zwar die ganze Nährpflanze durchwuchern und auf den verschiedenartigen Theilen dieser Reproductionsorgane bilden, aber bestimmte Fortpflanzungsorgane nur auf oder in bestimmten Theilen des Wirthes entwickeln. Cystopus Bliti bildet seine Conidien nur auf den Blattern, Oosporen nur in den Stengoeln der Nïhrpflanze (Amarantus Blitum ${ }^{-}$Auct.), Cyst. candidus bildet Conidien reichlich auf allen oberirdischen Organen seiner Nährpflanzen; seine Oosporen fand ich niemals in Laubblattern; manche Peronospora-Arten verhalten sich : ihnlich, z. B. die P. Arenariae Berk. auf Möhringia trinervia.

Ferner ist eine Anzahl pflanzenbewohnender Parasiten mit pleomorpher Reproduction bekannt, welche mehrere oder viele Nihhpflanzen bewohnen, auf allen Sporen bilden, aber, wenigstens in den Gegenden, wo die bisherigen Untersuchungen stattgefunden haben, nur auf einzelnen bestimmten Arten auch ihre Fructification, d. h. die höchstorg̨anisirten, den Gipfelpunkt der Entwickelung bezeichnenden Fortpflanzungsorgane. Von mehreren hierher gehörigen Fällen aus der genauer untersuchten Gruppe der Peronosporeen sei hier nur Crstopus cubicus erwähnt, ein Parasit, welcher auf Trayopogon-, Podospermum-, Scorzonera-Arten üppig gedeiht und Conidien entwickelt, mit Oosporen dagegen bis jetzt ausschliesslich - aber sehr häufig - auf Scorzonera hispanica gefunden worden ist. Aehnliches findet sich bei manchen Uredineen, bei Erysiphe-Arten, und es dürfte hier der Ort sein, die Erysiphe der Weintraubenkrankheit zu erwähnen. Trotz seiner verderbenbringenden weiten Verbreitung bildet dieser 
Parasit der Weinrebe östlich rom Rhein und nördlich von der Alpenkette nur Conidien Oidium Tuckeri Berk. ; in den transalpinen Ländern und dem westlicheren Europa ausserdem auch Pycniden (Ampelomyces Cesati, Cicinobolus Ehrbg.). Seine Perithecien sind bis jetzt unbekannt, die sichere Bestimmung der Species daher unmöglich. Ob die Perithecien auf anderen Nährspecies als Vitis vinifera zur Entwickelung kommen, welche diese und welches ihr Vaterland ist, muss noch untersucht werden.

Von solchen pleomorphen Arten, welche, wie die Uredineen, einen typischen Generationswechsel zeigen, können viele ihren ganzen Entwickelungsgang auf einer einzigen Nährspecies durchlaufen, oder beliebig zwischen einigen Arten von Wirthen wechseln. So lïuft z. B. die ganze Entwickelung von Uromyces Phaseolorum auf Phaseolus-Arten ab, die von Ur. appendiculatus auf Vicieen: Puccinia Tragopogonis auf Tragopogon; P. reticulata auf Mrrrhis und Chaerophyllum: P. Falcariae auf Falcaria Rivini; Puccinia Violarum auf Viola silvestris und Verwandten u. s. f. Ich nenne solche Parasiten a u töcische. Bei andern. die ich heteröcische nenne, ist dagegen, wie von vielen parasitischen Helminthen aus den Ordnungen der Trentatoden, Cestoden u. s. f. seit längerer Zeit bekannt ist. der Generationswechsel oder die Metamorphose mit Nothwendigkeit an einen bestimmten Wechsel des Wirthes gebunden. Ich habe eine solche Heteröcie zuerst für Puccinia graminis nachgewiesen, für welche sie, oder doch ihre Folgen, schon seit mehr als 100 Jahren den Landwirthen bekannt war, die trotz des Widerspruches der Botaniker, die Behauptung aufrecht erhielten, Getreide werde in der Nähe ron (äcidiumtragenden) Berberitzenstriuchern rom Roste, d. h. der Puccinia graminis, befallen. Dieser Parasit zeigt den oben beschriebenen Pleomorphismus und Generationswechsel der Lredineen in seiner reichstgegliederten Form (vergl. pag. 18\%). Seine Teleutosporen überwintern auf den alten Ilalmen cultivirter und wildwachsender Gramincen (zumal Tritieum repens', die Keimschliuche der im Frühling entwickelten Sporidien dringen in die Epidermiszellen von Berberis vulgaris ein und nur in diese, nie in eine Graspflanze. Sie wachsen in der Berberis rasch zu einem icidiumbilelenden, nie Uredo-oder Teleutosporen erzeugenden Mycolium heran (Aecidium Berberidis Gm.), und die heinschlauche der Aecidiumsporen entwickeln sich, wenn sie in die Stomata geeigneter Gramineen - und nur dieser - eingetreten sind, zu dem Lredo- und Teleutosporen bildenden Myeelium. Die Keimschliuche der Uredosporen entwickeln sich ihrerseits nur in Gramineen weiter, und zwar auf die für sïmmtliche Lredosporen beschriebene Weise.

Andere grasbewohnende Puccinien, deren Entwickelung ich bis jetzt rerfolgen komnte, sind in ganz derselben Weise heteröcisch wie Puccinia graminis, nur dass sie ihre Aecidien in anderen dicotylen Gewähsen entwickehn: Pucc. Straminis Fuckel in Borragineen (Anchusa, Lycopsis, - Aecidium Asperifolii P. ; Pucc. coronata Corda in Rhamnus Frangula und c a thartica (A ec. R ham n i P.) Oersted hat, nach einer kürzlich vertheilten vorliufigen Mittheilung, nachgewiesen, dass Pod is o m a Juniperi Sabinae eine heteröcische Uredinee ist; die aus ihren (durchaus mit Puccinia conformen) Teleutosporen entwickelten Sporidien dringen in die Blätter der Birnbäume, um hier die als $\mathrm{R}$ oest elia cancellata allgemein bekannte Aecidienform auszubilden. Auch für diesen Fall von Heteröcie waren schon rorher durch im Grossen gemachte 
Erfahrungen Andeutungen vorhanden (vergleiche Botanische Zeitung 1862, p. 288.)

Wie ich anderwäts ausführlicher angedeutet habe, ist zu erwarten, dass in der Heteröcie der Schlüssel zur Ermittelung vieler gegenwärtig noch räthselhafter Pilzentwickelungen gefunden ist - ein Schlüssel, der freilich vorsichtige Handhabung erfordert.

Schliesslich ist hervorzuheben, dass das Eindringen und die Entwickelung aller bisher näher untersuchten ichten Pflanzenparasiten keineswegs irgend eine Erkrankung oder «krankhafte Prädisposition» ilı'es Wirthes voraussetzt, was öfters behauptet worden ist, sondern dass dieselben völlig gesunde Pflanzen befallen. Es mag sein, dass Gewächse, zumal Culturpflanzen, in Folge von Ernährungsanomalien die Vegetation des Parasiten mehr fördern, demselben besser zusagen, als in ihrem völlig normalen und gesunden Zustande, allein es liegt kein Grund vor, ęinen krankhaften Zustand des Wirthes als Bedingung für die Entwickelung des Parasiten anzusehen. In der Regel dürfte im Gegenthcil ein Parasit um so besser gedeihen, je besser seine Nährpflanze ernährt ist. Und daran ist kein Zweifel, dass der Tod und die beginnende Füulniss der Nährpflanze immer den Parasiten tödten und nicht etwa, wie man oft gesagt hat, seine Entwickelung fördern oder gar erst ermöglichen. Behauptungen dieser Art beruhen theils auf der Mangelhaftigkeit früherer Untersuchungen, theils auf Verwechslung ächter Schmarotzer mit den auf bestimmte faulende Pflanzentheile angewiesenen Saprophyten.

Von der Vegetation der thie rbewohnenden Parasiten weiss man zur Zeit sehr wenig. Eine ziemliche Anzahl von Pilzen entwickelt ihr Mycelium in dem Körper lebender Gliederthiere, zumal Insecten, auf Kosten der Organe des Thieres und beginnt entweder schon zu Lebzeiten des letzteren die Fruchtträger aus der Körperoberfliache hervorzutreiben, wie bei den im vorigen Jahrhundert berühnten »regetirenden“ Insecten Westindiens. (Muscae vegetantes, Guèpes végétantes), oder fructificirt in den meisten Fällen erst nach dem unter eigenthümlichen Symptomen eingetretenen Tode des Thieres (Entomophthora, Botrytis Bassiana, Cordyceps s. Torrubia mit ihren Vorformen, vergl. Seite 175, 197).

Säet man die Sporen von Botrytis Bassiana, dem Muscardinepilz, auf den geeigneten Wirth, d. h. auf die lebende Seidenraupe, und nach Audouin auch andere Raupen (z. B. Papilio Machaon, Bombyx Neustria u. a.) aus, so wird das Thier von der Muscardine befallen, d. h. das Mycelium beginnt in der lebenden Raupe seine Entwickelung, und treibt, nachdem vor oder nach der Einpuppung, oder selbst nach dem Ausschlüpfen aus der Puppe der Tod eingetreten ist, seine zahlreichen schneeweissen Fruchthyphen aus dem mumienartig erstarrenden Körper hervor. Man erhält das gleiche Resultat, wenn die Sporen durch einen kleinen Hautstich eingeimpft oder nur aussen aufgestreut werden. Als jüngstes Entwickelungsstadium des Pilzes findet man einige Zeit vor dem Tode des Thieres zarte cylindrisch-spindelförmige, stumpfe Schläuche in der Blutflüssigkeit schwimmend. Die kleinsten derselben sind etwa $1 / 450 \mathrm{Mm}$. lang, viertels-oder drittelsso breit, alle Uebergänge von ihnen zu grösseren und zu verzweigten septirten Myceliumf:iden leicht zu beobachten. Wie sie sich entwickeln und bei blossem Aufstreuen der Sporen in die Körperhöhle gelangen, ist unbekannt. Da die Sporen in feuchter Luft und im Wasser leicht keimen, und nach den für die 
endophyten Pilze bekannten Thatsachen ist es wahrscheinlicher, dass die Keimschläuche die Haut durchbohren und im Innern der Leibeshöhle die Schläuche auf irgend eine Weise bilden (abschnüren?), als dass die runden Sporen als solche eindringen, und erst im Innern keimen, wie früher angenommen und ron Robin ausführlich erklärt wurde. Dass das ausgebildete Mỵcelium auf Kosten der Organe des Thieres lebt und diese fast aufzehrt, ist längst bekannt.

Soweit es aus den mitgetheilten Beobachtungen und aus ineinen wenigen eigenen Versuchen beurtheilt werden kann, ist kein zwingender Grund vorhanden, anzunehmen, dass die Entwickelung des Muscardinepilzes eine vorherige Erkrankung seines Wirthes nothwendig voraussetzt - eine Annahme, welche Robin für sämm tliche thierbewohnende Schmarotzerpilze aufstellt, und welche zwar nirgends experimentell widerlegt, aber für den vorliegenden und verwandte Fälle ebenso wenig bewiesen und, der Analogie zufolge, unwahrscheinlich ist. Die bekannten Thatsachen gestatten die Annahme, dass Botrytis Bassiana in die gesunde Raupe eindringt und sich in dieser ausbildet. Für die oben genannten übrigen insectenbewohnenden Gattungen, bei denen über das Eindringen noch gar nichts bekannt ist, darf auf Grund der übereinstimmenden späteren Entwickelungserscheinungen ein dem Muscardinepilz ähnliches Verhalten wenigstens vermuthet werden.

Erwähnt muss hier noch werden Lebert's P a n h is t oph y 10 n, Nägeli's Nosema Bombycis, die kleinen länglichen Körperchen, welche bei der gegenwärtig so verheerenden epidemischen Krankheit der Seidenraupe Gattine, Necrose) in dem kranken Thiere massenhaft gefunden werden. Ueber die Herkunft jener Körperchen, ihre causalen Bezichungen zur Krankheit liegt allerdings noch nichts Sicheres vor; ob sie überhaupt zu den Pilzen gehören, ist zweifelhaft. Leydig hat solche Gebilde auch in andern Insecten und in Daphnien gefunden.

Auf und in dem Körper höherer Thiere kommt eine Anzahl parasitischer Pilze in Begleitung von jeweils besonderen Krankheitssymptomen vor. Sie sind auf dem menschlichen Körper an genauesten untersucht (vergl. Robin's reichhaltiges Sammelwerk oder Küchenneisters Lehrbuch), die wichtigsten, hier zu erwihnenden: Achorion Schoenleinii Remak, der Pilz des Favus oder der Porrigo lupinosa; Trichophyton tonsurans Malmsten (Pilz der Tinea oder Herpes tonsurans, nach Köbner identisch mit dem Pilze der Sycosis oder Mentagra parasitica, Microsporon Audouini und M. Mentagrophytes Rob.); M i c r os p oron furfur Rob. (Pityriasis vérsicolor); Oidium albicans Rob., der Pilz des Soor (Mundschwimmchen, Muguet, Stomatitis pseudomembranacea etc.); Chiony phe Carteri Berk.

Die drei erstgenannten Pilze, denen sich andere, in der medicinischen Litteratur beschriebene, vi e ll e i c h $t$ specifisch verschiedene anschliessen, bewohnen die menschliche Haut bei ihren oben genannten charakteristischen Erkrankungen. Sie wuchern in und unter der Epidermis, in den Haarbälgen und Haaren. Trichophyton tonsurans ist auch auf Rindern, Pferden, Hunden, Kaninchen, Achorion auf der Ilausmaus, dem Kaninchen, dem Kopfe des Haushuhns beobachtet werden; Microsporon furfur wurde ron Köbner auf Kaninchen mit Erfolg übertragen. Alle drei sind also Parasiten, welche verschiedenerlei Säugethiere und Vögel bewohnen können. Sie lassen sich durch Aussaat ihrer Sporen von einem Individuum auf andere, von Menschen auf Thiere und umgekehrt übertragen, 
und mit ihrer Entwickelung tritt die jeweils characteristische Krankheitsform auf. Köbner übertrug alle drei genannten Pilze nebst den betreffenden Erkrankungen der Haut auf sich selbst; schon Remak säete den Favus auf seinem Vorderarm an; nach diesen Versuchen und zahlreichen, damit übereinstimmenden Erfahrungen dürfte es jedenfalls sehr zweifelhaft sein, dass die Vegetation genannter Schmarotzerpilze nicht auf gesunden Individuen stattfindet, und dass sie cine krankhafte Pridisposition ihres Wirthes - oder jede Species eine besondere Prädisposition - als nothwendig voraussetzen. Allerdings mögen Gründe vorliegen, welche dafür sprechen, dass gewisse Präidispositionen des Patienten die Entwickelung der oder eines bestimmten Pilzparasiten wenigstens begünstigen; Gründe, deren Discussion zu sehr auf medicinisches Gebiet führen würde, um hier Platz finden zu können.

Eine Frage, welche hier erörtert werden muss, ist dagegen die, ob die genamnten Pilze wirklich besonderen eigentlich parasitischen Species angehören oder nicht. Was man von Organen derselben bis jetzt kennt, sind lediglich Myceliumfäden, deren Zweige sich zu Reihen oder Ketten keimfähiger Sporen abgliedern, etwa wie dic Zweige des Myceliums von Mucor Mucedo, aus denen sich die reihenweise verbundenen Brutzellen entwickeln (Seite 179). Eigentliche, die Species characterisirende Fructificationsorgane sind nicht bekannt. Bei der Häufigkeit in Rede stehender Erkrankungen und ihrer Begleiter liegt es daher nahe, die vollständige Fructification letzterer anderwärts, und zwar in bekannten Pilzformen zu suchen. Cultivirt man den vom Thierkörper weggenommenen Parasiten in Wasser, Zuckerlösung u. s. w. , so wird die Keimung seiner Sporen beobachtet, und nach kurzer Zeit treten in der Cultur allverbreitete Schimmelformen, wie Penicillium glaucum, Aspergillus glaucus, oder Hefezellen auf; letztere und die Mycelfïden des Penicillium gleichen mehr oder weniger den Sporen und dem Mycelium fraglicher Parasiten; sie stehen mit diesen in unmittelbarer Beruhıung, so dass es scheint, als entwickelten sie sich, nach Verinderung des Mediums, aus denselben. Daher die vorzugsweise in England vertretene, von Tilbury Fox bis zur Carricatur ausgemalte Ansicht: Achorion, Trichophyton u. s. w. sind weiter nichts als brutzellenbildende Mycelien gewöhnlicher Schimmel- und Fermentpilze, zumal Penicillium, Hormiscium Cerevisiae, entwickelt auf dem zu ihrer Ausbildung irgendwie besonders pradisponirten Thicrkörper. Je nach der speciellen Prädisposition des letzteren kann sich derselbe Schimmel entweder zu Achorion oder Trichophyton u. s. w. entwickeln.

Wenn man bedenkt, wie ungemein oft Penicillium und IIorm. Cerevisae in den verschiedensten sorgfailtigst gehaltenen Pilzculturen auftreten, und zwar nachweislich aus ihren allverbreiteten Keimen entstanden; wenn man ferner im Auge behält, dass ein Fernhalten dieser Keime von den in Rede stehenden Culturobjecten ein Ding der Lnmöglichkeit ist; und dass selbst von geübten Mycologen Penicillium-Mycelium mit dem anderer Pilze leicht verwechselt werden kann, Hefezellen mit Sporen; so wird die obige Meinung, in der Form, wie sie bis jetzt von offenbaren Nichtmycologen ausgesprochen wurde, im höchsten Grade zweifelhaft. Dass Aspergillus, Penicillium glaucum und Horm. Cerevisiae selber ganz gewiss keine eigentlichen Fructificationsformen ron Pilzspecies sind, kann dabei sellost ganz ausser Acht bleiben. Jedenfalls muss obige Ansicht so lange für unerwiesen gelten, und die fraglichen Pilze für eigentliche specifische Para- 
siten, als es nicht experimentell erwiesen ist, dass durch Aussaat von Penicillium, Torula etc. auf geeignete Hautflächen unzweifelhafter Favus, Herpes tonsurans u. s. f. mit den charakteristischen Pilzen, oder aus Aussaat von einem der letzteren ein anderer Hautpilz entsteht. Aussaaten dieser Art, welche in neuester Zeit von Köbner angestellt worden sind, haben, bis jetzt wenigstens, nur negative Resultate ergeben.

Oidium albicans Rob., eine ebenfalls nur im fructificationslosen, Brutzellen oder Conidien bildenden Zustande bekannte Pilzform, entwickelt sich und wuchert in dem Pflasterepithel der Nundhöhle, des Rachens, Oesophagus und Kehldeckels der Soorkranken (meist kleiner Kinder, seltener kachektischer Erwachsener) Ueber sein jedenfalls exceptionelles Vorkommen an anderen Organen scheinen die Pathologen noch nicht einig zu sein. In den weissen Membranen, welche als charakteristisches Symptom auf den erkrankten Organen auftreten, und zwar, nach A. Vogel, in dem z we ite n Stadium der Krankheit, ist der Pilz massenhaft vorhanden. Bedingung seines Auftretens ist nach dem genannten Gewährsmann eine vorhergehende entzündliche Affection der Mundschleimhaut, verbunden mit dem Auftreten wenn auch geringer Menge freier Säure auf derselben. Die gesunde Schleimhaut befällt er nach den meisten Autoren nicht; Gubler berichtet jedoch über einige Versuche, bei denen Pilz und Krankheit mit Erfolg auf gesunde Schleimhaut übergesiedelt wurden. Nach Vogel wächst der Pilz auch ausserhalb des Organismus, in nicht alkalischen Flüssigkeiten, wie Zuckerwasser, Brunnenwasser etc. Da solches auch in gewissem Maasse bei ächten Parasiten (Keimschlïuche der Uredineen, Peronospora u. s. f.) eintritt, so kann hieraus nicht gefolgert werden, dass $O$. albicans kein specifischer Parasit sei; rielmehr muss die Entscheidung hierüber ferneren Untersuchungen überlassen bleiben.

Als einer der bemerkenswerthesten Fälle von Vorkommen parasitischer Pilze in lebenden menschlichen Körper ist endlich der von Dr. H. V. Carter und H. J. Carter in Indien beobachtete Pilz zu nennen, der in Form schwarzer, bis halbzollgrosser, aus verflochtenen Hyphen bestehender Massen in den Knochen und tiefer liegenden Wegichtheilen des Fusses wächst bei schweren Geschwulstbildungen und Zerstörungen dieser Theile. Eine genauere Beschreibung dieses Pilzes ist wohl von Berkeley zu erwarten, der ihn Chionyphe Carteri genannt hat; uber seine Entwickelungs- und Vegetationsbedingungen ist meines Wisșens noch nichts Positives bekannt.

Die angegebenen Beispiele genügen, um darzuthun, wie wenig über die Vegetationsbedingungen in Rede stehender Pilze bekannt und wie sehr ein genaueres Studium derselben im Interesse der Mỵcologie und Pathologie wünschenswerth ist. Für weitere Einzelheiten muss hier auf die medicinische Litteratur verwiesen werden.

Unzweifelhaft ist es auf der anderen Seite, dass in ziemlich zahlreichen Fällen aichte Schimmelpilze, Saprophyten, in und auf lebenden Thieren und Menschen gefunden werden, angesiedelt auf krankhaft veränderten und in Zersetzung begriffenen Organen oder Secreten. So besonders die Aspergilli und verwandte Formen - ihr richtiger Name dürfte wohl meistens Asp. glaucus und Penicillium glaucum lauten - in den Bronchien, Lungen, Luftsäcken von Vögeln, Säugethieren und Menschen, in dem menschlichen äusseren Gehörgange u. s. w. Virchow hat sie schon in der unten zu nennenden schönen Arbeit als secundäre 
Ansiedler auf zersetzten Theilen klar bezeichnet. Vom mycologischen Gesichtspuncte aus bedürfen sie allerdings noch genauerer Bearbeitung.

Schliesslich ist hier der Pilze kurz zu gedenken, welche im Innern intacter, angeblich frischer Hühnereier gefunden und solange mit besonderem Interesse betrachtet wurden, als man keine klare Kenntniss davon hatte, dass die Hyphen der Pilze durch Membranen hindurch in geschlossene Höhlungen einzudringen vermögen. Zur Zeit handelt es sich zunächst darum, die in den Eiern gefundenen Pilze genauer zu untersuchen und zu bestimmen, als seither geschehen ist. Erst wenn dieses gethan ist, wird es möglich sein, zu entscheiden, ob es sich hier um specifische Parasiten oder um Schimmel und Saprophyten handelt.

\section{L i t e r a t u r.}

a) Pflanzenbewohnende Parasiten.

Siehe die oben bei den Uredineen citirten Arbeiten, zumal von

Tulasne, Kühn, de Bary, Hoffmann's Mycol. Bericht. Bot. Ztg. 1865, p. 74.

Kühn, Durieu, über Claviceps. Vergl. Seite 198 und 199.

Oersted, Om Sygdomme hos Planterne. Kjobenhavn 1863.

Oersted, Compt. rend. provisoire de quelques observations sur le Podisoma Sabinae et la Roestelia cancellata.

de Bary, Die gegenwärtig herrschende Kartoffelkrankheit. Leipzig 1861.

Die ältere Litteratur findet sich in den genannten Arbeiten citirt.

Auch die Arbeiten über Chytridium sind hier zu nennen :

Cohn, Unters. über Entw. der mikr. Algen u. Pilze. Nov. Act. Acad. Nat. Cur. 1854.

A. Braun, Ueber Chytridium. Monatsber. Berlin. Acad. 1855 u. 1856. Abhandl. Berl. Acad. 1855 .

Cienkowski, Bot. Ztg. 1857, pag. 233.

Schenk, Verhandl. Physik. Med. Ges. Würzburg, T. VIII, IX.

de Baryu. Woronin, Beitr. z. Kenntn. der Chytridieen. Ber. Naturf. Ges. Freiburg. Bd. 3, Heft 2, p. 22.

b) Parasiten des Thierkörpers:

Ch. Robin, Histoire naturelle des végétaux parasites qui croissent sur l'homme et sur les animaux vivants. Paris 1853. (Reiches Sammelwerk; für die ältere Litteratur, die hier nicht aufgezählt wird, zu vergleichen).

Berkeley, On some entomogeneous Splıaeriae. Hooker's Journ. of Bot. Vol. II (1843), p. 205 .

Lebert, Colın, Bail, Fresenius, Ueber Entomophthora (vergl. Seite 175).

Le bert, Ueber einige Krankh. d. Insecten etc. Zeitschr. f. wissens. Zool. IX 1858), p. 439 .

Aufzählungen insectenbewohnender Pilze: Bail, Mycol. Studien (N. Act. Natur. Curios), und K irchner, in d. Zeitschr. Lotos, 1862, p. 73.

Ueber die gegenwärtige Krankh. der Seidenraupe vergl.:

Frey u. Lebert, in Vierteljahrsschr. naturf. Ges. Zürich 1856.

De Quatrefages, Mémoires de l'Acad. des Sciences. Tom. XXX (1860).

Leydig, in du-Bois-Reymond's u. Reichert's Archiv, 1863, p. 186.

Hoffmann's mycol. Bericht. Bot. Ztg. 1864, p. 30. u. a.

H. Hoffmann, Pilze im Bienenmagen. Hedwigia I, 117,

Keferstein, Paras. Pilze aus Ascaris mystax. Zeitschr. f. wiss. Zool. XI (1861). 
Kölliker, Ueber d. ausgebreitete Vorkommen von pflanzl. Parasiten in d. Hartgebilden niederer Thiere. Zeitschr. f. wiss. Zool. Bd. X (1859), p. 215.

Remak, Diagnost. u. Pathogen. Untersuchungen. Berlin 184ว, p. 193.

Reubold, Beiträge zur Lehre vom Soor. Virchow's Archiv f. pathol. Anat. etc. VII (1854), p. 76 .

A. Vogel, Beitr. z. Lehre vom Soor. Zeitschr. f. ration. Med. 2. Folge. Bd. 8 (1857). p. 317.

Gubler, Mucédinée du Muguet. Mém. de l'Acad. de Médecine. XXII_(nach Hoffmann's mycolog. Ber. Bot. Ztg. 1864, p. 37).

$\mathrm{K} \ddot{\mathrm{c}} \mathrm{ch}$ enme ister, Die in und an d. Körper d. lebenden Menschen vork. Parasiten. II. Lpzg. 1855 .

Virchow, Beitr. z. Lehre von den beim Menschen vork. pflanzl. Parasiten. Virchow's Archiv IX (1856), 557 .

Fresenius, Beitr. z. Mycol. p. 81.

Cramer, Ueber Sterigmatocystis. Vierteljahrsschr. Naturf. Ges. Zürich. 1859 u. 1860. Köbner, Ueber Sycosis etc. Virch. Arch. Bd. XXII (1861), p. 372.

Köbner, Klinische u. experimentelle Mittheilungen aus d. Dermatolog̣ie u. Sỵphilidologie. Erlangen 1864.

Strube, Exanthemata phyto-parasitica eodemue fungo efficiantur. Diss. inaugur. Berolin. 1863.

J. Lowe, On the identity of Achorion Schönleinii and other veg. parasites with Aspergillus glaucus. Ann. Mag. nat. History 2d. Ser. vol. 20 (1857), p. 152.

W. Tilbury Fox, Skin Diseases of parasitis origin. London 1863.

H. J. Carter, On the so called Fungus-Disease in India etc. Ann. Mag. nat. hist. 1862 (vol. IX), p. 442. Berkeley, über Chionyphe Carteri, Procedings Linn. Soc. 1864 (mir noch nicht näher bekannt).

Hogg, Vegetable Parasites infesting the human Skin. Trans. Micr. Soc. London. Vol. VII (1859), p. 39.

Weitere Litteraturangahen und Details s. in den citirten Schriften, zumal bei Robin, Küchenmeister; und in der Litteratur der Pathol. des Menschen.

Ueber Pilze in Eiern: Mosler, Mycol. Studien am Hülnerei. Virchow's Archiv. Band XXIX (1864). Robin l. c.

\section{Assimilation. Ausscheidung.}

Von den Besonderheiten, welche der Assimilationsprocess der Pilze, in Vergleich mit dem der grün gefärbten Vegetation darbieten muss, haben wir noch keine nähere kenntniss.

Was die Ausscheidungen wahrend des Vegetationsprocesses betrifft, so ist, wie lïngst bekannt, und neuerdings wiederum vielfach bestätigt worden ist (Pasteur, Jodin etc.), mit der Sauerstoffaufnahme aus der Luft Exhalation von Kohlensäure verbunden. Nach A. von Ilumboldt's Angabe, welche Decandolle und Marcet bestätigten, sollen die Fruchtträger grösserer, sowohl fleischiger als lederartiger Schwimme (im Dunkeln wenig) im Sonnenlichte beträchtliche Mengen von Wasserstoffgas exhaliren. So Agaricus campestris, androsaceus ( $\mathrm{v}$. Ilumboldt, Aphorismen), A. ericeus, deliquescens, phỵsaloides, leucocephalus (Marcet), Xylaria digitata, Bulgaria inquinans (Decandolle, Pflanzenphysiol. p. 460). Der Wasserstoff soll cine beträchtliche Menge - bis 70 Procent des ausgeschiedenen Gasgemisches - ausmachen, von dem nicht angegeben wird, ob es ausser- 
dem neben Stickstoff auch Koblensäure enthielt. Schlossberger und Döpping (vgl. Seite 9) konnten dagegen bei fleischigen Agaricis gar keine Ausscheidung von freiem Wasserstoff finden, jene älteren Angaben sind darum wenigstens noch einmal zu prüfen.

Sehr auffallend ist bei vielen Pilzen die Ausscheidung von Wasser. Von der Exhalation dunstförmigen Wassers ist hier, als von einer allen Landpflanzen zukommenden Erscheinung, nicht die Rede. Viele Pilze scheiden aber, wie zuzumal die neueren Mycologen oft gelegentlich bemerken, Wassertropfen in grosser Quantität aus, sobald sie von einer einigermassen feuchten Atmosphäre umgeben sind. Die Erscheinung findet sich besonders an den jugendlichen, in Ausbildung begriffenen Pilzen und hört auf mit dem Eintritt der Entwickelungshöhe und Reife. Sie zeigt sich sowohl bei freien Pilzfäden (Mucor, Pilobolus u. a.), als bei zusammengesetzten Pilzkörpern (Nyctalis asterophora, Hypochnus, Polypori spec, und vor allem bei den meisten Sclerotien; das Sclerotium ron Peziza Sclerotiorum insonderheit ist bis zu seiner Reife meist von grossen Wassertropfen bedeckt). Seltener (Merulius lacrymans P.) tropft von dem reifen Hymenium Wasser ab. Genaue Analysen des ausgeschiedenen Wassers fehlen. Bei Pilobolus zeigen die Tröpfchen saure Reaction (Coemans). An den jungen Sclerotien von Claviceps sind sie von reichlichen Mengen gelösten Zuckers (und Gummi?), die iibrigens vielleicht anderen Ursprung haben als das Wasser, nämlich diesem nur von dem Conidienlager her beigemengt werden, klebrig und süss schmeckend.

Die Ursache der Ausscheidung von Wassertropfen scheint, nach dem Verhalten von Pilobolus (vergl. Seite 146) wenigstens in manchen Fällen die gleiche zu sein, wie bei den Blättern phanerogamer Pflanzen; ob überall, ist noch zu untersuchen.

Von der Ausscheidung krystallinischen oxalsauren Kalkes ist in dem histiologischen Theile die Rede gewesen. Es ist leicht nachzuweisen, z. B. bei den sclerotienbildenden Pezizen, dass sie während des Wachsthums des Pilzes geschieht und mit oder schon vor seiner völligen Ausbildung aufhört.

III. Wärme-und Lichtentwickelung.

Es ist von vornherein anzunehmen, dass bei dem Oxydationsprocess der Respiration der Pilze Waime frei wird. Directe Beobachtungen hierüber sind nur wenige vorhanden: Pasteur erwähnt der Wïmeentwickelung bei der Vegetation von Mycoderma aceti; Dutrochet fand bei s Schwimmen aus den Gattungen Agaricus, Boletus und Lycoperdon eine Eigenwärme von 0,10 ${ }^{\circ}$ C. bis $0,45^{\circ}$ (Boletus aëneus; vgl. Ann. sc. nat., 2e sér. XIII, p. 81).

Bei einer Anzahl ron Pilzen hat man beobachtet, dass sie im Dunkeln ein oft helles phosphorescirendes, weisses, bläuliches oder grünliches Licht verbreiten. Es wird dieses theils von sterilen, wahrscheinlich Hymenomyceten angehörenden Mycelien angegeben, theils beobachtete man es bei den Rhizomorphen (Rh. subterranea und subcorticalis), theils bei den Fruchtträgern von mehreren Agarici : A. olearius DC. aus Südeuropa, A. Gardneri Berk. (Brasilien), A. igneus Rumph (Amboina), A. noctilucens Lér. (Manila) und nicht näher bestimmten, ron 
Jrummond gefundenen, neuholländischen Arten. Ausführliche Angaben, in denen auch die ältere Litteratur citirt wird, finden sich bei Nees von Esenbeck, Nöggerath und B isch off, Die unterird. Rhizomorphen, in N. Act. Ac. L. C. Nat. Cur. Vol. XI u. XII, 2; Schmitz in Linnaea 1843, p. 523. Tulasne, Ann. sc. nat. 3e Sér. IX, p. 338. Ferner: Hooker's Journ. of Bot. 1840, p. 426. 1842, p. 217. Flora, 1847, p. 756. Berkeley, Introd. to Crypt. Bot., p. 265. Th. Fries, Flora 1839 , p. 169 und in den pflanzenphysiol. Lehrbüchern.

Die Phosphorescenz findet bei den Rhizomorphen, wo sie von den fünf erstgenannten Autoren studirt wurde, und bei Ag. olearius, wo sie Tulasne und später Fabre (Cpt. rend. T. 41, p. 124:, Poggendorff's Ann. 18:6. Flora 1836, p. 220) genau untersuchten, an dem gesunden lebenden Schwamme statt, nicht an dem absterbenden oder abgestorbenen, wie früher behauptet worden war. Dasselbe gilt für die namhaft gemachten exotischen Agarici. Sie erlischt bei A. olearius, wenn derselbe sein Wachsthum vollendet hat, an dem kräftig wachsenden Fruchtkörper kommt sie an allen Theilen, manchmal auch auf Schnitt- und Bruchflachen vor, am intensivsten an den Lamellen. Bei Rhizomorpha leuchten caeteris paribus die schleimig klebrigen Enden junger Triebe, und die weissen Fadenbüschel, welche dem Ilervorbrechen letzterer aus den alten Stammen vorangehen (Seite 23), am intensivsten. Alte Stiimme leuchten oft nicht, oft strichweise, manchmal erscheinen die Stellen derselben, an denen später junge Triebe vorbrechen, als leuchtende Puncte, bevor aussen irgend eine andere Spur von Neubildung wahrnehmbar ist (Schmitz). Sowohl bei Rhizomorpha als bei 1 olearius geht das Leuchten continuirlich, ohne Intermission vorsich, kann an einem Exemplare mehrere Tage, resp. Wochen lang zu jeder Zeit beobachtet werden, es ist unabhïngig von vorheriger Einwirkung des Sonnenlichts. Bei $\Lambda$. olearius findet es bei jeder Temperatur zwischen $8-10^{\circ} \mathrm{C}$. und $50^{\circ} \mathrm{C}$. statl, unter genanntem Miminum erlischt es, um bei Temperaturerhöhung wieder aufzutreten, bei Erwärmung über $\% 0^{\circ}$ wird es für immer verniclıtet. Bei Rhizomorpha wurde das Leuchten zwischen $15^{0}$ und $31^{0}$ beobachtet, Maximum und Minimum dor Temperatur iibrigens nicht genauer bestimmt. Schmitz sah Exemplare, welche bei $17^{0}-18^{0}$ nicht leuchteten, bei ciner Erhöhung der Temperatur auf $20^{0}$ bis $31^{0}$ wiederum phosphoresciren. Durch Eintrocknen wird die Fihigkeit zu leuchten bei den Pilzen vernichtet; im Uebrigen ist für A. olearius die Fouchtigkeit der Luft ohne Einfluss (Fabre), Grundbedingung ist in beiden Fillen das Vorhandensein von Sauerstoff; im Wasserstoflgas, Kohlensiure u. s. w., im luftleeren Raume erlischt das Leuchten, wenn es gleich bei Rhizomorpha in einer nur wenige Procent $\mathrm{O}$ enthaltenden Luft noch fortdauert. In lufthaltigem Wasser dauert es an, in luftreiem ausgekochtem nicht. Bischoff und Fahre haben nachgewiesen, dass der leuchtende Pilz Satuerstoff absorbirt und Kohlensïure exhalirt; und zwar entwickelt A. olearius, so lange er leuchtet, eine grössere Menge $\mathrm{CO}_{2}$ als wenn die Periode der Phosphorescenz vorüber oder letztere durch Temperaturerniedrigung sistirt ist. Die Ursache der Erscheinung ist also ohne Zweifel irgend ein langsamer Verbrennungsprocess. Eine Temperaturerhöhung konnte Fabre nicht finden. Bischoff fand bei Rhizomorpha die Menge der ausgeschiedenen $\mathrm{CO}_{2}$ etwas geringer als der des aufgenommenen $\mathrm{O}$ entspricht.

Im Uebrigen ist die Phosphorescenz besagter Pilze ein phénomène capricieux, wie Tulasne sich ausdrückt; sie wird, ohne nachweisbare Ursache, 
bei verschiedenen Individuen in ungleichem Grade gefunden oder auch gänzlich vermisst.

Das phosphorescirende, dem der beschriebenen Pilze ähnliche und unter den gleichen Bedingungen eintretende Leuchten, welches an nassem weissfaulem Laub- und Nadelholze vielfach beobachtet wird, gehört nicht zu den physiologischen Processen. Es ist zwar oft schwer zu entscheiden, ob es von lebenden Pilzen herrührt, wie Manche vermutheten (Röper, in Decandolle's Pflznphys. II, 680. Treviranus Physiol.) oder von der Verbrennung des Holzes selbst, denn die modernden Zellen des letzteren werden oft allenthalben von Pilzfäden durchwuchert und können von diesen nicht getrennt werden. Man findet jedoch in solchen Fällen oft, dass die am meisten pilzführenden Stellen am wenigsten leuchten. Hartig beobachtete aber auch an pilzfreien Stücken faulen Pappelholzes eine lebhafte Phosphorescenz (Bot. Ztg. 1855̈, p. 148), und ich kann seine Angabe nach Untersuchung cines Stückes von leuchtendem Buchenholz, welches auf weite Strecken keine Spur von Pilzen enthielt, bestitigen.

Ebenso scheint das von Naudin und Tulasne (l. c.) beobachtete Leuchten faulen Laubes, das Leuchten fauler Pilze und thierischer Substanzen, über welches die oben genannten Schriften zu vergleichen sind, lediglich eine Erscheinung des Verwesungsprocesses zu sein.

\section{Wirkungen der Pilze auf ihr Substrat.}

Mit dem Vegetationsprocesse der Pilze stehen bestimmte und in vielen Fällen specifische Veränderungen der von ihnen bewohnten Körper in so unmittelbarem Zusammenhange, dass sie für das Verständniss jenes Processes wichtig sind und hier nicht übergangen werden können. Die Untersuchungen über die in Betracht kommenden Fragen finden sich grösstentheils in den Schriften, welche in den früheren Abschnitten dieses Capitels angeführt sind. Von denselben ist selbstverstindlich hier nur dasjenige mitzutheilen, was speciell botanisches Interesse hat, ohne auf die vielen sich anknüpfenden chemischen oder practischen Fragen einzugehen.

Von den Pilzen, welche todte organische Körper bewohnen, den Saprophyten, gilt zunichst, dass sic in ihrem Substrat Zersetzungs- und Gährungsprocesse verursachen. Den Pilzen schliessen sich in dieser Beziehung Nägeli's Schizomyceten 'Bacterien, Vibrionen u. s. f., rgl. Seite 3) an. Organische Körper, und selbst höchst zersetzbare, wie Eiweiss, Blut, Lrin, Milch, eiweisshaltige Zuckerlösung zeigen in reinem Sauerstoff; reiner atmosphärischer Luft und bei einer der Zersetzung günstigen Temperatur $\left(20^{0}\right.$ bis $\left.30^{\circ}\right)$ nur äusserst langsame Oxydation, wenn sie ror dem Zutritt organischer und speciell pilzlicher Keime geschützt sind; sie bleiben unter diesen Bedingungen selbst (1-3) Jahre lang und wohl noch länger ») frisch «. (Pasteur, Hoffmann, v. d. Broek in Ann. d. Chem. und Pharm. Bd. GXY, p. 75.)

Fäulniss tritt dann ein, wenn man, unter den genannten Bedingungen, Substanzen zusetzt, die schon zu faulen begonnen haben, selbst wenn diese frei (?) von lebenden Organismen sind (v. d. Broek). Siet man Pilze, Vibrionen u. s. w. in die zersetzbaren Körper, oder gestattet man den Zutritt jener, indem 
man letztere der freien Luft aussetzt, so erfolgt mit der Entwickelung der Pilze sofort rasche und lebhafte Zersetzung (vgl. speciell Pasteur, Cpt. rend. Tom. 56, p. 734.) Dass diese letztere eine Wirkung der Vegetation des Pilzes ist, folgt schon daraus, dass der Pilz aus seinem Substrat bestimmte Elemente oder Stoffe als Nahrung aufnimmt, jenes also zerlegt, und somit jedenfalls den Anstoss zu einer Umsetzung gibt. Der Zersetzungsprocess selbst ist, bei dem nämlichen Substrat, ein verschiedener, je nach dem darauf oder darin vegetirenden Organismus; viele und vielleicht alle Species erregen eine ganz specifische Ümsetzung. Die Vorgänge bei der letzteren bedürfen zumeist noch genauerer Untersuchung; doch haben wir, zumal durch Pasteur, bereits eine Reihe vortrefflicher Anhaltspunkte erhalten.

Unter der Einwirkung der Schimmelpilze und wohl der meisten Saprophyten überhaupt tritt an den organischen Körpern beim Luftzutritt Verwesung ein, lebhafte Oxydation, deren Producte Wasser, Kohlensäure, (Ammoniak) und einfachere organische Verbindungen als die ursprünglich vorhandenen sind. Der grösste Theil des rom Pilze occupirten Körpers zerfaillt auf diese Weise, während nur eine relativ kleine Menge seiner Substanz von dem Pilze als Nahrung aufgenommen wird. Jodin hat, leider ohne die jeweiligen Schimmelpilze anzugeben, für eine Anzahl Lösungen stickstofffreier organischer Körper (denen die zur Ernährung der Pilze nöthigen Aschenbestandtheile u. s. w. zugesetzt sein müssen), die Menge des Sauerstoffs bestimmt, welcher bei der Oxydation einer bestimmten Quantität des angewendeten Körpers absorbirt wird, sowie die Menge der dabei entstehenden $\mathrm{CO}_{2}$ und Schimmelpilzsubstanz. I Gr. Milchsäure z. B. absorbirte ihm Gr. 0,32 O, unter Production von Gr. 0, วٌ̈ $\mathrm{CO}_{2}$ und Gr. 0,08 Pilzsubstanz; Gr. 1 Zucker: Gr. 0,49 O, Gr. 0, $71 \mathrm{CO}_{2}$, Gr. 0,14 Pilzsubstanz u. s. w. Cpt. rend. Tom. 58, p. 917 .

Für die in Bezichung auf ihren Vegetationsprocess den Schimmelpilzen an die Seite zu stellenden II ycodermen, Pilzformen, welche, den Hefepilzenähnlich, aus torulösen, ästigen Reihen kurzer oder gestreckt-cylindrischer Zellen bestehen, und auf der Oberfliche von Wein, Bier etc. (Mycoderma vini, Cerevisiae Persoon, Desmazières) vegetiren, und auf der Essigmischung als Essigmutter, M. a ceti; für diese hat Pasteur die Art, wie sie die Oxydation ihres Substrats bewirken, genauer nachgewiesen. Cultivirt man M. aceti auf der Oberfläche einer zu seiner Ernährung geeigneten alkoholhaltigen Fliissigkeit, so wird, unter Vermehrung der Mycoderma-Menge, der Alkohol zu Essigsäure oxydirt. Jede sogenannte Essiggihrung, wie sie bei der Fabrication im Grossen auftritt, wird nach Pasteur von der Vegetation des Mycoderma begleitet, resp. verursacht und durch rationelle Cultur des letzteren kam die Fabrication rerbessert werden. Experimentirt man mit limitirten, genau bestimnten Luftmengen, so lässt sich nachweisen, dass der Pilz Sauerstoff aus der Luft a fnimmt und an den Alkohol abgibt. Ist die Vegetation einmal in Gang gebracht, so oxydirt die Essigmutter fortwihrend neue Mengen Alkohol zu Essigsäure. Vegetirt M. aceti auf Essig, so oxydirt es die Essigsäure zu Kohlensaiure und Wasser; die gleichen Verbrennungsproducte liefert die Vegetation von M. vini, sowohl auf Essig wie verdüntem Alkohol, nur bei besonderem Verfahren gelingt es durch letzteres schwache Essigbildung zu erhalten. Die genannten Wirkungen treten nur ein, so lange Mycoderma auf der Oberflïche der Flüssigkeit regetirt, also mit dem 
Sauerstoff der Luft in Berührung ist. Versenkt man die Haut, welche Myc. auf der Oberfläche der Flüssigkeit bildet, auf den Boden des Gefässes, so steht die Oxydation still, bis eine neue Haut entstanden ist (Cpt. rend. Tom. 5., p. 265, T. 55, p. 28). Nach Blondeau ist die oxydirende Wirkung des M. aceti eine rein physicalische Erscheinung; sie findet nur statt, so lange das M. eine Membran bildet und eine beliebige Membran aus Cellulose u. s. w. thut dieselbe Wirkung (Cpt. rend. T. 57, p. 953). Diese Angabe bedarf noch der Bestätigung. Mag sie nun aber richtig sein, oder die oxydirende Wirkung des Mycoderma in einem physiologischen Processe ihren Grund haben, so geht aus dem Mitgetheilten hervor, dass die auf der Oberfläche todter organischer Körper vegetirenden Pilze die Zersetzung letzterer auf zweierlei Weise bewirken: Einmal, indem sie ihre Nahrung und besonders ihren Kohlenstoff aus denselben beziehen, zweitens, indem sie den atmosphärischen Sauerstoff, der ohne Vermittelung der Pilze nur höchst langsam verändernd einwirkt, in einem (noch näher zu bestimmenden) Zustande auf dieselben übertragen, in welchem er sofort Verbrennung der organischen Substanz bewirkt.

Gleich der einfachen Oxydation zu Essigsäure, Kohlensäure und Wasser u. s. f. werden jedenfalls die meisten Gährungs p rocess e organischer Körper durch die Vegetation von Pilzen und anderen niederen Organismen erregt.

Die Alkoholgäh rung von Zuckerlösungen wurde schon durch Cagniard de Latour und Schwann für eine Wirkung der Vegetation der Hefe-Hormiscien erklärt, eine Ansicht, welche sich in der Folge bei den Chemikern geringer Gunst zu erfreuen hatte (vgl. Traube, Theorie der Fermentwirkungen. 1858. Schlossberger, Org. Chem. 5. Aufl., pag. 96), neuerdings aber durch Hoffmann (Bot. Ztg. 1860) und besonders durch Pasteur's treffliche Arbeiten wieder zu Ehren gebracht wurde. Die lange vorherrschende Meinung, nach welcher die Hefe ein in Zersetzung begriffener Körper ist, der die Gährung dadurch erregt, dass er die molecularen Bewegungen seiner Zersetzung den Zuckermolecülen in der Lösung mittheilt, ist unrichtig. Wenn es auch vielleicht einzelne andere Körper geben sollte, welche als Alkoholfermente wirken können, so ist doch zu der Erregung der gewöhnlichen Alkoholgährung die Einwirkung lebender Hefezellen nothwendig; die Flüssigkeit gährt nicht, wenn letztere ausgeschlossen oder getödtet sind und, die Gährung geschieht unter lebhafter Sprossung und Vermehrung der Hefezellen. Damit eine normale Gährung erfolge, muss die Flüssigkeit neben dem Zucker die zur Vegetation der Hefepilze nöthigen mineralischen und stickstoffhaltigen Substanzen enthalten, letztere in organischen oder anorganischen Verbindungen (Ammoniaksalzen). Die spontan gahrenden Fruchtsäfte enthalten diese Stoffe von Haus aus; in nicht spontan gährende Lösungen werden jene Substanzen mit der Hefe gebracht, die man ihnen zum Behuf der Gährung zusetzt; denn die Hefe, wie sie bei der Gährung im Grossen gewonnen wird, besteht theils aus entwickelungsfähigen Hefezellen, theils aus löslichen organischen und mineralischen Stoffen, welche von abgestorbenen alten Hefezellen herstammen. Die Vermehrung der Hefemenge während der Gährung lässt sich in allen Fällen mit der Waage nachweisen; am evidentesten ist sie bei solchen Versuchen, wo einer geeigneten gährungsfähigen Flüssigkeit (z. B. Gr. 10 Rohrzucker, Gr. 0,1 weinsaures Ammoniak, Asche von Gr. 1 Hefe auf Gr. 100 Wasser) ein Minimum frischer Hefe zugesetzt wird. Nach $24-36$ Stunden beginnt die Gährung 
und schreitet fort unter Trübung der Flüssigkeit durch sprossende Hefezellen und allmählicher Bildung eines aus solchen bestehenden relativ massigen Bodensatzes. Experimentirt man mit minimalen Quantitäten von Hefe und Zuckerlösungen, denen die stickstoffhaltigen und Mineralsubstanzen in Form anorganischer Verbindungen zugesetzt sind, so lässt sich nachweisen, dass der Zucker das Material ist, aus welchem die Hefe die Menge ihrer Cellulose, ihres Fettes vermehrt; der Zucker und die Ammoniaksalze das Material zur Vermehrung der eiweissartigen Hefebestandtheile. Die Menge der während einer Gährung neugebildeten organischen Hefesubstanz, und zwar der unlöslichen sammt den löslichen eiweissartigen Körpern, beträgt bis 1,2 und 1,5 Procent der angewendeten Zuckermenge. Der Rest des Zuckers zerfiallt, wie Pasteur ausführlich gezeigt hat, nicht einfach in Kohlensäure und Alkohol, sondern erleidet einen sehr complicirten Umsetzungsprocess, bei welchem $4-5$ Procent der verhandenen Zuckermenge zur Bildung von Glycerin und Bernsteinsäure verwendet werden.

In welcher Weise die vegetirende Hefe diese Umsetzung des Zuckers anregt, sucht Pasteur durch eine geistvolle Hypothese zu erkliiren (Cpt. rend. Tom. 52, p. 1260). Frische Hefezellen absorbiren, wie schon Traube zeigle, Sauerstoff. Wird Ilefe in eine geeignete gahrungsfähige Zuckerlösung gebracht, welche in einem flachen Gefässe dem Sauerstoff der Luft eine grosse Berührungsfläche darbietet, so absorbirt sie viel Sauerstoff, vermehrt sich auffallend stark, erregt aber nur schwache Gährung. Ungekehrt tritt in der nämlichen Zuckerlösung, wenn sie von der Luft abgesperrt und durch Auskochen luftrei gemacht ist, eine vielleicht hundertmal geringere Vermehrung der Ilefe, aber eine höchst energische Fermentwirkung ein; I Gewichtstheil Hefe zersetzt 60-100 Zucker, wahrend er bei freiem Luftzutritt $6-8$ Theile zersetzl, und vielleicht für Alkoholgährung ganz unwirksam gemacht werden kann. Pasteur grüundet hierauf die Ansicht, dass die vegetirenden Hefezellen gleich den Schimmelpilzen stets Sauerstoff anziehen und aufnehmen. Finden sie ihn frei, so absorbiren sie ihn begierig unter üppiger Vermehrung; wird ihnen kein freier Sauerstoff geboten, so entziehen sie denselben seinen Verbindungen, speciell der Zuckerlösung, und dieses gibt den Anstoss zur weiteren Umselzung des Zuckers.

Der Alkoholgihirung durchaus ähnlich werden, wie Pasteur gezeigt hat, andere Gährungsprocesse durch die Vegetation von Organismen - mögen dieselben nun den Pilzen oder den Vibrionen, Schizomyceten u. s. w. zuzurechnen sein erregt. Jede dieser Gïhrungen hat ihren specifischen Fermentorganismus, dieser seine specifischen Vegetationsbedingungen. Auf die einzelnen Fälle kann hier nicht ausfulurlicher eingegangen werden; man vergleiche Pasteur, über die Milchsäuregährung, Ann. de Chim. et de Phys. 3e Sér. Tom. ̋̈2, p. 4.04; über die Buttersäuregährung, Cpt. rend. Tom. כ22, p. 34ł; Schleimgïhrung, ibid.; Gïhrung der W e ins äure, Cpt. rend. Tom. 46, p. 615, und Tom. 36, p. 461 . Ueber die meisten dieser Arbeiten habe ich beriehtet in Flora 1 863. Hieran schliessen sich Pasteur's Untersuchungen über das Verderben des Weins, welche sechs verschiedene Formen der Verderbniss durch die Thäligkeit von Fermentorganismen erklären (Cpt. rend. Tom. 58, p. 142; eine Arbeit von Balard über denselben Gegenstand, ibid. Tom. 53, p. 1226); die Gährung des Harnstoffs (Pasteur Cpt. rend. T. 58, 142). Eine ganze Reihe kleinerer 
Mittheilungen über Ferment- und Schimmelwirkungen finden sich seit 1860 in den Comptes rendus.

Die zersetzende Wirkung der Pilzvegetation erklärt auch das Eindringen der Pilzfäden und Keimschläuche in feste, der optisch nachweisbaren Poren entbehrende Körper, wie Zellenmembranen, Eischalen u. s. f., oder deutet wenigstens den Weg an zu einer vollständigen Erklärung. Zunächst ist hier das Eindringen der Pilzfäden gemeint, welche todte oder absterbende Körper befallen. Vor allen die zum Theil schon von Hartig, Unger (Bot. Zeitung 1847) und neuerdings ausführlich von Schacht (Pringsheim's Jahrb. III, 442) und Wiesner (Sitzungsber. d. Wien. Acad. Bd. 49) beschriebene Erscheinung, dass Pilzfäden in dicke verholzte Zellenmembranen dringen, nicht nur um quer durch dieselben in die Lumina zu gelangen, sondern in der Membran selbst, der Richtung ihrer - spiraligen Streifung folgend, sich Wege bahnend, und eigenthümlich gestaltete Gänge, Spalten in dieselbe gleichsam einbohrend, die eine Zeitlang für Structureigenthümlichkeiten der lebenden Membran gehalten worden waren. Ferner die von Schacht (Lehrb. der Anat. I, 160. Monatsber. d. Berl. Acad. 1854) zuerst beschriebene Erscheinung, dass Schimmelfäden (Fusisporium Solani, „Oidium violaceum () in die Amylonkörner der faulenden Kartoffeln eindringen, Gänge in dieselben einbohren und von diesen aus die Körner mehr und mehr zerstören. Auch das von Kölliker (l. c.) beschriebene verbreitete Vorkommen von Pilzfäden und -Gängen in den Hartgebilden niederer Thiere dürfte vielleicht eher hier als bei den eigentlichen Parasiten zu erwähnen sein.

In wieweit das Eindringen der Keimschläuche von Schmarotzerpilzen ins Innere lebender Zellen auch hierher gehört, mag noch dahingestellt bleiben. Es ist, den beobachteten Erscheinungen nach, möglich, dass sich der Keimschlauch durch die Membran einen Weg bahnt, indem er deren Substanz in der Richtung seines Wachsthums auflöst. Es könnte aber hier auch ledigglich ein Eindrängen, ein Zurseiteschieben der Molecüle stattfinden, und hierfür spricht besonders der Umsland, dass die von dem eingedrungenen Schlauche erzeugte enge Oeffnung in der Membran nach vollendetem Eindringen wiederum unkenntlich wird, also geschlossen zu werden scheint - was freilich auch durch eine Regeneration der verlorenen Substanz geschehen könnte.

Für die auf lebende Organismen angewiesenen Schmarotzerpilze geht schon aus dem oben über ihre Vegetationsbedingungen Gesagten hervor, dass sie in den Organen ihres Wirthes, von deren Substanz sie sich ernähren, Störungen der normalen Entwickelung und Function, Krankheit und selbst Tod bewirken müssen. Auch in dieser Beziehung sind die pflanzenbewohnenden Parasiten genauer untersucht, als die thierbewohnenden.

Von jenen ist zunächst bekannt, dass sie an phanerogamen Pflanzen eine Menge von Degenerationen und Krankheiten verschiedenen Grades erzeugen, indem ihre Keime unter günstigen äusseren Bedingungen in den Wirth eindringen und sich in seinem Innern, meist intercellular weiter entwickeln, oder indem sie auf der Oberfläche des Wirthes keimen und wachsen. Eine Menge seit lange bekannter Pflanzenkrankheiten sind solche Producte parasitischer meist endophytischer Pilze, und die characteristischen Symptome derselben häufig nichts weiter als die an bestimmten Orten oder der ganzen Pflanze auftretenden Fortpflanzungsorgane des Schmarotzers. In den Organen und Geweben des Wirthes selbst er- 
zeugt der letztere Veränderungen der mannigfaltigsten Art und zwar jede Species specifische Erkrankung. Zuvörderst locale Veränderungen. Häufig beginnen diese mit einer Hypertrophie des befallenen Theiles, abnorm lebhafter Zellvermehrung, in Folge deren ein ganzes Organ monströs gross und dabei oft abnorm gestaltet wird, wie z. B. oft die von Cystopus bewohnten Cruciferenblüthen , die von Exoascus befallenen Früchte der Prunusarten (die Narren, Taschen) u. a. m. ; oder cinzelne Stellen der Organe Anschwellungen, Auswüchse, Beulen erhalten, wie z. B. die geschwollenen und verkrümmten Cruciferenstengel, die von Cyst. candidus, Prunuszweige, Pfirsichbläter, die von Exoascus bewohnt werden; die Birnbaumblätter an den von Roestelia, die Juniperuszweige an den von Podisoma bewohnten Stellen, die Stengel von Zea Mais an den oft über Faustgrösse aufschwellenden Orten, wo sich Ustilago Maidis zur Fructification anschickt u. s. w. Die hypertrophirten Theile und Excrescenzen bestehen hauptsächlich aus vermehrten, in ihrer Gestalt, Grösse, Structur von den normalen mehr oder minder verschiedenen, von assimilirten Substanzen oft überreich erfüllten Parenchymzellen, zwischen denen das Mycelium des Parasiten verbreitet ist. Hier schliesst sich die enorme Vergrösserung einzelner Epidermiszellen von Taraxacum, Succisa, Anemone an, in deren Innerem Synchỵtrium und andere Chytridieen sich entrickeln.

In einer zweiten Reihe von Fällen erhilt der von Parasit befallene Pflanzentheil, olne gerade hypertrophisch zu sein, eine durchaus ver:anderte Form, wie wenn er einer ganz andern Species, als seiner Nihrpflanze angehörte. So die bekannten, meist steril bleibenden Triebe von Euphorbia Cyparissias, E. am ygdaloides und anderen Arten, welche den Lromyces scutellatus Aecidium Euphorbiae Auct.) und Endophyllum Euphorbiae bergen, die Puecinia tragenden Blitter von Anemone nemorosa, und vor allen die unter dem Namen Hexenbesen ${ }^{1}$ bekannten, von dem Aecidium elatinum bewohnten Zweige der Weisstanne (Abies pectinata Lam.), welche sich von den horizontalen Aesten des Baumes senkrecht erheben, wie kleine, ihnen aufgepflanzte Bäumchen mil allseitswendigen Aestchen und ebenfalls allseitswendigen gelbgrünen, alljihrlich abfallenden Blättern. Die hypertrophirten und umgestalteten Theile sterben fruher ab, als diegesunden gleichnamigen derselben Species; solche von ein- und zweijahriger Dauer sobald der Pilz auf oder in ihnen seine Fortpflanzungsorgane gereift hat. Typisch mehrjiihrige können nit flem alljährlich fruchtbildenden Pilze mehrere Jahre dauern, wie z. B. manchmal die Endophyllum bergenden Rosetten von Sempervivum, und die llexenbesen, deren ich bis 16 jahrige beobachtet habe.

Eine dritte Reihe endophyter Parasiten zerstört und verdrängt nur mehr oder minder vollst:indig die Gewebselemente an den Stellen des Wirthes, wo sie vegetiren oder fructificiren. Mit der Reife des Pilzes ist in jenen Theilen das normale Gewebe, wahrscheinlich in Folge einer Resorption durch den Schmarotzer, bis auf kleine Reste geschwunden, der reife Pilz gleichsam an seine Stelle getreten; oder der Pilz zwischen die der Form nach noch vorhandenen, aber auseinander gedringten Gewebeelemente des Wirthes eingeschoben, seinerseits

1) Die dichtbuschig verzweigten Aeste von Kirschbäumen, Birken, Rothtannen, welche gleichfalls Hexenbesen genannt werden, sind, soweit ich, sie kenne, nicht Producte von Schmarotzerpilzen. Ihre Entstehungsursache ist unbekannt, bei Betula, wie es scheint, eine Milbe. 
eine Anschwellung bildend. Die Ustilagineen, zumal die Fruchtknoten- und Antherenbewohnenden, liefern für den ersteren Fall die zahlreichsten und bekanntesten Beispiele. Auch Claviceps schliesst sich hier an. Bei den blüthenbewohnenden Formen ist natürlich Unfruchtbarkeit die Folge dieser Parasitenentwickelung; doch kann, wenn nur die Antheren zerstört sind, durch Befruchtung mit dem Pollen gesunder Blüthen normale Frucht gebildet werden, wie z. B. nicht selten bei Knautia arvensis mit Ustilago flosculorum Tul. Für den zweiten Fall sind unter den Uredineen, und besonders den parasitischen Ascomyceten (Rhytisma, Polystigma u. s. w.) zahlreiche Beispiele zu finden.

In vielen Fällen endlich besteht die locale Wirkung der Parasitenvegetation in einem einfachen - rapiden oder allmählichen - Absterben der vom Mycelium bewohnten Stellen, ohne dass vorher Hypertrophie, Schwund oder Verschiebung der normalen Gewebeelemente in erheblichem Grade vorhanden war. Von Endophyten gehören z. B. viele einjährige Uredineen und Peronosporeen hierher. An den Theilen des Wirthes, wo sie sich angesiedelt haben, scheint das Gewebe zuerst langsam ausgesogen zu werden, an den grünen Organen verschwindet das Chlorophyll mehr und mehr, so dass eine bleiche Färbung den Parasiten verräth, welche sich mit dem Mycelium des letzteren in centrifugaler Richtung verbreitel. Nachdem der Pilz seine Fortpflanzungsorgane gebildet hat, stirbt das befallene Gewebe ab, meist unter Bräunung seiner Zellen und sofortiger Ansiedlung saprophyter Pilzformen.

An den von P. infestans befallenen Blättern der Kartoffelpflanze sterben die vom Pilzmycelium durchwucherten Theile unter intensiver Bräunung ab, sobald die Conidienbildung auf ihnen stattgefunden hat; vorher ist meist keine erhebliche Veränderung an der befallenen Stelle zu bemerken. Der Pilz erzeugt daher auf den Blättern die bekannten, für die »Kartoffelkranklieit « characteristischen, centrifugal wachsenden braunen Flecke. Wo der Pilz in die Knollen des Solanum tuberosum eingedrungen ist, tritt an den von seinem Mycelium berührten Gewebetheilen ebenfalls sofort, und ohne dass der Pilz Sporen bildet, Bräunung und Schrumpfung ein, die sich mit den Mycelium über das oberflächliche, unter der Schale gelegene Gewebe verbreitel. Spater folgt dann das Erscheinen ron Saprophyten (Fusisporium Solani Mart., Spicaria Solani Harting und anderen Schimmelpilzen) auf der Oberfläche der verdorbenen Knollen, und Fäulniss des inneren, nicht von dem Parasiten gebriunten Gewebes: Erscheinungen, welche nur secundare und keineswegs in allen Fällen ausnahmslos eintretende Folgen der Parasitenentwickelung sind, wenn sie auch, des öconomischen Schadens wegen, die grösste practische Bedeutung haben.

Es ist einleuchtend, dass die locale Affection auf den Gesundheitszustand des ganzen befallenen Pflanzenstockes Einfluss haben muss, insofern diesem ein grösserer oder geringerer Theil seiner assimilirten organischen Substanz, seiner Mineralstoffe und seines Wassergehalts durch den Parasiten direct oder durch die in Folge der Parasitenvegetation hypertrophirten Theile entzogen wird; insofern ferner da, wo der Parasit sich ansiedelt, die Tagesrespiration grüner Theile gestört, und da wo er, wie so häufig geschieht, zum Behufe seiner Fruchtbildung die Oberhaut zerreisst oder durchbohrt, die Transpiration alterirt, und zwar wohl in der Regel über das normale Maass erhöht werden muss. Daher sind Ernährungsstörungen verschiedener Art die nothwendige Wirkung, welche die 
locale Erkrankung auf das Allgemeinbefinden ausübt. Je nach der Species und je nach der Ueppigkeit, in welcher sich der einzelne Parasit entwickelt, ist der Grad der Allgemeinerkrankung verschieden, vom Unmerklichen bis zur völligen Zerstörung oder Verkïmmerung des befallenen Gewichses. Um aus der grossen Menge von Beispielen nur eines herauszugreifen, so sind Puccinia graminis, P. straminis Parasiten von beschränktem Wachsthum; sie gehen nur wenig über die Stelle hinaus, wo sie eingedrungen sind. Findet ihre Vermehrung nur in mässigem Grade statt, so sind sie unschädliche Gäste; bei hochgradiger Vermehrung und Entwickelung können sie dagegen eine totale Verkümmerung und Sterilitiit der befallenen Pflanzen, bei cultivirten Grisern, Cerealien eine totale Missernte oder Nichternte verursachen.

Ilier schliessen sich auch die Erscheinungen an, welche von den ErysipheArten verursacht werden, den einzigen bis jetzt genau untersuchten Schmarotzerpilzen, welche, soviel man bis jetzt weiss, nur die Oberfliche phanerogamer Pflanzen befalien. Wo das Mycelium des Pilzes vegetirt, erfolgt eine Bräunung und Vertrocknung des befallenen Pflanzentheils, und zwar zunächst nur der Epidermiszellen. Dieselbe geht, wie v. Mohl gezeigt hat, aus von den Puncten, wo sich das Mycelium mit seinen Haustorien (Seite 18) auf der Epidermis befestigt, sie verbreitet sich centrifugal um jeden dieser Auśgangspuncte, und die mit der Anzahl der Ilaustorien vermehrten gebriunten Stellen fliessen allmählich zu grösseren Flecken zusammen. Bei der Erysiphe der Weintraubenkrankheil (Oidium Tuckeri Berk.) bewirkt diese rein locale Veränderung einen grossartigen Ernteverlust, wenn der Pilz die jungen Beeren befallt, indem die vertrocknete und gebraunte Epidermis dem Wachsthum des Fruchtfleisches nicht folgen kann und daher die ganze Frucht entweder verkümmert oder aufplatzt und dann vertrocknet.

Ein ausführlicheres Eingehen auf die Semiotik und pathologische Anatomie der pllanzlichen Pilzkrankheiten würde hier nicht an Platze sein. Ausführlicheres darüber findet sich in den oben (besonders Seite 226) citirten Schriften, sowie in zahlreichen zerstreuten Mittheilungen Berkeley's im Gardener's Chronicle, die ich nicht sammeh und benutzen konnte. Die angeführten Beispiele beziehen sich, neben einigen besonders nambaft gemachten anderweitigen Einzelfallen, vorzugsweise auf die von Uredineen verursachten $\mathrm{R}$ os tkrankheiten der Pflanzen, die Brandkrankheiten (Ustilagineen), den Mehlthau (Erysiphe) und die von Peronosporeen erzeugten Krankheiten, weil diese am genauesten studirt sind. Dass sich alle übrigen iichten Pflanzenparasiten und die dazu gehörenden Krankheiten ähnlich verhalten, lässt sich übrigens nach den vorliegenden Daten mit Bestimmtheit behaupten. Das Gleiche gilt auch ron den in Folgendem zu erörternden Sätzen, welche sich zunächst auf meine und Kühn's Untersuchungen an Uredineen, Ustilagineen, Peronosporeen, Claviceps gründen, nach den vorliegenden Thatsachen aber füglich auf alle pflanzenbewohnenden aichten Parasiten bezogen werden können oder müssen.

Die Vegetation der Schmarotzerpilze ist für sich allein die unmittelbare U'rs a che der Pflanzenkrankheiten, bei denen sie gefunden werden. Aus dem krankhaften Verhalten der von Parasiten befallenen Gewichse hat man vielfach geschlossen, die Erkrankung sei das Primäie, und die Parasiten seien auf der krankhaft veräinderten organischen Substanz angesiedelt. Die Unrichtigkeit dieser 
Ansicht ist schon oben (Seite 222) hervorgehoben worden; sie stammt aus der Zeit, wo man die Vegetationsbedingungen des Parasiten nicht kannte und mit denen der Saprophyten confundirte. Die eigentliche nächste Ursache der Krankheiten wurde von den Vertretern jener Ansicht theils in äusseren Schädlichkeiten, in ungünstiger Beschaffenheit von Luft und Boden, theils in besonderer Prädisposition der kranken Pflanze gesucht. Wie es sich mit letzterer verhält, ist bereits oben (Seite 222) erörtert worden; eine specifische Prädisposition ist gewiss immer vorhanden, insofern jeder Parasit bestimmte Nährspecies befällt und sich auf der einen oft mehr entwickelt als auf der anderen; ebenso ist wohl anzunehmen, dass von derselben Species verschiedene Varietaten dem Parasiten in verschiedenem Grade zusagen, aber das ist nichtskrankhaftes. Die Ansicht, dass die Culturpflanzen eine besondere, durch die Culturmethoden selbst erzeugte Prädisposition für Parasitenkrankheiten besitzen, beruht auf nichts anderem als dem Umstande, dass man die Culturpflanzen mehr beachtet als die wildwachsenden. Letztere werden in der That nicht minder von Schmarotzerpilzen heimgesucht wie jene. Was den Einfluss von Luft- und Bodenbeschaffenheit betrifft, so ist solcher unzweifelhaft in hohem Grade vorhanden, die Versuche zeigen aber, dass seine Bedeutung in nichts anderem, als in der Förderung oder Hemmung der Parasitenentwickelung beruht. Zwischen Parasit und Nährpflanze besteht eine Art Wettkampf und der Ausgang dieses muss von den äusseren Bedingungen insofern abhängig sein, als diese dem Gedeihen beider Theile in verschiedenem Grade zuträglich sein können. Es ist eine ausgemachte Sache, dass die meisten Parasitenkrankheiten, z. B. Rost, Kartoffelkrankheit in nassen Jahrgängen und Lagen am verderblichsten, bei Trockenheit oft unschädlich sind, und einfache Versuche zeigen, dass dies seinen Grund darin hat, dass Feuchtigkeit der umgebenden Medien sowohl die Entwickelung und Fruchtbildung der betreffenden Parasiten, wenn sie einmal eingedrungen sind, als auch die Keimung der Sporen und das Eindringen der Keime, also die Vermehrung des Schmarotzers, in hohem Maasse fördert. Es ist ferner unzweifelhaft, dass die Parasitenkrankheiten um so verderblicher werden, in je früherer Entwickelungsperiode der Nährpflanzen sie beginnen, vorausgesetzt, dass die der Parasitenentwickelung günstigen Bedingungen andauern - eine Erscheinung, deren Erklärung aus dem soeben Gesagten von selber folgt. Es ist ferner durch Versuche leicht nachweisbar und im Grossen nicht selten zu beobachten, dass eine selbst hochgradige Parasitenkrankheit sistirt und in gewissem Sinne geheilt werden kann, wenn (z. B. durch Trockenheit der Luft) Bedingungen hergestellt werden, welche die Vermehrung. des Parasiten hemmen ohne die Vegetation der Nährpflanze zu beeinträchtigen.

Die pflanzlichen Parasitenkrankheiten sind a n s teckende K rankh ei t en, und die Ansteckung erfolgt durch die sich vermehrenden und verbreitenden, und in gesunde Individuen eindringenden Keime. Die Beweise hierfür sind in dem über die Entwickelung und die Vegetation der Schmarotzer Gesagten vollständig enthalten. Erscheinungen, welche das Gegentheil zu beweisen und für die individuelle Prädisposition zu sprechen scheinen, finden in der Biologie der Parasiten ihre Erklärung, zumal in der Thatsache, dass manche Keime nur in bestimmte Organe oder in bestimmten Alterszuständen des Wirthes eindringen (Cystopus auf Lepidium, Capsella; Ustilago, Tilletia u. s. f.), in der Heteröcie (Puccinia - Aecidium), in den Perenniren vieler Mycelien. Man vergleiche hier- 
über die früheren Abschnitte und besonders, da hier jeder einzelne Fall seine speciellen Eigenthümlichkeiten hat, die Monographien.

Die Contagiosität erklärt das ep i demis che A uftreten vieler Parasitenkrankheiten, welche gesellig wachsende Pflanzen befallen. Je rascher sich eine Pilzspecies entwickelt und je weniger ihre eindringenden Keime zwischen den verschiedenen Organen der Nährspecies eine Wahl treffen, desto rascher wird sich die Epidemie ausbreiten und desto vollständiger wird sic alle Individucn befallen. Daher die rapide Ausbreitung der Peronospora-Kartoffelkrankheit, des Rostes der Gräser, der Weintraubenkrankheit.

Wenn sich solche Epidemien vorzugsweise rasch üher Culturgewächse ausbreiten, so erklärt sich dies daraus, dass diese in grosser Zahl dicht bei einander zu stehen pflegen, der Parasit daher leicht von einem Individuum aus alle ubrigen erreicht. Es heruht auf einem allerdings leicht erklärlichen Irrthum, wenn man die Culturpflanzen allein epidemischen Pilzkrankheiten ausgesetzt glaubt; gesellig wachsende wilde Pflanzen sind es ganz ebenso, z. B. Asperula odorata der Zerstörung durch Peronospora calotheca, Gräser den Rostpilzkrankheiten, und hundert andere.

Es mag übrigens nicht überflüssig sein, zu bemerken, dass man, je mehr für bestimmte Pflanzenkrankheiten die unmittelbare Krankheitsursache in der Pilzvegetation nachgewiesen ist, um so vorsichtiger sein muss in der Beurtheilung solcher von Pilzen begleiteter Kranklieiten, über welche noch keine exacten Versuche vorliegen. Jeder Einzelfall bedarf hier besonderer Prifung.

Auf die Fragen endlich, welche Stoffe nimmt der Pilz aus der Nährpflanze auf, welches sind die chemischen Umsetzungen, dic er in ihren Organen erregt, welches die Krafte, durch die er bis zu gewissem Grade normale Neubildugen, Hypertrophien u. s. w. in den Geweben seines Wirthes verursacht, hat man zur Zeit keine präise Antwort. Eine genügende allgemeine Erklärung ergibt sich aber von selbst aus den oben beschriebenen Erscheinungen einerseits und andererseits den genauer erforschten Vegetationsprocessen der Saprophyten und ihren Wirkungen auf das Substrat. Von den Zersetzungserscheinungen, die manche Parasiten, wie z. B. Peronospora infestans und Erysiphe (v. Molıl) an ihrem Wirthe erzeugen, ist nachgewiesen, dass sie an den Berührungspuncten des Myceliums mit den Gewebstheilen des Wirthes beginnen, sich aber von diesen aus über die nicht direct berühten Gewebselemente fortpflanzen können.

Von den thierbewohenden Parasiten darf wohl nach den eben mitgetheilten Thatsachen wenigstens eine Anzahl Species als Erreger ebensovieler specifischer Krankheitsprocesse betrachtet werden; so der Muscardinepilz (Botrytis Bassiana), Entomophthora, und wohl noch viele andere Insectenbewohner. So Achorion, Trichophyton tonsurans, Microsporon, deren specifisch krankheitserregende Wirkung allerdings bestritten ist, für welche mir aber Köbner's Ansichten und Versuche besonderes Vertrauen zu verdienen scheinen. Aus den Versuchen mit dem Muscardinepilz, aus Remak's und Anderer, und zumal Köbner's Versuchen geht hervor, dass die betreffenden Krankheiten contagiös sind, und das Contagium aus den entwickelungsfähigen Sporen und Mycelien der Pilze selbst besteht. Epidemien sind hei der Muscardine beobachtet worden.

In diesen Puncten besteht also zwischen den thierischen und pflanzlichen Schmarotzerpilzkrankheiten eine vollstiandige Uebereinstimmung. Ob jene gleich 
den pflanzlichen auch jedes gesunde Individuum der geeigneten Nährspecies erkranken machen können, oder in der That immer eine krankhafte Prädisposition voraussetzen, bedarf noch genauer Prüfung, zu der in den für die pflanzlichen Parasitenkrankheiten dermalen gefundenen Thatsachen vielleicht Anregung und Anhaltspuncte gegeben sind.

Aus den geschilderten Wirkungen der Pilze auf ihr Substrat ergibt sich ihre hohe Bedeutung für den Gesammthaushalt der Natur. Die Saprophyten sind die Erreger und Beförderer der Zersetzung todter organischer Substanz; diese müsste sich, der alleinigen Einwirkung atmosphärischer Agentien überlassen, massenhaft und zum Nachtheil der lebenden Organismen anhäufen, die Pilze beseitigen diese Anhäufung, sie geben den Anstoss zum Zerfallen der todten organischen Körper in Kohlensäure, Wasser und Ammoniak, Verbindungen, in denen die Elemente jener von neuem zu dem Kreislauf des organischen Lebens zurückkehren. Die Pilze arbeiten in dieser Richtung gemeinschaftlich mit den zahlreichen niederen Thieren, welche auf faulende Körper angewiesen sind. Jodin's Angaben, nach welchen manche Pilze den bis auf 6 Procent steigenden Stickstoffgehalt ihrer organischen Substanz in Form von Stickgas aus der Atmosphäre absorbiren, würden für diese Pilze eine weitere wichtige Function im Naturhaushalte ergeben, wenn sie sich bestätigten. Bei der Fäulniss der Pilze selbst nämlich wird aus ihren stickstoffhaltigen Verbindungen Ammoniak gebildet; die Pilze würden daher die Menge der durch die chlorophyllführende Vegetation assimilirbaren Stickstoffverbindungen im Boden vermehren, und zwar das indifferente atmosphärische Stickgas hierzu verwerthen.

Für die ächten Parasiten wurde gezeigt, wie sie einerseits die Ernährung und Entwickelung ihrer Wirthe beeinträchtigen oder einen vorzeitigen Tod dieser verursachen, und wie sie andererseits in dem Maasse uberhandnehmen, als mit der Vermehrung und Geselligkeit ihrer Wirthe die Zahl ihrer Ansiedelungs- und Angriffspuncte wächst. Vom teleologischen Gesichtspuncte aus sind sie daher, gemeinschaftlich mit den auf lebende Organismen angewiesenen Thieren, als Regulatoren für das Ueberhandnehmen der besonders fruchtbaren und geselligen Arten höherer Organismen zu bezeichnen. Beide, die Saprophyten wie die Schmarotzer, sind durch ihre Artenzahl, Fruchtbarkeit und die Leichtigkeit, mit der ihre vielerlei Keime verbreitet werden, geeignet, eine mächtige Wirkung in den bezeichneten Richtungen auszuüben. 


\section{II. \\ Flechten.}

Capitel 8.

\section{Der 'Thallus der Flechten.}

Der Körper der Flechten besteht im ausgebildeten Zustande aus einem meist stattlich entwicketten Vegetationsorgane, Thall us, Flech ten lager (Blastema Waliroth), welches Fructificationsorgane - meist in reichlicher Menge - trïgt, die denen der Ascomyceten genau entsprechen: Apothecien, d. l. Sporenlager mit $\Lambda$ seis, Spermogonien, und in einzelnen Fillen auch Pyeniden.

Von dem Thallus, der hier zuer'st besprochen werden soll, unterseheidet man der ïusseren Gestalt nach drei, ibrigens gar nicht seharf gesonderte Ilauptformen : den strauchartigen (Th. fruticulosus, filamentosus, thanmodes) aus schmaler Basis von dem Substrat sich erhebend, einfach oder meist strauch:ihnlich verïstelt; den la ubartigen (Th. foliaceus, frondosus, placodes), von der Form eines flachen, blattartigen, meist gelappten und krausen Körpers, über die Oberfliache des Substrats ausgebreitet, diesem aber nur an einer oder an zerstreuten Stellen angewachsen, diher mit seringer Verletzung abtrennbar; und den krustenartigen (Th. crustaceus, l.podes), über das Substrat flach ausgehreitet, und diesem mit der ganzen Unterfliche überall fest aufgewachsen, als eine unverletzt nicht trennbare Kruste. Eigenthiimlich verhalten sich die Genera Cladonia und Stereoeaulon, bei denen sich ron schuppenförmigen oder körnigen, laubartigen Körpern (dem Thallus oder Protothallus der Lichenographen), strauchartige Bildungen (Podetien) erheben.

Der Bau des Flechtenthallus stimmt mit dem der Pilze darin überein, dass derselbe meistens der llauptmasse nach aus gesetzmiissig verbundenen und verflochtenen istigen Zellreihen mit farblosem Inhalte, II y phen, Fäden, Fasern, gebildet wird, von denen jede einzelne wie dort ein bis zu gewissem Grade selbstindiges Wachsthum besitz. Wie bei den Pilzen bilden dieselben miteinander entweder ein deutliches Fasergeflecht oder ein Pseudoparenchym, in dem auf Seite 2 bezeiehneten Sinne des Wortes. Schon Schleiden (Grund\%. II.) und Schacht (Pflanzenzelle) haben dieses angedeutet, Speerschneider und vor allen Schwendener haben es bestimmt nachgewiesen.

Zu den Hyphen komm in dem Flechtenthallus eine zweite Art von FormHandbuch d. physiol. Botanik. II. 
elementen: runde oder längliche, grün oder blaugrün gefïrbte Zellen, von welchen zwar für viele Fälle erwiesen ist, dass sie ursprünglich von den Hyphen erzeugt werden, welche aber später zwischen diesen eine bis zu gewissem Grade selbstiindige Entwickelung und eigenartige Vermehrung, meist mit Theilung nach drei Raumdimensionen zeigen. Seit Wallroth sind diese Zellen unter dem Namen Gonidien bekannt, einem Ausdrucke, welcher, insofern er wörtlich und der Meinung seines Urhebers entsprechend, Brutzellen, also Fortpflanzungsorgane bedeutet, allerdings unglücklich gewihlt ist. Stifenberger (Flora 1861, p. 216) hat daher vorgeschlagen, die erwïhnten Zellen Farbzellen, Gh ro midi en, zu nemnen und den Ausdruck Gonidien für erwiesene Reproductionszellen der Thallophyten zu reserviren. Er ist num aber zur Bezeichnung solcher dermalen weder nothwendig noch scibst zweckmässig, denn die Organe der Algen, für welche ihn A. Braun eine Zeitlang passend gebrauchte, sind jetzt Sporen zu nennen und seine frühere Anwendung durch Külzing ist lingst aufgegeben. Er fällt somit den Flechtengonidien wieder allein zu und ist so allgemein eingebürgert, dass er zweckmaissiger Weise beibehalten wird.

Seit Wallroth unterscheidet man zwei Hauptformen des Baues des Thallus: den heteromeren oder geschichteten und den homöomeren oder ungeschichteten. Jener ist den »ichten Lichenen " (Lichenes Fr., Lichenaceae $\mathrm{Ny}-$ lander, Gnesiolichenes Massalongo) eigen, letzterer den Phycolichenes Massalongo's (Collemaceae Nyl., Byssaceae Fr.). Nach den vorliegenden Untersuchungen unterscheide ich in Folgendem drei Structurtypen: 1) dengeschichteten, heteromeren Thallus; 2) den Thallus der Graphideen; 3) den der Gallertflechten und reihe diesen if) rinige keinem dieser Typen angehörende Formen als a no male an. Diese Unterscheidung ist nur ein Nothbehelf; viele Formen, wie die meisten Verrucarieen, der körnig-krustige Thallus der Calycieen, vieler erdbewohnender Lichenen (Biatorae spec. Baecomyces u. s. f.) mussten bei derselben unherücksichtigh bleiben, weil es an brauchbaren Untersuchungen über dieselben noch fehlt. In Urbrigen griundet sich die folgende Barstellung soweit als möglich auf die griundlichen Untersuchungen Schwendener's, von denen nur das eine zu bedauern ist, dass sie blos soweit sie den laub- und strauchartigen heteromeren Thallus betreflen ausführlich veröflentlicht sind. Für viele Einzelheiten, auf welche hier nicht eingegangen werden kann, sei cin-für allemal auf diese Arbeiten verwiesen.

I. Geschichteter, heteromerer Thallus.

1. Strauch-und la ubartige Formen.

a. B a u. Ein Durchschnitt durch den Thallus (Fig. 83, 84) zeigt fast immer zwei Haupt-Gewebelagen: eine relativ dünne (durehschnittlich etwa 1/100 bis 1/20 Mm. miichtige), meist durchscheinende, dichte peripherische - Rinde, Rindensehicht (Stratum corticale) und ein von dieser umgebenes, meist lockeres, überall mit lufthaltigen Lücken versehenes Fasergeflecht - Mark, Markschicht (Stratum medullare). Die Fasern des Markes setzen sich continuirlich in die Elemente der Rinde fort, beide sind Verzweigungen der nämlichen Hyphen. 
An der Grenze von Mark und Rinde liegen in fast allen Fällen die Gonidien. Sie bilden mit einander eine grüne Zone von verschiedener Mächtigkeit, an verschiedenen Puncten verschieden weit in das Mark einspringend, überall von einzelnen zur Rinde laufenden Fasern des letzteren durchsetzt, manchmal stellenweise grössere Unterbrechungen zcigend. Dies die gewöhnlich als dritte Gewebschicht bezeichnete Gonidien-, gon im ische, Gonimonschichte (Stratum Gonimon), besser als Gonidienzone zu bezeichnen. Einzelne Gonidien oder Gonidiengruppen finden sich ausserdem oft durch das Mark zerstreut (z. B. Solorina, Placodium), oder (Bryopogon) die ganze Menge der Gonidien ziemlich gleichförmig in dem Marke vertheilı.

Die strauchartigen Lager einer Anzahl Genera, zumal die cylindrischen, sind

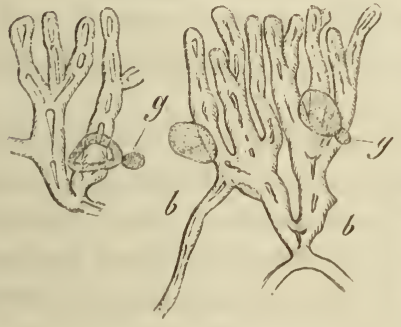

lig. 83 .

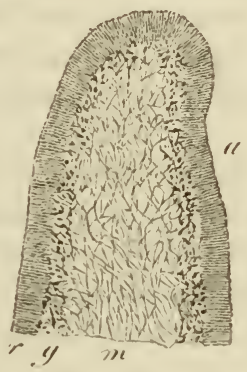

.)

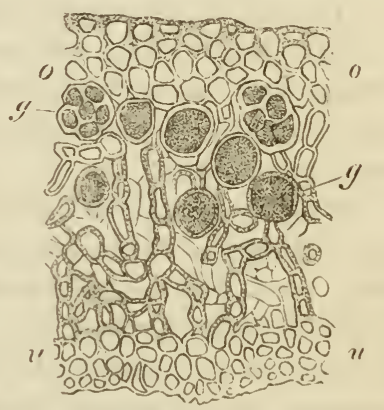

Fig. 84.

ringsum gleichartigg berindet (Usnea, Bryopogon, Roceella, Fiğ. 83, Sphaerophoron u. A.). Bei vielen stranchartigen mit flachem Thallus (z. B. Everniae, Cetrariae Spee.) und den meisten laubartigen formen ist die Rinde der dem Lichte zugewendeten oder oberen Flizche von der der unteren Flizche verschieden (Fig. 8' und bei IIagenia, Peltigera, Solorina, und den laubartigen Thallustheilen der Cladonien ist nur die Oberseite bis iiber den Rand hinaus berindet, die Unterfliche rindenlos.

Wo die bezeichnete Verschiedenheit heider Flichen besteht, ist die Gonidienzone (von den zerstreuten Gonidien abgesehen) nur auf der Lichtseite vorhanden. Selbst bei dem fast eylindrischen und ringsum gleichföımig berindeten Thallus von Sphaerophoron ist sie auf der Lichtseite oft stiaker entwickelt als auf der unteren. Die Podelien von Cladonia sind in der Jugend immer, bei manchen Arten zeitlebens unberindet (Cl. rangiferina z. B.), ilne Oberflache wird von einem lockern, gonidienführenden Fasergeflechte gebildet. Die meisten Species sind von warzenförmigen Rindenschiippchen theilweise bedeckt, einige vollstïndig berindet (Cl. furcata).

Die Befestigung der in Rede stehenden Thallusformen an das Substrat geschieht durch haar-oder borstenförmige II f f fasern, R hiz inen, oder Wrurzelhaare, in dem bei den Pilzen gebrauchten Sinne des Wortes, Organe, welche oft mit

Fig. 83. Roccella fuciform is Ich. a radialer Längsschnitt durch dic Thallusspitze. $r$ Rinde, g Gonidienzone (durch die Punctirung angezeigt), $m$ Mark. Umriss 90 mal vergr. Ausführung nach stärkerer Verger., daher etwas schematisirt. - $b$ Rindenhyphen nach Entfernung der Incrustationen durch Ammoniak, 390 fach vergr. $g$ Anhaftende Gonidien.

Fig. 84. Physcia parietina Kbr. Durchschnitt durch den jungen Thallus, $500 \mathrm{mal}$ vergr.; nach Schwendener copirt. o obere, $u$ untere Rindenschicht, $g$ Gonidien. 
dem Namen Hypothallus, ${ }^{1}$ ) von Schwendener als hypothallinische Anh angsgebilde bezeichnet werden.

Was die feinere Structur der bezeichneten Theile des Thallus anlangt, so besteht das Mark der Regel nach aus ungefiihr cylindrischen, schlanken, verastelten Hyphen, Zellreihen, deren Glieder im erwachsenen Zustande durchschnittlich 8 bis 10 bis 50 mal länger als breit werden, wobei jedoch kürzere Zellen immer auch vorkommen (s. auch Fig. 84). Beispielsweise beträgt nach Schwendener's Messungen bei Usnea barbata dic Dicke der Markfasern durchschnittlich 1/250 Mm., die Länge ihrer Zellen 1/33 Mm. bis 1/25 Mm. bis 1/5 Mm. Kurze, fast isodiametrische rundliche Glieder, manchmal ein Pseudoparenchym darstellend, finden sich an den Markfasern des (streng genommen krustenförmigen) Thallus von Endopyrenium und Catopyrenium. Dic Nembran der Fasern ist in der Regel dick, farblos, ohne deutliche Schichtung; bei stirkerer Verdickung liisst sie wenigstens eine mittlere weichere von einer äusseren und inneren dichteren Schicht unterscheiden. Der Inhalt ist an der intacten Zelle blass, schwach körnig.

Je nach dem Einzelfall divergiren die Aeste in spitzen oder stumpfen Winkehn. Ilförmige Verbindungen und selbst Schlingen und netzförmige Anastomosen zwischen benachbarten Aesten sind von Schwendener ofters gefunden worden (Usnea, Bryopogon). Die Verbindungsäste wachsen mit ihren Enden an die betreffenden Fïden nur fest an, ohne dass die Zellenwand an der Berührungsstelle durchbrochen wired.

In der Regel ist die ganze Markmasse ein lockeres Geflecht mit lufthaltigen Interstitien, wie oben schon erwihnt wurde. Ihre Ilyphen sind dabei im erwachsenen Zustande entweder ganz ordnungslos verflochten (z. B. Sphaerophoron, Roccella) oder zeigen einen auf radialen Durchsehnitten erkennbaren, ron der Basis resp. Milte des Thallus centrifugal ausgehenden Fascroug weniggstens vorherrschend, wenngleich immer eine Anzahl von Fasern regellos zwischen die anderen eingeflochten ist. Bei Cladonia und Thammolia ist die Faserung fast ausschliesslich longitudinal, das Mark bildet einen dimnen, hohlen Cylinder, dessen innere an die IJöhlung grenzende Ilyphen fast lïekenlos verlunden sind.

Usnea verhiblt sich insolern eigenthümlich, als hier ein solider axiler, aus lïckenlos verbundenen longiludinalen Fiaden bestehender Markstrang die Mitte des Thallus durelızieht. Seine Ilyphen entsenden an der Peripherie zahlreiche Aeste, wolche in die Rinde laufen und zwischen dieser und dem axilen Strange ein lockeres lufthaltiges Geflecht bilden (vergl. Fig. 8:3). Evernia vulpina, E. flavicans zeigen innerhalh des lufthaltigen Markgeflechtes longitudinale interstitienlose Stringe, deren Zahl (1 bis 10 und 12), Form und Gruppirung mit der Hobe wechseln und welche in der Nähe der Basis zu einem dicken, fast den ganzen von der Rinde umschlossenen Raum ausfiillenden Strange verschmelzen. Aehnliche Verhiblnisse finden sich bei Ramalina.

Es bedarf wohl kaum ciner besonderen Bemerkung. dass die Spiralgefiase, welche Jones und Areher in braunen Flecken der Evernia prumastri

1) Unter diesem Namen werden vielfach ganz heterogene Theile zusammengeworfen. Aus diesem Grunde, und weil ganz überflüssig, ist derselbe zu vermeiden, was schon Schärer gethan hat. 
gefunden haben, keine Organe dieser Flechte sind. Sie stammen der Abbildung nach offenbar aus dem Adernetze eines Dicotyledonenblattes und müssen auf gewaltsame Weise von aussen in den Flechtenkörper gelangt sein. (Dublin quart. Journ. of Se. Nr. XVII, p.91.)

Die Hyphen und Hyphenzweige, welche die Rindens chich t zusammensetzen, sind, mit Ausnahme von Rocella-Arten, lückenlos mit einander verbunden. Speerschneider's gegentheilige Angaben für Usnea, Imbricaria Acetabulum, Ramalina haben ihren Grund darin, dass er theils nur die Zellenlumina für die Fasern und die festverbundenen Membranen derselben für Interstitien, theils ungekehıt die Zellwände für anastomosirende Fasern und die Lumina für Lücken in Geflechte genommen hat. Die verzweigten Ilỵphen der Rinde sind entweder deutlich als solche erkembar, die Lumina ihrer Gliederzellen wenigstens deutlich gestreckt-cylindrisch, wenn auch ihre Linge geringer als die der Markzellen ist (Fig. 8:3) ; oder aus kurzen, isodiametrischen, gerundet prismatischen Zellen zusimmengesetzt, wodurch die kinde eine oft sehr regelmässige und zierliche P'seudoparenchynstructur (rhiblt (\%. Piamelia, Physcia, Fig. 84, Endocarpon, Sticta, Peltigera). Nur die langegestreckten Rindentasern von Bryopogon und llagenia ciliaris zeigen auch in erwachsenen Thallus einen ziemlich genau longritudinalen Verlauf. In allen übrigen Fiallen bilden die Fasern entweder ein nach allen Seiten hin unregrelurissig verflochtenes Fadengeflecht oder Pseudoparenchym; oder sie sind ziemlich genau senkecht zur Oberfliche gerichtet, wie \%. B. die psendoparenchymatischen Zellenreihen von Endocarpon, Peltigera und an exquisitesten die buischelig verzweigten Rindenfasern von Roccella, bei denen anch die seitliche Vereinigung rine zientich lockere und die Enden frei sind. Zumal bei li. fuciformis lassen sich auf dïmnen Schnitten die cinzelnen verzweigten Fasern ganz gesondert erkennen und durch Druck leicht isoliren (Fig. 8:3).

Die Dicke der Mtemban, die Wreite der Lmmina und das gegenseitige Verhailtniss beider ist je natch Gatlungen und Arten höchst mannighaltig; die Einzelheiten vergleiche man bei Schwendener. Zumal bei langghliederigen kindenhyphen (Usnea, Bryopogon, Sphaterophoron ele.) sind dic Zellwiude oft ungenein dick und bei ihrer imnigen Verbindung mit einander einer homogenen Masse gleichsehend, in woleher die Lumina als enge Cancile verlaufen. An dummen Schnitlen, zuinal nach Einwirkung verdiinnter Kali- oder Ammoniaklösung lisst sich jedoch jene homogrenc liasse als aus einzelnen dicken, undeutlich geschichleten Membranen bestehend, erkennen. Die Structur dieser Corticalschichten hat viele Achnlichkeit mit der der Sclerotion der Typen a und $f$ (Seite 33 ).

Die Differenzen zwischen Rinde der Ober- und Interseite betreffen die Dicke der Schicht, Grösse, Anordnungy der Zellen, Färbung u. s. w. (vg̨l. z. B. Fig. Sí).

Die Rindenoberflache ist in manchen Fillen (z. B. Oberscite von Ilagenia ciliaris, Peltigera malacea, auch P. canina in der Jugend, Lnterseite ron Sticta, Nephroma) fein filzig bohart durch cinzelne hervortretende Hyphenaistehen.

Unter den warzenförmigen Prominenzen, welche auf der Oberfliche mancher Lichenen vorkonmen, sind die der Peltigera aphthosa, die kleineren von Usnea Verdickungen oder Wucherungen der Rinde; die grösseren bei letzlgenamnter Gallumg, die Warzen und Schüppehen der Evernia furfuracea sind im fertigen Zustande gleichsam Ausstülpungen des Thallus, innerhalb der Rinde 
Gonidien und ein lufthaltiges, mit dem übrigen zusammenhängendes Mark umschliessend. Die schwirzlichen verzweigten Wucherungen auf der Oberseite von Sticta fuliginosa und Umbilicaria pustulata bestehen aus einem dichten gonidienführenden Fasergeflechte, umgeben von einer einschichtigen pseudoparenchymatischen braunhäutigen Rinde.

Die borsten-oder dornähnlichen Wimpern bei Gyrophora, Hagenia, Cetraria u. a. sind Prominenzen der Rinde allein, interstitienlos, mit unregelmässigem oder vorherrschend longitudinalem (Hagenia) Faserverlaufe. An diese, speciell an die von Hagenia schliessen sich unmittelbar an die $\mathrm{H}$ a $\mathrm{ft}$ fa se $\mathrm{r} n$, $\mathrm{Rh}$ i z ine $\mathrm{n}$, welche der Unterfläche des ringsum berindeten laubartigen Thallus entsprossen und diesen befestigen, indem sie sich dem Substrat anlegen oder in dasselbe eindringen (Parmelia, Imbricaria, Physcia u. s. w.). Der Thallus von Peltigera und Solorina ist unterseits rindenlos oder (Solorina) nur unter den Apothecien berindet, dagegen mit einem Netz anastomosirender Adern versehen, welche einfach Vorsprünge des lufthaltigen Markes sind. Von diesen entspringen die zahlreichen, gleichfalls locker verfilzten, lufthaltigen, gegen das Substrat gerichteten llaftfasern (Rhizinae stuppeae).

Die Befestigung des strauchartigen Thallus geschicht bei Hagenia ciliaris durch einzelne, dem Substrat sich anschmiegende, also als Rhizinen fungirende, marginale Wimpern. Andere strauchartige Flechten (wenigstens Usnea, Ranalina, Evernia vulpina, Cladonia) sind befestigt durch dichte, in das Substrat dringende oder eingekeilte (daher die Benennung Nagel, Gomphus Wallr.) Faserbündel, welche aus der unberindeten Basis direct rom Marke entspringen. Aehnlich scheint der Thallus von Sticta (St. pulmonaria) in seiner Mitte befestigt zu sein, was übrigens, gleich der Befestigung der meisten strauchartigen Formen, der Gyrophoren u. s. w., noch genauerer Untersuchung bedarf.

Eigenthümliche Unterbrechungen der Rinde sind der Unterseite des Thallus von Sticta eigen. Sie stellen entweder grössere, flache, wenig scharf umschriebene Flecke dar (z. B. St. pulmonaria) oder circumscripte Grübchen, deren Boden von dem blossgelegten Narke gebildet, deren Rand von der nach aussen gewölbten Rinde umgeben wird. Die Grübchen entstehen nach Schwendener, indem die Rinde durch eine Wucherung des Markes erst warzenförmig nach aussen vorgetrieben wird und dann in der Vortreibung zu wachsen aufhört, wïhrend die Flächenvergrösserung des Thallus im Linkreise derselben fortdauert. Bei mauchen Arten (St. macrophylla) geht der Unterbrechung der Rinde die Bildung eines Hohlraumes in der Markwucherung voraus. Die Grübchen werden C y phellen genannt; die ältere Ansicht, nach welcher sie Brutbecherchen Behälter von Soredien) sein sollen, ist unbegründet, oder höchstens für gewisse Arten (St. aurata) richtig (Schwendener).

Die speciellere Betrachtung der Gonidien, welche hier am Platze wäre, findet \%weckmässiger Weise am Schlusse des vom heteromeren Thallus handelnden Abschnittes I. statt.

b. Das IV ach sthum des strauch- und laubartigen Thallus gliedert sich in die Grössenzunahme durch Spitzenwachsthum der Hyphen, welche in dem Scheitel des strauchartigen, in dem Rande des laubartigen Thallus endigen (II arginal-resp. Sp i $\iota_{z}$ en wa c h s $t h u m$ ), und die Grössenzunahme der hinter 
Rand oder Spitze gelegenen Theile (in ter cal a res W a ch s th u m); bei letzterem ist wiederum zwischen Dicken- und Flächenwachsthum zu unterscheiden.

Spitzen-und Marginalwachsthum. Bei einigen straucharligen Formen, nämlich Usnea, Cornicularia tristis Web., Bryopogon, ist das wachsende Thallusende ein Bündel ästiger, paralle ler, oben kuppelförmig zusammenneigender, lü ckenlos vereinigter Hyphen (Fig. 85). Sowohl in der Scheitelzelle als in den oberen Gliederzellen einer jeden dieser finden, wie Messungen argeben, wiederholte Theilungen durch Querwinde statt; jene bedingen das eigentliche Spitzenwachsthum, letztere beginnen das intercalare. Nahe unterhalb der Spitze beginnt die Bildung der Gonidien und hiermit die Iniflerenzirung des homogenen Bündels in Mark oder Rinde.

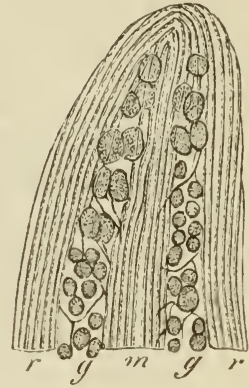

Fig. 85 .

Fast alle andern hierher gehörenden Formen zeigen eine von der parallelfaserigen verschiedene Anordnung der in Spitze oder Rand verlaufenden IIyphen. Dieselbe dürte vielleicht am passendsten als die s ym motrisch-divergirende bezeichnet werden. Auf dem radialen Lingsschnitt (vgl. Fig. 83, 86) erscheint das Ende etwas halbkreisförmig al)gerundet, die Fasern der Mittellinie verlaufen senkrecht in den Scheitel, die übrigen divergiren symmetrisch zu beiden Seiten der Mittellinie in nach oben convexen, die Oberfliche nahozu rechtwinkelig treffenden Curven. D)io Mittellinie des tadialen Lingssehnitts entspricht bei dem strauchartigen Thallus der Längsachse, bei dem laubartigen der (zur Oberflache parallelen) Miltelebene. Die Divergenz von der Millellinie nimmt nach unten derart zu, dass dic Fasern unterhalb der Endabrundung sowohl zur Mittellinie als zur Oberfliche anmiihernd senkrecht gestellt sind.

Während das Ende des Thallus vorruickt, bleibt der Verlauf seiner Fasern immer der gleiche. Nimmt man an, dass das Vorricken zunachst durch Spilzenwachsthum der divergirenden Hyphen geschicht und dass dic Krüunmung des Endes dabei unverindert bleibt, \%. B. halbkreisförmig, so beschreibt jede Ilyphe wahrend ihres Wachsthums eine Curve, welche den vorrückenden Halbkreis in allen Lagen, oder das ganze System von Ilalbkreisen, die den Durchschnill des vorrückenden Endes umschreiben, rechtwinkelig schneidet. Eine solche Curve heisst eine orthogonale Trajectorie, Schwendener newnt daher den in Rede stehenden Typus der Thallusenden

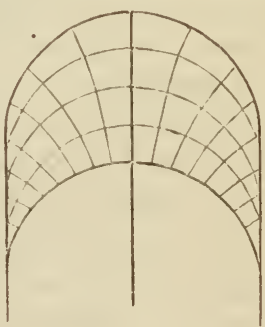

Fig. 86. den orthogonal-trajectorischen.

Bei dem beschriebenen Verlaufe müssten sich die Hyphen des Endes, wenn sie einfach in die Lïnge wïchsen, von einander entfernen, und zwar, wie ein Blick auf die Figur 86 zeigt, um so mehr, je niher sie der Mittellinie liegen. Die

Fig. 85. Usnea barbata. Längsschnitt durch die Mitte der Thallusspitze, nach Einwirkung von Kali, 545 mal vergr., nach Schwendener. $r$ Rinde, mexiler Narkstrang, $g$ Gonidienzone und lockeres peripherisches Markgeflecht. 
Verbindung der Hyphen in dem wachsenden Ende ist aber immer lückenlos; es muss daher eine stete Einschiebung neuer Aeste stattfinden. Nicht nur durch ihre lückenlose Verbindung, sondern auch durch ihre Gestalt, Structur und Farbe gleichen die Hyphenendigungen, von denen die Rede ist, vollkommen jungen Rindenfasern. Auf radialen Lïngsschnitten durch die Spitze erscheint der Thallus ringsum berindet, die Rinde in Scheitel nur zartzelliger als unterhalb derselben - im Gegensatze zu dem ersten, parallelfaserigen Typus, wo, wenigstens bei Usnea und Cornicularia, die Structur des Scheitels von der der alteren Theile ganz verschieden ist. Es erwächst hieraus eine nicht zu beseitigende Schwierigkeit für die Bestinmung, wieviel von der Vorschiebung des Thallusrandes auf Rechnung des Spitzenwachsthums der marginalen IIyphenenden kommt, oder eines andern Factors, näinlich des Flachenwachsthums der innerhalb und unterhalb des Scheitels gelegenen Rinde durch Einschiebung neuer Hyphenverästelungen. Dass letztere überhaupt stattfindet, wurde schon oben gesagt. - Dicht hinter oder selbst unmittelbar unter dem Scheitel beginnt auch hier die Bildung der Gonidien.

Der in Rede stehende Bau und Wachsthumsvorgang des Thallusendes kommt den strauchartigen Flechten, mit Ausnahme der drei genannten Genera, und den meisten laubartigen zu, manchen fast genau nach dem Schema, z. B. Roccella, Thamnolia, auch Lichina, Placodium cartilagineum (Schwendener l. c.); anderen mit Modificationen, welche durch die von der Ilalbkreisform mehr abweichende Gestalt des Enddurchschnitts und durch Schliingelung und Verflechtung der Hyphen bedingt sind.

An den symmetrisch-divergirenden oder orthogonal trajectorischen Structurund Wachsthumstypus schliesst sich ein dritter an, den man den unsymmetrisch-divergirenden nennen kann, und der einer Anzahl laubartiger Formen zukommt. Entweder fillt bei demselben die Linie, von welcher auf dem radialen Durchschnitt die Fasern nach oben und unten ausbiegen, nicht in, sondern unter die Mittelebene (z. B. Placodium diffractum, Schwendener) oder die Fasern laufen an der Unterseite der Fläche parallel, und nur auf der Oberseite in Bogenlinien, welche der Oberfliche annähernd rechtwinkelig treffen; so hei Parmelia Körber und Peltičera. Die Vorschicbung des Randes geschieht in den letzteren Fällen vorzugsweise durch Einschiebung von senkrecht gegen die Oberseite gerichteten Ver:astelungen.

Zwischen den drei bezeichneten Typen (in deren Bezeichnung ich der Gleichmaissigkeit wegen von Schwendener etwas abgewichen bin) kommen übrigens intermediaire Formen vor, "von denen man kaum weiss, ob sie dem einen oder dem anderen näher stehen. " Unter den laubartigen zeigen z. B. (nach Schw.) annihernd parallelfascrige Randstructur Parmelia aquila, speciosa, chrysophthalma.

Intercalares Wachsthum. In der hinter dem Rande oder Scheitel gelegenen Region dauert das Wachsthum eine Zeit lang an, und in diesem intercalaren Wachsen beruht die Vergrösserung des Thallus zum betrichtlichsten Theile. Zunaichst die intercalare Flächenausdehnung. Sie übertrifft die durch marginale Apposition geschehende stets um ein vielfaches, ist in der Nähe des Randes an starksten und sinkt in einer je nach der Art grösseren oder kleineren Entfernung von diesem auf Xull herab. Je nachdem sie in radialer und 
Langentialer Richtung gleichmässiğ oder ungleichmässị stattfindet, ist der laubartige Thallus glatt oder gerunzelt, seine Lappen seitlich ibereinander greifend oder spreizend. Eine genaue Viessung der intercalaren Flächenausdehnung ist nicht immer möglich, sicher aber da, wo auf dor Oberfläche bestimmte feste Puncte unmittelbar hinter dem Rande markirt sind, deren mit der Entfernung rom Rande wachsende Distanz von einander gemessen werden kann: w ic in dem Rande der Cyphellen von Sticta, den Runzeln von Lmbilicaria pustulata und Sticta pulmonaria, den Maschen des Adernetzes auf der Lnterfliche von Peltigera.

Zweitens die Dickenzunahme. Unmittelbar hinter der Spitze, resp. dem Rande, beginnt sowohl Flichen- als Dichenwachsthum der Rinde. Bei ringsum berindetem Thallus muss schon ersteres für sich allein eine Vermehrung der Dicke zur Folge haben, wenn es, wie meistens der Fall ist, lebhafter fortschreitet, als das eigentliche Spitzenwachsthum. Die Veristelung und Verdickung der axilen (oder, bei einseitiger Berindung, unteren Hyphen bleibt hinter der Vergrösserung des Rindenumfangs zurüch, daher die Differenzirunğ des lockeren lufthaltigen Markgeflechtes ron der dicht bleibenden Rinde. Es bedarf keiner ausführlichen Erwïhnung, dass der weite axile Ilohlraum bei Cladonia und Thammolia dadurch zu Stande kommen muss, dass sich das ganze Gewebe úberwiegend in der Richtung der Oberfliche vergrössert. Auch wo Rinde und Mark bereits differenzirt sind, dauert die I)ickenzunahme des Thallus viclfach noch fort, je nach den Arten versehieden lang̣e, bei den meisten laubartig̣en Formen hört sie dicht hinter dem Rande ganz oder nalıezu auf.

Alles intercalare Wachsthum beruht theils allein auf Ausdehnung vorhandener Zellen und Verdickung ihrer Membranen, theils auf Zelltheilung, Neubildung und Einschicloung ron Verëstelungen. Erhebliche Vergrösserunğ der Zellen, sowohl des Marks als der Rinde ist z. B. in der hinter dem Rande gelegenen Zone des Thallus von l'eltigera P. canina, aphthosaj zu beobachten. Die Zellen der Markhyphen ron Usmea, der inneren Rinde von Bryopogon, nehmen nach Schwendener mit Entfernung von der Spitze beträchtlich an Lainge zu. In anderen Hiillen ist mit der Strechung Theilung durch Querwande verbunden, \%. B. bei den itusseren Rindenzellen von Bryopogon, woldhe den innern urspriunglich ghleich lang sind und withend der Strechung dieser immerkur\% bleiben. Der wichtigste Factor beim interealaren Wachsthum ist jedenfalls die Einschichung neu entstehender Veristelumgen. Dieselbe lindet, wie vielfach leicht nachweishar ist, sowohl in dem lockeren Marke, als auch in dem interstitienlosen Gewebe der soliden Markstränge und der Rinde statl, und in letzterer, wie schon oben angedeutet wurde, ganz vorzugsweise. Je nach der Richtung, in welcher diese später cingeschobenen Aeste wachsen, bleibt die Anordnung der Hyphen in den ailteren Theilen entweder wesentlich die gleiche, wie in der Spitze oder dem Rande (\%. B. Thammolia, Rinde von Roccella, Bryopogon, Marhstrang von Usnea); oder sic indert sich dergestalt, dass in den äteren Theilen kaum eine Spur von der ursprüuglichen Anordnung erkennbar bleibt - z. B. Mark von Roceclla, Sphaerophoron, und vor allem die Rinde von letzterel Gattung und von Usnea, welche im älteren Zustande statt dor ursprüinglichen symmetrisch-divergirenden oder paralleleri Ilyphen ein dichtes Geflecht von nach allen Richtungen sich kreuzenden istigen Fiden darstellt.

Bei vielen Laub- und, wis hicr anticipirt werden mag, Krustenflechten fnach 
Schwendener, ich kenne es von Umbilicaria pustulata und einer Reihe Krustenflechten) ist mit dem Dickenwachsthum ein von aussen nach innen fortschreitendes Absterben der älteren Rinde verbunden. Die todte Schicht bleibt auf der lebenskräftigen oft als eine fast structurlose durchsichtige Masse liegen; in anderen Fällen wird sie durch die atmosphärischen Agentien rasch zerstört und unkenntlich. Der Verlust der Rinde wird durch Regeneration von der Innenfläche aus ersetzt, so dass jene immer ungefähr die gleiche Dicke behält. Die in der Gonidienzone verlaufenden Markhyphen nämlich verästeln und verflechten sich zu einem der Rinde gleichwerdenden und sich ihr innen anlegenden interstitienlosen Gewebe. Die äusseren Gonidien werden in dieses secundäre Rindengeflecht eingeschlossen, schrumpfen allmählich und sterben ab, während innen neue entstehen. Hat der beschriebene Vorgang längere Zeit gedauert, so ist die ganze Rinde mit absterbenden oder todten inhaltslosen Gonidien durchsäet. Dieselben lassen sich, zumal nach Einwirkung von Kali, durch die unten zu erwähnende Iodfärbung ihrer Membran nachweisen. Sie liegen in der älteren Rinde immer viel weiter auseinander, als in der ursprünglichen Gonidienzone, was einen weiteren Beweis für die intercalare Vermehrung der Rindenelemente liefert.

Die Verzweigung des Strauch-und Laub-Thallus ist theils eine ächte Gabelung, Dichotomie, theils geschicht sie durch Adventiväste, welche an beliebigen Puncten entstehen können. Von den bei Usnea vorkommenden Soredialisten wird unten die Rede sein.

Die Gabelung kommt bei dem strauchartigen Thallus dadurch zu Stande, dass das Längenwachsthum des Scheitels in der Mittellinie aufhört, und dafür an zwei symmetrisch neben dieser liegenden Puncten derart andauert, dass zwei dem ersten gleiche und das Lïngenwachsthum fortsetzende Scheitel entstehen. Die Adventiviste werden angeleğt, indem ein Bündel Rindenfasern über die Oberfläche hervorwächst und die Eigenschaften eines Thallusendes erhält. Ihr Wachsthum ist im übrigen dem der Gabelaste gleich. Der junge Adventivast sitzt zunächst der Rinde aussen auf. Dureh sein Dickenwachsthum wird später das tiefer gelegene Rindengewebe des Stammes an der Ansatzstelle gelockert und das sich entwickelnde Mark des Astes mit dem des Stammes in Berührung gebracht. Von den Hyphen jenes treten dann immer zahlreiche $\Lambda$ este in den Stamm ein, kreuzen und verflechten sich mit den Markhyphen des letzteren; eine Erscheinung, welche zumal in dem dichten Markstrange von Usnea auffallend hervortrill, in welchen die Fasern des Adventivastes von der Seite her eindringen und sich zwischen den longitudinalen Ilyphen strahlig ausbreiten. An der Trennungsstelle der Gabeliste findet diese Kreuzung der IIyphen nicht statt.

Gefördertes Wachsthum eines Adventivastes kann den Hauplstamm zur Seite drängen und somit eine falsche, scheinbare Gabelung bilden.

Es ist wahrscheinlich, dass die Verzweigung, beziehungsweise Lappung des laubartigen Thallus auf ahnliche Weise wie bei dem strauchartigen zu Stande kommt, doch liegen darüber keine eingehenderen Untersuchungen vor.

Der eigenthimliche, in laubartige Schuppen und Podetien gegliederte Thallus von Cladonia und Stereocaulon bedarf in vielen Puncten noch genauerer Untersuchung. Für Cladonia haben Schwendener's Arbeiten die Wahrscheinlichkeit ergeben, dass die Podetien im Marke der primären Schüppchen angelegt 
werden und durch die Rinde hervorbrechen. Die Berindung der Podetien bei genannter Gattung ist von allen übrigen verschieden. Das wachsende Thallusende besteht aus parallelen oder symmetrisch-divergirenden Hyphen, welche sich nach unten in die des Markes fortsetzen. Auf der unberindeten Oberfläche dieses, innerhalh eines dünnen, locker filzigen Fadengeflechtes, bilden sich einzelne, nach unten allmählich zahlreicher werdende Gonidiengruppen. Die partielle Berindung vieler Arten entsteht später, indem die Fäden des lockeren Geflechts dic Gonidiengruppen überwuchern und sich auf der Aussenseite derselben zu einem lückenlosen Rindengewebe verflechten. Durch Vergrösserung und Vereinigung der anfïinglich getrennten und bei vielen Arten als getrennte Schüppchen verbleibenden Rindenportionen kommt in manchen Fällen (Cl. furcata) eine fast oder ganz vollstindige Berindung zu Stande.

Die hlattartigen abstehenden Schuppen an den Podetien mancher Arten (Gl. squamosa, furcata u. s. f.) entstehen, indem sich entweder ganze Rindenschüppchen oder Theile des Randes von grösseren mit ihrer einen (unteren) Scite von dem oberflichlichen Fasergeflecht abheben, und sich um die entgegengesetzte (obere) befestigt bleibende wie ein Ventil drehen, bis sie horizontal stehen. Die Ursache dieser Bewegung ist in der Entwickelung der lockeren Faserschicht unterhalb der Anheftungsstelle zu suchen. Die beschrichenen Schuppen sind naturlich nur auf ihrer Oberseite berindel. Andere, an ihrer Basis beiderseits berindete Schuppen scheinen aus faltenartigen, später an ihrem freien Rande aufreissenden Vortreibungen der Rindenportionen zu entstehen.

Die Bildung der becherförmigen Thallusenden geschicht ahnlich wie die Gabelung, nur dass dic Ilyphen nicht nur nach zwei Seiten, sondern wie die Seitenlinien eines ungekehrten Kegels auseinander treten.

\section{Der krustenförmigg geschichtete Thallus.}

Es wurde schon Eingangs angedeutet, dass bei einer Anzahl sogenannter Krustenflechten (Verrucaria, Calycium, Bacomyees u. s. f.j der Thallus noch zu wenig untersucht ist, als dass über seine Structur und seine Entwichelung irgend bratuchbare Angaben möglich wiren. Für die iblerwiegende Mehrzahl der Krusteuflechten diurten aber zwei Ilaupttypen zu unterscheiden sein. Nach den mir zu Gebote stehenden Daten kann ich anch diese nur andeuten, eine sicher begründete Darstellung bedarf noch ausgedehnter Intersuchungen.

Der erste Typus, denı z. B. die Genera Psora, Psoroma, Thalloidima candidum angehören, unterscheidet sich von dem laubartigen nur dadurch, dass die Unterfliche des Thallus unberindet und allenthalben mit Wurzelharen bedeckt ist: Aesten oder Fortsetzungen der Markfasern, welche sich dem Substrat anschmiegen oder in dasselbe, oft tief, eindringen. Fornen, welche, wie Placodium-Arten, Pannaria, Endopyrenium unten berindet, aber gleichfalls mit W'urzelharen bedeckt sind, schliessen diesen Typus unmittelbar an den lauhartigen an; er würde, wie unir scheint, am besten geradezu mit diesem vereinigt werden.

Einem zweiten Typus gehört, wie Schwendener schon vor lingerer Zeit Vortrag über d. Flechtenthallus, p. 6, Flora 1861, p. 32:3) angedeutet hat, wohl die Mehrzahl der Lichenen mit gefelderter oder körniger Kruste an. Ich 
habe von diesen eine Anzahl rindenbewohnender Formen, Lecidella enteroleuca Kbr. (Lecidea parasema Nyl. et plurim.), Ochrolechia pallescens, Lecanora pallida, Pertusaria untersucht und kann mich zunächst nur an diese halten; für die Uebereinstimmung einer sehr grossen Zahl anderer spricht aber der gleiche Habilus.

Der Rand des Thallus (Fig. 87) besteht bei den genannten Flechten aus mehreren Lagen von Hyphen, welche in der Richtung der Flache strahlig divergiren $(A)$, im radialen senkrechten Längsschnitt parallel laufen $(\boldsymbol{B})$. Dieselben bilden miteinander eine continuirliche, in verschiedenen radialen Streifen oft verschieden dicke Randzone, über deren Umfang einzelne freie Hyphenenden hinausragen. Durch Spitzenwachsthum und Verästelung der marginalen Hyphen-enden wird der Rand vorgeschoben, die Fläche des Tallus also vergrössert. In einiger Entfernung rom hande beginnt die Bildung von Gonidien und zwar an zerstreuten Puncten und innerhalb der Hyphenlagen, so dass die Gonidiengruppen sowohl seitlich, als auch oben und unten von diesen bedeckt sind. In und um jede Gonidiengruppe findet num, unter steter Vermehrung der Gonidien, eine lebhafte Verästelung der Hyphen und eine immer dichtere, his zur Verwischung des ursprünglichen radialen Verlaufs fortschreitende Verflechtung der neu entstandenen Aeste stall, besonders auf der dem Substrat abgekehrten Seite. Es entsteht

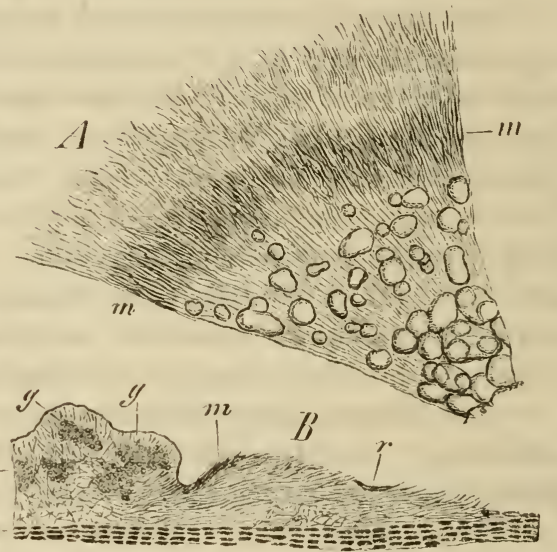

Fig. 57 . hierdurch an den bezeichneten Puncten ein dicht verflochtenes, zahlroiche Gonidien einschliessendes Fadenknäuel, von dem die oberflichlichsten Enden einen vorzugsweise zur Olnerfliiche senhrechten Verbauf zcrigen, eine meist sehr dünne, die äussersten Gonidien bedeckende Rindenschicht bildend (Fig. 87 B).

Die Stellen, in welchen die beschriehenen Bildungen stattinden, erheben sich auf der Flache der Marginalzone als gewölbte Hervorragungen, Wärzchen, deren Zahl und Grösse mit der Eulfernung vom Rande rasch zunimmt bis zu gegenseitiger Berührung und Zusammenfliessen. Jo nach der Gestalt der Ilervorragumgen, dem Grade ihrer Erhebung und ihres Zusammenfliessens erscheint der ausgebildete Thallus in verschiedenem Grade uneben, warzig, körnig, gefeldert. Seine Structur gleicht sowohl bei den speciell genannten, als den meisten anderen mit ahnlich aussehendem Thalfus versehenen Krustenflechten dem laubartigen. Die Rindenschicht ist, soweit meine Kenntniss reicht, dünn, aus Fasern des oben beschriebenen Verlaufes bestehend. Sie scheint iiberall in der früher angegehenen Weise (S. 250) aussen abgestossen und von innen regenerirt zu werden.

Fig. 87. Lecidella enteroleuca Kibr. Auf der Rinde von Tilia. $A$ junger, wachsender Thallusrand, schwach verg., von der Fläche gesehen. $B$ Radialer senkrechter Längsschnitt durch denselben, Umriss $4 \mathrm{5mal}$ vergr., Ausführung nach stärkerer Vergr., wie in Fig. 83. $m$ Der schwarze Randstreifen. g Gonidiengruppen. p Periderma. 
Die Gonidienzone springt verschieden weit in das Mark vor. Letzteres nimmt mit der Bildung der Vorragungen bedeutend an Mächtigkeit zu, seine Hyphen sind ordnungslos verflochten, die Interstitien lufthaltig. Bei den Krustenflechten mit sehr dickem Thallus, wie z. B. Lecanora ventosa Ach. (Haematomna vent. Mass.), L. Villarsii Ach. (Urceolaria ocellata DC.) bildet es weitaus die Hauptmasse, die Dicke der Rinde und Gonidienzone beträgt nach Tulasne kaum den 30sten Theil der des ganzen Thallus. Die Felderung der Oberfliche des letzteren hat, nach Schwendener (Vortr. p. 14), oft darin ihren Grund, dass die Rinde in Folge vorwiegender Ausdehnung des Markes Risse erhält - was natürlicher Weise unabhingig von der angegebenen ersten Anlegung der Felder geschehen kann.

Die Befestigung des Thallus geschieht in derselben Weise wie bei Psoroma, Psora u. s. w. durch Wurzelhaare, welche allenthalhen als Aeste von den unteren Markhyphen entspringen. Dieselben dringen wenigstens bei vielen steinbewohnenden Flechten in Menge tief in das dicliteste Substrat ein, oft ist der Thallus ganz oder nahezu vollstindig gleichsam in die Substanz des Gesteins eingeflochten (zumal Verrucariae). Bei den rindenbewohnenden Krustenflechten, welche ich untersucht habe, drïngen sich schon die Hyphenenden der Marginalzone theilweise zwischen die aussersten Peridermalagen. In geringer Entfernung vom Rande findet man einzelne Peridermastiuckehen der Oberfliche des Thallus aufliegend (Fig. 87, r). In den entwickelten Regionen des letzteren sind die der Rinde zugekelirten Markhyphen reichlich zwischen die oberflichlichen Peridermalagen aingedrungen, ein ordnungsloses Geflecht bildend, welches Peridermaportionen in reichlicher Menge einschliesst, entweder cinzelne Zellen und selbst nur Membranfragmente, oder grössere Stuicke, was auch bei der gleichen Flechtenspecies, je nach der Ait des Baumes, den sie bewohnt, wechselt. Die eingesehlossenen Fragmente sind aufs versehiedenartigste verschoben, oft weit von einander und von den flechtenfreien tieferen Peridermaschichten entfernt - was ein lebhaftes interealares Wachsthum in der unteren angewachsenen Vledullaroder Wurcelhatrage anzeigr. Ein Wurzel-oder myceliumbihnliches Eindringen der Hyphen in die lieferen Rindenlagen ist mir von keiner Kustenflechtebekannt.

Der Rand vieler kinstenflechten, unter den oben speciell bezeichneten z. B. der von lecid. enteroleuen Kbr., wird hiufig von einer vielbeschriebenen sehwarzen Linie umsïunt. An dem Thallus genannter Species sicht man leicht, dass dies von einer schwirzhichen birbung der Zellenmembranen der obers ten wenigen IIphenlagen herrïhr, wclche an der noch gonidienfreien Marginalzone in einem gew issen Alter cintritt. Wo der Thallus in lebhaftem Wachsthume begriflen ist, verliuft die schwarze linie, wemn sie iiberhaupt vorhanden ist, innen von dem farblosen jugendlichen Raude. Nufden gonidienführenden Prominenzen fohlt die schwarze Farbe, ohne Zweifol, weil die wenigen Zellagen, denen sie zukommt, durch die Ausdehnung der Prominenz auscinandergedrängt und bald abgestossen werden. Wo von den in Rede stehenden Arten mehrere Thallusindividuen aneinanderstossen, da bilden die heschriebenen schwarzen Linien wie es seheint dauernde, oft landkartenibuliche Grenzen zw ischen denselben. Der Grund hicroon diirfte darin liegen, dass bei dem Zusammentreffen init anderen das marginale Wachsthum des Thallus stille steht und die Fïbung in der Randzone damn eintritt und bleibt.

Line Anzahl ion Krustenflechten - z. B. Lecidea geographica, confervoides 
(Rhizocarporı Ram. Kbr.), Urceolaria ciLerea nach Tulasne's Abbildungen, zeigen um ihren scharf gefelderten Thallus einen Saum, gebildet aus strahlig divergirenden, verzweigten, confervenartigen und der Unterlage fest angeschmiegten Strängen, welche von bündelweise fest vereinigten Ilyphen gebildet werden. Auf dieser marginalen Ausbreitung erheben sich die Areolen des Thallus in centrifugaler Folge, zuerst als kleine Schüppchen oder Wärzchen, welche sich allmählich bis zur allseitigen Berührung mit einạnder vergrössern. Es ist noch durch genauere Untersuchungen festzustellen, ob zwischen dieser Entwickelungsweise und der erst beschriebenen andere Unterschiede bestehen, als der, dass hier die Marginalzone in die einzelnen Stränge getheilt, dort zusammenhängend ist. Der Bau der Areolen zeigt keine besonderen Eigenthümlichkeiten.

Die marginalen Stränge der letztbesprochenen Formen sowohl wie die Randzone der nach Art von Lecidella enteroleuca Kbr. wachsenden werden oft unter dem Namen Hypothallus mit den Rhizinen und Wurzelhaaren confundirt. Passender ist die Bezeichnung Protothallus, insofern sie einen Anfangszustand bedeutet; ob jedoch die in Rede stehenden Theile mit dem unten zu besprechenden, aus der Spore zunächst entstehenden Protothallus identisch sind, ist noch fraglich.

Ueber die Entwickelung der gänzlich anheftungslosen, ringsum berindeten, krustigen oder knolligen exotischen Formen, wie Chlorangium Jussuffii und die anderen Lichenes esculenti kennen wir nichts. Der Bau von Chlorangium, welcher durch J. Müller gut beschrieben worden ist (Bot. Ztg. 1858, p. 89) schliesst sich im Wesentlichen dem der heteromeren Lichenen an. Seine Haupteigenthümlichkeit besteht, ausser der allseitigen Berindung, darin, dass die Gonidien in längliche, radial verlaufende und dureh gonidienfreie Gewebsstreifen getrennte Gruppen angeordnet sind, welche zwischen der Rinde und dem massigen Medullarkörper liegen.

Die warzen- oder stabförmigen Excrescenzen, welche die Oberfläche mancher Krustenflechten oft dicht bedecken und das corallenähnliche Ansehen der sogenannten Isidium-Formen rerursachen, zeigen, soweit ich nach gelegentlichen Beobachtungen urtheilen kann, gleiche Beschaffenheit, wie die Seite 245 erwähnten grösseren Excrescenzen von Evernia furfuracea, Umbilicaria. Genauere Untersuchungen fehlen auch hier.

3. Stoffliche Beschaffenheit der Mark-und Rindenschichtdesgeschichteten Thallus.

Der Inhalt der Hyphen ist stets farblos, unscheinbar, schwach körnig, hie und da kleine Oeltröpfehen führend, er wird durch Iod lebhaft gelb bis braun gefärbt. Organisirte Inhaltsbestandtheile kommen nicht vor; insonderheit ist das von Nylander (Synops., p. 50) behauptete Vorkommen von Stärkekörnern zurückzuweisen. Die Membran der Fasern gehört zu den gallertartigen Cellulosemodificationen. Sie ist durchscheinend, im Narke und den inneren Rindenregionen fast immer farblos, im trockenen Zustande spröde, in kaltem Wasser erheblich quellend, weich und biegsam werdend. Nach einigen von Nylander (I. c. p. 14) mitgetheilten Messungen nimmt der trockene Thallus durch Quellung in Wasser bei Peltigera canina um etwa 38 , bei Hagenia ciliaris um etwa 30 Procént an Dicke zu. Es ist leicht zu beobachten, dass die Rinde vorwiegend in der Rich- 
tung ihrer Oberflache quillt, die lockeren Markfasern scheinen sich vorzugsweise in der Läingenrichtung zu strecken; genaue Untersuchungen hierüber fehlen. Die Rindenzellen enthaiten in trockenen Zustande wenigstens theilweise Luft, die ganze Schicht wird hierdurch undurchsichtig. Durch Wasser wird die Luft rasch verdı:ingt und die Transparenz der Membranen erhöht, so dass die grüne Gonidienzone durchschimmert; daher der beim Befeuchten eintretende Farbenwechsel der Oberfliche. Die Interstitien des Markgeflechtes bleiben auch bein Befeuchten lufthaltig, dieses daher undurchsichtig. In Iod bleiben die meisten Fasermembranen farblos, bei Zusatz von Schwefelsiure zerfliessen sie, entweder ungefärbt (z. B. Usnea barbata) oder nach vorheriger Bräunung (z. B. Hagenia ciliaris nach Speerschneider), oder nach Annahme einer manchmal intensiven (z. B. Mark von Lvernia furfuracea) Violetfirbung. Bei Cetraria islandica werden, wie schon Schleiden (Grundz. II) angibt, die Rindenmembranen, mit Ausnahme der oberflichlichen gefärbten, durch Iodlösung allein schön blau, nach Zusatz von Schwefelsiiure nehmen sie, sammt denen des Markes, eine violette Farbe an und zerfliessen. Die Medullarmembranen ron Sphaerophoron coralloides werden durch Iod hellblau, wihren die Membran der Rindenfasern farblos bleibt. Zusatz von $\mathrm{SO}_{3}$ bewirkt lebhaft violette Firbung der Mark-, braunviolette der Rindenmembranen. Stellenweises Blauwerden durch locl allein fand Schwendener noch in der Rinde von Cornicularia tristis Web. und einzelnen nicht niher bezeichneten Arten. Kupferoxydammoniak verursacht nach Schwendener höchstens ein sehr schwaches Aufquellen der Membranen. Ammoniak, Natron-, Kalilösung bewirken stets, und die letzlere meist sehr starke Quellung. (Sie dienen daher dazu, das dichte Gewebe zu lockern und durchsichtig zu machen, wenn es sich um Untersuchung des Faserverlaufs handelt; letzterer tritt besonders deutlich hervor, wenn der Zellinhalt, nach Neutralisation des Alkali, durch lod gefairlot wird.)

Mit Wasser gekocht quillt die Membran mancher Flechten zu amorpher Gallerte auf wie von Cetraria islandica allgemein bekannt ist; die Gallerte von der genannten Art und von Sphaterophoron coralloides wird durch Iod schön blau, die anderer Flechten, z. B. Sticta pulmonaria nicht. - Die beschriebenen Membranen sind die n Moos-oder Flechtenstia re, Lichen in "der Chemiker.

Die Membranen der Rincle, zumal die oberflichlichen Lagen, sind bei vielen Flechten verschiedentlich gefirbt von einem die Substanz gleichmaisig dureh dringenden Farbstoffe, z. B. Cetraria islandica, Bryopogon jubatus und viele andere; die dunkle Farbe der unteren Rinde von Evernia furfuracea rührt von einer Färbung der äusseren Membranschichten her: auf Durchschnitten sieht man die engen Lumina von dicken farblosen Membranen umgeben und zwischen diesen dunkelbraune Grenzstreifen. Genauere Untersuchungen über diese gleichförmig färbenden Stoffe, wenigstens mikrochemische, fehlen.

Eine zweite Reihe von Fïbungen wird bewirkt durch die körnigen Einlagerungen oder Incrustationen. Sehr vicle Flechten zeigen in ihrem Gewebe kleine, runde oder lingliche, aus or g a n is cher Substanz bestehende Körnchen, theils der freien Oberfliche und den Markhyphen auf-, theils den interstitienlos verbundenen Membranen eingelagert. Farblose, oder doch auch in Masse nur schwach gelblich gefirbte Körnchen dieser Art kommen z. B. vor: in der oberen Rinde von Placodium cartilagineum u. a., Imbricaria caperata Dill., incurva P. u. a., aul den Markhyphen von Peltigera, Solorina saccata, Sticta 
Spec. (Schwendener), auf der Rinde von Roccella, zumal R. fuciformis, Thamnolia, in der innern Rinde von Sphaerophoron coralloides; deutlich, oft intensiv gelbe: Aussenseite der Rinde von Evernia vulpina, Physcia parietina; eingelagert der peripherischen Rindenregion von Cetraria straminea (Schw.), Usnea barbata, der ganzen Rindenmembran von Psoroma gypsaceum, gruppenweise durch die Rinde zerstreut bei Bryopogon divergens (Ach.), sarmentosus, und besonders Br. ochroleucus, wo sie in der Nähe der Oberfläche eine ununterbrochene Schicht bilden; Markhyphen von Sticta aurata, auch Sticta crocata u. s. f. ; rothe Incrustationen auf den Markhyphen ron Solorina crocea. Alle diese Ein- und Auflagerungen bedingen theils lebhafte Färbung, theils matt-gelbliches Ansehen und Undurchsichtigkeit (z. B. Thamnolia, Roccella) der Theile, in denen sie enthalten sind. Alle stimmen darin überein, dass sie sich in Alkalien leicht lösen, unverändert oder unter Entfärbung, oder doch wenigstens unter Einwirkung dieser Agentien wolkig zerfliessen (Physcia parietina; Sol. crocea unter Farbenänderung). Nach diesem Verhalten ist es nicht unwahrscheinlich, dass die Körnchen aus den sogenannten Flechtensïuren (Usninsiure, Lecanorsïure u. s. f.) oder Verbindungen derselben bestehen, zumal da Knop gezeigt hat, dass bei Usnea, Bryopogon sarmentosus, wo die gelbe Farbe entschieden von den Körnchen herrührt, die Menge der ausziehbaren Usninsäure um so grösser ist, je intensiver gelb die Fïrbung (Ann. d. Chem. u. Pharm. Band 49, p. 108).

Eine zweite Reihe von Infiltrationen und Einlagerungen besteht aus a norgånischen Substanzen. Zunïchst sei hier die Rostfarbe erwïhnt, welche nicht selten einzelne Individuen (»formae oxydatae () vicler typisch anders gefärbter Krustenflechten annehmen, und von welcher vielfach bemerkt, neuerdings durch Gümbel nachgewiesen worden ist, dass sie durch Infiltration eines (pflanzensauern?) Eisensalzes zu Stande kommt. Bemerkenswerther ist das Vorkommen des oxalsauern Kalkes in vielen, zumal Krustenflechten. Derselbe tritt auf theils in Form octaedrischer Krystalle, theils unregelmässiger krystallinischer Körper, theils kleiner Körnchen. Er findet sich, wie in der Regel bei den Pilzen, niemals im Innern der Zellen, sondern entweder auf der Rindenoberfliche, auf den Markhyphen und in den Lücken zwischen diesen, oder - in Form feiner Körnchen - in die Membranen des dichten Rindengewebes eingelagert. Letzteres ist z. B. der Fall bei Psoroma lentigerum, dessen ganze Rinde vollkommen undurchsichtig, im reflectirten Lichte weiss ist, von dicht gedrangten Körnchen genannten Salzes. Ausser der genannten Species, deren Markhyphen gleichfalls durch den in Rede stehenden Körper incrustirt sind, seien als Beispiele für sein Vorkommen genannt: Ochrolechia tartarea Mass., Urceolaria scruposa, mit ungeheuren Mengen zum Theil sehr grosser Krystalle in den Marklücken; Thalloidima candidum: Rindenoberseite mit auf- und eingelagerten Körnern; der Thallus der Pertusarien, zumal P. fallax, mit grossen, unregelmaissigen, interstitiellen kṛ̣stallinischen Massen; körnige Incrustationen im Marke von Chlorangium Jussufii; vereinzelte kleinere Krystalle finden sich im Innern des Thallus zerstreut hei Megalospora sanguinea, affinis Mass., Ochrolechia pallescens Mass. u. s. f.

Es ist jedoch durchaus unrichtig, wenn behauptet wird, der kleesaure Kalk komme in allen Flechten, oder gar bei allen in Octaederform ror, und wenn dieses sogar (von Nylander, Synops. p. 4) unter die characteristischen Merkmale der 
Flechten aufgenommen ist. Er fehlt nicht nur allen Gallertflechten, sondern kommt nicht einmal allen krustigen heteromeren zu; so suchte ich ihn z. B. bis jetzt vergebens bei Lecanora pallida und Lecidella enteroleuca Kbr. Unter den laubartigen konnte ich ihn sowenig wie Schwendener finden, abgesehen von seinem Vorkommen bei Placodium und Endocarpon monstrosum, dessen dieser Beobachter erwähnt; auch bei den meisten strauchartigen sah ich ihn sowenig wie Schwendener. Nur in den jungen Zweigen von Roccella fuciformis fand ich ziemlich grosse (nicht chemisch untersuchte) Krystalle, und in der Rinde und dem Marke von Thannólia vermicularis Gruppen kleiner St:ibchen und Körner, welche aus dem in Rede stehenden Körper bestehen.

Als oxalsaurer Kalk wird dieser legitimirt durch die auf Seite 13 angegebenen Reactionen (untersucht bei Ochr. tartarea, Psor. lentiger., Pertusaria, Thamnolia). Zudem haben die makrochemischen Analỵsen in den incrustirten und krystallhaltigen Flechten mehrfach Oxalsiure nachgewiesen (z. B. Urceolaria, Ochr. tartarea, Pertusaria etc.). Es bestehen übrigens in dieser Bezichung Widersprüche: Gümbel konnte in Lecanora ventosa keine Oxalsiiure nachweisen, wihrend Braconnot grosse Mengen oxalsauren Kalkes angiebt, den ich gleichfalls sowohl mikroskopisch als makrochemisch nachweisen konnte.

Ausführliche Aufzihlung und Beschreibung der durch die Analyse nachgewiesenen organischen wie anorganischen Flechtenstoffe wäre hier nicht am Platze; es sei daher auf Rochleder's Zusammenstellung der Thatsachen und Litleratur in Gmelin's Handb. d. Chennic, Bd. VIII. verwiesen /separatim: Chemie u. Phys. d. Pfl. v. Rochleder. 18:38). Bemerkenswerth ist der oft sehr holıe Aschengehalt, der nach Thomson bei Cladonia rangiferma bis 12, it Procent, bei P. saxatilis bis 6,91 Proc., bei Cetr. islandica allerdings nur 1,8' Proc. der Trockensubstanz beträgt. Ferner die mit dem Substrate wechselnde Aschenmenge: Imbricaria saxatilis von einer Esche gegen 7 Proc, von Felsen 3,9 Proc. (Thomson), Evernia prunastri von Birkenrinde 4,12- ̈̈ Proc., von Sandstein 3,:5 Proc., wobei die relative Menge der Bestandtheile wechselt (Uloth). Endlich das, in der sonst qualitativ den ibrigen Pflanzenaschen ähnlich zusammengesetzten Asche sehr häufige Vorkommen relatir grosser Mengen von Thonerde (z. B. 3,49 Proc. der Aschenmenge in Er. prunastri von Sandstein). Ausfülılicheres über die Aschenanalysen siche bei:

Thomson, Ann. d. Chem. u. Pharm. Bd. 53, p. 254.

Knop, Erdın., Journ. f. pract. Chem. Bd. 38, p. 46. Bd. 40, p. 386.

Gümbel, Ueber Lecanora ventosa. Denkschr. d. Wiener Acad. Math. Naturw. Cl. Bd. XI.

Linds a y, Popul. hist. of Brit. Lich., p. 51.

Iloth, Flora 1861, p. 568 .

Th. Fries, Genera heterolichenum, p. $8-12$.

\section{Die Gonidien des geschichteten Thallus.}

Von diesen Organen sind bei den heteromeren Lichenen zwei Hauptformen zu unterscheiden, von denen jeder Species eine zukommt, und welche kurz als grüne (Chlorogonidien Wallr.) und blaugrüne bezeichnet werden können. Letztere finden sich bei den Genera Nephroma, IIeppia Nig., Peltigera, 
Solorina, Arten von Sticta (Stictina Nyl.) und den den Uebergang zu den Gallertflechten bildenden Gattungen Pannaria, Lecothecium, Racoblenna.

Die übrigen, weitaus zahlreicheren Gattungen haben grüne Gonidien. Was Speerschneider als farblose Gonidien bezeichnet, sind nichts weiter als leere Membranen, die durch die Priparation ilıren gefärbten Inhalt verloren haben, was bei Durchschnitten oft der Fall ist. Tulasne fand dagegen in dem Thallus von Lecidea albocaerulescens Fr. farblose, solide, ganz aus Cellulose bestehende Kugeln von $1 / 75 \mathrm{Mm}$. bis $1 / 62 \mathrm{Mm}$. Durchmesser, welche er für veriinderte Gonidien hält (Mém. Lich. p. 8:̈). - Von den übrigen wesentlich verschieden sind die Gonidien der Gattung R oc cella.

Das grüne Gonidium entsteht, wie Bayrhoffer zuerst zeigte, indem das Ende eines kurzen Seitenästchens der Hỵphen anschwillt und sich zu einer kugeligen, grïne Farbe annehmenden Zelle abgrenzt (Fig. $88 a, g)$. Einmal gebildet, zeigt es selbständiges Wachsthum und selbständige Vermehrung durch Theilung; eine Anzahl Gonidien liegl daher ungestielt in den Interstitien des Hyphengeflechtes.

Das fertige Gonidium (Fig. 88) ist eine kugelige Zelle von verschiedener Grösse. Das von Schwendener für Usnea gefundene Maximum von $1 / 80-1 / 55 \mathrm{Mm}$. dürfte für die meisten Flechten gültig sein. Bei Sticta ïberschreitet der Durchmesser selten 1/125 Mm. bis 1/100 $\mathrm{Mm}$. Die Gonidien haben eine farblose, ziemlich derbe Membran, welche in lod und Schwefelsiure, Chlorzinkjod die characteristischen Cellulosefärbungen zeigt, nach Erwairmung mit Kali auch durch wässerige lodlösung blau wird; Reactionen, die zur Auffindung der abgestorbenen Gonidien in der alten und abgestossenen Rinde dienen. Sie enthalten einen Protoplasmakörper, welcher ziemlich gleichförmig gelbgrün gefirbt ist, durch einen Farbstoff, dessen Vertheilung, Löslichkeit, Colorit dem Chloroph !ll vollkommen gleicht, der jedoch, nach Knop und Schnedermann, mit diesem nicht identisch, und als Thallochlor unterschieden worden ist (Ann. d. Chem. 1. Pharm. Bd. 55, p. 154). Der grüne Körper füllt entweder den Innenraum der Zelle vollstindig aus, oder er ist aul seiner Oberfliche uneben (gekerbt oder strahlig eingeschnitten in der Profilansicht) und nur die Vorsprünge mit der Wand in Berührung, die Vertiefungen durch wasserhelle Substanz ausgefüllt. Der peripherische Theil des grünen Körpers ist meistens deutlich dunkler gefirbt, als die Mitte. Sein Centrum wird bei der frischen Flechte von einem blassen runden Körper eingenommen, der entweder homogen oder blischenartig

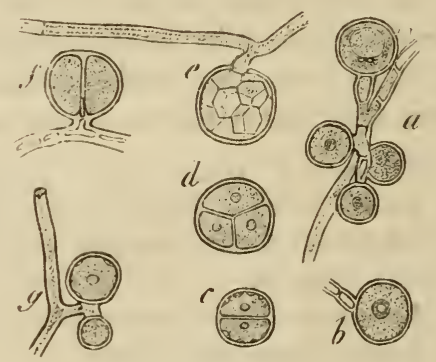

Fig. 58. hohl, soviel erkemnbar ungefirbt ist, und wetchen ich, nach Aussehen, Stellung und Verhalten zu Reagentien, als Zellkern bezeichnen möchte. Derselbe findet sich constant in dem frischen, feuchten Thalius. Er wird unkenntlich beim Eintrocknen des letzteren und ist an Prijparaten, welche von trocknen, wenn auch

Fig. ss. Grüne Gonidien $a-e$ von Imbricaria tiliacea, Vergr $390, g$ von $S$ phaerophoron coralloides, Vergr. $390 ; f$ von Us nea barbata (Vergr. 700 nach Schwend.). 
noch lebendigen Exemplaren entnommen sind, meist nicht sichtbar; er erscheint aber nach einiger Zeit wieder, wenn die Flechte wieder befeuchtet wird. $\left.{ }^{1}\right)$ Nicht selten finden sich ausserdem einzelne, verschiedenartig geordnete, farblose, ölartige Tröpfchen. Speerschneider's Angabe von mehreren Zellkernen und Schwendener's Leugnen des Vorhandenseins eines Kerns mögen theils in dem Auftreten der Oeltröpfchen, theils in der mit der Befeuchtung wechselnden Deutlichkeit des letzteren ihren Grund haben.

Die Vermehrung der Gonidien erfolgt durch wiederholte Zweitheilung (mit Scheidewandbildung) in gleichgrosse Tochterzellen. Nach Schwendener's Untersuchungen (die ich für die meisten, doch nicht für alle Stadien wiederholt habe) ) geht die erste Scheidewand durch den Anheftungspunct der Sticlzelle (Fig. 88, f) : die beiden folgenden setzen sich an die erste gewöhnlieh in der Weise an, dass die vier Theilzcllen annähernd tetracdriseh gestellt sind $(c, d)$, seltener so, dass letztere in derselben Elene liegen. Die Theilung schreitet hierauf in den verschiedensten Richtungen des Raumes fort, es bilden sich grössere Gruppen, die oft noch liangere Zeit. ihre ursprüungliche Kugelform behalten « $(e)$. Nach vollendeter Theilung beginmen die eivzelnen Tochterzellen sich auszudehnen und Kugelform anzunehmen, die ganze Gruppe erhiilt hierdurch zunichst maulheerförmiges Aussehen; zuletzt trennen sich die Tochler\%ellen von einander. Es ist mehr als wahrscheinlich, dass in den frei und kugelig gewordenen Tochtergonidien der Theilungsprocess von neuem vor sich gehen kann, ein sicherer Bewois hierfür jedoch kaum zu licfern, weil in den Präparaten diefreien von solchen nicht unterschieden werden können, welche von ihren Sticlen alggerissen sind.

Die bla ugrünon Gonidien entstelen nach Schwendener wie die grimen als Endzellen kurzer Sécitenistchen der Ilyphen und theilen sich wie jene; nnur folgen die Scheidewinde weniger rasch nach cinander und sind dabei hiufiger so gestellt, dass je vier zusammengehörige Theilzellen in einer libene liegen. Auch verlieren die aus einer Mullerzelle hervorgehenden Gruppen schon sehr früh ihre Kugelform, sie werden unregelmässig-länglich, oft viel linger als breit, und bilden alsdann doppelte oder mehrfache Reihen, deren filiederzahl sich haiufig durch wiederholte Theilung in der nimlichen Richtung vermehr." Zumal bei den Pannarien und Verwandten tritt die Anordnung zu Reihen oder Ketten sehr auffallend hervor; letztere schieben sich oft weit in das Mark hinein. Boi den anderen Gattungen sind die Gonidien zu unregelmissigen Gruppen oder Nestern vereinigt.

Die Membranen dieser Gonidien sind in der Regel im ausgebildeten Zustande verdickt, gallertartig weich, oft in eine weichere breite Mittelschicht und diinne, festere Aussen- und Innenschicht gesondert. Die gallertigen Schwestermembranen sind meist fest vereingl, anseheinend zu einer homogenen Gallerte zusammengeflossen, so dass die Gonidiengruppe aus blassgrünen Körpern oder Zellen zusammengesetzt zu sein scheint, welche, mehr oder minder weit von einander entfernt, in einer gemeinsamen Gallerthülle eingebettet liegen. Erinnert schon dieses Verhältniss an die Zellfamilien der Nostocaceen und Chroococeaceen, so

1) Nach Lutersuchungen an Imbricaria tiliacea, caperata, Physcia parietina, Hagenia ciliaris, Parmelia pulverulenta, stellaris, Usnea barbata, Sphaerophoron coralloides, Lecidea enteroleuca, Pertusaria, Evernia prunastri, Cetraria islandica. 
wird die Aehnlichkeit mit den Zellen dieser Algen eine sehr vollstindige durch die Inhaltsbeschaffenheit der in Rede stehenden Gonidien. Die Membran umschliesst einen ganz homogenen Protoplasmakörper, welcher durch Ph y c och rom gleichmässig rein oder schmutzig blaugrün gefärbt ist. Genauer untersucht ist der Farbstoff allerdings bis jetzt nicht, seine Bezeichnung als Phycochrom wird jedoch durch die vollkommene Aehnlichkeit mit dem der genannten Algen gerechifertigt.

Die blaugrünen Gonidien sind der (allerdings nicht ausnahmslosen) Regel nach kleiner als die grünen; dieser Umstand, die Ilomogenitit ihres Inhalts und ihre gallertige Umhüllung mag es erklären, dass sie Nỵlander als grains gonidiaux, granula gonima, von den Gonidien unterscheidet.

Die Gonidien von Roccella zeichnen sich bei trocknen Exemplaren von allen übrigen durch den blass gelbgrünen Inhalt aus, dessen Beschaffenheit an der frischen Flechte noch zu ermitteln ist. Ihre Entstehung ist der der grünem im Wesentlichen gleich; ihre Vermehrung geschieht dagegen durch Sprossung, ganz :ihnlich wie bei den hefeartigen Pilzzellen (Seite 119, 120), nur dass die zur Tochterzelle sich abgliedernde Ausstülpung mit etwas breiterer Basis als bei diesen der Mutterzelle aufsitzt (vgl. Fig. 83, b, g).

\section{Der Thallus der Graphideen.}

Eine Anzahl von Krustenflechten zeigt eine von der beschriebenen in wesentlichen Puncten abweichende Thallusstructur. Ich fand dieselbe bei Grapli id e en verschiedener Genera (Graphis scripta, Opegrapha varia, O. plocina Kbr., Lecanactis illecebrosa Kbr., Arthonia impolita Khr., ferner O. saxatilis Schaer. [Zwackh. Exs. Nr. 2], O. gyrocarpa Kibr.) und bezeichne sie daher nach dieser Familie; sie kommt ferner der Pyrenula nitida'j zu.

Die Haupteigenthümlichkeit dieser Thallusform besteht in der Beschaffenheit der Gonidien (Fig. 89). Die erste Entstehung und der Zusammenhang dieser mit den IIyphen ist mir nicht deutlich geworden. Sie finden sich vereinigt zu oft vielgliedrigen, confervenartigen, istigen Zellreihen, welche durch Theilung

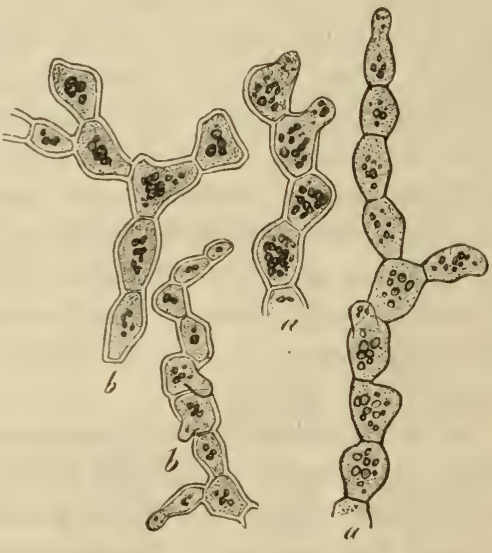

Fig. 89. der Endzelle in die Liinge wachsen, so zwar, dass diese ans ihrem abgerundeten

Fig. 89. Gonidienketten, $a$ von Lecanactis illecebrosa Duf. $b$ von Graphis scripta; Vergi. 390. Die runden hörper im Innern der Zellen stellen die braunrothen Oeltropfen vor.

1) Inwieweit die übrigen Verrucariaceen mit dieser übereinstimmen, muss ich dahingestellt sein lassen. Die ächten Verrucarien, z. B. V. Dufourei DC., V. calciseda DC. scheinen entschieden nicht hierher zu gehören. 
Scheitel eine am Grunde verschmälerte, und sich hier später durch eine Querwand zur neuen Endzelle abgrenzende Ausstülpung treibt. Die Reihen veristeln sich, indem eine ebensolche Ausstülpung unter dem oberen Ende der Gliederzellen hervortritt, als Anlage der ersten Zelle des Astes. Eine Theilung der Gliederzellen durch Querwände habe ich nie beobachtet.

Die Gestalt der Zellen ist höchst mannigfaltig; die verschiedensten Formen kommen in demselben Thallus vor, und zwischen den untersuchten Arten besteht keine erhebliche Verschiedenheit. Die Mehrzahl hat eine unregelmässig-ovale, elwa tonnenförmige Gestalt, ist in der Mitte aufgetrieben und mit ebenen kleinen Endflächen den Nachbarzellen angefügt, so dass die Reihe rosenkranzförmig erscheint. Daneben kommen fast kugelige, oder ganz unregelmässig ausgebuchtete Formen vor, und, zumal am Rande des Thallus, schmal und langgestreckt cylindrische. Die Zellen sind im Vergleich zu den Gonidien anderer Flechten sehr gross, die tonnenförmigen z. B. bei Opegrapha plocina bis zu $1 / 27 \mathrm{Mm}$. lang, $1 / 35 \mathrm{Mm}$. breit, bei Lecanactis bis über $1 / 42 \mathrm{Mm}$. lang, bei etwa 1/75 $\mathrm{Mm}$. Breite. Uebersehreitungen dieses Maasses finden sich ofters, die gestreckt cylindrischen sind dagegen viclfach $n u r \frac{1}{1} 250 \mathrm{Mm}$. dick.

Die Zellen besitzen eine maissig dicke, nicht gallertartige Cellulosemembran. Diese umschliesst entweder einen durch Chlorophyll gleichmässig gelbgriun gefärbten Protoplasmakörper, in dessen Mitte eine Anzahl verschieden grosser rothgelber oder rothbrauner, anscheinend ölartiger Körner oder Tröpfchen zerstreut liegen; oder die letzteren nehmen, dicht gehïuft, den Innenraum beinahe oder ganz vollstiandig ein, eine körnige, rothbraune Inhaltsmasse erscheint nur von einer schmalen peripherischen grünen Schicht umgeben oder ohne letztere, die ganze Zelle erfüllend. Bei den fünf oben zuerst genannten, hinreichend frisch untersuchten Arten fand ich alle Modificationen des Inhalts in demselben Thallus, den relativ grössten Chlorophỵllreichthum in den anscheinend jüngeren Zellen. Bei Pyrenula nitida fehlte das Chlorophyll nie, die rothgelben Oeltropfen waren immer sparsam, in einzelnen Zellen gar nicht vorhanden. Aus der angegebenen Inhaltsbeschaflenheit erkliitt sich ohne W' eiteres die vielfach beschricbene braunrothe oder gelbe Farbe des intacten oder verletzten Thallus der hierher gehörigen Formen, welche Farbe Wallooth zur Bildung des Nanens Ch r s ogonidie $n$ veranlasst hat. An alten, trockenen Exemplaren ist der Inhalt meist ganz ausgebleicht.

Die Gonidienketten sind bei den oben genannten steinbewohnenden Formen, bei Lecan. illecebrosa, Arth. impolita, schrigy oder senkrecht zur Oberfliche des Substrates gestellt und allenthalben umsponnen von verzweigten, farblosen, dimnen (etwa $1 / 300$ Mur. durchschnittlich starken) Ilyphen mit fast zum Verschwinden des Lumens verdickter Membran. Der ganze Thallus besteht lediglich aus einem solchen, in den Interstitien lufthaltigen Geflechte von Gonidienketten und Hyphen, ohne Differenzirung in Mark und Rindenschicht; er bildet einen zarten, centrifugal wachsenden verschieden dicken Ueberzug auf der Oberfliche des Substrates. Seine weisse Farbe rührt bei genannter Lecanactis und Arthonia theils von dem Luftgehalte, theils daher, dass an der Oberfliche zwischen dem IIyphengeflechte schr vicle farblose leere Membranen abgestorbener Gonidien liegen.

Bei Graphis scripta, Opegrapha varia und ahnlichen rindenbewohnenden 
Formen hat der Thallus, fuir sich allein betrachtet, im Wesentlichen den beschriebenen Bau; das Geflecht von Gonidienketten und Hyphen ist aber ausgebreitet zwischen den äussersten Peridermalagen der Rinde und die Gonidienketten vorzugsweise in der Richtung der Oberfläche geordnet und verzweigt. Sie dringen sich sammt den Hyphen allenthalben zwischen die Lagen und einzelnen Zellen des Periderma ein, an Thallusrande oft ein zierliches Netz bildend. Der ganze Thallus dieser Formen erreicht nur eine geringe Dicke und seine Aussenfläche ist stets bedeckt von einem dünnen, aus einer oder einigen Lagen von Zellen bestehenden Peridermaüberzuge: daher unterrindiger Thallus, Th. hypophlocodes. Nach Tulasne's Angaben schliesst sich diesen Formen als einfachste, fast rudimentiare der Thallus von Arthonia galactites (vielleicht auch »Verrucaria epidermidis () an, ein spärliches, unter der oberflichlichsten Peridermaschicht verbreitetes Fasergeflecht mit einzelnen kleinen Gonidienketten (chapelets). Die anscheinend weisse oder weissliche Farbe dieser unterrindigen Thalli ribrt, wie schon Wallroth angab, vielfach von Luftansammlung in und unter dem vertrockneten oberflichlichen Periderm her; bei Graphis scripta kommt hierzu reichliche Anhäufung unregelmäissiger krystallinischer Stücke von oxalsaurem Kalk.

Der Thallus von Pyrenula nitida endlich (nach Exemplaren auf Carpinus Betulus) ist gleichfalls unterrindig, aussen ron einer festen Lage Periderma bedeckt, und sein dichtes massiges Hyphengeflecht bis in die tiefsten Schichten dieses Gewebes ein-, diese weit auseinanderdrängend. Seine Gonidienketten sind fast lückenlos verflochten zu ausgedehnten, mächtigen, nur wenige Ilyphen umschliessenden, unter der Oberfläche liegenden Gruppen oder Lagern.

Schliesslich sei bemerkt, dass die Structur der hierher gehörigen Thallusformen, zumal die Gonidienketten, am leichtesten und deutlichsten hervortreten, wenn man die Prapalate nach Einwirkung etwa I0procentiger Kali- oder Natronlösung vorsichtig zerdriickt und zerfasert.

\section{Gallertfechten.}

Hierher gehören die Phỵcolichenes Massalongo's, die Collemaceae Nylander's zum allergrössten Theile, d. h. mit Ausnahme der im nächsten Abschnitte zu besprechenden » anomalen «.

Der Thallus der Gallertfechten hat laubartige oder klein-strauchartige Gestalı, oder besteht aus Körnchen, die mit cinander eine Kruste bilden (Synalissae spec.). Er ist in trockenen Zustande knorpelig-spröde, saugt Wasser begierig ein und quillt durch dasselbe zu einem ziih-gelatinösen Körper auf. Durchschnitle zeigen, dass er in allen Fällen zusammengeselzt ist aus 1) Gonidien, deren rundlicher oder etwas liinglicher Protoplasmakörper homogen-feinkörnigg und durch Phycochrom gleichförmig blaugruin bis violettbraun gefiarht ist, genau wie bei den oben beschriebenen von Pannaria, Peltigera u. s. f., und wie bei den Zellen der typischen Nostocaceen; 2 engen, verzweigten und of Ilförmig oder netzörmig anastomosirenden 11 ỵ he n, Reihen meist schmal - und langgestrecht-cylindrischer zellen, seltener aus kurzen, ovalen Gliedern zusammengeselzt und daher rosenkranzförmig Thyrea decipiens Mass.), mit zarter dünner Wand und blassem Protoplasmainhalte. Beide Theile, die blaugrünen Gonidien- 
körper (schlechthin Gonidien genannt) und die Hyphen sind einer anscheinend homogenen Gallerte eingebettet, welche die meist weiten, oft sehr grossen Zwischenräume vollständig ausfüllt, ohne luftführende Lücken frei zu lassen. Alle Theile sind entweder in der ganzen Dicke des Thallus gleichförmig vertheilt und mit einander gemengt (Synalissa, Thyrea decipiens Mass.) oder die Gonidien sind unter der Oberfliche reichlicher als in der Mitte vorhanden, ohne jedoch in letzterer völlig zu fehlen. So z. B. bei Mallotium, Collema conglomeratum, C. conchilobum, furvum, Omphalaria pulvinata Nỵl, coralloides Nyl. und wohl den meisten grösseren Formen. Ilierzu kommt bei laubartigen (Mallotium, Coll. furvum, conchilobum u. a.) ein grösserer Gonidienreichthum an der oberen oder Lichtseite als an der unteren.

1. Die Gonidien sind entweder zu Reihen (Schnüren, Kelten) oder in verschiedenartiger anderer Weise gruppirt.

a. Die erstgenannte Anordnung Fig. 90, 91) komınt, wie lingst hekannt, der alten Gattung Collema zu und ihren Verwandten Synechoblastus, Leptogimm, Mallotium, Obryzum, Plectopsora u. a., Lempholemma nach Schwendener). Die Kette kommt dadureh zu Stande, dass sich alle Zellen wiederholt durch Scheidewainde theilen, welche mit der ersten parallel sind. Die Theilung dauert in allen Theilen der Kette lange an, die Zahl der Glieder kann daher eine schr grosse werden. Diese sind rundlich oder abgerundet kurz - eylindrisch, die Kette daher rosenkranzförmiğ, genau w iebei der $\mathrm{Algengattung}$ Nostoc, und wie beidieser werden einzelne zer-

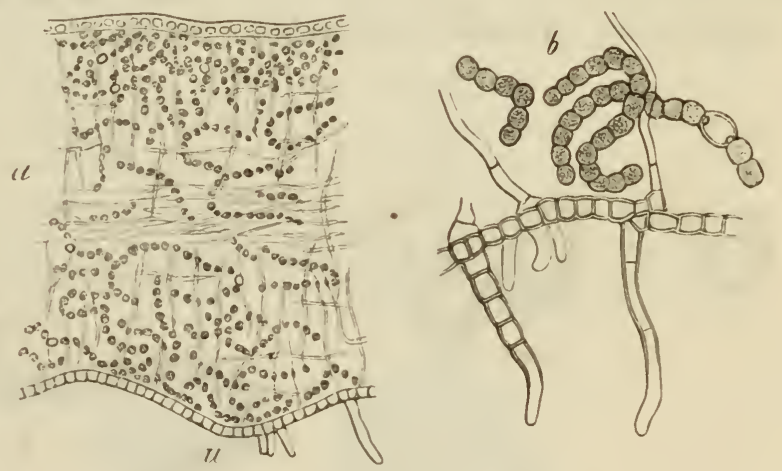

Fig. 90 . streute Glieder der Reihen, während in den meisten die Theilung andauert, zu theilungsunfihigen Grenzzellen, Interstitial-, Dauerzellen. Sie erhalten eine beträchtlichere Grösse als die gewöhnlichen Gliederzellen, derbere, zuletzt gelbliche Nembran, meist mit einer kleinen, knopfförmig nach Innen vorspringenden Verdickung auf jeder Endfliche, und farblosen, wasserhellen Inhalt - Eigenthümlichkeiten, welche bei den gleichnamigen Orgauen vieler Nostocacen wiederkehren Fig.90 b, 9/i). Die Ketten sind in dem Thallus vielfach wurmförmig gekrimmt und nach allen Seiten hin zwischen einander und zwischen die Hyphen eingeschlungen. Ueber ihren Zusammenhang mit diesen und ihren Lrsprung sind die Angaben sehr verschieden. Nach Schwendener's kurzer Andeutung entsteht die erste Zelle der Kette in derselben Weise, wie die Gonidien der hete-

Fig. 90. Mallotium Hildenbrandii Garov. $a$ Radialer Längsschnitt durch den Thallus. $u$ Unterscite. Vergr. 190. $b$ Stück eines sehr dünnen Schnitts durch die Cnterseite, $390 \mathrm{mal}$ vergr. 
romeren Flechten; die erste Theilung geht-durch ihren Anheftungspunct. Caruel (Aıti Soc. ital. Sc. Nat. Vol. VII, 1864) fand, dass von den Keimschläuchen, welche Sporen des Collema pulposum hei Aussaat auf feuchten Badeschwamm trieben, einzelne Zellen sich in eine Reihe kugeliger Glieder theilten, welche die blaugrüne Farbe der Gonidien annahmen. Körber, Sachs und ebenfalls Caruel geben ferner an, dass die Glieder der Gonidienketten ihrerseits zu verästelten, farblosen Hyphen auswachsen, also der umgekehrte Process wie bei den heteromeren Flechten, bei wolchem die Gonidien die primären Organe wären. Was die letztere Behauptung betrifft, so stehe ich nicht an, sie mit Schwendener in Abrede zu stellen. Ferner sah ich bei sehr zahlreichen Aussaaten von verschiedenen Species aus den keimenden Sporen immer nur lange, farblose, verzweigte Hyphen, wie sie Tulasne beschreibt, hervorgehen, nie Gonidien an denselben entstehen. Auch Schwendener's Ansicht kann ich wenigstens nicht bestätigen; mit einer alsbald zu nennenden Ausnahme war es mir nie möglich, einen auch nur muthmasslichen genetiselen Zusammenhang zwischen Gonidien und Hyphen zu finden. Dass ein solcher bei den meisten Formen jedenfalls nur selten beobachtet werden kann, und Gonidien und Iyphen meist selbständig und in gewissem Sinne unabhingig von einander wachsen, darüber sind alle Autoren einig. Die Zahl der Gonidienketten vermehrt sich (wie es auch für Nostoc unzweifelhaft ist) durch Trennung der vorhandenen in mehrere Stücke.

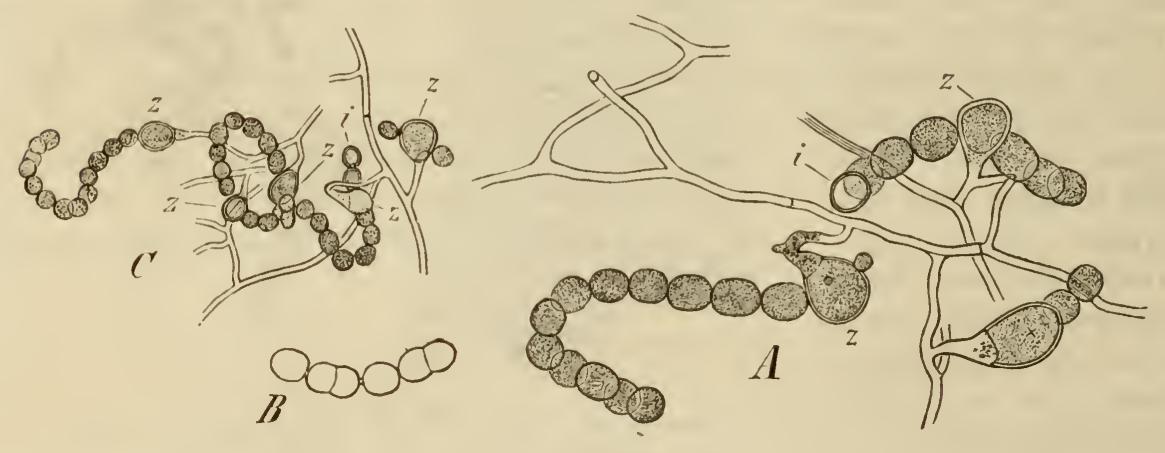

Fig. 91.

Nur bei Plectopsora crathodes Mass. (und Lempholemma nach Schwendener) ist ein Zusammenhang der Gonidienketten mit den Hyphen leicht zu finden (Fig. 91). Einzelne Glieder (sie mögen der Kürze halber Insertionszellen heissen) der ersteren sind bedeutend grösser als die übrigen, derbwandig, sonst den theilungsfähigen gleich und dureh ihren blaugrünen Inhalt von den gleichfalls vorkommenden Interstitialzellen leicht zu unterscheiden. Sie sitzen auf einem Stiele, welcher durch einen kurzen Seitenast einer Hyphe gebildet wird, der mit verbreitertem Ende der Insertionszelle fest angewachsen ist. Diese Er-

Fig. 91. Plectopsora cyathodes Mass. $A$ ästige Ilyphe mit 3 daran befestigten fonidienketten. $i$ Interstitialzelle, $\approx$ Insertionszellen, $x$ eine sammt den dazu gehörenden Gonidien abgestorbene Insertionszellen. Vergr. 720. B Stücke einer Gonidienkette mit zwei Theilungen. $C 390 \mathrm{mal}$ rergr. $z$ und $i$ wie in $A$. Die mittlere Gonidienkette ist mittelst dreier Insertionszellen an Hyphenzweige befestigt. 
scheinungen lassen sich auf zweierlei Weise erklären. Entweder ist die Insertionszelle ursprünglich die Endzelle des Stiels, aus welcher durch Theilung oder Sprossung die Gonidienkette herrorgegangen ist. Oder jene entsteht, indem ein stielförmiger Hyphenzweig gegen irgend eine vorhandene Gonidie wächst, sich dieser anlegt und die Gonidie sich in Folge hiervon zur Insertionszelle vergrössert. Letztere Ansicht vertritt Schwendener. In den beobachteten Erscheinungen lïsst sich für und gegen beide eine Anzahl von Argumenten finden, deren Discussion hier zu weit führen würde, und darauf hinauslïuft, dass directe Beobachtung an frischen Exemplaren die Entscheidung wird geben müssen.

b. Bei Omphalaria, Synalissa und Verwandten (Thỵrea, Paulia Fée, Peccania Mass., Enchy̧liuuı) sitzen die Gonidien meist sehr deutlich stielförmigen Hyphenzweiglein auf, was Thwaites schon 1849 dargestellt hat (Ann. Magaz. Nat. hist. Ser. 2, Vol. 3). Die Gonidien theilen sich nach 2 oder 3 abwechselnden, auf einander senkrecht stehenden Richtungen. In den meisten Fïllen findet nach jeder Theilung eine Gabelung der Sticlzelle statt, derart, dass jede Tochterzelle einen besonderen Stiel erhill; die successiven Gabclungsebenen schneiden einander rechtwinkelig. Auf diese Art entstehen, wenn die Sticle kurz bleiben, cynöse Gonidiengruppen (Fig. 92 b). Bei S!nalissa (Fig. $92 c$ ) finde ich die Gonidien nur paarweise zusammengestellt, es muss daher zwischen je zwei Theilungen eine betrichtliche Streckung des Stiels stattfinden. Bei Synalissa spec. kommen auch Gruppen zahlreicher, nach drei Raumdimensionen geordneter Gonidien ohne Stielzellen vor. Auch bei Phylliscum endocarpoides Nyl. sind die sehr grossen, dickwandigen, nach diei abwechselnden Richtungen sich theilenden Gonidien vielfach mit Stielen versehen, Hỵhenaisten, welche durch die Membran bis dicht an den Protoplasmakörjer dringen. Die Verzweiğung der Stiele lisst sich hier, wegen der dichten Vereingung der Gewebstheile, schwer verfolgen.
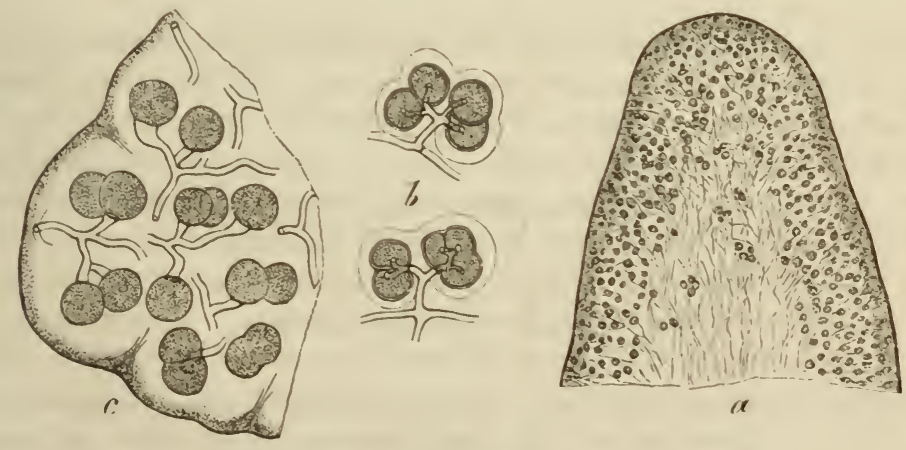

Fig. 92 .

2. Von den II y phe n sind ausser den schon angegebenen beine Structureigenthumlichkeiten zu berichten. Ihre Anordnung ist wohl in allen Fällen

Fig. $92 a, b$. Thyrea pulvinata Massal. $a$ Senkrechter Längsschnitt durch den Thallusrand, Umriss 90 fach vergr., Ausfihtung wie in Fig. 83. b Gonidiengruppen, 390 fach vergr. $c$ S y nalissa Spec. ("Plectopsora hotryosa ", Jack, Leiner und Stitzenberger, hrypt. Bad. Nr. 301) Stück eines dümen Querschnitts durch ein Thallusläppchen, 720 mal vergr. Die in der Figur schattirte Oberfläche der Gallerte ist violettroth gefärbt. 
die, dass sie in der Mittellinie oder Mittelebene der ThaHusabschnitte vorherrschend longitudinal, von der Basis zum Rande laufen, gerade oder wellig - was bei den meisten Collemen, Mallotium, Omphalarieen, Phylliseum, sehr deutlich hervortritt (Fig. 92 a), aber auch bei Synalissa, Thyrea decipiens, wenigstens im unteren Theile des Thallus bcobachtet werden kann. Nach aussen von dem axilen Bindel bilden die Hyphen ein nach allen Richtungen verschlungenes weitmaschiges Geflecht oder Netz zwischen den Gonidiengruppen, das in den einzelnen Fällen verschiedene Gestalt hat. Bemerkenswerth ist der gerade, zu beiden Thallusflichen fast senkrechte Verlauf der peripherischen Hyphen bei Leptogium cyanescens, Mallotium (Fig. 90) und der bogige bei Synalissa, Thyrea decipiens, wo sie auf Durchschnitten ein zierlich-rundmaschiges Netz darstellen, dessen Lücken von den Gonidiengruppen ausgefüllt werden.

Bei den meisten Genera verlaufen zahlreiche peripherische Zweige senkrecht in die von Gallerte gebildete Oberflache, um hier blind zu endigen. Eine Ausnahme hiervon machen Leptogium, Obryzum, Mallotium (Fig. 90), bei denen die peripherischen Zweigenden in eine den ganzen Thallus umziehende $\mathrm{R}$ ind e oder Oberhaut übergehen: cine lückenlose, cinfache oder stellenweise dopjelte Schicht zierlich polyedrisch-tafelförmiger Zellen mit wasserhellem Inhalt und farbloser oder brauner Membran. Letztere ist auf der Oberseite des Thallus oft stärker und aussen melı als innen verdickt, an dic Epidermis höherer Gewächse erinnernd. Bei Mallotium entspringen von den Zellen der unteren Rinde überall zahlreiche vielzellige Haare, theils vereinzelt und kurz, theils lainger und zu Bündeln vereinight. Die Befestigngug des Thallus geschicht durch diese Haare. Auch bei den anderen berindeten Formen (Leptogium) finden sich solche da, wo der Thallus dem Substrate autliegt.

Bei den unberindeten treten an den Befestigungspuncten Aeste der. Iyphen, mit meist derber Membran verselıen, als Wurzelhate aus der Gallerte hervor.

3. Die Gallerte entsteht nach den dermaligen Kenntnissen rom Bau und Wachsthum der Zellmembran, deren Darstellung sich im ersten Bande dieses Handbuches finden wird, dadurch, dass die Zellmembranen des Thallus gelatinös verdickt und lückenlos vereinigt sind. Wo sie, wie z. B. bei Collema-Arten, Plectopsora, Leptogium, Mallotium, eine völlig homogene, durchscheinende, meist farblose Masse bildet, ist diese ihre Entstehung allerdings kaum direct nachweisbar, und ebensowenig eine sichere Entscheidung über den Antheil möglich, welehen Gonidien und Hyphen an ihrer Bildung haben. Hiufig ist dagegen die Gallerte geschichtet, z. B. bei Synechoblastus Laureri, S. turgidus, Omphalaria und verwandten Formen, und hier sieht man deutlich die einzelnen Gonidienschnüre in dicke Gallertscheiden, die Gonidiengruppen in dicke, oft generationsweise ineinandergeschachtelte Gallertmembranen eingeschlossen. Die Gallerthïllen henachbarter Schnüre oder Gruppen schliessen oft deutlich fest aneinander, die Ilyphen drängen sich zwischen ihnen durch. Bei Thyrea decipiens gelingt es nicht selten, durch Druck ein ganzes Thallusstück in einzelne Gonidiengruppen zu zerlegen, die mit generationsweise geschichteten Gallerthüllen umgeben sind; die llyphen haften diesen theils aussen an, theils drägen sie sich zwischen die Schichten ein, ohne eigene Gallerthüllen erkennen zu lassen.

Nach diesen Thatsachen ist es wohl unzweifelhaft, dass die Gallerte wenig- 
stens der Hauptmasse nach den Gonidienmembranen angehöıt - wie bei den heteromeren Fkechten mit blaugrünen Gonidien; und bei der nahen Verwandtschaft aller Gallertflechten mit einander wird es erlaubt sein, diese Ansicht auch auf die mit ungeschichteter Gallerte versehenen auszudehnen.

Wohl bei allen unberindeten Formen ist die Gallerte in der Mitte des Thallus weicher, in höherem Grade quellbar als an der Oberfläche, und farblos; gegen die Oberfliiche nimmt sie an Derhheit zu, und eine oft intensive, violette oder meist gelblichbraune Farbe an. Bei den berindeten (Mallotium, Leplogium) kommt diese letztere nur den Membranen der Rindenlage zu, die Gallerte innerhalb dieser ist, soweit meine Erfahrungen reichen, farblos.

Was das Verhalten gegen Reagentien betriffit, so sei hice erwähnt, dass die Gallerte von Plectopsora evathodes, zumal die festere oberflächliche, dureh Chlorzinkjod und Iod mit Schwefelsiure die characteristischen Cellulosefirbungen annimmt; chenso die Membran der Interstitialzellen. Auch bei Phỵlliscum werden die Gallertmembranen im oberflichlichen Theile des Thallus durch genamnte Reagentien blau. Bei anderen, gelegentlich in dieser Beziehung untersuehten Arten sah ich genannte Firbungen nicht auftreten; es fehlt jedoch an planmaissigen Beobachtungen hieriiber.

4. Ueber das Wachsthu un der Gallertflechten follt es noch an genatuen Untersuchungen. Dass dassolbe in eentrifugaler Richtung fortschreitet, lehit schon die oberflichliche Beohachtung. Man findet selur oft das Gewebe der Basis oder Mitte sehon im Mbsterben, wihlıend Spitze und Rand in offenbarer Vergrösserung begriffen sind. Bei Mallotium sind die Zellen der Rindenschichte in dem Rande jugendlicher Exemplare bedeutend kleiner und zarter, als in den vom Rande entfernten Regionen, was auf eine marginale Neubildung hindeutet. Im Lebrigen fand ich hier sowohl als bei Thyrea pulvinata Fig. 92) bis in den äussersten Rand die gleiche Anordnung der Ilyphen und Gonidien, wie in den älteren Theilen, nur die Gallerte wenigger entwickelt, das Geflecht daher enger und dichter. Bei allen Collemaceen findet man auf weite Entfernung hinter dem Rande zahlreiche Theilungen der Gonidien, und da die Gonidiensehnüre jedenfalls einen sehr betrabhtichen Theil der Thallusmasse ausmachen, so ist hicraus auf ein lange andatuerndes interealares Wachsthum zu schliessen.

\section{Anomale Formen.}

1. Den vorhandenen Iarstellungen zufolẹe (N!lander, S!n. 139, Tab. W.) gehort hierher in crster Linie der hrustige Thallus von Ml yriangium, der als ungeschichtet, aus gleichlörmigem Zellgewebe bestehend beschrieben w ird, und ïber dessen Gonidien nichts vorliegt. Er bedarf neuer Lntersuchung.

2. Der strauchartige Thallus von Lichina, welchen besonders Schwendener genau untersucht hat, besteht aus einer diinnen, höchst kleinzelligen, überall, auch iiber dem Scheitel, gleichförmigen Rindenschichte und cinem Marhe mit ibbeall deutlicher, in den ïleren Theilen allerdings oft verschobener symmetrisch-divergenter Faserungy. Die Markhyphen sind lückenlos verbunden und 
mit dünnen, nicht gelatinösen Membranen verschen. Unter der ganzen Rinde liegt eine breite Gonidienzone und einzelne Gonidiengruppen sind durch das ganze Mark vertheilt. Structur und Farbe des Inhaltes der Gonidien sind die gleichen, wie bei den Gallertflechten. Sie theilen sich wechselnd nach verschiedenen Richtungen und bilden, indem sie sich aus ihrer ursprünglichen Anordnung verschieben, gekrümmte, einfache oder mehrfache Reihen. Nach allen diesen Thatsachen hält Lichina in vieler Beziehung die Mitte zwischen den strauchartigen heteromeren und den Gallertflechten.

3. Ephebe pubescens Fr. besitzt, wie aus zahlreichen Beschreibungen bekannt ist, einen strauchartigen, sehr astigen Thallus, dessen Zweige stark borstendick werden. Untersucht man ein in Wasser liegendes junges Zweigende, so sieht man zunächst deutlich die Gonidien der Pflanze, innerhalb einer festen, dicken, geschichteten, das Ganze umziehenden Gallertscheide in eine Reihe übereinander gestellt (vgl. Fig. 93). Die Reihe verlingert sich durch Spitzenwachsthum, indem sich ihre kuppelförmige Scheitelzelle durch Querwände wiederholt in eine Scheitelzelle höherer Ordnung und eine scheibenförmige Gliederzelle theilt. Jede Gliederzelle theilt sich späterhin weiter, und zwar zunächst durch einander rechtwinkelig schneidende Lingswinde in zweimal zwei kreuzweise gestellte Tochterzellen. Jede dieser theilt sich wiederum durch eine Querwand in eine obere und untere; spaiter erfolgen Theilungen abwechselnd nach drei Richtungen, jedoch in minder regelmaissiger Folge als die ersten; und zwar scheint die Theilungsfähigkeit eine unbegrenzte zu sein. Aus den ursprünglichen Gliederzellen werden somit ebensoviele unregelmässig - v i e l z e 11 i g e Glieder des Thallus, die lange deutlich von einander unterscheidbar sind. Die einzelnen Gonidien sind in den

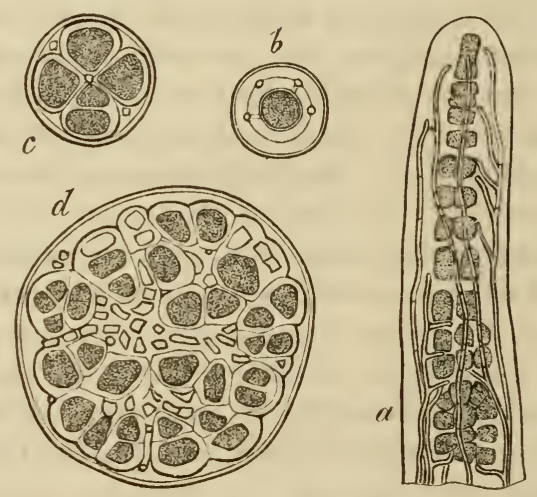

Fig. 93. alteren Theilen in der Regel noch grösser als die primären Gliederzellen, der Thallus nimmt daher nach unten an Dicke beträchtlich zu. Dic Gonidien haben im Wesentlichen die Structur von denen der Gallertflechten oder der Zellen der Nostocaceen, sie sind blaugrün oder briunlichviolell gefäbt. Achtet man allein auf die bisher beschriebenen Erscheinungen, so ist nicht der mindeste Grund vorhanden, Ephebe zu den Flechten zu stellen, vielmehr scheint sie in die nächste Nahe der Nostocaceengattung Sirosiphon Kg. zu gehören, wo sie schon Agardh und Kützing (Spec. alg. p. 318 , als Stigonema atrovirens Ag. hinstellten. Erwärmt man aber die Thallusenden in Kalilösung, so treten innerhalb der sich entfärbenden und quellenden Gallerthülle zarte, farblose, mit Querwänden ver-

Fig. 93. Ephebe pubescens Fr. $a$ Thallusspitze nach Erwärmung in Kalilösung. $b, c$ Querschnitte durch den obersten, $d$ solcher durch den unteren älteren Theil eines Astes. Die Gonidien sind durch die punctirte Schattirung bezeichnet. Vergr. 390. 
sehene und verästelte Hyphen hervor. In dem obersten Ende verlaufen diese gerade, longitudinal rings um die Gonidienreihe, die 2-ŏ oder mehr längsten reichen meistens (nicht immer) bis zur Scheitelzelle oder neigen über dieser zusammen. Schon wenig unterhalb der Spitze sind die Hyphen reichlicher verästelt und bilden ein netzartiges Geflecht um die Gonidienreihe; zugleich dringen ihre Zweige gegen die Mitte des Thallus zwischen die Gonidien ein, sich hier weiter verästelnd und letztere verschiebend. In den : alteren Theilen des Thallus verzweigen sich die Hyphen vorzugsweise in der Mitte, und zwar in dem Grade, dass sie die Gonidien gegen die Peripherie hin diängen, die Mitte zuletzt volwiegend von dem Hyphengeflechte gebildet wird. Die Hyphen selbst werden dabei stïrker und weiter als in der jugendlichen Spitze (Fig. 93).

Neubildung von Gonidien an den Hyphen ist nie beobachtet worden.

Wo ein Zweig entsteht, gliedert sich, wie bei dem Thallus von Sirosiphon, eine seitliche Ausstülpung einer Gonidie zur Scheitelzelle des Astes ab, dessen Gonidienreihe sich dann in der beschriebenen Weise verlingert; und gleichzeitig treiben die Hyphen des Stammes Zweige, welche die Astreihe umgeben und mit ihr weiterwachsen, wie angegeben wurde. An den Befestigungsstellen treten Hyphenzweige als Wurzethaare aus der Oberfliche herror, wie bei den unberindeten Gallertllechten.

Der Thallus von Ephebe besteht somit gleich dem der übrigen Lichenen, und speciell der Gallertflechten aus den zweierlei IIauptelementen: Gonidien und Hyphen; er ist von jenen allerdings wesentlich durch die Anordnung und Vermehrung der Gonidien verschieden.

Aus dem mitgetheilten Sachverhalte erkliiren sich die Widersprüche, welche über Ephebe auch in neuester Zeit noch bestehen (über die alteren Angaben vergl. Bornet, in $\Lambda$ nn. se. nat. 3 Sér. T. 18). Zu den Lichenen wurde Ephebe gestellt vorzugsweise auf Grund der an ihr gefundenen Apothecien. Bei der ohne Einwirkung von Reagentien anscheinend unzweifelhaften Nostocaceenstructur ist es daher begreiflich, wenn Hepp (Lichen. Europ. exsiec. Nr. 712) und Stitzenberger (Hedwigia II, 1) im Anschluss an die äteren Algologen den Thallus von E. für eine Algeve und die Apothecien für Organe eines Schmarotzerpilzes erklärten. Freilich weisen schon die'Darstellungen Bornet's (I. c.) und noch deutlicher Nylander's Srn. p. 90, Tab. II.) auf die von Algen verschiedene Structur des ialteren Thallus hin. Klar dargestellt wurde diese aber wiederum erst durch Schwendener (Flora 1863, p. 241). Es darf übrigens nicht verschwiegen werden, dass die Parasitenansicht zur Zeit zwar minder wahrscheinlich, aber keineswegs völlig ausgeschlossen ist, indem auch der sterile Thallus von Ephebe gebildet sein könnte aus einem Sirosiphon und einem die Zellwandungen dieses durchwuchernden Pilzmycelium.

Wie Schwendener (i. c.) gleichfalls schon angedeutet hat, stimmt der Thallus von Gonionema Nỵl. und Spilonema Born. (Nyl. Synops. p. 88, Bornet, Mém. Soc. Sc. nat. Cherbourg IV, p. 226, pl. 1, 2) mit dem von Ephebe in allen wesentlichen Puncten uberein - auch darin, dass sämmtliche Zellmembranen nach Einwirkung von Kali durch lod tieflalaue Farbe annehmen.

Auch der Bau von ltzigsohn's E phebella Ilegetschwe ile r i (Iledwigia I, 123) erinnert an den der soeben beschriebenen Formen, wenn er auch die Annahme einer Parasitenwucherung noch näher legt, als diese. Wie Itzigsohn, 
Hepp, Stitzenberger schon beschreiben, zeigt der frische Thallus, im Wasser liegend, genau die Structur und Verzweigung der Nostocaceengattung Scytonema: innerhalb einer braunen dicken Gallertscheide cine einfache Reihe phycochromhaltiger Zellen, durch Quertheilung der Scheitelzelle und der Gliederzellen in die Liange wachsend, mit einzelnen theilungsunfähigen Interstitialzellen; und eine scheinbare Verzweigung, dadurch zu Stande kommend, dass sich die in die Länge wachsenden Stücke der Zellreihe neben den Interstitialzellen vorbeischieben und seitlich ausbiegen. Nach Erwärmen mit Kali bemerkt man aber auch hier die ganze Gallertscheide, bis zur Scheitelzelle hin, durchwuchert von einem dichten Geflechte vorzugsweise longitudinal laufender :uusserst dünner farbloser IIyphen. Zwischen die blaugrünen Zellen (Gonidien?) sah ich diese nie eindringen.

4. Ganz eigenthümlich, wenn auch in mancher Beziehung an Ephebe erinnernd, ist der Bau des Thallus von Coenogonium Ehr. und der nur steril hekannten Gattung Gystocoleus Thwaites (Racodium Fries, S. veg. scand.). Wie Thwaites (Ann. Mag. nat. hist. 2. Ser. vol. III) für letztgenannte Gattung, Schwendener (Flora 1862, p. 225) und Karsten (Geschlechtsleben d. Pfl., p. 42) für die andere beschrichen haben, besteht der Thallus (Fig. 94) aus confervenartigen, selten bis 1/50 Mın. dicken ästigen Fiden, die bei Coenogonium zu cinem flachen, fächerförmigen Körper verfilzt sind, bei Cystocoleus aufrechte Räschen bilden. Die Mitte der Fiden wird eingenommen von einer Reihe gestrecktcylindrischer Zellen mit farbloser Cellulosehaut und (durch Chlorophyll?) grüun gefärbten Inhalte, Zellen, welche den Gonidien verglichen werden können. Diese Gonidien reihe verlängert sich, soviel bekannt, durch Spitzenwachsthum. Sie wird umgeben von einer Schichte longitudinal verlaufender, septirter IIyphen, welche der Reihe fest anliegen und iuber dem Scheitel derselhen mit ihren Enden zusammenneigen. Bei Gystocoleus sind dieser Hyphen in der Regel 5 bis 6 , sie haben dunkelbraune, derbe Nembranen, farblosen Inhalt und bilden eine überall liichenlos geschlossene Rinde oder Scheide ưm die Gonidienreihe. Bei Coenogonium sind sie oft zahlreicher, zart, ganz farblos, und seitlich Lücken zwischen sich lassend, die Gonidienreihe also wie ein durchbrochenes Netz umspinnend. Die Verasstelung des Thallus geschieht in wesentlich der gleichen Weise wie bei Ephebe. Eine Gallerthülle ist nirgends vorhanden; genetische Beziehungen zwischen den Gonidien und Hyphen und Eindringen

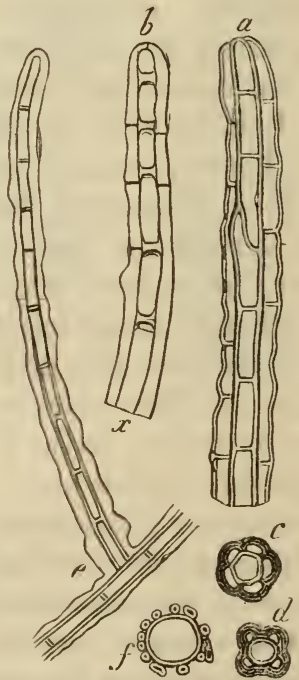

Fig. 94 . der letzteren zwischen jene bis jetzt nicht beobachtet.

Fig. 94. $a-d$ Cystocoleus ebeneus Thw. Vergr. 390. $a$ Astende, von der Aussenseite gesehen. $b$ Solches im optischen Längsschnitt, $x$ Gonidienieihe; beides nach Präparaten, welche mit Schulze'scher Mischung durchsichtig gemacht sind. $c, d$ Querschnitte.

$e, f$ Coenogonium Linkii Ehrb. $e$ (Vergr. 390) dünner Thallusast mit einem Seitenzweig; optischer Längsschnitt. $f$ Querschnitt durch einen stärkeren Ast, $300 \mathrm{mal}$ vergr. nach Schw. 
Es ist endlich, insonderheit durch Tulasne, eine Anzahl Flechten beschriehen worden, welche des Lichenenthallus völlig entbehren; so die Genera Ahrothallus de Not, Scutula Tul., Celidium Tul., Phacopsis Tul., SphincIria de Not., u. a. (Körber, Parerg., p. 4.52). Die Apothecien, Pycniden und Spermogonien dieser Pflanzen sitzen auf einem unbedeutenden, faserigen oder pseudoparenchymatischen Triger dem Thallus anderer Lichenen auf, sie schmarotzen auf demselben. Ihr Gewebe schliesst sich an das ihres Wirthes unmittelbar an, ein in diesen eindringendes Mycelium ist nicht beobachtet worden. Da diese Parasiten der einzigen Organe, deren Besitz die Lichenen von den Ascomyceten auszeichnet, nïmlich der (ionidien, ermangehn, so scheint mir kein Grund vorzuliegen, sie zu den Lichenen und nicht zu den Pilzen zu stellen, denen sie auch Montagne (Amı. Se. nat. T. XVI, 3e Sér., p. z8) angereiht hat.

\section{Capitel 9.}

\section{Fortpflanzungsorgane der Flechten.}

\section{I) ie Soredien.}

Mit dem genannten Namen werden seit Acharins pulverige Massen bezeichnet, welche bei sehr vieden Flechten an die Oberfliche des Thallus treten, oft dicke, polster-oder wulstformigne Kïrper bildend, regellos über den Thallus zerstreut, oder an bestimmte Orte, z. B. den Rand der Lappen gebunden. Aechte Soredien kommen nur den heteromeren Flechten zu. Beispiele dafür liefern viele Genera, wie U'snea, Bryopogon, Ramalina, Evernia, Imbricaria, Physcia, Parmelia, Pertusaria u. s. f. - man vergleiche die descriptiven Werke. Uebermässige Entwickelung von rundlichen, Apothecien entfernt : ihnlich sehenden Soredienhaufen auf krusten - und laubartig̣em Thallus, mit ğleichzeiligem Ausbleiben der Apothecienbildung, bedingt die kintstehung der Formen, welehe Acharius in das Psendogenus Variolaria stellte. Seit Wallroth, Mever, E. Fries ist die Natur dieser Bildungen allgemein bekannt; Pertusaria-, Parmelia-, Lecanoraarten zeigen, nach Mejer (Flechten, p. 198), die Variolarienbildung vorzugsweise. - Manchen heteromeren Formen, \%. B. Lecidea geographica und Verwandten, seheint die Soredienbildung ganz zu fehlen.

Es ist wiederum Schwendener's Verdienst, die ganze Entwickelung der Soredien zuerst klar dargelegt zu haben, nachdem allerdings Tulasne (Mém. p. 24) ihren Bau schon naturgetreu geschildert hatte. Die wohl vorzugsweise durch unzureichende Mikroskope veranlassten, an sich schwer verstandlichen Angaben :ilterer Beobachter erkliiren sich leicht dureh genannte Untersuchungen, und letztere allein sind bei der folgenden Darstellung zu bericksichtigen.

Die Soredien (Fig. 9:3) entwicheln sich in der Gonidienzone, und zwar (mit Ausnahme von Roccella) dadurch, dass Gonidiengruppen mit eigenthümlichen Hyphen- oder Faserhüllen umgeben werden. Bei der oben beschriebenen Ver- 
mehrung der Gonidien bleibt die ursprüngliche Stielzelle unver:indert oder theilt sich höchstens durch Querwände. Die Soredienentwickelung beginnt mit der Bildung und Theilung eines Gonidiums. Wo die hieraus entstandene Gruppe der ursprünglichen Stielzelle aufsitzt, treibt letztere eine bis zwei Ausstülpungen,
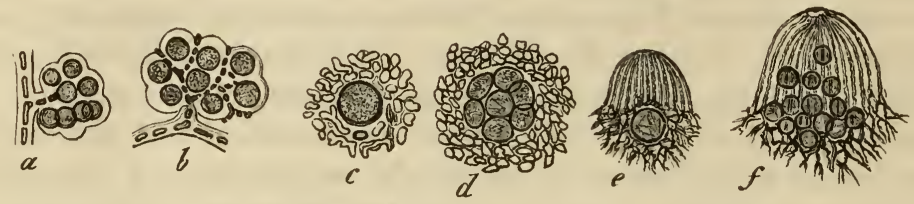

Fig. 9 .

welche zwischen die Theilzellen ins Innere der Gruppe eindringen und sich hier, unter Bildung von Querwinden, nach allen Seiten verzweigen $(a, b)$. Thre Zweige wachsen gegen die Oberfliche der Gruppe, und auf dieser, den Gonidien fest angeschmiegt weiter, oft wiederum Aeste zwischen die Theilzellen ins Innere zurücksendend. Dieses Wachsthum dauert in der Regel fort, bis jede. Theilzelle von einem dichten Geflechte von Hyphen umsponnen ist $(c)$, welches entweder faserige oder (Physcia parietina) pseudoparenchymatische Structur erhält. Bei manchen Flechten (z. B. Bryopogon Pannaria) bleibt das Hyphengeflecht unvollstiindig. Die umsponnenen Gonidien wachsen rasch und theilen sich $(d)$, die Theilzellen erhalten wiederum Faserhüllen, welche sie von der ursprünglichen aus umwachsen. Indem dieser Process sich ohne bestimmte Grenze wiederholt, häufen sich die beschriebenen Körper unter der Rinde dergestalt an, dass sie auf dieselbe einen bedeutenden Druck ausüben und sie endlich vortreiben und durchbrechen. Die aus dem oft weit klaffenden Risse hervorbrechende Soredienmasse wird durch ein lockeres Fasergeflecht lose zusammengehalten, welches aus einzelnen, von den Hïllen auswachsenden Hyphenzweigen, die sich zwischen die primairen Markfasern einflechten, und auch wohl aus Wucherungen der letzteren besteht. Da die Fasern der Iüllen vorzugsweise der Oberfliche der Gonidien parallel laufen, so trennen sich die Gruppen leicht in der Art, dass die einzelnen, von ihrer Ilülle unsponnenen Gonidien isolirt werden.

Schwendener nennt das einzelne Gonidium sammt seiner Hülle Soredium, und diese Bezeichnung soll hier beibehalten werden. Die Anhäufungen der in Rede stehenden Organe sind somit Soredienhaufen (Sori). Dem ursprünglichen Sinne des Wortes nach bedeutet Soredium allerdings eher den ganzen Haufen.

Auch nach dem Hervorbrechen aus der Rinde und selbst nach der Trennung und Ausstreuung kann die Vermehrung der Soredien auf die beschriebene Weise unbegrenzt weiter gehen; letzteres z. B. in den an beschatteten Orten häufigen gelben oder grünlichen »Soredialanflügen « der Physcia parietina. Bei allen diesen Processen behalten die Gonidien ihre ursprüngliche (im achten Gapitel

Fig. 95. Usnea barbata. Soredienentwickelung. Nach Schwendener (Vergr. 500 bis 700). $a$ Gonidiengruppe von 8 Zellen, nach Einwirkung von Iod. Verzweigung des eindringenden Stiels beginnend. $b$ Achnliche, ebenfalls mit Iod behandelte Gruppe. Verzweigung des Stiels weiter vorgeschritten. $c$ Fertiges Soredium, optischer Längsschnitt. $d$ Ebenso, Gonidien wicderum getheilt. $e$ keimendes Soredium, das bereits einen Scheitel gebildet hat. $f$ Ebensolches, weiter entwickelt. 
beschriebene Beschaffenheit und Farbe. Ein Auswachsen derselben in Hyphen, welches früher oft behauptet wurde, kommt nach den jetzigen Kenntnissen nie vor. Die von der ggelbgrünen oder blaugrünen verschiedenen Farben der Soredien, wie die lebhaft gelbe bei Sticta crocata, die bläuliche bei Parmelia caesia u. S. f. rühren nicht von den Gonidien, sondern von ihren Faserhüllen her und kommen in diesen auf dieselbe Weise zu Stande, welche im vorigen Capitel für Mark- und Rindenschicht beschrieben wurde.

Unter geeigneten iusseren Bedingungen vermag sich das Soredium zu einem neuen Thallus zu entwirkeln. Auch hierbei bleiben die Gonidien, ausser dass sie sich auch fernerhin theilen, unverandert, wachsen nicht in Hyphen aus. Die Verïinderungen betrefien lediglich die fibröse Hülle, deren Elemente sich vermehren, Haftfasern treiben und alhmiblich die Anordnung und Differenzirung wie im ausgebildeten Thallus annehmen. Bei laubartigen Formen entsteht, wie die Beobachtung an Phỵscia parietina gezeiğt hat, der neue Thallus oft aus der Vereinigung zahlreicher Soredien. Dass jedoch ein einziges Soredium mit einer Gonidie zur Erzeugung eines Thallus genuigl, ist nach Schwendener's Beobachtungen bei Usnea unzweifelhaft. In der vom Suhstrat abgokehrten Seite des einfachen Sorediums Fig. 9:j e, / treibt hicr die Faserhülle Aeste, welche nach derselben Richtung und dicht ancinanderschliessend weiter wachsen und in ihrem ganzen ferneren Verhalten mit den Hyphen eine Thallusspit\%, wie sie im vorigen Capitel beschriehen wurde, ubereinstimmen. Auf der unteren, das Substrat berïhrenden Seite, treibt die Hiille zorstreute, unregentmissige Aeste, welche als Wurzelhare den jungen Thallus an jenes befestigenen.

Die Soredien von Lsmea entwickeln sieh nach Schwendener haiufig zu Individuen, welche mit dem Mutterthallus verbunden bleiben in Form rechitwinkelig abstehender Aeste Soredialiiste). Yon den aus oiner Rindenöffinung hervorgetretenen Soredien wichst aines rasch in der socben beschriebenen Weise, draingt die andern zur Seite und nimmt loald die ganze Breite der Oeffnung ein, sie pfropfartig verschliessend. In seiner weiteren Ausbildung erhailt es die Eigenschaften rines Thallusistes, seine Markhyphen dringen gleich denen der Adventiviste in den Medullarstrang des Stammes ein, sich strahlig in demselben ausbreitend; nur die Rinde geht nicht ununterbrochen in die des Stammes über, sondern legt sich dieser blos an.

Die von den übrigen verschiedenen Soredienhaufen ron Roce lla bestehen nach Schwendener aus einem lockeren lufthaltigen Geflecht vielfach veristelter Fasern, mit Tausenden ron zarten Enden und zahlreichen in Vermehrung begriffenen Gonidien. Die Bildung der Soredien scheint auf localen Wucherungen der peripherischen Markhyphen und Neubildung von Gonidien an ihren Zweigen (nicht Theilung erstrorhandener, zu beruhen.

Unter den Graph i d e e $n$ kommen bei Opegrapha varia und ahnlichen Rindenbewohnern auf der Oberfliche des Thallus oft mehr oder minder zahlreiche freic rothbrame Gonidien und kurze Gonidienketten vor, welche von einzelnen Hyphen umsponnen sind und hierdurch an die Soredien erinnern. Diese Gonidien sind durchschnittlich grösser als die im Thallus eingeschlossenen, rund und vorzugsweise von dem Seite 261 erwihnten rothbraunen Oele erfüllt. Ihr Freiwerden erklin' sich leicht durch die allmihliche Abschuppung der ober- 
flächlichen, den Thallus bedeckenden Peridermalagen. Ob sie sich wiederum zu neuen Thallusindividuen aushilden können, ist unbekannt.

Den Gallertflechten kommen keine eigentlichen Soredien zu, dafür aber Prolificationen, Auswüchse, welche sich von dem Thallus trennen und zu neuen Individuen entwickeln. Dieselben enthalten von Anfang an beiderlei Gewebselemente. Sie sind, wenigstens bei Collema und Verwandten, sehr häufig und stellen die bekannten Körnchen dar, mit denen der Thallus oft bestreut erscheint.

Nach den mitgetheilten Thatsachen sind die Soredien entschieden ungeschlechtliche Propagationsorgane, und zwar, insofern sie aus einer besonderen Entwickelung und Abtrennung von Theilen des Vegetationsorgans hervorgehen, den Brutknospen höherer Gewächse zu vergleichen. Diese Anschauung wird schon von Fries (Lich. Eur. p. LVI) bestimmt ausgesprochen. Die Entwickelung junger Individuen aus den Soredien ist schon seit Micheli vielfach beobachtet worden.

\section{Spermogon i e $n$.}

'Tulasne hat in seinem Mémoire sur les Lichens zuerst nachgewiesen, dass unter den Lichenen Spermogonien und Spermatien allgemein verhreitet sind, welche denen der Ascomyceten in allen wesentlichen Puncten genau entsprechen. Nach den seitdem bekannt gewordenen Erfihrungen der Systematiker, besonders Nylander's, und der Arbeit von Lindsay (Transact. Roy. Soc. Edinburgh, Vol. 22, Part I, p. 101-303, plate 4-1:3), welche die Darstellung der Spermogonien an einer sehr grossen Anzahl Gattungen und Arten zun Gegenstand hat, kann man jetzt mit Bestimmtheit sagen, dass diese Organe fast allen Genera und Species zukommen. Eine Ausnahme machen unter den genauer untersuchten die Arten der Gattung Solorina, bei welchen noch keine Spermogonien gefunden wurden, und in gewissem, unten zu erörterndem Sinne auch Peltiger a. Ferner dürften hier Myriangium und Siphula zu nennen sein.

Die Spermogonien knnmen bei relativ wenigen »diöcischen « Flechten (z. B. Spilonema Born.) Ephebe pubescens Fr. auf besonderen, nicht apothecientragenden Individuen vor, während andere Individuen nur Apothecien tragen. Bei der überwiegenden Mehr\%ahl kommen sie mit den Apothecien auf demselben Thallus vor, entwickeln sich gleichzeitig mit diesen odler als Vorliufer derselben, und sind, oft in sehr grosser Zahl, entweder ordnungslos über die Thallusfliche zerstreut, oder sitzen (bei Nephroma, Lichina, Cladonia, Sphaerophoron u. a.), : :Hhlich wie die Apothecien, an Rande des Thallus oder an den Spitzen seiner Zweige.

Alle Flechtenspermogonien sind, gleich den Seite 167 und 168 für viele Pyrenonyceten beschriebenen, Conceptakeln welche nur mittelst eines sehr engen Canals nach aussen münden (Fig. 96). In den meisten Fällen sind sie der Oberseite, bei den soeben genannten Formen (Lichina, Cladonia ete.) dem Rande oder den Spitzen des Thallus eingesenkt, Hhr oberer Theil mit dem Mündungscanal ragt oft in Form einer Papille vor und ist dann meistens durch dunkle, braune Firbung ausgezeichnet. Die Gestalt der Spermogonien ist entweder rundlich, nit glatter einfacher Höhlung, oder letztere ist, wie Seite $16 z$ beschriehen wurde, 
gyrös ausgebuchtet und gekammert, das Ganze alsclann unregelmässig gelappt. Upher ihren Bau ist dem a. a. O. und Seite 100 Gesagten nichts Wesentliches hinzuzufügen. - Die iusseren Zelllagen ihrer Wand, welche unmittelbar von den angrenzenden Mark- und Rindenhyphen entspringen, sind oft mit derben, braunen Membranen versehen, die inneren schr zart, farblos. Von letzteren entspringen, nach der Mitte conver-
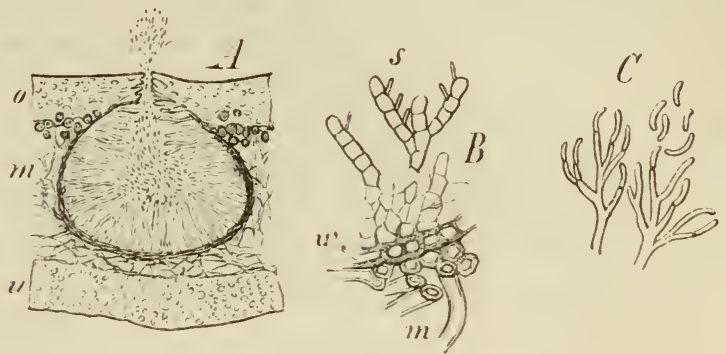

Fig. 96 .

girend und die ganze Höhlung bis auf einen engen Mittelraum ausfüllend, die Spormatien abschnürenden Sterigmen. Diese bestehen je nach den Genera entweder aus einer einzigen (?) gestreckt-cylindrischen Zelle, oder viner ästigen Reihe solcher und bilden dann die Spermatien nur auf den Zellen- und Astenden (Fig. 96 C, Sterigmata Nylander); oder sie stellen vielgliedrige Reilen von Zellen dar, die wenig linger als breit sind, und deren jede dieht neben ihrem oberen linde Spermatien abschnurt (Fig. $96 \mathrm{~B}$, Arthrosterigmata Nyl.). Die Spermalien sind kleine, stablörmige, schmal spindelförmige oder schmal lingliehe Kïrperchen, von deren Bau, Menge, Entleerung, Keimungssunfiihigkeit nach den vorliegenden Untersuchungen Alles gilt, was über die Pilzspermatien im fünften Ciapitel gesigt wurde, auf welches daher zu verweisen ist. ${ }^{1}$ )

Nach Lindsay (1. c.) kommen bei Roccella Montagnei Bél. zweierlei Spermogonien vor: 1) kleine punctförmige, ohne sterile Fäden im Innern und mit sehr zarten gekrümmten Spermatien, und 2) grössere, mit kurzen, ziemlich dicken stabförmigen Spermatien auf langen Sterigmen, zwischen welchen zarte anastomosirende Hyphen verlaufen. Eine aihnliche Dinorphie fand L. bei Opegrapha vulgata Ach.

Gibelli (Sugli org. reprod. del gen. Verrucaria, Mem. Soc. ital. di Sc. natur. Vol. I) gibt an, dass bei einer Anzahl Verrucarieen, besonders bei denen mil einfachen sporen und paraphysenfreiem Ilymenium, keine eigentlichen Spermogonien vorkommen, sondern der untere Theil des Apotheciums von den Asci, der obere von spermatienbildenden Sterigmen ausgekleidet wird; was mit den Angaben anderer Beolachter im Widerspruch steht.

Bei der allgemeinen Verbreitung der Spermogonien ist es fast selbstrerstindlich, dass dieselben auch bei den Flechten ilteren Beobachtern nicht entgangen

Fig. 96. A, 13. Gy rophora cylindrica. A Senkrechter Durchschnitt durch die Mitte eines Spermogonium und den angrenzenden Thallus. o Obere, $u$ untere Rindenschicht, m Markschicht des letztern. Vergr. 90. B Stück eines sehr dünnen schnitts durch den Girnnd eines Spermogoniums, 390 mal vergr. $s$ Sterig̣men mit stabförnigen Spermatien. $u$ die hraunhäutige, äussere ZeHenlage der Wand, $m$ Markhyphen. - $C$ Sterigmen und Spermatien von Cladonia Novae Angliae Delise, stark vergr., nach Tulasne.

1) Massalongo's Namen Spermatokalia, Erismata und Tromodoblasti für Spermogonien, Sterigmen und Spermatien mögen hier beiläufig erwähnt sein. 
sind. Sie wurden von diesen, ähnlich den gleichnamigen Organen der Ascomyceten, vielfach für die Perithecien besonderer (parasitischer) Pyrenomycetenarten gehalten; oder für abortirte oder »anamorphotische " Apothecien, oder für Organe besonderer Flechtenspecies (vgl. Tulasne, l. c. p. 153). Bayrhoffer hielt sie für Apothecienanfänge oder verwechselte sie mit solchen. Kurz vor der ausfühırlichen Publication ihrer Entdeckung durch Tulasne machte Itzigsohn auf sie aufmerksam als auf dic Antheridien der Flechten, in welchen spiralig gewundene, lebhaft bewegliche Spermatozoiden gebildet werden sollten. Letztere traten indessen nur nach Maceration in Wasser auf und erwiesen sich in der Folge als Spirillen, welche sich bei der Fäulniss in Wasser eingefunden hatten. (Vgl. Bot. Ztg. 1850, p. 393, $913 ; 1831$, p. 152.)

\section{P y c n iden. St ylos poren.}

Bei ganz einzelnen Flechtenarten hat man Conceptakeln gefunden, welche den Spermogonien ihnlich sind, auf ihren Sterigmen aber grössere Fortpflanzungsorgane, als die Spermatien sind, abschnüren. Sie gleichen hierdurch den Pycniden der Ascomyceten, ihre Producte den Stylosporen dieser, sie werden daher mit den gleichen Namen bezeichnet. Durchaus berechtigt ist diese Benennung für diejenigen Fälle, wo neben den Pscniden noch ächte Spermogonien vorkommen. Ausser den parasitischen, thalluslosen, und wie oben bemerkt wurde, eher zu den Pilzen zu stellenden Genera Scutula und Abrothallus, bei denen Tulasne die Pỵcniden auffand, gehören hierher nach Lindsay (I. c.) Bryopogon jubatus Kbr., Imbricaria saxatilis und sinuosa Kbr. Gibelli (l. c.) fand Pyeniden bei "Verrucaria carpinea Pers. ", Sagedia carpinea Mass., S. Zizyphi Mass., S. callopisma Mass., S. Thuretii Kibr., Pyrenula minuta Näg., P. olivacea Pers., Verruc. Gibelliana Gar. Fuisting fand sie bei Opegrapha varia, Acrocordia gemmata Mass., Acrocordia tersa, Sagedia netrospora Hepp, Sagedia aenea (vergl. Gibelli, Sugli org. reprod. del gen. Verrucaria. Mem. Soc. Sc. nat. Ital. Vol. I). Die Stylosporen sind bei Alect. jubata, Acroc. tersa einzellig, bei den genannten Op. varia, Acr. gemmata, Sagedia und den von Gibelli beschricbenen septirt. Ihre Keimung wurde nicht beobachtet.

Bei Peltigera sind durch Tulasne randständige Conceptakeln bekannt geworden, in welchen ovale, relativ grosse Zellen von Sterigmen abgeschnürt werden. Die Keimung derselben ist nicht bekannt. Tulasne nennt diese Organe Spermogonien, Nylander und Lindsay Pycniden. Anderweitige Spermogonien sind unbekannt, und die das Maass der übrigen Spermatien überschreitende Grösse genannter Zellen der einzige Grund, welchen Lindsay und Nylander zur Zeit geltend machen können. Nach den bei den Pilzen vorliegenden Erfahrungen ist es rein Sache der Willkür, den einen oder den anderen Namen zu wählen.

Bei Lecidea sabuletorum oder einer verwandten Form fand Berkeley angebliche Stylosporen (oder Conidien) nicht in Pycniden, sondern in den Apothecien, zu mehreren nebeneinander den Enden der Paraphỵsen aufsitzend (vgl. Ann. Mag. Nat. hist. 2( Ser. Vol. IX, und Crypt. Bot. p. 391); - eine Beobachtung, von der Tulasne (1. c. 110) gewiss mit Recht andeutet, dass sie noch sehr der Bestätigung bedarf. 
IV. A potheci e $\mathrm{n}$.

Die Apothecien der Flechten gleichen sowohl ihrer Form, als ihrer Structur nach theils den Fruchtträgern der Discomyceten, z. B. Pezi»en, Hysterien (Lichenes gyinnocarpi) theils den Perithecien der Pyrenomyceten (Lich. angiocarpi). Unter Hinweisung auf diese (Capitel 3, 4) können dieselben daher hier kul'z behandelt werden.

\section{Entwickelung und Bau des Apotheciums.}

Nach Schwendener's und Fuisting's Untersuchungen. kann gegenwärtig für alle Lichenen (Coenogonium ausgenommen) behauptet werden, dass die Entwickelung der Apothecien im Innern des Thallus beginnt; bei den heteromeren meistens (immer?) unterhalb der Rindenschicht, im unteren Theile der Gonidienzone, oder, bei manchen Krustenflechten, in dem tiefsten, dem Substrat unnittelbar angrenzenden Theile des Thallus; bei den hypophlöodischen Graphịdeen ebenfalls in letzgenannter Region; bei den Gallertflechten, denen sich Ephebe und Verwandte anschliessen wird, eine Strecke weit innerhalb der Oberfläche.

Die erste Anlage dergymnocarpen Apothecien ist bei den untersuchten heteromeren Formen ein rundliches, kleines (bei Lecanora cerina Hedw. z. B. kaum 1/100 Mm. grosses) Kn̈̈̈uel ordnungslos verflochtener Hyphen, von dessen ganzer der Rinde zugekehrter (iusserer) Seite sich sehr frühe ein dichtes Büschel nach auss'n gerichteter, zarter und verzweigter Fïden, die ersten Paraphysen erheben. Eine iusserste, oben oflene, je nach dem Einzelfalle versehieden mächtige Schicht solcher Fäden umgiht das Paraphysenbüschel und verläuft in die Oberfliche des primären Knäuels; diese Schicht ist als Ex c ipulum zu bezeichnen, freilich nicht ganz in dem Sinne, in welchem die bisherige beschreibende Lichenologie dieses Wort gebraucht. Das Excipulum entsteht entweder gleichzeitig mit den ersten Paraphysen, so zwar, dass die iussersten Reihen dẹs Büschels zu den Fasern des Excipulums werden .Placodium, Lecanora, auch wohl Lecidea u. s. w.), oder das Excipulum ist früher als die Paraphyseṇ vorhanden (Blastenia ferrugina Huds. nach Fuisting). Indem num die Fäden des primären Paraphysenbüschels in die Linge wachsen und neue, sich senkrecht zwischen die ersten einschichende Aeste treiben; indem ferner das Excipulum durch Bildung neuer, sich einschiehender Fasern seine Fliche ïberall vergrössert; indem dasselbe endlich durch Neubildung in seinem Rande wächst und innerhalb dieses fortwaihrend neve Hyphenzweige treibt, welche den primairen Paraphysen gleich sind und sich diesen aussen anlegen; indem alle diese Processe gleichzeitig erfolgen, wichst das junge $\Lambda$ pothecium durch Neubildung in die Höhe und Dicke. In dem unteren Theile des ursprïnglichen Paraphysenbuschels dauert die Einschiebung neuer Zweige eine Zeitlang in der Art fort, dass aus dem zuerst parallelfaserigen ein unordentlich verflochtenes, von dem primären Kniucl nicht mehrunterscheidbares Geflecht entsteht. Der Neubildung folgt unmittelbar Vergrösserung durch Ausdehnung der vorhandenen Elemente. Das ganze Wachsthum ist am ersten in der Mitte des Apotheciums vollendet, am längsten, und oft lange nach dem Hervortreten des Apotheciums an die Thallusoberfläche, dauert es in dem oberen Rande des Excipulums und dicht unterhalb desselben in der bezeichneten Weise fort, hier werden daher dem Apothecium andauernd neue Formbestandtheile durch Apposition hinzugefügt.

I) ie Asci entstehen nach Schwendener und Fuisting in eigenthümlicher Weise. 
Schon in dem jugendlichen Knäuel und zwisehen den ersten Anlagen der Paraphysen sieht man dickere, protoplasmareiche, querwandlose Hyphen mit zahlreichen Verzweigungen zwischen die übrigen eingeflochten (Fig. 97 sh). Aufrechte, zwischen die Paraphysenenden sich einschiebende Astenden dieser Hyphen werden zu den keulenförmigen Asci, - daher Schlauchfasern, Schlauchhyphen. Die Schlauchfasern sind von den Paraphysen besonders leicht zu unterscheiden dadurch, dass sich ihre Membran, nach Einwirkung von Kali, durch Iod blau färbt, während die jener farblos bleibt. Schon frühe verschwinden sie aus dem unteren Theile der Apotheciumanlage und bleiben nur in einer schmalen Schicht erhalten, welche der Oberseite des Apotheciums parallel läuft und da liegt, wo die unteren Enden der reifen Asci befestigt sind. In dieser Schicht verästeln sie sich in centrifugaler Richtung in dem Maasse als der Rand des Excipulums wächst und senden neue Asci zwischen die neugebildeten Paraphysen. Die ersten Asci treten im Centrum des Apotheciums auf. Ein genetischer Zusammenhang zwischen den Sehlauchfasern und den übrigen Hyphen ist nach Schwendener und Fuisting nicht zu finden. Beide bilden gesonderte, nur durcheinandergeflochtene Systeme. Ol) dies bei allen Flechten der Fall und welches der erste Ursprung der Schlauchfasern sei, ist noch aufzusuchen.

Die beschriebenen Theile setzen das fertige Apothecium zusammen (siehe Fig. 97). Nach dem Angeführten ist an demselben zu unterscheiden: 1) Excipulum, 2) die Schicht, in welcher die Schlauchfasern verlaufen: Subli ymenialschicht (Hypothecium nach fuisting), 3) II ymenium: die über der Subhymenialschicht liegende Schichte, bestehend aus den parallelen Paraphysenenden (Paraphysen $x \alpha \tau^{\prime} \varepsilon^{\prime} \xi \circ \chi^{\prime}, \nu$ ) und $\Lambda$ scis Thalamium, Lamina proligera, sporigera, Fruchtschicht der Systematiker), 4) die durch spïteres Wachsthum oft

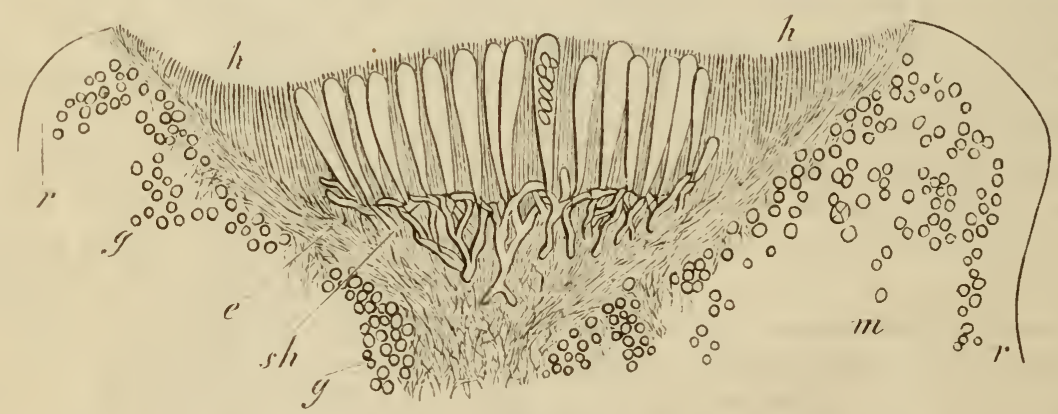

Fig. 97.

mächtig entwickelte, unter der Subhymenialschicht liegende Masse: aus den Hyphen gebildet, deren Aeste in dem Hymenium als Paraphysen endigen, und

Fig. 97. Lecanora subfusca. Senkrechter Durchschnitt durch die Mitte eines jungen Apotheciums. Vergr. 190. Der Schnitt ist durch Behandlung mit Ammoniak derart gequollen, dass die Hymenialfläche bedeutend grösser ist als im frischen Zustande. Die Ausführung der Figur ist insofern schematisch, als eine Anzahl Asci z wis chen den vorhandenen weggelassen, die Schlauchfasern deutlicher als sie auf Durchschnitten in der Regel hervortreten, die Paraphysen und die Hyphen des Excipulum nur durch Striche dargestellt siñd. $h-h$ Hymenium. sh Schlauchlyphen, von denen die Asci entspringen. $e$ Excipulum. $r$ Rindenschicht. $m$ Mark. $g$, d. h. alle die runden liorper, Gonidien des das Excipulum umgebenden Thallusrandes. 
den Resten des prinären Knäuels. Nach der üblichen Terminologie wird diese Gewebsmasse Hypotlecium, auch Excipulum genannt; sie ist im fertigen Zustande, der Natur der Sache nach, von dem Excipulum oft schwer oder kaum $\mathrm{zu}$ unterscheiden.

Früher oder später wölbt das sich vergrössernde Apothecium die darüber liegenden Thallusschichten empor und durchbricht sie schliesslich, so dass mindestens das Hymenium frei liegt. Die bedeckenden Thallusschichten verhalten sich hicrbei entweder so zu sagen passiv, sie werden durch das wachsende Apothecium zur Seite gedrängt, zerreissen über der Oberseite des Apotheciums, und die Stücke sterben ab, das Hymenium und der Rand des Excipulum treten uber die Thallusoberflache, in letzterem dauert auch nach dem Hervortreten das Wachsthum fort (Apothecia lecidina, biatorina). Oder dic den Rand des Excipulums ungebende Thallusportion wïchst mit diesen, so dass die Aussenflaiche des Excipulums bedecht bleibt von einem aus Mark, Rinde und Gonidienzone bestehenden Thallusïberzug, welcher entweder bis zu dem Rande des Excipulums reicht (Apothecia lecanorina) oder von diesem ïberragt wird (Apoth. zeorina, eine, wie Schwendener mit Recht urgirt, nicht durchfiihrbare L'nterscheidung). In dem ersten Falle hat das Apothecium ein Excipulum proprium nach dem üblichen Sprachgebrauch, welches entweder cinen leisten- oder wulstförmigen kand um das Hymenium bildet, oder durch starke Wölbung des letzteren zuriichgesehlagen und bei dem unversehrten Apothecium undeutlich wird (Lecidca, Biatora). In dem \%writen Falle redet die übliche Terminologie von einem Excipulum thallorles, richtiger von einem (das eigentliche Excipulum einschliessenden) Thallusande oder Thalluswulst. Das Excipulum ist hier dem Markgeflecht eingesetzt, in dieses nicht selten später Hyphenzreige sendend, "wie Wurzeln in den Boden . Die das Apothecium umgebenden Markhyphen bilden bei vielen formen spiter Zahlreiche Gonidien, so dass dessen Basis und Excipulum einer Gonidienzone auggesetzt erscheinen.

Die Entwickelungsgeschichte, welche hier zu shizziren versucht wurde, griundet sich zunächst auf eine Reihe eingehender, von den genannten beiden Autoren mitgetheilter Lntersuchungen an Arten von Placodium, Lecanora, Zeora, Callopisma, Lecidea, Blastenia, Bacidia, Pannaria. Nach den vorliegenden vercinzelten und durch ausgedehnte Untersuchungen noch zu vervollstandigenden Daten kann jedoch wohl mit Bestimmtheit behauptet werden, dass das gymnocarpe Apothecium ibbrall in wesentlich der gleichen Weise als Yeubildung im Thallus entsteht, und wesentlich die gleiche Organisation zeigrt. Die grosse Mannigfaltigheit der Formen, in denen es bei den verschiedenen Genera auftritt, wird sich auf die versehiedene relative Machtigkeit der einzelnen Theile und reine Gestaltdifferenzen reduciren. Für die Parmeliaceen, die Collemen kann dies wohl mit aller Sicherheit behamptet werden. Ehenso im Wesentlichen fïr Peltigera und Solorina, wo das schildförmigere, unberandete Apothecium unter der Rindenschicht, in der Gonidienzone entsteht mnd jene frühe wie ein Schleier abgehoben wird und abfillt (vgl. Tulasne, Mém. pl. 8). Die Sticle des Apotheciums von Baeomyces Nyl., Calygeium und Verwandten sind oflenbar nichts weiter als die stark gestreckte, das Hymenium weit über den Thallusrand emporhebende Basalportion des Hypotheciums. Die unberandeten Apothecien zeigen theils ein diinnes, der oberfláchlichen Betrachtung entgehendes, theils ein Excipulum, welches durch starke 
Wölbung der Hymenialschicht zurückgebogen und von den peripherischen Ilymeniumtheilen bedeckt wird (Lecidea spec., Megalospora). Im Grunde gilt dasselbe für die Apothecien (Lirellae) der Graphideen, hinsichtlich welcher ich auf Fuisting's Dissertation verweise. Auch die wirklich exceptionellen Fülle schliessen sich nahe an die typischen an. Hervorzuheben ist von solchen Phialopsis rubra, bei der das mächtig entwickelte Excipulum anfangs ringsum geschlossen ist und später erst, durch Zerreissen und Absterben des oberen Theils geöffnet wird (seine erste Entstehung ist noch unbekannt). Vergl. Fuisting, I. c.

Auch bei Coenogonium findet, nach Schwendener's Untersuchungen, die Apothecienentwickelung wesentlich nach dem beschriebenen Typus statt, nur, wegen der eigenthümlichen Structur des Thallus (vgl. Seite 270) nicht im Innern, sondern an der Oberfliche dieses. Ueber einem kurzen, ein - bis zweizelligen Aste der confervenartigen Gonidienreihe verästeln und verflechten sich die peripherischen Hyphen zu einem runden Knäuel, an dessen dem Thallus abgekehrter Seite die Differenzirung in IIymenium und Excipulum stattfindet. Von der Basis des in allen Theilen wachsenden Apotheciums wachsen zahlreiche Hyphen gegen den Thallusast, an dein es entstand, und gegen andere benachbarte, um es an diese $z u$ befestigen, wie ein selbstiandiges Gewaichs an dem Boden befestigt ist. Karsten's an sich schwer verstindliche Angaben (Geschl. d. Pfl. p. 42), nach welchen der einzellige Ast der Gonidienreihe der Centralzelle eines "Archegoniuıns entsprechen, von den ihm anliegenden Hyphenzweigen befruchtet werden, und in Folge hiervon die Elemente des Ilymeniums durch endogene Zellbildung erzeugen soll, fand Schwendener nicht bestatigt, und den Resultaten dieses mit der Entwickelungsgeschichte der Lichenen vorzugsweise vertrauten Beobachters ist umsomehr Gewicht beizulegen, als sie in $\mathrm{klarer}$ Weise zeigen, wie die in Rede stehenden Apothecien mit anderen ebensowohl im jugendlichsten wie in fertigen Zustande übereinkommen.

Für weitere Eigenthümlichkeiten einzeher (ienera, insonderheit die eigenthümlichen Prolificationen der Hymenialfliche von Gyrophora, ist auf die descriptive Litteratur und besonders auf Schwendener's zu citirende Arbeiten zu verweisen.

Ueber die Entwickelung der angiocarpen Apothecien hat Fuisting eine Anzahl von Beobachtungen mitgetheilt, und diese scheinen eine grosse Aehnlichkeit mit der Seite 98 dargestellten Perithecienentwickelung der Xylarien zu ergeben. In den tieferen Schichten des Thallus erscheint ein Faserknäuel, und von diesem erhebt sich ein Bündel paralleler Ilyphen, welches senkrecht gegen die Oberfliache und bis zu dieser hin wächst. Das Gewebe des hierdurch entstehenden, etwa flaschen- oder kegelförmigen Körpers differenzirt sich alsbald in eine mittlere Portion, welche nach und nach zu Grunde geht, und eine äussere, die das allmählich wachsende Excipulum darstellt. Im Grunde des Excipulums sprossen die Theile des Hymeniums auf der Innenfliiche hervor, in dem oberen Theil entsteht schon bei der ersten Differenzirung ein enger Mündungscanal. Mehr kann ich aus dem dunkeln Dissertationslatein nicht entziffern. Die Asci entwickeln sich wie bei den gymnocarpen Formen. In dem Mündungscanal von Pyrenula, in demselben und dem oberen Theile des Conceptaculums von Verrucaria, Thelidium, Endopyrenium, Endocarpon entwickeln sich von der Wand nach innen gerichtete zarte Haare, zwischen denen keine Asci stehen, und welche 
Nylander Filaments ostiolaires, Fuisting Periphysen nennt. Sie gleichen bei Endocarpon miniatum, wo ich sie untersuchte, in ihrer Anordnung genau denen im Perithecium und Mündungscanale von Xylaria. Das Hymenium entsteht an den von Periphysen nicht occupirten Theilen der Innenfliche. Es zeigt bei Pyrenula Paraphysen zwischen den Ascis, bei den anderen genannten Genera nur letztere, ohne Paraphysen. Bei Sagedia, Acrocordia, Lembidium, Segestrella unterbleibt die Bildung des Mündungseanals. Die schwarze Wand der fertigen angiocarpen Apothecien besteht theils aus den iusseren Lagen des Excipulums, theils aus den veränderten angrenzenden Thalluselementen.

In den Apothecien von Stigmatomma cataleptum kommen Gonidien vor, welche den liaum zwischen den Periphysen ausfüllen. Fuisting hat es wahrscheinlich gemacht, dass dieselben durch Theilung von Thallusgonidien entstehen, die in den ursprünglichen Faserkniuel mit eingeschlossen werden. Die Gonidies hyméniales, welche Nylander (Syn. p. 4i) bei einigen anderen, mit der genannten Flechte verwandten Arten fand, diiften den gleichen Lrsprung haben.

Auch von angiocarpen Flechten sind die Apothecien vielfach noch nicht hinreichend genau, zumal auf die Entwichelungsgeschichte, untersucht.

Einen ganz anomalen, sowohl von den angiocarpen als gymnocarpen verschiedenen Bau besitzen die Apothecien von Myriangium Mont. et Berh. Den Beschreibungen zufolge liegen die linglichen oder rundlichen Asei einzeln und ordnungslos einem unregehnaissigen Pseudoparenchym eingebettet. (Nylander, Syn. P. 139, Tah. IV).

Die mannigfaltigen Fiarbungen der Apothecien gehören jedenfalls der Mehrzahl nach den Zellemmembranen an; die der IImenimmoberfliche öfters einer derselben aufgelagerten structurlosen Masse, welche einer Desorganisation der Paraphysenendzellen ihre Entstehung zu verdanken scheint. Andere, wie der graue Reif auf dem Ilỵmenium von Roceella, Ilagenia ciliaris, scheinen sich den körnigen Einlagerungen, welche beim heteromeren Thallus beschrieben wurden, anzuschliessen; sio bediurfen jedoch noch simuntich genauerer Untersuchung.

Simmtliche dem $\Lambda$ pothecium eigene Theile sind aus fest und lïckenlos verbundenen Formelementengebildet, und diese haben, :ihnlich denen in den diickenlosen Theilen des Thallus, dicke, gallertartige Membranen. Auf Iurchschnitten erscheinen die Lumina derselben, insbesondere der Paraphysen, of einer anseheinend structurlosen, massigan, durchscheinenden Gallerte eingebettet. Durch Anwendung von Ammoniak oder Kaliliosung lassen sich, wie beim heteromeren Thallus, die einzelnen Iyphen am besten isoliren. I)ie Gallertmembranen des Hymeniums werlen vielfach durch wässerige Iodlösung sofort intensiv blau gefarbt. Auch das Ilypothecium nimmt an dieser Farbung oft Theil. Durchschnitte durch ältere IIymenien scheinen sehr oft ihrer ganzen Ausdehnung nach blau zu werden, höchstens mit Ausnahme der Paraphysenenden. Wenn man jedoch die einzelnen Elemente duch Ammoniak oder Kali von einander trennt, oder sehr dïnne Quersehnitte oder junge, noch nicht schlauchfïhrende Theile des Iymeniums untersucht, so zeight sich, dass die Membranen der Paraphysen ihrer ganzen Austehnung nach nicht blau werden. Die Färbung tritt nur an den Membranen der Asei und Schlauchhyphen auf, sowohl den jüngeren, als den bereits entleerten, mehr oder minder desorganisirten. Dies gilt auch für diejenigen 
Arten, für welche (Tulasne, Mém.) ein Blauwerden der Paraphysen angegeben wird, wie Physcia parietina, Parmelia stellaris, Peltigera aphthosa, horizontalis, es kann daher als allgemeine und vielleicht ausnahmslose Regel angenommen werden, dass besagte Färbung immer nur von den Ascis und ihren Trïgern herrührt.

\section{Asci und Sporen.}

1. Die $\Lambda \mathrm{sci}$ sind nach Gestalt und Bau den keulenförnigen der Ascomyceten gleich, mit versehieden dicker, oft sehr mächtiger und undeutlich geschichteter Membran versehen, dic bei Terletzung ähnliche Quellung in die Dicke zeigt, wie die Seite 109 beschriebene. Ein longitudinaler Porencanal findet sich in ihrem verdickten Scheitel bei Pertusaria und wohl auch anderwärts. Jene eigenthümliche Streckung der Innenschicht, wie sie gerade den flechtenähnlichsten Pyrenomycetenschliuchen eigen ist (Fig. 37), kommt bei Lichenen nicht vor. Die Membran ist meist deutlich gelatinös und fest mit der der umgebenden Paraphysen verklebt, was die Isolirung unversehrter Schläuche oft erschwert. Das Protoplasma der Flechtenasci ist in den meisten Fällen reich an Oeltröpfehen, es erfüllt, wie es scheint, vor der Sporenbildung immer den ganzen Schlauch von oben bis unten.

Die Sporen entstehen simultan innerhalb des Protoplasma. Ihre ersten Anfänge erscheinen als höchst zart umschriebene Zellen, welche, wie im ersten Abschnill des vierten Capitels beschrichen wurde, allmählich die Eigenschaften der fertigen Spore annehmen. Bei der Schwierigkeit, die Asci in grösserer Menge zu isoliren und der gerade bei den grössten und leichtest isolirbaren besonders starken Trübung des Protoplasma durch Oeltröpfehen, ist es sehr schwer, die ersten Stadien der Sporenentwickelung vollstiindig und genau zu verfolgen. Alle bekannten Zustinde deuten jedoch auf eine Uebereinstimmung des Entwickelungs̀processes mit dem der Ascomyecten hin. Besonders deutlich wird diese angezeigt dadurch, dass es wenigstens in manchen Fällen möglich ist, vor der Sporenbildung den primairen Zellkern in den Schläuchen nachzuweisen. Ich fand ihn bei Lecidella enteroleuca, Pertusaria leioplaca, Lecanora pallida, Sphaerophoron coralloides (Fig. 98 a) in der Form und constanten Stellung, welche Seite 104 fiir Peziza tuberosa u. $\Lambda$. beschrieben ist, und bei fernerem Suchen wird man ihn sicherlich vielfach finden. In den jungen sporen konnte ich nie einen Kern sehen, und es ist nach den Abbildungen unzweifelhaft, dass die derl contourirten Körper, welehe von Sehleiden (Grundz. II) und nach ihm von Anderen (Buhse, Schacht) für Kerne gehalten wurden, nichts anderes sind als entweder Oeltropfen oder die jungen Sporen selbst.

Die Zahl der in einem Ascus gebildeten Sporen ist auch hier in den meisten Fällen 8. Ausnalımen von dieser Regel finden sich wie bei den Pilzen, z. B. typisch einsporige oder ein- bis zweisporige bei Umbilicaria, Megalospora Mass., tỵpisch zwei- bis drei-, oder vier- bis sechssporige bei mehreren Pertusarien, typisch vielsporige, oft mit hundert und mehr Sporen bei den Massalongo'schen Genera Bactrospora, Acarospora, Sarcogyne u. s. w. Die neueren descriptiven Arbeiten zahlen bekanntlich diese Verhältnisse mit besonderer Genauigkeit auf.

lis ist ein Irrthum, wenn nach Schleiden vielfach angegeben wird, dass bei 
weniger als acht Sporen in einem Schlauche ursprïnglich acht angelegt, aber nur einige von diesen ausgebildet worden. Gerade bei der von Schleiden angeführten Megalospora sanguinaria ("Lecidea sanguinea "Schleid.) und bei den oligosporen Pertusarien sind die ersten Anlagen der Sporen von den ausgebildeten der Zahl nach nicht oder nur wenig verschieden.

Soweit meine Beobachtungen reichen, werden die Sporen eines Ascus immer gleichzeitig angelegt. In ihrer Ausbildung kommen dagegen weit häufiger als bei den Ascomyceten init simultaner Sporenbildung Ungleichheiten vor, was darin scinen Grund haben mag, dass bei der langsameren Entwickelung die Ausbildung des Flechtenaseus häufgere Störungen erleiden kann, als die der Pilzasci. Man findet daher oft Sporen sehr ungleicher Entwickelung in einem Schlauche, und dieses hat die Annahme suceedaner Anlegung veranlasst (Schacht, Anat. d. Gew. I, 73). Sehr oft bleiben von mehreren Sporen in einem $\Lambda$ scus eine oder einige ganz unentwickelt und werden zuletzt mit den reifen entleert als kleine, keimungsunfïhig̣e Kiimmerling̣e nit diumner Membran und wasserhellem Inhalte. Tulasne fühıt solehes für Ereeolaria, Calycium u. a. an, ich fand es bei vielen Formen, besonders auffallend z. B. bei Ochrolechia tartarea, immer jedoch als eine keineswegs typische, sondern nur diesem oder jenem Ascus zukommende Erseheinunge. Ein typischer Ahort scheint nach Tulasne's Beschreibung bei Collema cheileum vorzukommen, indem hier der reife Ascus immer (?) verkümmerte, wasserhelle neben ausgobildeten sporen enthäh, erstere oft unregelmissig mil einander oder den letzteren verklebt. Hie: nörner, spitzen oder sonst wunderlichen Ausw ïchse", welche nach Schleiden und Buhse an den Sporen von Megalospora sanguinaria didurch entstehen sollen, dass sich abortirende an die ausgebildeten ankloben, existiren an frischen, reifen Exemplaren nicht. Möglich, dass keimende Sporen oder, wie nach Lindsay's Abbildung (Brit. Lich. pl. XIV) wahrscheinlich ist, unreife, mit anhingendem Protoplasma eingelroeknete jene Angabo veranlasst haben.

Hinsichtlich des Baues der reifen spore ist hier auf das äber die Pilzsporen Gesagte zu verweisen (Soitr 126). Wesentliche Verschiedenheiten von diesen kommen nicht vor, und die zahllosen Variationen in Gestalt, Grösse und Specialstructur zu beschreiben, ist eine neuerdings mit Vorliebe, allerdings nicht immer mit Gliick betriebene $\Lambda$ ufgabe der Systematik. Eine solır gute Uebersicht geben die Cmrisszeichnungen in Hepl's Lichenes exsiec. und mbbildung und Beschreibung der Sporen der Flechten Europas. «

Je nach Gattungen und Arten sind auch hier die Sporen entweder einfache Zellen oder septirt ( $\mathrm{g}$ gl. Seite 1:4). Die Bildung der letzteren aus ihrer ursprünglich einfachen Mutter\%elle erfolgt durch gewöhnliche Zelltheilung, und es ist ïberhaupt von den Flechtensporen hoine Erscheinung bokannt, welche sich nicht an der Hand der elementarsten Lehrsitze von Zellbildung, Zelltheilung, Membranverdickung leicht verstehen liesse. Insonderheit ist die ganze Körber'sche Sporoblastenannahme und Sporoblasten - Terminologie theils unrichtig, theils iiberflissig. Itoth hat neuerdings (Ber. d. Oberhess. Ges. f. Naturk. 186\%, p. 146 die Entwickelung einer Anzahl ron septirten sporen richtig dargestellt, dic Structur der sogenannten "blasteniosporischen " hat er gleichfalls offenbar verkannt, dieselben sind (wenigstens bei Physeia parietina) nichts weiter als farblose Sporen, deren Lumen in der Mitte durch eine wulstige Verdickung der 
Membian stark verengert und an der engsten Stelle durch eine sehr zarte Querwand getheilt ist.

Die verschiedenen Färbungen der Sporen gehören inmmer dem Episporium an; wenigstens erscheint der Inhalt der einzelnen Spore unter dem Mikroskop immer farblos oder kaum gelblich, bläulich u. s. w. Auffallend selten kommen auf der Aussenfläche des Epispors Unebenheiten vor: Einige Solorina-Arten (S. saccata) und Pannarien (P. hypnorum nicht nur, sondern auch P. brunnea, triptophylla) mit warziger, Thelotrema exanthematicum mit feinstacheliger Oberfläche, sind die wenigen bisher beschriebenen Beispiele hierfür. Gelatinöse Appendices kommen nicht vor, wohl aber in einer Reihe von Fällen weich-gelatinöse Umhüllungen (Aussenschichten) der ganzen Spore, z. B. Pertusaria, Verrucariae Spec. (vgl. Tulasne, Mém., Nylander, Syn. p. 33.)

2. Ausstreuung der Sporen. Die reifen Asci zeigen in Beziehung auf Vertheilung und endliche Befreiung der Sporen ein zweifaches Verhalten. Bei der überwiegenden Mchrzahl der Flechten sind die reifen Sporen in dem relativ weiten Schlauche in wässeriger Flüssigkeit suspendirt, wie bei den Ascomyceten, und werden zuletzt aus der aufreissenden Spitze des Schlauches hervorgeschleudert. Die Schliutuche entleeren sich einer nach dem andern, ein plötzliches Staiuben findet nicht statt, was in dem Umstande begrüundet sein dürfte, dass die reifen Asci auch bei den gymnocarpen Apothecien niemals über die Hymeniumoberfläche vorragen, sondern höchstens so lang, meistens jedoch etwas kürzer sind als die Paraphysen. Die Ejaculation findet mit nicht unbeträchtlicher Kraft statt : die Sporen werden, nach Tulasne's Messungen, bis auf I Cm. Entfernung fortgeschleudert. Sie geschicht sowohl bei den gymnocarpen als angiocarpen Apothecien. Wie bei den Ascomyceten wird mit den Sporen eine Quantitat Inhaltsflüssigkeit, die unverbrauchten Körnchen, abortirte Sporen, welche in dieser enthalten sind, ausgespritzt. Der Mechanismus der Ejaculation ist ein ähnlicher, doch nicht genau der gleiche, wie der oben für die Discomyceten beschriebene. Wie Tulasne gezeigt hat, findet die Ausschleuderung statt, wenn das Apothecium feucht, von Wasser durchdrungen wird. Es muss hierbei die Menge der Inhaltsflüssigkeit im $\Lambda$ scus und somit der von innen auf seine Membran ausgeubte Druck vermehrt werden. Andererseits aber quellen die Gallertmembranen der Paraphysen und entleerten Schliiuche gewaltig auf und zwar, wie Durchschnitte zeigen, vorzugsweise in der Richtung der Hymenialfliche. Die hierdurch bedingte Flichenausdehnung des Iỵmeniums findet aber einen Widerstand theils in dem Thallus, wenn es diesem eingesenkt ist oder aufliegt, theils, wie Tulasne gezeigt hat, in dem Excipulum und Thallusrande; denn diese krümmen sich bei Einsaugung von Wasser energisch in dem Sinne, dass sie der Flächenvergrösserung des Hymeniums entgegen wirken. Hiernach erleidet der flüssigkeitserfüllte Ascus einen hohen Druck von aussen auf allen Puncten seiner Seitenwand, und in diesem ist eine Hauptursache der Ejaculation zu suchen. Die leeren, gallertartig weichen Schlauchmembranen werden meistens sofort von den Seiten her zusammengedrückt und sind oft schwer aufzufinden. Sie tragen jedenfalls sehr viel bei zur Bildung der homogenen, durch Iod blau werdenden Gallertmasse aitterer Hymenien. Wegen des frühen Undeutlichwerdens der Membranen ist es schwer, die Form, in welcher sie bei der Entleerung aufreissen, sicher zu er- 
mitteln. Bei Pertusaria gelingt es am leichtesten, zu sehen, dass ihr Scheitel durch einen kurzen, über seine Mitte laufenden Längsriss zweiklappig gespalten wird; bei Peltigera, Umbilicaria, Urceolaria scheint nach Tulasne's Darstellung ein Zerreissen der Länge nach in mehrere kurze Lappen stattzufinden.

Verschieden von der beschriebenen Mehrzahl der Lichenen verhalten sich die Asci von Sphaerophoron (Fig. 98), Acroscyphus, den Calycieen, Lichina, Paulia, wie Montagne (Ann. Sc. nat. XV. 2. Ser. 1841), Fresenius (Flora 1848, p. 7.33) und Tulasne (Mém. p. 77) gezeiğt haben. Eine Ejaculation findet hier gar nicht statt. Die jugendlichen Sporenanlagen werden früh den engen, zarten Ascis fast gleich breit und ordnen sich in eine einfache, oder stellenweise doppelte ununterbrochene Reihe in dem oberen Theile des Schlauches, ron dessen Wand nur durch eine dünne Lage Protoplasmas (oder Epiplasmas) getrennt $(a, b)$. Indem sie sich hierauf in höherem Maasse, als die umgebende Schlauchwand ausdehnen und das Protoplasma verschwindet, fuillen sir die Wand zuletzt völlig aus, als eine zarte, zwischen je zwei Sporen oft eingeschnürte Scheide $(c)$. Bei Sphaerophoron, den meisten Calycieen, zerbröckelt diese zuletzt, die Sporen werden hier-
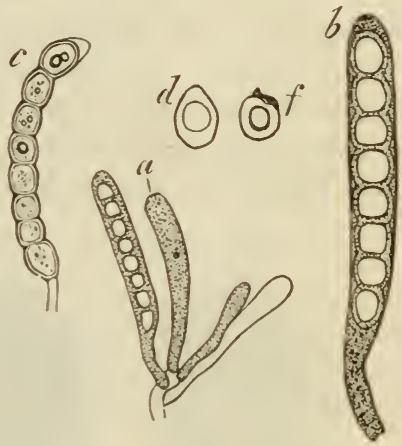

Fig. 98 . durch von einander getrennnt und hiufen sich als ein lockeres Pulver auf der II!̣menimnfliche an. Bei Lichina und Paulia bleiben die Sporen fest vereinigl, wic sie aus den Conceptakeln herauskommen, ist nicht bekannt. Nach Lntersuchungen an Sphaerophoron und Acolium ocellatum ist es mir kam zweifelhaft, dass die Sporen noch nach ihrer Trennung zu wachsen fortfahren, denen von Elaphomyces vergleichbar (vgl. Fig. 98, $c$ und $d$ ).

3. Die Keimung der Flechtensporen hat wohl schon Meyer Entw. d. FI., p. (75) gesehen, mit besseren Mikroskopen wurde sie für einzelne Fälle von Buhse, von Holle beobachtet; ausgedehntere genaue Lntersuchungen rerdankt man auch hier erst Tulasne. Seine Beobachtungen erstrecken sich auf Arten aus den Genera Peltigera, Solorina, Parmelia, Physcia, Endopyrenium, Collema, Lecanora, Lecidea, Verrucaria, Sphaerophoron, Ochrolechia, Opegrapha, denen die viel untersuchte Hagenia ciliaris, Graphis scripta, hinzuzufiigen ist. Die Keimung erfolgt nach Aussaat auf feuchten Boden, auch feuchten Objectträger. Sie besteht bei fast allen untersuchten Flechten in dem Austreiben eines oder zweier Keinschlauche aus jeder Sporenzelle, und die hierbei stattfindenden Erscheinungen sind sowohl bei septirten als unseptirten Sporen den für die Pilze

Fig. 98. Sphaerophoron coralloides P. $a$ junge Asci. $b$ der eine derselben stärker vergr. $c$ Fast reifer $A$ scus. $d$ Umriss einer freien, reifen Spore. $f$ Umriss einer solchen, von der das violettschwarze Epispor bis auf ein kleines stuickchen abgelöst ist. $b$ etwa $700-$, die übrigen alle 390 mal vergr. 
bekannten so vollständig gleich, dass dem auf Seite 148 und 149 Gesagten hier nichts hinzuzufügen ist.

Eine kleine Anzahl von Flechten, nämlich die Genera Och rolech ia Mass., Megalospora Mass. und Pertusaria zeigt Keimungserscheinungen, welche auf den ersten Blick von denen der übrigen total verschieden sind.

Die Sporen dieser Genera (Fig. 99) sind ungemein gross, unseptirt, oval oder elliptisch, mit Oeltropfen dicht erfüllt und mit derber, oft vielschichtiger, farbloser Membran versehen. Jede treibl beim Keimen gleichzeitig zahlreiche - bis 100 - schlanke Keimschliuche, welche entweder von der ganzen Oberfliiche der Spore, oder (bei Pertusaria) nur von der dem Substrat zugekehrten Seite entspringen. Einmal gebildet zeigen diese Schläuche keine besonderen Eigenthümlichkeiten. Die Entstehung eines Keimschlauches beginnt mit dem Auftreten eines engen, von dem Innenraum der Spore senkrecht zur Oberfläche gerichteten Porencanals in den inneren Membranschichten (Endosporiunı); dieser ist, soweit irgend erkennbar, eine Neubildung, nicht etwa eine Erweiterung eines von Anfang an vorhandenen. Innerhalb der äusseren Membranschichten
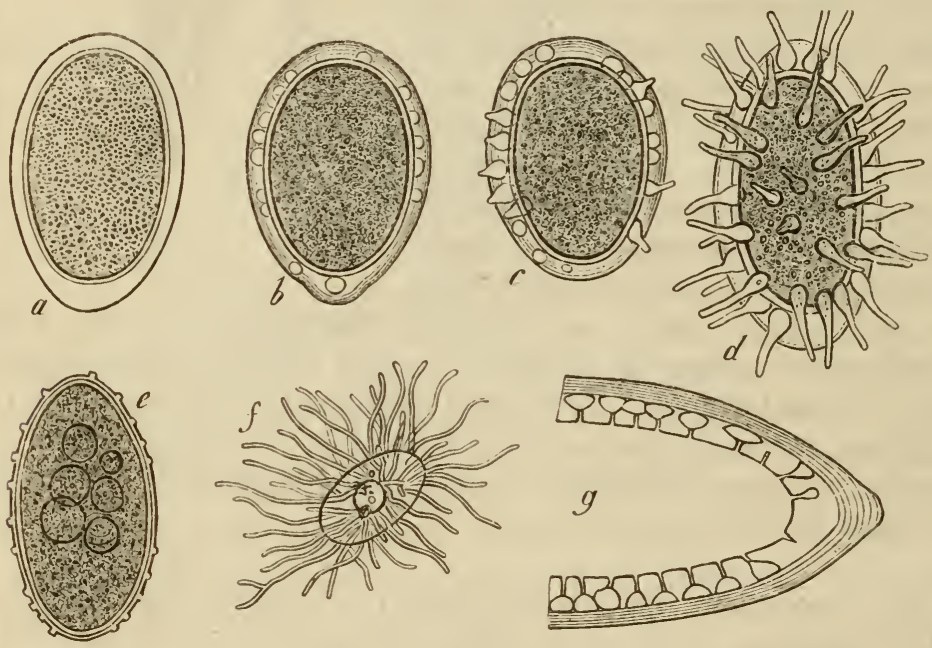

Fig. "99.

und aul Kosten dieser dehnt sich das Ende des Canals zu einem linsenförmigen oder kugeligen Hohlraum aus, in welchem sich homogenes Protoplasma ansammelt und weleher alsbald mit einer eigenen, sehr zarten Membran umgeben erscheint, als ein Blischen, das sich nach aussen zu dem Keimschlauch verlingert und das Episporium durchbohrt. In dem Maasse, als die Keimschliuche wachsen, ver-

Fig. 99. Vergr. von $f 190$, der übrigen 390. $a-d$ Megalospora affinis Kbr. $a$ reife, ejaculirte Spore. $\quad b-d$ Keimungsanfang, Entwickelungsfolge nach den Buchstaben. In $b$ u. $c$ nur der optische Läng̨sschnitt, in $d$ auch die Oberfläche gezeichnet. - $e, f$ Ochrolechia pallescens Mass. $e$ Erster Keimungsanfang (optischer Längsschnitt). $f$ Mit gestreckten Keimschläuchen. $g$ Pertusaria ceuthocarpa? Hälfte einer Spore mit beginnender Keimung, optischer Längsschnitt durch die Membran, die Porenkanäle mit ihren blasigen Erweiterungen zeigend. Letztere haben frisch die Gestalt wie in $b$. Das Präparat war mit Glycerin behandell, der Inhalt ist in der Figur weggelassen. 
mindert sich der Sporeninhalt. Bei den dickwandigen Pertusariasporen treiben die Schläuche oft innerhalb des Episporiums Ver:istelungen, welche sich in diesem, der Sporenoberflache entlang, ausbreiten. Die Porencaniale sind meistens so eng, dass Blischen und Keimschlïuche auf den ersten Blick ringsum geschlossen zu sein scheinen. Bei Ochrolechia ragen jene, wegen der geringen Dicke des Episporiums, sehr früh über die Sporenoberfliche hervor und lassen sich oft, wie Tulasne beschreibt, mit dem Epispor von dem anscheinend unverletzten Endosporium loslösen. Anwendung von Reagentien, zumal Chlorzinkjodlösung, lässt überall den beschriebenen Sachverhalt deutlich erkennen, bei den grossen Pertusariasporen ist derselbe auch an der unversehrten spore deutlich (rgl. die Erklärung der Fig. 99).

\section{Capitel 10.}

\section{Entwickelungsgang der Flechten. Physiologie.}

Nach Analogge der Ascomyceten und nach einig̣en sehr wenigen directen Beobachtungen ist nicht zu bezwrifoln, dass von der heimenden Spore wiederum ein $\Lambda$ pothecien bildender Thallus erzeuget wird. Auf welche Weise dieses geschicht, ist noch keineswegs recht klar.

Die vollstimdigste Beobachtung dariuber machte Tulasne Mém. p. 90) an Verrucaria muralis. Auf cinen gegalitteten Kalhstein ausgesitet trieben die Sporen dieser Flechte Keinschliuche, die allmahlich wuchsen, Querwinde emielten, sich verzweigten und, zwei bis drei Monate uach der Aussaal, mil einander ein ziemlich dichtes Geflecht bildeten. Auf diesem entwichelie sich nun neine weiss)liche Schichte runder, 4 bis 6 Zehntausendstel Millimeter grosser Zellchen, fest mit einander und mit den Fïden, von denen sie erzeugh wurden, verbunden, mlie einen anseheinend leer, die andern von Protoplasma erfiillt. Bald nachher ssah man auf dieser ersten Lage da und dort Zellchen mit grünem Inhalt ersscheinen', und man durfte nicht mehr zweifeln, dass ein neuer Thallus der V. "muralis aus den zum Versuche dienenden Sporen entstanden war." I)ie grünen Zellen waren von den Gonidien der erwachsenen V. muralis in nichts verschieden.

Bei einer Aussaat von Physcia parietina (I. c. p. 9:3) entwickelten sich auf dem Geflechte von Keimfiiden schr kleine weissliche Zellen und später grosse, die einen grumen Inlalt erhielten. Hierbei blieb aber die Entwickelung stehen.

Speerschmeider (Bot. Ztg. 1853, p. \%21) beschreibt Aussaatrersuche mit Hagenia eiliaris, aus denen wenigstens das mit Sicherheit hervorgeht, dass die Sporen die für diese Species characleristischen kurzen, aber sehr istigen Keimfiiden trieben und dass spiiter junge Thallusanlagen auf dem besïeten Holze auftraten.

Hierauf beschrinken sich die vorliegenden directen Beobachtungen; denn die Angaben, welche nach Untersuchungen mit älteren oder miltehuaissigen Mikroskopen gemach wurden, missen der vielerlei möglichen Täuschungen halber bei Seite gelassen werden, sellost wemn sie von Gewaihrsmainnern wie Meyer und 
Fries herruhren; und von der Angabe Berkeley's (Crypt. Bot. 373), nach der sich Gonidien direct auf dem »Mycelium von Parmelia parietina « entwickeln, ist es nicht klar, ob sie hierher gehört.

Die überwiegende Mehrzahl der in neuerer Zeit angestellten Keimversuche blieben immer bei der Bildung der mehr oder minder gestreckten, querwändigen, verästelten (bei Pertusaria auch Hförmig verbundenen) Keimfäden stehen.

An spontanen Flechten findet man öfters ganz jugendliche Thallusanfïnge einzeln oder in grosser Zahl von einem dem Boden aufliegenden Hyphengeflechte entspringend, welches dem oben für Verrucaria muralis beschriebenen ähnlich ist und aus der Vergrösserung von Keimfaiden entstanden zu sein scheint. So z. B. bei Peltigera, Cladonia, Tulasne, Mém. pl. VIII, XI, XVI. Seit Meyer nennt man ein solches Geflecht, aus welchem Thallusanlagen hervorsprossen, Prothallus, Protothallus (auch mit dem unklaren, daher zu vermeidenden Namen Hypothallus).

Die verschiedenen soeben angeführten Thatsachen combinirend sind die Bearbeiter der Flechtenmorphologie einig in der Annahme: die Keimschläuche der Spore wachsen unmittelbar zu dem Prothallus heran, und auf diesem werden dann die Thallusanlagen gebildet; entweder bleibt der Prothallus klein und geht möglicher Weise nach Bildung einer' Thallusanlage zu Grunde; oder er wächst lange fort, um immer neue Thallusanlagen zu erzeugen. Der Prothallus. ist hiernach dem primären Mycelium der Pilze in Ilinsicht auf seine morphologische Bedeutung zu vergleichen.

Gegen diese Anschauung ist nichts einzuwenden, als dass sie noch des sichern Beweises bedarf. Denn die erwähnten spontanen Prothallusbildungen könnten doch auch secundiiren hypothallinischen Anhangsgebilden (Wurzelhaaren) ihre Entstehung verdanken, umsomehr als eine alte Beobachtung Schärer's das Hervorsprossen junger Thallusanfänge aus unzweifelhaften hypothallinischen Anhängen, nämlich den Rhizinen von Gyrophora vellea, nachgewiesen hat (vergl. Schärer, Enum. p. XVII). Unentschieden nuss es bleiben, inwieweit der oben erwähnte fädige Saum vieler Krustenflechten (Lecid. geographica) dem hier in Rede stehenden Prothallus oder dem Thallusrande, und die einzelne Areole der Kruste etwa einem ganzen Peltigera-Thallus entspricht.

Dass die Apothecien die Fructification in dem Seite 202 bezeichneten Sinne darstellen, ist selbstverstindlich. Dass die Asci und Sporen ungeschlechtliche Fortpflanzungsorgane sind, ist nach $\Lambda$ nalogie der Ascomyceten anzunehmen, und die vorliegenden Thatsachen sprechen nicht dagegen. Ob und wo eine geschlechtliche Zeugung stallfindet ist zweifelhaft und Andeutungen dafür höchstens von den Pilzen zu entnehmen. Insbesondere ist es unklar, in welcher Beziehung zu der Entwickelung die Spermogonien und Spermatien stehen, die Zweifel und Fragen sind genau dieselben, wie bei den Pilzen, und den verschiedenen, des sicheren thatsïchlichen Bodens enthehrenden Hypothesen, welche eine nothwendige und speciell eine geschlechtliche Beziehung zwischen Spermatien und Apothecien annehmen, steht schon die eine Erfahrung entgegen, dass bei der überall reich fruetificirenden Solorina saccata noch nie Spermogonien gefunden worden sind.

Was die Soredien betrifft, so sind dieselben unzweifelhaft Multiplicationsorgane, und, wie ihr öfteres Fehlen anzeigt, keine nothwendigen Glieder des 
Entwichelungsprocesses. Den Pycniden kommt, den mitgetheilten Thatsachen zufolge, rine wohl sehr untergeordnete Bedeutung zu.

Eine Anzahl von Beobachtungen und Meinungen liegt vor, nach welchen der Entwirkelungskreis der - oder vieler - Flechten mit der Bildung der bisher genannten und allgemein anerkannten Organe nicht abgeschlossen ware. Die Angaben sind von sehr ungleichen Werthe, je nachdem sie sich auf die typischen hetromeren Lichenen, die Gallertflechten und die Graphideen bezichen, und daher nach diesen drei Gruppen zu sondern.

Was die erstgenannten, mit chlorophyllgrünen Gonidien versehenen Formen betrifft, so wurde schon durch Haller, Gleditsch und Andere die Meinung oder Vormuthung ausgesprochen, dass die grünen Leberzüge auf Baumrinden und dergleichen, welche gegenwirtig zu den Palmellaceen gerechnet worden (zumal Prolococcus vulgaris $\mathrm{Kg}$. = Pleurococcus vulgaris Mengh., Chlorococeum Grev, Lepraria botryoides, viridis Auct.), und welche aus freien oder familienweise verbundenen, isodiametrischen, grinen Zellen bestehen, Rudimente von Flechten seien.') Einen bestimmteren Ausdruck gaben dieser Ansicht Wallroth (I. e.) und Fries (Lich. Eur. XX), indem sie jene grimen Zellen als freigewordene, für sich vegetirende Flechtengonidien betrachteten. Spiitere, wie Körber, Küitzing Linnaea 1833, Phyc. gen. 167) traten dieser Ansicht im Wesentlichen bei, Kutzing wenigstens insofern, als er die Entwichelung von Lichenenthalli aus den grünen Zellen behauptel. Nenerdings hat sich Diesen besonder's llicks angeschlossen Microse. Journ., Ser. I, Vol. VIII, 1. 2.39; auch New Series, Vol. 1, p. 157).

Die iilteren Autoren mochten mit ihrer Jeinung lheilweise Recht haben, insofem sie von Soredien gehildete grüue Ueberzige sahen und jene mit ihren optischen Itülfsmitteh nicht sicher von den Palmellaceen unterscheiden honnten. Gergenwitrlig steht die Sache aber anders. Lisst nan die Soredien bei Seite, so sind die Bestandtheile der grünen Ueberzige, insonderheit der Pleurococeus vulgaris, den Gonidien zwar durch die Beschaffenheit ihrer Membran und ihres griinen lnhaltes ithnlich, aber unzweifelhaft verschieden sowohl der Gestalt als besonders der Theilung nach: die Zellen von Pleurocoecus theilen sich abwechsehnd nach drei Richtungen so, dass die Scheidewinde der successiven Generationen einander meist rechlwinkelig schneiden, die in benachbarten Schwesterzellen aber parallel sind, daher die Anordnung der Zellen zu quadratischen oder eubischen (nicht tetracdrischen) Gruppen. Ferner liefern die genauen neuren Untersuchungen (Schwendener) kein Beispiel dafuir, dass Gonidien anders als innerhalb der Soredien aus dem Thallus frei werden. Auch Hicks ist weit entfernt, diese Einwiufe zu beseitigen oder auch nur genügend zu berüksichtigen. Die in Rede stehende Ansicht ist daher als unerwiosen und die griunen Palmellaceen als autonome Organismen zu betrachten, wenn auch nicht verschwiegen werden darf, dass die unten zu rrwihnenden Beobachtungen an anderen Lichenen die dereinstige Auffindung wirklich freiwerdender, selbstiundig vegetirender grüner Gonidien nicht unmöglich erscheinen lassen.

Noch weniger stichhaltig als die besprochene ist die von Sachs (Bot. Ztg. 185:, p. 6) früher geausserte, ron Hicks neuerdings (1. ( New Series I, 1) 15) wieder aufgenommene Meinung, nach welcher Gloeocapsa-Formen die frei vege-

1) Vgl. Wallroth, Naturg. d. Fl. I, 309.

Handbuch d. physiol. Botanik. 11 . 
tirenden Gonidien von Cladonien sein sollen. Zwischen letzteren und den Gloeocapsen besteht nicht einmal eine grosse Aehnlichkeit. Wenn diese zuweilen den oberflächlichen Rindenhyphen aufsitzen, so erklärt sich dies leicht aus einem geselligen Vorkommen von Cladonia und Gloeocapsa; dass letztereaber als eine besondere zweite Art Gonidien von den genannten Hyphen abgeschnürt werden, dafür liegt keine irgend sichere Beobachtung vor.

Von den Gallertflechten sind zunächst die mit Gonidienschnüren versehenen, die Collemen und ihre nächsten Verwandten, Gegenstand hierher gehöriger Discussionen gewesen. Cassini sprach schon im Jahre 1817 die Vermuthung aus, dic unter den Algen aufgezählten Formen von Nostoc möchten nichts anderes als Zustände von Collemen sein (Opusc. phytolog. II, p. 361), und führt eine ähnliche Vermuthung Ventenat's aus viel früherer Zeit an. Seitdem wurde überall auf die Aehnlichkeit und auf eine mögliche Verwandtschaft beider Formenreihen aufmerksam gemacht. Itzigsohn (Bot. Ztg. 1854, p. 521), Hicks (1. c. p. 90) haben genetische Beziehungen zwischen beiden behauptet; Bayrhoffer (Bot. Ztg. 1857, p. 157) hat Wallroth's Ansicht, nach welcher Nostoc commune geradezu unter die Flechten gestellt wird, von neuem zu erweisen gesucht. Am klarsten hat Sachs seine Ansicht über das Zusammengehören von Nostoc commune Vauch. und » Collema pulposum ( ausgesprochen (Bot. Ztg. 185̋, 1). Nach ihm entsteht aus den Gonidien von Collema allmählich ein Geflecht von Gonidienschnüren, welches einer aussen scharf abgegrenzten Gallerte eingebettet, mit anderen Worten ein Körper, wie er für die Algengattung Nostoc characteristisch ist. Je nach äusseren Umständen vergrössert sich dieser Körper entweder ohne Structurver:inderung und wird zu dem unregelmaissigen Lager von Nostoc commune; oder es wachsen einzelne Zellen der Gonidienschniire zu den für Collema characteristischen Hyphen aus, diese flechten sich mehr und mehr zwischen die Schnüre ein, und es entsteht hierdurch der später fructificirende Collemathallus. Es ist nun zwar schon oben gesagt worden, dass der soeben erwahnte genetische Zusammenhang der Hyphen mit den Gonidien zweifelhaft ist. Aber selbst wenn es ausgemacht wäre, dass ein solcher Zusammenhang nie besteht, würde die begründete Vermuthung einer genetischen Bezichung zwischen den Collema- und Nostoc-Formen bestehen bleiben miissen. Die Gründe hierfür sind folgende. Die Gonidienschnüre der Collemen sind den Nostocschnüren nicht ähnlich, sondern in allen wesentlichen Puncten gleich, und für die ungebende Gallerte gilt dasselbe. Denkt man sich die Hyphen aus einem Collema entfernt, so bleibt die Gestalt des Thallus allerdings eine von Nostoc verschiedene, ein Structurunterschied besteht aber nicht mehr, oft selbst nicht mehr in dem Grade, wie zwischen den einzelnen Formen oder Species von Nostoc. Zweitens findet man hiufig auf unzweifelhaftem Collementhallus neben dessen kugeligen, soredienartigen Sprossen einzelne Gonidienschnüre oder Convolute solcher in scharf umschriebenen Gallerthullen, ohne Hyphen; dieselben sind jungen Nostocexemplaren in jeder Hinsicht gleich, und ich glaube mich nicht getiiuscht zu haben in der Beobachtung, dass sie sich wirklich aus dem Collemathallus loslösen. Drittens ermangeln alle die zahlreichen bisher untersuchten Nostoc-Formen einer eigentlichen Fructification. Die in Thuret's schöner Arbeit ${ }^{1}$ ) beschriebene Bildung junger Exemplare aus den

1) Observations sur la réproduction de quelques Nostochacées. Mém. soc. imp. hist. nat. Cherbourg, Tom. V (1857). Vgl. Flora. 1863, p. 556. 
alten kann füglich nur als eine Propagation, als eine Art von Brutknospenbildung betrachtet werden.

Bei den Gallertflechten mit nicht gereihten Gonidien, wie Synalissa, Omphalaria u. s. f. finclet man zwar oft auf der Thallusoberfläche anscheinend losgelöste, von Hyphen freie Gonidiengruppen, welche mit Chroococcaceen, zumal Gloeocapsen, die grösste Aehnlichkeit haben (vgl. Bornet, Mém. soc. Cherbourg, IV, 231). Die Untersuchungen über diese Körper sind jedoch noch nicht ausgedehnt und eingehend genug, um ihre Identitiat mit den Gonidien ausser Zweifel zu setzen.

Unzweifelhaft besteht dagegen ein genetischer Zusammenhang zwischen Ephebe und Verwandten und gewissen Nostocaceen. Denkt man sich die Hyphen entfernt, so stellt der Thallus von Ephebe pubescens, Spilonema, zumal die diinnen Aeste, typische Formen der Gattung Sirosiphon dar, wie schon Hepp's und Stitzenberger's oben erwähnte Ansichten uber Ephebe andeuten. Aechte, unzweifelhafte Sirosiphon-Lxemplare kommen in dem Rasen genannter Flechten sehr oft vor, und es gelingt manchmal, zu beobachten, dass sie von den EphebeFialen als Zweige entspringen. Ich habe ein (mit Kali deutlich gemachtes) Prïiparat, in dem ein aus 32 Gliedern bestehender Sirosiphon-Faden mit vielen Seitenzweigen von einem starken Ephebetrieb entspringt; und dass er diesem nicht blos anhaftet, sondern ein ichter Ast ist, geht an sichersten daraus hervor, dass aus dem Haupttriebe einige llyphen in ihn eintreten und bis zum vierten Gliede reichen.

Nach allen diesen Daten ist es wohl nicht zu bezweifeln, dass ein grosser Theil der Nostocacen und Chroococeaceen zu den Gallertflechten, Ephebe u. s. f. in naher genetischer Bezichung steht. In weleher? das bleibt zu untersuchen. Dirf ich meine subjective Meinung, deren ausführlicho Motivirung zu weil führen wiirde, hier kurz andeuten, so scheinen nir zwei Vermuthungen berechtigt zu sein : Entweder sind die in Rode stehenden Lichenen die vollkommen entwickelten, fiructificirenden Zustande von Gewachsen, deren unvollstindig entwickelte Formen als Nostocaceen, Chroococeaceen bisher unter den Algen standen. Oder die Nostocaceen und Chroococeaceen sind typische Algen; sie nehmen die Form der Collemen, Epheben u. s. f. an, dadurch, dass gewisse parasitische Ascomyceten in sie eindringen, ihr Mycelium in dem fortwachsenden Thallus ausbreiten und an dessen phycochromhaltige Zellen öfters befestigen (Plectopsora, Omphalarieen). In letzterem Falle wiirden die in Rede stehenden Gewaichse Pseudolichenen scin, vergleichbar den durch Schmarotzerpilze gleichsam ungeformten Phanerogamen, wie Euphorbia degener u. a. m. -

Schliesslich sind hier cinge benerkenswerthe Thatsachen von den Graphideen-Gonidien zu crwïhnen. Bei den hypophlöedischen Arten, wie Op. varia, werden, wie oben erwihnt, mil der Abstossung der oberflächlichen Periderınalagen Gonidienketten sammt den sie umspinnenden Hyphen frei. Auf dem Thallus genannter Flechten, und noch mohr in seinem Umkreis, aber auch an entfernteren Orten, finclet man h:̈ufig massenhafte Anhäufungen solcher Gonidienketten, rothbraune oder grünlichbraune pulverige Ueberzüge auf den Rinden verschicdener Bäume bildend. Dieselben sind unter dem Namen Chroolepus umbrinum Kg., Protococcus crustaceus Kg. allgemein bekannt (Kützing, Spec. alg., p. 203, 497), ein Unterschied zwischen dieser » $\Lambda$ gge « und den in Thallus be- 
findlichen Gonidien ist nicht vorhanden, ausser dass die freien Gonidien in der Regel (aber nichts weniger als durchgehends) etwas derbwandiger und runder sind. Auch die Hyphen finden sich an den Zellen des Protococcus, sie sind ron Kützing, Caspary gesehen, wenn auch nicht richtig gedeutet worden. Von welcher Species der Pr. crustaceus abstammt, ist bei der grossen Aehnlichkeit der Gonidien verschiedener Graphideen nicht mit Sicherheit anzugeben, es sei denn, dass er sich unmittelbar auf dem Thallus befindet. Die von Hyphen umsponnenen Gonidienketten sind zunächst den Soredien an die Seite zu stellen, und daher hier nicht zu erwähnen. Es kommen aber auch Ketten oder einzelne losgelöste Glieder ohne umgebende Hyphen vor - also wirklich freie -Gonidien. Und wie schon v. Flotow, später Cohn, Stitzenberger und Caspary beobachtet haben, bilden sich in den Zellen des Protococcus crustaceus Schwärmsporen. Was aus diesen wird, ist noch unermittelt. Die Thatsache genügt aber, um zu zeigen, dass hier der Entwickelungsgang nicht auf die Bildung von Thallus, Apothecien und Spermogonien beschränkt ist. (Ueber Pr. crustaceus, seine Synonyma und seine Schwärmsporenbildung vgl. Wallroth, Naturg. I, 305, Kützing, Spec. alg., p. 203, 427; Phycol. gener., p. 169, 283; Cohn, in Hedwigia I, 1; Stizenberger, ibid. 78; Caspary, Flora, 18.58, Nr. 36. Taf. VI.)

Hypothesen über andere Chroolepus-Formen hier anknüpfen zu.wollen, wäre ubereilt. Wenn Massalongo (vgl. Flora, 185\%, p. 375) bei einer solchen Form besondere Apothecien fand und diese daher als neue Flechtengattung beschreibt, so dürfte dieselbe entweder etwas nicht hierher gehörendes oder ein von einem Parasiten bewohnter Chroolepus sein.

\section{Capitel 11.}

\section{Physiologische Processe in den Flechten.}

Von einer Physiologie der Flechten ist, ausser den Entwickelungserscheinungen, so gut wie nichts zu berichten. Man weiss, zumeist aus gelegentlichen Beobachtungen, dass die Flechten, sowohl Thallus als Apothecien, ein langsames Wachsthum besitzen und ein hohes Alter erreichen, und dass nur relativ wenige Arten hiervon Ausnahme zu machen scheinen. Eine Anzahl genauerer Untersuchungen und Messungen hierüber theilt Meyer (Flecht. p. 39) mit. Es ist bekannt, dass sehr viele Flechtenarten an ein bestimmtes Substrat gebunden sind, theils anorganisches, theils die Borke und Peridermalagen der Bäume oder bestimmter Baumspecies. Ueber die Ursache hiervon liegen höchstens Vermuthungen vor, von denen die einen die chemische, die andern die physikalische Beschaffenheit des. Substrates für massgebend halten. Wenn man ferner eine Menge Lichenen auf kahlem festem Gestein, manche selbst auf Glasscheiben, Eisenbahnschienen u. s. f. sich ansiedeln und gedeihen sieht, so liegt der Schluss nahe, dass dieselben nur anorganische Substanzen als Nahrung bedürfen, und im Hinblick auf die Cormophyten der weitere, dass die Gonidien die assimiliren- 
den Organe sein düıften, und der Assimilationsprocess ein ähnlicher wie bei der chlorophyllhaltigen Vegetation. An Untersuchungen hicruber fehlt es aber vollständig. Selbst daruber ist man nicht einig, ob die feucrbeständigen Bestandtheile der Lichenen aus dem Substrat stammen und stammen müssen, also von den Rhizinen und Wurzelhaaren aufgenommen werden, oder ob sie "aus der Luft«, d. h. aus den löslichen Mineralkörpern bezogen werden, die mit dem Staub auf den Thallus gelangen und von dessen ganzer Oberfläche mit dem Wasser aufgesogen werden können. Allerdings hat die erstere Ansicht grössere Wahrscheinlichkeit für sich, weil erstens die oben angeführten Aschenanalysen zeigen, dass die Menge der feuerfesten Bestandtheile und ihre quantitative $\mathrm{Zu}$ sammensetzung mit dem Substrat in hohem Grade wechseln, und weil zweitens die Haftorgane oder selbst der ganze Thallus tief in das härteste Gestein eindringen. Das Eindringen setzt ein theilweises Löslichmachen voraus, und es ist kaum denkbar, dass die löslichen Körper nicht aufgenommen werden, wenn sie mit den befeuchteten Membranen der Flechte in steter Berührung stehen. Die auf cin bestimmtes organisches Substrat angewiesenen Flechten bewohnen, soweit sicher bekannt, immer nur abgestorbene Theile. Welcherlei Nihrstoffe sie aus diesen aufnchmen, ob bestimmte organische Körper, ob nur anorganische Zersetzungsproducte und Mineralsubstanzen ist wiederum ungewiss.

Es ist cine allbekannte Thatsache, dass die auf anorganischem Boden wachsenden Fleehten die Verwitterung dieses in hohem Grade fördern, und dies auf dreierlei Weise: durch das Feuchthalten des Gesteins, durch die ohne Zweifel stattfindende Kohlensiiureausscheidum und dureh die rein mechanische Wirkung der eindringenden IIaftorgane. In dieser Urbarmachung des Bodens für die iibrige Vegetation beruht jedenfalls die hauptsichlichste Bedeutung der Flechten fuir den Naturhaushalt.

Veber die hier angedeuteten Puncte und Fragen sind zu vergleichen: die Seite 257 angefubrlen analytischen Irbeiten. Th. Fries, Vloth, I. c., v. Krempelhuber, in Flora 1861, p. 115; Denkschr. d. K. bot. Ges. zu Regenshurg, Bd. 1V, 2. Ibth., p. 8-69. Goppert, Flora, 1860, p. 161. Senfl, ibid., 1, 193. Eine Ihhandlung De Candolle's vom Jahre 1798 (Journ. de Phys. de Delaméllerie, Tom. IV), "Sur la nutrition des Lichens henne ich uur aus dem Citat bei Tulasne.

\section{Litteratur.}

Die Quellenlitleratur fü Morphologie und Physiologie der Flechten ist, ausser einzelnen im Texte citirten hleineren Arbeiten in folgenden Scluriften enthalten:

G. F. W. Me yer, Entwickelung, Metamorphose und Fortpflanzung der Flechten. Göttingen. 182 s.

E. Fries, Lichenographia Europaea reformata. Lundae. 1831. Einleitung.

J. R. Tulas ne, Mémoire pour servir à l'lnistoire organographique et physiologique des Lichens. Inn. Sc. nat. 3e Sér. Tom. XV'II, mit 16 Tafeln.

Speerschneider, Inatomie und Entwickelung der Hagenia ciliaris. Bot. Ztg. 1853, p. 705, 1834, p. 393 ; — der Usnea barbata dasypoga, iljid. 1854, p. 193; - der Parmelia Acetabulum, ibid. 1854, p. 481; _- der Ramalina calicaris, ihid. 1855, P. 345 ; — der Peltigera scutata, ibid. 1857, p. 521. 
S. Sehwendener, Ueber den Bau und das Wachsthum des Flechtenthallus. Vierteljahrsschrift d. naturf. Ges. Zürich, 1860 (citirt als Schw., Vortrag).

$1 \mathrm{dem}$, Untersuchungen über den Flechtenthallus. I. Strauchartige Flechten, mit 7 Taf. In Nägeli, Beitr. z. wiss. Bot. Heft $2(1860)$. II. Laubartige Flechten, mit 4 Taf. Ibid. Heft 3 (1862).

Idem, Ueber die Entwickelung der Apothecien von Coenogonium. Flora 1862, 224. Ueber Ephebe pubescens. Ibid. 1863, p. 240. Ueber die Apothecia primitus aperta u. d. Entwickelung der Apothecien im Allgemeinen. Ibid. 1864, p. 320.

Fuisting, De nonnullis Apothecii Lichenum evolvendi rationibus. Diss. inaugur. Berol. 1865. Eine vielversprechende, leider in sehr undeutlichem Latein geschriebene Arbeit. Ich konnte sie nur theilweise benutzen, da sie mir est beim Abschluss dieser Darstellung zukam.

Ferner sind anzufiihren:

Buhse, Ueber den Fruchtkörper der Flechten. Bull. soc. imp. des Naturalistes de Moscoll. Tom. XIX (1846), p. 318.

G. v. Holle, Zur Entwickelungsgesch. d. Borrera ciliaris. Göttg. 1849. (Diss. inaug.)

rerner die systematischen Werke, insonderheit die Einleitungen zu:

Nylander, Synopsis meth. Lichenum. Vol. I. Paris. 1858-60.

Th. M. Fries, Genera heterolichenum recognita. Upsala. 1861.

Reichhaltige Anführungen älterer Litteratur bei $\mathrm{T}$ ulas n e, l. c.

Körber, Grundriss d. Cryptogamenkunde, p. 39-91, 195-200.

W. La uder Lindsay, Popular history of British Lichens. London. 1836.

Die Flora des letzten Decenniuns enthält ein reiches Repertoriun der lichenologischen Litteratur.

\section{Eudlich nenne ich}

Fée, Essai sur les cryptogames des écorces exotiques officinales. 1. Strassbourg. 1824. Il. 1837 (Sporen, Asci).

Wallroth, Naturgeschichte der Flechten. 2 Bände. Frankfurt. 1823-27.

Körber, De gonidiis Lichenum. Diss. inaug. Berol. 1839. - Ueber die individuelle Fortpflanzung d. Flechten. Flora. 1841. Nr. 1 und 2.

Ba yrhoffer, Einiges über die Lichenen und deren Befruchtung. Bern. 1851.

Die vier letzgenannten . Irbeiten enthalten viele eigenthümliche, mit den jetzigen kenntnissen unverträgliche. Insichten. Wallroth's "Naturgeschichte " ist meines Erachtens, bei allem Verdienst, ein arger IJemmschuh für die Flechtenkunde gewesen. Bayrhoffer's reiche Beobachtungen sind leider dirch Verwirrung der auf Fortptlanzung und Befruchtung bezüglichen Begriffe ganz ungeniessbar. Man wird mir verzeihen, dass ich über die Ansichten genannter Autoren und andere veraltete Inschaungen im Texte geschwiegen habe, denn eine historische Darlegung und kiritik derselben würde wohl für sich einen ganzen Band beansprucht haben. 


\section{III. \\ My x o m yceten.}

Hierzu die Kupfertafel.)',

\section{Capitel 12.}

\section{Ban mud Entwickelung der Nyxomyceten.}

I. Sporenbehilter und Sporen.

Die reifen Sporenbehiblter stellen bei den meisten Mysomyceten runde, längliche, gestielte oder ungestictte, einen bis einige Millimeter grosse Blasen dar; seltener (\%. B. Didymium serpula, Trichia serpula) horizontal liegende, cylindrische oder platte, netzförmige Schliuche. Ich nenne diese Behiilter Sporangien, anstatt des friheren, an die Gastromyceten erinnernden Namens Peridien (Fig. 1, 2, 6).

Die Wand des Sporangimms wird von einer Membran gebildet, welche in ihrem Bau den pflanzlichen Cellulosehauten gleicht. Sie stellt entweder eine structurlose, hyaline, manchumal (z. B. Diachea, Physarum Spec.) ïberaus zarte Haut dar, oder ist diek, fest, deutlich geschichtet (\%. B. Leocarpus vernicosus, Craterium, Triehia varia u. a.), bei den in der alten Gattung Didernat vereinigten Physarum- und I)idymiumarten selbst doppelt, d. h. in zwei leicht von einander tremnbare und oft spontan sichtrennende Lagen gesondert. Warzen-und leistenförmige, vorspringende Verdickungen von verschiedener Michtigheit finden sich in einzelnen Fillen, z. B. auf der ganzen Oberfliche der derben, olivenbraunen Aussenschichte von Licea serpula Fr., auf der Innenfliche der Sporangiumbasis von Areyria incarnata, punicea, nutans. Bei Cribraria, Dictydium zeigt die ganze Membran auf der Innenfliche vorspringende, flach-leistenförmige, zu einem zierlichen Netz verbundene Verdickungen. Je nach Gattungen und Arten ist die Membran an sich farblos oder in verschiedenen Nüancen von Violett, Braun, Roth und Gell gefirbt.

Bei den stiellosen Formen breitet sich die Membran rings un die derbwandige Cirundfliche des Sporangiums zu einem dem Substrate fest anliegenden

1) Die Figureuder Tafel werden im Textedurch halbfette Schrift bezeichnet. 
scheibenförmigen Rande aus, der meist unregelmäissige Gestalt und runzelige Oberfläche besitzt. Wo die Sporangien gesellig bẹi einander stehen, sind die häutigen Ausbreitungen mehrerer oft in zusammenhängende Iliute vereinigt; so besonders bei den Trichien aus der Gruppe von Tr. chrysosperma.

Die Stiele sind (abgesehen von Stemonitis und Enerthenema) Röhren unit meist derber, der Lïnge nach gerunzelter und gefalteter Wand, welche sich oben in die des Sporenbehilters fortsetzt. Ihr Lumen steht mit dem des letzteren entweder in offener Communication (z. B. Trichia, Areyria) oder ist von diesen durch eine (oft nach oben convexe, und alsdann Columella, Mittelsiiule genannte) Querwand getrennt (Fig. 2, 6). Der Ilohlraum des Stieles ist, je nach den Arten, von verschiedener Weite und entweder leer, lufthaltig (z. B. Physarum hyalinum P.) oder in unten zu beschreibender Weise ausgefüllt. Die Basis des Stiels sitzt dem Substrat mit einer häutigen Ausbreitung auf, von welcher das über die häutigen Ausbreitungen der stiellosen Formen Gesagte gilt.

Bei den meist lebhaft gefirbten Formen, welche ich als Trichiaceen zusammengefasst habe Licea, Perichaena, Cribraria, Arcsria, Trichia u. s. f.) zeigt die Membran in der Regel nur die soeben beschriebenen Structurverhältnisse. Bei einigen derselben kommen gefärbte, aus organischer Substanz bestehende Körnchen hinzu, deren Beschaffenheit und Ursprung noch nïher zu untersuchen sind, und welehe bei Cribraria und Dietydium den starkeren Verdickungsleisten eingelagert, bei Licea pannorum Wallr. einzeln oder haufenweise der Aussenflïche aufgelagert sind. Die olivenlraune Aussenschicht ron Licea serpula Fr. zeigt ihrer ganzen Diche nach ein unregelnässig körniges Gefüge.

Die Sporangimmand der meisten Physareen ist dagegen mit kohlensa urem Kalke incrustirt, je nach den Genera und Arten ganz oder theilweise. Dieser tritt bei einer Reihe ron Gattungen, deren Repraisentant Physarum (Fig. 1, 3) ist, auf in Form kleiner runder Körnchen, welche theils vereinzelt der Membran ein-oder innen angelagert sind, theils dichte unregeluaissige Haufen auf deren Innenseite bilden. Bei vielen Arten sind die Kalkhörnchen, zumal die gehäuften, von einem in $\Lambda$ hohol löslichen gelben Pli. aureum P., Ph. sulphureum A. S. etc.), selten (Ph. psittacinum Ditm.) rothgelben Farbstoffe ungeben. Die Kalkhäufchen erscheinen in diesem Falle dem blossen Auge auf dem trockenen Sporangium als gefirbte, wo das Pigment fehlt, als weisse Fleckchen oder Wärzchen.

D) id y mitu (Fig. 6; 7) ist ausge\%eichnet durch einen hrystallinischen, aus sternförmigen Drusen und einzelnen kleinen Krystallen bestehenden reifartigen Ueberzug kohlensauren Kalkes auf der Aussenfliche der Sporangien. Die oben erwähnten, theils zu Physarum, theils zu Didymium gehörenden Didermen zeigen an ihrer Sporangienwand eine zarte, meist halkfreie innere, und eine äussere Schicht, welche eine spröde Kalkhruste darsteltt und aus dicht gehiuften, runden oder kristallinischen Kalktheilehen bešteht, die durch cine geringe Menge organischer Substanz zusammengehalten werden. Letztere bleibt nach Auflösung des kalkes als eine zarte llaut zurüch.

Besonder's reichliche Mengen körnigen oder kṛ̣stallinischen kohlensauren Kalhes sind bei viclen halkführenden Formen der Basalwand stielloser Sporangrien, bei gestielten der Wand des Stiels eingelagert. Bei letzteren befindet sich auch in Innern des Stiels und der ron ilm sich erhebenden Columella oft eine grosse Quantititgenannten Körpers, der nicht selten mit unregelmaissigen Klum- 
pen organischer Substanz den Hohlraum grösstentheils ausfüllt (z. B. Didı̀mium leucopus, Diachea). .

Der Innenraum des Sporangiums wird entweder, wie bei Licea, Cribraria, ausschliesslich von den zahlreichen Sporen angefüllt; oder, bei den meisten Gattungen; befinden sich zwischen diesen Röhren Fasern verschiedener Form, das sogenannte Hargeflecht, Capillitium. Das Haargeflecht von Physarum und seinen nähsten Verwandten (Fig. 2,3) besteht aus zicmlich dünnwandigen Röhren, welche nach allen Seiten hin verzweigt, netzförmig verbunden und ohne alle Querwainde sind. Zahleeiche Zweige gehen von der Peripherie des Röhrennetzes zur Wand und sind dieser, meist mit trichterförmig erweiterten Enden, fest angewachsen. An den Knoten des Notzes sind die Röhren blasig aufgetricben (Kalkblasen) mit Anhiufungen von Kalkkörnern erfüllt, welche die gleiche Beschaffenheit wie auf der Wand zeigen und bei den gefirbten Aiten wie auf letzterer von Pigment umgeben sind. Alle Physareen haben ein in der beschrichenen Weise mittelst seiner Zweigenden der Wand allenthalben fest angewachsenes Capillitiumnetz. Bei Did y mi um (Fig. 6, 7), welcher Gattung sich Spumaria, Diachea nahe anschliessen, besteht dies aus Fasern, die sehr schmal (Breite 1/75s Mm. bis 1/490 Mm. bei D. nigripes, leucopus, bis 1/380 Mm. bei D. firrinaceum), eylindrisch oder wenig abgeplattet, solide oder mit einer einfachen axilen Lingslinie als Andeulung eines Hohlraums, und weniggstens an den breiteren Stellen meist schmutzig violetthraun gefirbt sind. Die Fasern sind ganz kalkfrei; bej einer Art (I). phỵsaroides schliessen sie einzelne echige Kalkdrusen oder Krystalle ein. Sie laufen bei Didỵmium der Mehrzahl nach gerade oder wellig von unten nach oben, oder radienartig von, der Stielinsertion zur oberen und seitlichen Wand, ihre Anastomosen sind meist spitzwinkelig. Did. serpulat ist ausgezeichnet dadurch, dass den Catpillitiunfasern zahlreiche runde, mil gelloem Farbstoffe erfuille Blasen (Pigmenthebilter) anliaften, wolche, den Sporen älnlich, mit violettbrauner Membran versehen, aber vier- his serelismal grosser sind als diese (1)urehmesser bis $1 / 20$ MIII.).

Bei den mit Capillitiun versehenen Trichiaceen (Areyria, Trichia, besteht dieses aus röhrigen, Faseru, welehe nie kislkablagerungen fiilnen und der Sporangeiumwand entweder gar nicht odernuran einzelnen bestimmten P'uncten angewachsen sind. Bei Areyria Fig. 100 , ist es gleichsam eine in unzihlige net\%-

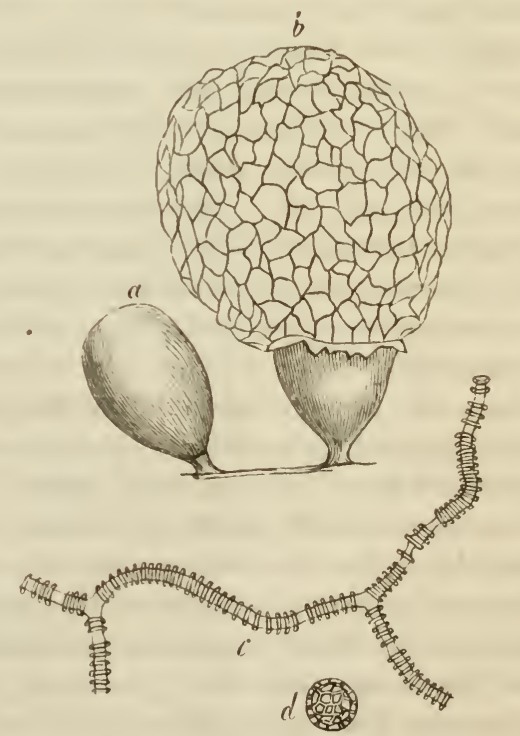

Fig. 100 .

förmig anastomosirende Zweigge getheilte Röhre, es besteht aus hohlen, cylindri-

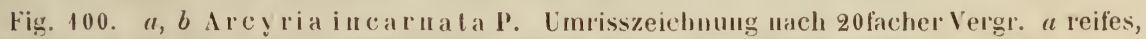
geschlossenes sporangium, $b$ geoffinetes, mit ausgedehntem Capillitiumnelz. - $c$. $d$ Are. serpula Wigcl. (A. anomala dBy.), $c$ stuck Capillitium, $d$ spore, 390 fach vergr. 
schen oder zusammengedrickten Fasern, welche nach allen Richtungen hin reich verzweigt und netzförmig verbunden sind ohne jegliche Querwand. Die derbe, homogene Wand der Röhren hat die gleiche Farlue wie die Sporangiummembran und ist meistens auf ihrer Aussenfliche mit rorspringenden Verdickungen versehen, welche, je nach den Arten, die Gestalt von Stachelchen, Wärzchen oder querlaufenden ring-oder halbringförmigen Leisten haben. Bei Are. punicea, cinerea ist das Capillitium befestigt mittelst blind endigender Zweige des Röhrennetzes, welche dem Grunde der Sporangium wandangewachsen sind. Bei den meisten Arten (z. B. A. incarnata, nutans) steht es mit letzterer nirgends in Berührung, es ist lose befestigt durch rinige in den Sticl hinabsteigende und zwischen die unten zu beschreibenden Zellen, welche diesen ausfüllen, cingeklemmte Röhrenaste. So lange das Capillitium in dem Sporenbehälter eingeschlossen ist, sind seine sämmtlichen Aeste in vielen Krümmungen hin und her gebogen, die vier-, liunf- und mehrseitigen Maschen eng und unregelmaissig. Wenn das Sporangium sich nach der Reife öfnet, strecken sich bei den meisten Arten (A. cinerea ausgenommen), die Röhren mehr gerade, die Maschen werden hierdurch erweitert und der-Umfang des Netzes 1 m ein Vielfaches vergrössert (Fig. 100,a,b); ein auch nur annäherndes Zurückkehren zu der urspriunglichen Form findet nie mehr statt.

Die vielbeschricbenen Capillitiumröhren von Trichia sind nur bei einzelnen Arten (Tr. rubiformis P., clavata P., serpula P.) zu einem Netze verbunden, das zugleich vicle frei endigende Zweige zeiğt. Bei den meisten (Fig. 101) sind sie ganz frei, einfach oder mit einzelnen kurzen Zweigen versehen, die Enden in der Regel spitz, bei manchen Arten (z. B. Trichia fallax) sehr fein ausgezogen, selten stumpf. Die Lainge der freien Röhren schwankt (bei durchschnittlicher Dicke ron $1 / 17$ Mm. bis $1 / 133 \mathrm{Mm}$.) meist $\%$ wischen $1 / 3 \mathrm{Mm}$. und $7 \mathrm{Mm}$, lingere und viel kürere kommen hie und da vor (Details siehe bei 1 ig̣and, Jahrl). für wiss. Bot., Bd. III). Ber Querschnitt der Röhren ist meist kreisrund. Ihr Inhalt erscheint wasserhell, doch zeigt sich nach Einwirkung von Kali oft rin aus tribber, durch lod gell) werdender Substanz bestehender axiler Strang, ein Ueberbleibsel des Inhalts der jungen Röhren. I)ie Membran ist derb. nicht deutlich geschichtet, je nach den Arten in rerschiedenom Grade biegsam und in verschiedenen Nïaneen von Gelb, Roth, Rothbraun gefirbt. Auf ihrer $\Lambda$ ussenseite zeigl sie bei allen Arten leistenförmige Vorsprúnge oder Verdichungen, welche spiralig um die Röhre rerlaufen und öfters wie Falten der Membran erscheinen Tr. varia, rubiformis. indem das Lumen der Röhre in ihrem Verlaufe erweitert, in den Interstitien eingeschnürt ist.

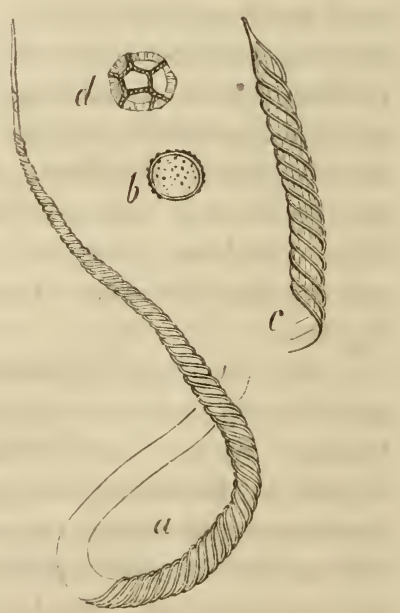

Fig. 101 .

Die Windungrsrichtung ist - mit seltenen mir nur bei $\mathrm{Tr}$. varia vereinzeit

Fig. 101. « Hälfte einer Capillitiumröhre, $b$ spore (Oberflachenansicht) von Trichia fallax Fr.; $c$ Ende einer Capillitiumröhre, $d$ Spore von Tr. chrysosperma (DC. DBy.) Vergr. 390. 
vorgekommenen) Ausnahmen - rechts (im Simne A. Braun's, d. h. die Windungen steigen auf der dem Bcobachter zugekehrten Seite von rechts nach links in die Höhe). Die Zahl der Spiralleisten wechselt je nach den Arten zwischen 2 (z. B. Tr. varia) und 3- 3 (ะ. B. Tr. fallax, chrysosperma). Schwankungen der Zahl an derselben Röhre kommen theils durch Gabelıng der Leisten, theils dadurch zu Stande, dass einzelne dieser das Ende der Röhre nicht erreichen. Bei manchen Arten (z. B. Tr. rubiformis) ist der Rücken der Leiste mit stachelförmigen Fortsaitzen besetzt. Trichia chrysosperma hat zwischen den Spiralleisten zahlreiche feine, der Liingsachse der Röhre parallele Leistchen, welche je zwei Spiralleisten leiterartig verbinden (Fig. 101, c). Bei einer verwandten Form fand Wigand Leistchen, die sich mit den Spiralen rechtwinkelig kreuzen, bei den übrigen Arten sind die Interstitien zwischen letzteren glatt.

In dem Sporangium liegen die Röhren des Capillitiums in grosser Zahl und in vielen Krummungen durcheinander gewirrt. Beim Austrocknen (oder Wasserentziehung durch Alkohol) strecken sie sich mehr, jedoch nic völligg gerade, um bei erneuerter Befeuchtung wieder stitikere krummungen anzunehmen, und die gleichen Erscheinungen wiederholen sich bei jedem Wechsel der Bofouchtung. Sowohl dic hygroskopische Beweglichkeit als die Spiralleisten erimnern an die Elateren der Lebermoosfrüchte, obg̣leich diese allerelings bei genauerer Betrachtung von den Trichiarohren sehr verschieden sind. Letztere sind daher gleichfalls Elateren genannt worlen.

Die Sporangexion der Stemonitern (Stemonitis, Enerthenema) sind, abgesehen von ihree Entwickelung, auch im reifen Zustande dureh einige Eigenthümlichkeiten von den ïbrigen ausgereichnel. Sie werden bei simmtlichen unzweifelhaften Aiten von cinem hatr-bis borstendicken, nach oben allmählich verschmälerten Sticle getragen, welcher in die Basis des Sporangiums eintritt und, als Mittelsiiule (Columella), durch die Liingsachse desselhen verliuft; entweder bis in den Scheitel, wo er sich bei Enerthenema und Stemonitis pumila zu einer hibutigen, der Wand fest anliegenden Scheibe ausbreitet; oder unterhall, des Scheitels infhört, sich gleichsam in Capillitimnfisern spaltet. Stiel und Columella sind röhrigghohl, dic IJöhlung enthïlt Luft und Kilumpen orgànischer Substan/. Die Wand ist dich, lingstunzelig und dunkel schwarzhraun, letzteres entweder in ihrer ganzen Diche oder so, dass die Aussenseite von einer farblosen Schicht uberzogen wird. Die Basis des Sticls breitet sich in cine unregelmässige häutige, dem Substrat aufsit\%ende Scheibe aus. Von der ganzen Aussenseite der Columella, oder, bei Enerthenema, nur von ihrer scheibenförmigen Endausbreitung entspringen mit breiter Basis dic Ilauptiste des schwarzbraunen Capillitiums. Diese sind nach allen Richtungen wiederholt verzweigl, die Zweige zu cinem ïberaus reichmaschiggen Netze verbunden. Nur von den peripherischen Maschen des letzteren gohen zahlreiche feine Aeste ab, welehe sich mit freien Enden der Sporangiumwand ansetzen. Der Bau der stirheren Capillitiumzweige gleicht dem der Columella, ihr Lumen steht aber mit dem dieser nicht in Communication; die feineren sind denen von Didỵmium und Diachea ahnlich. Die Sporangiumwand ist eine einfache, meist sehr zarte Membran, und gleich allen iibrigen Theilen frei von Kalkablagerungen.

Bei einigen Myxomycetengattungen sind die reifen Sporenbehiblter von conplicirterer Structur als die beschriebenen Sporangien. Ich unterscheide die- 
selben, zumal auf Grund ihrer im IV. Abschnitt zu beschreibenden Bildungsgeschichte von letzteren als Fru chtkölper.

Die Fruchtkörjer von $\Lambda$ ethalium, die bekannte sogenannte Lohblüthe, sind polsterförmige oder platte kuchen von verschiedener form; sie werden zollbis fast fussbreit, einige Linien bis ïber 1 Zoll dick, und sitzen dem Substrat mit ebener oder demselben wenigstens fest anliegender Grundfläche auf. Der ganze Körper ist ron einer einige Millimeter dicken, spröden Rin de umgeben, welche anfangs goldgelb, spitter blass oder zimnetfarbig ist und sich rings um den Rand in eine den Substrat aufliegende hiutige Ausbreitung fortsetzt. Die Rinde umgibt eine schwarzgraue, fein gell gesprenkelte, leicht zu Pulver zerfallende Masse. Genauere Untersuchung zeigt, dass letztere aus Röhren besteht, welche bis fast I Mnı. dick und nach allen Richtungen eng mit einander verflochten und netzförmig verbunden sind, im Uebrigen genau die Structur, auch das Capillitium der Physarumsporangien besitzen. Die Rinde besteht aus dicht verflochtenen, unregelmässigen Strïngen, oder richtiger collabirten Röhren, welche innerhalb der zarten, eingesunkenen Membranen, ungeheure Mengen von Kalkkörnern, nebst ursprünglich gelhem Pigment enthalten, letzteres in der bei Physarum beschriebenen Vertheilung. Der Aethaliumkuchen ist somit im Wesentlichen ein Geflecht schlauchföruniger, von der kalkigen Rinde ungebener Physarum-Sporangien.

Achnlich wie Aethalium zu Physarum verhält sich Spumaria Fr. zu Didymium. Reticularia (wenigstens R. umbrina) scheint sich in ähnlicher Weise an Licea anzuschliessen, bedarf jedoch noch sehr der genaueren, zumal entwickelungsgeschichtlichen Untersuchung.

Einen durchaus eigenthümlichen Bau haben die erbsen-bis nussgrossen, runden und stiellosen Fruchtkörper von L yeogala epidendron Fr. Sie gleichen kleinen Lyeoperdaceen-Fruchttrigern. Thre Oberfliche wird von einer papierartigen Haut, li inde ("Peridiex), nungeben, welche aussen unregelmässig-warzig ist, und von deren Innenseite zahlreiche verworene Fasern (Capillitium) in den sporenerfïlten Raum des Körpers ragen. Die Rinde besteht aus zwei leicht - tremnbaren, durch eine Lage frinkörnigen Schleims von einander geschiedenen schichten. Die innere ist eine ron der Fläche gesehen röllig homogene oder fein punctirte, im Durchschnitt betrachtet deutlich geschichtete, etwa $1 / 130 \mathrm{Mm}$. dicke, hellbrame Membran. Die iussere, weit dickere Schicht besteht dagegen der Ilauptmasse nach aus einem unregelmaissig-mehrschichtigen Geflecht cylindrischer, röhrig hohler, istiger Fasern, deren Dicke meist 1/50 $\mathrm{Mm}$. bis 1/31 Mm. beträgt. Die Wand dieser ist (bis $1 / 100$ Mur.) dick, geschichtet, die äusseren Schichten homozen-gallertartig, die innerste fester und mil spaltenförmigen Tüpfeln oder netzförmiger Verdichung versehen. Zahlreiche Zwoige der Rindenfasern biegen gegen die innere Rindenhaut und treten, diese durchbolıend, als Capillitiumfasern in den Innenraum. Sie sind lier nur von der innersten getüpfelten oder netzförmig, manchmal auch ringförmig rerdickten Membranschicht bekleidet, die äusseren Schichten hören in der Innenrinde auf. I)ie erwähnten Membranverdickungen ragen nach a us sen vor, als verschieden hohe und breite, oft sehrflache, runzelartige Leisten. Die Capillitiumfasern sind of bandförmig zusammengedrïcht, reich verästelt und vielfach netzartig verbunden. Die auf der Oberfliche der Kinde befindlichen Warzen 
endlich sind derbwandige, ringsum geschlossene, mit dicht körnigem Inhalt erfüllte Blasen.

In sïmmtlichen Sporenbehältern der Myxomyceten wirl der vom Capillitium frei gelassene Raum durch die - meist in grosser Zahl vorhandenen - Sporen vollstiindig ausgefüllt. Alle Theile sind bis zur Reife von Wasser durchfeuchtet, mit der Reife verdunstet letzteres, die Wand des Sporenbehïlters trocknet ein, um sich zum Behufe der Sporenausstreuung in verschiedener Weise zu öffnen. Ihre Dehiscenz gesehieht meistens sehr unregehniassig: sie wird mit dem Austrocknen spröde und zerbricht bei der leisesten Berührung oder ganz spontan in Stuickchen. So bei fast allen Physareen, auch Aethalium, Spumaria, Stemonitis u. s. f. Bei den Cribrarien zerfallen die nicht verdickten Stellen der Menbran, die verdickten Leisten bleiben als zierliches Gitterwerk stehen. Die Rinde von Lyeogala, Reticularia reisst auf dem Scheitel unregehmissig (ob spontan?) ein. Bei Diderma floriforme spalted die iussere Sehicht der Sporangienwand rom Scheitel aus in sternförmig divergirende Lappen. Bei Trichia und Areyria wird die Dehiscenz und die Sporenausleerung jedenfalls durch die beim Austrocknen stattfindende Strecking des Capillitiums gefördert, bei ersterer Gattung überdies noch durch die hygroskopischen Bewegungen. Die Wand reisst hierbei entweder spontan ringförmig durch, im untersten (Are. punicea, cinerea) oder oberen (Trich. rubiformis) Theile des Sporangiums, oder sie öfnet sich in unregelmissigen Rissen (Fig. 100, a, b), sei es spontan, sei es nach leiser Verletzung. Für die Einzelheiten sind die unten anzuführende Litteratur und zumal die șstematischen Werke zu vergleichen.

Die reifen Sporen sind je nach den Arten verschicelen gross, ihr Durchmesser schwankt etwa $\%$ wischen $1 / 1 ; 2 \mathrm{Mm}$. (I, ycogala epidendron) und 1/64 Mm. (Trichia chrysosperma). Bei vielen Arten kommen zwischen den typischen oft einzelne abnorm grosse vor. Von Wasser durchdrungen haben sie immer rundliche Form, heim Eintrochnen sinhen sie oft zu concaver oder kahuförmiger Gestalt ein, vielen Pilzsporen gleich (val. Seite 133). Sie sind mit einer derben, ungeschichteten, selten (Trich. Callax, Didymium spec.) zweischichtigen Membran versehen, welche bei vielen Arten eine dimnere Stelle zeigt, die beim Keimen durehbrochen wird. Wenige Ausnahmen ahgerechnet (z. B. Areyr. cinerea) ist die Membran gleichmiassig gefirl)t: violett und violetthraun hei allen Physareen und Stemoniteen, gelb, roth u. s. w. bei anderen Formen. Die Farbe der Sporen gehört unzweifellaft bei allen leblaft gefirbten, und wahrscheinlich bei simmntlichen, ausschliesslich der Membran an. Die Aussenfliche letzterer ist je nach Arten und Genera glatt oder warzig-punctirt, oder mit netzförmigen Leisten versehen (vgl. Fig. $100, d, 101,3,7,8,9$ ).

Die Membran umschliesst einen dichten, homogen-triben Protoplasmakörper, in welchem ein, bei abnorm grossen Exemplaren manchmal жwei Zellkerne liegen: durchscheinende runde Körper mit kleinem centraleni Nucleolus. Ausserdem kommen zuweilen einzelne oder zahlreiche Oeltröpfehen oder Protoplasmakugeln ("Schleimklümpehenc) in dem Protoplasmakïıper vor (Fig. 7-9 .

Zellen, welche den Sporen durchaus ihnlich, nur meist grösser und unregelmäissig gestaltet sind, füllen bei manchen Trichien und Aregrien die ganze Höhlung des Stieles aus. Sie sind keimungsunfaihig.

Was die stoffliche Beschaffenheit der Membranen von Sporangien 
Capillitium und Sporen betrifft, so verhalten sich dieselben gegen Reagentien den incrustirten oder cuticularisirten pflanzlichen Cellulosehäuten im Allgemeinen ahnlich. Ihre Quellbarkeit in concentrirten Mineralsäuren und Alkalilösungen ist je nach dem Einzelfalle sehr verschieden. Die meisten Sporenmembranen zeigen in den genannten Flüssigkeiten kaum andere Veränderungen, als dass sie durchsichtiger werden; die violetten und braunvioletten der Physareen und Stemoniteen, sowie die Capillitiumfasern dieser Gruppen ändern durch Schwefelsäure ihre Farbe in blauviolett bis fast rein blau. Analysen der Membranen sind nicht vorhanden. Die blaue oder violette Iodfärbung der Cellulose tritt bei den meisten Membranen niemals ein. Ausnahmen hiervon fanden Wigand und ich bei Trichia furcata Wig., pyriformis und varia, wo die innersten Schichten junger Sporangienwände durch Iod und Schwefelsäure schmutzig blau werden; ferner bei den Membranen der Sporen und sporenähnlichen, den Stiel ausfüllenden Zellen von Arcyria cinerea, punicea, nutans, sowie den Sporen von Lycogala epidendron, deren Membranen sänmmtich durch lod und Schwefelsäure schöne blaue Farbe annehmen. Weitere Einzelheiten vergleiche man in Wigand's und meinen unten zu nennenden Arbeiten.

\section{H. Keimung der Sporen und Bildung der Plasmodien.}

Die Sporen haben bei den darauf untersuchten Arten von dem Augenblick der Reife an die Fihigkeit zu keimen und behalten dieselbe, wenigstens bei den Physareen, Licea pannorum, zwei bis drei, selbst vier (Physarum macrocarpun nach Hoffmann) Jahre lang, wenn sie trocken aufbewahrt werden. An sechs Jahre aufbewahrten sah ich keine Keimung eintreten. Trichia rubiformis, varia keimen noch 6 bis 7 Monate nach der Reife, später, soweit die Beobachtungen reichen, nicht mehr. Bei den meisten Trichiaceen scheint die Keimfähigkeit noch schneller zu erlöschen, zumal bei den typischen Liceen und Cibrarien, deren Keimung noch nie beobachtet wurde.

Die Keimung erfolgt bei der Frühlings - und Sommertemperatur unserer Gegenden, wenn die Sporen in Wasser kommen, sowohl auf dem Objecttriger des Mikroskops als auf den faulenden Pflanzenresten, welche die Schleimpilze im spontanen Zustand bewohnen. Ihre Anfänge wurden vielleicht schon 18 it von Berkeley gesehen, denn es ist nach den Abbildungen (Hooker's Journ. III.) kaum zweifelhaft, dass dessen Endodromia, in deren Sporen drehende Protoplasmabewegungen auftreten, einen Myxomyceten aus der Verwandtschaft von Stemonitis darstellt. Genauer bekannt wurden die Erscheinungen erst durch meine Arbeiten. Die Kcimung erfolgt bei den untersuchten Genera (Physarum, Aethalium, Leocarpus, Didymium, Stemonitis, Trichia, Arcyria, Licea pannorum, Reticularia, Lycogala) immer in wesentlich gleicher Weise. Einzelne Widersprüche und Zweifel hieruber sind durch ihre Urheber selbst beseitigt worden.

Die keimende Spore schwillt zunächst durch Wasseraufsaugung etwas an, in dem Protoplasma erscheinen nahe seiner Oberfliche eine oder zwei kleine, abwechselnd verschwindende und wiederauftretende Vacuolen, in dem Protoplasma beobachtet man oft drehende Bewregungen, endlich - meist 12 bis 24 Stunden 
nach der Aussaat - reisst die Membran auf, und der Protoplasmakörper quillt oder kriecht langsam aus der Oeffnung hervor (Fig. 9, 14); Unmittelbar nach dem Ausschliuplen nimmt der Körper Kugelgestalt an und bleibt ruhig vor der leeren Meinbran liegen. Bald, oft nach wenigen Minuten, treten auffallende Gestaltveranderungen ein. Der Umriss der Kugel beginnt sich undulirend zu bewegen und diese streckt sich, unter Austreiben und Wiedereinziehen spitzer Fortsiitzchen, zu einem länglichen Körper, welcher sich, den Schwairmsporen der Algen ähnlich, schaukelnd im Wasser fortbewegt und hiernach als Schwirmer bezeichnet wird.

Dieser (Fig. 11, 27 d) ist an seinem boi der Bewegung vorderen Ende fein zugespilzt und die Spitze in eine lange, undulirend hin und her schwingende Cilie (ausnahınsweise zwei Cilien) ausgezogen. Das hintere Ende ist gewöhnlich stumpf abgerundet und triggt nur in seltenen, als Monstrositaten zu betrachtenden Fällen ebenfalls eine Cilie. Die Structur des Schwämers ist eine iihnliche, wie vor dem Ausschlüpfen, nur dass die Körnchen des Proloplasmas in dem grösseren hinteren Theile des Schwärmers angesammelt sind, der vordere hörnerfrei ist. Der'Zellkern liegt in dem vorderen Theile. In dem Hinterende liegen eine bis drei Vacuolen, von denen mindestens cinc eine sogenannte contractile ist, d. h. binnen etwa einer Minute abwechselnd bis zum völligen Verschwinden kleiner wird, dann wieder auftritt und sich bis zu einem $1 / 3$ bis $1 / 2$ der Körperbreite betragenden Maximum ausdehnt.

Die körnigen Einschlüsse, Schleimklümp̧chen u. s. f. bleiben entweder in dem Schwirmer, oder sie werden vor dem Ausschliipfen anfgelöst oder ausgeschieden und in der Membran zurükgelassen. Eine Membran im eigentlichen Sinne des Wortes hat der Schwairmer nicht, wohl aber findet man ihn bei genauer Beobachtung von einer ziemlich breiten, schleimig-weichen, wasserhellen und nicht scharf umschriebenen II ii lle umgeben.

Die Bewegung des Schwirmers ist von zweierlei Art: cine hiipfende und eine kriechende. Bei ersterer schwimmt derselbe frei in dem Wasser, in der Rogel nit aufwäls gerichteten Vorderende. Er rotirt um seine Längsachse und zwar in dem Mantel eines Kegels, dessen Spitze vom Ilinterende gebildet wird. Die Cilie sehwingt wellig hin und her, wodurch eine schaukelnde Bewegung und und ein Fortricken nach einer Seite bewirkt wird. Die Rotation fehlt zuweilen. Gleichzeitig zeigt der Körper fortwahrend mannigfache wellige Bewegungen seiner Oberfliche, Krümmungen, Zusammenziehung und Wiederausstreckung.

Bei der kriechenden Bewegung (Fig. 14, 26) liegt der Schwirmer dem festen Substrat auf, entweder wurmförmig nach einer Seite fortrickend, die Cilie vorangestreckt; odler I'undliche (Festalt annehmend und wechsehnd nach allen Seiten hin Fortsitze austreibend und wieder einzichend, nach Art von Amöben. Die Cilie ist hicrbei oft völlig verschwunden, sie scheint eingezogen zu werden. Die kriechende Bewegung ist völlig derjenigen gleich, welche die frühere Protozoengattung Amocha charakterisirt. Die wechselnden Fortsatze entsprechen den sogenannten P'seudopodien dieser und mögen im Folgenden mit diesem Namen benamnt werden. Beide Arten der Bewegung, die kriechende und die hüpfende, gehen vielfach in rinander über und könmen nicht selten an demselhen Individuum mit cinander abwechselnd beobachtet werden (vgl. Fig. 27, b-d).

Viele, viclleicht alle Sehwirmer, vermehren sich durch Zweitheilung, und 
zwar, wie aus ihrer in manchen Aussaaten enor'm wachsenden Menge zu schliessen ist, mehrere Generationen hindurch. Vor der Theilung (Fig. 14) wird die Bewegung träger, der Schwärmer zieht sich zur Kugelform zusammen, Cilie, Vacuolen und Kern verschwinden. Hierauf erscheint in der Mitte eine ringförmige Einschnürung, welche rasch tiefer wird, um den Körper nach wenigen Minuten in zwei kugelige Hälften zu theilen. Diese nehmen sofort wiederum die Eigenschaften beweglicher Schwirmer an.

Bei Didymium Libertianum und D. praccox wurde, ungefähr ebenso häufig wie das oben beschriebene Ausschlüpfen, eine Theilung des Protoplasmas innerhalb der Sporenmembran, und somit ein Auskriechen von je zwei Schwirmern beobachtet (Fig. 10, 12, 13 ).

Die weitere Entwickelung der Schwirmer besteht darin, dass sie sich zu grösseren beweglichen Protoplasmakörpern, Plasmodien nach Cienkowski's Bezeichnung, vereinigen. Die hierbei stattfindenden Vorgänge hat Cienkowski bei Didymium leucopus, Libertianum und Licea pannorum auf dem Objectträger direct und lückenlos verfolgt. Eine Anzahl von mir mitgetheilter minder vollstaindiger Beobachtungen an Lycogala, Aethalium, Stemonitis, sowie die Aehnlichkeit aller fertigen Plasmodien_unter einander, begründen die Annahme eines in Wesentlichen gleichen Entwickelungsvorganges für alle Myxomyceten.

Die direct beohachteten Erscheinungen bei der Plasmodienentwickelung sind folgende. Aın zweiten, dritten Tage nach der Aussaat werden die Theilungen seltener, die Mehrzahl der Schwirmer geht in die kriechende, cilienlose Form über, viele sind etwas grösser als zu Anfang und enthalten einzelne grössere, stark lichthrechende Körnchen. Die Schwirmer treten nun zu zwei bis vielen in Gruppen dicht zusammen und wieder anseinander (Fig. 16-19 a), endlich sieht man je zwei bis drei in innige Berührung treten und mit einander zu ein em Körper, dem jungen Plasmodium verschmelzen (Fig. 18, 19, b). Dieses vergrössert sich, indem sich neue Schwämer seiner Oberfliche anlegen und mit ihm vereinigen. Das neugebildete Plasmodium ist durch betıäichtlichere Grösse von den cilienlosen Schwirmern unterschieden. Seine Bewegungen und Formveränderungen sind die gleichen wie bei diesen. Die Kerne und contractilen Vacuolen, welche an den Schwirmern bis zur Verschmelzung deutlich sind, verschwinden im Momente, wo letztere geschieht. Grössere, zahlreichere Vacuolen treten auf, und mit dem Wachsthum almählich die Körnerströmung und die festen Einschlüsse, welche in dem folgenden Abschnitt beschrieben werden sollen (Fig. 20 bis 22).

\section{II. D a s Plas mo diu m.}

Dic Plasmodien, deren erste Entstehung eben beschrieben wurde, sind jene schleimigen oder rahmartigen Körper, aus welchen, wie man seit Micheli und besonder's durch Fries' treffliche Darstellungen weiss, die Sporenbehälter aller Myomyceten entstehen, und welche diesen den Namen Schleimpilze verschafft haben.

Die fertigen Plasmodien treten in zweierlei Modificationen auf. Erstlich als 
verzweigte, netzförnig verbundene Adern (Mesentericae Fries, wegen ihres gekröseartigen Aussehens), welche sich auf der Oberfliche oder in grösseren Lücken des Substrats und auf jedem beliebigen feuchten Körper, auch dem Objectträger, ausbreiten können; zweitens in Form dünner, unscheinbarer, im Innern faulen Holzes vorkommender Stränge. Die erstere Forn ist vorzugsweise den Physareen, die andere den meisten übrigen Myxomyceten eigen.

Die Eigenschaften des lebenden Plasmodiums können, dem Gesagten zufolge, an den Mesentericae, z. B. Aethalium, Physarum, Didymium, am besten studirt werden. Wie schon angedeutet, stellen diese reich verzweigte Adernetze dar (Fig. 4), welche meist fächerförmig ausgebreitet und an dem einen, vo rderen Rande der Ausbreitung mit besonders zahlreichen Zweigen und Anastomosen versehen sind. Letztere sind in vielen Fällen breit und mit Ausnahme des iussersten Randes flach. Das Vorderende erhïlt hierdurch das Ansehen einer siebartig durchlöcherten Platte, welche mit wulstigem, gekerbtem Rande versehen und von den stäkeren Zweigen wie von angeschwollenen Venen durchzogen ist. Die Grösse dieser Körper ist nach Arten und Individuen verschieden. Bei Didym. leucopus, Libertianum sind sie oft mit blossem Auge kaum erkennbar, bei anderen, z. B. Didym. praecox, serpula, Leocarpus vernicosus, Diachea werden die Ausbreitungen zoll- und fussgross, die stirkeren Aeste bis 1 Millimeter dick. - Die meisten Plasmodien sind farblos, viele gelb (z. B. Aethal. septicum, Did. serpula) oder rothgelb (Plıys. psittacinum) gefirbt. Alle sind von weicher Consistenz, leicht zu einer formlosen Schmiere verstreichbar. Das Mikroskop lässt an dem Plasmodium zunächst einefarblose, homogen tribe Grundmasse unterscheiden, welche die Eigenschaften des Protoplas mas besitzt (Fig. 20-23). Diese ist an der Oberfliiche der starkeren Aeste oft deutlich dichter als in der Mitte, eine feste $\mathrm{R}$ andsch ich t bildend, welche in der Durchschnittsansicht oft einer Membran gleicht, jedoch nie von dem ibligen Protoplasma scharf trennbar ist und an demselben Puncte abwechselnd verschwinden und wieder deutlich werden kann. Im Innern der Grundsubstanz treten häufig Vacuolen auf, theils kleine, abwechselnd verschwindende und wiedererscheinende, theils grössere, stabile. Die Grundsubstanz ist ferner stets durchsiet von zahlreichen Körnern, deren Menge nach Arten wechselt. Diesellen sind theils kugelig, dunkel contourirt, gliinzend und aus kohlensaurem Kalk gebildet (Fig. 23); theils klein, auch bei starker Vergrösserung punctförnig und von unbestimmbarer stofflicher Beschaffenheit. Hie und da kommen einzelne grössere, dem Protoplasma anscheinend stofllich gleiche Kugeln vor. Der Farbstoff ist, wo er vorkommt, stets ein Begleiter der Körner, zumal der aus Kalk bestehenden. Er scheint theils einen dumnen Veberzug über diese zu bilden, theils kommt er vor in Form grösserer, zarter rundlicher oder unregehnässig gestalteter Körper, deren Mitte ein oder mehrere Kalkkörner eingelagert sind. Der Farbstoff ist in Alkohol löslich, wenigstens bei Aethalium und Didym. serpula.

Die auffallendste Esscheinung an dem Plasmodium ist seine stete, je nach Species und nach noch näher zu untersuchenden äusseren Bedingungen verschiedene, l e b haft e Bewegung. Dieselbe besteht theils in Ge sta l treraind erungen, theils in einem lebhaft strömenden Fortrücken der Körnermasse im Innern. Erstere sind an den stärkeren Aesten grösserer Formen schon mit blossem Auge oder der Lupe sichtbar. Mit dem Mikroskop erkennt man an 
den Zweigen jeglicher Ordnung einen continuirlichen Wechsel des Umrisses, theils in Form leichter welliger Bewegung, theils eines steten Austreibens und Wiedereinziehens kleiner spitzer tentakelartiger Fortsätzchen oder Pseudopodien, (Fig. 21, 23). Einzelne dieser, oder einzelne flache Vorragungen der Hauptäste schwellen zu kolbiger Forın und alsbald zu grösseren Zweigen an, während anderwärts Aeste kleiner werden und allmählich in den Hauptstamm zurückfliessen. Hier wachsen zwei Aeste gegen einander bis sie sich berühren und zu einer Anastomose verschmelzen; dort schnürt sich ein Ast irgendwo ein bis zur Trennung in zwei Stücke. Es ist klar, dass durch diese Vorgänge cin Plasmodium in mehrere getrennt und mehrere zu einem vereinigt werden können. Nach Cienkowski's und meinen Beobachtungen vereinigen sich jedoch niemals die Plasmodien verschiedener Species. Die Aeste jeden Grades und jeder Staike nehmen an den Bewegungen Theil, am lebhaftesten je kleiner sie sind. Der Wechsel der Bewegungen findet an allen Puncten des Plasmodiums statt, so jedoch, dass an dem vorderen Rande das Austreiben, an dem entgegengesetzten das Einziehen der Aeste vorwiegt. Daher ein oft lebhaftes Fortwandern des Plasmodiums nach der Scite des jeweiligen Vorderrandes, dessen Lage übrigens sclbst einem Wechsel unterworfen ist.

An der strömenden Bewegung nimmt oft, zumal in den farlenförmigen Zweigen, die ganze Masse des Plasmodiums Theil, mit Ausnahme der festeren Randschicht; die letztere umgibt eine von Körnern dicht durchsäete Masse, welche der Liinge des Zweiges nach fortzufliessen scheint. In anderen Fïllen ist die Peripherie strömungsfrei, einen entweder nur aus homogenem Protoplasma bestehenden oder vor ruhenden Körnern durehsieten Saum bildend, dessen Umriss sich wellig bewegt oder Pseudopodien treibt und einzieht. In den häutigen Ausbreitungen sieht man oft schmale Ströme das r'uhende Protoplasma durchziehen. Es hat alsdann oft den Anschein, als bewege sich eine körnerführende Fluissigkeit in festwandigen Canailen; allein man sieht nicht selten die strömende Masse die Beschaffenheit der ruhenden annehmen und umgekehrt in letzterer an beliebigen Puncten Strömungen beginnen, Ruhe und Bewegung also in der gleichen Substanz abwechseln. Die Richtung der einzelnen Ströme ist gleich den peripherischen Bewegungen einem steten Wechsel unterworfen. Doch beobachtet man immer, dass in die anschwellenden und vorrükenden Enden die Körnermasse vorzugsweise einströmt, die hiermit abwechselnte, riickliufige Bewegung schwiicher und von kürzerer Dauer ist; und dass das ungekehrte Verhältniss bei den Zweigen stattlindet, welche eingezogen werden. Für die Gestaltveränderungen im Grossen und die Fortbewegung des Plasmodiums ist daher das Strömen von vorwiegender Bedeutung.

Für die ausführlichere Beschreibung der wechselvollen Erscheinungen und die Erklärung der Protoplasmabewegungen muss hier auf die Monographien und Band I und IV dieses Handbuches verwiesen werden.

Die Oberfliche der Physareen-Plasmodien, welche ich untersucht habe, wird von einer schleimig-weichen, nach aussen nicht scharf abgegrenzten Hülle iiber\%ogen, welche von der Randschichte wohl zu unterscheiden ist. Sie bildet um die stirkeren Zwoige einen oft über 1/100 Mm. dicken Saum, welcher an sich farblos und glashell, sehr oft aber mit anklebenden Sehmutztheilchen bedeckt ist. Sie besteht aus einer klebrigen, in Wasser quellenden, in Alkohol schrumpfenden, 
durch Iod kaum gefärbten, also vom Protoplasma verschiedenen Substanz. Sie folgt den Bewegungen passiv. An den Orten, welche ein Plasmodium verlassen hat, bleiben von ihr oft Theile kleben, als diunne Schleimstreifchen. Um die rasch anschwellenden Zweigenden ist die Hülle oft sehr dünn, um die feinen Pseudopodien nicht nachweisbar, also entweder von diesen durchbohrt oder bis zur Unkenntlichkeit vorgetrieben.

Die Plasmodien der Stemoniteen, Trichiaceen und L y cogala haben in der Hauptsache jedenfalls die gleiche Structur und Beweglichkeit wie die Mesentericae der Physareen. Nur ermangeln sie inmer der Kalkkörnchen, erscheinen daher meistens viel feinkörniger als bei genannter Gruppe. Eine Ausnahme hiervon machen die schwarzblauen oder violettbraunen der Cribrarien und Dictydien, welche grosse braune, aus organischer Substanz bestehende Körnchen enthalten, übrigens noch sehr unvollstiindig untersucht sind. Die in faulem Ilolze lebenden Plasmodien von Lycogala sind, wie ich neuredings wiederum bestatigt fand, von einer derben, farblosen Membran umgeben: iihnliches beobachtete ich früher bei Arevria punicea. Wie sich diese Membran bei den Bewegungen verhialt, ist noch zu untersuchen; an in Wasser cultivirten Exemplaren von Lycogala konnte ich sie früher nicht wahrnehmen. Alle die letzterwihnten Plasmodien sind unseheinbare lörper, deren stirkere Leste bei Areyr. punicea nicht über 1/64 Mm., bei. Lyeogala nicht über $1 / 3$ s Mm. dick werden. Sie leben meist im Innern fauler Pflanzentheile, zumbl faulen Holzes und werden dem unbewaffineten Auge erst sichtbar, wenn sie zum Behuf der Fruchthildung an die Oberfliche treten.

Im Innern der Plasmodien, zumal der Phıssireen, beobachtet man sehr oft feste fremde Körper, Fragmente abgestorbener P'flanzenzellen, Sporen von Pilzen, Myxomyceten u. s. f., Stiirkekörner, Farbstoffstüchchen, wenn solche in die Nihe des Plasmodimms gebracht worden waren (Fig. 21, 22). Sie finden sich selion in den kleinsten, aus der Vereinigung cilienloser Sehwirmer entstandenen Exemplaren, deren Enterscheidung von den Schwairmern sie erleichtern. Die festen Körper werden durch bestimmte Bewegungen aufgenommen. Die Oberfliche des Plasmodiums erheht sich nimlich w ulstartig um den sie berührenden Körper, und die Wulstränder fliessen nach und nach über diesem zusammen. Es ist hiernach nicht anzunehmen, dass die fremden Körper hloss zufällig in das Plasmodium eindringen. Rings um den aufgenommenen Körper sammelt sich oft eine Schichte wiisseriger Flüssigheit, so dass derselbe in eine Vacuole zu liegen kommt, wie die Ingesta der Infusorien in die sogenannten Magenblasen. Ueber die Veranderungen, welche die aufgenommenen Körper im Innern des Plasnodiums etwa erleiden, liegt die eine sichere Beohachtung vor, dass bei J)idỵ. serpula Carmin aufgelöst wurde. Diese Species nahm genannten Farbstoff in Menge auf, wiihrend Did. Libertianum denselben kanm oder gar nicht schluckte und nie löste. Von den aufgenommenen festen Körpern werden, wie directe Beobachtung zeigt, wenigstens die grösseren - vor der Sporangienbildung - aus dem Plasmodium wieder ausgestossen. Alle diese Thatsachen deuten darauf hin, dass die festen Ingesta zum Zwecke der Ernährung gefressen werden. Beobachtungen an Did. Libertianum haben gozeigt, dass die Plasmodien auch ohne Verschmelzung mit anderen oder mit neuhinzukommenden Schwämerm bedeutend an Grösse zunehmen können. Inwieweit hierbei cine Vermehrung der festen Körper- 
substanz stattfindet, inwieweit solche auf Rechnung der festen Ingesta oder flüssiger Nahrung kommt, ist noch zu untersuchen.

\section{Entwi ckelung der $\mathrm{Sporenbehälter.}$}

Die Sporenbehälter der Myxomyceten entstehen unmittelbar aus den Plasmodien, und zwar in verschiedener Weise, je nachdem sie zu den oben bezeichneten Sporangien oder den Fruchtkörpern werden.

Die Sporangienentwickelung gliedert sich in den Process der Formung, die Bildung der Sporangiumwand, die Sonderung des Sporenplasma, die Ausbildung des Capillitiums und der Sporen.

Die Formung besteht darin, dass sich ein Plasmodium unter den beschriebenen Bewegungserscheinungen entweder zu einem zuletzt stabile Form annehmenden Sporangium zusammenzieht, oder sich in mehrere und viele, zu je einem Sporangium werdende Stücke trennt. Bei den flach auf dem Substrat sitzenden Sporangien, zumal den röhren - und netzförmigen, ist der Vorgang nicht wesentlich von den oben beschriebenen Gestaltveränderungen verschieden. Aufrechte, mit schmaler Basis ansitzende oder gestielte Sporangien beginnen als knotenförmige Anschwellungen, welche sich allmählich zu der definitiven Form erlieben, indem die Substanz des Plasmodiums oder seiner Stücke in sie einwandert (Fig. 4, 5). Bei den mit büschelig gehäuften Sporangien versehenen Arten (z. B. Stemonitis fasciculata P., Trichia rubiformis) ziehen sich die Plasmodien erst zu circumscripten, flachen, neist wulstig unebenen Körpern zusammen, von deren Oberfläche sich dann die Anlagen der Sporangien als Anschwellungen erheben. Bei den auf die Formung folgenden Vorgängen verhalten sich Stemonitis und Enerthenema abweichend von den übrigen Genera. Von letzteren soll zuerst die Rede sein.

Die Ilülle des Plasmodiums ungibt die Sporangiumanlage von Anfang an; ein Theil derselben bleibt meistens, collabirend und endlich vertrocknend, am Substrat haften. Der die Sporangiumanlage umgebende Theil nimmt allmählich die Structur und Festigkeit der fertigen Sporangiumwand an; bei den gestielten Formen beginnt das Festwerden an der Stielbasis und schreitet nach oben fort, die ersterhärteten Membranportionen dienen dem aufwärts wandernden Protoplasma als Stuitze.

Hat das Sporangium seine definitive Gestalt angenommen, so beginnt die Sonderung des Sporenplasma. Am auffallendsten tritt diese bei den Physareen hervor, deren Plasmodium Kalkkörnchen und Pigment enthält. Bei Physarum und den anderen Genera mit körnigen Kalkanhäufungen in dem reifen Sporangium lagern sich diese Theile theils der Wand ein und an, theils rücken sie zu verschieden gestalteten Massen zusammen, welche durch den Raum des Sporangiums zerstreut sind und den späteren Kalkblasen entsprechen. Bei Didymium und analogen Formen werden die in dem Plasmodium enthaltenen Kalkkörnchen gelöst und die Lösung aus denı Sporangium ausgeschieden, denn während die Körner im Innern verschwinden, erscheinen auf der Aussenflaiche die Krystalle. Bei Didym. serpula, der einzigen hierher gehörenden genauer bekannten Art 
unit gefirbten Plasmodien, ballt sich der gelbe Farbstoff zu rundlichen Massen zusarimen, den Anfängen der Pigmenthehälter. Die durch diese Processe von Kalk und Pigment, vielleicht auch noch ron den letzten Ueberbleibseln fester Ingesta befreite Hauptmasse des Protoplasma, welche ich Sporenplasma nenne, stellt eine farblose, gleichmissig feinkörnige, schleimige Substanz dar. Bei den kalkfreien Arten (Trichiaceen) wird die ganze Protoplasmamasse zum Sporenplasma; wenigstens sind die aus diesem ausgeschiedenen, vielleicht von festen Ingesten herrührenden klumpigen Massen, welche zumal im Stiele zurückbleiben, relativ unbedeutend.

Ein verhäiltnissmissig kleiner Theil des Sporenplasmas wird zur Bildung des Capillitiums, die Ilauptmasse zur Sporenbildung verwendet. Es treten in derselben Zellkerne in rasch wachsender Zahl auf, zuletzt theilt sich das Plasma simultan in sehr zahlreiche, rundliche Portionen, deren jede einen Zellkern einschliesst und, sich mit einer Membran umgebend, zur Spore heranreift. Die eben angelegten Sporen sind meist etwas grösser, jedenfalls nie kleiner als die reifen. - Die Bchamptung, dass die Sporen von dem Capillitium abgeschnürt werden, ist für alle Fiille unrichtigg; Angaben, welche sie zu mehreren in einer Mutterzelle entstehen lassen, haben nur fuir seltene, und theilweise abnorme Ausnahmsfiille Geltung (vgl. Mycetozoen, p. 72, und die Erklarung der Fig. 8).

Die Entwickelung des Capillitiums beginnt gleichzeitig mit den Auftreten der ersten Sporenkerne, oder vielleicht schon vorher; und zwar wird dasselbe in seiner ganzen $A$ usdehnung ungemein schnell angelegt. Die jüngsten sicher beobachtelen Zustinde desselben zeigen inmer schon alle Theile wie zur Zeit der Reife angeordnet, nur dass dieselben zunichst überaus zart sind und erst allmailılich ihre spïtre Derbheit, Membranverdickungen u. s. f. annehmen.

Die besonderen Eigenthünlichkeiten von Stemonitis, auf welche oben hingedeutet wurde, betreffen dic Bildung ron Stiel und Columella. Nach Beginn der Formung tritt in der noch mit breiter kreisrunder Fliche auf dem Substrat sitzenden Sporangiumanlage cine axile, hellhraune, hohleylindrische Mittelsiule auf, deren Basis sich in eine dem Substrat aufliegende IIaut ausbreitet. Die Mittelsiule verlangert sich durch Spitzenwachsthum und nimmt, von unten nach oben fortschreitend, allmihlich die im Abschnitt I. beschriebene Stielstructur an, während sich die umgebende Protoplasmamasse gleichzeitig streckt, und zunal an ihrer Basis derart verschmiilert, dass sie das Substrat zuletzt nur in einer dem Linfang der Mittelsiule entsprechenden Kreislinie beruhrt. Die Mittelsäule fiihrt auch jetzt fort, sich zu verlaingern, und der Protoplasmakörper ruickt, sie fest umfassend, an ihr in die Hibhe. Ihr unterer Theil wird hierdurch vom Protoplasma enthlösst, er stellt den Stiel dar. Je nach den Arten bleibt die Sporangiumwand $\mathrm{um}$ den Stiel erhalten, als ein Sack, innerhall (lessen das Protoplasma in die Höhe rïckt und dessen unterer, entleerter Theil den Stiel als eine runzelige Scheide umgiht (St. typhoides), oder die Wand löst sich mit dem Protoplasna von der Sticlbasis los und rückt mit jenem, ihm überall fest anliegend, in die Höhe. Oas obere Ende der Mittelsäule bleibt während dieser Bewegung eine Strecke weit ron dem Scheitel des Sporangiums entfernt. Ist der Stiel auf die fiir die Species characteristische Lainge entblösst, so steht die Bewegung still und innerhalb des Protoplasmas erfolgt nun sofort die Bildung des Capillitiums und der Sporen auf die oben beschriebene Weise. 
Bei Enerthenema (Stem. papillata P.) ist der Entwickelungsprocess dem beschriebenen ähnlich, die Mittelsäule erreicht aber in der Sporangiumanlage ihre volle Länge, ohne dass sich das Protoplasma von den Substrat ablöst. Sie erhält innerhalb jenes eine bogig gekrimmte Gestalt, ihr oberes Ende reicht bis zu der dem späteren Scheitel entsprechenden Stelle der Oberfläche. Zuletzt streckt sich die Säule gerade und hebt die sie umgebende Protoplasmamasse gleichsam in die Höhe; ihr unterer Theil wird hierdurch enthlösst und zum Stiele.

Die grossen, oben als Fruchtkörper bezeichneten Sporenbehälter entstehen dadurch, dass viele Plasmodien von allen Seiten her an eine Stelle wandern und sich zur Anlage des Körpers vereinigen. Dieser besteht anfangs aus einem überall gleichartigen Geflechte von Plasmodiumisten. Hat das Hinzutreten neuer Plasmodien sein Ende erreicht, so beginnt die Differenzirung der Theile. Bei Aethalium sondert sich das farblose, feinkörnige Sporenplasma von den Kalkkörnern und dem Pigment genau wie bei Physarum. Jenes wandert aus dén peripherischen Lagen des Geflechts vollstiandig in die hierdurch anschwellenden Aeste des Mitteltheils, und in diesen erfolgt Sporen-, Capillitium- und Wandbildung wie in den Physarum-Sporangien. In den peripherischen Lagen bleibt nur Kalk und Pigment innerhalb der Hüllen: diese collabiren daher zu der im I. Abschnitt beschriebenen kalkigen Rinde.

In welcher Weise bei Lycogala, Reticularia die Differenzirung erfolgt, ist noch nicht genau bekannt. Die Sporen entstehen hier überall auf die oben beschriebene Weise.

Die Entwickelung der Myxomyceten erfolgt, wie schon viele ältere Angaben zeigen, unter guinstigen Bedingungen sehr schnell.

Bei Aussaaten ron Didym. Libertianum auf den Objecttriger erhielt Cienkowski nach vier Tagen ausgebildete Plasmodien, die an fünften Tage Sporangien bildeten. Nach einer Anzahl von Beobachtungen an spontan entwickelten Plasmodien ist zu der Ausbildung der Sporenbehiilter, von dem ersten Beginn der Formung bis zur Reife ein Zeitraum von durchschnittlich etwa 12 Stunden erforderlich, schnellere oder langsamere Entwickelung findet theils bei einzelnen Arten, theils je nach Temperatur und Wassergehalt der L'mgebung statt.

Der reife Sporenbehäter ist zuerst überall von Wasser durchtrainkt, die Sporen durch zwischengelagerte dünne Wasserschichten verbunden. Nach vollendeter Reife erfolgt Verdunstung des Wassers, und hiermit die im I. Abschnitt beschriebene Dehiscenz und Verstäubung der Sporen.

\section{Ru he z u s t i n d e.}

Die beweglichen Entwickelungsglieder der Myxomyceten haben die Fähigkeit, in Ruhezustiande iiberzugehen, aus welchen sie, unter geeigneten Bedingungen, wiederum in den Zustand der Beweglichkeit zuriickkehren können. Man kennt zur Zeit drei Ruheformen: Mikrocysten, derbwandige Cysten (Cienkowski) und Sc lerotien.

Wie Culturen von Did. Libertianum bestimnt gezeigt haben, sind die Ruhe- 
zustinde keinesfalls nothwendige Glieder des Entwickelungsganges. Ihre Bildung scheint vielmehr überall dadurch veranlasst zu werden, dass die Fortentwichelung der Schwärmer zu Plasmodien oder dieser zu Sporangien gestört wird durch unzureichende Ernihhung, langsame Austrocknung, langsame Abküihlung unter ein gewisses Minimum. Allerdings liegt eine Anzahl von Beobachtungen vor, welche auf noch andere, zur Zeit unbekannte Ürsachen hindeuten. Die Wiederaufnahme der Beweglichkeit erfolgt, wenn die Körper nach Austrocknung (bei geeigneter Temperatur) wiederum in Wasser gehracht werden.

Nit lem Namen Mikroeysten hat Cienkowski den Ruhezustand der Schwirmer bezeichnet. Unter den angegebenen Bedingungen nehmen diese die Gestalt von Kugeln an, wolchekleiner als die Sporen, von einer sehr zarten, farblosen Membian umgeben (Licea pannorum nach Cienkowski) oder membranlos, aber mit einer sehr festen Randschicht versehen sind Fig. 25). In [e] rigen bleibt ihre structur der von beweglichen schwirmern gleich; nur dass die Vaeuolen in vielen Fillen verschwinden und das Protoplasma grössere Dichtigheit erhailt. Die Schwirmer bleilen in diesem eingehugelten Zustande bei völliger Austrocknung lebensfihig wann ihre Lodensfihigheit aufhoirt, ist noch nicht motersucht. Wieder in Wasser gebracht, hehren sie zu der beweghlichen Schwirmerform zuriich, um so schmeller, je kürzer die Austrockmung gedauert hatte lrig. 26, 27. Die von licea pannorum streifen hierbei ihre Membran ab.

Die derbwandigen Giston und Selerotien sind Rubezustinde der Plasmodien. Jene wurden von mir hei Acthalium in vereinzelten Fiallen beobachtet, von Ciemhowski bei Licea pannormm in ihrer Entwickelung vollständig verfolgt. Bei beiden Arten waren es jugendliche Pasmodien, wolche die Cysten bildeten. Nach Cienkowshi's Beobachinng lheilt sich das Plasmodium durch Zerreissung seiner Zweige in Stuiche von sehr ungleicher Grösse, welche ihre Fortsitze einzichen und die Gestalt enlatter Kigern annehmen. Auf der Oberfliche dieser trilt nun eine Membran aul; woldhe betrichtliche Dicke, runzelig hrause Oberfliiche und dumbelbsaune Farbe erhiilt. Innerhall, dieser Membran zieht sich das Protoplasma noch weiter zusammen und bildet an seiner Oberfliche eine zweite, doppelt contouriete Hatt. Nach mehrwöchentlichem Austrocknen wiederum in Wasser ge hatht, blieben die Kugeln zuerst einigge Woehen

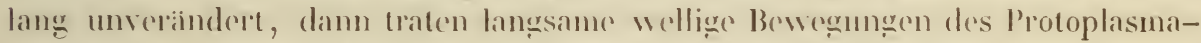
körpers ein, endlich sah man diesen ansehwellen, die mmgebenden Iliiute durchbohren und, mit allen Eig̣ensehaften cines Plasmodimms versehen, langsam aus denselben hervorkriechen.

Die Sclerotien sind die Ruherustinde der erwachsenen Plasmodien. Sie wurden beobachlet bei Didymium leucopus, Libertianum, serpula, Aethalium septicum, Plı̣sarum sinuosum, licea pannorum und ciner Anzahl nicht niher bestimmler Physareen, vielleicht auch von Corda Icon. fung. II, Fig. 8\%, b) bei Stemonitis. Sie stellen zum Theil die Formen dar, aus wolchen Persoon seine Pilzgattung Phlehomorpha bildete.

Wenn ihre Bildung beginnt, Werten die feineren Fortsitze des Plasmodiums eingezogen, dieses nimmt die Gestalt einer siebartigen Platte oder (Aethalium) eines unregehmissig höckerigen knöllchens an, die Körner vertheilen sich gleichmässig in der Grundsubstanz, die festen Ing̨esta werden ausgeschieden, allmählich 
hört die Bewegung auf und der ganze Körper zerfällt in eine Unzahl rundlicher oder polyedrischer Zellen von durchschnittlich 1/40 Mm. bis 1/27 Mın. Durchmesser. Der Körper erhält hiermit wachsartige Consistenz und trocknet zu einer hornartig spröden Masse ein, ähnlich vielen Pilzsclerotien.

Die einzelne Zelle (Fig. 24, 28) besteht die Hauptmasse nach aus einem festen Protoplasmakörper, welcher Vacuolen verschiedener Zahl und Grösse, Pigment und Körner in ähnlicher Vertheilung wie die beweglichen Plasmodien einschliesst und meist eine scharf abgesetzte Randschicht zeigt. An den kräftig entwickelten Sclerotien mancher Arten (๘. B. Aethalium, Didym. serpula) ist der Protoplasmakörper von einer deutlichen farblosen Membran umgeben (Fig. 28), welche bei den genannten beiden Arten in Iod und Schwefelsaiure oder Chlorzinkjod Cellulosefärbung annimmt. Die Membranen sind mit einander fest verbunden, entweder unmittelbar oder (Aethalium) durch eine lomogene, in Wasser erweichende Zwischensubstanz. Kleine, schwach entwickelte Exemplare der genannten Arten, sowie alle bis jetzt untersuchten Sclerotien anderer (z. B. Did. Libertianum) lassen keine deutlichen Memloranen um die Protoplasmakörper erkennen.

Die Aussenfliche der Sclerotien wird meistens von einer Lage jener homogenen quellbaren Substanz bedecht, welche sich bei Aethalium zwischen den Zellen findet. Auf derselben sind ferner vielfach (Aethalium, Didymium) Schuppen oder Körner, oder Kiystalle von kohlensaurem Kalk abgelagert, welcher bei der Sclerotienbildung ausgeschieden werden muss.

Wenn ein reifes, trockenes Sclerotium in Wasser gebracht wird, so quillt es sofort auf, und, oft schon nach 6 bis 15 Stunden, bei alteren Exemplaren nach liingerer, selbst mehrere Tage dauernder Frist, fliessen seine Zellen wiederum zu einem beweglichen Plasmodium zusammen. Wo Cellulosehäute vorhanden sind, werden diese zuvor aufgelöst. Der Vorgang beginnt an der Oberfliche und schreitet nach der Mitte zu for't.

Beobachtet man isolirte Sclerotienzellen, so sieht man einige Stunden nach dem Befeuchten contractile Vacuolen in ihnen auftreten, dann beginnt Austreibung beweglicher Aeste und Pseudopodien und Fortkriechen nach Art von Plasmodien. Wo die beweglichen Zellen einander begegnen und berühren, verschmelzen sie, wo sie noch ruhenden begegnen, werden diese verschluckt. Auf diese Weise entsteht allü̈hlich ein grösseres, viele verschluckte Sclerotiumzellen enthaltendes Plasmodium. Diese von Cienkowski zuerst an Did. Libertianum beobachteten Erscheintugen geben ïber die Entstehung des Plasmodiums aus dem zusammenhiingenden Selerotium Aufschluss. Auch in den aus unzerlegten Sclerotien neu entstandenen Plasmodien sicht man immer eine Menge Sclerotiumzellen, theils unveränderte, theils deutlich abgestorbene, ron dem Körnerstrome mitgeführt werden. Yach und nach werden dieselben seltener, um zuletzt ganz zu verschwinden; sie werden also entweder aufg̣elöst oder verschmelzen mit der iibrigen Plasmodiumsulostanz.

Die trockenen Sclerotien, welche untersucht sind, bleiben zumeist etwa 6 bis 8 Monate lebenskräftig. Aethalium und Didym. serpula verbringen, nach mehrfacher directer Beobachtung, kalte und trockene Jahreszeit im Sclerotiumzustand, um bei feuchter und warmer Witterung wieder in den beweglichen überzugehen. Linger als 7 bis 8 Monate dauerte die Lebensfähigkeit in den 
meisten beobachteten Fïllen nicht, doch blicben Sclerotien von Didym. serpula uber ein Jahr lebend (andere nur $\mathbf{I}$ Monate), und Léveillé führt (Ann. sc. nat. 2e Sér. T. XX, p. 216) eine Beobachtung an, derzufolge ein Myxomycetensclerotium nach 20 jaihriger Aufbewahrung noch in den beweglichen Zustand überging.

Die vorstehenden Abschnitte enthalten die zur Zeit von der Entwickelung der Myxomyceten bekannten Thatsachen. Ob wir mit diesen den ganzen Entwickelungsgang kenuen, hahen fernere Lntersuchungen zu entscheiden. Zu solchen fordert die von Cienkowski und mir wiederholt beobachtete Erscheinung auf, dass (z. B. bei Did. Libertianum) in Aussaten auf dem Objecträiger öfters keine Plasmodiumbildung eintritt, die gewöhnlichen cilienlosen Schwärmer aber seltener werden und dafür grössere Körper auftreten, welche jenen in Bau und Bewegung ähnlich sind und Arten des vieldeutigen Formgenus A moeba (A. guttula, Limax Dujard.) gleichen. Diese Amöben erhalten sich wochenlang unverindert. Ob sie aus den Schwarmern entstehen oder fremden, vielleicht auf Kosten letzterer lebenden Organismen zugehören, und was zuletzt aus ihnen wird, ist ungewiss.

Mit den beweglichen Zustinden der Myxomyceten hat eine zur Zeit 9 Arten umfassende Gruppe mikroskopisch kleiner Organismen grosse Achnlichkeit, welche Cienkowski, dem wir ihregenatue Kenntniss verdanken, als Mo naden bezeichnet. Eine Anzahl derselben (Monas, Pseudosjora, Colpodella) beginnt ilne Entwickelung in der Form von bewimperten Schwamern, welehe denen der Myxomyceten im Wesentlichen gleich sind. Die Schwarmer wachsen heran und zwar, Colpodella ausgenommen, zu Körpern, welehe sich nach Art kleiner Plasmodien kriechend und Pseudopodien atustreibend bewegen. Dieselben gleichen den Amöben der :ilteren Zoologen und werden nit diesem Namen bezeichnet. Von den Plasmodien sind sie dadurch rerschieden, dass sie nicht aus der Vereinigung mehrerer Schwirmer entstehen und bei der Mehrzahl der Arten einen oder selbst mehrere (Nuclearia) deutliche Zellenkerne enthalten. Nur Mo nas am yli Cienk. bildet, den Myxomyceten ihnlich, durch Verschmelzung mehrerer Schwiimer kleine Plasmodien. Diese, bei den anderen Arten die Amöben, bei Colpodella die Schwirmer selbst, nehmen zuletzt Kugelform an, sondern an ihrer Oberfliche eine Membran ab, und innerhalb dieser theilt sich das Protoplasma in eine Anzahl Segmente, welche sofort als Schwirmer wieder ausschlüpfen und den Entwickelungsgang von neuem beginnen. Andere Exemplare gehen innerhalb der erwihnten Membran in einen den derbwandigen Myxomyeeten eysten durchaus ähnlichen Ruhezustand über.

Eine andere Gruppe von Gattungen (Vampyrella, Nuclearia) ist von den beschrichenen dadurch verschieden, dass der Schwïmerzustand fehlt; der eingekugelte Protoplasmakörper theilt sich innerhall, der zarten Membran in zwei bis vier Portionen, deren jede in Form einer mit fadenförmigen Pseudopodien versehenen Amöbe die Membran verlaisst. Bei Nuclearia simplex sah Cienkowski 
aus der Gyste wieder eine Amöbe ausschlüpfen, für alle anderen Formen ist das Ende des Ruhezustandes nicht beobachtet.

Alle hierher gehörenden Formen nehmen grosse Mengen fester organischer Körper in sich auf und zwar als Nahrung, denn die Ingesta werden zu Gunsten der wachsenden Körpersubstanz in der Monade grossentheils aufgelöst; ein anderer Theil wird hiufig vor der Theilung oder Encystirung innerhalb der Membran unverbraucht ausgestossen, meist in Form missfarbiger Klumpen oder Körner.

Die Nahrungsaufnahme und Qualitit der Nahrung ist je nach den einzelnen Arten verschieden. Erstere findet entweder an beliebigen Stellen des Körpers und wie die Aufnahme fester Ingesta durch die Myxomycetenplasmodien statt (Vampyrella vorax, Monas, Pseudospora) oder an hestimmten Puncten der Körperoberfliche. Was die Qualitit der Nahrung betriflt, so nehmen Nuclearia, Pseudospora Nitellarum Theile zersetzter Algenzellen auf, Monas amyli Stärkekörner, Vampyrella voras lebende Diatomeen und Desmidiaceen. Colpodella pugnax, Vampyrella pendula, V. Spiroggrae saugen aus lebenden Conferven-und Volvocinenzellen, deren Wand sie durchbohren, das Protoplasma und Chlorophyll aus, und zwar haben sie entweder die Wahl zwischen verschiedenen oder sind (๘. B. V. Spirogyrae) auf einzelne bestimmte Gattungen angewiesen.

Es liegt auf der Hand, dass diese Erscheinungen (welche vielleicht geeignet sind, auch ïber die Bedeutung der festen Ingesta bei den Mrxomyceten Aufschluss golm zu helfen) an die Nahrungsaufnahne niederer Thiere aufs bestimmteste erinnern, und ein ausführliches Eingehen auf dieselben dürfte schon aus diesem Grunde die Grenzen dieser Arbeit übersehreiten.

L i t t e r a 1 u r.

E. Fries, Systema mycologicum III (1829).

A. de Bary, Die Mycetozoen. Zeitschr. f. wiss. Zoologie, Bd. X (1859). 2. Auflage. Leipzig, 1864. Für viele Einzelheiten und ausfuhrliche Litteraturangaben sei auf diese 2. Auflage verwiesen und auf die folgenden Schriften:

L. Cienkowski, Zur Entwichelungsgeschichte der Myxomyceten; und Das Plasmodium. Pringsheim's Jahıl). f. wiss. Bol. III, 325 und 400. Beiträge zur Kenntniss der Monaden. M. Schultze's Archiv f. mikrosk. Anatomie. Bd. I, p. 203, Taf. XII - XIV. 


\section{Erklärung der Tafel.}

\section{Figur I bis 3. Physarum albipes Fr.}

Fig. 1. Gestieltes Sporangium, von aussen betrachtet. Verĝ̣. 25.

rig. 2. Ein solches halbirt, von der Schnittfläche aus gesehen, Columella und Capillitium durch Eutfernung der Sporen freigelegt. Vergr. 30.

Fig. 3. Verg. 390. Ein Stiick Sporangiumwand nelst einem ihm angewaclısenen Stiick Capillitium in Wasser ausgebreitet. a Anheftungsstellen der Capillitiumröhren. b Kalkblasen.

c Eine von einer Membran ungebene Kalkanhïufung. sp) Sporen.

Figur \& und :5. Physarum plumbeum Fr. (Schwach vergr.)

Fig. 4. Plasmodium, an Rande mit dicken Anschwellungen, den ersten Anfängen der Sporallgien.

Fig. 5. Ciruppe junger sporangien, während der Formung, noch durch fadenförmige Reste des Plasmodiums verbunden.

Figur 6. Didymium leucopus Fr. (Vergr. 2: bis 30.)

Sporangium, dessen Wand nicht ganz zur Hälfte weggenommen und dessen Sporen entleert sind; in Inner'n Columella und Capillitium, aussen auf der Wand Kalkdrusen.

Figur 7. Didymium farinaceum Fr. (Verger. 390.)

Stück Sporangiumwand mil Capillitium und kalhdrusen. Ersteres innen, letztere aussen der Wand ansitzend, der Einfachheil haher in eine Figur zusammengezeichmet. a Einzelne Capillitiunfaser. sp Sporen.

\section{Figur 8 bis 27. Didymium Libertianum.}

Die Figuren 16, 18 bis 21 sind hach Cienkowski's Mbbildungen copirt, $350 \mathrm{mal}$ vergrössert; alle iibrigen nach 390 facher Vergrösserung, zum Theil ein wenig zu gross gezeichnet.

Fig. 8. Sporen mit fast farbloser Membran; $a$ von gewöhnlicher Struetur und Grösse; im Innern der ker'n nelost einem ihı sehr ähnlichen, von einem hellen Hofe ungebenen glänzenden "körnchen “. Die anderen klein und zu 2, 3 und 4 in einer Blase liegend, Was ofters bei Exemplaren, die in der Ausbildung gestört waren, nicht aber bei völlig normal entwickelten beobachtel wurde.

Fig. 9. Violetthäutige Sporen, mit einem dunkehn runden "Schleinklumpen". Bei zweien derselben ist die Membran zum Behufe der Schwärmerbildung aufgerissen.

Fig. 10. Spore von derselben Aussaat wie Fig. 9. a Zwei Schwärmer durch Theilung des Protoplasmas gebildet; $b$ Ausschliipfen derselben. Der Schleimhlumpen wurde bei der Theilung ausgeschieden und bleibt in der Membran zurück.

Fig. 11. Schwärmer, aus Sporen wie Fig. 9 entwickelt; zwei mit, einer ohne Schleimkugel im Innern. a Schwärmer mit dem eine Schleinkugel enthaltenden Hinterende in die verengle Oefrnung der Mlembran eingeklemmt. Das eingeklenmute Stück reisst später los.

Fig. 12 bis 14. lieimung der in Fig. 8 dargestellten fast farblosen Sporen. 
Fig. 12. Durch Theilung des Protoplasmas zwei Schwärıner innerhalb der Sporenmembran gebildet. Das glänzende Körnchen ausgeschieden.

Fig. 13. $a$ Spore mit zwei Schwärmern im Beginne des Ausschlüpfens; $b$ dieselbe nach vollendetem Ausschlüpfen. Das Körnchen bleibt in der Membran zurück.

Fig. 14. Ausschlüpfen eines Schwärmers und Theilung desselben. Entwickelungsfolge nach den Buchstaben $a-n$. Die Sporeı waren um 7 Uhr Vorm. ausgesäet worden. $a \mathrm{Um}$ $10 \mathrm{Uhr} 45 \mathrm{M}$. zuerst beobachtet, bleibt bis 11 Uhr 53 M. unverändert, mit Ausnahme der Pulsation der Vacuolen. $b, c$ um 11 Uhr 53 M., $d$ um 12 Uhr, $h$ um 12 Uhr 15 M. : der Schwärmer hat dauernde Kugelform angenommen, Kern und Vacuolen sind noch deutlich; $i$ um 12 Uhr 30 M.: Kern und Vacuolen plötzlich verschwunden. $k$ Beginı der Theilung um 12 Uhr $40 \mathrm{M}$. Kerne sind nicht sichtbar bis nach vollendeter Theilung; in $n$ (um 12 Uhr 50 M.) erscheinen sie plötzlich. Die beiden Theilungsproducte nahmen später die Form gewöhnlicher Schwärıner an.

Fig. 15. Cilienloser Schwärmer, aus einer monströs grossen Spore, wie sie öfters zwischen den anderen vorkommen, ausgeschlüpft, mit zwei Kernen.

Fig. 16. Schwärner, welche nach mehrtägiger Cultur die Cilie verloren haben. Kern und contractile Vacuole noch deutlich.

Fig. 17. Zwei solche cilienlose Schwärmer, sich an einander legend.

Fig. 18. $a$ Zwei ebensolche; $b$ dieselben zu einem jungen kernlosen Plasmodium verschmolzen.

Fig̣. 19. $a$ Gruppe von drei cilienlosen Schwärmern; $b$ zwei derselben sind zu einem Körper (Plasmodium) verschmolzen.

Fig. 20. Kleines junges Plasmodium.

Fig. 21 bis 22. Zwei grössere Exemplare, die feste Ingesta in sich aufgenommen haben.

Fig. 23. Zweigende eines erwachsenen, auf dem Objectträger ausgebreiteten Plasmodiums.

Fig. 24. Zwei Zellen aus einem mehrere Monate trocken aufbewahrten Sclerotium, nach mehrtägigem Liegen in Wasser.

Fig. 25. Schwärmer im Ruhezustande, nach mehrwöchentlicher Austrocknung frisch in Wasser gebracht. Das Protoplasma von einer scharf hervortretenden Randschicht umgeben, ohne Membran.

Fig. 26. Ruhender, mehrere Wochen lang trocken aufbewahrter Schwärmer, nach ungefähr 24 stündiger Einwirkung von Wasser. In a die Randschicht noch unverändert, dicht unter derselhen vier pulsirende Vacuolen, welche abwechselnd verschwinden und wiederkoınmeı; in der Figur sind drei sichtbar. $b-e$ Rückkehr in den beweglichen Zustand, Entwickelungsfolge nach den Buchstaben. Das Austreiben des ersten Pseudopodiuns erfolgte $5 / 4$ Stunden nach Beginn der Beobachtung; die Form $e$ war $1 / 4$ Stunde später vorhanden; darauf sehr rasch Uebergang iı die Form der gewöhnlichen cilientragenden Schwärmer.

Fig. 27. Anderes Exemplar, aus derselben Cultur wie das in Fig. 26 dargestellte, dicht neben diesem gelegen. Entwickelungsfolge nach den Buchstaben $a-d$; in $a$ zwei abwechselnd pulsirende Vacuolen. $a$ kain 11 Uhr zur Beobachtung, $d$ war um $12 \frac{1}{2}$ Uhr fertig.

Figur 28. (Vergr. 390.)

Fragment eines dünnen Querschnittes durch das rothgelbe Sclerotium eines Physarum. Die Zellen mit je einer grossen Vacuole und deutlichen Membranen; viele der letzteren durch den Schnitt entleert. Die Membranen sind etwas zu dick gezeichnet und aus Versehen dunkel schattirt. 


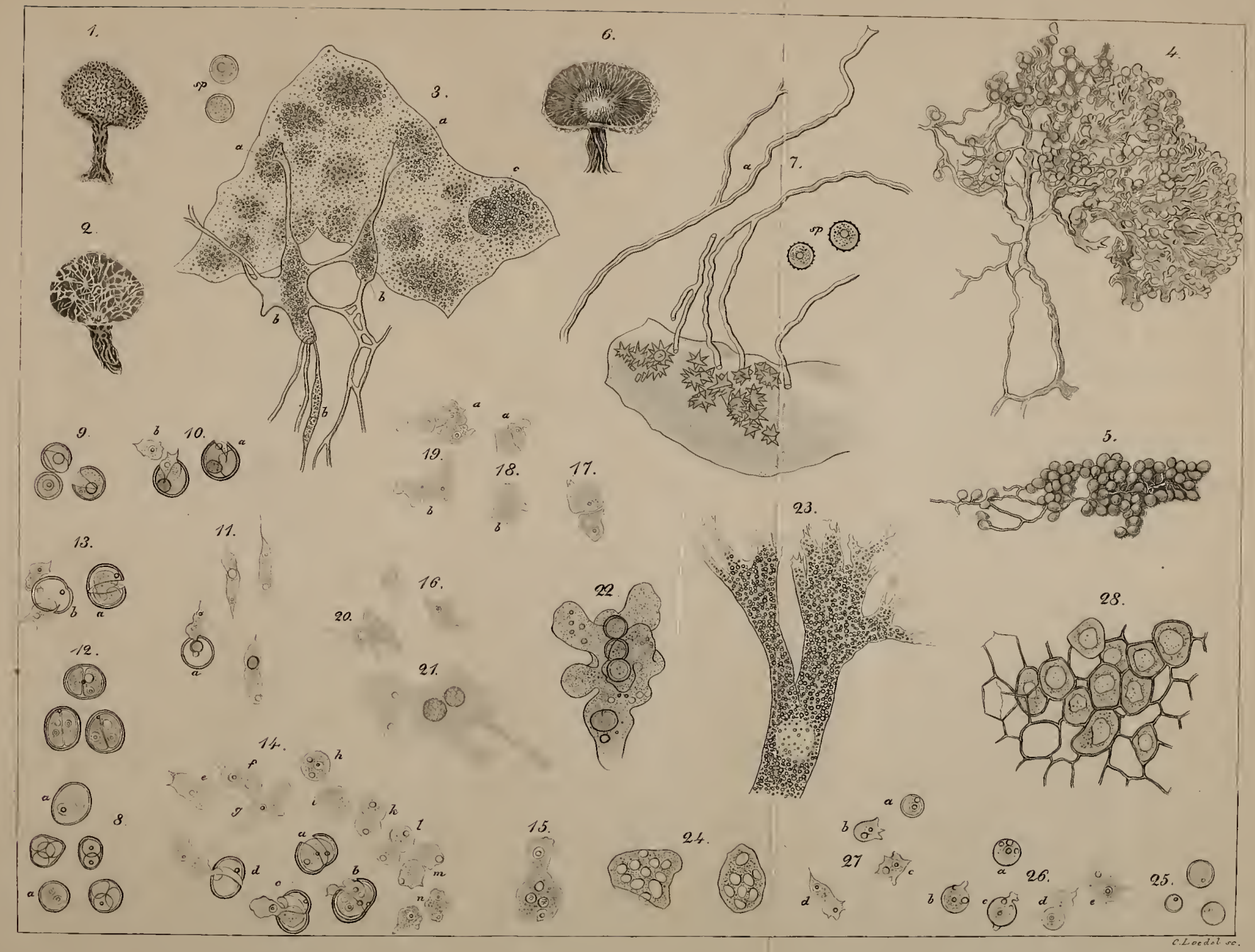






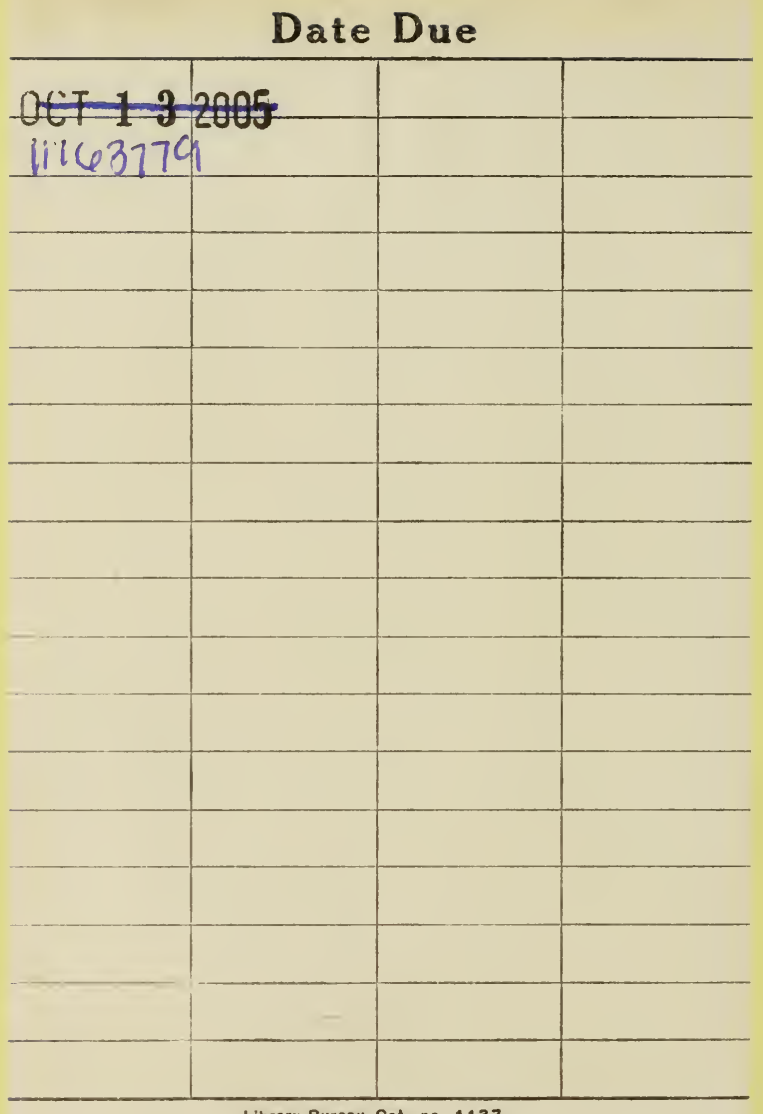

Library Bureau Cat, no. 1137 


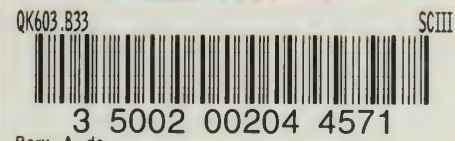

Bary, A. de 002002044571

Morphologie und Physiologie der Pilze, F

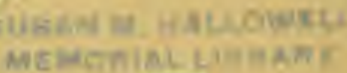

QK

603

B33

14526 
a

a.s.

t.

89

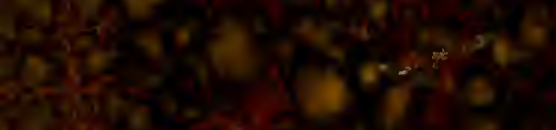

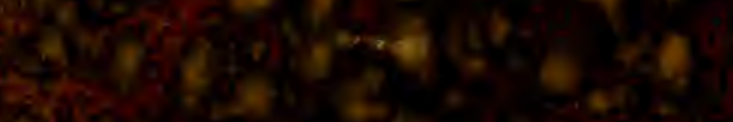

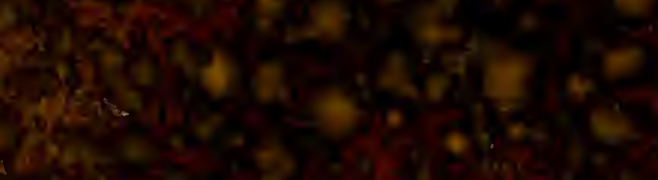

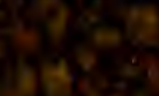

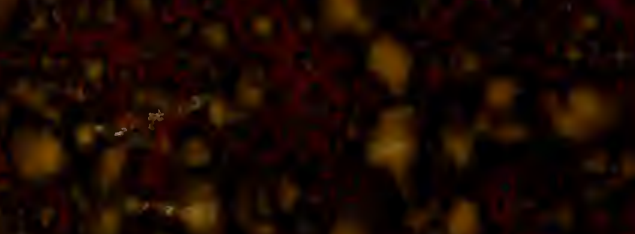

